DEPARTMENT OF THE INTERIOR

UNITED STATES GEOLOGICAL SURVEY

CHARLES D. WALCOTT, DIRECTOR

\title{
PRELIMINARY LIST
}

oF

\section{DeEP BORIngs in the UNited STATES}

SECOND EDITION, WITH ADDITIONS

BY

\section{N. H. DARTON}

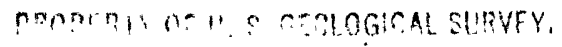

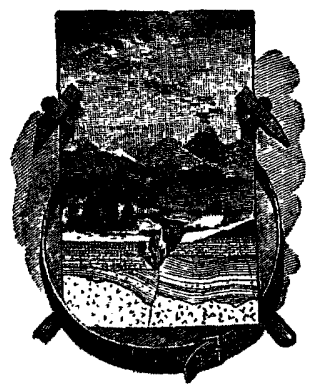

WASHINGTON

GOVERNMENT PRINTING OFFICE

1905 



\section{CONTENTS.}

Letter of transmittal

Introduction . . . . . . . .

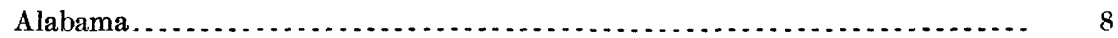

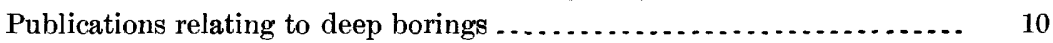

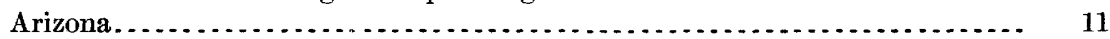

Publications relating to deep borings .......................... 11

Arkansas ........................................................ 11

Publications relating to deep borings........................... 14

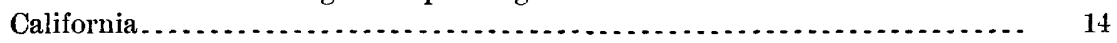

Publications relating to deep borings.......................... 18

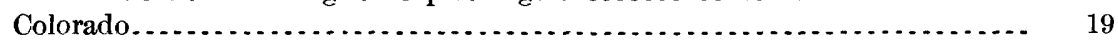

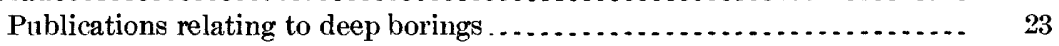

Connecticut . . . . . .

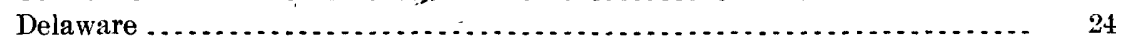

Publications relating to deep borings.......................... 24

District of Columbia ............................................ 24

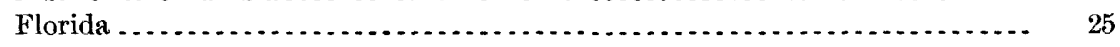

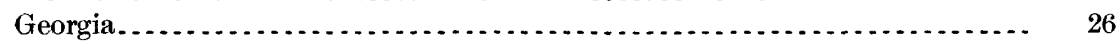

Publications relating to deep borings $\ldots \ldots \ldots$
Idaho $\ldots \ldots \ldots \ldots$

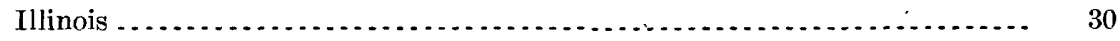

Publications relating to deep borings.......................... 38

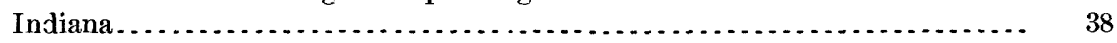

Publications relating to deep borings........................... 46

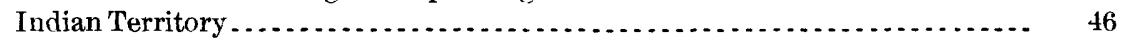

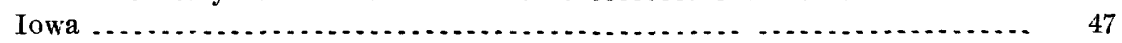

Publications relating to deep borings.......................... 50

Kansas ....................................................... 50

Publications relating to deep borings............................ 56

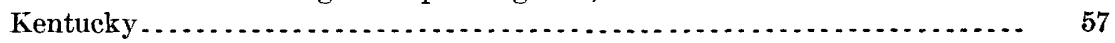

Publications relating to deep borings.......................... 59

Louisiana ......................................................... 60

Publications relating to deep borings. ............................ 63

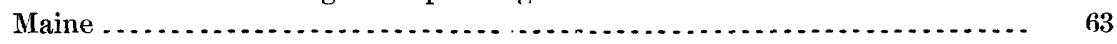

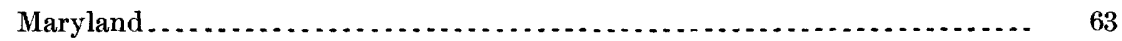

Publications relating to deep borings.......................... 64

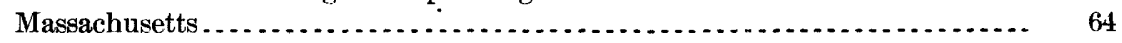

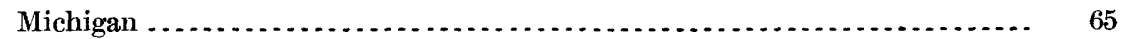

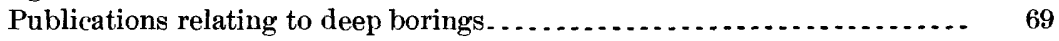

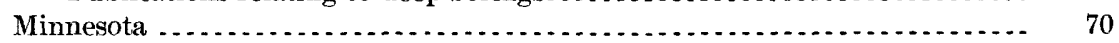

Publications relating to deep borings............................ 72

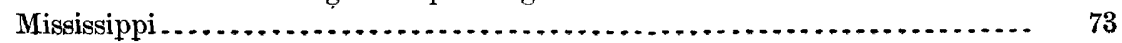


Missouri

Publications relating to deep borings.......................... 78

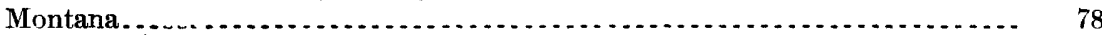

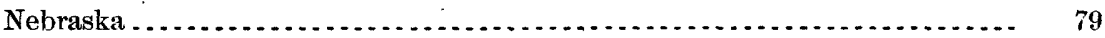

Publications relating to deep borings .......................... 81

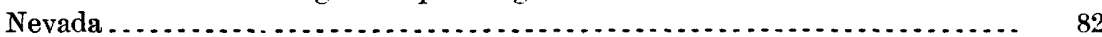

New Hampshire................................................. 82

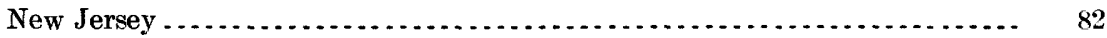

Publications relating to deep borings ........................... 85

New Mexico ................................................... 85

Publications relating to deep borings $\ldots \ldots \ldots \ldots \ldots \ldots \ldots \ldots \ldots \ldots \ldots . \ldots \ldots$

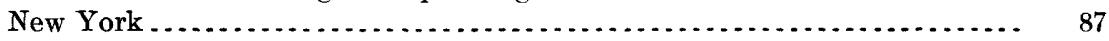

Publications relating to deep borings.......................... 93

North Carolina.............................................. 94

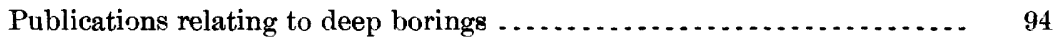

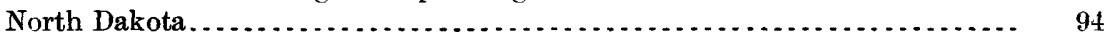

Publications relating to deep borings .......................... 95

Ohio ......................................................... 96

Publications relating to deep borings .......................... 109

Oklahoma ......................................................... 109

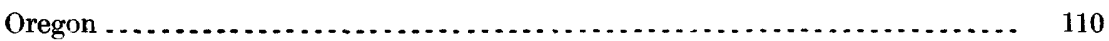

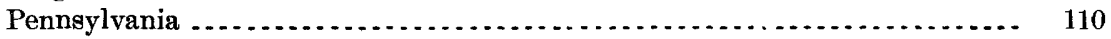

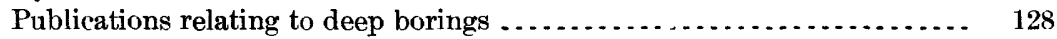

Rhode Island ................................................ 128

South Carolina................................................. 128

Publications relating to deep borings ........................... 129

South Dakota . . ................................................ 129

Publications relating to deep borings .......................... 140

Tennessee ................................................ 141

Publications relating to deep borings.......................... 141

Texas ..................................................... 142

Publications relating to underground waters ...................... 155

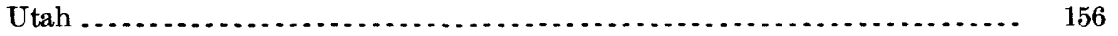

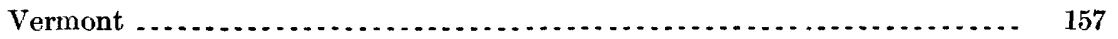

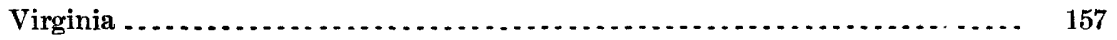

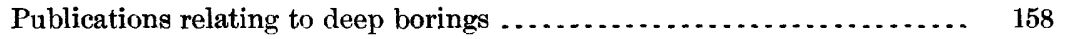

Washington .................................................. 158

West Virginia........................................................ 159

Publications relating to deep borings ............................ 172

Wisconsin ............................................................ 172

Publications relating to deep borings ........................... 174

Wyoming................................................ 174

Publications relating to deep borings ........................... 175 


\title{
LETTER OF TRANSMITTAL.
}

\author{
DEPaRTMENT OF THE INTERIOR, \\ United States Geological Survey, \\ DIVISION CF HYDROGRAPHY, \\ Washington, D. C., June 15, 1905.
}

SrR: I transmit herewith a preliminary list of deep borings in the United States (400 feet or more in depth), by Mr. N. H. Darton, and request that it be published in the series of Water-Supply and Irrigation Papers.

Very respectfully,

F. H. Neweld,

Hydrographer in Charge.

Hon. Charles D. Walcott,

Director United States Geological Survey. 



\section{PRELIMINARY LIST OF DEEP BORINGS IN THE UNITED STATES.}

By N. H. Darton.

\section{INTRODUCTION.}

The first preliminary list of deep borings in the United States was issued as Water-Supply Papers Nos. 57 and 61. The present priblication includes all of the wells listed in these two papers, together with many additional borings, mostly of recent date. Messrs. M. L. Fuller and A. C. Veatch, of the eastern section of hydrology, and other geologists of the Survey have contributed many new data. Dascriptions of borings published in reports issued since 1901 have been incorporated as far as practicable. All the entries are by counties.

The wells and borings reported in the paper are all more than 400 feet in depth. The information concerning them has been oftained partly from replies to circular letters sent to all parts of the United States and partly from geological reports and other published sources. Owing to the difficulty of obtaining replies to the circulars, to lack of knowledge on the part of correspondents, and to the incompleteness of published records, doubtless there are borings which have not been reported. In regions of oil and gas wells, where borings are numerous, the individual wells can not be listed here, but representative wells are given. References to logs or records of the wells or extended descriptions of them are given in footnotes, and after the list of wells in each State there is added a list of the principal publications relating to deep borings in that State.

The bearing of the information given in the columns of the lists probably is apparent unless, perhaps, in the one headed "Height to which the water rises." In this column an entry such as " -45 " indicates that the water rises to within 45 feet of the surface; " +45 " indicates that it is a flowing well and has sufficient head to raise the water 45 feet above the surface in an open pipe 45 feet or more in height. The yield in gallons per minute usually is estimated. Depths and diameters often have been reported from memory and different sources of publication sometimes give different tigures. Most wells which are not stated to be "for oil," "for gas," " brine," "abandoned," 
etc., in the remarks column, or "not any" in the yield column, generally afford more or less water. Many of the gas and oil wells, active or abandoned, yield salt water.

\section{ALABAMA.}

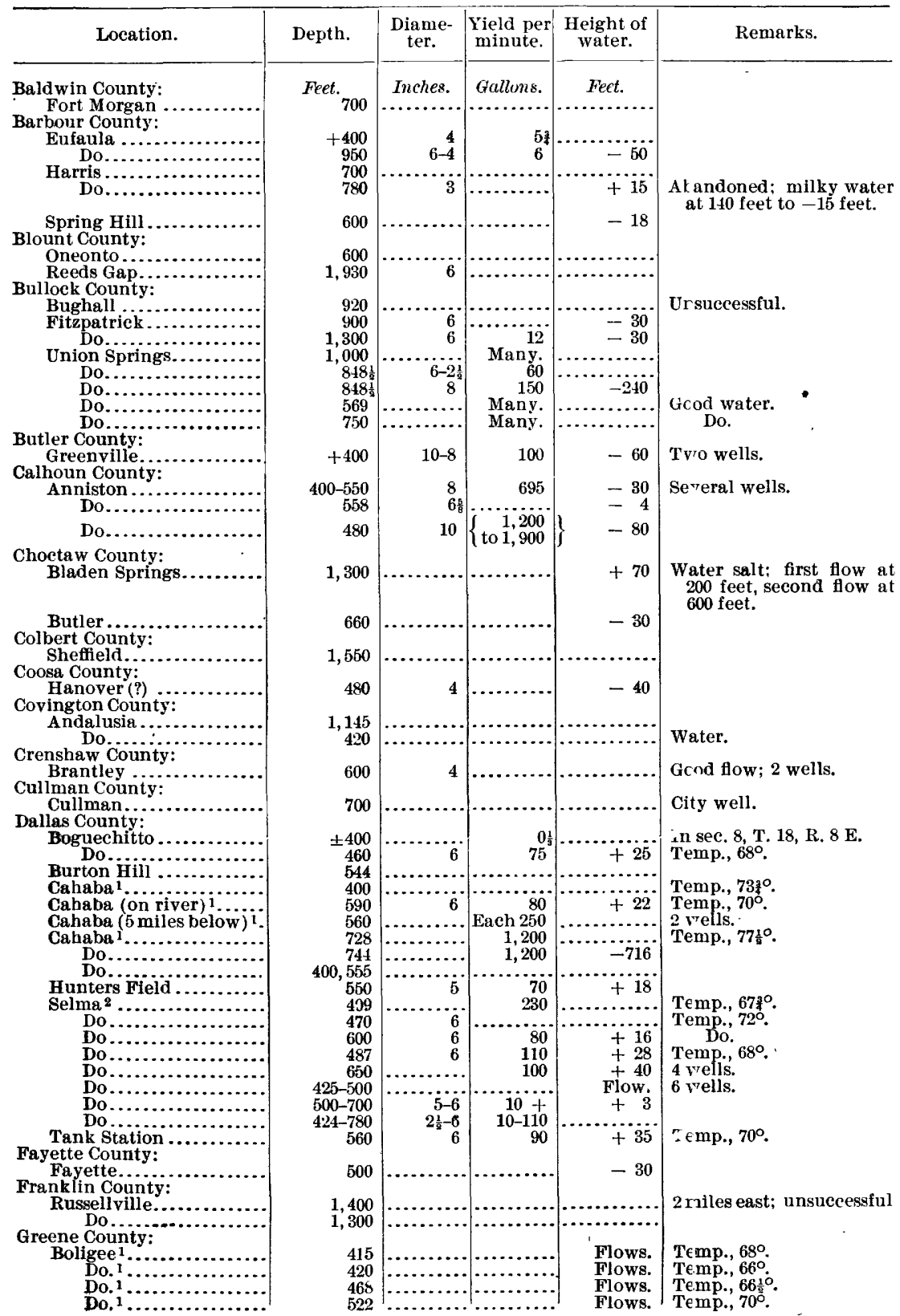

1 Record, Am. Assoc. Adv. Science Proc., vol. 1v, p. $95 . \quad 2$ Ibid, pp. 97-98. 
ALABAMA-Continued.

\begin{tabular}{|c|c|c|c|c|c|}
\hline Location. & Depth. & $\begin{array}{l}\text { Diame- } \\
\text { ter. }\end{array}$ & $\begin{array}{l}\text { Yield per } \\
\text { minute. }\end{array}$ & $\begin{array}{l}\text { Height of } \\
\text { water. }\end{array}$ & Remarks. \\
\hline $\begin{array}{l}\text { Greene County-Continued. } \\
\text { Boligee (at Finche's }\end{array}$ & ${ }^{\text {Feet. }}{ }_{560}$ & $\begin{array}{l}\text { Inches. } \\
\text {............ }\end{array}$ & $\begin{array}{l}\text { Gallons. } \\
\text {........... }\end{array}$ & $\begin{array}{l}\text { Feet. } \\
\text { Flows. }\end{array}$ & Temp., $71^{\circ}$ \\
\hline $\begin{array}{l}\text { ferry } .^{1} \\
\text { Do } \ldots \ldots \ldots \ldots \ldots \ldots\end{array}$ & - & & 40 & +22 & \\
\hline Do & 450 & 3 & 10 & +10 & \\
\hline Burton Hill 1 . & 544 & & $\cdots$ & ........ & Temp., $70^{\circ}$. \\
\hline $\begin{array}{l}\text { Do. } 1, \ldots \ldots \\
\text { Do. } 1, \ldots \ldots\end{array}$ & $\begin{array}{l}420 \\
555\end{array}$ & & & & Temp., $75^{\circ}$. \\
\hline Eutaw ${ }^{1}$ & 743 & & & -10 & \\
\hline Eest). 1 . & $440-550$ & & & & Temp.,71 ${ }^{\circ}-721^{\circ} ; 4$ wells. \\
\hline Eutaw $\ldots \ldots \ldots \ldots \ldots \ldots$ & $400-1,106$ & $3-4$ & & & Several wells. \\
\hline 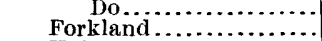 & $\begin{array}{l}420 \\
575\end{array}$ & $\ldots \ldots \ldots \ldots$ & 20 & +3 & \\
\hline Hairston ....... & 530 & & 4 & $+2 \frac{1}{6}$ & $2 \frac{1}{8}$ miles east. \\
\hline $\begin{array}{l}\text { Steeles Bluff.. } \\
\text { Hale County: }\end{array}$ & 400 & 3 & 22 & +25 & \\
\hline $\begin{array}{l}\text { Hale County: } \\
\text { A kron } \ldots \ldots . . . . .\end{array}$ & 400 & 3 & & -15 & \\
\hline Evansvilie Station....... & 633 & 4 & & -3 & \\
\hline Greensboro $\ldots \ldots \ldots \ldots \ldots$ & $\begin{array}{r}400-800 \\
1,600\end{array}$ & ... & Many. & $-\mathbf{3 0}$ & Several wells; good water. \\
\hline $\begin{array}{l}\text { Greeusboro (10 miles } \\
\text { southwest). }\end{array}$ & 450 or 850 ? & 12 & Many. & & \\
\hline Laneville............... & 710 & & & Flows. & Temp., $75^{\circ}$. \\
\hline Do...... & 719 & $\cdots$ & 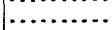 & Flows. & Temp., $76^{\circ}$. \\
\hline Do...... & 750 & & & -20 & In progress. \\
\hline $\begin{array}{l}\text { Do....... } \\
\text { Do.... }\end{array}$ & 715 & $\cdots \cdots \cdots$ & 7,10 & $\ldots \ldots \ldots$ & 2 wells. \\
\hline 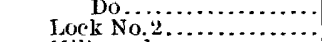 & 300 & $\ddot{3}$ & $\ddot{30}$ & …........ & \\
\hline Millwood............... & 500 & 6 & 75 & , n........... & \\
\hline Do $\ldots \ldots \ldots \ldots \ldots \ldots$ & 500 & $4 \frac{1}{2}$ & 75 & +2 & 2 wells. \\
\hline 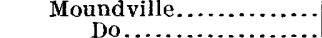 & $\begin{array}{l}600 \\
480\end{array}$ & $3-1 i$ & 1 & -1 to -16 & - \\
\hline Newbern .................. & $\mathbf{4 5}$ & & $\begin{array}{l}10 \\
30\end{array}$ & $\begin{array}{r}-110+10 \\
+4\end{array}$ & \\
\hline Do....... & $410-500$ & one, 3 & $3-35$ & One fiows. & 5 wells. \\
\hline Powers ..... & 406 & 3 & & +25 & \\
\hline Sawyerville ... & $440-640$ & 3 & ${ }^{1} 17^{*}$ & -8 to -10 & 4 wells: \\
\hline Stewart..... & & & & +8 & \\
\hline $\begin{array}{l}\text { Do } \ldots . . . . . . \\
\text { Henry County: }\end{array}$ & $400-620$ & 3 & 6,8 & -39 to +35 & \\
\hline Dothan........ & 625 & 8 & & -150 & \\
\hline Houston County: & & & & & \\
\hline Dolnmbia......................... & 485 & $8-6$ & 50 & -8 & 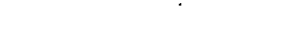 \\
\hline 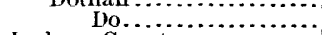 & $\begin{array}{l}620 \\
625\end{array}$ & $8-6$ & 50 & -150 & \\
\hline Jackson County: & & & & & \\
\hline Carpenter ........... & 400 & & & & Unsuccessful. \\
\hline Larkinsville.......... & 400 & & &. & Do. \\
\hline $\begin{array}{l}\text { Jefferson County: } \\
\text { Birmingham .... }\end{array}$ & 550 & & 70 & -30 & \\
\hline Lauderdale County: & 500 & & 70 & -30 & \\
\hline Florence.......... & +400 & & & & For gas; unsuccessful. \\
\hline $\begin{array}{l}\text { Lawrence County: } \\
\text { Jennings ( } 3 \text { miles south- }\end{array}$ & 5,120 & 6 & & & Gas, oil, and se.lt water. \\
\hline Jennings ... & & & & & \\
\hline $\begin{array}{l}\text { Jennings } \\
\text { Town Creek }\end{array}$ & 2,120 & 6 & & & Ahondoned \\
\hline Macon County: & & & & & Abandoned. \\
\hline Armstrong .. & 442 & & & & Good water. \\
\hline Fort Davis..................... & $4: 2$ & 4 & & -62 & \\
\hline $\begin{array}{l}\text { Roba } \ldots \ldots \ldots \ldots \ldots \ldots \\
\text { Tuskegee }\end{array}$ & 450 & $\cdots$ & $\cdots \cdot$ & $\cdots \cdots \cdot$ & Good water suoply. \\
\hline $\begin{array}{r}\text { Tuskegee } \ldots \ldots \ldots \ldots \\
\text { Do } \ldots \ldots \ldots\end{array}$ & $\begin{array}{l}500 \\
760\end{array}$ & $\begin{array}{l}6 \\
8\end{array}$ & $\cdots$ & 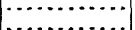 & $\begin{array}{l}\text { Unsuccessful. } \\
\text { Do. }\end{array}$ \\
\hline Madison County: & & & & & \\
\hline Hazlegreen.............. & 954 & & & & For oil; unsuccessful; \\
\hline Newmar & 965 & 2 & & Flows. & \\
\hline Marengo County: & & & & & \\
\hline Demopolis........ & 765 & $\mathbf{3}$ & 30 & +20 & Temp., $64^{\circ}$ \\
\hline Do $\ldots \ldots \ldots \ldots \ldots$ & 735 & 4 & 15 & +12 & \\
\hline 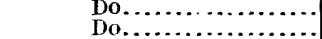 & $\begin{array}{l}850 \\
800\end{array}$ & $\begin{array}{l}6 \frac{1}{4} \\
3\end{array}$ & $\begin{array}{r}60 \\
\text { Many. }\end{array}$ & $\begin{array}{r}\text { Flows. } \\
+52\end{array}$ & \\
\hline $\begin{array}{l}\text { Demopolis (3 miles } \\
\text { south). }\end{array}$ & 1,350 & ........... & Many. & -30 & \\
\hline Demopolis (4 miles & 500 & & 200 & Flow. & Several wells. \\
\hline $\begin{array}{l}\text { northeast). } \\
\text { Faunsdale.............. }\end{array}$ & 700 & $\ldots \ldots \ldots$ & 8 & $+2 \frac{1}{2}$ & \\
\hline & & & & & \\
\hline
\end{tabular}

1 Record, Am. Assoc. Adv. Science Proc., vol. $\quad$ s Record, Pa. $2 d$ Geol. Surv. Rept. I. p. 283. 10, p. 95. 4 Record, Ala. Geol. Surv. Rept. Valley Regions, Ala. Geol. Surv. Rept. Valley Regions, part 1, part 1, p. 127. pp. 61-62. 
ALABAMA-Continued.

\begin{tabular}{|c|c|c|c|c|c|}
\hline Lneation. & Depth. & $\begin{array}{l}\text { Diame- } \\
\text { ter. }\end{array}$ & $\begin{array}{c}\text { Yield per } \\
\text { minute. }\end{array}$ & $\begin{array}{l}\text { Height of } \\
\text { water. }\end{array}$ & Remarks. \\
\hline $\begin{array}{l}\text { Marengo County-Cont'd. } \\
\text { Linden } \ldots . . \ldots \ldots \ldots \ldots \ldots\end{array}$ & $\begin{array}{l}\text { Feet. } \\
\qquad 1,193\end{array}$ & Inches. & $\begin{array}{r}\text { Gallons. } \\
1\end{array}$ & $\begin{array}{l}\text { Feet. } \\
\text { Flows. }\end{array}$ & Wate $r$ at 1,040 to 1,115 \\
\hline $\begin{array}{l}\text { Do.......... } \\
\text { Marshall County: }\end{array}$ & 1,200 & $1 \frac{1}{8}$ & $\cdot 20$ & Flows. & \\
\hline $\begin{array}{l}\text { Guntersville... } \\
\text { Mobile County: }\end{array}$ & 1,006 & $8-6$ & & & Temo., $60^{\circ}$. \\
\hline $\begin{array}{l}\text { Mobile County: } \\
\text { Fort Gaines. }\end{array}$ & 919 & 6 & & & \\
\hline $\begin{array}{r}\text { Mobile.............. } \\
\text { Do.......... }\end{array}$ & 700 & 6 & 400 & & Temo., $76^{\circ}$. \\
\hline $\begin{array}{l}\text { Do } \ldots \ldots \ldots \ldots \\
\text { Do.............. }\end{array}$ & 835 & $\dddot{6}$ & $\begin{array}{l}\text { Many. } \\
500\end{array}$ & +90 & Temo., $78^{\circ}$. \\
\hline Do.......... & $\begin{array}{l}800 \\
800\end{array}$ & $\begin{array}{l}6 \\
6\end{array}$ & $\begin{array}{r}500 \\
1,000\end{array}$ & +70 & $\begin{array}{l}\text { Temb., } 76^{\circ} \text {. } \\
\text { Temp., } 78^{\circ} \text {. }\end{array}$ \\
\hline Do.... & 850 & & .......... & & \\
\hline Do. ${ }^{1} \ldots$... & 1,556 & & ........... & ......... & \\
\hline 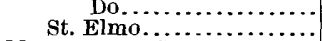 & $\begin{array}{r}1,526 \\
550\end{array}$ & & (n...... & (n) & \\
\hline $\begin{array}{l}\text { Montgomery County: } \\
\text { Montgomery ...... }\end{array}$ & $650-450$ & 6 & $974-300$ & -60 & 4 wells; originally flowed \\
\hline $\begin{array}{l}\text { Do................ } \\
\text { sprague Junction }\end{array}$ & $\begin{array}{r}448-1,091 \\
400\end{array}$ & $8-6$ & \begin{tabular}{|c|}
$60-130$ \\
$\cdots$
\end{tabular} & $\begin{array}{r}-45 \text { to }+6 \\
-75\end{array}$ & Several wells. \\
\hline $\begin{array}{l}\text { Morgan County: } \\
\quad \text { Hartsell } 2 . . . \ldots . .\end{array}$ & 1,730 & 2 & & & $\begin{array}{l}1 \text { mile north of town; salt } \\
\text { water at } 352 \text { and } 1,730 \\
\text { feet; gas at } 602 \text { and } 1,094 \\
\text { feet; sulphur water at } \\
160 \text { feet. }\end{array}$ \\
\hline $\begin{array}{l}\text { Perry County: } \\
\text { Uniontown. }\end{array}$ & 895 & 8 & & -125 & \\
\hline Do......... & 1,195 & 8 & 300 & -120 & Wat or from 870 feet. \\
\hline Do....... & 1,085 & & & -200 & \\
\hline $\begin{array}{l}\text { Iniontown (10 miles } \\
\text { south). }\end{array}$ & 875 & $4-3$ & 10 & -40 & Water at 775 feet. \\
\hline $\begin{array}{l}\text { Pickens County: } \\
\text { Dancey } \ldots \ldots \ldots \ldots \ldots \ldots\end{array}$ & $450-903$ & One 2 & One $3 \frac{1}{2}$ & -22 to +20 & \\
\hline Sherman ... & $600-725$ & 4 & $6 \frac{1}{2}-30^{2}$ & …........... & 3 wells. \\
\hline $\begin{array}{l}\text { Pike County: } \\
\text { Troy........ }\end{array}$ & & & & & \\
\hline Do............. & $\begin{array}{l}2,700 \\
2,632\end{array}$ & & 75 & (n) & Unsice esstul. \\
\hline Do......... & $350-650$ & & & & \\
\hline Hannon & 480 & 4 & $\cdots$ & -40 & \\
\hline $\begin{array}{l}\text { Russell County } \\
\text { Hatchechubbee ......... }\end{array}$ & 420 & & 8 & No flow... & Small supply of water at \\
\hline Hurtsboro & 530 & 4 & & -9 & \\
\hline & 530 & 4 & \pm 10 & & \\
\hline Do.. & 550 & 3 & \pm 11 & -9 & \\
\hline Do... & 565 & 3 & \pm 12 & -23 & \\
\hline & 526 & 3 & & -8 & \\
\hline Oswichee............ & 465 & & 12 & (n........... & \\
\hline Pittsboro ..................... & 445 & $\because$ & $\cdots \cdots \cdots$ & $\cdots \cdots \cdots+\cdots$ & \\
\hline $\begin{array}{l}\text { Seale } \ldots \ldots \ldots \ldots \ldots \\
\text { Sumter County: }\end{array}$ & 400 & 4 & …........ &.-60 & \\
\hline $\begin{array}{r}\text { Epes } \ldots \ldots \ldots \\
\text { Do } \ldots \ldots \ldots \ldots\end{array}$ & $\begin{array}{r}700 \\
500-930\end{array}$ & $2-5$ & $\begin{array}{r}3 \\
1-28\end{array}$ & $\left|\begin{array}{c}+1 \frac{1}{2} \\
-24 \text { to }+30\end{array}\right|$ & Many wells. \\
\hline Livingston .. & 1,010 & $\ldots$ & ..... & (n.......... & 2 wells. \\
\hline $\begin{array}{c}\text { Warsaw } \\
\text { Tnscaloosg county }\end{array}$ & $400-702$ & $2-4$ & $1-5 \frac{1}{2}$ & -30 to +40 & Several wells. \\
\hline $\begin{array}{l}\text { Tnsealoosa County: } \\
\text { Holton } \ldots \ldots \ldots \ldots \ldots \ldots\end{array}$ & 544 & & 50 & & \\
\hline Tuscaloosa ............ & 520 & 6 & $\cdots$. & -14 & \\
\hline $\begin{array}{l}\text { Landing (Syl- } \\
\text { t-office). }\end{array}$ & & & & $\cdots \cdots \cdots \cdots$ & \\
\hline sledges ................. & 490 & 4 & Many. & -60 & \\
\hline
\end{tabular}

1 Seience, vol. 16, p. 836, Nov. 21, 1902.

2 Ala. Geol. Surv. Rept, Valley Regions, part 1, pp. 62-6ङ.

\section{LIST OF PUBLICATIONS RELATING TO DEEP RORINGS IN ALABAMA.}

Report on Valley Regions, Alabama Geological Survey, part 1.

American Association for the Advancement of Science Proceed ings, vol. 10.

Science, vol. 16, Nov., 1902. 
ARIZONA.

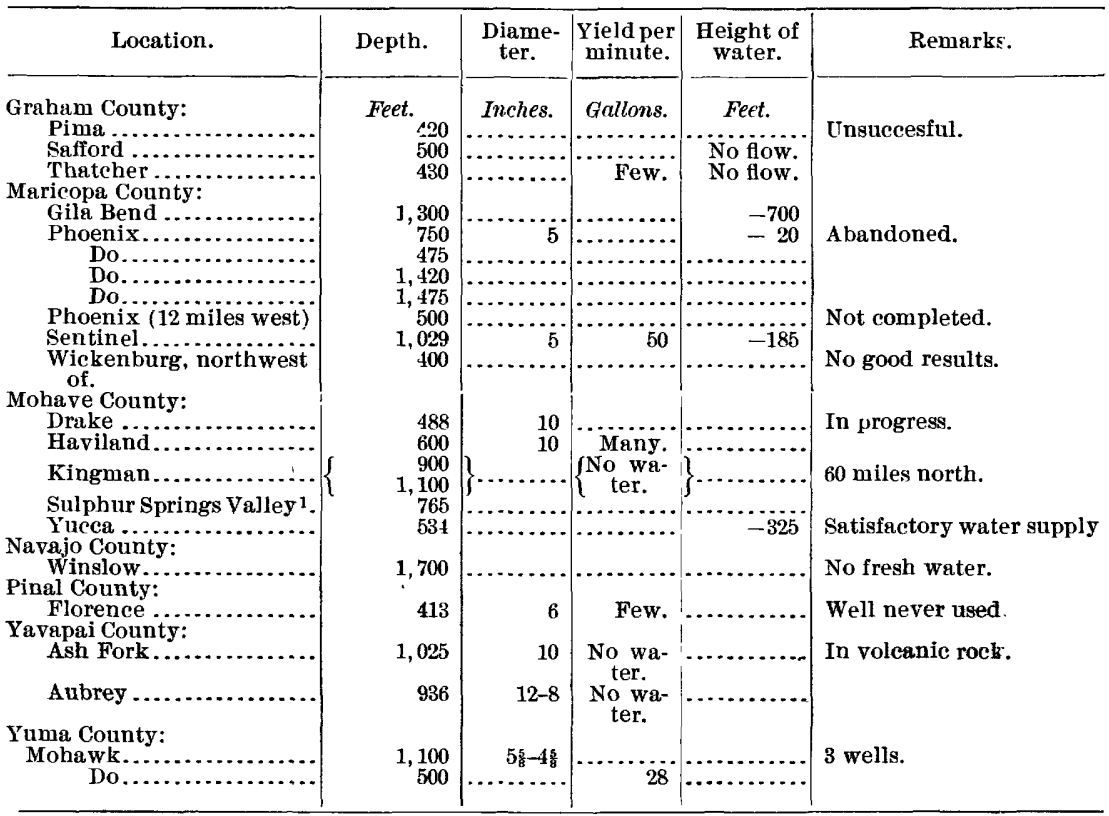

1 Record, Am. Philos. Soc. Proc., vol. 40, No. 167, pp. 161-164, 1902.

PUBLICATIONS RELATING TO DEEP BORINGS IN ARIZONA.

American Philosophical Society Proceedings, vol. 40, No. 167., pp. 161-164, 1902.

ARKANSAS.

\begin{tabular}{|c|c|c|c|c|c|}
\hline Location. & Depth. & $\begin{array}{l}\text { Diame- } \\
\text { ter. }\end{array}$ & $\begin{array}{l}\text { Yield per } \\
\text { minute. }\end{array}$ & $\begin{array}{l}\text { Depth to } \\
\text { water. }\end{array}$ & Remarks. \\
\hline Ashjey County: & Feet. & Inches. & Gallons. & Feet. & \\
\hline Crossett ................. & 976 & & & $\begin{array}{l}-74 \\
-36\end{array}$ & Sulphur water 470 feet. \\
\hline Do... & 450 & & & & Abandoned. \\
\hline Portland .... & 400 & & & -30 & Alkaline. \\
\hline $\begin{array}{l}\text { Benton County: } \\
\text { Gentry }\end{array}$ & & $8-61$ & 490 & -19 & \\
\hline $\begin{array}{r}\text { Gentry } \\
\text { Do........... }\end{array}$ & 700 & $0-\sigma_{\overline{\mathbf{g}}}$ & 920 & No flow. & \\
\hline Do $\ldots \ldots \ldots \ldots \ldots \ldots$ & $\begin{array}{r}1,000 \\
+1,350\end{array}$ & 7 & $\ldots \ldots \ldots$ & -30 & Water at 700 and 900 feet. \\
\hline Bradley County: & & & & & \\
\hline $\begin{array}{l}\text { Warren ( } 1 \text { mile east) .... } \\
\text { Chicot County: }\end{array}$ & 648 & $2 \frac{1}{8}$ & 100 & -36 & \\
\hline Dermott $\ldots \ldots \ldots \ldots$ & 750 & $4-2 \frac{1}{2}$ & $\ldots \ldots \ldots$ & -11 & $\begin{array}{l}\text { Water from sand at about } \\
600 \text { feet,pumps } 75 \text { gallons } \\
\text { per minute. }\end{array}$ \\
\hline $\begin{array}{l}\text { Clark County: } \\
\text { Arkadelphia } \quad(1 \text { mile }\end{array}$ & 551 & & & Flow. & Strong flow of salt water \\
\hline $\begin{array}{c}\text { Arkadelphia (2 miles } \\
\text { east). }\end{array}$ & 410 & , $\quad 6-4$ & Large. & +26 & Salt water. \\
\hline Gurdon ...................... & 760 & $10-6$ & & & $\begin{array}{l}\text { Oil well; abandoned arte- } \\
\text { sian water at } 198 \text { feet; salt }\end{array}$ \\
\hline $\begin{array}{l}\text { Gurdon (4 miles south } \\
\text { of, at old Empire mill). }\end{array}$ & 402 & $3 \frac{1}{4}$ & & -60 & water at about 600 feet. \\
\hline $\begin{array}{l}\text { Okolona (3 miles south- } \\
\text { east). }\end{array}$ & 400 & & & -30 & Hard water. \\
\hline $\begin{array}{l}\text { Cleveland County: } \\
\text { Anderson....................... } \\
\text { Kedron (1 mile.west, at }\end{array}$ & 432 & $2 \frac{1}{2}$ & 42 & -32 & \\
\hline 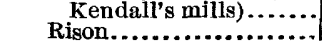 & $\begin{array}{l}457 \\
700\end{array}$ & 3 & Large. & $\begin{array}{l}-50 \\
\ldots \ldots\end{array}$ & $\begin{array}{l}\text { Sulphur water. } \\
\text { No water. }\end{array}$ \\
\hline
\end{tabular}


ARKANSAS-Continued.

\begin{tabular}{|c|c|c|c|c|c|}
\hline Location. & Depth. & $\begin{array}{l}\text { Diame- } \\
\text { ter. }\end{array}$ & $\left\{\begin{array}{c}\text { Yield per } \\
\text { minute. }\end{array}\right.$ & $\begin{array}{l}\text { Height of } \\
\text { water. }\end{array}$ & Remarks. \\
\hline $\begin{array}{l}\text { Columbia County: } \\
\text { Waldo................... }\end{array}$ & $\begin{array}{l}\text { Feet. } \\
\quad 1,038\end{array}$ & $\begin{array}{r}\text { Inches. } \\
5-1\end{array}$ & $\begin{array}{l}\text { Gallons. } \\
\text { G.......... }\end{array}$ & 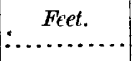 & Abandoned. Some water \\
\hline Craighead County: & & & & & $\begin{array}{l}\text { at } 510 \text { reet, rose to }-70 \\
\text { fiet. }\end{array}$ \\
\hline $\begin{array}{l}\text { Jonesboro (waterworks) } \\
\text { Jonesboro }(\text {................... }\end{array}$ & $\begin{array}{r}+600 \\
1,298\end{array}$ & 8-6 & Many. & -35 & \\
\hline Crittenden County: & & & & & \\
\hline 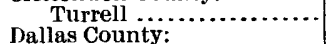 & 860 & $6-4$ & Many. & -10 & \\
\hline 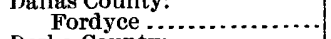 & 502 & 4 & 60 & -70 & Temp., $72.5^{\circ}$. \\
\hline $\begin{array}{l}\text { Desha County: } \\
\text { Arkansas City ..... }\end{array}$ & 552 & 6 & 65 & $\rightarrow 12$ & Temp., $72^{\circ}$. \\
\hline $\begin{array}{l}\text { Drew County: } \\
\quad \text { Blissville ............. }\end{array}$ & 490 & $10-4$ & & -11 & Wa.ter at $30,80,200,400$, \\
\hline - Monticello (cotton mill) - & 810 & $6-2 \frac{1}{8}$ & 52 & -144 & \\
\hline $\begin{array}{l}\text { Monticello (cit } \\
\text { Monticello (ice }\end{array}$ & $\begin{array}{l}750 \\
800\end{array}$ & $\begin{array}{l}8 \\
21\end{array}$ & 110 & $\begin{array}{l}-126 \\
-145\end{array}$ & Temp., $78^{\circ}$. \\
\hline $\begin{array}{l}\text { Monticello (i } \\
\text { Monticello... }\end{array}$ & $\begin{array}{l}800 \\
500\end{array}$ & 8 & & $\begin{array}{l}-1+5 \\
-125\end{array}$ & \\
\hline Do.................. & 604 & $8-4 \frac{1}{3}$ & 100 & -110 & \\
\hline Wilmer.............. & 455 & $4-2 \frac{i}{2}$ & 380 & -2 & Temp., $72^{\circ}$; pumped. \\
\hline Do.............. & 800 & 1 & & Flows. & $\begin{array}{l}\text { We.ter at } 184,313,400 \text {, and } \\
890 \text { feet. }\end{array}$ \\
\hline Do......... & 400 & & & & \\
\hline $\begin{array}{l}\text { Garland County: } \\
\text { Hot Springs .... }\end{array}$ & 860 & 6 & 13 & & \\
\hline Hempstead County: & & & & & \\
\hline $\begin{array}{l}\text { Columbus } \ldots \ldots \ldots \\
\text { Fulton } \ldots \ldots \ldots\end{array}$ & $\begin{array}{l}730 \\
700\end{array}$ & $\begin{array}{l}3 \\
2\end{array}$ & & Flows. & $\begin{array}{l}\text { No water. } \\
\text { Goxd water: well caved }\end{array}$ \\
\hline 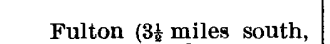 & 480 & 2 & & Flows. & kecause it was not cased. \\
\hline $\begin{array}{l}\text { at Moore place). } \\
\text { Fulton ( } 4 \text { miles south. }\end{array}$ & 480 & & & Flows. & \\
\hline at Smith place). & 700 & & & Flows. & \\
\hline $\begin{array}{l}\text { Fulton (7 mijes south, at } \\
\text { Ferguson place). }\end{array}$ & 655 & 4 & & Flows. & Caved in and abandoned. \\
\hline Do................ & $\begin{array}{l}755 \\
460\end{array}$ & 6 & 58 & $\ddot{0}$ & $\begin{array}{l}\text { No water, } \\
\text { Water first struck at } 316\end{array}$ \\
\hline Guernsey ( $1 \frac{1}{2}$ miles south) & 434 & 2 & & +18 & \\
\hline $\begin{array}{l}\text { Guernsey (1 } 1 \frac{1}{2} \text { miles south- } \\
\text { east). }\end{array}$ & 427 & $\overline{2}$ & & +6 & \\
\hline Hope (city well) ......... & 950 & $5-4$ & & ..... & $\begin{array}{l}\text { Water } 375 \text { to } 440 \text { feet; no } \\
\text { vater below; abandon- } \\
\text { ed. }\end{array}$ \\
\hline Hope . & 404 & 2 & & $-70 ?$ & \\
\hline Hope (waterworks) & 500 & $9-6$ & 150 & -66 & \\
\hline Hope (ice factory) $\ldots \ldots$. & 428 & 4 & $\cdots$ & -58 & \\
\hline $\begin{array}{l}\text { Hope (oil mill) ................. } \\
\text { Hope }\end{array}$ & 426 & 3 & $\cdots \cdots$ & $\begin{array}{l}-62 \\
-47\end{array}$ & \\
\hline $\begin{array}{l}\text { Hope } \ldots \ldots \ldots \ldots \ldots \ldots \ldots \\
\text { Hope (5 miles southeast) }\end{array}$ & $\begin{array}{l}400 \\
580\end{array}$ & 4 & $\cdots \cdots$ & $\begin{array}{l}-48 \\
\ldots \ldots \ldots\end{array}$ & Akandoned. \\
\hline Hope ........................ & 400 & 4 & (n) & -2 & 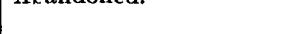 \\
\hline$\ldots \ldots \ldots \ldots \ldots \ldots$ & 410 & & $\cdots \cdots$ & -30 & . \\
\hline 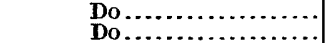 & $\begin{array}{l}406 \\
420\end{array}$ & & $\cdots .$. & $\begin{array}{l}-15 \\
-18\end{array}$ & \\
\hline 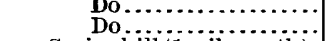 & $\begin{array}{l}420 \\
427\end{array}$ & (n.......... & (n........... & -26 & \\
\hline $\begin{array}{l}\text { Springhill (1mile north) } \\
\text { Spring hill ( } 1 \frac{1}{2} \text { miles }\end{array}$ & 580 & 2 & Large. & -30 & \\
\hline 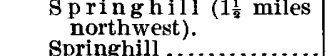 & 556 & & Large. & -20 & \\
\hline $\begin{array}{l}\text { Springhill (amiles north- } \\
\text { Springhill (2mon. }\end{array}$ & 500 & 2 & & \pm 25 & \\
\hline $\begin{array}{l}\text { Springhill (2 miles north- } \\
\text { west). }\end{array}$ & 434 & 4 & & Flows. & \\
\hline Springhill $\ldots \ldots \ldots \ldots \ldots$ & 541 & 2 & & -16 & \\
\hline Do...................... & $408-498$ & 2 & & $\left\{\begin{array}{c}-37 \text { to } \\
+18\end{array}\right.$ & \}5 vrells. \\
\hline Washington ............... & 750 & 3 & & $\ldots \ldots \ldots$ & Ne water. \\
\hline y & 700 & & & & Do. \\
\hline Hot Spring County. & 478 & & 50 & & \\
\hline Howard Co & & & & & \\
\hline$(1$ mile east $) ..$. & $\begin{array}{l}430 \\
500\end{array}$ & 2 & 6 & $\begin{array}{l}+17 \\
-18\end{array}$ & \\
\hline 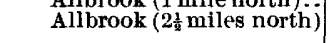 & 480 & 3 & & $\begin{array}{l}=10 \\
-80\end{array}$ & Water first encountered at \\
\hline Allbrook (2 miles west)... & 466 & 3 & & Flows. & \\
\hline Allbrook.................. & $400-496$ & 2-3 & & +17 & SSereral wells. \\
\hline $\begin{array}{l}\text { Buckrange, center point } \\
\text { ( } 2 \text { miles south). }\end{array}$ & 500 & 2 & $\cdots$ & -98 & \\
\hline & 466 & & & & \\
\hline Saratoga.............. & $\begin{array}{l}600 \\
440\end{array}$ & 3 & .... & No fiow. & Supplies gin. \\
\hline & & & & & \\
\hline
\end{tabular}


ARKANSAS-Continued.

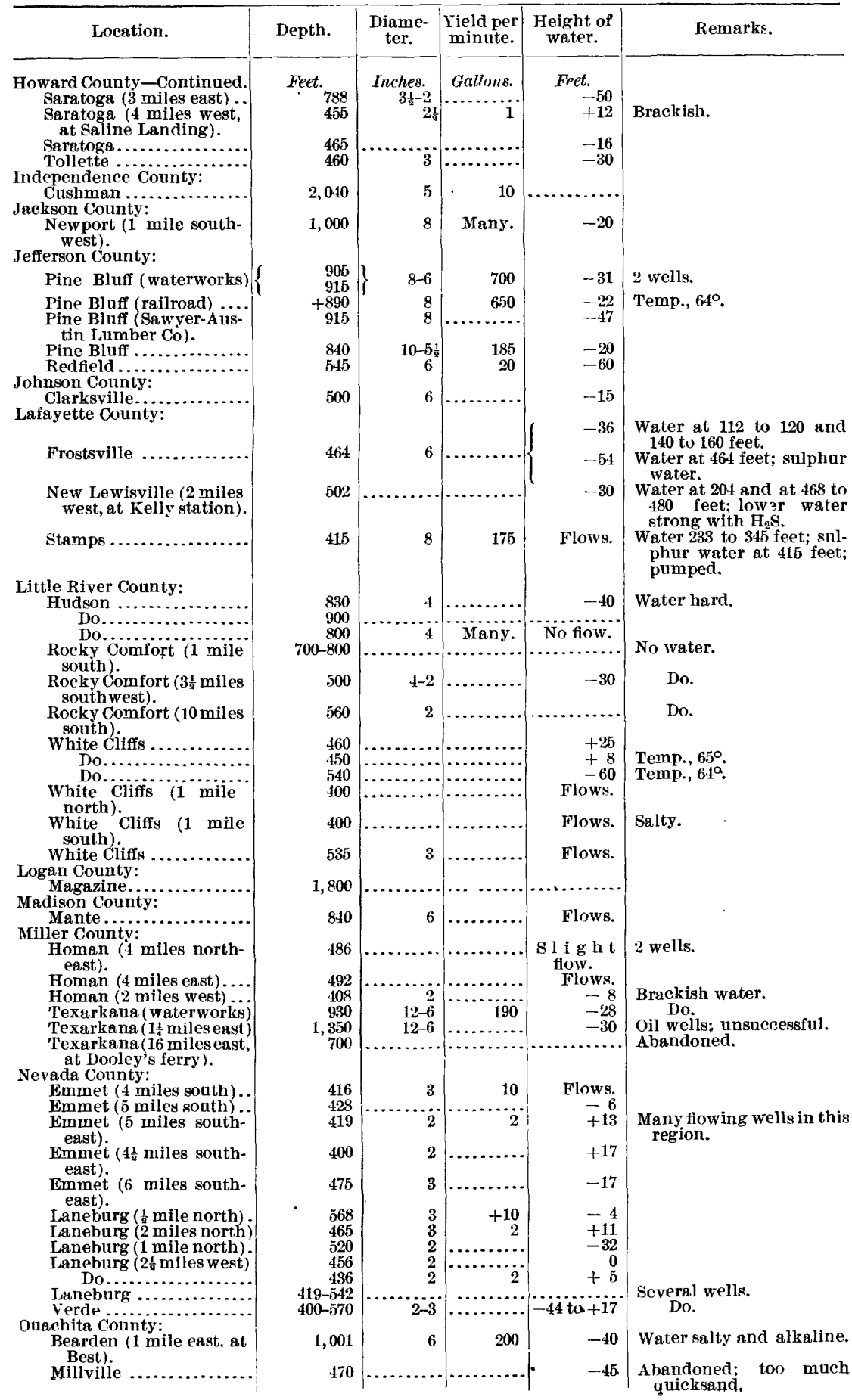


ARKANSAS--Continued.

\begin{tabular}{|c|c|c|c|c|c|}
\hline Location. & Depth. & $\begin{array}{l}\text { Diam- } \\
\text { eter. }\end{array}$ & $\begin{array}{c}\text { Yield per } \\
\text { minute. }\end{array}$ & $\begin{array}{l}\text { Height of } \\
\text { water. }\end{array}$ & Remarks. \\
\hline $\begin{array}{l}\text { Phillips County: } \\
\quad \text { Helena } \ldots \ldots \ldots \ldots \ldots \ldots \\
\text { Do } \ldots \ldots \ldots \ldots \ldots \ldots \ldots\end{array}$ & $\begin{aligned} & \text { Fet. } \\
& 500 \\
& 543\end{aligned}$ & $\begin{array}{r}\text { Inches. } \\
12-6 \\
8\end{array}$ & $\begin{array}{r}\text { Gallons. } \\
10 \\
656\end{array}$ & $\begin{aligned} & \text { Feet. } \\
&-30 \\
&-30\end{aligned}$ & \\
\hline 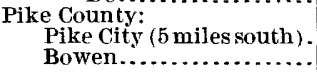 & $\begin{array}{r}1,400 \\
400\end{array}$ & 0 & $\begin{array}{l}\text { Small. } \\
\text { Many. }\end{array}$ & $\begin{array}{l}\text { Flow. } \\
\text { No flow. }\end{array}$ & $\begin{array}{l}\text { Oil well: unsuccessful. } \\
\text { Several wells of this kind }\end{array}$ \\
\hline $\begin{array}{l}\text { Polk County: } \\
\quad \text { Mena } . . . . . . . . . . .\end{array}$ & 1,615 & & & -20 & $\begin{array}{l}\text { in the county. } \\
\text { Abundant supply: pro- } \\
\text { posed as supply for city } \\
\text { waterworks. }\end{array}$ \\
\hline $\begin{array}{l}\text { Do } \ldots . . . \ldots \ldots \\
\text { Pope County: }\end{array}$ & +700 & 10 & Many. & No flow. & \\
\hline $\begin{array}{l}\text { Russellville (railroad } \\
\text { well). } \\
\text { Randolph County: }\end{array}$ & 1,006 & $12-10$ & & & $\begin{array}{l}\text { Abandoned; a little water } \\
\text { at } 90 \text { feet. }\end{array}$ \\
\hline 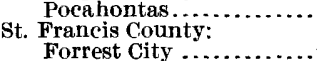 & 650 & 6 & Many. & $\ldots \ldots$ & In progress. \\
\hline $\begin{array}{r}\text { Do } \\
\text { Sebastian Gounty. }\end{array}$ & 460 & 6 & ............. & -160 & \\
\hline $\begin{array}{l}\text { Sebastian County: } \\
\text { Huntington ........... }\end{array}$ & 501 & $5 \frac{1}{2}$ & 20 & -25 & \\
\hline $\begin{array}{l}\text { Sevier County: } \\
\text { Ben Lomond (1 mile } \\
\text { south). }\end{array}$ & 400 & & & -6 & Water struck at 300 feet. \\
\hline $\begin{array}{l}\text { Ben Lomond ( } \frac{1}{4} \text { mile } \\
\text { south). }\end{array}$ & 540 & 3 & & -125 & \\
\hline 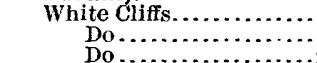 & $\begin{array}{l}460 \\
450 \\
540\end{array}$ & & & $\begin{array}{l}+25 \\
+8 \\
+60\end{array}$ & $\begin{array}{l}\text { Temp., } 65^{\circ} . \\
\text { Temp. } 64^{\circ}\end{array}$ \\
\hline $\begin{array}{l}\text { Washington County: } \\
\text { Fayetteville }^{1} \ldots \ldots \ldots \ldots\end{array}$ & 1.480 & & & & \\
\hline
\end{tabular}

${ }^{1}$ Record, Ark. Geol. Surv. Rept., vol. 2, 1891, pp. 67-69.

\section{LIST OF PUBLICATIONS RELATING TO DEEF BORINGS IN ARKANSAS.}

Arkansas Geol. Surv. Report, vol. 1, 1891.

Geology and water resources of northern Louisiana and southern Arkansas, by A. C. Veatch: Prof. Paper U. S. Geol. Survey. No. 46. (In preparation.)

\section{CALIFORNIA.}

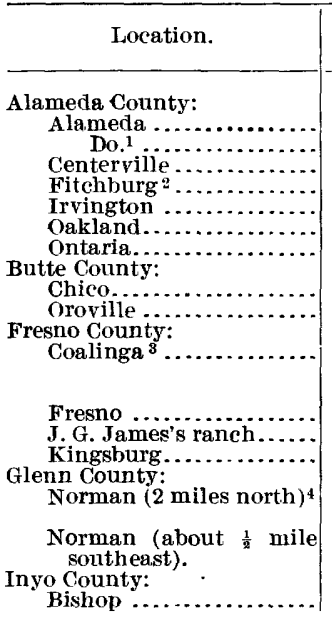

1 Record, Cal. State Mining Bureau, 11th Rept. 1891-92, pp. 135-136.

Ibid., p. 134 .

\begin{tabular}{|c|c|c|c|c|}
\hline Depth. & $\begin{array}{l}\text { Diam- } \\
\text { eter. }\end{array}$ & $\begin{array}{l}\text { Yield per } \\
\text { minute. }\end{array}$ & $\begin{array}{l}\text { Height of } \\
\text { water. }\end{array}$ & Remarks. \\
\hline Feet. & Inches. & Gallons. & Feet. & \\
\hline 409 & n...... & . & -8 & \\
\hline $\begin{array}{r}442 \\
400-500\end{array}$ & ${ }_{7-12}$ & 1,000 & $\begin{array}{l}\text { Flows. } \\
\text { No flow. }\end{array}$ & Several wells. \\
\hline $\begin{array}{l}450 \\
506 \\
457\end{array}$ & (n.......... & $\cdots \cdots{ }_{1 i 2}$ & $\begin{array}{l}\text { Flows. } \\
\text { Flows. } \\
\text { No flow. }\end{array}$ & \\
\hline $\begin{array}{l}686 \\
800\end{array}$ & $\ldots \ldots$ & $\operatorname{Several}_{4}$ & $\begin{array}{l}\text { No flow. } \\
\text { lows.? }\end{array}$ & \\
\hline $400-650$ & & & $\ldots \ldots \ldots \ldots$ & $\begin{array}{l}\text { Numerous oil wells in two } \\
\text { groups: one } 3 \text { miles west, } \\
\text { the other } 9 \text { miles nortl. }\end{array}$ \\
\hline $\begin{array}{r}600-800 \\
600\end{array}$ & $7-8$ & Flows. & No flow. & Several wells. Temp. $60^{\circ}$. \\
\hline 940 & 2 & 4 & . $\quad+15$ & Small amount of gas at \\
\hline 1,100 & & & Surface. & $\begin{array}{l}\text { Small amount of gas at } \\
500 \text { feet. }\end{array}$ \\
\hline 420 & & & & In progress. \\
\hline
\end{tabular}

${ }^{3}$ Analysis, ibid., 12th Rept., 1893-94, pp. 352-353. 4 Record, ibid., 11th Rept., 1891-92, p. 224. 
CALIFORNIA-Continued.

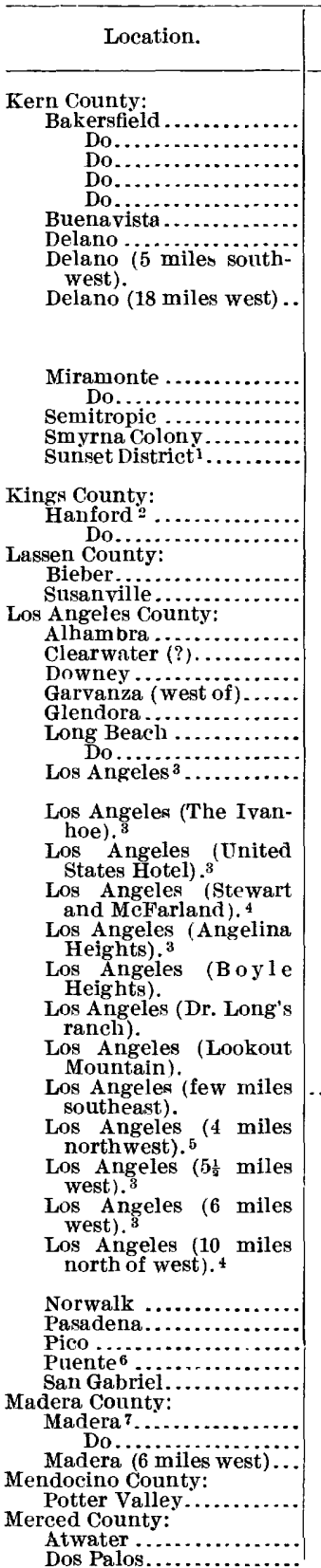

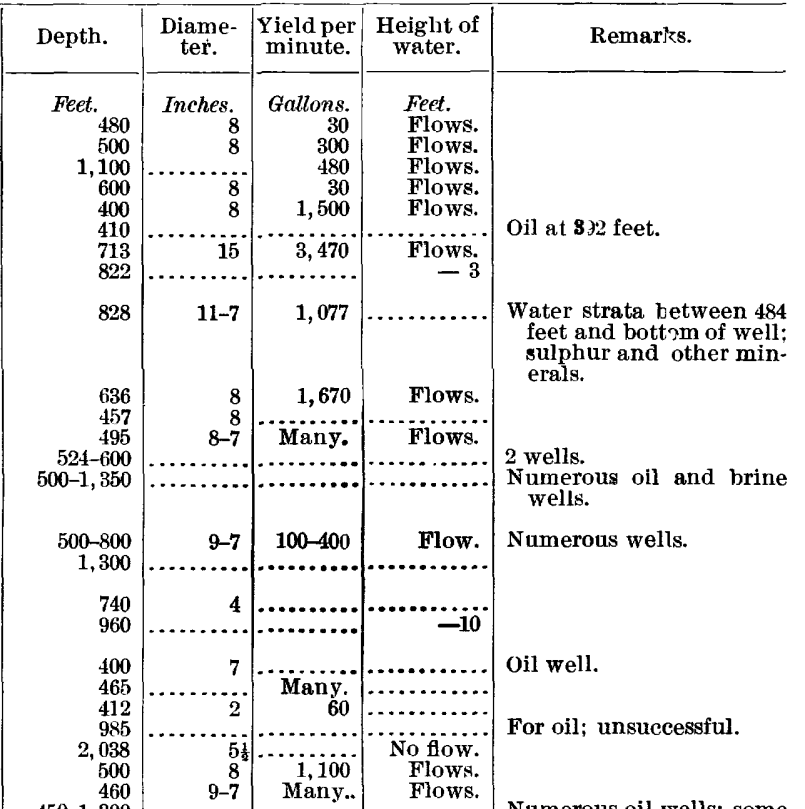

$450-1,300$

$+1,000$

$+900$

1,485

1,186

600

500

550

820

$\pm 500$

658-1, 485

520

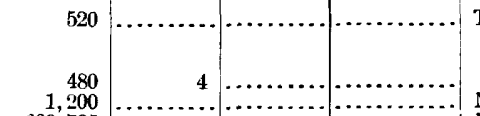

$600-735$

100-1,750

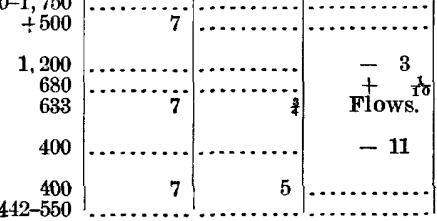

442-550
Numerous oil rells; some abandoned.

Small supply of oil; abandoned.

Gas at 900 feet.

For oil; unsuccessful.

For oil or gas; sbandoned.

For oil: unsuccessful.

Small supply of oil; abandoned. Do.

Gas well.

Small supply of oil.

Small flow of gas; abandoned.

Two wells, for oil; unsuccessful.

Two welis, sulphur water and some gas; abandoned.

No water.

Numerous oil wells. Do.

4 Ibid., 7th Rept., 1887, p. 79.

5 Ibid., p. 77.

6 Ibid., Bull. No, 11, Oil and Gas Yielding Formations of Los Angeles, Ventura, and Santa Barbara counties, part 1, pp. 18-21.

7 Ibid., 11th Rept., 1891-92, p. 211. pp. 353-354. record Cal State Mining Bureau Bull. No. 3, Gas and Petroleum Yielding Formations, Central Valley, p. 30.

Ibid., 11th Rept., 1891-92, p. 489.

3 Ibid., Bull. No. 11, oil and Gas Yielding Formations of Los Angeles, Ventura, and Santa Barbara counties, part 1 , pp. 14-17. 
CALI FORN IA-Continued.

\begin{tabular}{|c|c|c|c|c|c|}
\hline Location. & Depth. & $\begin{array}{l}\text { Diame- } \\
\text { ter. }\end{array}$ & $\begin{array}{l}\text { Itield per } \\
\text { minute. }\end{array}$ & $\begin{array}{l}\text { Height of } \\
\text { water. }\end{array}$ & Remarks. \\
\hline $\begin{array}{l}\text { Merced County-Continued. } \\
\text { Los Banosi } \ldots \ldots \ldots \ldots \ldots\end{array}$ & Feet. ${ }_{434}$ & Inches. & Gallons. & $\begin{array}{l}\text { Ffet. } \\
\text { Flowa. }\end{array}$ & \\
\hline Merced...$\ldots \ldots \ldots$ & $600-700$ & & $167-175$ & & \\
\hline $\begin{array}{l}\text { Merced (13 miles south- } \\
\text { west). }\end{array}$ & 1,013 & 10 & & $+1 \frac{1}{2}$ & $\begin{array}{l}\text { Strongest flow at } 66.5 \text { ancl } \\
680 \text { feet. }\end{array}$ \\
\hline San Lewis Ranch........ & $410-426$ & 7 & $128-160$ & & Two wells. \\
\hline $\begin{array}{l}\text { Modoc County: } \\
\text { Cedarville } . \ldots \ldots \ldots \ldots \ldots\end{array}$ & & & & & \\
\hline $\begin{array}{l}\text { Cedarville } \ldots \ldots \ldots \ldots \ldots \\
\text { Eagleville } \ldots \ldots \ldots\end{array}$ & $\begin{array}{l}433 \\
508\end{array}$ & $\dddot{4} \frac{1}{2}$ & . & No flow. & \\
\hline Monterey County: & & & & & \\
\hline $\begin{array}{c}\text { Salinas } \ldots \ldots \ldots \ldots \\
\text { Do } \ldots \ldots \ldots\end{array}$ & $\begin{array}{l}1,435 \\
1,100\end{array}$ & $\begin{array}{r}8 \\
11-9\end{array}$ & & $\begin{array}{r}-6 \\
-10\end{array}$ & \\
\hline seaside (near)....... & 617 & $\ldots$ & 30 & Flows. & $\begin{array}{l}\text { Main flow at } 610 \text { feet. } \\
\text { Water-bearing beds at }\end{array}$ \\
\hline $\begin{array}{l}\text { Napa Gounty: } \\
\text { St. Jelena... }\end{array}$ & 2,000 & & 1 & & 270 and 540 feet. \\
\hline $\begin{array}{c}\text { Orange County: } \\
\text { Fairview } . . .\end{array}$ & & & & & \\
\hline $\begin{array}{l}\text { Fairview } \ldots \ldots \ldots \\
\text { Placer County: }\end{array}$ & 450 & 7 & & & \\
\hline Auburn $\quad$ Sheridan.......... & 730 & & & & \\
\hline $\begin{array}{l}\text { Sheridan } 2 . . . . \\
\text { Plumas County: }\end{array}$ & 734 & & & --19 & \\
\hline Beckwith ..... & 400 & 3 & 80 & Flows. & \\
\hline Do $\ldots \ldots \ldots \ldots$ & $\begin{array}{r}500-860 \\
1000-1.900\end{array}$ & 3 & $\begin{aligned} 100 \\
\operatorname{sany}\end{aligned}$ & Flow. & Numerous wells. \\
\hline $\begin{array}{c}\text { Beckwith } \\
\text { above })\end{array}$ ( 8 miles & $\begin{array}{r}1,000-1,200 \\
900\end{array}$ & $\begin{aligned} 2-3 \\
3\end{aligned}$ & $\begin{array}{l}\text { Many. } \\
\text { Many. }\end{array}$ & Flow. & $\begin{array}{l}\text { Very warm mineral } \\
\text { water. }\end{array}$ \\
\hline Summit...$\ldots \ldots \ldots \ldots$ & $400-800$ & 3 & $5-125$ & Flow. & Numerous wells. \\
\hline $\begin{array}{r}\text { Do } \ldots \ldots \ldots \ldots \\
\text { Vinton } \ldots \ldots \ldots\end{array}$ & $\begin{array}{r}1,009 \\
700\end{array}$ & $\begin{array}{l}3-1 \\
-\ldots\end{array}$ & $\cdots \cdots$ & $\begin{array}{l}\text { Flow. } \\
\text { Flows. }\end{array}$ & \\
\hline Riverside County: & & & & & \\
\hline $\begin{array}{l}\text { Riverside............... } \\
\text { Winchester............ }\end{array}$ & 580 & 10 & Many. & Flows. & \\
\hline $\begin{array}{l}\text { Winchester........ } \\
\text { Sacramento County: }\end{array}$ & 400 & & & & \\
\hline $\begin{array}{l}\text { Arcade } \ldots \ldots \ldots \ldots \\
\text { Sacramento } \\
3\end{array}$ & 2,160 & & & & \\
\hline $\begin{array}{c}\text { Sacramento }^{3} \ldots \ldots \ldots \ldots \\
\text { Do. }{ }^{3} \ldots \ldots \ldots \ldots\end{array}$ & $\begin{array}{l}876 \\
965\end{array}$ & & & & $\begin{array}{l}\text { Gas well. } \\
\text { Do. }\end{array}$ \\
\hline Do. ${ }^{3} \ldots \ldots \ldots$ & 970 & $\cdots$ & $\cdots \cdot$ & Flows. & Water salty and alkaline. \\
\hline $\begin{array}{c}\text { Sacramento }(9 \text { miles } \\
\text { northeast }) .4\end{array}$ & 2,250 & & , & Floivs. & Some gas. \\
\hline San Bernardino Conuty: & & & & & \\
\hline $\begin{array}{c}\text { Chino (about } 2 \frac{1}{2} \text { miles } \\
\text { northwest). } \\
\text { Colton } 6 \ldots \ldots \ldots \ldots \ldots\end{array}$ & 600 & & & & $\begin{array}{l}\text { Abandoned. } \\
408 \text { flowing wells. }\end{array}$ \\
\hline Danby...$\ldots \ldots \ldots \ldots \ldots$ & 630 & 10 & & -200 & TOO HOWIIS WeTE. \\
\hline Fenner ........ & 800 & 10 & Many. & -200 & \\
\hline Ludlow ... & 1,800 & $\cdots$ & Few. & (......... & Not in use. \\
\hline North Cucamonga. & 450 & $\cdots$ & Many. & .... & \\
\hline North Ontario..... & 2,200 & & Menis & & Failure. \\
\hline San Bernardino. & 605 & 6 & Many, & Flows. & \\
\hline 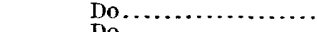 & 425 & 3 & & Flows. & \\
\hline Do.......... & 415 & 3 & 7 & Flows. & \\
\hline $\begin{array}{l}\text { San Diego County: } \\
\text { Flowing Well .... }\end{array}$ & \pm 400 & & & & \\
\hline Point Lon & -400 & $6-5$ & 24 & -253 & \\
\hline San Jacin & $456-650$ & 7 & & & Several wells. \\
\hline $\begin{array}{l}\text { San Francis } \\
\text { San Fra }\end{array}$ & & & 87 & & \\
\hline $\begin{array}{l}\text { San Francisco ............. } \\
\text { San Joaqun County: }\end{array}$ & 865 & $8-5$ & $8 \gamma$ & & \\
\hline Cutler Salmon Ranch & 1,250 & $7-4$ & & & Gas well. \\
\hline Lathrop Junction. & 1,420 & 8 & & Flows. & \\
\hline Roberts Island..... & 1,43 & $7-5$ & & Flows. & Gas well, saline water. \\
\hline Stockton $\ldots \ldots \ldots \ldots$ & 420 & 8 & & $+\frac{3}{4}$ & Warm water. \\
\hline $\begin{array}{l}\text { Stockton is. F. and S. J. } \\
\text { V.R.R.) }\end{array}$ & 49 & 7 & Many. & -19 & \\
\hline Stockton ${ }^{6} \ldots \ldots \ldots \ldots$ & 1,002 & & & +7 & Ternp., $77^{\circ}$. \\
\hline $\begin{array}{r}\text { Do............... } \\
\text { Stockton (Jackson }\end{array}$ & $1,400-2,000$ & $12-93$ & Many. & $\cdots \cdots$ & Gas wells. \\
\hline $\begin{array}{l}\text { Stockton (Jackson well) }{ }^{7} \\
\text { Stockton }{ }^{7} \ldots \ldots \ldots \ldots \ldots \ldots\end{array}$ & $\begin{array}{l}1,700 \\
1,400\end{array}$ & $12-9$ ? & & & $\begin{array}{c}\text { Gas well. } \\
\text { Do. }\end{array}$ \\
\hline Stockton Asylum (Jack- & $+600-1,750$ & & Many. & & Two gas wells. \\
\hline $\begin{array}{l}\text { son well). } \\
\text { Stockton (st. Agnes Col- }\end{array}$ & 1,720 & & Many. & & Do. \\
\hline $\begin{array}{l}\text { lege). } \\
\text { Stockton (court-house) }\end{array}$ & 1,917 & $12-8$ & Many. & & Gas well. \\
\hline $\begin{array}{l}\text { Stockton (Citizens' Gas } \\
\text { Co.). }\end{array}$ & 2,061 & $\cdots \cdots$ & Many. & & Do. \\
\hline
\end{tabular}

1 Record, Cal. State Mining Bureau, 10th Rept., 1890 , p. 326 .

2 Ibid.. 11th Rept., 1891-92, p. 319.

3 Cal. State Mining Bureau, 12th Rept., 1893-91. p. 350 .

4 Record, lbid., 10th Rept., 1890 , p. 505.

5 Physical Data and Statisties of Calıfornia (State

${ }^{6}$ Record, Cal. State Mining Bureau, 8th Rept., 1888 , pp. $559-560$.

7 Ibid. Bull No. 3, Gas and Petroleum Formations, Central Valley, p. 17.

8 Ibid., p. 18

9 Ibid., pp. 15-16.

Eng. Dept.), 1886, p. 530 . 
CALIFORN IA-Continued.

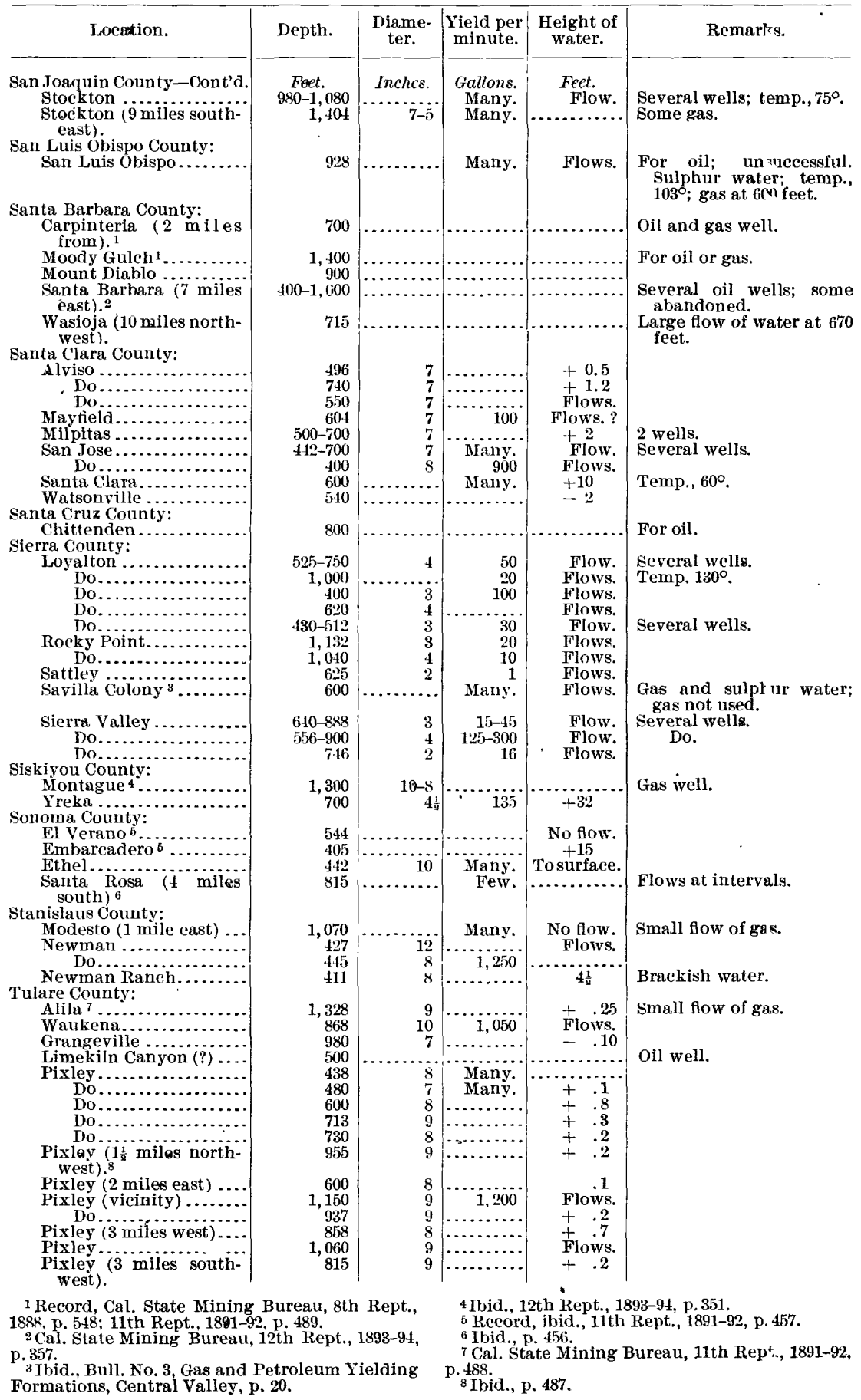

IRR $149-05-2$ 
CALIFORNIA-Continued.

\begin{tabular}{|c|c|c|c|c|c|}
\hline Location. & Depth. & $\begin{array}{l}\text { Diame- } \\
\text { ter. }\end{array}$ & $\begin{array}{l}\text { Yield per } \\
\text { minute. }\end{array}$ & $\begin{array}{l}\text { Height of } \\
\text { water. }\end{array}$ & Remarks. \\
\hline $\begin{array}{l}\text { Tulare County-Continued. } \\
\text { Pixley ( } 6 \text { miles south- } \\
\text { west }) .1\end{array}$ & $\begin{array}{l}\text { Fet. } \\
\qquad 1,150\end{array}$ & $\begin{array}{r}\text { Tnches. } \\
9\end{array}$ & Gallens. & $\begin{array}{l}\text { Fctt. } \\
+1\end{array}$ & \multirow{9}{*}{$\begin{array}{l}\text { Several wells about the } \\
\text { same depth. } \\
\text { Several wells. }\end{array}$} \\
\hline Pixley (6 miles west) $\ldots$. & 950 & 8 & & +.7 & \\
\hline $\begin{array}{l}\text { Pixley ( } 10 \text { miles south- } \\
\text { west). }\end{array}$ & 895 & 10 & & +.4 & \\
\hline Pomona ................ & $450-550$ & 6 and 9 & & & \\
\hline Tipton............... & 400 & & & +.04 & \\
\hline Do $\ldots \ldots, \ldots, \ldots, \ldots, \ldots$ & 480 & $8-6$ & & +.04 & \\
\hline Do.................... & $503-1,012$ & $8-9$ & Many. & Flow. & \\
\hline & 960 & 7 & F'ew. & & \\
\hline 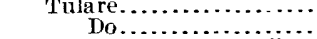 & $\begin{array}{l}400 \\
460\end{array}$ & $\begin{array}{l}6 \\
7\end{array}$ & 500 & $\begin{array}{l}+.8 \\
+\ldots .\end{array}$ & \\
\hline $\begin{array}{l}\text { Tulare (about } 20 \text { miles } \\
\text { west). }\end{array}$ & 500 & 7 & & +.15 & $\begin{array}{l}\text { Several wells about this } \\
\text { depth. }\end{array}$ \\
\hline $\begin{array}{l}\text { Tulare (E. Jacob's } \\
\text { ranch). }\end{array}$ & 539 & 9 & & +.1 & Some gas. \\
\hline Do. ${ }^{3} . \ldots \ldots$ & 498 & 9 & & & Do. \\
\hline Do. ${ }^{4} \ldots \ldots \ldots \ldots \ldots \ldots$ & 847 & 9 & & +.35 & Gas well. \\
\hline $\begin{array}{l}\text { Do } \ldots \ldots \ldots \\
\text { Tulare (city welis) } \ldots . . .\end{array}$ & 83.5 & 9 & & $+: 3$ & \\
\hline $\begin{array}{l}\text { Tulare (city wells) ........ } \\
\text { Tulare................. }\end{array}$ & $\begin{array}{l}552 \\
720\end{array}$ & $\begin{array}{l}9 \\
8\end{array}$ & $\operatorname{Many}_{300}$ & $\begin{array}{l}-15 \\
\text { Flows. }\end{array}$ & $\begin{array}{l}\text { Several wells. } \\
\text { Several wells about this }\end{array}$ \\
\hline $\begin{array}{l}\text { Tulare (about } 20 \text { miles } \\
\text { south west; Lambert- } \\
\text { son ranch).2 }\end{array}$ & 1,058 & 9 & Many. & +.75 & Gias at 600 and 700 feet. \\
\hline Tulare ( 7 miles west $)^{5}$.. & 730 & 8 & & +.35 & \multirow{11}{*}{$\begin{array}{l}\text { Several wells. } \\
\text { Many oil wells, yielding } \\
\text { 900 barrels per month. } \\
\text { Several oil wells. } \\
\text { Several wells. } \\
\text { o'l well. } \\
\text { Several odl wells. } \\
\text { Do. } \\
\text { O'l well. } \\
\text { Several oil wells. }\end{array}$} \\
\hline Visalia ................... & 775 & 7 & 190 & Flows & \\
\hline Waukena...... & $450-816$ & $8-9$ & Many. & Flows. & \\
\hline $\begin{array}{l}\text { Ventura County: } \\
\text { Adams Canyon }{ }^{6} . . .\end{array}$ & $40^{-}-2,780$ & & & & \\
\hline Aliso Canyon....... & $600-700$ & & & & \\
\hline Brownstone...$\ldots \ldots \ldots$ & $400-800$ & & & & \\
\hline $\begin{array}{l}\text { Buckhorn station } \\
\text { miles north). }\end{array}$ & 400 & & & & \\
\hline Four Forks $7 . . . \ldots \ldots \ldots$ & $700-1,100$ & & & & \\
\hline Kentuck ................ & $700-730$ & & & & \\
\hline Little Sespe district..... & 805 & & & & \\
\hline $\begin{array}{l}\text { Mount Cayetana (south- } \\
\text { west slope, near Santa } \\
\text { Paula Creek). }\end{array}$ & $430-1,170$ & & & & \\
\hline Nordhoff (1 mile south). & $500-800$ & & 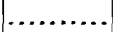 & & \multirow{13}{*}{$\begin{array}{l}\text { Do. } \\
\text { Do. } \\
\text { Numerous oil wells. } \\
\text { Several oil wells. } \\
\text { Do. } \\
\text { Numerous oil wells. } \\
\\
\text { Do. } \\
\text { Do. } \\
\text { Oil wells. } \\
\text { Several wells. } \\
\text { O't wells. }\end{array}$} \\
\hline Peru ( $1 \frac{1}{4}$ miles south $) . .$. & $400-570$ & & & & \\
\hline Sisi Canyon ............ & $400-800$ & ....... & & & \\
\hline Salt Marsh Ca & $400-1,600$ & & & & \\
\hline Santa Paula region....... & $530-800$ & & & & \\
\hline $\begin{array}{l}\text { Silverthread oil district } \\
\text { (near Santa Pa ula } \\
\text { Creek) }\end{array}$ & $400-1,600$ & & & & \\
\hline Tar Creek ${ }^{7} \ldots \ldots \ldots$ & $700-1,000$ & & & & \\
\hline Tar Creek Canyon. & $400-905$ & & & & \\
\hline Torrey Canyon ............ & $450-1,000$ & & Many. & Flow. & \\
\hline Wheeler Canyon ${ }^{9} . . . . .$. . & $400-900$ & & ........... & & \\
\hline Wild Bill Gulch ${ }^{9} \ldots \ldots$. & $850-975$ & & & & \\
\hline Yolo County: & & & & & \\
\hline Grafton..... & 450 & 6 & Many. & & \\
\hline
\end{tabular}

1 Cal. State Mining Bureau, 11th Rept., 1891-92, tions of Los Angeles, Ventura, and Santa Barbara pp. 487-488.

2 Ibid., p. 488

3 Ibid., p. 489 .

4 Ibid., pp. $488-489$

5 Ibid., p. 487.

6 Ibid., Bull. No. 11, Oil and Gas Yielding Formacounties, part 1 , pp. $35-31$.

counties, part 1 Ibid., p. 27 .

8 Ibid., pp. $37-38$.

9 Ibid., pp. 36-37.

10 Ibid., pp. $33,35,37$.

\section{PUBLICATIONS RELATING TO DEEP BORINGS IN CALIFORNIA.}

California State Mining Bureau, Seventh Annual Report of the State Mineralogist for the year ending October 1, 1887, 315 pages, Sacramento, 1888.

California State Mining Bureau, Eighth Annual Report of the State Mineralogist for the year ending October 1, 1888, 948 pages, plates, Sacramento, 1888.

California State Mining Bureau, Tenth Annual Report of th? State Mineralogist for the year ending December 1, 1890, 983 pages, plates, Sacramont $\rho, 1890$.

Physical Data and Statistics of California (State Eng. Dept.), 1886. 
California State Mining Bureau, Eleventh Report of the State Mineralogist (first biennial), two years ending September 15, 1892, 612 pages, Sacramento, 1893.

California State Mining Bureau, Twelfth Report of the State Mineralogist (second biennial), two years ending September 15, 1894, 541 pages, Sacramento, 1894.

California State Mining Burean, Bulletin No. 3, the Gas and Petroleum Yielding Formations of the Central Valley of California, by W. L. Watts, 99 pages, plates and maps, Sacramento, 1894.

California State Mining Bureau, Bulletin No. 11, Oil and Gas Yielding Formations of Los Angeles, Ventura, and Santa Barbara counties, part 1, by W. L. Watts, 94 pages, plates, map, Sacramento, 1897.

\section{COLORADO.}

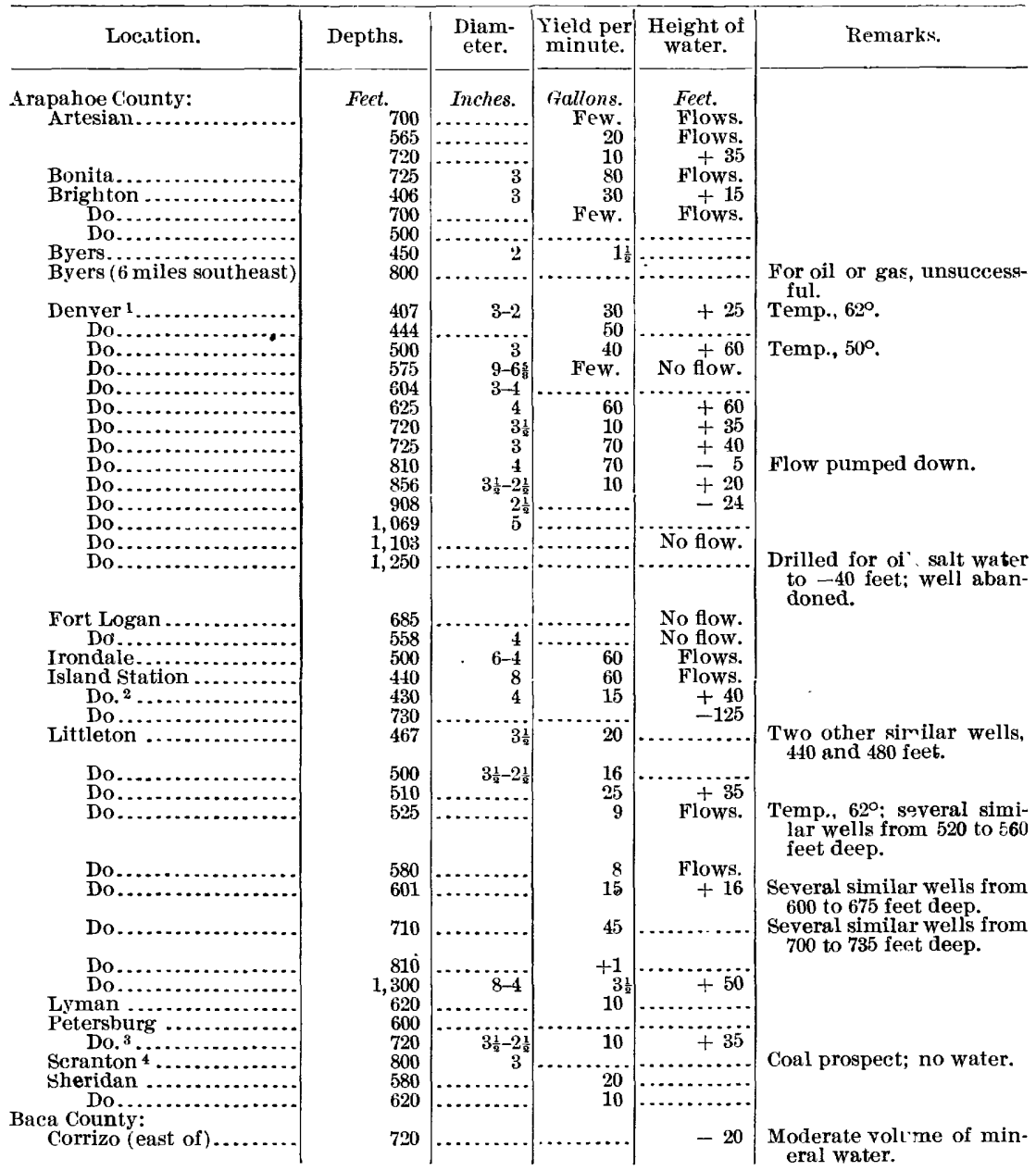

1 In Denver and vicinity there are several hundred wells, mainly from 350 to 1,000 feet deep. They yield flows of considerable size from several horizons, but owing to large number of wells the volume of water is now greatly decreased. The wells are described in the following publications: 51st Congress, 1st session, Senate Ex. Doc. No. 222, pp. 175-205, 227-228, Washington, 1890; Monograph, U. S. Geol. Surv., vol. 27, Geology of the G. H. Eldridge, $4^{\circ}$, Washington, 1896.

2 Record, 51st Congress, 1st session, Senate Ex. Doc. No. 222, p. 197.

3 Ibid., p. 204

4 Ibid., p. 207. 
COLORADO-Continued.

\begin{tabular}{|c|c|c|c|c|c|}
\hline Location. & Depth. & $\begin{array}{c}\text { Diame- } \\
\text { ter. }\end{array}$ & $\begin{array}{l}\text { Yield per } \\
\text { minute. }\end{array}$ & $\begin{array}{c}\text { Height of } \\
\text { water. }\end{array}$ & Remarks. \\
\hline $\begin{array}{l}\text { Bent County: } \\
\text { Caddoa...... } \\
\text { Fort Lyon ... }\end{array}$ & $\begin{aligned} & \text { Feet. } \\
& 582 \\
& 815\end{aligned}$ & $\begin{array}{l}\text { Inches. } \\
\ldots \ldots \\
\cdots\end{array}$ & $\begin{array}{c}\text { Gallons. } \\
. . . . . . . . . .\end{array}$ & $\begin{array}{c}\text { Feet. } \\
\cdots \cdots+\cdots \\
\cdots \cdots\end{array}$ & $\begin{array}{l}\text { Water at various depths. } \\
\text { A b and oned; s m a } 11 \\
\text { anount of water at } 430 \\
\text { fet. }\end{array}$ \\
\hline Fort Lyon, northeast of . & 780 & & & $\begin{array}{l}-200 \text { or } \\
-580 ?\end{array}$ & \\
\hline $\begin{array}{c}\text { Las Animas } \\
\text { Las Animas } \\
\text { northeast }) .\end{array}$ & $\begin{array}{r}500 \\
+815\end{array}$ & & $(?)^{82}$ & Flows. & $\begin{array}{l}\text { Small amount of water at } \\
\text { 43) feet. }\end{array}$ \\
\hline T. 21, R. 52 , sec. $36 . \ldots$... & 720 & & & -300 & $\begin{array}{l}\text { Goot water supply in sand- } \\
\text { stone from } 452 \text { to } 474 \text { feet, } \\
\text { br t well is regarded as } \\
\text { a failure. }\end{array}$ \\
\hline Do.......... & 418 & & & $\begin{array}{l}-150 \text { or } \\
-268\end{array}$ & \\
\hline $\begin{array}{l}\text { Boulder County: } \\
\text { Boulder ........ }\end{array}$ & 400 & 2 & 5 & Flows. & \\
\hline Do....... & $+1,000$ & & & +20 & Wator too alkaline. \\
\hline $\begin{array}{l}\text { Boulder (4 miles east).... } \\
\text { Hygiene } 1 . \ldots \ldots \ldots \ldots \ldots \ldots\end{array}$ & $\begin{array}{l}600 \\
905\end{array}$ & & & $\ldots \ldots . . .6$ & $\begin{array}{l}\text { Unsuccessful. } \\
\text { Flowed at } 675 \text { feet. }\end{array}$ \\
\hline $\begin{array}{l}\text { Langford (4 miles north- } \\
\text { east). }\end{array}$ & 400 & 2 & 3 & Flows. & \\
\hline Longmont ${ }_{\text {Do }} \ldots \ldots \ldots$ & $\begin{array}{l}431 \\
506\end{array}$ & 4 & $\begin{array}{l}+2 \\
\ldots \ldots\end{array}$ & No flow. & \\
\hline Do.. & $\begin{array}{l}200 \\
600\end{array}$ & 6 & 40 & $\begin{array}{r}\text { No } \\
+30\end{array}$ & \\
\hline $\begin{array}{l}\text { Do } \ldots . . . \\
\text { Cheyenne Con }\end{array}$ & 640 & $3 \frac{1}{2}$ & Few. & & \\
\hline Cheyenne & 1,770 & & & & For water; abandoned. \\
\hline $\begin{array}{l}\text { Do...... } \\
\text { Kit Carson. }\end{array}$ & 1,700 & & & & For gas: failure. \\
\hline Clear Creek Countv. & 1,460 & & & & $\begin{array}{l}\text { No fresh water; salt water } \\
\text { at } 450 \text { feet. }\end{array}$ \\
\hline $\begin{array}{l}\text { Clear Creek County: } \\
\text { Georgetown } . . . \ldots \ldots \ldots\end{array}$ & & & & & \\
\hline $\begin{array}{l}\text { Georgetown } \\
\text { Conejos County: }\end{array}$ & 658 & 2 & 120 & +100 & \\
\hline 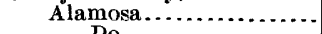 & 505 & 3 & 3 & Flows. & \\
\hline Do......... & 604 & $\begin{array}{r}3 \\
6-8\end{array}$ & $\begin{array}{r}225 \\
1000\end{array}$ & $\begin{array}{l}\text { Flows. } \\
\text { Flows. }\end{array}$ & \\
\hline Do........ & 465 & $3 \frac{1}{2}$ & Many. & Flows. & Tento., $65^{\circ}$. \\
\hline Do. & 474 & 2 & Many. & Flows. & \\
\hline $\begin{array}{l}\text { Do. } \\
\text { Do. }\end{array}$ & 1,000 & $75-6$ & Many. & Flows. & Tern., $75^{\circ}$ \\
\hline Costilla County: & 900 & 8 & Many. & Flows. & 2 wells; temp., $70^{\circ}$. \\
\hline Mosca........ & 610 & $4 \frac{1}{2}$ & & +3 & \\
\hline Custer County: ', & 420 & 4 & & Flow. & \\
\hline $\begin{array}{l}\text { Colfax } \\
\text { Westeliffe.......... }\end{array}$ & $\begin{array}{l}627 \\
500\end{array}$ & & & Flows. & \\
\hline Delta County: & 000 & & None. & & Abandonea. \\
\hline Delta $\quad . . . . . . .$. & $\begin{array}{l}575 \\
580\end{array}$ & $\begin{array}{l}21 \\
3\end{array}$ & Few. & $\begin{array}{l}\text { Flows. } \\
\text { Flows. }\end{array}$ & \\
\hline $\begin{array}{l}\text { Denver County: } \\
\text { Denver (east of) }\end{array}$ & 795 & & & & Unsq.tisfactory. \\
\hline Denver (St. Luke's Hos- & & & & & Lar 3 e flow of flne water. \\
\hline Denver............. & $400-1,100$ & & & & Seviral hundred wells. \\
\hline Douglas County: & $1,350-1,500$ & & & & $\begin{array}{l}\text { Water from lowest Lara- } \\
\text { mie and top Foxhills; } \\
\text { ccnsiderably mineral- } \\
\text { iz?d. }\end{array}$ \\
\hline Acequia..... & 442 & 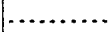 & 15 & Flows. & \\
\hline & 596 & & 4 & Flows. & \\
\hline $\begin{array}{l}\text { Castle Rock } \\
\text { Larkspur } . . .1\end{array}$ & $\begin{array}{r}1,700 \\
560\end{array}$ & & $\cdots \cdots \cdot$ & 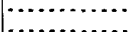 & Failure. \\
\hline 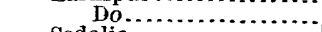 & 502 & & & & Dry: abandoned. \\
\hline Sedalia ............. & 650 & $2 \frac{1}{2}$ & .... & $\ldots \ldots \ldots$ & \\
\hline 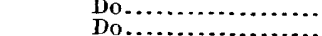 & $\begin{array}{r}710 \\
440\end{array}$ & & ............. & No flow. & \\
\hline & 1,440 & & & & or'y. \\
\hline $\begin{array}{l}\text { Sedalia (5 miles south) }{ }^{4} \text {. } \\
\text { El Paso County: }\end{array}$ & & & & & \\
\hline Calhan $5 . . . . .$. & 566 & 6 & $\ldots \ldots \ldots \ldots$ & - & Saline water. \\
\hline Colorado City .. & 1,300 & & .... & ......... & $\begin{array}{l}\text { Gas pressure } 155 \text { pounds to } \\
\text { square inch; now fllled } \\
\text { with surface water. } \\
\text { Gas at } 216 \text { feet: shut off by } \\
\text { w ter. (Blue shale be- } \\
\text { low } 35 \text { feet.) }\end{array}$ \\
\hline
\end{tabular}

${ }^{1}$ Record. 51st Congress, 1st session, Senate Ex. Doc. No: 222 , p. 208 .

2 Record, U. S. Geol. Surv., 16th Ann. Rep., 189495 , part 2, p. 563 .
3 Record, 51st Congress, 1 th session, Senate Ex. Doc. No. 222, 1890 , p. 223.

4 Ibid., p. 207. 
COLORADO-Continued.

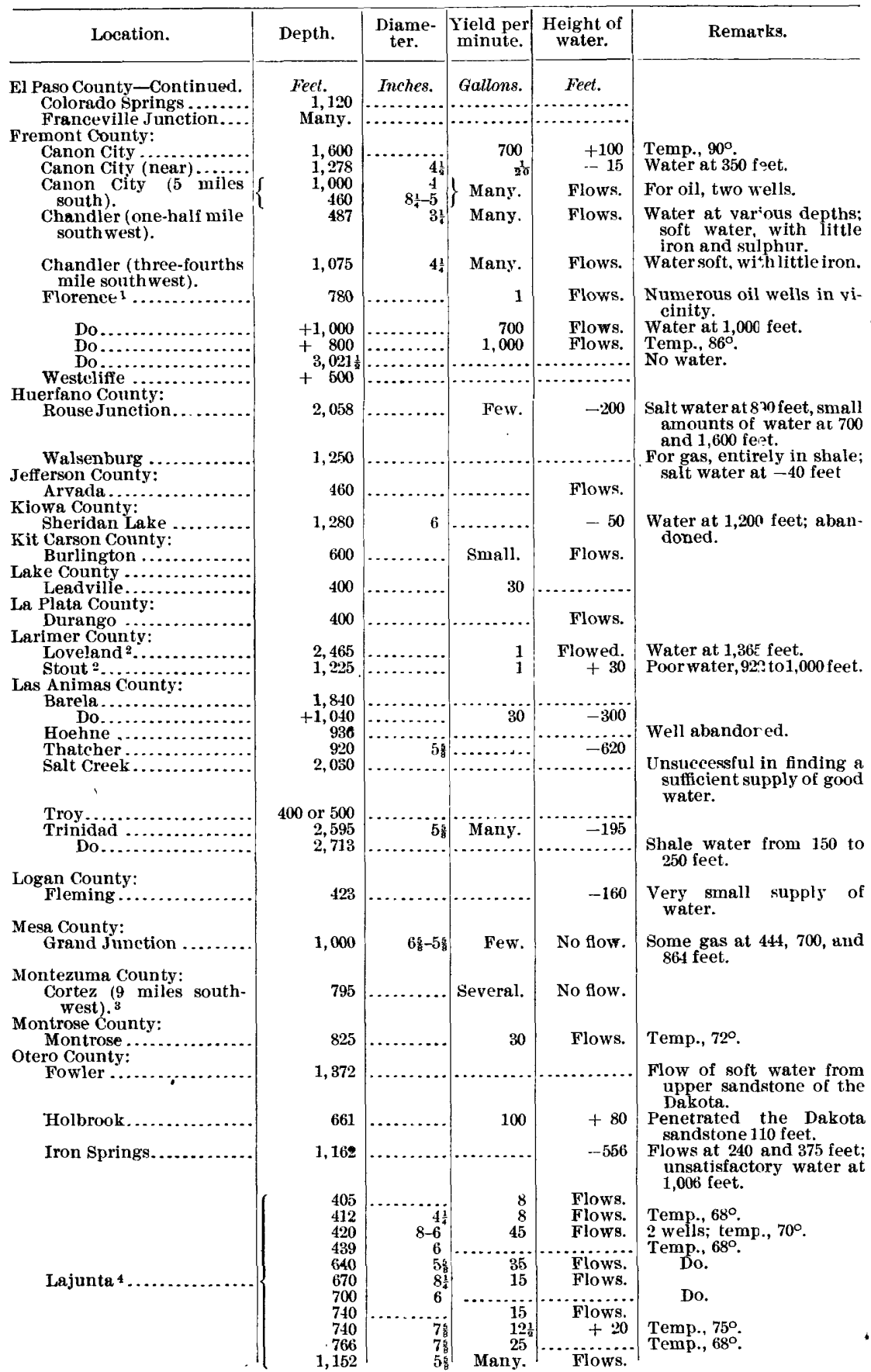

1 Record, 51st Congress, 1st session, Senate Ex. Doc. No. 222, pp. 214

2 Ibid., pp. 210-211.
${ }^{3}$ Record, Colorado State Engineer. Eighth Annual Report, 1895-96, pp. 69-70.

${ }^{4}$ Ibid., Ninth Biennial Report, 1897-98, pp. 28-29. 
COLORADO-Continued.

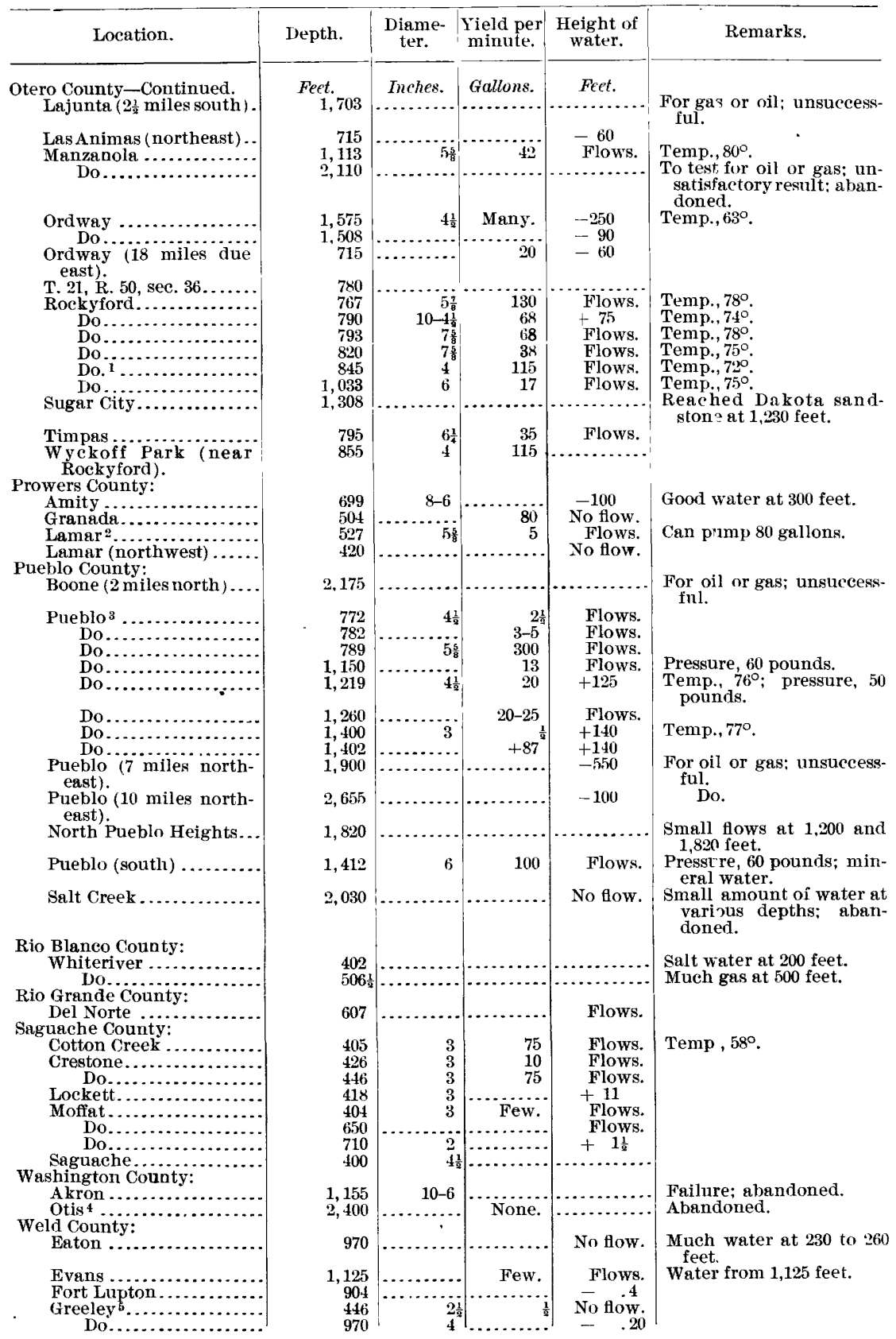

1 Record, Colorado State engineer, Ninth Biennial Report, 1897-98, pp. 28-29.

z Ibid., p. 29; analysis, 51st Cong, 1st session,

3 Record, 51st Cong., 1st session, Senate Ex. Doc. No. 222,1890 , pp. 213-214; anal 'sis, ibid., p. 229.

+ Ibid., p. 217.

s Ibid., pp. 209-210.

Senate Ex. Doc. No. 222, 1890, p. 228 . 
COLORADO-Continued.

\begin{tabular}{|c|c|c|c|c|c|}
\hline Loration. & I epth. & $\begin{array}{l}\text { Diame- } \\
\text { ter. }\end{array}$ & $\begin{array}{c}\text { Yjeld per } \\
\text { minute. }\end{array}$ & $\begin{array}{l}\text { Height of } \\
\text { wa er. }\end{array}$ & Remarks. \\
\hline $\begin{array}{l}\text { Weld County-Continued. } \\
\text { freeley................... }\end{array}$ & $\begin{array}{l}\text { Feet. } \\
\qquad 1,165\end{array}$ & Inches. & $\begin{array}{r}\text { Gallons. } \\
40\end{array}$ & $\begin{array}{l}\text { Fett. } \\
\text { Flowed }\end{array}$ & Several wells. \\
\hline Do. ${ }^{1} \ldots \ldots$ & 2,260 & $8-4$ & Few. & -0.40 & $\begin{array}{l}\text { Water from } 1,165 \text { to } 1,200 \\
\text { feet. }\end{array}$ \\
\hline $\begin{array}{l}\text { Grover } \ldots \ldots \ldots \ldots \ldots \ldots \\
\text { Yuma Connty: }\end{array}$ & 710 & & & & In progress. \\
\hline Wray ......... & +500 & & & & $\begin{array}{l}\text { For oil or coal; cnsuccess- } \\
\text { ful. }\end{array}$ \\
\hline
\end{tabular}

${ }^{1}$ Analysis, 51st Congress, 1st session, Senate Ex. Doc. 222, p. 226.

\section{PUBLICATIONS RELATING TO DEEP BORINGS IN COLORADO.}

Report of L. G. Carpenter, field agent for Colorarto, Fifty-first Congress, first session: Senate Ex. Doc. No. 222, pp. 173-232, Washington, 1890.

Report of P. H. Van Diest, on the geological conditions of artesian basins in eastern Colorado and New Mexico, Fifty-first Congress, first session: Senate Fx. Doc. No. 222, pp. 87-97, Washington, 1890.

Artesian wells of Colorado and their relation to irrigation: State Agricultural College Bulletin No. 16, July, 1891, 28 pages.

Economic geology, by George H. Eldridge, Geology of the Denver I Colorado: United States Geological Survey Monngraph No. 27, pp. 317-465, Washington, 1896.

Underground waters of the Arkansas Valley in Eastern Colorado, by G. K. Gilbert: United States Geological Survey, 17th Annual Report, 1895-96, part 2, pp. 1-51, plates, Washington, 1896.

United States Geological Survey, Geologic Atlas of the United States. No. 36, Pueblu folio, by G. K. Gilbert, Washington, 1897.

United States Geological Survey, Geologic Atlas of the United States, No. 58, El Moro folio, by R. C. Hills, Washington, 1899.

United States Geological Survey, Geologic Atlas of the United States, No. 68, Walsenburg folio, by R. C. Hills, Washington, 1899.

Pieliminary Report on the Geology and Underground Water Resourcer of the Central Great Plains, by N. H. Darton: United States Geological Survey Profescional Paper No. 32, Washington, 1905.

\section{CONNECTICU'T.}

\begin{tabular}{|c|c|c|c|c|c|}
\hline Lncation. & Depth. & $\begin{array}{l}\text { Diame- } \\
\text { ter. }\end{array}$ & $\begin{array}{l}\text { Yield per } \\
\text { minute. }\end{array}$ & $\begin{array}{l}\text { Height of } \\
\text { water. }\end{array}$ & Remarks. \\
\hline 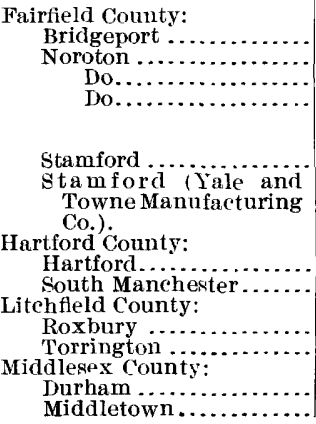 & $\begin{array}{r}\text { Fett. } \\
800 \\
700 \\
1,500 \\
494 \\
\\
450 \\
416\end{array}$ & 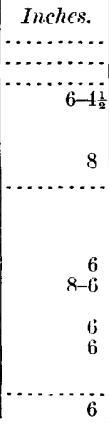 & $\begin{array}{r}\text { Gallons. } \\
\text { Several. } \\
\text { None. } \\
4 \\
4 \\
\\
\\
\ldots \ldots\end{array}$ & 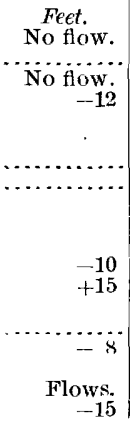 & $\begin{array}{l}4 \text { gallons at } 900 \text { feet, } \\
\text { Water-bearing teds at } 300 \\
\text { and } 350 \text { feet. Water } \\
\text { hard. } \\
\text { Water unsatisfartory. }\end{array}$ \\
\hline
\end{tabular}


CONNECTICUT-Continued.

\begin{tabular}{|c|c|c|c|c|c|}
\hline Location. & Depth. & $\begin{array}{l}\text { Diame- } \\
\text { ter. }\end{array}$ & $\begin{array}{l}\text { Yield per } \\
\text { minute. }\end{array}$ & $\begin{array}{l}\text { Height of } \\
\text { water. }\end{array}$ & Remarks. \\
\hline 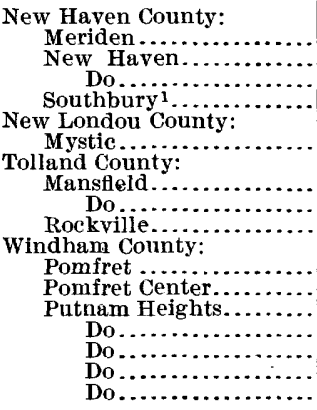 & $\begin{array}{r}530 \\
800 \\
850 \\
3.440 \\
600 \\
610 \\
800 \\
400 \\
700 \\
420 \\
6,004\end{array}$ & 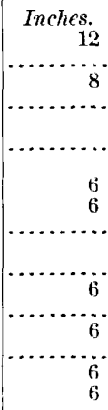 & 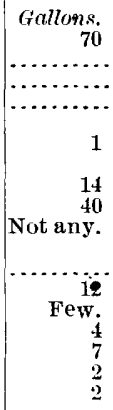 & 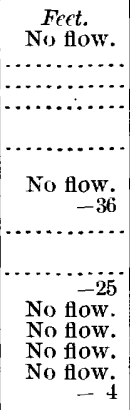 & $\begin{array}{l}\text { Water very hard. } \\
\text { Tnanccessiul. }\end{array}$ \\
\hline
\end{tabular}

${ }^{1}$ Am. Jour, Sci., vol. 62, p. 275, 1890; also Hobbs, 21st Ann.

DELAWARE.

\begin{tabular}{|c|c|c|c|c|c|}
\hline Location. & Depth. & $\begin{array}{c}\text { Diame- } \\
\text { ter. }\end{array}$ & $\begin{array}{l}\text { Yield per } \\
\text { minute. }\end{array}$ & $\begin{array}{c}\text { Height oi } \\
\text { water. }\end{array}$ & Remarks. \\
\hline 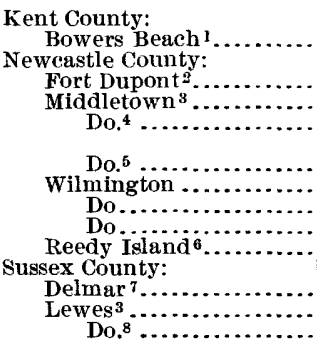 & $\begin{array}{r}\text { Feet. } \\
500 \\
\\
734 \\
535 \\
698 \\
\\
821 \\
400 \\
1,077 \\
416 \\
570\end{array}$ & 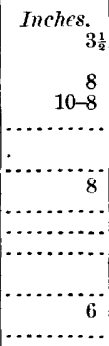 & 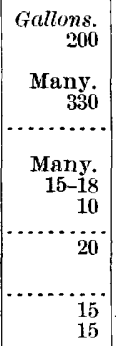 & $\begin{array}{l}\text { Fcet. } \\
\text { No flow. } \\
\text { Flows. } \\
-50 \\
-35 \\
\\
\text { Flows. } \\
\\
\text { At surface. } \\
\text { Flows. }\end{array}$ & $\begin{array}{l}\text { Not much water below } \\
240 \text { feet. } \\
\text { Water also at } 475 \text { feet. } \\
\text { Water from } 535 \text { and } 660 \text { - } \\
686 \text { feet. }\end{array}$ \\
\hline
\end{tabular}

1 N.J. Geol. Surv. Rept., 1899, p. 110.

2 Record, N. J. Geol. Surv. Rept., 1900, pp. 132-134; 1901, pp. 105-107.

${ }^{3}$ Reeord, U. S. Geol. Surv. Bull. No. 138, p. 123.

4 Record, N. J. Geol. Surv. Rept., 1898, p. 115.
5 Ibid., 1901, pp. 107-109.

6 Ibid., 1897, pp. 248-249.

7 Ibid., 1899, pp. 111-112.

8 Ibid., 1898, pp. 83-87.

\section{LIST OF PUBLICATIONS RELATING TO DEEP BORINGS IN DELAWARE.}

New Jersey Gelogical Survey Reports, by the State Geologist, for 1897, 1898, 1899, 1900 , and 1901.

Artesian well prospects in the Atlantic Coastal Plain region. by N. H. Darton: United States Geological Survey Bulletin No. 1,38.

\section{DISTRICT OF COLUMBIA.}

\begin{tabular}{|c|c|c|c|c|c|}
\hline Location. & Depth. & $\begin{array}{c}\text { Diame- } \\
\text { ter. }\end{array}$ & $\begin{array}{c}\text { Yield per } \\
\text { minute. }\end{array}$ & $\begin{array}{l}\text { Height of } \\
\text { water. }\end{array}$ & Remarks. \\
\hline $\begin{array}{l}\text { Washington, Heurich's old } \\
\text { brewery. } \\
\text { Washingten, Riggs House... }\end{array}$ & $\begin{array}{r}\text { Feet. } \\
900 \\
558\end{array}$ & 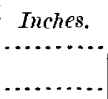 & $\begin{array}{r}\text { Gallons. } \\
7 \\
\text { None. }\end{array}$ & $\begin{array}{c}\text { Feet. } \\
\text {.......... }\end{array}$ & $\begin{array}{l}\text { Aivandoned. } \\
\text { Unsuccessful. }\end{array}$ \\
\hline
\end{tabular}


FLORIDA.

\begin{tabular}{|c|c|c|c|c|c|}
\hline Location. & Depth. & $\begin{array}{c}\text { Diame- } \\
\text { ter. }\end{array}$ & $\begin{array}{c}\text { Yield per } \\
\text { minute. }\end{array}$ & $\begin{array}{l}\text { Height of } \\
\text { water. }\end{array}$ & Remarks. \\
\hline $\begin{array}{l}\text { Bradford County: } \\
\text { Starke......... }\end{array}$ & $\begin{array}{l}\text { Feet. } \\
529\end{array}$ & Inches. & $\begin{array}{r}\text { Gallons. } \\
300\end{array}$ & $\stackrel{\text { Feet. }}{-} 81$ & . \\
\hline Brevard County: & & & & & \\
\hline Artesia & $\begin{array}{l}425 \\
484\end{array}$ & $\cdots \cdots$ & $\begin{array}{r}100 \\
2,500\end{array}$ & $\begin{array}{l}+18 \\
+\quad 46\end{array}$ & Temp $78^{\circ}$ \\
\hline $\begin{array}{l}\text { Eau Gallie.... } \\
\text { Do........ }\end{array}$ & $\begin{array}{l}484 \\
435\end{array}$ & $\begin{array}{l}6 \\
1 \frac{1}{n}\end{array}$ & $\begin{array}{l}2, \text { bo0 } \\
\text { Many. }\end{array}$ & $+\stackrel{+}{\mathrm{M} a n y}$. & Temp., $78^{\circ}$ \\
\hline Mico........ & 530 & 4 & Many. & +10 & \\
\hline $\begin{array}{l}\text { Orehid } \ldots . . . . \\
\text { Roseland } . . . .\end{array}$ & $\begin{array}{r}450 \\
440-465\end{array}$ & 4 & $\begin{array}{l}\text { Many. } \\
\text { Many. }\end{array}$ & $+\quad 30$ & \\
\hline $\begin{array}{l}\text { Roseland } \ldots \ldots \ldots \ldots \ldots \ldots \\
\text { Sebrstian.................. }\end{array}$ & $\begin{array}{r}440-465 \\
460\end{array}$ & $\begin{array}{l}4 \\
4\end{array}$ & $\begin{array}{l}\text { Many. } \\
\text { Many. }\end{array}$ & $\begin{array}{l}+0 \text { to } 21 \\
+\quad 16\end{array}$ & 3 Wells \\
\hline Malabar ................ & 510 & 3 & Many. & Fíows. & $\begin{array}{l}\text { Temp., } 780 \text {; bored for oil, } \\
\text { none found. }\end{array}$ \\
\hline Melbourne. & 400 & 6 & & +48 & Temp., $78^{\circ}$ \\
\hline Orchid..... & 480 & 4 & Few. & Flows. & sulphur water. \\
\hline $\begin{array}{l}\text { Roseland } \\
\text { Clay County: }\end{array}$ & $462-450$ & 6 & Many. & Flow. & 2 wells. \\
\hline $\begin{array}{l}\text { Clay County: } \\
\text { Green Cove Springs ...... }\end{array}$ & 600 & 6 & 600 & +30 & Temp., $80^{\circ}$. \\
\hline Do...................... & 673 & 4 & 150 & $\begin{array}{ll}T & 00 \\
T & 15\end{array}$ & \\
\hline $\begin{array}{l}\text { Do........... } \\
\text { Columbia County: }\end{array}$ & 815 & 4 & 300 & +33 & \\
\hline $\begin{array}{l}\text { Columbia County: } \\
\text { Lake City ..... }\end{array}$ & +400 & & & & \\
\hline $\begin{array}{r}\text { Do......... } \\
\text { Dade County: }\end{array}$ & 520 & 10 & Many. & $\cdots+100$ & \\
\hline $\begin{array}{l}\text { Dade County: } \\
\text { Gomez.......... }\end{array}$ & & 4 & & & \\
\hline $\begin{array}{l}\text { Gomez......... } \\
\text { Hobe Sound... }\end{array}$ & $\begin{array}{l}1,200 \\
1,100\end{array}$ & $6-4$ & Several. & + & Sulphur water. \\
\hline Lake Worth ${ }^{1}$. & 1,212 & 4 & 313 & +40 & Suspitur water. \\
\hline Palm Beach .. & 1,200 & 4 & Several. & Flows. & \\
\hline $\begin{array}{l}\text { De Soto County: } \\
\text { Punta Gorda }\end{array}$ & 467 & & & & Water too salty fcr use. \\
\hline Do.......... & 400 & & & Flows. & \\
\hline Do.. & 425 & & 25 & Flows. & Salt water only. \\
\hline Do........ & 408 & 8 & 6.50 & +40 & \\
\hline $\begin{array}{c}\text { Wanchula ..... } \\
\text { Do......... }\end{array}$ & $\begin{array}{l}650 \\
800\end{array}$ & 3 & 80 & & \\
\hline Duval County:..... & 800 & & & & \\
\hline $\begin{array}{r}\text { Jacksol } \\
\text { Do }\end{array}$ & $\begin{array}{l}793 \\
711\end{array}$ & 6 & & +17 & \\
\hline Do...... & $\begin{array}{l}711 \\
630\end{array}$ & & & Flows. & Sulphur water. \\
\hline Do....... & $\begin{array}{l}650 \\
660\end{array}$ & $\begin{array}{l}6 \\
61\end{array}$ & 432 & +64 & $\begin{array}{l}\text { Temp., } 74^{\circ} \text { to } 77^{\circ} \text {. } \\
\text { Do. }\end{array}$ \\
\hline Do...... & 1,020 & 107 & & & Temp., $81^{\circ}$ \\
\hline $\begin{array}{l}\text { Do... } \\
\text { Do.. }\end{array}$ & 937 & 12 & 432 & & Temp., $77^{\circ}$ \\
\hline $\begin{array}{l}\text { Do... } \\
\text { Do... }\end{array}$ & $\begin{array}{l}490 \\
637\end{array}$ & 3 & 180 & +62 & Temp., $75^{\circ} \cdot$ \\
\hline Do......... & $\begin{array}{l}637 \\
650\end{array}$ & $\begin{array}{l}0 \\
6\end{array}$ & $\begin{array}{l}600 \\
900\end{array}$ & $\begin{array}{l}+\quad 02 \\
+\quad 62\end{array}$ & $\begin{array}{l}\text { Temp., } \\
\text { Do. }\end{array}$ \\
\hline Do.... & 1,020 & & 2,333 & +62 & Temp., $78^{\circ}$. \\
\hline $\begin{array}{l}\text { Do................ } \\
\text { Do..... }\end{array}$ & $616-5,000$ & $\begin{array}{l}8-4 \\
4-8\end{array}$ & $60-400$ & $+2-50$ & 7 wells. \\
\hline Mandarin ....... & 625 & 4 & Many. & $\begin{array}{l}+2-200 \\
+\quad 40\end{array}$ & \\
\hline Plummer........ & 600 & 4 & & +20 & \\
\hline Do $\ldots \ldots \ldots$ & 700 & 8 & Many. & Flows. & \\
\hline St. Nicholas ... & 678 & 6 & Many. & +30 & Temp $77^{\circ}$ \\
\hline $\begin{array}{l}\text { Do } \\
\text { South Jacksonvili }\end{array}$ & $\begin{array}{l}750 \\
800\end{array}$ & 6 & $\begin{array}{l}\cdots \\
\cdots \\
\cdots\end{array}$ & $\begin{array}{l}+\quad 60 \\
+\quad 55\end{array}$ & remp., \\
\hline Do ${ }^{2} \ldots \ldots \ldots$ & 750 & $\dddot{6}$ & (n........... & +69 & Do. \\
\hline $\begin{array}{l}\text { Escambia County: } \\
\text { Pensacola ................. }\end{array}$ & 1,400 & & & & Nayy-yard well; no good \\
\hline & & & & & water. \\
\hline $\begin{array}{l}\text { Do } \ldots . . . . . . . . . . \\
\text { Franklin County: }\end{array}$ & $1,252-1,702$ & $4 \frac{1}{8}$ & & & 4 wells. \\
\hline Apalachicola. & 475 & $3 \frac{1}{2}$ & & & Temp., $68^{\circ}$. \\
\hline Do......... & 450 & 3 & 40 & +4 & \\
\hline $\begin{array}{l}\text { Gadsden County: } \\
\text { Quincy ........ }\end{array}$ & & & & & \\
\hline $\begin{array}{l}\text { Quiney .......... } \\
\text { Hamilton County: }\end{array}$ & 610 & $6-4 \frac{1}{9}$ & $\frac{1}{9} \mid \cdots \ldots \ldots . . .6$ & -190 & \\
\hline Jasper ............ & +550 & & & & In progress. \\
\hline $\begin{array}{l}\text { Lee County: } \\
\text { Buckingham }\end{array}$ & 406 and 407 & & & & \\
\hline Buckingham .... & $\begin{array}{r}406 \text { and } 407 \\
406-575\end{array}$ & $\begin{array}{r}3 \\
2-4\end{array}$ & $\begin{array}{r}200 \\
100-200\end{array}$ & Flow. & 2 wells. \\
\hline $\begin{array}{l}\text { St. James City -. } \\
\text { Leon County: }\end{array}$ & 400 & & $100-200$ & $\begin{array}{l}+4-40 \\
+\ldots \ldots\end{array}$ & \\
\hline $\begin{array}{l}\text { Leon County: } \\
\text { T'allahassee... }\end{array}$ & & & & & \\
\hline $\begin{array}{l}\text { T'qliahassee... } \\
\text { Madison County: }\end{array}$ & $7 \mathrm{Ib}$ & & $\cdots$ & -98 & \\
\hline $\begin{array}{l}\text { Madison ...... } \\
\text { Manatoe County: }\end{array}$ & 530 & 6 & 100 & -117 & \\
\hline $\begin{array}{l}\text { Manatoe County: } \\
\text { Ellentown.... }\end{array}$ & & ' & & & \\
\hline $\begin{array}{l}\text { Ellentown..... } \\
\text { Palmetto ...... }\end{array}$ & $\begin{array}{l}400 \\
450\end{array}$ & $\begin{array}{l}4 \\
4\end{array}$ & Many. & $\begin{array}{l}+20 \\
+\quad 10\end{array}$ & \\
\hline & 426 & $\begin{array}{l} \pm \\
3\end{array}$ & & $\begin{array}{r}10 \\
+\quad 4\end{array}$ & \\
\hline $\begin{array}{l}\text { Sarasota ......... } \\
\text { Marion County: }\end{array}$ & 400 & 6 & & +3 & \\
\hline $\begin{array}{l}\text { Marion County: } \\
\quad \text { Citra }\end{array}$ & 1,200 & & & & \\
\hline Ocala............... & 1,210 & $\ddot{8}$ & & $\begin{array}{l}=15 \\
-\quad 74\end{array}$ & \\
\hline Do $\ldots \ldots \ldots \ldots$ & 1,400 & & . & -30 & \\
\hline
\end{tabular}

1 Record, Am. Jour. Sci., 3d ser., vol. 41, pp. 105-106. $\quad 2$ Representative wells. 
FLORIDA - Continued.

\begin{tabular}{|c|c|c|c|c|c|}
\hline Ior at'on. & $1 \mathrm{e}, 1 \mathrm{l}$. & $\begin{array}{l}\text { Diame- } \\
\text { ter. }\end{array}$ & $\begin{array}{l}\text { Yield per } \\
\text { minute. }\end{array}$ & $\begin{array}{l}\text { Height of } \\
\text { water. }\end{array}$ & Femarks. \\
\hline $\begin{array}{l}\text { Monroe County: } \\
\text { Key West.... }\end{array}$ & $\begin{array}{l}\text { Fect. } \\
\quad 2,350\end{array}$ & $\begin{array}{l}\text { Inches. } \\
\text {.......... }\end{array}$ & Gallons. & Feet. & \\
\hline Nassau County: & & & & & \\
\hline $\begin{array}{r}\text { Fernandina }{ }^{1} \ldots \ldots \\
\text { Do } \ldots \ldots\end{array}$ & $\begin{array}{l}640 \\
750\end{array}$ & $\begin{array}{l}8 \\
6\end{array}$ & 800 & $\begin{array}{l}+50 \\
+\quad 61\end{array}$ & Water from 618 feet. \\
\hline Fernandina (city park).. & 700 & 8 & 810 & $\begin{array}{l}+61 \\
+-40\end{array}$ & $\begin{array}{l}\mathrm{T}>\mathrm{mp} ., 77^{\circ} \\
\mathrm{T}>\mathrm{mp} ., 74^{\circ}\end{array}$ \\
\hline Fernandina $\ldots . . . . . .$. & 762 & & & & \\
\hline $\begin{array}{l}\text { Heart's Road? (railroad } \\
\text { junction). }\end{array}$ & 7.50 & 6 & Many. & +64 & 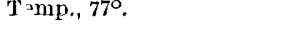 \\
\hline $\begin{array}{l}\text { Osceola County: } \\
\quad \text { Kissimmee ................ }\end{array}$ & $40 t i$ & 4 & & & \\
\hline $\begin{array}{r}\text { Do } \ldots \ldots \\
\text { Narcoosee }\end{array}$ & 606 & & & & \\
\hline $\begin{array}{l}\text { Narcoossee } \ldots \ldots \ldots \ldots \ldots \\
\text { Polk County: }\end{array}$ & 416 & 3 & & --27 & \\
\hline $\begin{array}{c}\text { Bartow }(8 \text { miles south- } \\
\text { west }) . \\
\text { Do } \ldots \ldots \ldots \ldots \ldots \ldots \ldots\end{array}$ & $\begin{array}{l}600 \\
400\end{array}$ & & & & Small. \\
\hline Bartow ....................... & 725 & & & & Water. \\
\hline $\begin{array}{l}\text { Pasco County: } \\
\text { Pasadena.... }\end{array}$ & & & & & \\
\hline $\begin{array}{l}\text { Pasadena ................... } \\
\text { Putnan County: }\end{array}$ & 450 & & & -86 & \\
\hline$\underset{\text { Riverside }}{\text { Huntington }} \ldots \ldots \ldots \ldots \ldots$ & $4: 0$ & 4 & Several. & $\begin{array}{l}-12 \\
\text { Flow. }\end{array}$ & .? wells \\
\hline $\begin{array}{l}\text { St. John County: } \\
\text { St. Augustine } 2 \ldots \ldots\end{array}$ & 1,400 & & 5,500 & & T 3 mp., $86^{\circ}$. Strong flows \\
\hline Do $\ldots \ldots \ldots \ldots \ldots$ & 1,500 & & Many. & Flows. & $\begin{array}{l}\text { also at } 400-450 \text { and } 500- \\
550 \text { feet. }\end{array}$ \\
\hline St. Augustine............... & 1,278 & & (........... & ……... & $\begin{array}{l}\text { F"ows at } 46 x, 1,110 \text {, and } \\
1,200 \text { feet; latter" milky } \\
\text { with lime." Flow also } \\
\text { at } 1,225 \text { feet. }\end{array}$ \\
\hline $\begin{array}{l}\text { u wanee County: } \\
\text { Liveoak ................ }\end{array}$ & 1,050 & 6 & Many. & -54 & \\
\hline $\begin{array}{l}\text { Volusia County: } \\
\text { De Land }\end{array}$ & & & & & \\
\hline $\begin{array}{l}\text { De Land ................ } \\
\text { Washingtonl County: }\end{array}$ & 485 & 6 & 50 & -22 & \\
\hline Caryville ............. & 769 & $4 \frac{1}{w}$ & Many. & -10 & \\
\hline
\end{tabular}

\section{GEORGIA.}

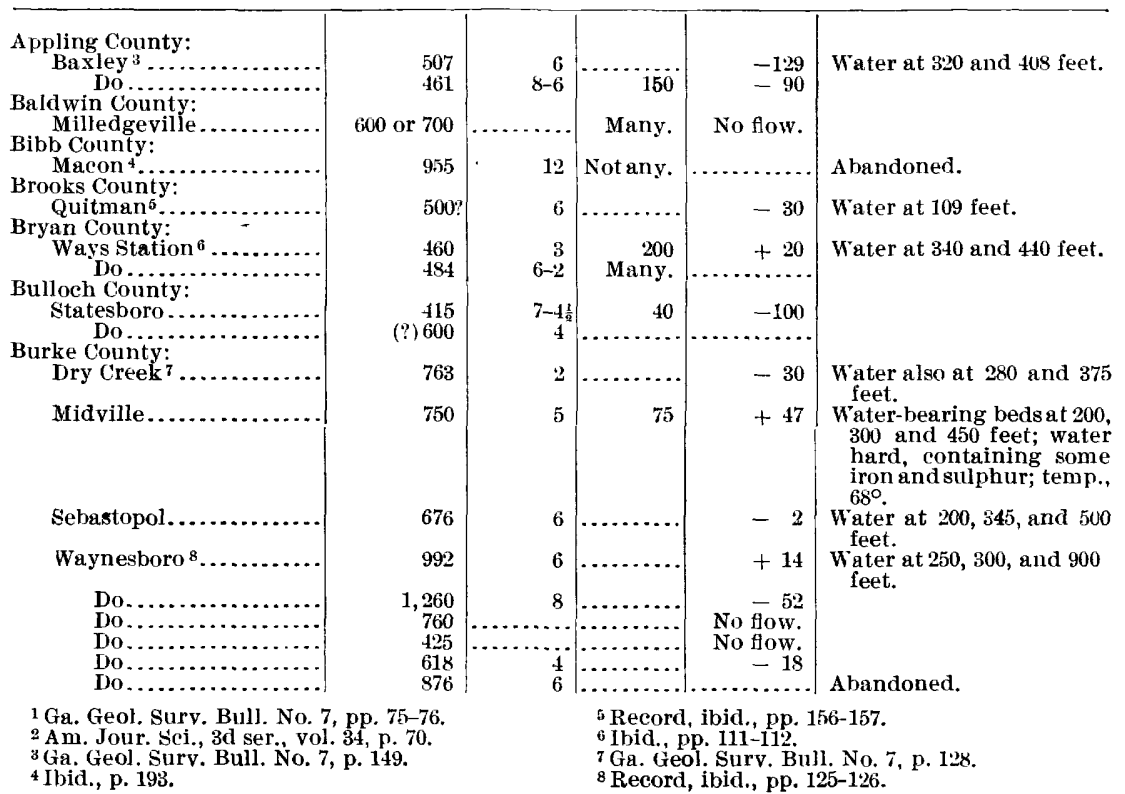


GEORGIA-Continued.

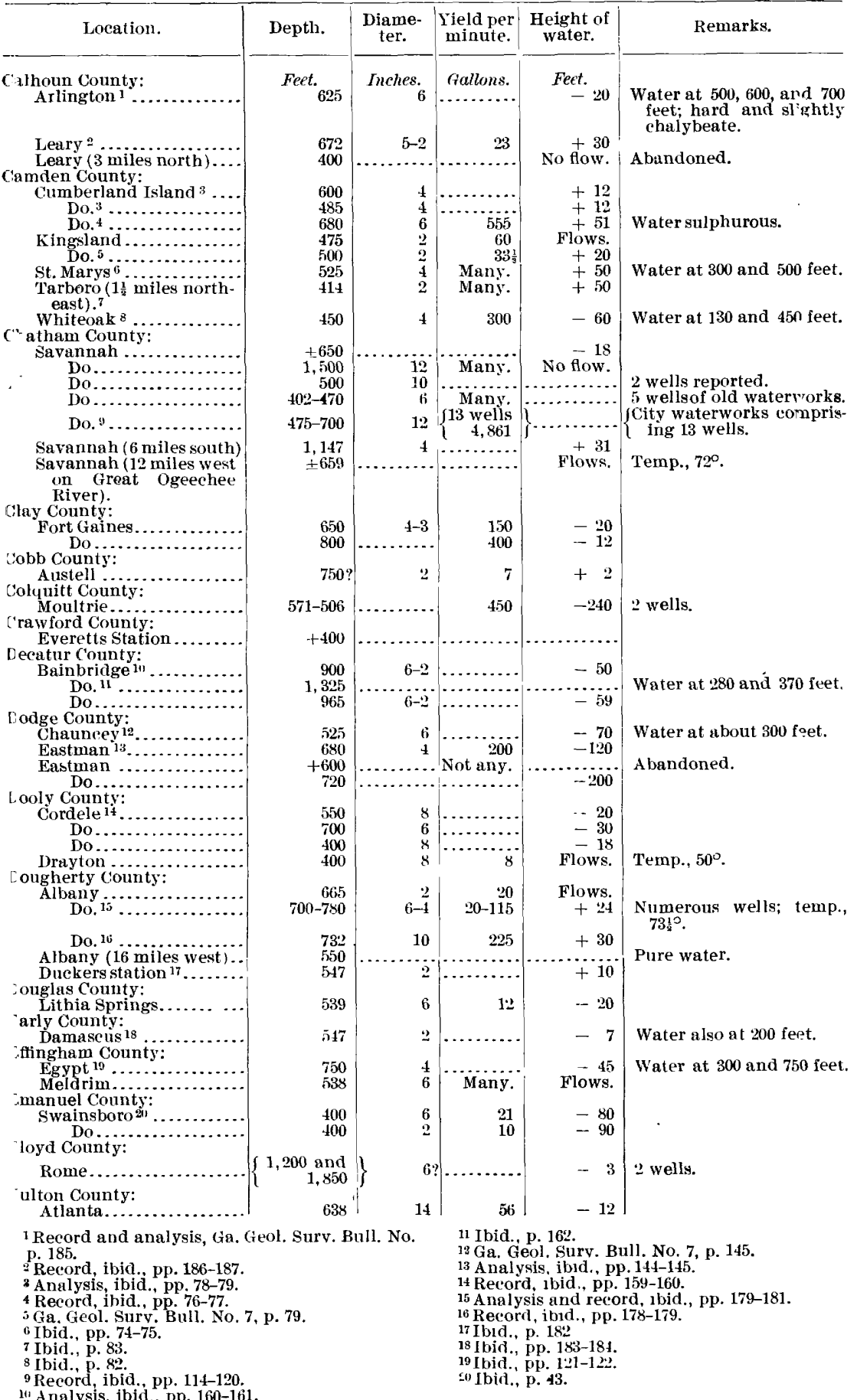


GEORGIA - Continued.

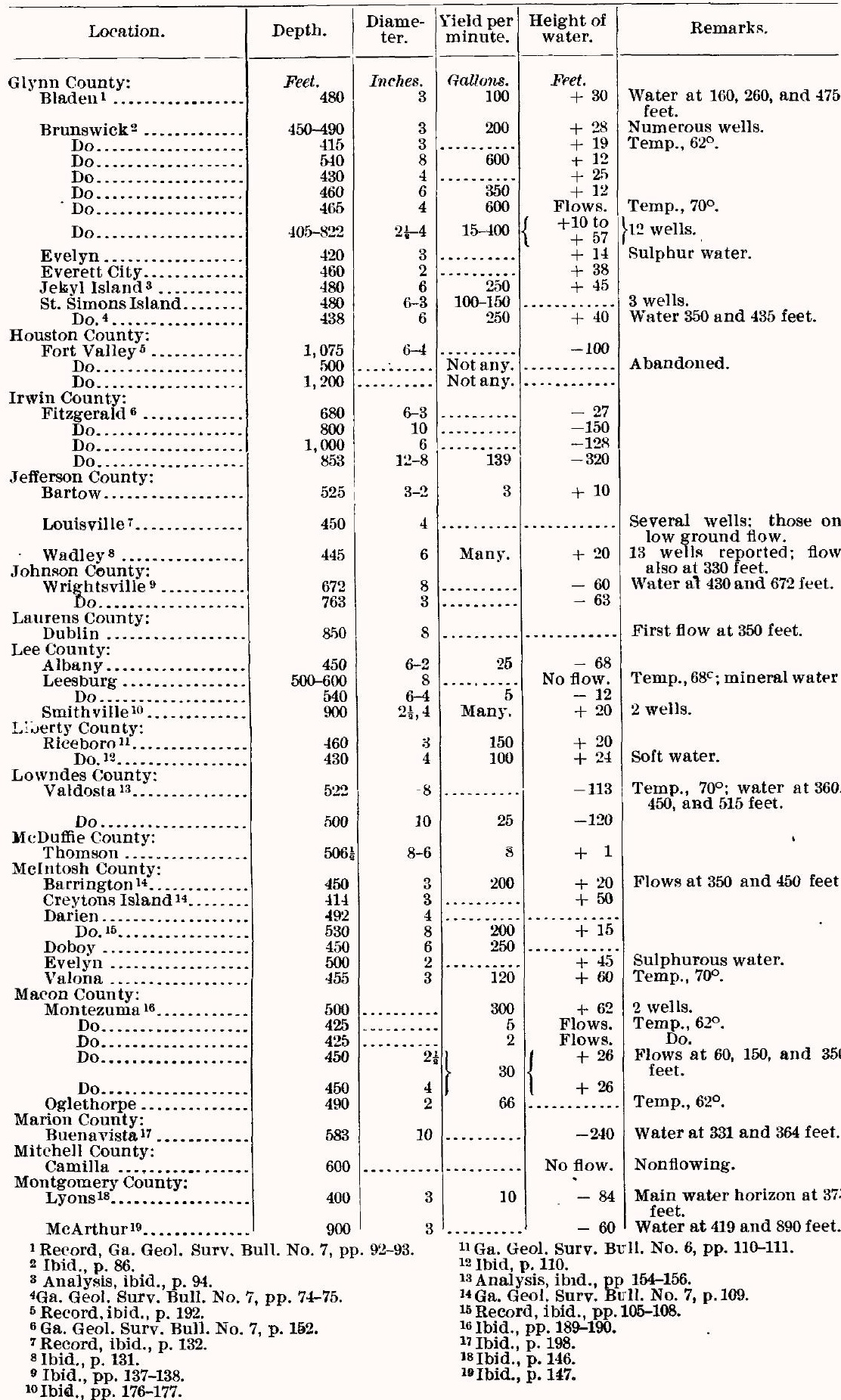




\section{PUBLICATIONS RELATING TO DEEP BORINGS IN GEORGIA.}

Preliminary report on the artesian well system of Georgia, by $\mathrm{S}$. W. McCallie: Geological Survey of Georgia Bulletin No. 7, 214 pages, plates, Atlanta, 1898.

Artesian prospects in the Atlantic Coastal Plain region, by IT. H. Darton: Inited States Geological Survey Bulletin No. 138, 232 pages, plates, Washington, 189 ? $^{\text {. }}$

IDAHO.

\begin{tabular}{|c|c|c|c|c|c|}
\hline Location. & Depth. & $\begin{array}{l}\text { Diame- } \\
\text { ter. }\end{array}$ & $\begin{array}{l}\text { Yield per } \\
\text { minute. }\end{array}$ & $\begin{array}{l}\text { Height of } \\
\text { water. }\end{array}$ & Remarks. \\
\hline $\begin{array}{l}\text { Ada County: } \\
\text { Boise.... }\end{array}$ & Feet. ${ }_{450}$ & $\begin{array}{l}\text { Inches. } \\
\text {............ }\end{array}$ & $\begin{array}{r}\text { Gallons. } \\
270\end{array}$ & $\begin{array}{l}\text { Fcet. } \\
\quad+10\end{array}$ & $\begin{array}{l}\text { Temp., } 80^{\circ} \text {. Deepest of } \\
\text { several wells. Hot wells } \\
\text { average } 555 \text { gallons per } \\
\text { minute, and have a } \\
\text { height of +30 feet. } \\
\text { Temp., } 170^{\circ} \text {. }\end{array}$ \\
\hline $\begin{array}{l}\text { Boise County: } \\
\text { Idaho City..... }\end{array}$ & +400 & & & & Prospect well: not in use. \\
\hline Cassia County: & & & & & \\
\hline $\begin{array}{l}\text { Oakley .................. } \\
\text { Elmore County: }\end{array}$ & \pm 400 & & & & \\
\hline 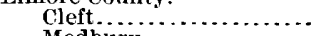 & 450 & 8 & & & \\
\hline $\begin{array}{l}\text { Medbury .................. } \\
\text { Fremont County: }\end{array}$ & 832 & 8 & 70 & Flows. & \\
\hline 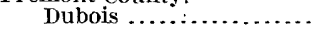 & 615 & $\cdots \cdots \cdot$ & 50 & No flow. & $\begin{array}{l}\text { Water-bearing beds began } \\
\text { at } 375 \text { feet. }\end{array}$ \\
\hline 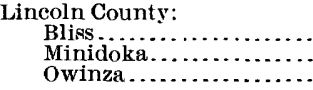 & $\begin{array}{l}4 \times 3 \\
425 \\
400\end{array}$ & 8 & $\cdots$ & . & \\
\hline
\end{tabular}

ILLINOIS.

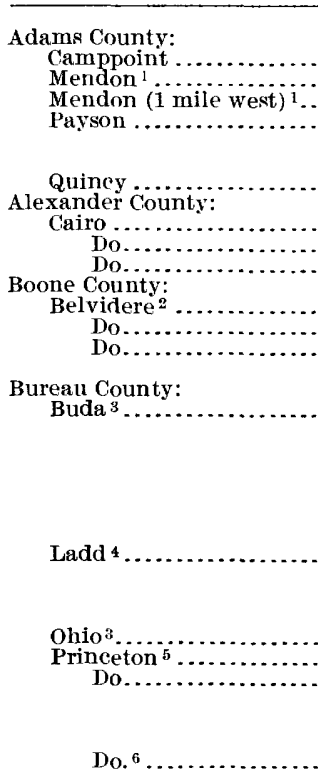

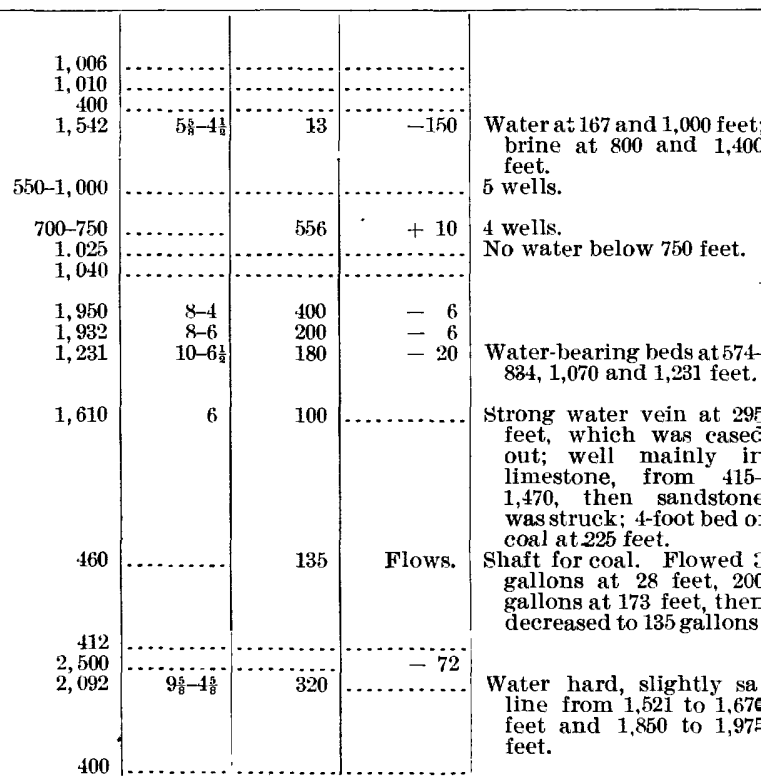

1 U.S. Geol. Surv. Monograph No. 38, 1899, p. 715.

2 T.S. Geol. Surv., 17th Ann. Rept., 1895-96, part

2, p. 810; Monograph No. 38, 1899, p. 573 .

Ibid., Monograph No. 38, 1899, pp. 628-629.

4 Columbia College, School of Mines.Quarterly,

5 U. S. Geol. Surv, 17'h Ann. Rept., 1895-96, par 2 , p. 816; analysis, ibid., pp. 808, 828; Monograpł No. 38,1899 , p. 627 .

6 Record, Economic Geology, Ill., vol. 3, p. 178. vol. 16, pp. 238-248. 
ILLINOIS-Continued.

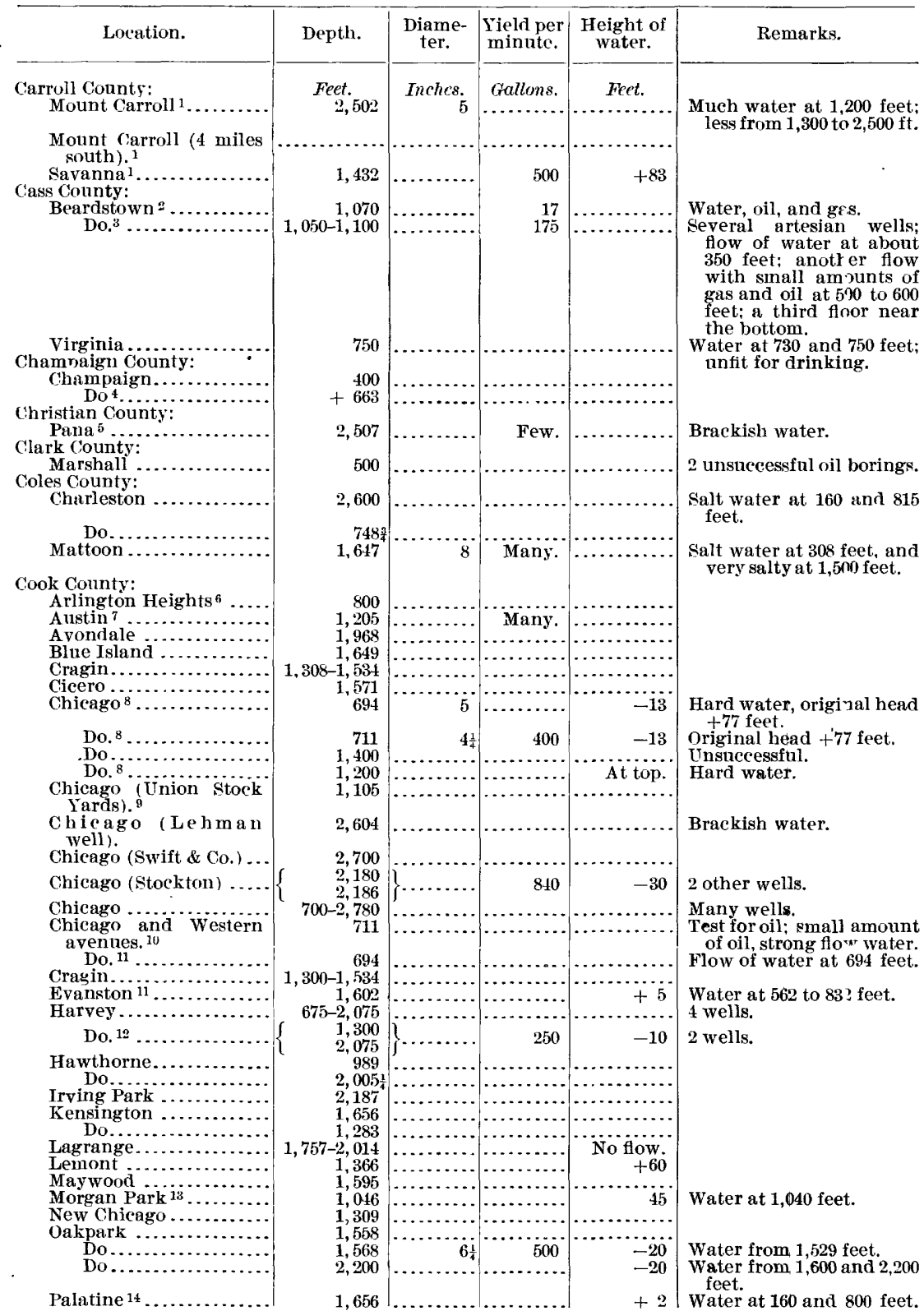

1 T. S. Geol. Surv. Monograph No. 38, 1899, pp. 611-612.

2 Record, Ill, Geol. Surv., pp. 61, 66.

${ }^{3}$ U.S. Geol. Surv. Monograph No. 38, 1899, p. 711.

4 Ibid, Folio No. 67.

5 Ibid., Monograph No. 38, 1899, p. 726.

${ }^{6}$ Ibid., p. 587.

'U.S. Geol. Surv., 17th Ann. Rept., 1895-96, part $2, \mathrm{p} .810$.

8 Ibid., p. 811.
9 Record, Economic Geology, Ill, vol. 2, p. 186. ${ }^{10}$ U. S. Geol. Surv. Monograph No. 38, 1879, p. 584. 11 Ibid., 17th Ann. Rept., 1895-96, part 2, p. 813 analysis, ibid., p. 827; Monograph No. 38,1899 , p. 587.

${ }_{12}$ Ibid., Monograph No, 38, 1899, p. 590.

13 Ibid., pp. $58^{\circ}-590$.

14 Record, ibid., 17th Ann. Rept., 1895-@6, part 2, p. 816; Monograph No. 38, 1899, p. 585 . 
ILLINOIS-Continued.

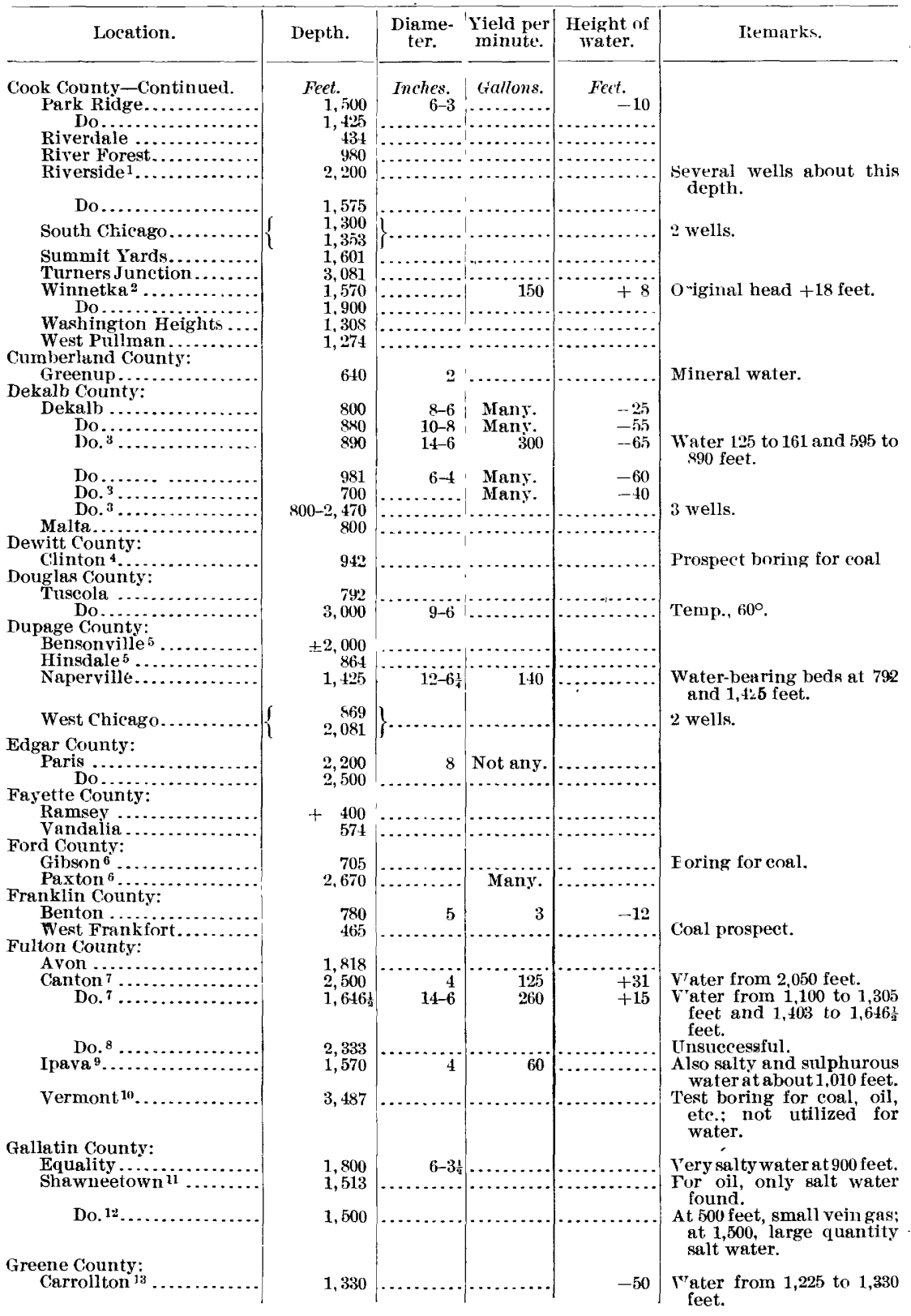

1 U. S. Geol. Surv. Monograph No. 38, 1899, p. 589. 2 Analysis, ibid., 17th Ann. Rept., 1895-96, part 2, p. 828; Monograph No. 38, 1899, p. 587.

I Ibid., Monograph No. 38, 1899 , p. 602.

4 Partial record, ibid., pp. 705-706.

5 U.S. Geol. Surv. Monograph No. 38, 1899, p. 592.

6 Ibid, pp. 662-663.

${ }^{7}$ Record, ibid., 17th Ann. Rept., 1895-96, part 2,

p. 849; Monograph No. 38, 1899, p. 687 .

${ }^{8}$ Record, IIl. Geol. Surv. Rept., vol. 8, pp. 62-63.
${ }^{9}$ Ibid., 17th Ann. Rept., 1895-96, part 2, p. 813; Monograph No. 38,1899 , p. 688 .

10 Ibid., Monograph No. 38, 1899, p. 688.

11 Ibid., 17th Ann. Rept., 1895-96, part 2, p. 817.

$12 \mathrm{Ky}$. Geol. Surv. Rept., Petroleum, Natural Gas, ete., by E. Orton, p. 205.

13 Record U. S. Geol. Surv., 17th Ann. Rept., 1895-96, part 2, p. 849; Monograph No. 38, 1899, p. 745 . 
ILLLNOIS-Continued.

\begin{tabular}{|c|c|c|c|c|c|}
\hline Location. & Depth. & $\begin{array}{c}\text { Diame- } \\
\text { ter. }\end{array}$ & $\begin{array}{c}\text { Yield per } \\
\text { minute. }\end{array}$ & $\begin{array}{l}\text { Height of } \\
\text { water. }\end{array}$ & Remarks \\
\hline Grundy County & Feet. & Inches. & Gallons. & Feet. & \\
\hline $\begin{array}{l}\text { Carbon Hill } 1 \\
\text { Minooka }{ }^{1} \ldots\end{array}$ & $\begin{array}{l}1,900 \\
2,100\end{array}$ & & $\mid \ldots \ldots \ldots \ldots$ & $\cdots \cdots+46$ & Strong water vein at 1,985 \\
\hline - Do..... & 1,162 & & & & feet. \\
\hline Morris 2. & $\begin{array}{r}1,106 \\
406\end{array}$ & 10 & Many. & Fluws. & \\
\hline $\begin{array}{l}\text { Do. } \\
\text { Do... }\end{array}$ & 600 & & & $-2 \operatorname{son}^{\circ}$ & \\
\hline $\begin{array}{l}\text { Do } \ldots . . . . \\
\text { Hamilton Coun }\end{array}$ & 604 & ...... & & (n........... & \\
\hline MeLeansbor & 800 & $8-5 \frac{5}{8}$ & & & \\
\hline $\begin{array}{l}\text { Hancock County } \\
\text { Carthage }{ }^{3} . .\end{array}$ & 1,800 & $5-3$ & & -16 & Brackish water at about \\
\hline Do. ${ }^{3}$. & 1,000 & $10-8$ & & -20 & Water at 865 and 975 feet. \\
\hline Do. & 1,787 & & & +5 & Mineral water. \\
\hline Do. ${ }^{5} \ldots \ldots$ & 975 & & Many. & .......... & Do. \\
\hline $\begin{array}{l}\text { Hawilton.... } \\
\text { Denver (near }\end{array}$ & $\begin{array}{r}840 \\
\end{array}$ & & Many. & & \\
\hline Hamilton. & $\begin{array}{r}1,050 \\
680\end{array}$ & & 314 & $\begin{array}{l}-40 \\
+63\end{array}$ & Sulphur water: King - \\
\hline Riverside ${ }^{4}$ & 680 & & 35 & +63 & Mineral water. \\
\hline Do..... & $\begin{array}{l}1,300 \\
2,200\end{array}$ & 3 & 1,000 & +20 & \\
\hline Warsaw .. & $780-800$ & 4 & 100 & +65 & 3wells; watersulphurous \\
\hline Do. & 750 & 6 & 90 & +155 & Do. \\
\hline Do. ${ }^{7}$.. & 860 & 6 & 200 & +62 & Original head +98. \\
\hline $\begin{array}{l}\text { Do. } \\
\text { Henderson }\end{array}$ & 1,600 & & & & \\
\hline Strongh & 1,601 & & & --30 & Test for oil. \\
\hline Henry County: & & & & & \\
\hline Cambridge ... & 1,329 & $9-6$ & 74 & -146 & " \\
\hline Galva ........... & 1,470 & $9-6$ & 50 & -178 & \\
\hline $\begin{array}{c}\text { Geneseo } \\
\text { Do... }\end{array}$ & $\begin{array}{l}2,2=0 \\
1,354\end{array}$ & 6 & 190 & $+31 ?$ & \\
\hline Kewanee $10 \ldots$ & 1,480 & $9-6$ & 130 & 150 & Water from 1,000 feet; \\
\hline Do. ${ }^{10}$ & 1,050 & $-7-4$ & 80 & & 2 wells; temp., $65^{\circ}$ \\
\hline Do.. & 1,073 & $12-6$ & 80 & -350 & Coal, 3 feet, at 187 feet; \\
\hline Woodhull & 1,394 & & & & \\
\hline $\begin{array}{l}\text { Iroquois County: } \\
\text { Danforth } 11 \text {.. }\end{array}$ & $+1,200$ & & & & No good water sroply. \\
\hline Gilman..... & 1,746 & ...... & 150 & -7 & No good water st ppiy. \\
\hline Onarga (near) ${ }^{1}$ & 400 & & & & Coal boring; no rock en- \\
\hline Sheldon. & 1,800 & $10-5$ & 100 & -40 & \\
\hline $\begin{array}{l}\text { Jackson Connty: } \\
\text { Murphysboro }\end{array}$ & 509 & 8 & & & Good water at 400 feet; \\
\hline Do. 12 & 1,800 & & & & well at brewery; flow of \\
\hline Jersey Coun & & & & & $\begin{array}{l}\text { salt water al about } 1,300 \\
\text { feet. }\end{array}$ \\
\hline & 2,003 & $12-3$ & 200 & 100 & Water at 1,400 to 1,600 feet. \\
\hline $\begin{array}{l}\text { Jo Daviess County: } \\
\text { East Dubuque it. }\end{array}$ & & & & & \\
\hline $\begin{array}{r}\text { East Dubuque } 14 \ldots \\
\text { Do.................... }\end{array}$ & $\begin{array}{r}940 \\
1,000\end{array}$ & 5 & 420 & $\begin{array}{l}-95 \\
\ldots .6\end{array}$ & \\
\hline Galena $16 .$. & 1,209 & 8 & 166 & +85 & \\
\hline $\begin{array}{l}\text { Warren......... } \\
\text { Kane County: }\end{array}$ & 697.875 & & $\cdots \cdots$ & 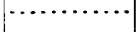 & 2 wells. \\
\hline $\begin{array}{l}\text { Kane Cotndy: } \\
\text { Aurora } 16 . .\end{array}$ & & & & & \\
\hline Do. 17 : & 1,388 & $8-6$ & 350 & & \\
\hline Do. 17 & 2,270 & & & +60 & \\
\hline Do. ${ }^{17}$ & 2,255 & & ..... & +60 & \\
\hline Do... & $2,235-2,250$ & .... & ... & ............. & 3 weils. \\
\hline Do.. & 1,971 & $\cdots \cdots$ & & & \\
\hline 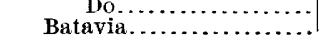 & $\begin{array}{l}1,467 \\
1,279\end{array}$ & & & & \\
\hline
\end{tabular}

1 U. S. Geol. Surv. Monograph No. 38, 1899, p. 647 387.

U. S. Geol. Surv. Monograph No. 38,1899, p. 647

I Ibid., 17th Ann. Rept., 1895-96, part 2, p. 810; Monograph No. 38, 1899 , p. 682 .

4 Record, Ill. Geol. Surv. Rept., vol. S, pp. 64-65. Ibid., p. 62 .

6U.S. Geol.Surv. Monograph No. 38, 1899, p. 684

7 Ibid., p. 683 .

8 Ibid., p. 680

9 Ibid., 17th Ann. Rept. 1895-96, part 2, p. 813; analysis, p. 827; Monograph No. 38, 1899, p. 623.

1" Record, ibid., p. 814; analysis, p. 821; Mono graph No. 38,1899, p. 624 .
11 It. S. Geol. Surv. Monograph No. 38, 1899, pp. $657-658$.

12 Ibid., p. 780

13 Ibid., 17th Ann. Rept. 1895-96, part 2, p. 814; analysis, ibid., pp. 808, 827; Monograph .No. 38, 1899, p. 747

14 Ibid. Monograph No. 38,1899, p. 565

15 Ibid., 17th Ann. Rept. 1895-96, part 2, p. 813 analysis, p. 827; Monograph No. 38, 1899, p. 565.

16 Ibid. p. 810; Monograph.No. 38, 1899 p. 599.

17 A nalysis, ibid., p. 820; Monograph Nc. 38,1899 , p. 599 .

IRR $149-05-3$ 
ILLINOIS-Continued.

\begin{tabular}{|c|c|c|c|c|c|}
\hline Location. & Depth. & $\begin{array}{l}\text { Diame- } \\
\text { ter. }\end{array}$ & $\begin{array}{l}\text { Yield per } \\
\text { minute. }\end{array}$ & $\begin{array}{l}\text { Height of } \\
\text { water. }\end{array}$ & Remarks. \\
\hline $\begin{array}{l}\text { Kane County-Continued. } \\
\text { Carpentersville.......... }\end{array}$ & $\begin{array}{c}\text { Feet. } \\
\text { 692and } 2,300\end{array}$ & $\begin{array}{l}\text { Inches. } \\
\ldots \ldots \ldots\end{array}$ & Gallons. & $\begin{array}{l}\text { Feet. } \\
\text {.......... }\end{array}$ & 2 wells. \\
\hline Elburn ....................... & 1,375 & & & & Evens. \\
\hline $\begin{array}{l}\text { Geneva } \\
\text { Gray W }\end{array}$ & $\begin{array}{r}400-2,500 \\
500\end{array}$ & & & & 4 wells. \\
\hline Elgin $=$ & 1,400 & & & (n.......... & $\begin{array}{l}\text { Water at } 487 \text { to } 514 \text { feet; } \\
\text { sulphur water at } 650 \text { to } \\
700 \text { feet. }\end{array}$ \\
\hline Do. ${ }^{3}$. & 1,876 & & & +2 & $\begin{array}{l}\text { Also sulphur water at } 650 \\
\text { to } 700 \text { feet. }\end{array}$ \\
\hline Do. ${ }^{3} \ldots$ & 2,026 & 6 & & $+: 27$ & $\begin{array}{l}\text { Silphur water at } 650 \text { to } \\
700 \text { feet; soft water at } \\
2,024 \text { feet. }\end{array}$ \\
\hline Do. ${ }^{4} \ldots$ & 2,230 & & & -4 & $\begin{array}{l}\text { Also snlphur water at } 650 \\
\text { to } 700 \text { feet. }\end{array}$ \\
\hline $\begin{array}{l}\text { Kankakee County: } \\
\text { Kankakee } 5 . . . .\end{array}$ & 1,000 & 4 & & -15 & Water from 900 feet. \\
\hline Kendall County: & & & & & \\
\hline $\begin{array}{l}\text { Plattville (2 miles north } \\
\text { of })^{6} \\
\text { Knox County: } \\
\text { Galesburg }{ }^{\top} \ldots \ldots \ldots \ldots \ldots\end{array}$ & 1,236 & & & No flow. & 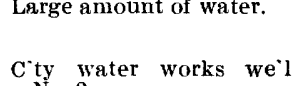 \\
\hline Do. ${ }^{8}$. & 1,226 & $14-6$ & 120 & -102 & No. 2 . \\
\hline Do $\ldots . . .$. & 1,999 & & & & temp., $60^{\circ} \mathrm{F}$ \\
\hline Lake Countw. & 1,350 & 8 & 80 & & $\begin{array}{l}\text { Water from } 1,180 \text { to } 1,350 \\
\text { feet; temp., } 68^{\circ} \mathrm{F} \text {. }\end{array}$ \\
\hline $\begin{array}{l}\text { Lake County: } \\
\text { Highland Park }{ }^{10} . .\end{array}$ & $\begin{array}{c}2,200 \\
1,800 \text { and }\end{array}$ & $8-5$ & 150 & +9 & $\begin{array}{l}\text { Water at } 900,1,300 \text {, and } \\
1,700 \text { to } 2,200 \text { feet; slightly } \\
\text { saline and hard. }\end{array}$ \\
\hline Do. ${ }^{11} \ldots$ & $\left\{\begin{array}{c}1,800 \text { and } \\
\text { over, }\end{array}\right.$ & & & & 3 wells. \\
\hline Lake Forest ${ }^{12}$ & 560 & & 60 & +50 & \\
\hline Do... & $\begin{array}{l}1,200 \\
1,757 \\
1,135\end{array}$ & & & ….... & 2 wells. \\
\hline Waukegan ${ }^{11}$. & $\begin{array}{l}1,600 \\
2,005\end{array}$ & & & & Jrony water; 3 wells. \\
\hline $\begin{array}{l}\text { Lasalle County: } \\
\text { Lasalle }{ }^{13} \ldots\end{array}$ & 502 & 6 & 200 & & \\
\hline $\begin{array}{l}\text { Marse } \\
\text { Mend }\end{array}$ & $\begin{array}{r}2,189 \\
400\end{array}$ & & 1 & Flow. & Flow is from 298 feet. \\
\hline 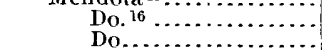 & $\begin{array}{r}850 \\
857 \\
470-504\end{array}$ & & & $\begin{array}{l}+14 \\
+\ldots \ldots\end{array}$ & $\begin{array}{l}\text { Flows at } 187 \text { and } 687 \text { feet. } \\
3 \text { wells. }\end{array}$ \\
\hline Ottawa $17 . \ldots . . . . . .$. & $\begin{array}{r}40-800 \\
400\end{array}$ & & & (n........ & $\begin{array}{l}\text { Has } 200 \text { wells } 400 \text { feet deep; } \\
\text { water from } 290 \text { to } 400 \\
\text { feet. }\end{array}$ \\
\hline Do. ${ }^{18}$. & 1,840 & & & +177 & $\begin{array}{l}\text { Water from } 1,640 \text { to } 1,840 \\
\text { feet. }\end{array}$ \\
\hline Feidicord .......... & 2,189 & & 8 & At surface. & Water from Potsdam 1,845 \\
\hline $\begin{array}{l}\text { I'eru }{ }^{19} \ldots \ldots \ldots \ldots \ldots \\
\text { Do } \ldots \ldots \ldots \ldots \ldots\end{array}$ & $\begin{array}{l}1,360 \\
2,300\end{array}$ & & 200 & +120 & Water at 750 feet also. \\
\hline Do. & 1,250 & .... & 450 & +85 & \\
\hline $\begin{array}{l}\text { Ransom }(\text { near })^{21} \ldots \ldots \\
\text { Seneca }=2 \ldots \ldots\end{array}$ & $\begin{array}{r}543 \\
600-650\end{array}$ & & & & 2 wells. \\
\hline Do.:s & 680 & 4 & ... & +15 & $\begin{array}{l}\text { water, which is hard and } \\
\text { sulphurous, is from } 350 \\
\text { and } 380 \text { feet. }\end{array}$ \\
\hline Streator... & 1,115 & $8-6$ & 130 & No flow. & $\begin{array}{l}\text { water-bearing beds at } 596, \\
706,834,1,056 \text {, and } 1,096\end{array}$ \\
\hline
\end{tabular}

1 U.S. Geol. Surv. Monograph No. 38, 1899, p. 597. 2 Ibid., 17tb Ann. Rept. 1895-96, part 2, p. 812 .

3 Ibid., p. 812; Monograph No. 38, 1899, p. 595-596.

4 Ibid., p. 812; analysis, p. 827; Monograph No. 38,1899 , p. 595 .

5 Record ibid., 17th Ann. Rept. 1895-96, part 2, p. 814, analysis, p. 821; Monograph No.38, 1899, p. 653 .

U.S. Geol. Surv. Monograph No. 38, 1899, p. 644 i Analysis, Am. Inst. Mining Eng. Trans., vol. 27, p. 135 .

8 U. S. Geol. Surv., 17th Ann. Rept. 1895-96, part

2, p. 813; Monograph No. 38,1899 , p. 677 .

Ibid., p. 814; Monograph No. 38, 1899, p. 677.

${ }^{10}$ Ibid., p, 813; Monograph No. 38, 1899, p. 580 .

11 Jbid., Monograph No. 38,1899, p. 580.

1: Ibid., 17th Ann. Rept. 1895-96, part 2, p. 814; Jonograph No. 38, 1899, p. 580 .
13 Ibid., p. 814; Monograph No. 38, 1899, p. 637

14 Record, Ill. Geol. Surv., vol. 8, p.50; U. S. Geol Surv. Monograph No. 38, 1899, p. 639.

${ }_{15}$ U.S. Geol. Surv., 17th Ann. Rept., 1895-96, part 2, p. 815 .

16 Record, Minn. Geol. Surv., 13th Ann. Rept. pp. 55,56 .

1i U.S. Geol. Surv.,17th Ann. Rept. 1895-96, part 2, p. 816; Monograph No. 3R 1899, p. 638 .

18 Record, ibid., pp. $79 R^{2}$ 799; Monograph No. 38 1899 , p. 638 .

${ }^{19}$ Analysis, ibid., p. 828 Monograph No. 38, 1899, p. 637 .

20 U.S. Geol. Surv. Monograph No. 38, 1899, p. 637 . 21 Ibid., p. 641 .

22 I bid., p. 638

:8 U. S. Geol. Surv., 17th Ann. Rept., 1895-96, part2, p. 817; Monograph No. $3 R_{1}, 1899$, p. 638 
ILLINOIS-Continued.

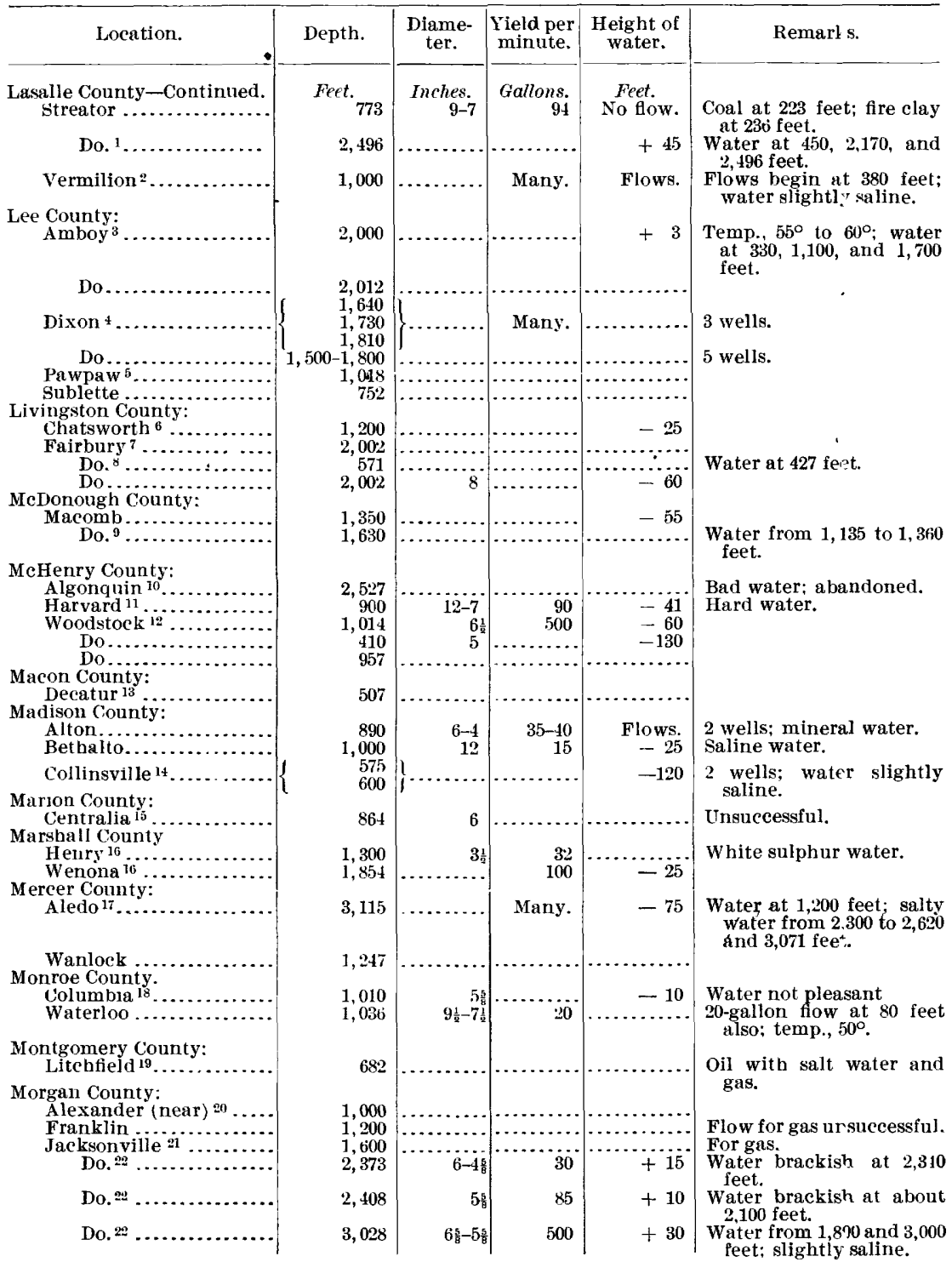

1 Ill. Geol. Surv., vol. 7, pp. 50, 59; record, U. S. Geol. Surv., 17th Ann. Rept., 1895-96, part 2, p. 798; analysis, p. 821; Monograph No. 38, 1899, p. 639.

2 Ú. S. Geol. Surv., 17th Ann. Rept., 1895-96, part 2, p. 818; Economic Geol., I1l., vol. 2, p. 235; U. S. Geol.Surv. Monograph No. 38, 1899, p. 639. 3 Ibid., p. 810; Monograph No. 38, 1899, p. 610.

4 Analysis, ibid., p. 827; Monograph No. 38, 1899, p. 609.

6 U. S. Geol. Surv. Monograph No. 38, 1899, p. 611. ${ }^{6}$ Record, Economic Geol., Ill., vol. 3, pp. 595-596. 7 U. S. Geol. Surv. Monograph No. 38, 1899, p. 666. 8 Ill. Geol. Surv., vol. 6, p. 242

9 Analysis, U. S. Geol. Surv. 17th Ann. Rept. 1895-96, part 2, pp. 808, 827; Monograph No. 38, 1899 , p. 685 .

10 U. S. Geol. Surv.. 17th Ann. Rept., 1895-96, part

2, p. 810; Monograph No, 38, 1899, p. 578.
11 Ibid., Monograph No. 38, 1899, p. 576.

12 Ibid., p. 577.

13 Record, Economic Geol., Ill.,vol. 3. pp.538-539. 14 U. S Geol Sury Monograph No. 38,1899 , 749 15 Record, Economic Geol., Ill.,vol. 2.pp. 138-139. 16 U. S. Geol. Surv. Monograph No. 38 1899,p. 669. 17 Ibid., 17th Ann. Rept., 1895-96, part 2, p. 810; Monograph No. 38, 3899, p. 622

18 Ibid., Monograph No. 38, 1899, pp. 765-766.

${ }^{19}$ Record, Ill. Geol. Surv. vol. 7, p.37; U. S. Geol. Surv. Monograph No. 38,1899 , p. 741 .

${ }_{20}$ U. S. Geol. Surv. Monograph No. 38 1899, p. 724. 21 Ill. Geol. Surv, vol. 8, p. 67.

22 U. S. Geol. Surv., 17th Ann. Rept., 1895-96, part 2, p. 814; analysis, p. 820; Monograph No. 38, 1899, p. 723. 
ILLINOIS-Continned.

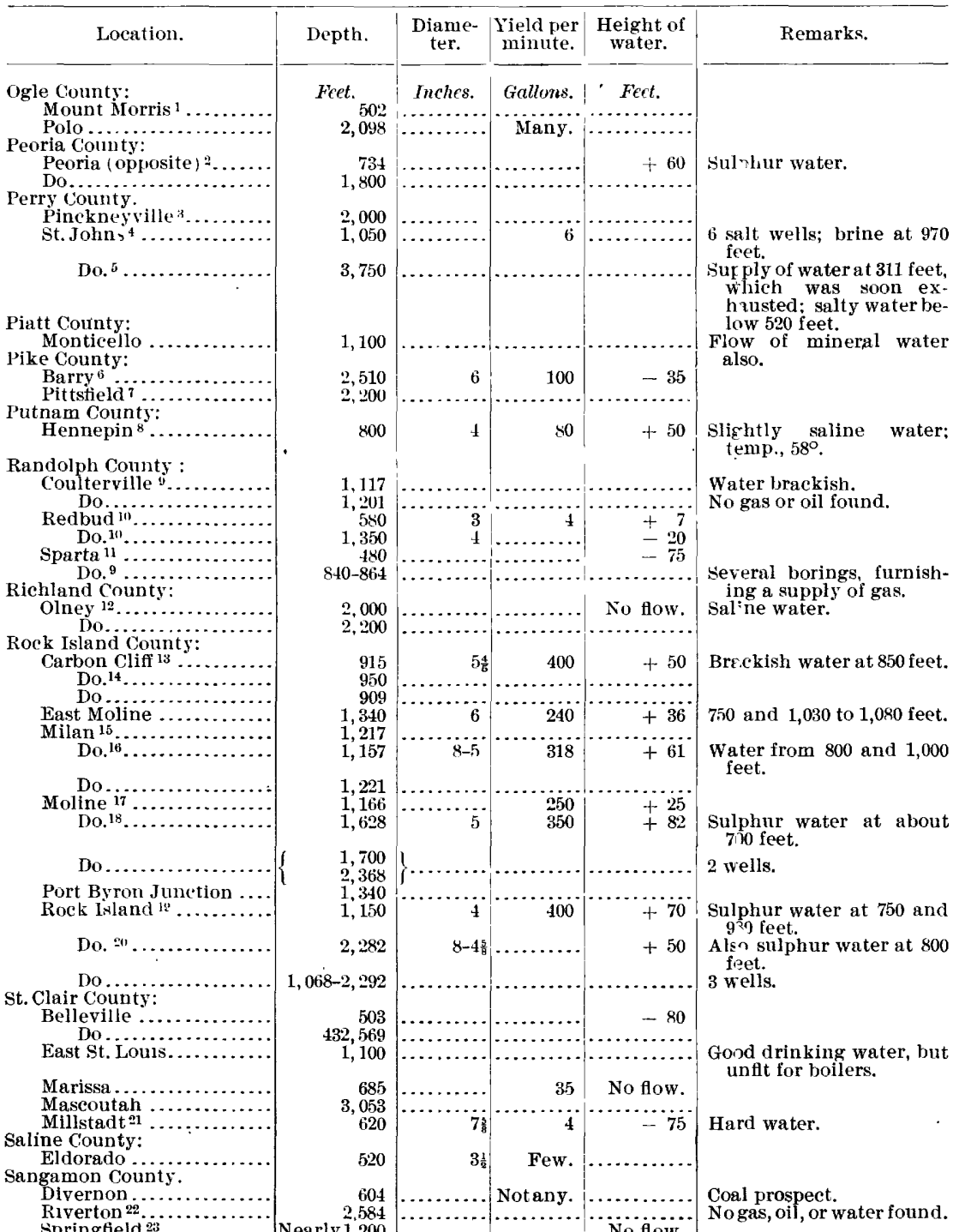

1 U. S.Geol. Surv., Monogra ph No. 38 1599, p 605.

2 Economic Geol. Ill, vol 2 , p. 449

3 U.S. Geol. Surv. Monograph No. 38, 1899, p. 771.

4 III. Geol. Surv., vol. 7 , p. 38

5 Partial record. ete., UT. S Geol. Surv. Monograph No. 38, 1899, pp. 772-773

${ }^{6}$ Analysis, 1bid., 17th Ann Rept., 1895-96, part

2, p. 827 , Monograph No. 38,1899 , p. 719

7 U.S.Geol. Surv. Monograph No. 38, 1899, p 721

8 1bid., p. 634

9 Ibid., p. 769

101 bid., p. 768

11 Ibid., 17 th Ann. Rept, 1895-96, part 2, p 817.

12 Ill. Geol. Surv. Rept., vol. 7, p. 8, U., S. Geol.

Surv. Monograph No. 38,1899 , p. 757 .

13 Record, ibid , vol, 8, pp. 64-65

14 Record, U. S. Geol. Surv., 17th Ann. Rept., 1895-96 part, p 849.

15 U. S. Geol Surv., 17th A nn. Rept, 1895-96, part $2, \mathrm{p} 846$.

${ }^{16}$ Ibid , p. 815 , analysis, pp. 808, 827: Monograph

No $38,1899, p$ p 621 .

is Record, ibid., pp. $847,848$.

18 Ibid.. p 848, analysis, pp. 808,827 .

19 U.S. Geol, Surv., 17th A nn. Rept., 1895-96, part

2 , p. 816. analysis, pp. 808, 828; record, pp. 845-846. 20 Ibid., pp. 817, 845

II Ibld., Monngraph No, 38, 1899, p. 762.

stil Geol. Surv. Report? vol. 8, p. $6 \%$.

23 Ibid., vol. 5 , p. 312. 
ILLINOIS-Continued.

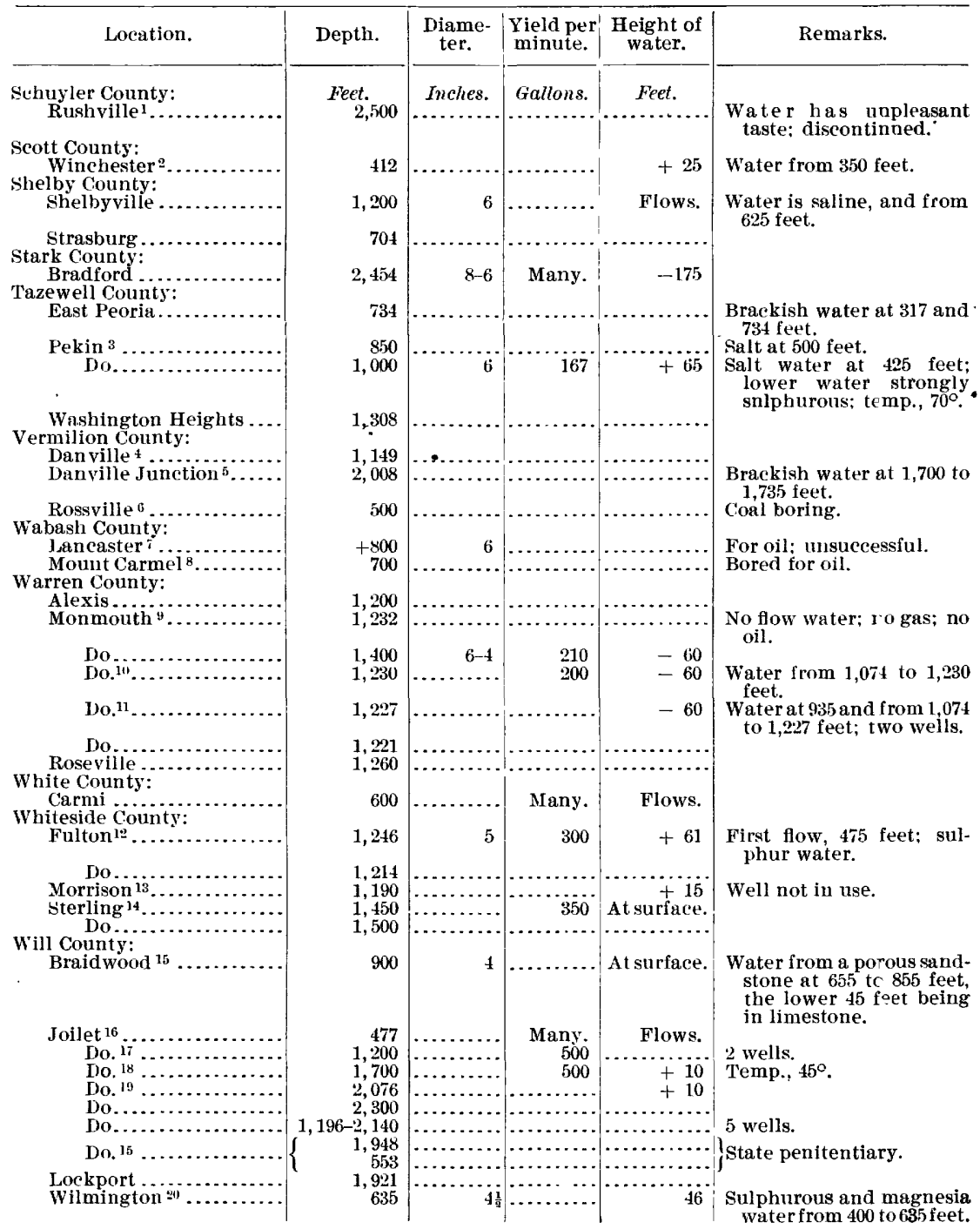
712 .

${ }^{1}$ IT. S. Geol. Surv. Monograph No. 38, 1899, p.

$\because$ Ibid., p. 722.

3 Ibid., p, 691.

4 Record, U. S. Geol, Surv. Folio No. 67.

5 Ibid., Monograph No. 38, 1899, p. 699, record,

U. S. Geol. Surv. Folio No. 67 .

6 Ibid., p. 699

7 Record, Economic Geol. Ill., vol. 3, pp. 58-60.

${ }^{8}$ Record in part, ibid, vol. 3 pp. 386-387.

3 Record, III, Geol Surv. Rept., vol. 8, pp. 62-66.

${ }^{10}$ Record, U S. Geol. Surv., 17th Ann. Rept. 1895-96, part 2 p. 848, analysis, pp. 808.827.

${ }^{11}$ Ibid., p. 818; analysis, pp. 808. 827, Monograph No. 38,1899, p. 678

12 U. S. Geol Surv., 17th Ann Rept., 1895-96, part 2 , p. 813 , Monograph No 38,1899, p. 615.
13 Ibid., Monograph No. 38, 1899, p. 616.

14 Analysis, U. S. Geol. Surv., 17th Arn. Rept., 1895-96 part 2, p. 828, Monograph No. 38, 1899, p.

616-617. ${ }_{15}$ U. Geol. Surv. Monograph No. $3^{*}$ 1899, p. 650 .

${ }_{16}$ Record, Economic Geol., Ill., vol. 2, pp. 482, 487; U. s. tieol. Surv. Monograph No. 38, 1899, p. 649

${ }_{17}^{6}$ U. S. Geol. Surv, Monograph No. $3^{R}$ 1899, p. 649.

${ }_{18}$ Ibid., 17th Ann. Rept., 1895-96, part 2, p. 814; analysis, $p, 821$

19 Record, 1bid., pp. 799, 814, Monograph No. 38, 1899 , p. 650 .

20 Ibid., 17th Ann. Rept., 1895-96, part 2, p. 818; Monograph No. 38, 1899, p. 650 . 
ILLINOIS-Continued.

\begin{tabular}{|c|c|c|c|c|c|}
\hline Location. & Depth. & $\begin{array}{c}\text { Diame- } \\
\text { ter. }\end{array}$ & $\begin{array}{c}\text { Yield per } \\
\text { minute. }\end{array}$ & $\begin{array}{l}\text { Height of } \\
\text { water. }\end{array}$ & Remarks. \\
\hline $\begin{array}{l}\text { Williamson County: } \\
\text { Marion ............. }\end{array}$ & $\begin{array}{l}\text { Feet. } \\
\qquad 1,715\end{array}$ & Inches. & Gallons. & $\begin{array}{l}\text { Feet. } \\
\text { Flow. }\end{array}$ & Forgas andoil; sulphurous \\
\hline $\begin{array}{l}\text { Winnebago County: } \\
\text { Harlem................ }\end{array}$ & 1,047 & & & & \\
\hline $\begin{array}{r}\text { Rockford } 1 . . \ldots \\
\text { Do. }{ }^{2} \ldots \ldots\end{array}$ & $1,300-1,996$ & $8-6$ & $116-260$ & $\begin{array}{l}+8 \\
-8\end{array}$ & $\begin{array}{l}5 \text { we'!s: water from } 380 \text { to, } \\
400 \text { feet and } 1,200 \text { to } 1,300 \\
\text { fett. }\end{array}$ \\
\hline $\begin{array}{l}\text { Woodford County: } \\
\text { Minonk }{ }^{3} \ldots \ldots\end{array}$ & 1,755 & ............. & 100 & -149 & $\begin{array}{l}\text { Moderately hard water at } \\
750 \text { feet and at about } \\
1,700 \text { feet. }\end{array}$ \\
\hline 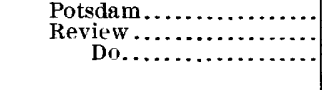 & $\begin{array}{l}1,500 \\
1,400 \\
1,233\end{array}$ & (n) & $\begin{array}{l}\text { Many. } \\
208\end{array}$ & 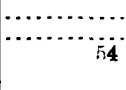 & $\begin{array}{l}\text { Temn., } 62^{\circ} \text {. } \\
\text { salt water from } 600 \text { to } 1,008 \\
\text { feet. }\end{array}$ \\
\hline
\end{tabular}

\section{PRINCIPAL PUBLICATIONS RELATING TO DEEP JORINGS IN ILLINOIS.}

Illinois Geological Survey, Reports on Geology and Palæontology, volumes 5, 1873; 6,$1875 ; 7,1883$, and 8,1890 .

Economical Geology of Illinois, by State geologist, volumes 2 and 3, Springfield 1882.

The water resources of Illinois, by Frank Leverett: United States Geological Survey Seventeenth Annual Report, 1895-96, part 2, pp. 695-849, plates, Washington, 1896.

Wells of Illinois, by Frank Leverett: United States Geological S rrvey Monograph No. 38,1899 , pages $550-787$.

U. S. Geol. Surv. Folio No. 67 (Illinois-Indiana), by M. R. Carppbell and Frank Leverett, Washington, 1900.

\section{INDIANA.}

The numerous deep borings in Indiana are for oil or gas, but a few of them yield water supplres. The wells are in groups or "districts," often many square miles in extent. Where localities given in the following list are in districts, only representative wells are described, for it would not be practicable here to list all the individual wells. In some localities new wells are constantly being sunk.

\begin{tabular}{|c|c|c|c|c|c|}
\hline Loeation & Depth. & $\begin{array}{l}\text { Diame- } \\
\text { ter. }\end{array}$ & $\begin{array}{l}\text { Yield per } \\
\text { minute. }\end{array}$ & $\begin{array}{l}\text { Height of } \\
\text { water. }\end{array}$ & Remarks. \\
\hline $\begin{array}{l}\text { Adams County. } \\
\text { Decatur }{ }^{1} \ldots \ldots \ldots \ldots \ldots\end{array}$ & $\begin{array}{l}\text { Feet. } \\
\quad 1,300\end{array}$ & $\begin{array}{l}\text { Inches. } \\
\text {. }\end{array}$ & $\begin{array}{l}\text { Gallons. } \\
\text { G.......... }\end{array}$ & Feet. & For gas; unsuccessful; \\
\hline $\begin{array}{l}\text { Allen County. } \\
\quad \text { Fort Wayne ............. }\end{array}$ & $250-150$ & & 5,000 in & $-6(?)$ & $5 t$ wells at waterworks. \\
\hline $\begin{array}{l}\text { Fort Wayne (Bass foun- } \\
\text { dry). }\end{array}$ & 1,458 & & all. & & For gas, unsuccessful. \\
\hline Fort Wayne (Abott s & 1,900 & & & -900 & For gas; unsuccessful; \\
\hline 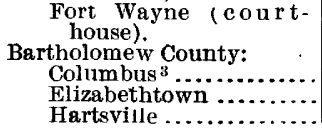 & $\begin{array}{r}1,700 \\
+914 \\
+861\end{array}$ & & & (n) & $\begin{array}{l}\text { For gas, unsuceessful. } \\
\text { Gas well. } \\
\text { Do. } \\
\text { Do. }\end{array}$ \\
\hline
\end{tabular}

1 Record, U.S. Geol. Surv.,11th Ann. Rept., 1889-

90, part 1, p. 740.

Surv., 16th Ann. Rept., 1888, pp. 129-130.

${ }^{3}$ Record, U. S. Geol. Surv., 11th Ann. Rept., 188990 , part 1, p. 722; 18th Ann. Rept., 1896-97, part 4, pp. $487-488$. 
INDLANA - Continued.

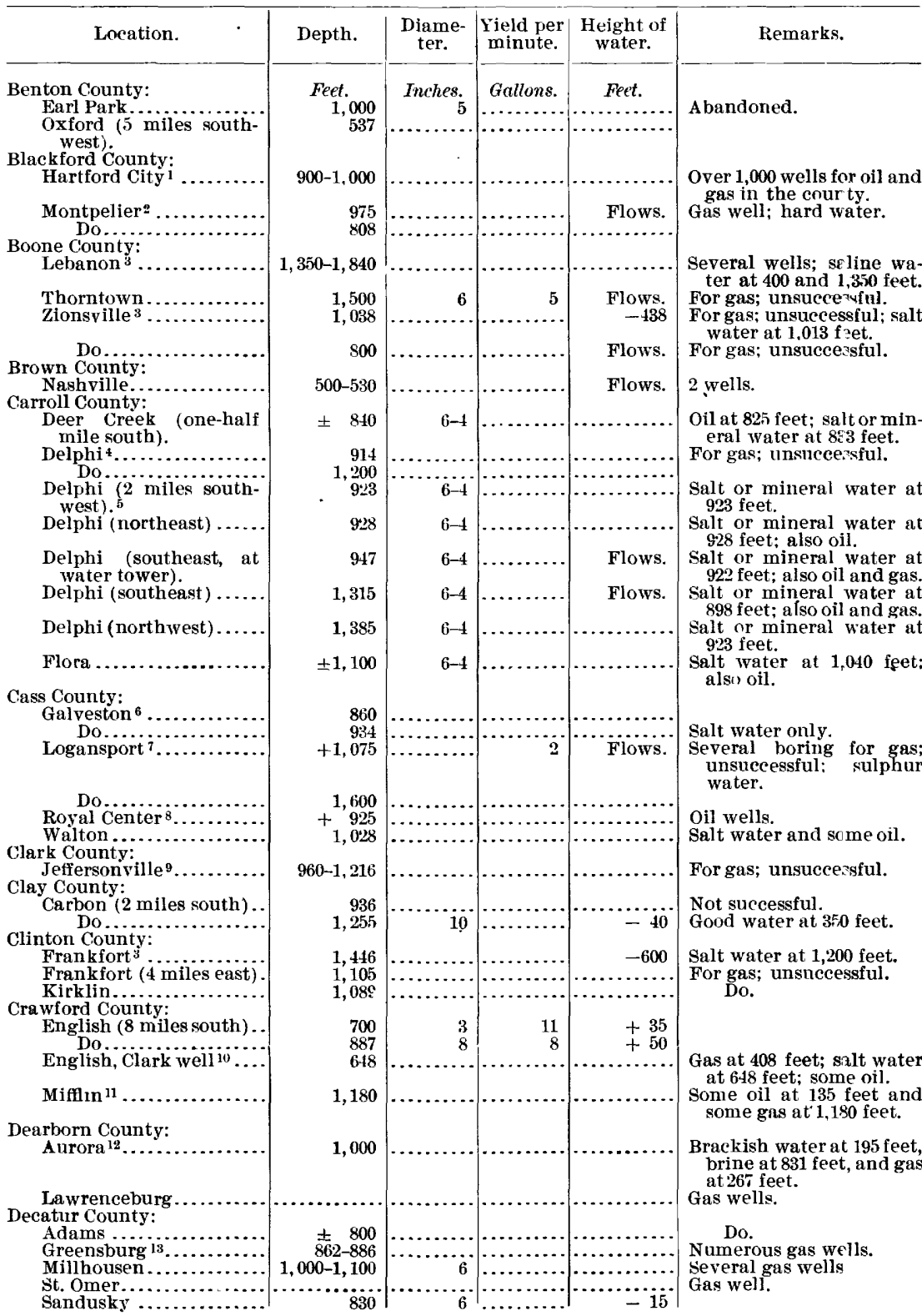

1 Record, U.S. Geol. Surv., 11th Ann. Rept., 188990 , part 1, pp. 678-681.

2 lbid., p. 680 .

3 Ibid., p. 730 .

4 Ibid., p. 731.

5 Record, Mich. Geol. Surv., 1881-1893, p. 54, pl.14.

6 Record, Ind. Geol. and Nat. Hist. Surv., 19th Ann. Rept., 1894, p. 39.

I Ibid., p. 38; U. S. Geol. Surv., 11th Ann. Rept. 1889-90, part 1, p. 732 .

8 U. S. Geol. Surv., 11th Ann. Rept., 1889-90, part 1 , p. 732

Record, ibid, p. 724 .

10 Record, Ind. Geol. and Nat. Hist. St rv., 17th Ann. Rept., 1891, p. 311.

11 Ibid., pp. 311-312

12 Record, U. S. Geol. Surv., 11th Ann. Rept., 188990 , part 1, p. 705.

13 Ibid., pp. 703-704 
INDIANA-Continued.

\begin{tabular}{|c|c|c|c|c|c|}
\hline Location. & Depth. & $\begin{array}{l}\text { Diame- } \\
\text { ter. }\end{array}$ & $\begin{array}{l}\text { Yield per } \\
\text { minute. }\end{array}$ & $\begin{array}{l}\text { Height of } \\
\text { water. }\end{array}$ & Remarks. \\
\hline $\begin{array}{c}\text { Dekalb County: } \\
\text { Auburn }\end{array}$ & Fect. & ites. & & & Gas wells \\
\hline Autler....... & $\begin{array}{r}+1,953 \\
600\end{array}$ & & & & Hard water. \\
\hline Do. ${ }^{1} .$. & 2,139 & & & & For gas, unsuccessful; salt \\
\hline Garrett .... & & & & & Snall gas well. \\
\hline Waterloo... & & & & & Gas well. \\
\hline $\begin{array}{l}\text { Delaware County: } \\
\text { Albany }{ }^{2} \ldots \ldots\end{array}$ & & & & & \\
\hline $\begin{array}{c}\text { Albany²........ } \\
\text { Do } . . . . . .\end{array}$ & $\begin{array}{r}978 \\
1,262\end{array}$ & $8-6 \frac{1}{4}$ & & & $\begin{array}{l}\text { Do. } \\
\text { Oil in small quantity. }\end{array}$ \\
\hline Cowan...... & $\begin{array}{r}1,505 \\
+\quad 935\end{array}$ & & & & Gas well. \\
\hline Daleville..... & +870 & & & & Do. \\
\hline 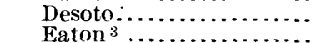 & & & & & $\begin{array}{l}\text { Do. } \\
\text { Do. }\end{array}$ \\
\hline Muncie $4 .$. & $870-955$ & & & & Nimerous wells in vicin- \\
\hline Do. ${ }^{5} \ldots \ldots$ & 1,600 & & & -506 & Brine at 1,390 feet. \\
\hline Do......... & 1,243 & & & & oil. \\
\hline New Corne & & & & & Gas well. \\
\hline $\begin{array}{l}\text { Oakvill } \\
\text { Royerts }\end{array}$ & $\cdots$ & & & & Do. \\
\hline $\begin{array}{l}\text { Royer } \\
\text { Selm? }\end{array}$ & 1,025 & & & & $\begin{array}{l}\text { Do. } \\
\text { Do. }\end{array}$ \\
\hline Shide & & & & & Do. \\
\hline Union Grox & 944 & & & & Do. \\
\hline $\begin{array}{l}\text { Yorktı } \\
\text { Dubois Co }\end{array}$ & 940 & & & & Do. \\
\hline Jasper & 1,100 & 8 & & & $\begin{array}{l}\text { Salt water at } 460 \text { feet, gas } \\
\text { at } 600 \text { feet, oil and min- } \\
\text { eral water at } 955 \text { feet. }\end{array}$ \\
\hline $\begin{array}{r}\text { Elkhart County: } \\
\text { Elkhart }{ }^{7} \ldots\end{array}$ & 615 & 5횽 & & Flowed. & For gas; unsuccessful: salt \\
\hline$\underset{\text { Farette Count }}{\text { Goshen }^{8} \ldots \ldots \ldots \ldots}$ & 2,059 & & & Flows. & $\begin{array}{l}\text { water at bou reet. } \\
\text { For gas; unsuccessful; salt }\end{array}$ \\
\hline Connorsville & 851 & 8 & & & $\begin{array}{l}\text { water. } \\
\text { Gas well. }\end{array}$ \\
\hline $\begin{array}{l}\text { Flojd County: } \\
\text { Boone Landing }\end{array}$ & & & & & \\
\hline & & & & & Gas wells. \\
\hline Tobe & & & & & $\begin{array}{l}\text { For gas; unsuceessfnl. } \\
\text { Gas wells. }\end{array}$ \\
\hline Fountain Coun & & & & & \\
\hline Attica $\ldots \ldots \ldots \ldots \ldots$ & 900 & & & Flowe. & Sulphurous water. \\
\hline $\begin{array}{l}\text { Covington ( } 3 \text { miles be- } \\
\text { low). }\end{array}$ & 1,000 & & & & \\
\hline Lodi 10 ...... & 1,155 & 10 & 35 & +43 & For oil; yields mineral \\
\hline $\begin{array}{l}\text { Franklin County: } \\
\text { Brookville } \\
\text { if miles }\end{array}$ & 1,254 & & & & $\begin{array}{l}\text { water. } \\
\text { Gas wells. }\end{array}$ \\
\hline Mount Carmel ( 1 mile & 590 & & & & \\
\hline $\begin{array}{l}\text { west }){ }^{12} \\
\text { Fuiton County: } \\
\text { Fulton } \ldots \ldots \ldots \ldots \ldots .\end{array}$ & 1,150 & & & & Salt water only. aban- \\
\hline Kewanna 13 . & 1,089 & & & -84 & $\begin{array}{l}\text { doned. } \\
\text { For gas; unsuccessful. }\end{array}$ \\
\hline Roche & 1,185 & & & & Do. \\
\hline Do................... & 500 & & Many. & +5 & Sulphur water. \\
\hline $\begin{array}{l}\text { Rochester ( } 1 \frac{1}{3} \text { miles } \\
\text { south). }\end{array}$ & 1,157 & & & -15 & Salt water at 1,157 feet. \\
\hline $\begin{array}{l}\text { Rochester } \\
\text { Gibson Count }\end{array}$ & 1,500 & & & & Water flcwe at 240 feet; \\
\hline $\begin{array}{l}\text { Gibson County: } \\
\text { Fort Branich }{ }^{14} \ldots\end{array}$ & & & & & well a.jandoned. \\
\hline Princeton ......... & $600-790$ & & & & Several wells. \\
\hline Do. & 1,274 & & & $\cdots$ & \\
\hline $\begin{array}{r}\text { Do } \\
\text { Grant Con }\end{array}$ & $422-1,020$ & & & & Do. \\
\hline $\begin{array}{l}\text { Grant Coun } \\
\text { Fairmo }\end{array}$ & $500-1,000$ & $8-4$ & & & Ges wells. \\
\hline Herbst stat & $\begin{array}{r}1,045 \\
1,000\end{array}$ & & & & Ges well. \\
\hline Jonesbe & 935 & & & & Do. \\
\hline Marion ${ }^{17} . . .$. & $+865-1,010$ & 4 & & Flow. & $\begin{array}{l}\text { Nimerous gas wells; some } \\
\text { yield oil. }\end{array}$ \\
\hline Point Gabel ... & & & & & Ges well. \\
\hline
\end{tabular}

${ }^{1}$ Record, U. S. Geol. Surv., 11th Ann. Rept., 1889-

90 , part 1, p. 738

I Ibid., p. 715

3 Ibid., p. 713 .

4 Ibid., pp. 713-719.

5 rbid., p. 731

6 Ibid., pp. 715-716.

7 Ibid., p. 735, Mich. Geol, Surv., 1881-1893, p. 57 pl. 17.

s U. S. Geol. Surv., 11th Ann. Rept., 1889-90, part

1, p. 7ษ5, Mich. Geol. Surv., 1881-1893, p. 60, pl.19.

Ibld, p. 721 .

${ }^{10}$ Record, Ind. Geol. Surv., 1st Ann. Rept., 1869,

pp. 29-31. 1889-90, part 1 , p. 707.

${ }_{12}$ Ibid., Folio No. 105, 1@?4. p. 8.

13 Ibid., 11th Ann. Rept. 1889-90, part 1, p. 733.

14 U. S. Geol. Surv. Folic No. 105, 1904, p. 8.

15 Record, ibid., 11th Ann. Rept., 1889-90, part 1, p. 685

16 Ibrd., p. 688

${ }^{17}$ Ibid., pp. $685-687$ 
INDIANA - Continued.

\begin{tabular}{|c|c|c|c|c|c|}
\hline Location. & Depth. & $\begin{array}{c}\text { Diame- } \\
\text { ter. }\end{array}$ & $\begin{array}{l}\text { Yield per } \\
\text { minute. }\end{array}$ & $\begin{array}{l}\text { Height of } \\
\text { water. }\end{array}$ & Remarks. \\
\hline 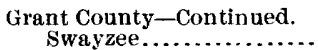 & $\begin{array}{l}\text { Feet. } \\
\text {. }\end{array}$ & & ons. & & Gas wells. \\
\hline Sweetzer ............ & & & & & $\begin{array}{l}\text { Gas wels. } \\
\text { Gas well. }\end{array}$ \\
\hline Upland........ & 1,040 & & & & Do. \\
\hline $\begin{array}{l}\text { Van Buren } 1 . . \\
\text { Greene County. }\end{array}$ & & & & & Do. \\
\hline $\begin{array}{l}\text { Greene County: } \\
\text { Worthington .. }\end{array}$ & 1.445 & & & Flows? & \\
\hline Hamilton County: & 1,440 & & & Flows? & Sulphur water. \\
\hline $\begin{array}{l}\text { Arcadia } 2 . . . \\
\text { Atlanta....... }\end{array}$ & 974 & & & & Gas well. \\
\hline $\begin{array}{l}\text { Atlanta...... } \\
\text { Carmel ..... }\end{array}$ & & & & & $\begin{array}{l}\text { Do. } \\
\text { Gas welı; small product. }\end{array}$ \\
\hline Cicero........... & & & & & Gas well. \\
\hline $\begin{array}{l}\text { Eagletown } \\
\text { Fishers station }\end{array}$ & & & & & Gas well: small product. \\
\hline $\begin{array}{l}\text { Fisners stat } \\
\text { Joliet....... }\end{array}$ & & & & & $\begin{array}{l}\text { Gas well. } \\
\text { Gas well: small flow. }\end{array}$ \\
\hline Myers .......... & & & & & Gas well; small product. \\
\hline New Britton & & & & & Gas wells. \\
\hline $\begin{array}{l}\text { Noblesville }{ }^{3} . \\
\text { Sheridan .... }\end{array}$ & $\begin{array}{r}843-860 \\
1,076\end{array}$ & & & & $\begin{array}{l}\text { Do. } \\
\text { Do. }\end{array}$ \\
\hline $\begin{array}{l}\text { Sheridan ....... } \\
\text { Swainville .... }\end{array}$ & & & 370 & & Gas well; small product. \\
\hline Westfleld....... & 1,080 & & & & Gas well: much salt water. \\
\hline $\begin{array}{l}\text { Do .............. } \\
\text { Hancoek County: }\end{array}$ & $\pm 1,068$ & & & & Gas wells. \\
\hline Charlottesvilie... & & & & & Gas well. \\
\hline $\begin{array}{l}\text { Greenfield } 4 . . . \\
\text { McCordsyille. }\end{array}$ & 990 & & & & Gas wells. \\
\hline New Palestine. & 1,060 & & & -400 & $\begin{array}{l}\text { Gas well. } \\
\text { Salt water at } 1,003 \text { feet: } \\
\text { some gas at } 625 \text { and } 900 \\
\text { feet. }\end{array}$ \\
\hline $\begin{array}{l}\text { Fortville .... } \\
\text { Palestine }^{5} . .\end{array}$ & $(?)$ & & & & $\begin{array}{l}\text { feet. } \\
\text { Gas wells. }\end{array}$ \\
\hline $\begin{array}{l}\text { Palestine } 5 \ldots . . . \\
\text { IIarrison County: }\end{array}$ & & & & & Gas well. \\
\hline $\begin{array}{l}\text { IArrison County: } \\
\text { Corydon........ }\end{array}$ & 1,200 & & & & Gas boring \\
\hline Do............ & $423-728$ & $8-5 \frac{5}{8}$ & & & $\begin{array}{l}\text { Gas boring. } \\
\text { Fresh water } 3 c-130 \text { feet; }\end{array}$ \\
\hline $\begin{array}{l}\text { IIendricks County: } \\
\text { Danville....... }\end{array}$ & & & & & $\begin{array}{l}\text { also salt wate in lower } \\
\text { strata. }\end{array}$ \\
\hline $\begin{array}{r}\text { Danville.......... } \\
\text { Do......... }\end{array}$ & 830 & & & & Abandoned. \\
\hline $\begin{array}{l}\text { Do. } \\
\text { Plainfielc }\end{array}$ & $\begin{array}{l}1,500 \\
1,385\end{array}$ & $8-5$ & 30 & & First water at 700 feet. \\
\hline $\begin{array}{l}\text { Henry Cou } \\
\text { Cadiz } 7\end{array}$ & & & & & Gas well. \\
\hline $\begin{array}{l}\text { Cadiz } 7 . \ldots . . . \\
\text { Dunreith } . . . . .\end{array}$ & 421 & & & • & Do. \\
\hline $\begin{array}{l}\text { Dunreith ............. } \\
\text { Greensboro (near).. }\end{array}$ & $\cdots \ldots$ & & & $\cdots \cdot$ & $\begin{array}{l}\text { Do. } \\
\text { Do. }\end{array}$ \\
\hline Honey Creek ...... & +980 & & & & $\begin{array}{l}\text { Do. } \\
\text { Gas wells. }\end{array}$ \\
\hline Knightstown - & ........... & & & & Gas well. \\
\hline $\begin{array}{l}\text { Mechanicsburg ............ } \\
\text { Middleton ................ }\end{array}$ & +935 & & & & Gas wells. \\
\hline Mount Summit ${ }^{8} . . . . . .$. & 1,082 & & & -720 & $\begin{array}{l}\text { Do. } \\
\text { Gas wells; salt water at }\end{array}$ \\
\hline Newcastle ${ }^{9} .$. & & & & & Several gas walls with \\
\hline $\begin{array}{l}\text { Ogde } \\
\text { Spice }\end{array}$ & & & & & $\begin{array}{l}\text { flows of salt water. } \\
\text { Gas well. }\end{array}$ \\
\hline $\begin{array}{l}\text { Spiceland } 10 \\
\text { Springport } 11\end{array}$ & & & & & Gas wells. \\
\hline $\begin{array}{l}\text { Springport }{ }^{11} \\
\text { Sulphur Sprin }\end{array}$ & & & & & For gas; unsuccessful. \\
\hline Valley Mills.. & & & & & Gas well. \\
\hline $\begin{array}{l}\text { Howard Cou } \\
\text { Greentov }\end{array}$ & & & & & \\
\hline $\begin{array}{l}\text { Greentown } . \\
\text { Kokomo }\end{array}$ & $920-1,000$ & & Many. & Flows & Do. \\
\hline & & & & & 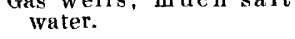 \\
\hline & & & & Flows. & \\
\hline $\begin{array}{l}\text { Sycai } \\
\text { Tam }\end{array}$ & & & & & Gas well. \\
\hline $\begin{array}{l}\text { Tampico.......... } \\
\text { Huntington Counity: }\end{array}$ & +950 & & & & Gas wells. \\
\hline $\begin{array}{l}\text { Huntington County: } \\
\text { Huntungton } 13 . .\end{array}$ & & & & & \\
\hline $\begin{array}{l}\text { Huntington }{ }^{13} \ldots \ldots \\
\text { Markle } \ldots . . . . . . .\end{array}$ & $\begin{array}{l}1,037 \\
1,700\end{array}$ & 8 & & $\begin{array}{r}-87 \\
\text { Flows. }\end{array}$ & For gas; unsuccessful. \\
\hline $\begin{array}{r}\text { Warren } \\
\text { Jackson County: }\end{array}$ & 969 & $\cdots$ & & & Sorne oil, abanconed. \\
\hline $\begin{array}{l}\text { Jackson County: } \\
\text { Brownstown } 14 . \ldots \ldots \ldots . .\end{array}$ & 1,891 & & & -291 & $\begin{array}{l}\text { Flow of magnesia water } \\
\text { at } 565 \text { feet; salt water at } \\
1,891 \text { feet. }\end{array}$ \\
\hline
\end{tabular}

1 Record, U.S. Geol. Surv., 11th Ann. Rept., 1889 90 , part 1, p. 689

Ibid., p. 699 .

3 U. S. Geol.Surv., 11th Ann. Rept., 1889-90, part

1, p. 697 .

4 Record, ibid., pp. 701-702.

5 Ibld., p. 702

${ }^{6}$ U. S. Geol. Surv., 18th Ann. Rept., 1896-97, part

4, p. 488; 11 th Aun. Rept., 1889-90, part 1, p. 725 .

I Ibid., Water-Sup. and Irr. Paper No. 26, 1899.

p. 31 .

${ }^{8}$ Record, ibid., 11th Ann Rept., 1889-90, part 1,
9 U. S, Geol, Surv, 11th Ann. Rept., 1889-90, part

1 , pp. $705-707$

10 Ibid., p. 707

11 Ibid., p. 706 .

12 Ind. Geol. and Nat. Hist. Surv., 18?5-86, 15th Ann. Rept., pp. 323-326: U. S. Geol. Eurv., 11th Ann. Rept., 1889-90, part 1, pp. 691-693.

13 Record, U. S. Geol, Surv, 11th Ann. Rept. $1889-90$, part 1 , p. 739 .

14 Ibjd., p. 726 . 
INDI ANA - Continuer.

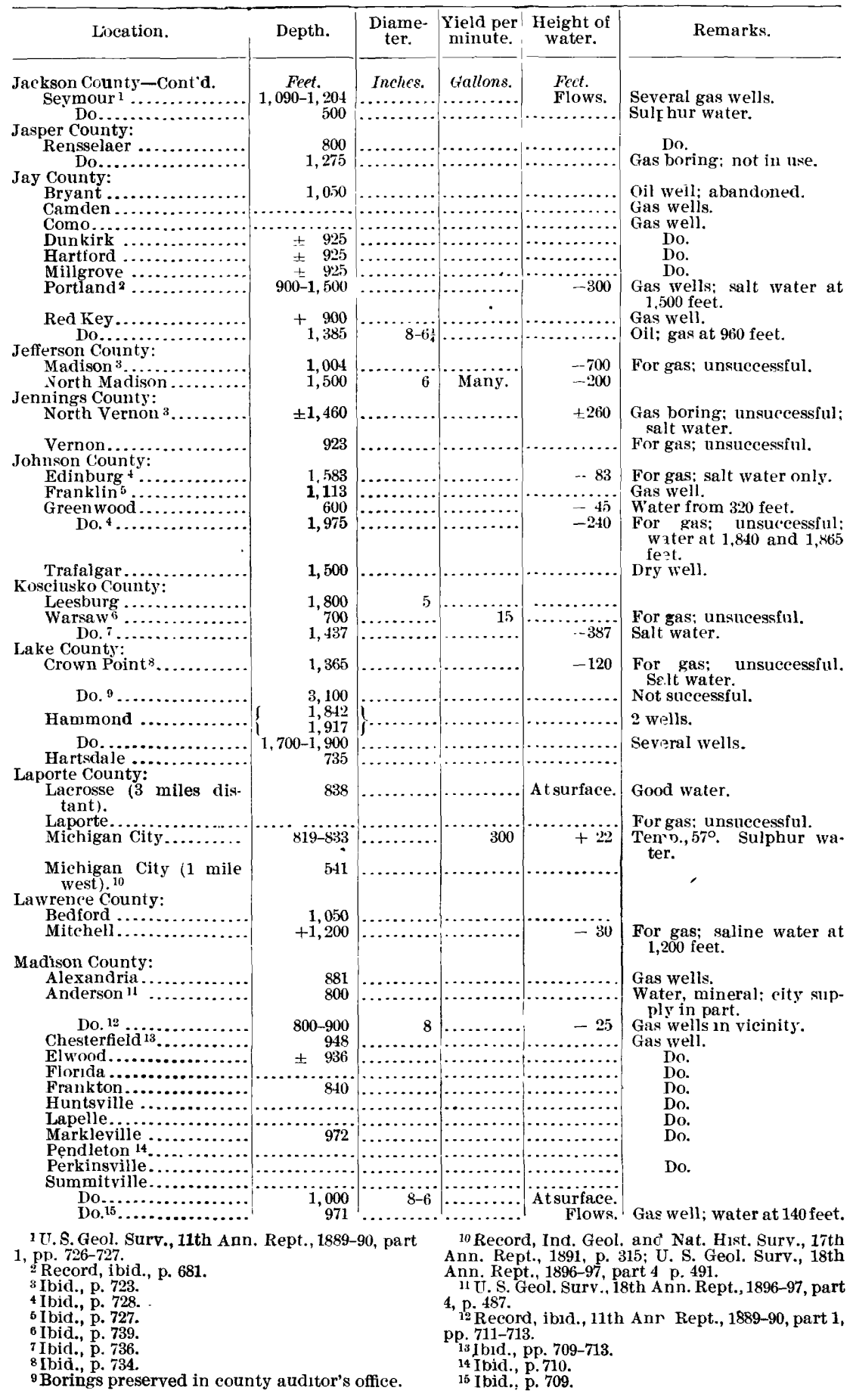


INDIANA - Continued.

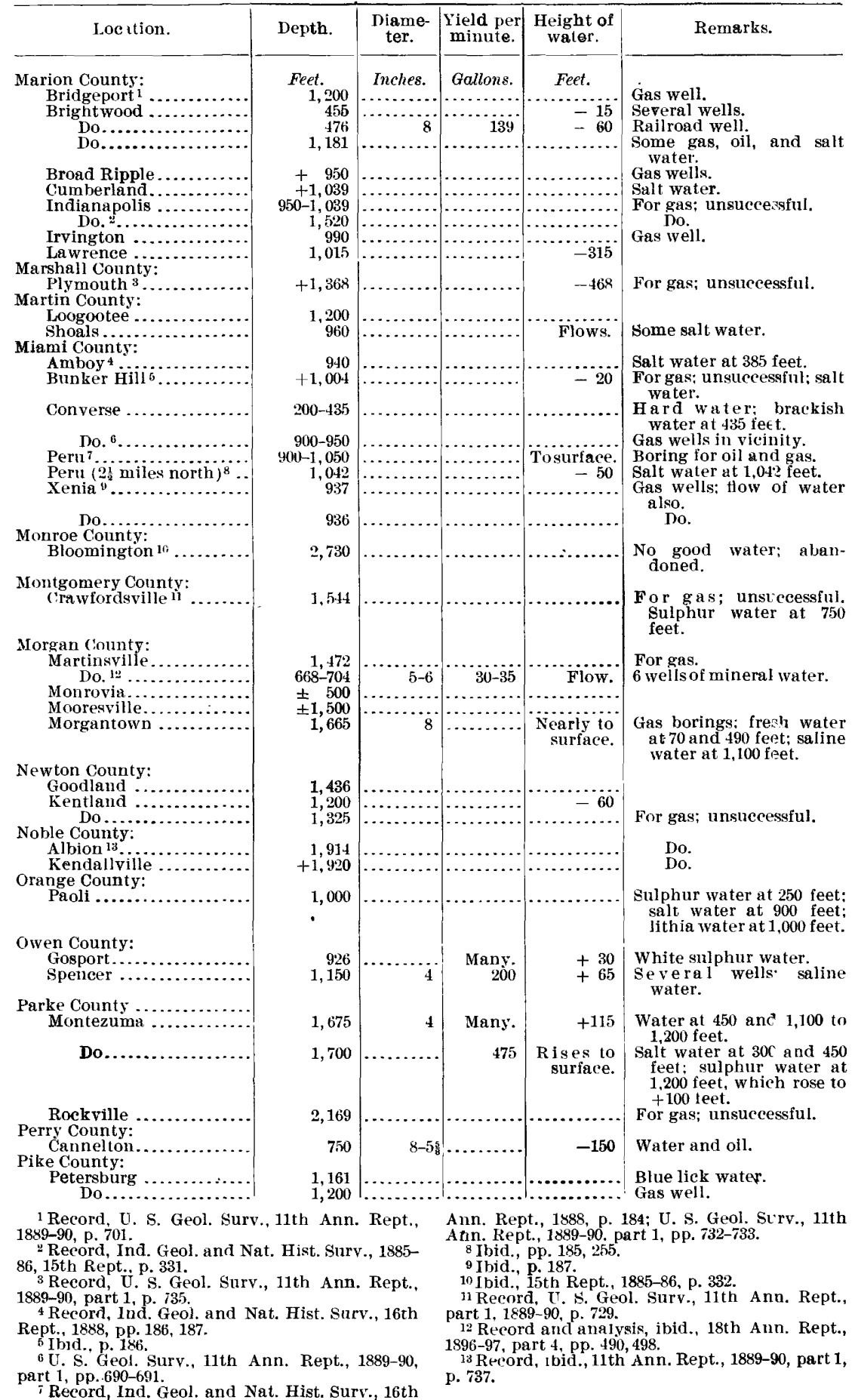


INDIANA-Continued.

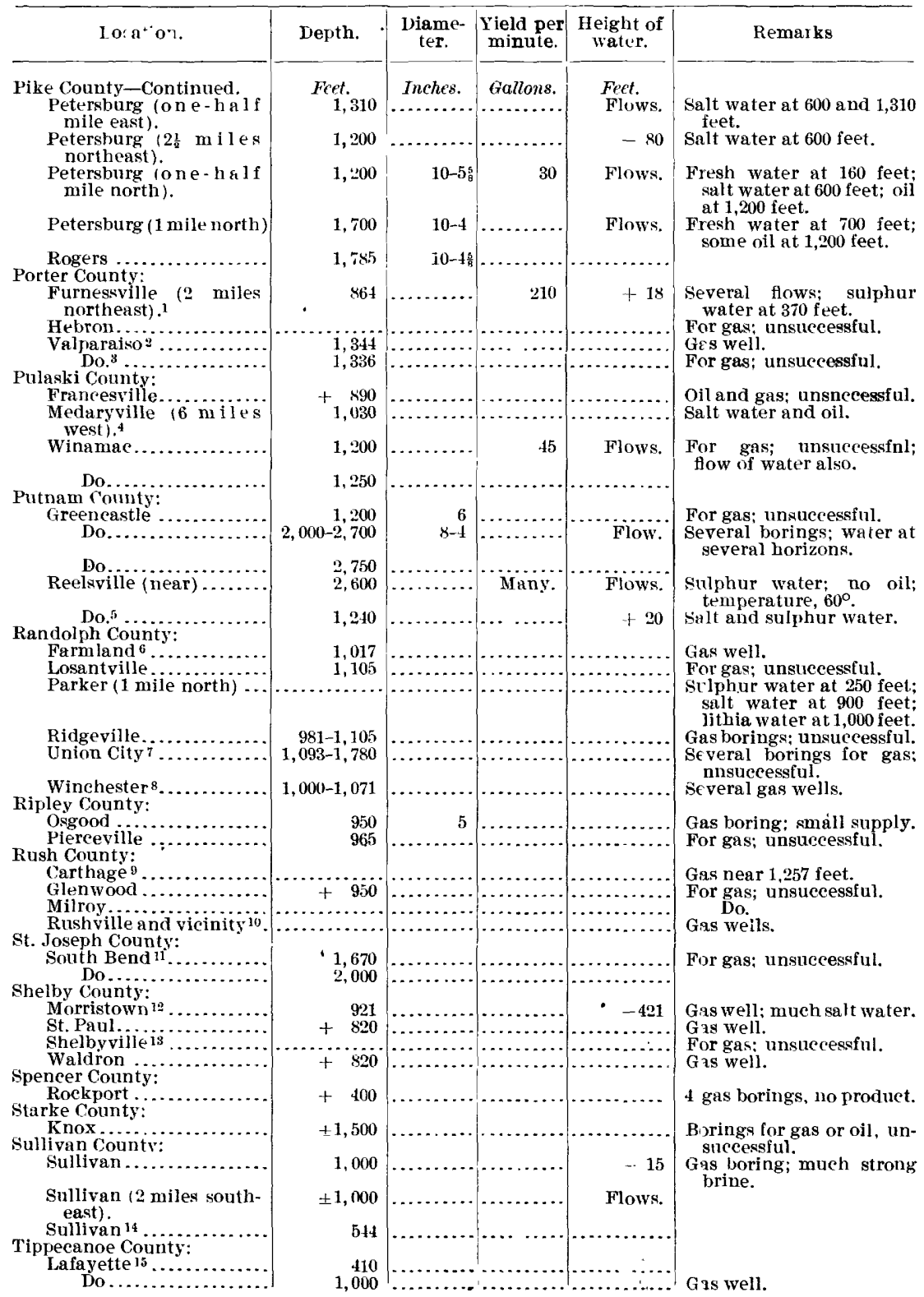

1 Record, U. \& Geol. Surv, Water-Sup and Irr. Paper No. 21, p. 16, 1899

I Ibid., 11th Ann. Rept., 1889-90, part 1, p. 733.

3 Record, Ind. Geol. and Nat. Hist. Surv 16 th

Ann. Rept., 1888, p. 264.

+ Ibid., 17th Ann. Rept., 1891, p. 315.

6 Record, Ind, Geol, Surv., 1st Ann. Rept., 1869, pp. $29-31$

6U.S. Geol Surv., 11th Anr. Rept., 1889-90, part

1 , pp, $6 \times 8 \times 689$.

7 Record, ibid., p. 684.

8 Ibid., pp. $683-685$.

9 Ibid, p. 704.
I0 U.S. Geol. Surv., 11th Ann. Rept., 1889-90, part 1, p. 704 .

11 Record, Mich. Geol. Surv.. 1881-1893, p. 84, pl. 64; U. S. Geol. Surv., 11th Ann. Rept., 1889-90, part 1, pp. 734-735.

12 Record, U. S. Geol. Surv., 11th Ann. Rept., $18 \times 9-90$, part 1, p. 703.

${ }_{13}$ U. S. Geol. Surv.,11th Ann. Rept., 1889-90, part 1, pp. 702-703.

14 Record, Ind, Geol. Strv., 1870, pp. 193-194.

15 Ind. Geol. and Nat Hist. Surv., 1885-86, 15th Ann. Rept., pp. 69-71. 
INDIANA - Continued.

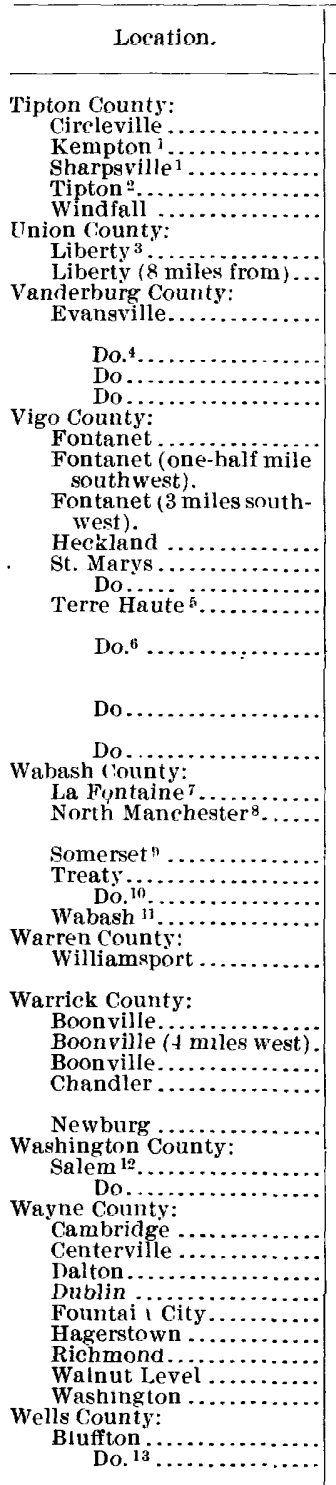

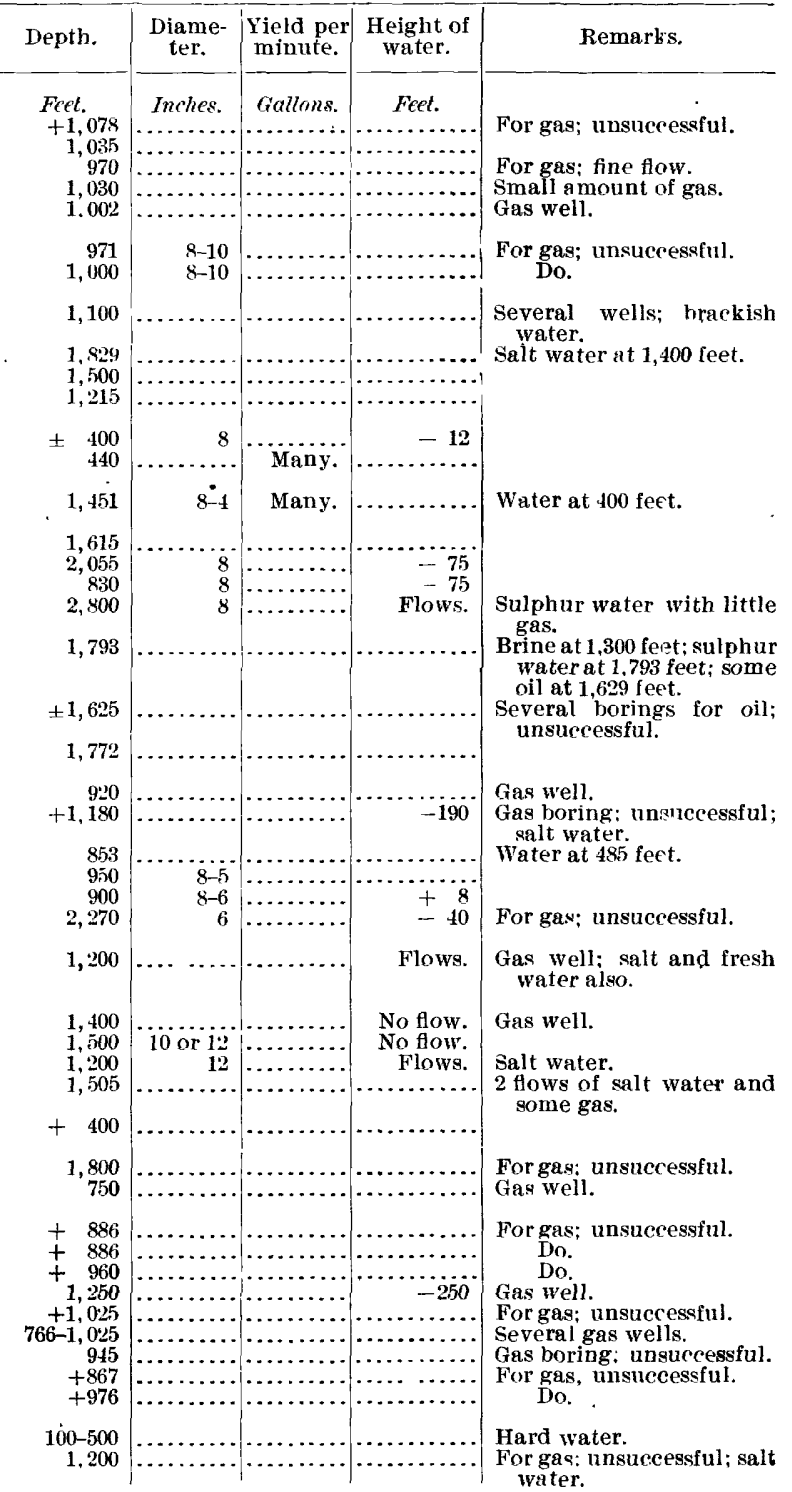

1 Record, [T. S Geol. Surv., 11th Ann Rept. $1889-90$, part 1, p. 696

2 Record, lbid., pp. 695-697; Ind. Geol. and Nat.

Hist. Surv, 1885-86 15 th Rept., p. 330.

3 Record, etc. ibid., pp. 720-7's1.

$4 \mathrm{Ky}$. Geol. Surv., Petroleum, Gas, etc., by Orton, pp. 197-198.

5 Record. Ind. Geot. Surv., 1870, pp. 126-134.

6 Ibid., p. 1:6. Ind. Geol. Surv., 1869, pp. 28-'29

31. Am. Jour. Sci., $2 d$ ser., vol. 48, p. 271.

7 Record, etc., [T. S. Geol Surv., 11th Ann.

8 U. S. Geol. Surv., 11 th Ann. Rept., 1889-90, part

1, p. 739

9 Record. Ind. Geol. and Nat. Hist. Surv., 17th Ann. Rept., 1891 pp. 252-253

16. Record, Ii. S. Geol. Surv., 11th Ann. Rept., $1889-90$, part 1, p. 714 .

11 lnd. Geol. and Nat. Hist. Surv. Fapt., 1875, pp. $43-4 x$

12 U.S. Geol. Surv., 11th Ann. Rept., 18\$9-90, part

1. pp. 725-726

13 Record, ibid., p. 710.

Rept., $1889-90$, part 1, pp. 689-690. 
INDIANA - Continued.

\begin{tabular}{|c|c|c|c|c|c|}
\hline Location. & Depth. & $\begin{array}{l}\text { Diame- } \\
\text { ter. }\end{array}$ & $\begin{array}{l}\text { Yield per } \\
\text { minute. }\end{array}$ & $\begin{array}{l}\text { Height of } \\
\text { water. }\end{array}$ & Remarks. \\
\hline $\begin{array}{l}\text { White County: } \\
\text { Monon }^{1} \ldots\end{array}$ & $\begin{array}{l}\text { Feet. } \\
\pm 920\end{array}$ & $\begin{array}{l}\text { Tnches. } \\
. . . . . . . .\end{array}$ & $\begin{array}{c}\text { Gallons. } \\
\ldots . . . . . .\end{array}$ & $\begin{array}{l}\text { Feet. } \\
\text { Nearly to }\end{array}$ & Salt water at 880 feet. \\
\hline Do.... & +880 & & & Nearly to & Gas boring; salt water at \\
\hline Monticello. & $+1,050$ & & & $\begin{array}{r}\text { surrace. } \\
-550\end{array}$ & Salt water at 1,050 feet. \\
\hline Monticello ${ }^{1}$ & $+1,150$ & & & -650 & \\
\hline $\begin{array}{l}\text { Whitley County: } \\
\text { Columbia City } 2 . .\end{array}$ & 1,375 & & & -20 & For gas; unsuccessful; salt \\
\hline Larwell ${ }^{ \pm}$. & 1,593 & & & -.200 & Do. \\
\hline
\end{tabular}

${ }^{1}$ Record, U. S. Geol. Surv., 11th Ann. Rept., 1889-90, part 1, p. 731.

2 Ibid,, p. 736.

\section{PUBLICATIONS RELATING TO DEEP BORINGS IN INDIANA.}

The natural gas field of Indiana, by $\dot{A}$. J. Phinney: United States Geological Survey Eleventh Annual Report, 1889-1890, part 1, pp. 579-740. plates, Washington, 1891.

Water resources of Indiana and Ohio, by Frank Leverett: United States Geological Survey Eighteenth Annual Report, 1896-1897, part 4, pp. 423-559, plates, Washington, 1897.

Wells of northern Indiana, by Frank Leverett: United States Geological Survey, Water Supply and Irrigation Papers Nos. 21 and 26, 1899.

\section{INDIAN TERRITORY.}

\begin{tabular}{|c|c|c|c|c|c|}
\hline Lncation. & Depth. & $\begin{array}{l}\text { Diame- } \\
\text { ter. }\end{array}$ & $\begin{array}{l}\text { Yield per } \\
\text { minute. }\end{array}$ & $\begin{array}{l}\text { Height of } \\
\text { water. }\end{array}$ & Remarks. \\
\hline $\begin{array}{l}\text { Cherokee Nation: } \\
\text { Bartlesville............. }\end{array}$ & $\begin{array}{l}\text { Fect. } \\
\qquad 1,700\end{array}$ & $\begin{array}{l}\text { Inches. } \\
\ldots \ldots \ldots\end{array}$ & Gallons. & & Oil at 1,286 feet. \\
\hline $\begin{array}{c}\text { Bartlesville ( } 2 \text { miles dis- } \\
\text { tant). }\end{array}$ & 1,800 & & Few. & Flows. & $\begin{array}{l}\text { Small quantity erude pe- } \\
\text { troleum. }\end{array}$ \\
\hline Chelsea ( 5 miles west) $\ldots$ & $300-600$ & 8 & & & Several oil wells. \\
\hline $\begin{array}{l}\text { Salina ( } 1 \frac{1}{2} \text { miles south- } \\
\text { east). }\end{array}$ & 470 & & & Flows. & Salt water. \\
\hline $\begin{array}{l}\text { Do........................... } \\
\text { Creek Nation: }\end{array}$ & 520 & & & do & Do. \\
\hline Redfork $\ldots \ldots \ldots$ & 1,487 & & & & Incomplete; prom is es \\
\hline Sapulpa ............... & 1,480 & 6 & & & Flow of oil: some salt wa- \\
\hline Sapulpa (6 miles north). & 1,440 & 6 & & & $\begin{array}{l}\text { Flow of gas at } 1,280 \text { feet } \\
\text { with } 60 \text { pounds pressure; } \\
\text { very little water. }\end{array}$ \\
\hline Sapulpa ... & 1,550 & & & & $\begin{array}{l}\text { Gas at } 1,250 \text { feet, with } \\
\text { pressure of } 50 \text { to } 60 \\
\text { pounds. }\end{array}$ \\
\hline $\begin{array}{r}\text { Do } \ldots \ldots \ldots \ldots \ldots \ldots \ldots \\
\text { Tulsa } \ldots \ldots \ldots \ldots \ldots \ldots \ldots\end{array}$ & $\begin{array}{l}1,560 \\
1,430\end{array}$ & & & & $\begin{array}{l}\text { Oil: salt water. } \\
\text { Salty water. }\end{array}$ \\
\hline & 1,424 & & & & $\begin{array}{l}\text { Salty water: fresli at } 266 \\
\text { fett. }\end{array}$ \\
\hline $\begin{array}{l}\text { Do } \\
\text { Chickasaw Nation: }\end{array}$ & 1,417 & & & & Salty water. \\
\hline 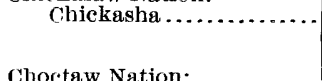 & 876 & 10 & & & $\begin{array}{l}\text { Salt water at } 298 \text { feet; no } \\
\text { water below; well in } \\
\text { progress. }\end{array}$ \\
\hline $\begin{array}{l}\text { Chortaw Nation: } \\
\quad \text { Atoka (15 miles west) ... }\end{array}$ & 1,414 & $\cdots$ & & & $\begin{array}{l}\text { Small indications of oil at } \\
807 \text { feet; oil at } 917 \text { feet; } \\
\text { much salt water; salt } \\
\text { water and oil at } 1,235 \\
\text { feet and } 1,347 \text { feet; oil } \\
\text { and gas at } 1,391 \text { feet. }\end{array}$ \\
\hline $\begin{array}{l}\text { Osage Nation: } \\
\text { Pawhuska..... }\end{array}$ & 2,000 & & & & $\begin{array}{l}\text { Water at } 1,145 \text { feet; gas } \\
\text { pressure at } 2,000 \text { feet pre- } \\
\text { vented further drilling. }\end{array}$ \\
\hline
\end{tabular}




\section{IOWA.}

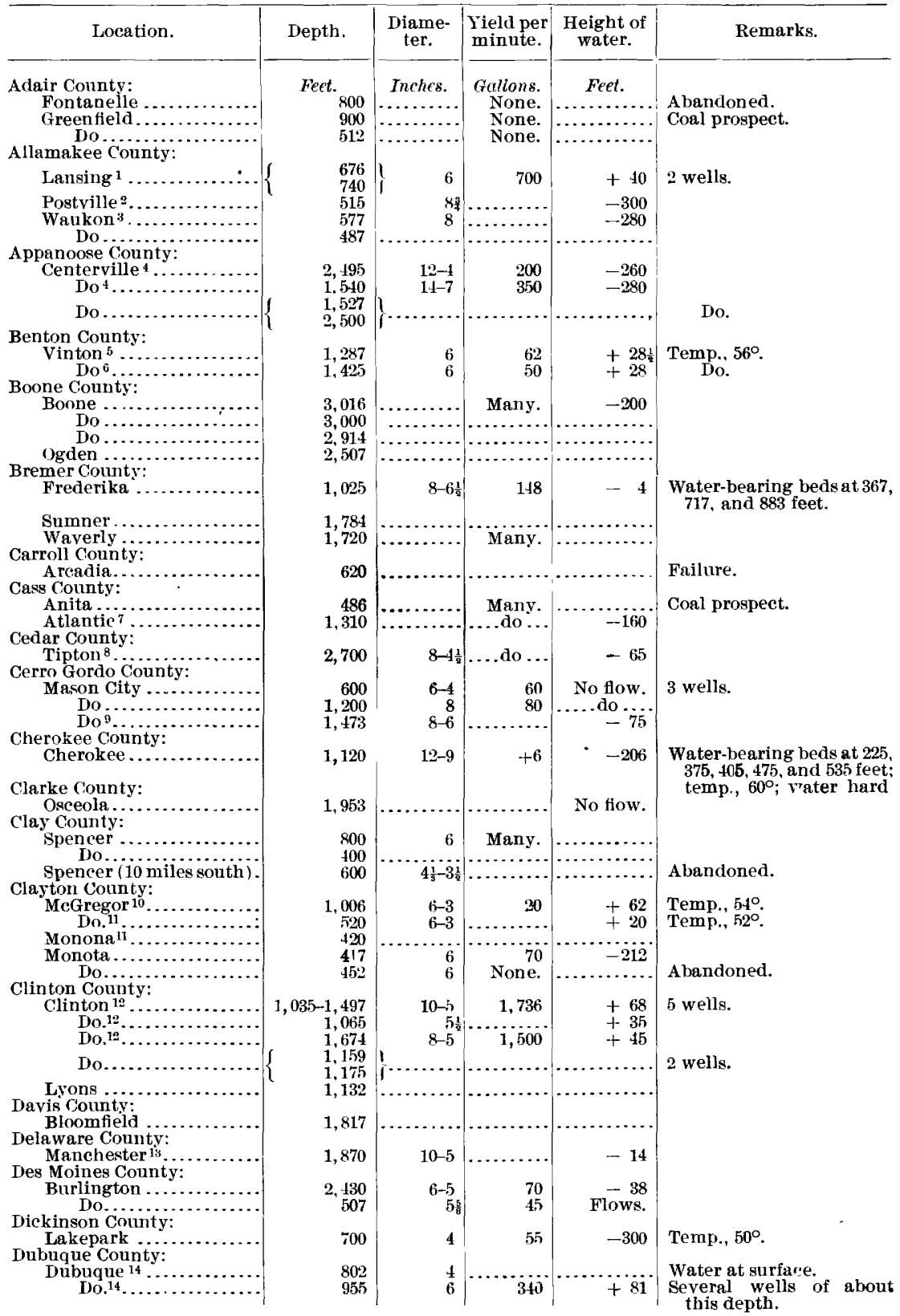

1 Record, Iowa Geol. Surv. Rept., vol, 6, 1896, p.

${ }^{8}$ Ibid., pp. 261-262.

9 Record and analysis, ibid., pp. 193-195.

10 Ibid., pp. 185-188.

11 Iowa Geol. Surv. Rept., vol. 6, 1893 , p. 188.

2 Ibid., p. 189.

3 Ibid., p. 202.

* Record and analysis, ibid., pp. 326-328.

5 Record, ibid., vol. 3, pp. 192-195.

- Record and analysis, ibid., vol. 6, 1896, pp. 266-267.

12 U. S. Geol. Surv., 17th Ann. Rept., 1895-96, part 2, p. 811; analysis, p. 827 .

1: Record and analysis, Iowa Geol. s'rurv, Rept., vol. 6,1896 , pp. 214-419.

₹ Record, ibid., pp, 336-339.

14 Ibid., pp. 208-214. 
IOWA-Continuerl.

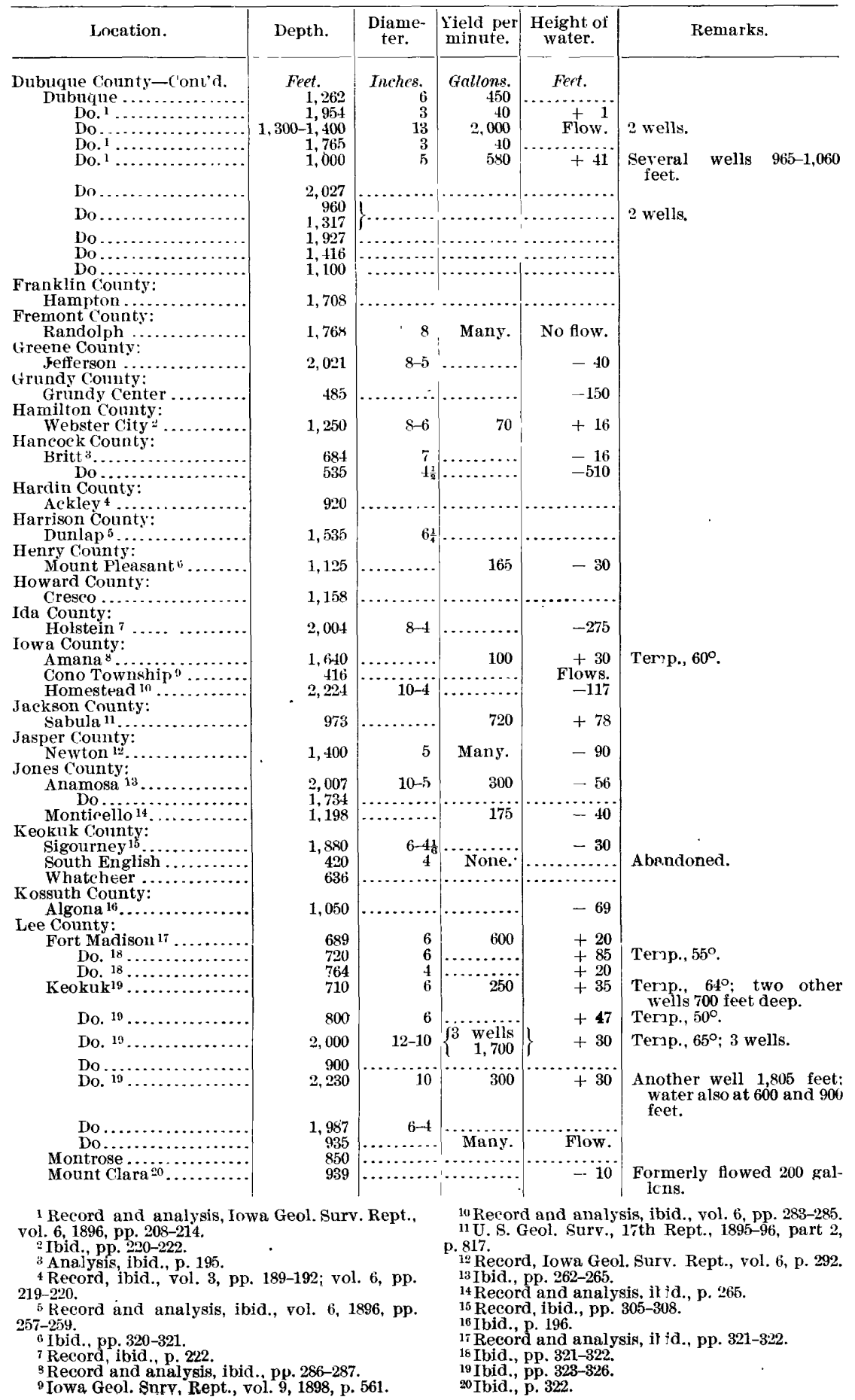


IOWA-Continued.

\begin{tabular}{|c|c|c|c|c|c|}
\hline Location. & Depth. & $\begin{array}{l}\text { Diame- } \\
\text { ter. }\end{array}$ & $\begin{array}{l}\text { Yield per } \\
\text { minute. }\end{array}$ & $\begin{array}{l}\text { Height of } \\
\text { water. }\end{array}$ & Remarks. \\
\hline $\begin{array}{l}\text { Linn County: } \\
\text { Cedar Rapids............ }\end{array}$ & Feet. & $\begin{array}{r}\text { Inches, } \\
5\end{array}$ & $\begin{array}{r}\text { Gallons. } \\
150\end{array}$ & $\begin{array}{l}\text { Feet. } \\
\quad+14\end{array}$ & 3 wells. \\
\hline Do................... & $\begin{array}{r}1,300 \text { to } \\
2,100\end{array}$ & & & & Do. \\
\hline $\begin{array}{c}\text { Mahaska County: } \\
\text { Oskaloosa }^{1} \ldots\end{array}$ & $2,800-3,000$ & & & & Abandoned. \\
\hline Marion County: & 2,517 & & $\cdots \cdots$ & …..... & \\
\hline $\begin{array}{l}\text { Marion County: } \\
\text { Pella } 2 \text {......... }\end{array}$ & 1,803 & $12-5$ & 250 & -90 & \\
\hline $\begin{array}{l}\text { Mills County: } \\
\text { Glenwood } 3 . . .\end{array}$ & 2,000 & $10-4 \frac{3}{4}$ & 83 & -173 & \\
\hline $\begin{array}{l}\text { Do. }{ }^{3} \\
\text { Montgomery County: }\end{array}$ & 1,910 & & 80 & -5 & \\
\hline $\begin{array}{l}\text { Montgomery County: } \\
\text { Redoak............. }\end{array}$ & 560 & & & & Coal prospect. \\
\hline $\begin{array}{l}\text { Muscatine County: } \\
\text { West Liberty }{ }^{4} \ldots \ldots \ldots \ldots\end{array}$ & & & & & \\
\hline Wilton Junctions .......... & $\begin{array}{l}1,768 \\
1,360\end{array}$ & $\begin{array}{l}6-4 \frac{3}{6} \\
8-6\end{array}$ & $300^{\frac{1}{12}}$ & $\begin{array}{r}\text { Flows. } \\
-78\end{array}$ & Temp.,65\%. \\
\hline $\begin{array}{l}\text { O'Brien County: } \\
\text { Sanborn } \ldots . . . \ldots \ldots \ldots \ldots\end{array}$ & & & & & \\
\hline Osceola County: & 1,224 & 6 & 80 & -459 & \\
\hline $\begin{array}{l}\text { Sibley ......... } \\
\text { Page County: }\end{array}$ & 763 & $4 \frac{1}{8}$ & 106 & -200 & \\
\hline $\begin{array}{l}\text { Clarinda } 6 \\
\text { Shenandoah................ }\end{array}$ & 1,002 & & & Flowed. & Coal prospect. \\
\hline $\begin{array}{l}\text { Shenandoah........... } \\
\text { Palo Alto County: }\end{array}$ & 700 & & & & \\
\hline $\begin{array}{r}\text { Emmetsburg }{ }^{7} \ldots \ldots \\
\text { Do } \ldots \ldots \ldots\end{array}$ & 874 & & & -34 & \\
\hline $\begin{array}{l}\text { Do } \ldots . . . . . . . . \\
\text { Plymouth County: }\end{array}$ & 810 & 6 & 42 & -26 & \\
\hline $\begin{array}{l}\text { Lemars }^{8} \text {....................... } \\
\text { Pocahontas County: }\end{array}$ & 1,560 & & & & \\
\hline $\begin{array}{l}\text { Pocahontas County: } \\
\text { Pocahontas ( } 3 \text { miles } \\
\text { south). }\end{array}$ & 632 & & & & Unsuceessful. \\
\hline $\begin{array}{l}\text { Pocahontas (near) ........ } \\
\text { Bellvalle Township..... }\end{array}$ & 1,300 & & Many. & & \\
\hline $\begin{array}{l}\text { Bellville Township } \\
\text { Polk County: }\end{array}$ & 1,300 & & & & Abundant supply. \\
\hline Des Moínes $9 . . . .$. & 3,000 & $10-3$ & 400 & -45 & \\
\hline $\begin{array}{l}\text { Saylorville .......... } \\
\text { Pottawattamie County: }\end{array}$ & 1,800 & …..... & $\cdots \cdot$. & ............ & \\
\hline Council Bluffs ${ }^{11} \ldots \ldots$ & 1,114 & & & $\cdots$ & \\
\hline Do. ${ }^{10}$ Bluncils (school & 1,091 & 4 & 56 & +50 & \\
\hline $\begin{array}{l}\text { for deaf) } 10 \\
\text { Council Bluffs........... }\end{array}$ & 2,000 & & & & \\
\hline Poweshiek County: & 840 & & & & \\
\hline Grinnell ${ }^{\prime \prime} \ldots \ldots \ldots \ldots$ & 2,003 & $10-4$ & 105 & -230 & \\
\hline $\begin{array}{l}\text { Do..................... } \\
\text { Sac County: }\end{array}$ & 2,002 & (n........ & $\cdots .$. & $\cdots \cdots$ & \\
\hline 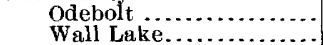 & $\begin{array}{l}500 \\
427\end{array}$ & & & & \\
\hline Seott County: & & & & & \\
\hline $\begin{array}{l}\text { Davenport } \\
\text { works). }{ }^{12}\end{array}$ & 780 & & 300 & +59 & \\
\hline $\begin{array}{l}\text { Davenport (Malt and } \\
\text { Grain Co.). } 12\end{array}$ & 1,076 & 5 & 300 & +13 & Water from 1,050-1,076 feet. \\
\hline Davenport (Gas Co.).12.. & 1,200 & $5-4$ & 400 & +47 & 2 wells; water from near \\
\hline$\underset{\text { Co.). }{ }^{\text {Davenport }}}{\text { (Glucose }}$ ( & $2,100-2,107$ & 5 & & +77 & 4 wells. \\
\hline $\begin{array}{c}\text { Do. }{ }^{14} \\
\text { Dayenport (city park jis }\end{array}$ & 1,500 & 5 & 250 & +54 & \\
\hline Davenport (city park) ${ }^{15}$ & 1,797 & 5 & +125 & -22 & Water at 1,175 feet. \\
\hline $\begin{array}{l}\text { Davenport ( } \mathrm{K} \text { im ball } \\
\text { House). } 16\end{array}$ & 1,080 & 5 & 120 & +20 & Water at 1,075 feet. \\
\hline $\begin{array}{l}\text { Davenport (packing } \\
\text { company). } 14\end{array}$ & 1,180 & $8-5$ & 250 & +45 & \\
\hline $\begin{array}{l}\text { Davenport (Sch mid t } \\
\text { Building). }{ }_{14}\end{array}$ & 1,200 & 4 & 73 & +24 & \\
\hline $\begin{array}{l}\text { Davenport (woolen } \\
\text { mills). } 14\end{array}$ & 1,053 & $3 \frac{1}{2}$ & 300 & +35 & $\begin{array}{l}\text { Water from } 700 \text { and } 1,050 \\
\text { feet. }\end{array}$ \\
\hline $\begin{array}{c}\text { Davenport (ice com- } \\
\text { pany).14 }\end{array}$ & 1,067 & $6-4$ & 240 & +10 & $\begin{array}{l}\text { Water from } 775 \text { and } 1,064 \\
\text { feet. }\end{array}$ \\
\hline
\end{tabular}

1 Record, Iowa Geol. Surv. Rept., vol. 6, pp. 308310 .

2 Ibid., pp. 310-315.

3 Record and analysis, ibid., pp. 340-347.

4 Ibid., pp. 281-282.

5 Ibid., pp. $280-281$.

6 Iowa Geol. Surv. Rept., vol. 6, pp. 339-340; ecord, ibid. vol. 12 , pp. $28-32$

7 Record, jbid., pp. 196-197.

8 Ibid., pp. 232-235.

9 Ibid., pp. 294-299.

${ }^{10}$ Analysis, Iowa Geol. Surv. Rept., vol. 6, p. 340.
${ }^{11}$ Record and analysis, ibid.,pp. 287-292.

32 U. S. Geol. Surv., 17th Ann. Rept., 1895-96, part 2, p. 812; Iowa Geol. Surv. Rept., vol, 6, p. 272

${ }_{13}$ Record, ibid., p. 842; Iowa Geol. Surv. Rept., vol. 6, p. 272 .

14 Ibid., p. 811; Iowa Geol. Surv. Rept., vol. 6, p. 272.

${ }_{15}$ Am. Geol. vol. 3, 1889, p. 117; Iowa Gecl. Surv. Rept., vol.6, pp. 272-280; record, U. S. Geo'. Surv., 17th Ann. Rept., 1895-96, part 2, pp. 842-845.

16 Record, U.S. Geol.Surv.,17th Ann.Rert., 189596 , part 2, p. 844 . IRR $149-05-4$ 
IOWA-Continued.

\begin{tabular}{|c|c|c|c|c|c|}
\hline Location. & Depth. & $\begin{array}{l}\text { Diame- } \\
\text { ter. }\end{array}$ & $\begin{array}{l}\text { Yield per } \\
\text { minute. }\end{array}$ & $\begin{array}{l}\text { Height of } \\
\text { water. }\end{array}$ & Remarks. \\
\hline $\begin{array}{l}\text { Scott County-Continued. } \\
\text { Javenport (MaltingCo.). } \\
\text { Davenport (Syrup Refin- }\end{array}$ & $\begin{array}{l}\text { Feet. } \\
2,088 \\
2,107\end{array}$ & $\begin{array}{l}\text { Inches. } \\
\ldots \ldots \\
\ldots\end{array}$ & $\begin{array}{l}\text { Gallons. } \\
\cdots\end{array}$ & $\begin{array}{c}\text { Feet. } \\
\cdots \cdots \cdots \cdots \\
\cdots \cdots \cdots\end{array}$ & \\
\hline Davenport $\ldots \ldots \ldots \ldots$ & 1,300 & $10-8$ & 310 & Flows. & $\begin{array}{l}\text { Water began to fluw at } 99 \\
\text { feet. }\end{array}$ \\
\hline $\begin{array}{l}\text { Sioux County: } \\
\quad \text { Granville } \ldots \ldots \ldots \ldots \ldots \ldots \\
\text { Hull }{ }^{1} \ldots \ldots \ldots \ldots \ldots \ldots \ldots\end{array}$ & $\begin{array}{r}450 \\
1,230\end{array}$ & $10-6$ & Many. & $\begin{array}{r}150 \\
-100\end{array}$ & \\
\hline $\begin{array}{l}\text { Story County: } \\
\text { Nevada } \ldots \ldots \ldots \ldots\end{array}$ & & $10-3$ & & -100 & \\
\hline Taylor County: & 940 & $11-6$ & & -49 & \\
\hline $\begin{array}{l}\text { Bedford .............. } \\
\text { Union County: }\end{array}$ & 425 & & & & Coal prospect. \\
\hline Creston.......... & $500-600$ & & & & $\begin{array}{l}\text { Two borings for coal; un- } \\
\text { successful; found water. }\end{array}$ \\
\hline $\begin{array}{l}\text { Van Buren County: } \\
\quad \text { Farmington .............. } \\
\text { Wapello County: }\end{array}$ & 705 & & & & \\
\hline 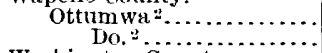 & $\begin{array}{l}2,047 \\
1,554\end{array}$ & $\begin{array}{r}8 \\
10-4\end{array}$ & 700 & $\begin{array}{l}+108 \frac{1}{2} \\
+\quad 49 \frac{1}{2}\end{array}$ & $\begin{array}{l}\text { Temp., } 70^{\circ} \\
\text { Temp., } 64^{\circ}\end{array}$ \\
\hline Washington County: & & & & & \\
\hline 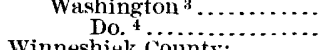 & $\begin{array}{l}1,611 \\
1,217\end{array}$ & $\begin{array}{l}10-4 \frac{1}{2} \\
12-6\end{array}$ & $\begin{array}{l}95 \\
62\end{array}$ & $\begin{array}{l}-54 \\
-58\end{array}$ & \\
\hline $\begin{array}{l}\text { Winneshiek County: } \\
\text { Calmar } \ldots \ldots \ldots \ldots \ldots \\
\text { Do. }{ }^{5} \ldots \ldots \ldots \ldots \ldots\end{array}$ & $\begin{array}{l}1,140 \\
1,223\end{array}$ & $\begin{array}{l}4 \\
8\end{array}$ & 70 & $\begin{array}{l}-320 \\
-100\end{array}$ & \\
\hline $\begin{array}{l}\text { Woodbury County: } \\
\text { Sioux City }{ }^{6} \ldots \ldots \ldots \ldots \ldots\end{array}$ & 2,011 & & 3 & Flows. & $\begin{array}{l}\text { Water at } 570 \text { and rose to } \\
-12 \text {; at } 1,250 \text { feet flower. }\end{array}$ \\
\hline $\begin{array}{l}1 \text { Analysis, Iowa Geol. Surv } \\
2 \text { Reroord and analysis, ibid } \\
{ }^{3} \text { Ibid., pp. 304-305; Am. Ge }\end{array}$ & $\begin{array}{l}317-320 \\
\text { ol. } 1, p\end{array}$ & 199. & $\begin{array}{l}\text { 4 Ibid., p } \\
\text { 5 Ibid., p } \\
6 \text { Record }\end{array}$ & $\begin{array}{l}304-305 . \\
191-192 . \\
\text { ibid., vol. }\end{array}$ & p. 258 . \\
\hline
\end{tabular}

\section{PUBLICATIONS RELATING TO DEEP BORINGS IN IOWA.}

Iowa Geological Survey, Second Annual Report, 1893, volure 3, with accompanying papers, 502 pages, plates, Des Moines, 1895.

Artesian wells of Iowa, by IV. H. Norton: Iowa Geological Survey, volume 6, pages $113-428$.

The water resources of Illinois, by Frank Leverett: United States Geological Survey Seventeenth Annual Report, 1895-96, part 2, page 811.

Artesian wells of the Belle Plaine area, by H. R. Mosnat: Iowa Geological Survey Report, volume 9, 1898, pages 521-562.

\section{KANSAS.}

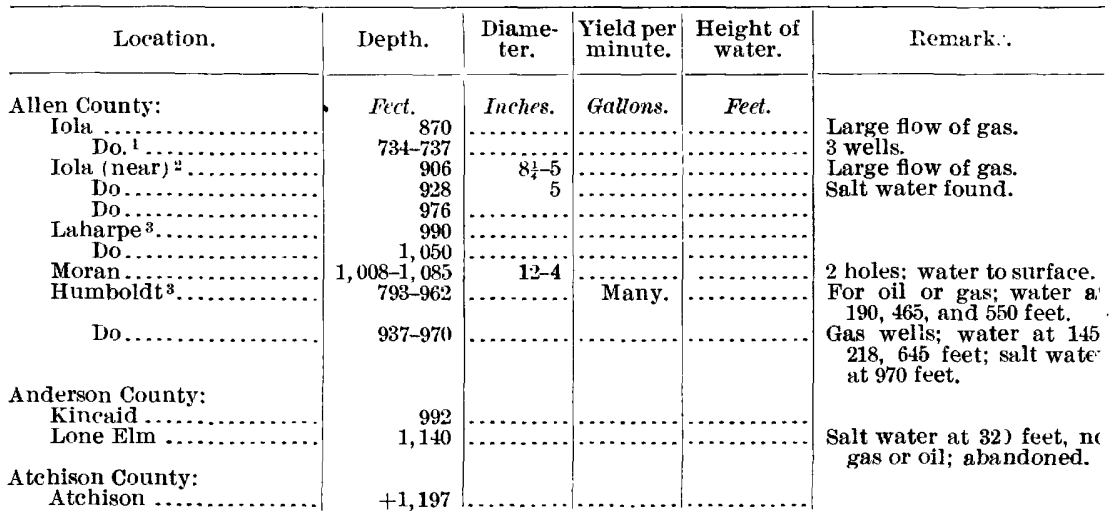

${ }^{1}$ Record, Kan. Univ. Geol. Surv. Rept., vol. 1,

2 Analysis, ibid., vol. 7, pp. 249-252 pl. 15.

I Ibid., vol. 1, pl.14; vol. 3 , pl. 23 . 
KANSAS-Continued.

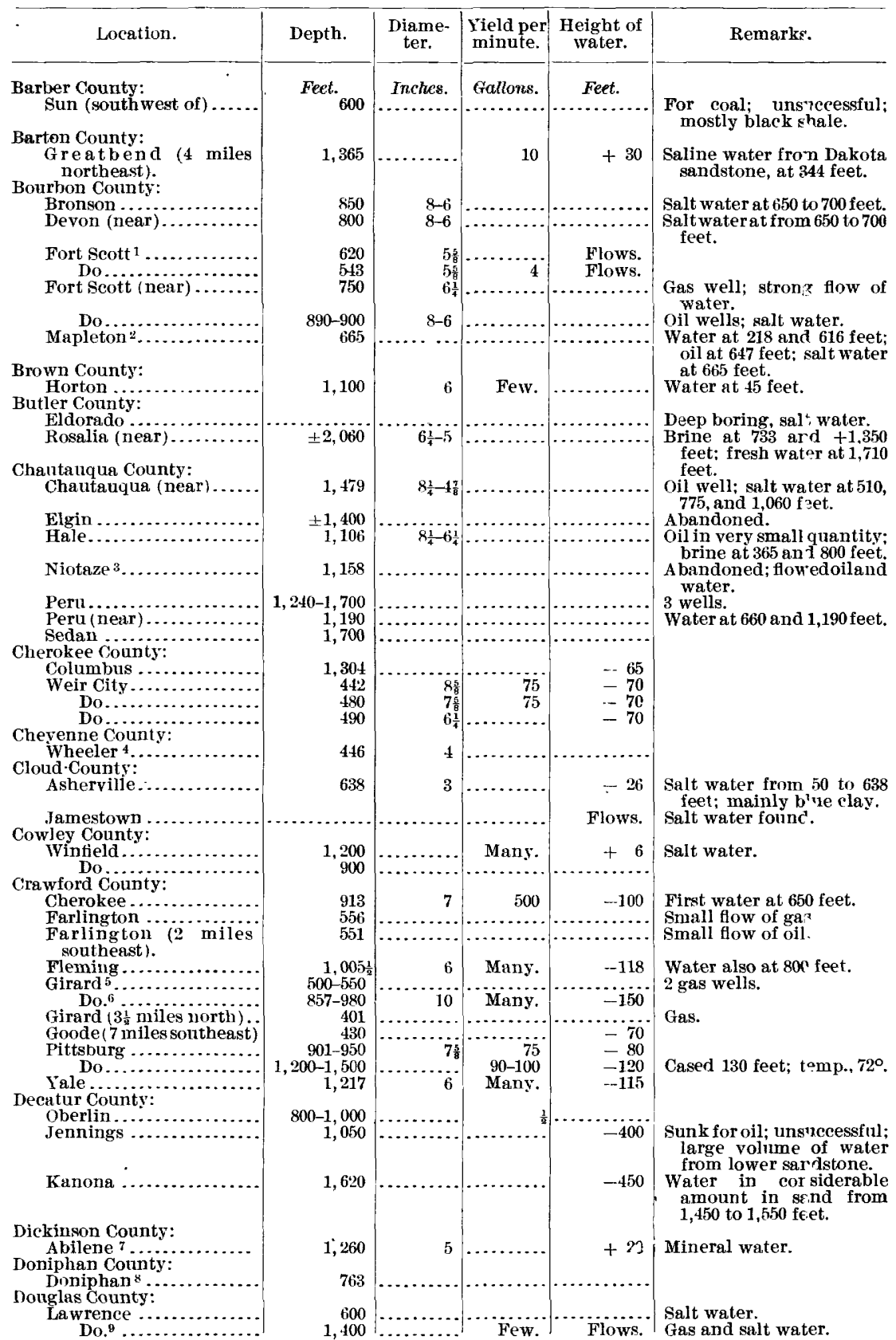

1 Analysis and record, Kan. Univ. Geol. Surv. Rept., vol. 7, pp. 262-267.

2 Record, ibid., vol. 1, pl. 16.

3 Ibid., pl. 12; vol. 3 , pl. 24 .

4 U. S. Geol. Surv. Bull. No. 131, p. 115, 1895.
${ }^{5}$ Record, Kan. Univ. Geol. Surv. Rept., vol. $3, \mathrm{p} .148$.

6 Analysis, ibid., vol. 7, pp. 267-268.

7 Ibid., pp. 130-131

${ }^{8}$ Record, ibid., vol. 1, pl. 18

9 Analysis, ibid., vol. 7 , p. 151. 
KANSAS-Continued.

\begin{tabular}{|c|c|c|c|c|c|}
\hline Location. & Depth. & $\begin{array}{l}\text { Diame- } \\
\text { ter. }\end{array}$ & $\begin{array}{c}\text { Yield per } \\
\text { minute. }\end{array}$ & $\begin{array}{l}\text { Height of } \\
\text { water. }\end{array}$ & Remarks. \\
\hline $\begin{array}{l}\text { Elk County: } \\
\text { Howard . }\end{array}$ & Feet. & Inches. & $\begin{array}{l}\text { Gallons. } \\
\text { None. }\end{array}$ & Fect. & Abr ndoned. \\
\hline Do. 1 ... & $1,226-1,410$ & & & & A \\
\hline $\begin{array}{l}\text { Ellis County: } \\
\text { Hays (15 miles south- } \\
\text { west). }\end{array}$ & 1,177 & & & +15 & $\begin{array}{l}\text { Artesian water at } 500 \text { feet; } \\
\text { sa.lt water a short dis- }\end{array}$ \\
\hline $\begin{array}{l}\text { Ellsworth County: } \\
\quad \text { Ellsworth } \ldots \ldots \ldots \ldots \ldots\end{array}$ & 1,300 & & & & $\begin{array}{l}\text { tervals to } 933 \text { feet. } \\
\text { Salt, } 730 \text { to } 880 \text { feet; salt } \\
\text { water at } 1,300 \text { feet. }\end{array}$ \\
\hline $\begin{array}{l}\text { Do......... } \\
\text { Kanopolis }\end{array}$ & 730 & $4 \frac{1}{2}$ & & -114 & Salt water. \\
\hline $\begin{array}{l}\text { Kanopolis } 2 . . . \\
\text { Wilson }{ }^{3} \ldots . . .\end{array}$ & $\begin{array}{r}881 \\
1,385\end{array}$ & $\begin{array}{l}8-4 \\
8-5\end{array}$ & & & $\begin{array}{l}\text { Salt water at } 645 \text { to } 875 \text { feet. } \\
\text { Salt water; abandoned. }\end{array}$ \\
\hline $\begin{array}{c}\text { Finney County: } \\
\text { Eminence.... }\end{array}$ & & & & & \\
\hline Garden City (one-half & $+1,000$ & & & & \\
\hline $\begin{array}{l}\text { Garden City.............. } \\
\text { Garden City (8 miles } \\
\text { south). }\end{array}$ & $\begin{array}{r}902 \\
1,250\end{array}$ & & & & \\
\hline Ravanna (north of) ..... & +400 & & Many. & -200 & Abandoned. \\
\hline $\begin{array}{l}\text { Ravanna } \\
\text { Ford County: }\end{array}$ & +400 & & & -45 & Do. \\
\hline Dodge City ( $1 \frac{1}{2}$ miles east) & 800 & & & & Unsuccessful. \\
\hline $\begin{array}{l}\text { Franklin County: } \\
\quad \text { Ottawa ............................ }\end{array}$ & 1,002 & 8 & & & Oil at 675 and 702 feet: \\
\hline $\begin{array}{l}\text { Geary County: } \\
\text { Junetion City (vicinity) }\end{array}$ & 1,065 & & & & $\begin{array}{l}\text { Sal* water at } 384 \text { and } 622 \\
\text { feet; fresh water at } 715 \\
\text { and } 755 \text { feet; gas and } \\
\text { Water at } 490 \text { feet. } \\
\text { Sal* water; abandoned. }\end{array}$ \\
\hline Gove county: & 200 & & & & 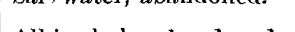 \\
\hline $\begin{array}{l}\text { Goodwater ................. } \\
\text { Catalpa (vicinity)...... }\end{array}$ & $\begin{array}{l}501 \\
400\end{array}$ & 3 & Few. & & All in shale; abandoned. \\
\hline Jerome & 400 & & & & \\
\hline Jerome & 400 & & & & Good supply of fine water \\
\hline $\begin{array}{l}\text { Graham County: } \\
\text { Hill City (3 miles from }\end{array}$ & 100 & & & No flow & - \\
\hline miles from) - & $\$ 00$ & & & No now. & Shale to bottom. \\
\hline Horace. & 1,370 & 10 & 30 & -830 & $\begin{array}{l}\text { Dakota sandstone reached } \\
\mathrm{a}^{+}, 1,050 \text { feet. }\end{array}$ \\
\hline $\begin{array}{l}\text { Tribune ....... } \\
\text { Greenwood Count }\end{array}$ & 500 & & & & Un zuccessful. \\
\hline Eureka ${ }^{5}$. & 503 & & & & Cos.l prospect; abandoned. \\
\hline Do.... & $+1,000$ & & & & $\begin{array}{l}\text { In progress } 1900 \text {; salt } \\
\text { water } 500 \text { to } 700 \text { feet and } \\
800 \text { to } 900 \text { feet. } \\
\text { Brine at } 499 \text { feet. }\end{array}$ \\
\hline Fall River. & 986 & $10-5 \frac{5}{8}$ & 1,000 & 77 & $\begin{array}{l}\text { Water at } 416 \text { feet; salt } \\
\text { vrater at } 972 \text { feet. }\end{array}$ \\
\hline 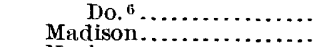 & $\begin{array}{l}1,480 \\
1,896 \frac{1}{2}\end{array}$ & & Many. & & Fo" gas: unsupcessful \\
\hline Neal................... & 940 & $10-8 \frac{1}{4}$ & & $\cdots \ldots$ & $\begin{array}{l}\text { Fo oil; water-bearing bed } \\
\text { at } 822 \text { feet. }\end{array}$ \\
\hline Do.................. & 875 & & & & \\
\hline $\begin{array}{l}\text { Coolidge } . . . . . . . . \\
\text { Kendall } . . . \ldots \ldots\end{array}$ & $\begin{array}{r}500 \\
500\end{array}$ & $5 \frac{5}{8}$ & 90 & Flows. & \\
\hline Do................... & 537 & & 70 & (2) & Pumped; no flow. \\
\hline ........... & 1,000 & & & -90 & \\
\hline Anthor & 2,335 & & & & \\
\hline $\begin{array}{l}\text { Harvey County: } \\
\quad \text { Halstead } \ldots \ldots \ldots \ldots \ldots \ldots\end{array}$ & +400 & & & & \\
\hline $\begin{array}{r}\text { Newton }{ }_{\text {Do }} \ldots \ldots \ldots \\
\text { Do }\end{array}$ & $\begin{array}{r}1,045 \\
910-1,076\end{array}$ & & & $\cdots \cdots \cdots$ & $\begin{array}{l}\text { Prospect borings. } \\
\text { Do. }\end{array}$ \\
\hline $\begin{array}{l}\text { Haskell County: } \\
\text { Santa } \mathrm{Fe}, \ldots \ldots \ldots \ldots\end{array}$ & & 6 & & & \\
\hline & 300 & & & 200 & f'et. \\
\hline Hodgeman County: & - -000 & 1000 y & & & \\
\hline 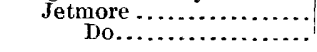 & $\begin{array}{r}1,000 \\
700 \text { or } 800\end{array}$ & & & $-20-30$ & $\begin{array}{l}\text { For coal. } \\
\text { Not in use; abandoned. }\end{array}$ \\
\hline $\begin{array}{l}{ }^{1} \text { Record, Kan. Univ. Geol. } \\
\text { pl. } 29 . \\
2 \text { Record, Mineral Resourc } \\
\text { pp. } 94-95 . \\
\text { 3 Ibid., p. } 97 . \\
\text { 4 Record, Kans. Univ. Ged } \\
\text { 2, p. } 27 \text {. }\end{array}$ & $\begin{array}{l}\text { Surv. Rept., } \\
\text { es of Kansa }\end{array}$ & $\begin{array}{l}\text { vol. 3, } \\
\text { s, } 1898\end{array}$ & $\begin{array}{l}\text { 5 Ibid., } \\
\text { 'Ibid., v } \\
\text { 'Ibid., y } \\
\text { sas, 1898, }\end{array}$ & $\begin{array}{l}\text { ol. } 3 \text {, pl. } 27 \text {. } \\
\text { ol. 1, pl. 13; } \\
\text { ol. 1, pl. } 21 \text {; } \\
\text { 90. }\end{array}$ & $\begin{array}{l}\text { vol' } 3 \text {, pl. } 25 . \\
\text { Mireral Resources of Kan- }\end{array}$ \\
\hline
\end{tabular}


KANSAS-Continued.

\begin{tabular}{|c|c|c|c|c|c|}
\hline Location. & Depth. & $\begin{array}{l}\text { Diame- } \\
\text { ter. }\end{array}$ & $\begin{array}{l}\text { Yield per } \\
\text { minute. }\end{array}$ & $\begin{array}{l}\text { Height of } \\
\text { water. }\end{array}$ & Remarks. \\
\hline $\begin{array}{l}\text { Jackson County: } \\
\text { Hoyt } \ldots \ldots \ldots \ldots \ldots\end{array}$ & $\begin{array}{l}\text { Feet. } \\
1,206 \text { or } \\
1,406(?)\end{array}$ & $\begin{array}{r}\text { Inches. } \\
6\end{array}$ & $\begin{array}{l}\text { Gallons. } \\
\text { None. }\end{array}$ & $\begin{array}{l}\text { Feet. } \\
\ldots \ldots\end{array}$ & \\
\hline $\begin{array}{l}\text { Jefferson County: } \\
\text { Valley Falls }\end{array}$ & 1,174 & 3 & 2 & & Very saline water. \\
\hline $\begin{array}{l}\text { Jewell County: } \\
\text { Ionia....... }\end{array}$ & 432 & & & & Salt water: absndoned. \\
\hline 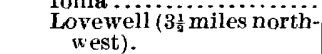 & 400 & & & $\therefore$ & $\begin{array}{l}\text { Salt water; absindoned. } \\
\text { Salt water only. }\end{array}$ \\
\hline $\begin{array}{l}\text { Mankato } \ldots \ldots \ldots \ldots \ldots \\
\text { Johnson County: }\end{array}$ & 500 & 8 & & -50 & Salt water. \\
\hline 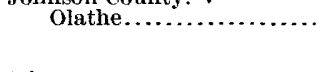 & 600 & & & & $\begin{array}{l}\text { Water at } 85 \text { feet; salt } \\
\text { water at } 530 \text { feet; weak } \\
\text { flow of gas at } 361 \frac{1}{2} \text { feet. }\end{array}$ \\
\hline $\begin{array}{l}\text { Kingman County: } \\
\text { Kingman............... }\end{array}$ & +800 & & & & Salt shafts. \\
\hline$\underset{\text { Korth }) .1}{\text { ing an }}$ & 1,410 & & & & Salt. \\
\hline 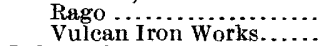 & $\begin{array}{l}1,000 \\
1,000\end{array}$ & & & & $\begin{array}{l}\text { Salt well; } 175 \text { f set of salt. } \\
\text { Two salt shafts }\end{array}$ \\
\hline $\begin{array}{l}\text { Labette County: } \\
\quad \text { Mound Valley }{ }^{2}, \ldots \ldots \ldots\end{array}$ & 762 & $7 \frac{1}{1} \frac{1}{6}-6 \frac{1}{8}$ & $1 \frac{1}{2}$ & +6 & Temp., $70^{\circ}$. Sal't, water and \\
\hline $\begin{array}{r}\text { Oswego } 2 \ldots \ldots \ldots \ldots \ldots \ldots \\
\text { Do } \ldots \ldots \ldots \ldots\end{array}$ & $\begin{array}{l}985 \\
600\end{array}$ & 6 & & $\begin{array}{r}-\quad 100 \\
-\quad 40\end{array}$ & $\begin{array}{l}\text { Small amount of gas at } \\
548 \text { feet; salt water at } \\
\text { 606 feet. }\end{array}$ \\
\hline Pursons and vieinity .... & $500-1,500$ & & & & $\begin{array}{l}\text { Several wells for gas; not } \\
\text { much found; salt water } \\
\text { at } 400 \text { to } 500 \text { feet; no } \\
\text { flow; abandoned. }\end{array}$ \\
\hline $\begin{array}{r}\text { Stover } \ldots . . . \\
\text { Lane County: }\end{array}$ & .530 & 7 & & -16 & \\
\hline Shields (3 miles north) .. & 400 & & & & $\begin{array}{l}\text { Limited supply of water } \\
\text { from thin saudstone in } \\
\text { upper part of Benton. }\end{array}$ \\
\hline 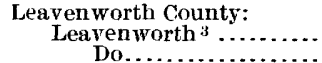 & $\begin{array}{l}1,170 \\
2,116\end{array}$ & & & Flows. & Gas and water. \\
\hline Tonganoxie .................. & 854 & & & & City well. \\
\hline $\begin{array}{l}\text { Linn county: } \\
\text { Pleasanton } \ldots \ldots \ldots\end{array}$ & 729 & 5 & & & Salt water. \\
\hline Do............................... & 918 & $6 \frac{1}{4}$ & & & $\begin{array}{l}\text { Salt water at } 828 \text { and } 918 \\
\text { feet. }\end{array}$ \\
\hline Pleasanton (near) ${ }^{4} \ldots . .$. & 757 & $6 \frac{1}{4}-5$ & & & $\begin{array}{l}\text { Water at } 132 \text { and } 656 \text { feet: } \\
\text { salt water at } 348 \text { and } 757 \\
\text { feet, and trace of oil at } \\
353 \text { and } 730 \text { feet. }\end{array}$ \\
\hline $\begin{array}{l}\text { Logan County: } \\
\text { Elkader } \ldots \ldots \ldots \ldots \ldots \ldots .\end{array}$ & 408 & & & & \\
\hline Elkader ( 7 miles south). & 500 & & & & $\begin{array}{l}\text { Unsuccessful; all in blue } \\
\text { shale. }\end{array}$ \\
\hline Dakley ............. & 725 & & & -.30 & $\begin{array}{l}\text { Unsucessfnl; water at in- } \\
\text { tervals to } 200 \text { feet, then } \\
\text { shale to bottom. }\end{array}$ \\
\hline Winona...... & 1,356 & & & & Unsucessful. \\
\hline Emporia $5 . . . \ldots . .$. & 2,005 & 6 & & & Gas prospect; cbandoned. \\
\hline $\begin{array}{l}\text { McPherson County: } \\
\text { Canton ( } 5 \text { miles south- } \\
\text { east). }\end{array}$ & 500 & & & & \\
\hline tte $\ldots \ldots \ldots \ldots \ldots$ & 400 & 6 & Few. & -.70 & Salt water. \\
\hline Marion ............. & 1,800 & & & & For coal; unsurcessful. \\
\hline $\begin{array}{l}\text { Montgomery County: } \\
\text { Cherryvale }\end{array}$ & $609-617$ & & & & Gas wells. \\
\hline $\begin{array}{l}\text { Do. }{ }^{6}, \ldots \ldots \\
\text { Do................. }\end{array}$ & $\begin{array}{r}1,220 \\
1,397-1,500\end{array}$ & $1 \frac{3}{4}$ & & & $\begin{array}{l}\text { Salt water and gas found. } \\
\text { Oil wells; water at several }\end{array}$ \\
\hline Coffeyville & 550 & & & & $\begin{array}{l}\text { horizons. } \\
\text { Gas well. }\end{array}$ \\
\hline $\begin{array}{l}\text { Independ } \\
\text { Do. } 7 \text {. }\end{array}$ & $\begin{array}{l}1,020 \\
1,100\end{array}$ & & & Flows. & Oil and gas. \\
\hline Do.............. & 1,041 & $8 \frac{1}{4}$ & & ............. & Gas well. \\
\hline Do..... & 1,160 & $8 \frac{1}{4}-6 \frac{1}{4}$ & & ........... & $\begin{array}{l}\text { Gas well; water-bearing } \\
\text { beds at } 275, \mathrm{e} 40 \text {, and } 895 \\
\text { feet. }\end{array}$ \\
\hline
\end{tabular}

1 Record, Mineral Resourees of Kansas, 1898, p. 91 , pl. 8 .

2 Record, Kans. Univ. Geol. Surv. Rept., vol. 1, pl. 10; vol. 3, pl. 21.

3 Ibid., vol. 1, pl, 20; vol. 3, pl. 26 .
IIbid., vol. 1, pl. 16.

5 Ibid., vol. 3 , pl. 28

6 Ibid., vol. 1, pl. 11; vol. 3, pl, 22 .

7 Analysis, ibid., pp. 149-150. 
KANSAS-Continued.

\begin{tabular}{|c|c|c|c|c|c|}
\hline Location. & Depth. & $\begin{array}{c}\text { Diame- } \\
\text { ter. }\end{array}$ & $\begin{array}{l}\text { Yield per } \\
\text { minute. }\end{array}$ & $\begin{array}{l}\text { Height of } \\
\text { water. }\end{array}$ & Remarks. \\
\hline $\begin{array}{l}\text { Morton County: } \\
\text { Richfield }{ }^{1} \ldots\end{array}$ & Feet. ${ }_{670}$ & $\begin{array}{l}\text { Inrhes. } \\
\text {........... }\end{array}$ & $\begin{array}{r}\text { Gallons. } \\
22\end{array}$ & $\begin{array}{l}\text { Feet. } \\
\text { Flows. }\end{array}$ & \\
\hline Do...... & 701 & & 6 & +125 & $\begin{array}{l}\text { Wat } \begin{array}{l}\text { is of unsatisfactory } \\
\text { quality. }\end{array}\end{array}$ \\
\hline Do............. & 600 & & 6 & Flows. & Temp., $66^{\circ}$; water at 570 \\
\hline Do......... & 640 & & 15 & +25 & 2 wells; temp., $60^{\circ}$ \\
\hline $\begin{array}{l}\text { Marshall County: } \\
\text { Marysville.......... }\end{array}$ & 1,360 & & Few. & Flows. & \\
\hline Marysville (near)... & 1,100 & & & & \\
\hline $\begin{array}{l}\text { Meade County: } \\
\text { Fowler } \ldots . . \ldots \ldots \ldots .\end{array}$ & & & & & \\
\hline Meade........ & 800 & 6 & & & $\begin{array}{l}\text { Red Beds at } 200 \text { feet; salt } \\
\text { below. }\end{array}$ \\
\hline $\begin{array}{l}\text { Miami County: } \\
\text { Paola }{ }^{2} \ldots \ldots \ldots \ldots \ldots \ldots\end{array}$ & 1,075 & & & & City well. \\
\hline $\begin{array}{l}\text { Do } \\
\text { Mitchell County: }\end{array}$ & $500-580$ & $58-4 \frac{1}{4}$ & Many. & -0 to -400 & Several gas wells. \\
\hline Asherville........... & 638 & $\ldots$ & & -26 & Abundant supply of very \\
\hline $\begin{array}{c}\text { Cawker City (2 miles } \\
\text { northeast). }\end{array}$ & 468 & ........ & & -217 & Salt water. \\
\hline $\begin{array}{l}\text { Cawker City (10 miles } \\
\text { north). }\end{array}$ & 416 & & & No flow. & Do. \\
\hline $\begin{array}{l}\text { Neosho County: } \\
\text { Chanute }{ }^{3} \ldots \ldots \ldots \ldots \ldots .\end{array}$ & & & & & 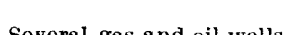 \\
\hline Do.................... & $\begin{array}{r}741-982 \\
806\end{array}$ & $6 \frac{1}{4}-5^{\frac{1}{8}}$ & & (n.......... & $\begin{array}{l}\text { Several gas and oil wells. } \\
\text { Lare flow of gas: some } \\
\text { water. }\end{array}$ \\
\hline Do.................... & 752 & 5 & 5 & & $\begin{array}{l}\text { Oil well: brine at } 385 \text { leet: } \\
\text { oil at } 720,724 \text {, and } 728 \\
\text { feet. }\end{array}$ \\
\hline Erie $\ldots \ldots \ldots \ldots \ldots \ldots$ & 750 & $\ldots . .$. & 400 & & Min ral water. \\
\hline Erie (2 miles north)..... & 833 & & Many. & Flows. & $\begin{array}{l}\text { Large flow of oil and gas, } \\
\text { and salt water. }\end{array}$ \\
\hline Erie $\ldots \ldots \ldots \ldots \ldots \ldots$ & 813 & & & & $\begin{array}{l}\text { Salt water at } 400 \text { feet; oil } \\
\text { sand at } 550 \text { to } 585 \frac{1}{2} \text { feet. }\end{array}$ \\
\hline Galesburg ............... & 975 & & & & Salt water; abandoned. \\
\hline Rollin (near) .............. & 652 & & 48 & $\ldots . . . \cdots$ & Oil well. \\
\hline 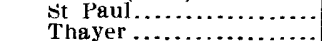 & $\begin{aligned} 661-668 \\
8: 25\end{aligned}$ & & $\cdots$ & Flows. & Salty water; abandoned. \\
\hline Thayer (near) $\ldots \ldots \ldots \ldots$ & 1,064 & $6 \frac{1}{4}-1 \frac{7}{8}$ & $\cdots$ & (n) & Water at $376,575,805$, and \\
\hline Thayer .................. & 895 & $8 \frac{1}{4}-6 \frac{1}{4}$ & & & $\begin{array}{l}1,064 \text { reet. } \\
\text { Wat? at } 215 \text { feet; gas }\end{array}$ \\
\hline Ness County: & & & & & \\
\hline $\begin{array}{l}\text { Danby (6 miles south- } \\
\text { west }) \text {. }\end{array}$ & 385 & & & -110 & \\
\hline Ness City (14 miles north) & 65 & 3 & 30 & -356 & - \\
\hline $\begin{array}{l}\text { Ness City ( } 8 \text { miles south). } \\
\text { Ness City (10 and } 12 \\
\text { miles southwest). }\end{array}$ & $\begin{array}{r} \pm 400 \\
450,437\end{array}$ & 6 & & (n) & $\begin{array}{l}\text { Satirfactory supply of soft } \\
\text { water from Dakota }\end{array}$ \\
\hline Ransom ................. & 653 & $6-3$ & several. & -60 & $\begin{array}{l}\text { Water in sandstone under } \\
\text { bl'te shale. }\end{array}$ \\
\hline $\begin{array}{l}\text { Osage County: } \\
\quad \text { Lyndon }{ }^{4} \ldots \ldots \ldots \ldots \ldots\end{array}$ & 1,007 & & & & Salt water at 239 feet; salt \\
\hline Osage Mission 5 & 700 & & & & \\
\hline $\begin{array}{l}\text { Osborne County: } \\
\text { Osborne } \ldots \ldots \ldots \ldots \ldots\end{array}$ & 500 & & & & \\
\hline $\begin{array}{l}\text { Portis ( } 6 \text { miles north- } \\
\text { west). }\end{array}$ & 546 & & & No tlow. & Salt water. \\
\hline $\begin{array}{l}\text { Portis (8 miles north- } \\
\text { west). }\end{array}$ & 543 & 6 & & -200 & Do. \\
\hline $\begin{array}{l}\text { Pawnee County: } \\
\text { Larned ...................... }\end{array}$ & 756 & & 400 & & \\
\hline $\begin{array}{l}\text { Do } \\
\text { Philhps County: }\end{array}$ & 743 & $10-3$ & 250 & +50 & Temp., $65^{\circ}$; salt water. \\
\hline $\begin{array}{l}\text { Cactus ( } 6 \text { miles south) ... } \\
\text { Kirwin }\end{array}$ & 480 & & & -50 & \\
\hline $\begin{array}{l}\text { Kirwin } \\
\text { Long Island ( } 4 \frac{1}{2} \text { miles } \\
\text { northeast). }\end{array}$ & $\begin{array}{l}514 \\
650\end{array}$ & & & 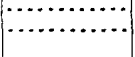 & Bored for oil or gas. \\
\hline $\begin{array}{l}\text { Phillipsburg (a few } \\
\text { miles northwest). } \\
\text { Pottawatomie County: }\end{array}$ & 430 & & & & Small supply of water. \\
\hline 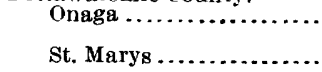 & 1,123 & $3-2$ & 5 & Flows. & $\begin{array}{l}\text { Gas and flowing water at } \\
53.3 \text { to } 559 \text { feet. } \\
\text { Salt water. }\end{array}$ \\
\hline
\end{tabular}

1 Record, 51st Cong., 1st sess., Senate Ex. Doc. No. 222, p. 157.

2Record, Kans. Univ. Geol. Surv. Rept., vol. 1, pl. 17.

3 Ibid., p. 77, pl. 13; vol. 3 pl. 25.

4 Record, Kans. Univ, Geol. Surv. Rept., vol. 3, pl. 27.

Ibid., vol. 1, pl. 15. 
KANSAS-Continued.

\begin{tabular}{|c|c|c|c|c|c|}
\hline Location. & Depth. & $\begin{array}{c}\text { Diame- } \\
\text { ter. }\end{array}$ & $\begin{array}{c}\text { Yield per } \\
\text { minute. }\end{array}$ & $\begin{array}{l}\text { Height of } \\
\text { water. }\end{array}$ & Remariks. \\
\hline 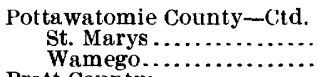 & $\begin{array}{r}\text { Fect. } \\
520 \\
1,000\end{array}$ & $\begin{array}{l}\text { Inches. } \\
\ldots \ldots \ldots \ldots \\
0 \ldots \ldots\end{array}$ & Gallons. & $\begin{array}{l}\text { Feet. } \\
\text { Flows. } \\
+6\end{array}$ & $\begin{array}{l}\text { Salt water. } \\
\text { Do. }\end{array}$ \\
\hline Pratt County: & & & & & \\
\hline Pratt. & \pm 800 & & & -15 & $\begin{array}{l}\text { Thick salt beds f00 to } 800 \\
\text { feet; not used. }\end{array}$ \\
\hline $\begin{array}{l}\text { Pyramids (near)..... } \\
\text { Reno County: }\end{array}$ & 408 & 8 & & No flow. & Bad water. \\
\hline $\begin{array}{l}\text { Reno County: } \\
\text { Arlington .. }\end{array}$ & 1,000 & & & & Salt. \\
\hline Hutehinson & +800 & & & & Several salt wells \\
\hline Hutchinson (so & 1,307 & & & ….. & Salt. \\
\hline $\begin{array}{l}\text { Republic County: } \\
\text { Scandia ....... }\end{array}$ & & & & & \\
\hline $\begin{array}{l}\text { Scandia } \\
\text { Rice Count }\end{array}$ & 1,110 & & & -16 & Good wate \\
\hline Little River ${ }^{2}$.. & 1,230 & 8 & & & $\begin{array}{l}\text { Mnch water to } 400 \text { feet, } \\
\text { then } 600 \text { feet of salt and } \\
\text { shale. } \\
\text { Salt prospect; abandoned. }\end{array}$ \\
\hline Lyor & 1,625 & $8-5$ & .... & -30 & Salt well. \\
\hline $\begin{array}{l}\text { Lyon } \\
\text { Sterli }\end{array}$ & , 916 & $10-2 \frac{1}{4}$ & None. & & Do. \\
\hline Do. & 980 & $10-2 \frac{1}{2}$ & Few. & -3 & Do. \\
\hline $\begin{array}{l}\text { Riley Cou } \\
\text { Rando }\end{array}$ & 400 & & & & \\
\hline Rooks C & & & & & \\
\hline $\begin{array}{r}\text { Stock } \\
\text { Rush Col }\end{array}$ & 460 & & & -60 & Much good water. \\
\hline Bisc & 1,403 & & & Flows. & Salt water. \\
\hline Lac & $\begin{array}{l}44 \\
558\end{array}$ & $\begin{array}{c}3 \\
81 \\
8\end{array}$ & 20 & -240 & Water pure. \\
\hline $\mathrm{MeC}$ & 558 & $8 \frac{1}{4}-6 \frac{5}{6}$ & 20 & & $\begin{array}{l}\text { Water-bea ring beds at } 278 \\
\text { and } 382 \text { feet; water salty. }\end{array}$ \\
\hline $\begin{array}{l}\text { Russell County: } \\
\text { Russell ....... }\end{array}$ & 997 & $10-5$ & Many. & -300 & Saline water. \\
\hline Sedgwicl & 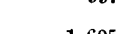 & Now & - & 000 & 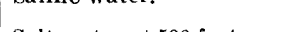 \\
\hline $\begin{array}{l}\text { Wichit } \\
\text { Do }\end{array}$ & $\begin{array}{l}1,605 \\
1,025\end{array}$ & $14-4 \frac{1}{2}$ & & 120 & Salt water at 500 feet. \\
\hline $\begin{array}{l}\text { Seward C } \\
\text { Liber }\end{array}$ & 485 & 7 & 52 & -130 & Water at 130 feet. \\
\hline $\begin{array}{l}\text { Scott County: } \\
\text { Elkador }(7 \mathrm{mi}\end{array}$ & 500 & & & & No wáter supply. \\
\hline $\begin{array}{r}\text { Shawnee County } \\
\text { Topeka }{ }^{6} . . .\end{array}$ & 900 & & & & 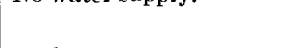 \\
\hline Do.? & 1,638 & & & & Coal prospect; no coal; no \\
\hline $\begin{array}{l}\text { Smith County } \\
\text { Cedarville ( }\end{array}$ & +400 & & & & $\begin{array}{l}\text { Howing water. } \\
\text { No water supply. }\end{array}$ \\
\hline $\begin{array}{l}\text { Portis ( } 6 \text { miles north- } \\
\text { west). }\end{array}$ & & & & & Salty water. \\
\hline Smith Cen & 600 & 7 & & -390 & $\begin{array}{l}\text { Salt water at } 590 \text { feet; } \\
\text { abandoned. }\end{array}$ \\
\hline $\begin{array}{l}\text { Smith Center (12 miles } \\
\text { southeast). }\end{array}$ & 540 & & Many. & --140 & $\begin{array}{l}\text { Salt water from sand } 535 \\
\text { to } 540 \text { feet unde } 535 \text { feet }\end{array}$ \\
\hline $\begin{array}{l}\text { Stanton County: } \\
\text { Johnson ........ }\end{array}$ & 420 & 8 & Many. & -180 & \\
\hline Sumn & & & & & \\
\hline $\mathrm{C}$ & 800 & 6 & & & Salt water only at 457 feet. \\
\hline ner ................... & 438 & 6 & Few. & -150 & All in shale. \\
\hline $\begin{array}{l}\text { Three miles north of } \\
\text { Smoky Hill River, near } \\
\text { western border of the } \\
\text { county. }\end{array}$ & 446 & & & & \\
\hline $\begin{array}{c}\text { Wakeeney (12 miles } \\
\text { southeast). } \\
\text { Wabaunsee County: }\end{array}$ & $\begin{array}{l}700 \\
438\end{array}$ & & 30 & & No flow. \\
\hline & 2,000 & & & & Gelt untor and ono \\
\hline & 1,912 & $4-2 \frac{1}{2}$ & & Flows. & Salt water and gạ. \\
\hline $\begin{array}{l}\text { MeFar } \\
\text { Wellin }\end{array}$ & $\begin{array}{l}2,000 \\
1,000\end{array}$ & & & & Notin use. \\
\hline Wallace County: & & & & & \\
\hline Wallace (vicinity) & $\begin{array}{l}800 \\
448\end{array}$ & $\begin{array}{l}4 \\
7\end{array}$ & & & Did not reach bottom of \\
\hline $\begin{array}{r}\text { Washington County: } \\
\text { Washington ........ } \\
\text { Do } \ldots \ldots \ldots \ldots \\
\text { Do........... }\end{array}$ & $\begin{array}{r}1,100-1,200 \\
1,350 \\
2,200\end{array}$ & $\begin{array}{l}6 \\
6\end{array}$ & $\begin{array}{l}1 \\
\text { None. } \\
\text { None. }\end{array}$ & & $\begin{array}{l}\text { Abandoned. } \\
\text { Do. }\end{array}$ \\
\hline
\end{tabular}
Q.2.

2 Ibid., p. 95

3 I bid., p. 93

4 Ibid., p. 97.
5 Record, 5lst Cong., 1st sess., Senate Ex. Doc. No. 222, p. 158 .

6 Record, Kans. Univ. Geol. Surv, Rept., vol. 1, pl. 17 .

7 Ibid., vol. 3, pl. 27.

8 Ibid., vol. 1, pl. 19; vol. 3 , pl. 30. 
KANSAS-Cortinued.

\begin{tabular}{|c|c|c|c|c|c|}
\hline Location. & letpth. & $\begin{array}{c}\text { Diame- } \\
\text { ter. }\end{array}$ & $\begin{array}{c}\text { Yield per } \\
\text { minnte. }\end{array}$ & $\begin{array}{l}\text { Height of } \\
\text { water. }\end{array}$ & Remarks. \\
\hline 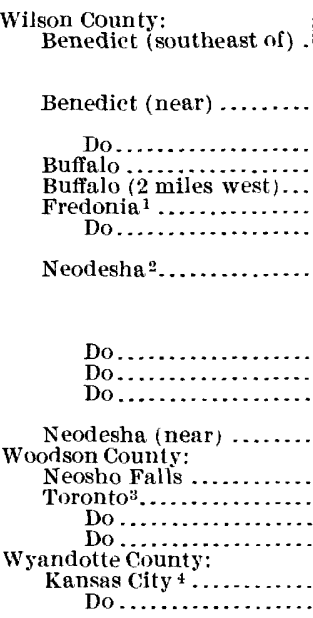 & $\begin{array}{r} \\
\pm 2,400 \\
1,310 \\
2,414 \\
1,078 \\
1,275 \\
1,452 \\
940-7 \times 2 \\
1,140 \\
\\
758 \\
2,360\end{array}$ & 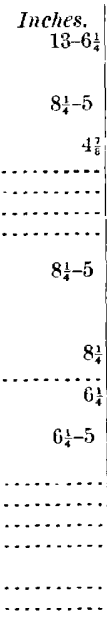 & 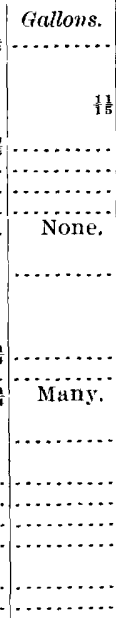 & $\begin{array}{l}\text { Flows. } \\
0 \\
0\end{array}$ & $\begin{array}{l}\text { Fresh water at } 403 \text { feet; } \\
\text { strong salt water at from } \\
1,096 \text { to } 2,414 \text { feet. } \\
\text { oil well; fresh and salt } \\
\text { water also found. } \\
\text { For oil; salt water only. } \\
\text { Only salt water. } \\
\text { Cil and water wells. } \\
\text { salt water at } 354 \text { and } \\
1,195 \text { feet; abandoned. } \\
\text { oil prospect: water at } 230 \\
\text { and } 820 \text { feet: salt water } \\
\text { at } 420,685, \text { and } 775 \text { feet, } \\
\text { and gas at } 655 \text { feet. } \\
\text { sulphur water at } 1,423 \\
\text { feet: salt water below. } \\
\text { oil and gas wells; water } \\
\text { at s1l and } 1,078 \text { feet. } \\
\text { salt water at } 361 \text { feet. } \\
\text { salt water and some oil. } \\
\text { 2 wells; some gas. } \\
\text { oil at bottom of well. }\end{array}$ \\
\hline
\end{tabular}

1 Record Kans. Univ. (ieol. Surr. Rept., vol. 1, pl. 12: vol. 3, pl. 24

3 Ibid., vol. 3, p. 149, p' 29

"Ibid., pl. 11: vol. :3, pl, 22

${ }^{4}$ Ibid., vol, 1, pl. 18; analysis, vol. 7, p. 255.

\section{PUBLICATIONS RELATING TO DEEP BORINGS IN KANSAS.}

Report of J. W. Gregory, field agent for the middle division: Fifty-first Congress, first session, Senate Ex. Doc. No. 222, pp. 145-172, Washington, 1890.

Water resources of a portion of the Great Plains, by Robert Hay: United States Geological Survey Sixteenth Annual Report, 1894-95, part 2, pp. 535-588, plates. Washington, 1895.

The University Geological Survey of Kansas, by Erasmus Haworth and assistants, vol. 1, 320 pages, plates, Topeka, 1896.

Report of the Board of Irrigation, Survey, and Experiment for 1895 and 1896 to the Legislature of Kansas, 238 pages, plates, Topeka, 1897.

The University Geological Survey of Kansas, Special Report, by Erasmus Haworth and W. R. Crane, vol. 3, 347 pages, plates, Topeka, 1898.

Mineral Resources of Kansas, 1898.

The United States Geological Survey Bulletin No. 131, p. 115, Washington, 1895.

Mineral waters, by E. H. S. Bailey and others: University Geological Survey of Kansas, vol. 7, 1902.

Preliminary report on the geology and underground water resources of the central Great Plains, by N. H. Darton. United States Geological Survey Professional Paper No. 32, Washington, 1905. 
KEN'TUCKY.

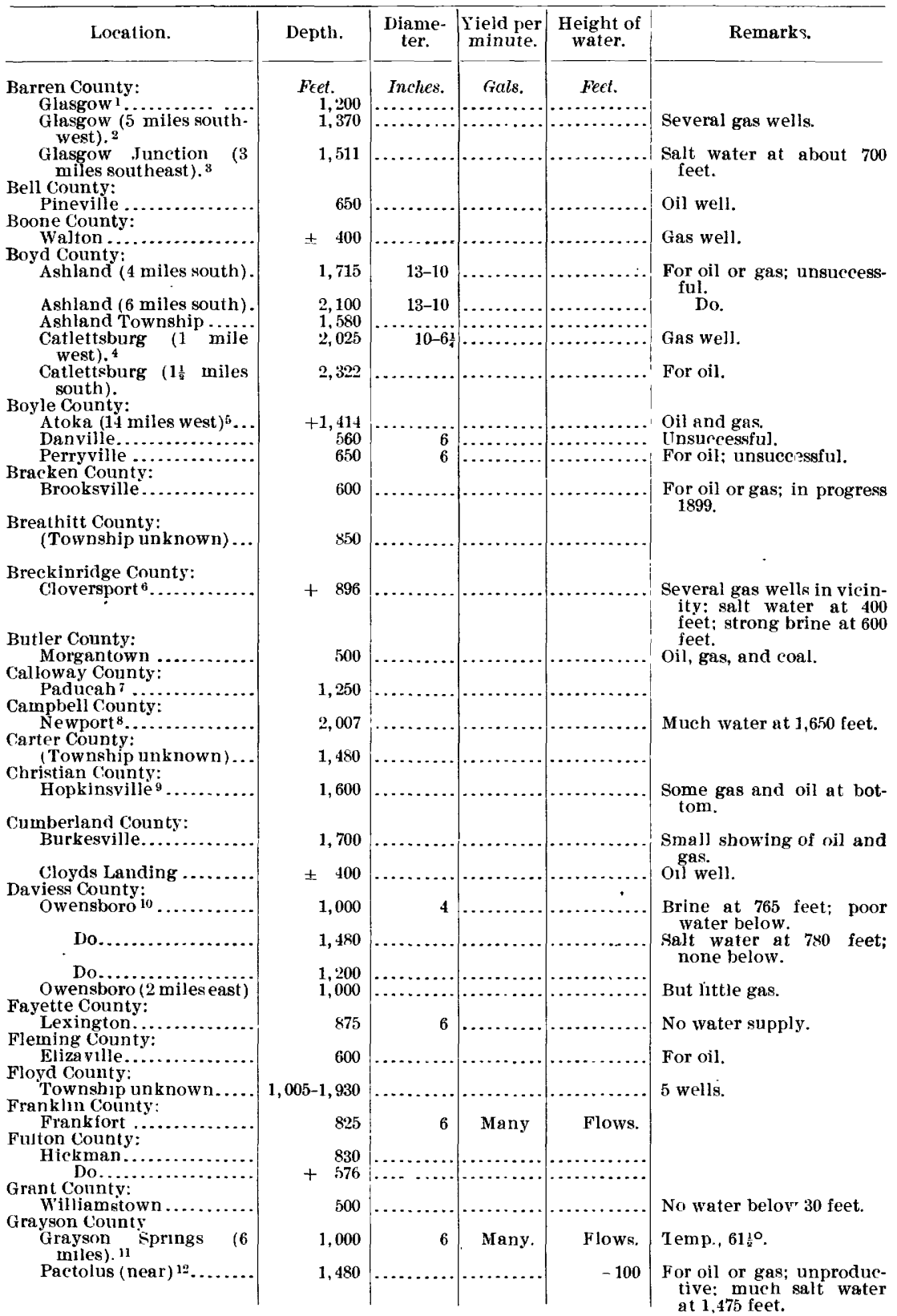

1 Ky, Geol. Surv., Petroleum, Gas, etc., by E. Orton, p. 154 .

2 Record, ibid., p. 154

s Ibud., pp. 155-156.

4 Record, U.S. Geol. Surv. Folio No. 69, p. 3,1900

b Record, Pa, 2d Geol. Surv. Rept., Vol. $I^{5}, \mathrm{pp}$ 340-341.

i Ky. Geol. Surv., Petroleum, Gas, ete., by E. Orton, pp. 191-193. i Record, Ky. Geol. Surv., Description of Jackson Purchase Region, pp. 321-326.

8 Record and analysis, Ohio Geol. Surv. Rept., 1888 , vol. 6 , pp. $298-300$.

${ }^{9}$ Ky. Geol. Surv., Petroleum, Gas, etc., by E. Orton, pp. 162-165.

10 Ibid., p. 194.

11 Ky.Geol. Surv. Rept., vol. 1, new sar., p. 92.

is Record, Pa. Geol Surv. Rept., Vol I5, p. 340. 
KENTUCKY -Continued.

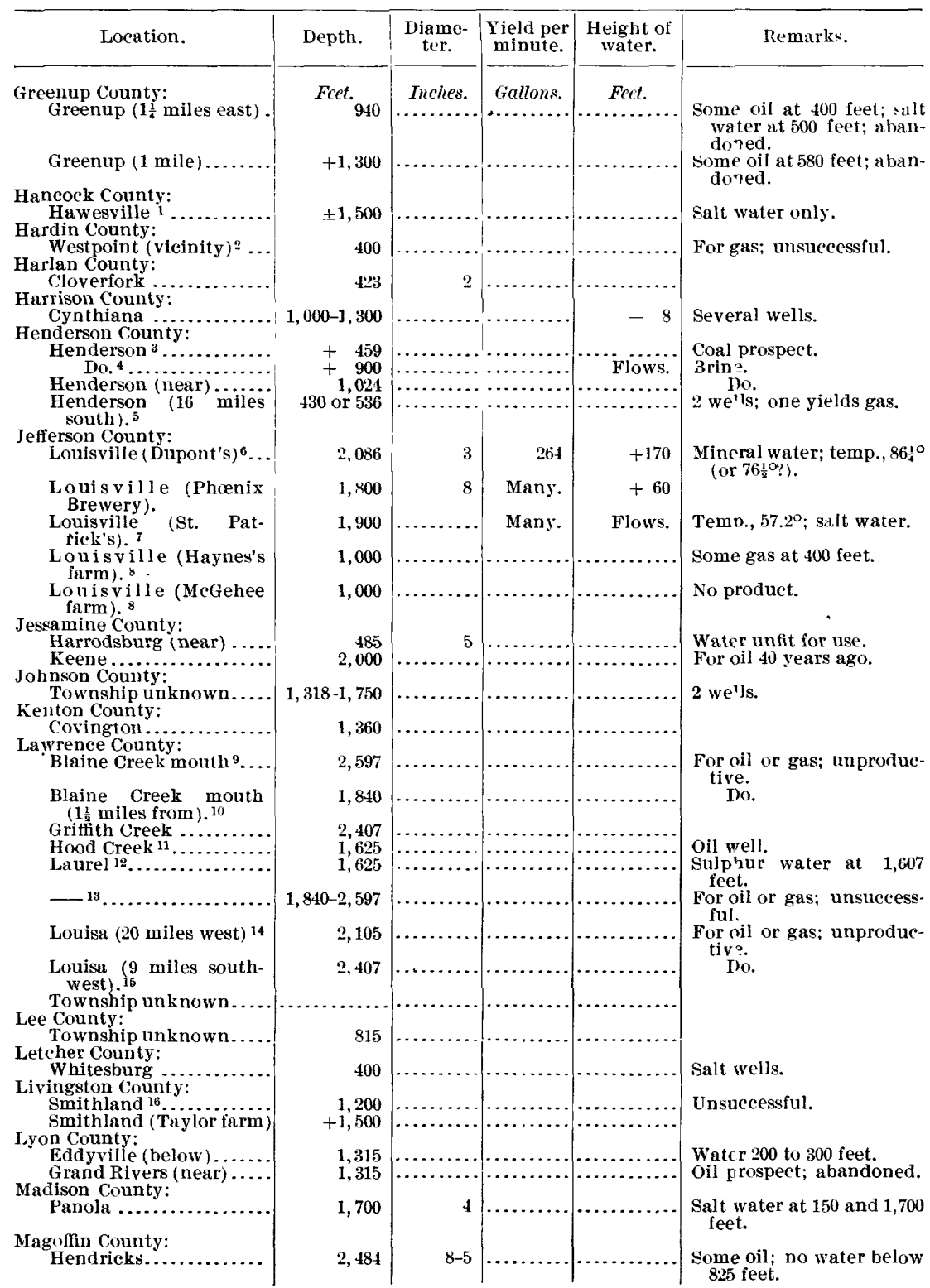

1 Ky. Geol. Surv., Petroleum, Gas, etc., by E. Orton, p. 194.

Record, Pa. Geol. Surv. Rept., Vol. $1^{5}$, pp.180181.

3 Record, Ky. Geol. Surv. Rept., 1854-55, pp. 32-36; Petroleum, Gas, etc., pp. 195-196.

4 Ky. Geol. Surv., Petroleum, Gas., etc., p. 195.

5 Ibid., p. 196.

${ }^{6}$ Record and analysis, Am. Jour. Sci., 21 ser. vol. $27, \mathrm{pp}$. 174-178.

${ }^{7} \mathrm{Ky}$. Geol. Surv., Petroleum, Gas, etc., pp. 169-170.
8 Ibid., p. 173.

9 Record, Pa. 2d Geol. Su'v. Rept., Vol. ${ }^{5}$, pp. ${ }^{10}$ Ibid., pp. 336-337, U. S. Geol. Surv. Folio No. 105.

11 Ibid., p. 339.

12 Record, Pa. $2 d$ Geol. Surv. Rept., Vol. ${ }^{5}$, p. 339.

${ }_{13}$ Ibid., pp. 335-339.

14 J bid., p. 338.

15 Ibid., pp. 337-338.

16 Ky. Geol. Surv., Petroleum, Gas, ete., p. 198. 
KEN'TUCKY-Continued.

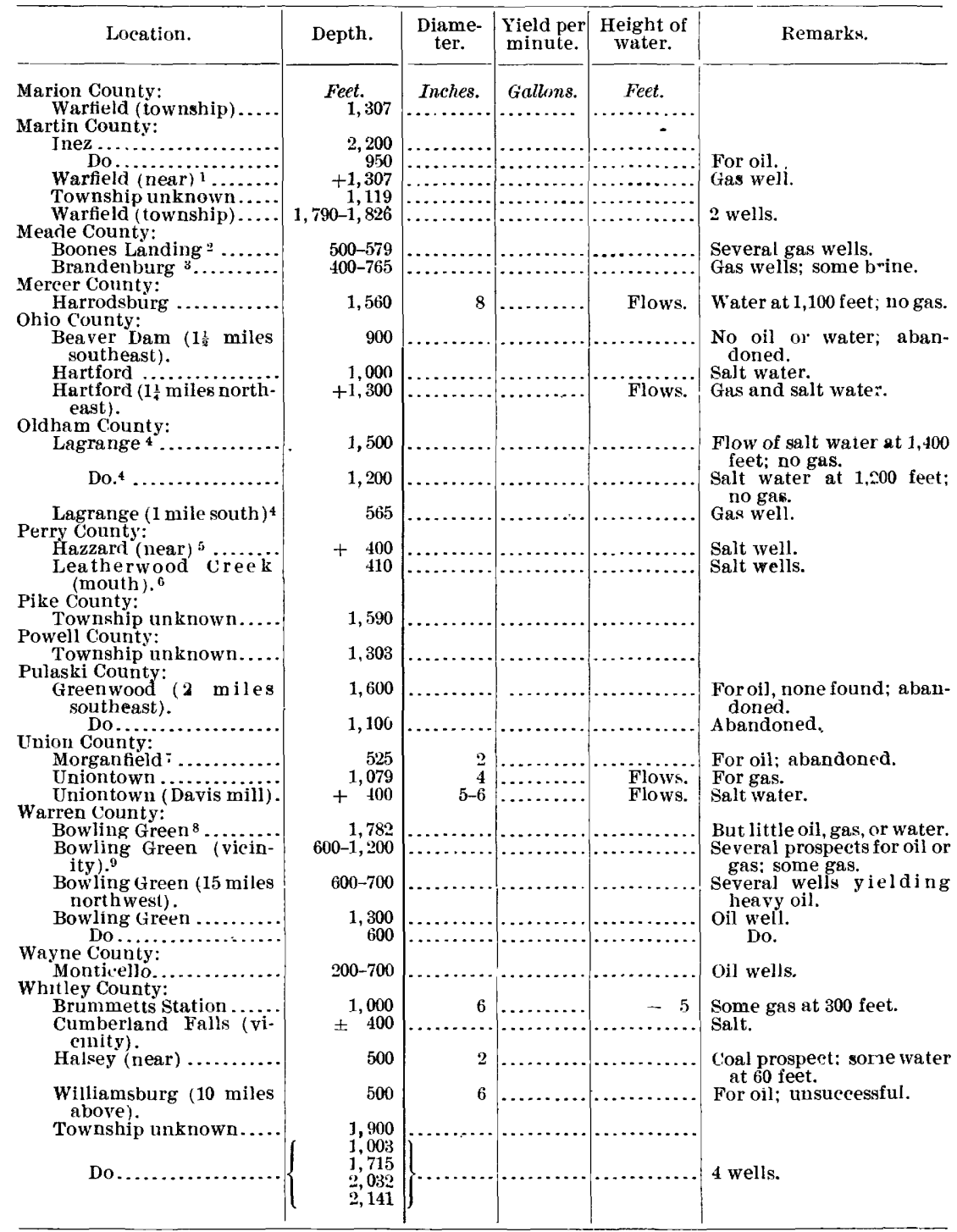

1 Record, Pa. 2 d Geol. Surv. Rept., Vol. $I_{z}^{5}$ pp. 339-340.

Ky. Geol. Surv., Petroleum, Gas, etc., pp. 176-177.

${ }^{3}$ Ibid., pp. 171-172, 176.

${ }^{4}$ Ibid., pp. 167-168.
5 Record, Ky. Geol. Surv. Rept., 185t-55, pp. 36-39.

6 Ky. Geol, Surv. Rept., 1854-55, p. 228.

7 Ky. Geol. Surv., Petroleum, Gas, etc., p. 205. 8 Ibid., pp. 159-160.

Ibid., pp. 160-162.

\section{PRINCIPAL PUBLICATIONS RELATING TO DEEP BORINGR IN KENTUCKY.}

Seventh report on oil and gas fields of western Pennsylvania for 1887-88, by John F. Carll: Pennsylvania Second Geological Survey Reports, Volume $\mathrm{I}^{5}, 356$ pages. Harrisburg, 1890. 
Kentucky Geological Survey Report for 1854-55, by D. D. Owen, Frankfort, 1856.

Occurrence of petroleum, natural gas, and asphalt in wes'ern Kentucky, by Edward Orton: Kentucky Geological Survey Report, 1888-89, 232 pages, Frankfort.

LOUISIANA.

\begin{tabular}{|c|c|c|c|c|c|}
\hline Location. & Depth. & $\begin{array}{c}\text { Diame- } \\
\text { ter. }\end{array}$ & $\begin{array}{c}\text { Yield per } \\
\text { minute. }\end{array}$ & $\begin{array}{l}\text { Height of } \\
\text { water. }\end{array}$ & Remarks. \\
\hline $\begin{array}{l}\text { Acadia Parish: } \\
\text { Crowley } . . . .\end{array}$ & Feet. ${ }_{635}$ & Inches. & $\begin{array}{r}\text { Gallons. } \\
312\end{array}$ & Fect. 6 & $\begin{array}{l}\text { Pumps } 347 \text { gallons; temp., } \\
620 \text {; supply from } 120 \text { to } \\
180 \text { feel. } \\
\text { Many oil wells. }\end{array}$ \\
\hline $\begin{array}{c}\text { Avoyelles Parish: } \\
\text { Marksville.... }\end{array}$ & & $16-4$ & & & Oil well in progress. \\
\hline $\begin{array}{l}\text { Aienville Parish: } \\
\text { Arcadia (Raillroad well) }\end{array}$ & 540 & $8-6$ & 50 & -130 & Water at 40,165 , and 520 \\
\hline $\begin{array}{l}\text { Arcadia (compress) } \\
\text { Bosier Parish. }\end{array}$ & 535 & $5-3 \frac{1}{8}$ & & -36 & \\
\hline & 600 & 4 & & -30 & $\begin{array}{l}\text { Water at } 225 \text { feet; blue } \\
\text { clay, no water } 250 \text { to } 600 \\
\text { feet. }\end{array}$ \\
\hline $\begin{array}{l}\text { Collinsburg (6 miles } \\
\text { southwest of, at Lake } \\
\text { Point). } \\
\text { Caddo Parish: }\end{array}$ & 600 & $2 \frac{1}{2}$ & & -15 & $\begin{array}{l}\text { Water } 232 \text { to } 242 \text { feet: blue } \\
\text { clay, no water } 242 \text { to } 600 \\
\text { feet. }\end{array}$ \\
\hline $\begin{array}{l}\text { Caddo Parsh: } \\
\text { Dixie ( } 3 \text { miles south- } \\
\text { west of }) \text {. } \\
\text { Furrh }\end{array}$ & 425 & 3 & & & $\begin{array}{l}\text { Hard, salty water; aban- } \\
\text { doned. } \\
\text { No water. }\end{array}$ \\
\hline Shreveport (ice factory $)^{2}$ & 996 & 4 & 30 & +15 & $\begin{array}{l}\text { Brine with gas; temp. } 83^{\circ} \text {; } \\
\text { fresh water at } 200 \text { feet, } \\
\text { which pumps } 25 \text { gallons. }\end{array}$ \\
\hline $\begin{array}{l}\text { Shreveport (Texas and } \\
\text { Pacific Junction). }\end{array}$ & 561 & 7 & & -50 & $\begin{array}{l}\text { Water at } 280 \text { feet; } 110 \text { water } \\
\text { below. }\end{array}$ \\
\hline $\begin{aligned} \text { U } \\
\text { Carca }\end{aligned}$ & 650 & & & & \\
\hline n........... & $\begin{array}{r}2,200 \\
535\end{array}$ & 10 & $\begin{array}{l}250 \\
225\end{array}$ & $\begin{array}{l}\text { No flow. } \\
\text {. }\end{array}$ & $\begin{array}{l}\text { Oil well; salty water. } \\
\text { Pimps 1,800 gallons per } \\
\text { minute; wat er very } \\
\text { warm. }\end{array}$ \\
\hline iles south- & 100 & & & & Oil well; abandoned. \\
\hline (n)..... & $\begin{array}{l}535 \\
500\end{array}$ & $\begin{array}{r}6-4 \\
6\end{array}$ & $\begin{array}{l}104 \\
210\end{array}$ & $\begin{array}{l}+18 \\
\text { Flows. }\end{array}$ & Four wells; temp., $64^{\circ}$. \\
\hline Lake Charles (Hoo-Hoo & $\begin{array}{r}510 \\
2,400\end{array}$ & $6-4$ & - & Flows. & $\begin{array}{l}\text { Tro wells. } \\
\text { For oil: unsuccessful. }\end{array}$ \\
\hline $\begin{array}{l}\text { Park). } \\
\text { Lake Charles (2 miles } \\
\text { east). }\end{array}$ & 498 & 4 & 100 & +10 & For on; unsuccessiur. \\
\hline $\begin{array}{l}\text { harles (2 miles } \\
\text { ast). } 5\end{array}$ & 2,406 & & & & Do. \\
\hline Money Hill.... & 2,200 & & 250 & Flows. & $\begin{array}{l}\text { Artesian salt water, } 1,000 \\
\text { to 1,005 feet; hot artesian } \\
\text { salt water, } 2,200 \text { feet. }\end{array}$ \\
\hline $\begin{array}{l}\text { iles south- } \\
\text { ing Hill) } .^{6}\end{array}$ & & & & & oductive. \\
\hline $\begin{array}{l}\text { Sulphur }{ }^{7} \ldots \ldots \ldots \ldots \ldots \\
\text { Do }^{7} \ldots \ldots \ldots \ldots \ldots \\
\end{array}$ & $\begin{array}{r}450 \\
1,230\end{array}$ & & & & $\begin{array}{l}\text { Sulphur test well. } \\
\text { Sulphur test well; strong } \\
\text { flow of artesian water. }\end{array}$ \\
\hline niles south- & $\begin{array}{r}602 \\
+\quad 800\end{array}$ & & & & Oil well in progress. \\
\hline Sulphur ( 3 miles west) ${ }^{9} .$. & 450 & & & & $\begin{array}{l}\text { For oil; abandoned in } \\
\text { large gravel. }\end{array}$ \\
\hline Vinton in... & 1,000 & & & & $\begin{array}{l}\text { Artesian sulphur water, } \\
400 \text { to } 500 \text { feet. }\end{array}$ \\
\hline $\begin{array}{l}\text { Do } 11 \\
\text { Vinton ( } 4 \text { miles north)ia. }\end{array}$ & $\begin{array}{l}540 \\
500\end{array}$ & & 33 & Flows. & Oil well abandoned in \\
\hline$w$ & 1,500 & & & & $\begin{array}{l}\text { A bandoned oil well: many } \\
\text { oll wells in this vicinity. }\end{array}$ \\
\hline & 503 & $4-2$ & 20 & +35 & \\
\hline & 1,457 & & & & For oil; unproductive. \\
\hline 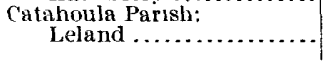 & 1,850 & 6 & & +6 & $\begin{array}{l}\text { Salt water with gas; temp. } \\
86.4^{\circ}\end{array}$ \\
\hline \multicolumn{3}{|c|}{$\begin{array}{l}\text { ' La. Geol, Surv. Rept., 1902, p. 268, U. S. Geol. } \\
\text { Surv. Bull. 212, pp. 127-130. } \\
\text { 2 Record, La. Geol. Surv. Rept., 1899, p. } 200 . \\
\text { 3 U. S. Geol. Surv. Bull. } 212 \text {, p. 137. } \\
4 \text { La. Ueol. Surv., 1902, p. } 240 . \\
\text { 5 Record, ibid., p. 271. } \\
\text { 6 La. Geol. Surv., 1902, p. } 270 .\end{array}$} & \multicolumn{3}{|c|}{$\begin{array}{l}\text { T Record, ibid.. 1899, p. } 25 . \\
8 \text { Ibid., } 1902, \text { p. } 272 . \\
9 \text { U. S. Geol. Surv. Bull. 212, p. } 137 . \\
10 \text { Ibid., p. 135. } \\
11 \text { La. Geol. Surv., 1902, p. 241. } \\
12 \text { U. S. Geol. Surv. Bull. 212, p. } 136 .\end{array}$} \\
\hline
\end{tabular}


LOUISIANA-Continued.

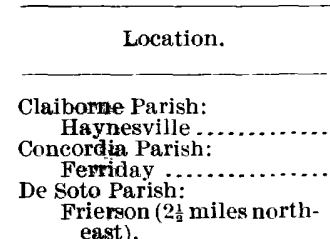
east).

East Batoli Ronge Parish:

Baker 1 .........
Baton Rouge

$$
\text { Do..... }
$$

Grant Parish:

Colfax ${ }^{3}$.

Pollock.

Rochelle

Iberia Parish:

Avery Island (Petite

Anse.) 4

Delcambre (Jeffersons Island. ) 5

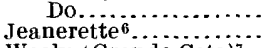

Weeks (Grande Cote) ${ }^{7}$

Jackson Parish:

Jonesboro ..............

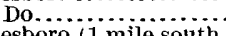

Jonesboro (1 mi
at Plymouth).

Lincoln Parish:

Ruston (waterworks) ...

Ruston (compress)

Madison Parish:

Delta ............

Natchitoches P
Goldonna.

donna ...............

Marthaville (3 miles west, at Boleyn).

Montrose ....................

Natchitoches (Normal School). 8

Orleans Parish:

New Orleans ${ }^{9}$

Do.

Do. 9

New Orleans (2 miles north, at Lake City) ${ }^{10}$ Ouachita Parish:

Cheniere (3 miles south-

east).

Monroe (ice factory) ... Do..................

Monroe (light and powor house).

Monroe.

Do

Monroe (one-half to $1 \frac{1}{2}$ miles north).

Rapides Parish:

Alexandria (waterworks).

Do.................

Alexandria (city square)

Alexandria.

Alexandria (ice factory)

Alexandria............

Alexandria (ice factory)

Alexandria (railroad well).

1 La. Geol. Surv. Rept., 1902, p. 230.

2 Ibid. p. 229.

3 Record. ibid, p. 211

4 Ibid. Rept. 1899, p. 244.

5 Ibid, p. 255 .

\begin{tabular}{|c|c|c|c|c|}
\hline Depth. & $\begin{array}{l}\text { Diame- } \\
\text { ter. }\end{array}$ & $\begin{array}{l}\text { Yield per } \\
\text { minute. }\end{array}$ & $\begin{array}{l}\text { Height of } \\
\text { water. }\end{array}$ & Remark \\
\hline Feet. 600 & $\begin{array}{l}\text { Inches. } \\
\text { 4-3 }\end{array}$ & $\begin{array}{r}\text { Gallons. } \\
1\end{array}$ & $\begin{array}{l}\text { Feet. } \\
\quad-20\end{array}$ & Soft water. \\
\hline 950 & & & Flows. & Brine. \\
\hline 1,500 & $8-1$ & 10 & Flows. & $\begin{array}{l}\text { Salt water with gas at } 998 \text {; } \\
\text { temp., } 70^{\circ} \text {. }\end{array}$ \\
\hline $\begin{array}{l}850 \\
758 \\
760\end{array}$ & $\begin{array}{c}2 \\
8-4 \frac{1}{2} \\
10-6\end{array}$ & $\begin{array}{r}350 \\
\cdots \ldots\end{array}$ & $\begin{array}{r}+16 \\
-\quad 6 \\
\text { Flows. }\end{array}$ & Pumps 350 gallons. \\
\hline 1,128 & $2 \frac{1}{2}$ & 40 & +65 & Temp., $62^{\circ}$; salt water; \\
\hline 910 & $8-4$ & 2 & Flow. & $\begin{array}{l}\text { Artesian water at } 225 \text { feet; } \\
\text { no water below. }\end{array}$ \\
\hline $\begin{array}{r}565 \\
1,005\end{array}$ & $\ldots \ldots \ldots$ & 1 & Flows. & $\begin{array}{l}\text { Salt water with some gas; } \\
\text { pumps } 75 \text { gallons. } \\
\text { Rock salt belov } 166 \text { feet. }\end{array}$ \\
\hline 2,090 & & & & Rock salt belor 344 feet. \\
\hline $\begin{array}{l}442 \\
700 \\
500\end{array}$ & & & -5 & Ruck salt belor 140 feet. \\
\hline $\begin{array}{l}545 \\
538\end{array}$ & $\begin{array}{l}5 \\
4\end{array}$ & 40 & $\begin{array}{l}-34 \\
-34\end{array}$ & \\
\hline 521 & $\ldots \ldots \ldots$ & $\cdots$ & $\ldots \ldots \ldots$ & $\begin{array}{l}\text { Water at } 360 \text { to } 380,418 \text { to } \\
430,492 \text { to } 520 \text { feet. }\end{array}$ \\
\hline 425 & $8-6$ & 68 & -110 & Water from 100 to 126 and \\
\hline 449 & 4 & 68 & -140 & \\
\hline 1,200 & $\ldots \ldots \ldots$ & $\ldots \ldots$ & -38 & No water below 135 feet. \\
\hline $\begin{array}{l}475 \\
707\end{array}$ & & & Flows. & $\begin{array}{l}\text { Test well. } \\
\text { A rtesian salt water at } 640\end{array}$ \\
\hline 412 & 1 & & +20 & $\begin{array}{l}\text { Bored deeper and lost } \\
\text { flow. }\end{array}$ \\
\hline 496 & 6 & & & Abandined; no water. \\
\hline 726 & $6-2 \frac{1}{2}$ & $\ldots$. & Flow's. & $\begin{array}{l}\text { Salt water; purips } 25 \text { gal- } \\
\text { lons. }\end{array}$ \\
\hline 457 & 4 & $\ldots \ldots \ldots$ & -4 & Salt water. \\
\hline $600-700$ & & & Flows. & $\begin{array}{l}\text { Many wells; water brack- } \\
\text { ish. }\end{array}$ \\
\hline $1,000-1,200$ & & & +15 & Several wells; tomp., $68^{\circ}$. \\
\hline $\begin{array}{r}\overrightarrow{1}, 356 \\
900\end{array}$ & & $\ldots \ldots \ldots$ & $\begin{array}{l}\text { Flows. } \\
+60\end{array}$ & $\begin{array}{l}\text { Salty, gas escajes } 830 \mathrm{cu}- \\
\text { bic feet in } 24 \text { hours. } \\
\text { Temp., } 78^{\circ} \text {. }\end{array}$ \\
\hline 515 & & & Flows. & $\begin{array}{l}\text { Artesian water } 265 \text { to } 275 \text {, } \\
355 \text { to } 430,465 \text { to } 515 \text { feet. }\end{array}$ \\
\hline $\begin{array}{l}485 \\
400 \\
500\end{array}$ & $\begin{array}{r}5-3 \frac{1}{2} \\
7-3 \frac{1}{2} \\
\ldots \ldots\end{array}$ & $\begin{array}{l}50 \\
20\end{array}$ & $\begin{array}{l}+40 \\
\text { Flows. } \\
\text { Flows. }\end{array}$ & $\begin{array}{l}\text { Soft water. } \\
\text { Do. }\end{array}$ \\
\hline $\begin{array}{l}+400 \\
\pm 400 \\
\pm 400\end{array}$ & $\begin{array}{c}7-3 \frac{1}{4} \\
4 \\
\ldots \ldots\end{array}$ & $\mid \begin{array}{r}\cdots \\
30 \\
\cdots \cdots\end{array}$ & $\begin{array}{l}+40 \\
\text { Flows. } \\
\text { Flow. }\end{array}$ & $\begin{array}{l}\text { Many artesian wells. } \\
\text { Soft water. } \\
3 \text { wells. }\end{array}$ \\
\hline 560 & $4-2 \frac{1}{2}$ & 70 & +12 & $\begin{array}{l}\text { Pumping eapac'ty } 250 \text { gal- } \\
\text { lons. }\end{array}$ \\
\hline $\begin{array}{l}760 \\
473\end{array}$ & $\begin{array}{r}10-1 \\
1 \frac{1}{2}\end{array}$ & $\begin{array}{r}\cdots \\
\quad \pm 10\end{array}$ & $\cdots 60$ & $\begin{array}{l}\text { Flowed until city water- } \\
\text { works installed. }\end{array}$ \\
\hline 606 & 2 & & -49 & Do. \\
\hline $5 \times 0$ & 8 & $\ldots \ldots .$. & -60 & Abandoned. \\
\hline 621 & 8 & …....... & $\cdots$ & Do. \\
\hline $\begin{array}{l}924 \\
858\end{array}$ & $6-4$ & $\mid \begin{array}{c}125 \\
\cdots \ldots \ldots\end{array}$ & Mows. & $\begin{array}{l}\text { Woft water. } \\
\text { doned. }\end{array}$ \\
\hline
\end{tabular}

6 Ibid., 1902. p. 232.

7 Ibid., 1899, pl. 27.

8 Record, La. Geol. Surv. Rept., 1902, p. 210.

9 Ibid., pp. 221-232.

10 Ibid., p. 222. 
LOUISIANA-Continued.

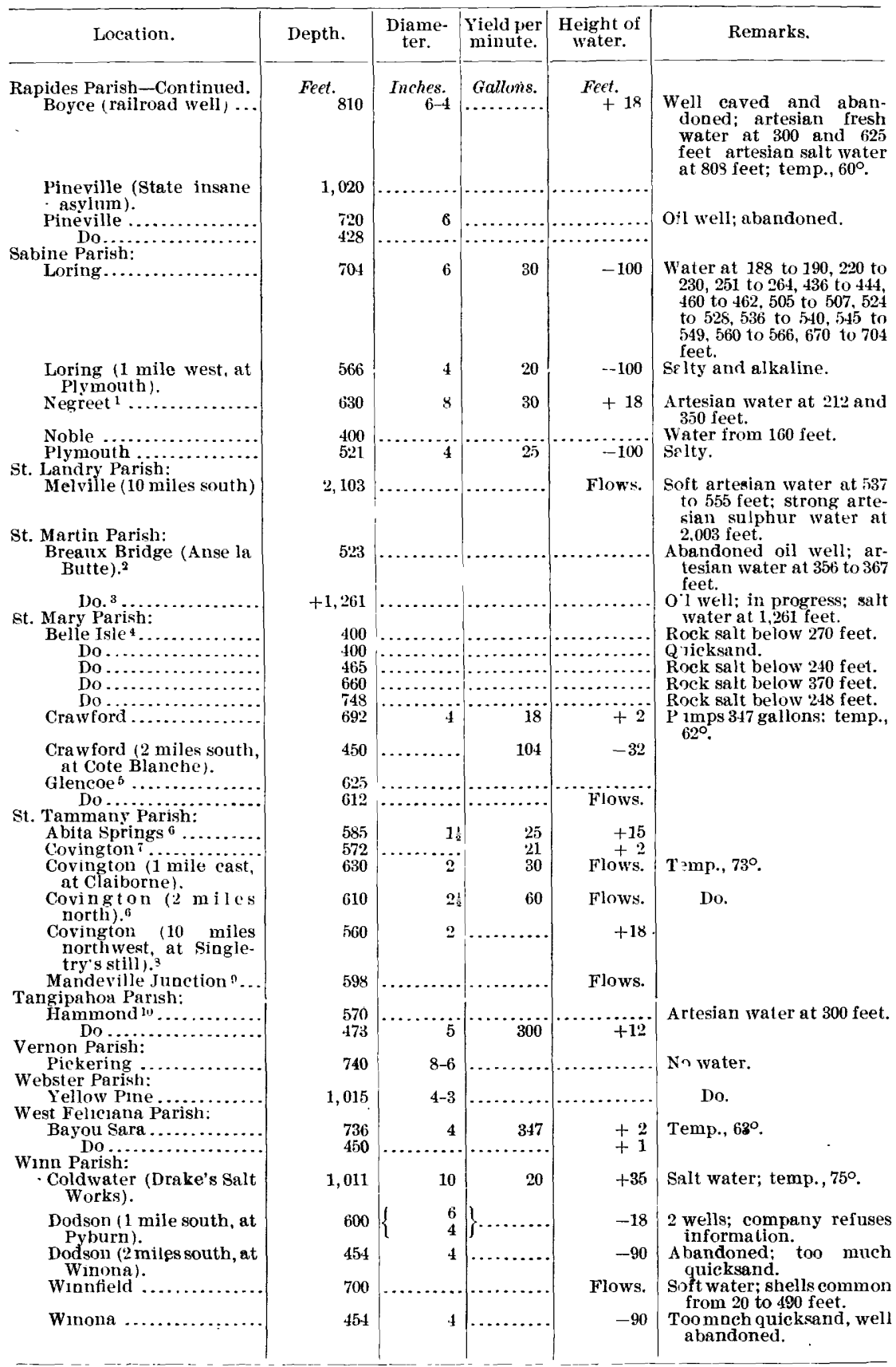

${ }^{1}$ Record, U. S. Geol. Surv. Bull. 212, p. 65. 2 lbld., pp. 130-131.

31 bid., p. 63.

4 Record, La. Geol. Surv. Rept., 1899, p. 224.

6 Ibid., p. 258.
6 La. Geol. Surv. Rept., 1902, p. 226.

7 Ibid., p. 224.

8 Ibid., p. 227.

Ibid., p. 223

10 Record, ibid., p. 228 


\section{PRINCIPAL PUBLICATIONS RELATING TO DEEP BORIITGS IN LOUISIANA.}

Subterranean waters of Louisiana, by G. D. Harris: Geological Survey of Louisiana, Report of 1902, pp. 203, 260.

Oil in Louisiana, by G. D. Harris, ibid., pp. 265-275.

Underground Waters of Southern Lonisiana, by G. D. Harris.

Oil fields of the Texas-Louisiana Gulf Crastal Plain, by C. W. Hayes ard William Kennedy: U. S. Geological Survey Bulletin 212, 1903.

Geology and water resources of northern Louisiana and sonthern Arkansas, by A. C. Veatch: Prof. Paper U. S. Geol. Survey No. 46. (In preparation.)

\section{MAINE.}

\begin{tabular}{|c|c|c|c|c|c|}
\hline Location. & Depth. & $\underset{\text { ter. }}{\text { Diame- }}$ & $\mid \begin{array}{c}\text { Yield per } \\
\text { minute. }\end{array}$ & $\begin{array}{l}\text { Height of } \\
\text { water. }\end{array}$ & Rems.rks. \\
\hline 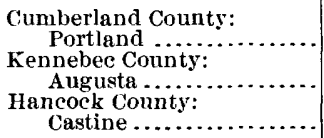 & $\begin{array}{r}\text { Feet. } \\
505 \\
570 \\
675\end{array}$ & $\begin{array}{r}\text { Inches. } \\
6 \\
8\end{array}$ & $\begin{array}{r}\text { Gallons. } \\
13 \\
10 \\
\end{array}$ & $\begin{array}{r}\begin{array}{r}\text { Fett. } \\
-100 \\
\text { No flow. } \\
-27\end{array}\end{array}$ & $\begin{array}{l}\text { Rock at } 100 \text { feet. } \\
\text { In granite. }\end{array}$ \\
\hline
\end{tabular}

\section{MARYLAND.}

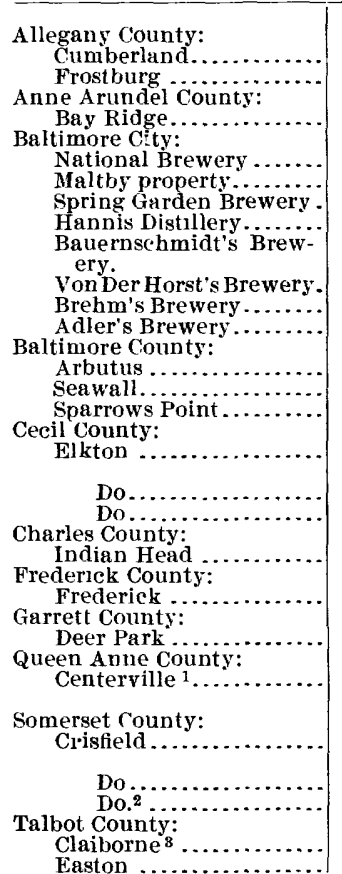

1 Record, N. J. Geol. Surv. Rept., 1899, pp. 81-83.

2 Record, U. S. Geol. Surv. Bull. 138, pp. 128-130.
Abandoned.

Do.

Irony water.

Not flnished; in gneiss.

No water below 210 feet.

Water very unsatisfactory;

temp., $45^{\circ}$.

Abandoned.

Unsuccessful

No flow.

$+3$

Flows.

Near sur- Water at 428 and 665 feet. face.

Flows. Flows 40 gallons; saline water.

Flows. - Saline water.

Flows. $\quad$ Do.

Water also at 380 feet.

No water below 100 reet.

3 U. S. Geol. Surv. Bull. 138, p. 132. 
MARYLAND-Continued.

\begin{tabular}{|c|c|c|c|c|c|}
\hline Location. & Depth. & $\begin{array}{l}\text { Diame- } \\
\text { ter. }\end{array}$ & $\begin{array}{l}\text { Yield per } \\
\text { minute. }\end{array}$ & $\begin{array}{l}\text { Height of } \\
\text { water. }\end{array}$ & Remarks. \\
\hline $\begin{array}{l}\text { Talbot County-Continued. } \\
\text { Tilghmans Istand ....... }\end{array}$ & $\begin{array}{l}\text { Fect. } \\
370-420\end{array}$ & $\begin{array}{l}\text { Inches. } \\
\text {. }\end{array}$ & $\begin{array}{c}\text { Gallons. } \\
\text { Many. }\end{array}$ & Feet. & 4 wells. \\
\hline Tunis Mills.............. & 430 & 2 & $\begin{array}{l}\text { Pumps } \\
100 .\end{array}$ & Flows. & Flo*vs 6 gallons. \\
\hline $\begin{array}{l}\text { Wicomico County: } \\
\text { Salisbury }{ }^{1} \ldots \ldots \ldots \ldots \ldots\end{array}$ & 424 & & & & Water at 267 feet. \\
\hline $\begin{array}{l}\text { Worcester county: } \\
\text { Pocomoke City }\end{array}$ & 496 & 6 & 50 & Flows. & $\begin{array}{l}\text { Pumps } 100 \text { gallons per } \\
\text { minute. }\end{array}$ \\
\hline
\end{tabular}

1 Record, N. J. Geol. Surv. Rept,, 1899, pp. 113-115.

2 Ibif., pp. 116-117.

\section{PUBLICATIONS RELATING TO DEEP BORINGS IN MARYLAND.}

United States Geological Survey Bulletin No. 138, pp. 128-132.

New Jersey Geological Survey Reports for 1898 and 1899.

\section{MASSACHUSETTS.}

\begin{tabular}{|c|c|c|c|c|c|}
\hline Location. & Depth. & $\begin{array}{l}\text { Diame- } \\
\text { ter. }\end{array}$ & $\begin{array}{c}\text { Yield per } \\
\text { minute. }\end{array}$ & $\begin{array}{l}\text { Height of } \\
\text { water. }\end{array}$ & Remarks. \\
\hline $\begin{array}{l}\text { Berkshire County: } \\
\text { Dalton .......... }\end{array}$ & $\begin{array}{l}\text { Fect. } \\
\quad+100\end{array}$ & Inches. & Gallons. & Feet. & \multirow{7}{*}{$\begin{array}{l}\text { Very hard water. } \\
\text { Unsilecessful. }\end{array}$} \\
\hline 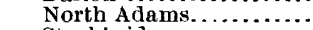 & 500 & 8 & 625 & 100 $-i$ & \\
\hline Stockbridge ................. & 650 & 8 & & & \\
\hline Bristol County: & & & & & \\
\hline $\begin{array}{l}\text { Fall River (?) } \\
\text { New Bedford................ }\end{array}$ & 407 & 8 & 75 & & \\
\hline $\begin{array}{l}\text { New Bedford............. } \\
\text { New Bedford (Clarks }\end{array}$ & 510 & 6 & $2 \frac{1}{2}$ & No flow. & \\
\hline $\begin{array}{l}\text { New Bedrord (Clarks } \\
\text { Cove Guano Co.). }\end{array}$ & & & & & \\
\hline Taunton.................... & 975 & 8 & 52 & -12 & \multirow{6}{*}{$\begin{array}{l}\text { Water too irony. } \\
\text { Water too hard. }\end{array}$} \\
\hline $\begin{array}{l}\text { Franklin County: } \\
\text { Turners Falls: }\end{array}$ & & & & & \\
\hline $\begin{array}{l}\text { Turners Falls... } \\
\text { Hampden County: }\end{array}$ & 900 & 6 & & No flow. & \\
\hline Holyoke........ & 400 & 8 & 400 & -20 & \\
\hline Do...... & 800 & 8 & 600 & -20 & \\
\hline Do $\ldots \ldots \ldots \ldots \ldots$ & 720 & 8 & & -14 & \\
\hline $\begin{array}{l}\text { Do........................... } \\
\text { Hampshire County: }\end{array}$ & 1,005 & 8 & Many. & No flow. & \multirow{7}{*}{$\begin{array}{l}\text { Water too irony. } \\
\text { Unsuecessful. } \\
\text { Do. } \\
\text { Water too irony. } \\
\text { Water of fair quality. }\end{array}$} \\
\hline Northampton ..... & 3,710 & 8 & 7 & No flow. & \\
\hline $\begin{array}{r}\text { Do } \ldots \ldots \ldots \\
\text { West Cummington }\end{array}$ & $\begin{array}{r}4,022 \\
625\end{array}$ & & $\dddot{2} \frac{i}{2}$ & No flow. & \\
\hline Middlesex County: & & & & & \\
\hline Malden.............. & 650 & 8 & & No flow. & \\
\hline $\begin{array}{l}\text { Waltham ......... } \\
\text { Watertown }\end{array}$ & 460 & & Veryfew & No flow. & \\
\hline $\begin{array}{l}\text { Watertown }:- \\
\text { Norfolk County: }\end{array}$ & 700 & & Many. & & \\
\hline Franklin .... & 450 & 6 & 27 & -10 & \multirow{16}{*}{$\begin{array}{l}\text { Bul water. } \\
\text { Sulphur water; good water } \\
459-484 \text { feet; well aban- } \\
\text { doned. } \\
\text { No water below } 500 \text { feet. } \\
\text { Unsuecessful. } \\
\text { Do. } \\
\text { Do. } \\
2 \text { w } 3 l \text {;s; water very salty. }\end{array}$} \\
\hline $\begin{array}{l}\text { Reudville........... } \\
\text { Walpole } \ldots . . . \ldots\end{array}$ & 500 & 8 & 1,500 & -15 & \\
\hline $\begin{array}{l}\text { Walpole .............. } \\
\text { Suffolk County: }\end{array}$ & 1,000 & & & …............ & \\
\hline 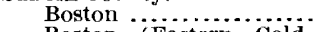 & 610 & & & & \\
\hline $\begin{array}{l}\text { Boston (Eastern Cold } \\
\text { Storage). }\end{array}$ & 400 & 8 & 70 & No flow. & \\
\hline $\begin{array}{l}\text { Boston (corner Hunt- } \\
\text { ington avenue and } \\
\text { Gainesboro street). }\end{array}$ & 512 & 8 & Few. & No flow. & \\
\hline $\begin{array}{l}\text { Boston (corner Com- } \\
\text { mercial and Prince } \\
\text { strects). }\end{array}$ & 1,750 & & & No flow. & \\
\hline $\begin{array}{l}\text { Boston (No. } 34 \text { Provi- } \\
\text { dence street). }\end{array}$ & 2,503 & $7 \frac{5}{8}$ & & 5 & \\
\hline Boston (Park square).... & 2,567 & & & & \\
\hline $\begin{array}{c}\text { Cambridge (Dow Soap } \\
\text { Works). }\end{array}$ & 500 & & & & \\
\hline $\begin{array}{l}\text { Cambridge (Morse and } \\
\text { White streets). }\end{array}$ & 462 & 6 & & & \\
\hline Cambridge ........... & 400 & & & & \\
\hline Dorchester .................. & $870-900$ & & & No flow. & \\
\hline Roxbury .............. & 502 & 6 & & -20 & \\
\hline Do $\ldots \ldots \ldots \ldots \ldots$ & 403 & & & & \\
\hline $\begin{array}{l}\text { Worcester county: } \\
\quad \text { Princeton ........... }\end{array}$ & 900 & & Few. & & \\
\hline
\end{tabular}




\section{MICHIGAN.}

\begin{tabular}{|c|c|c|c|c|c|}
\hline Location. & Depth. & $\begin{array}{l}\text { Diame- } \\
\text { ter. }\end{array}$ & $\begin{array}{l}\text { Yield per } \\
\text { minute. }\end{array}$ & $\begin{array}{l}\text { Height of } \\
\text { water. }\end{array}$ & Remarks \\
\hline $\begin{array}{l}\text { Alger County: } \\
\text { Grand Marais ........... }\end{array}$ & $\begin{array}{l}\text { Feet. } \\
1,215\end{array}$ & $\begin{array}{l}\text { Inches. } \\
\text {........... }\end{array}$ & $\begin{array}{l}\text { Gallons. } \\
\text { None. }\end{array}$ & Feet. & Abiandoned. \\
\hline Allegan County: & & & & & \\
\hline Allegan ${ }^{1} \ldots \ldots \ldots \ldots \ldots$ & $1,275-1,400$ & 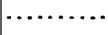 & & & Several borings for oil; not \\
\hline $\begin{array}{l}\text { Alpena County: } \\
\text { Alpena } \ldots \ldots \ldots \ldots \ldots \ldots\end{array}$ & 650 & 5 & 200 & +20 & $\begin{array}{l}\text { much found. } \\
\text { Temp. } 52^{\circ} \text { : several wells. }\end{array}$ \\
\hline Do. ${ }^{2} \ldots \ldots$ & $1,026-1,269$ & $\ldots \ldots$ & & ...... & Several sait wells. \\
\hline$\underset{\text { (near bed) } .^{3}}{\text { Thunder }} \quad$ River & 1,025 & $\cdots \ldots$ & & $\cdots$ & $\begin{array}{l}\text { Salt well; flow of mineral } \\
\text { water at } 400 \text { feet. }\end{array}$ \\
\hline Barry County: & & & & & \\
\hline $\begin{array}{l}\text { Assyria....... } \\
\text { Bay County: }\end{array}$ & $1,8 \mathfrak{0} 0$ & $\cdots$ & $\cdots$ & $\cdots$ & For oil; unsuccessful. \\
\hline 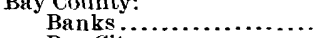 & $774-980$ & & & & Salt wells. \\
\hline 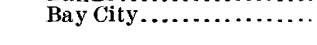 & $715-1,200$ & $\cdots$ & & & $\begin{array}{l}\text { Numerous salt wells in } \\
\text { vicinity. }\end{array}$ \\
\hline Do. ${ }^{4} \ldots \ldots \ldots \ldots \ldots$ & 505 & $\ldots \ldots$ & & .... & $\begin{array}{l}\text { Salt wells in upper salt } \\
\text { beds. }\end{array}$ \\
\hline Do $\ldots \ldots \ldots \ldots \ldots$ & 1,600 & & & & \\
\hline $\begin{array}{l}\text { Do } \\
\text { Do. }{ }^{6} \ldots \ldots \ldots \ldots \ldots\end{array}$ & $\begin{array}{r}1,003-1,007 \\
2,865\end{array}$ & $\cdots \cdots$ & & $\cdots$ & $\begin{array}{l}2 \text { wells. } \\
\text { Brine at } 2,141-2,306 \text { feet. }\end{array}$ \\
\hline Bay City (near) $6 \ldots$. & 495 & & & & \\
\hline $\begin{array}{l}\text { Essexville } \ldots \ldots \ldots \ldots \ldots \ldots \\
\text { Garfleld }{ }^{8} \ldots \ldots \ldots \ldots \ldots\end{array}$ & $\begin{array}{l}755 \\
800\end{array}$ & $\cdots$ & & $\cdots$ & \\
\hline Kawkawlin ${ }^{9} \ldots \ldots \ldots$ & $810-1,133$ & $\ldots$ & & & 2 salt wells. \\
\hline $\begin{array}{l}\text { Kawkawlin (3 miles } \\
\text { east). } 10\end{array}$ & 465 & $\ldots$ & & & \\
\hline Portsmouth........... & 1,000 & $\cdots$ & & & \\
\hline Do. ${ }^{11} \ldots \ldots \ldots \ldots$ & 664 & & & $\ldots$ & Salt well. \\
\hline 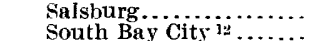 & $\begin{array}{r}1,000-1,013 \\
3,508\end{array}$ & $\ldots \ldots$ & & $\ldots \ldots$ & Several salt well? \\
\hline 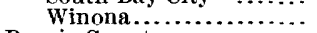 & 1,020 & $\cdots$ & & a............... & Drill hole for conper ore. \\
\hline $\begin{array}{l}\text { Benzie County: } \\
\text { Frankfort } 1 \mathbf{3} \ldots \ldots . .\end{array}$ & 1,800 & & & & \\
\hline Do. ${ }^{14} \ldots \ldots$ & 2,200 & $\ldots$ & 160 & Flows. & Temp., 580; minewal water. \\
\hline $\begin{array}{l}\text { Berrien County: } \\
\text { Benton Harbor } 15 . .\end{array}$ & 205 & & & & \\
\hline Do.................... & 1,400 & $10-6$ & Many. & -30 & \\
\hline Do.................. & 750 & 8 & $\cdots \cdots$ & -30 & $\begin{array}{l}\text { Abundant yield of strong } \\
\text { mineral water. }\end{array}$ \\
\hline Berrien Springs $16 \ldots \ldots$ & $87 t$ & & & $\cdots$ & \\
\hline $\begin{array}{r}\text { Niles } \ldots \ldots \ldots \ldots \ldots \ldots \\
\text { Do. } 17 \ldots \ldots \ldots \ldots \ldots\end{array}$ & $\begin{array}{l}1,488 \\
1,140\end{array}$ & $10-5$ & 15 & +15 & Temp., $60^{\circ}$. \\
\hline $\begin{array}{l}\text { Niles and Benton } \mathrm{Har} \\
\text { bor (between). }\end{array}$ & $700-1,600$ & & $\cdots$ & an. & \\
\hline Niles $^{19} \ldots \ldots \ldots \ldots \ldots$ & 600 & $\cdots$ & & & Strong brine at $\$ 70$ feet. \\
\hline $\begin{array}{l}\text { Branch County: } \\
\text { Coldwater (west of) }{ }^{2} \text {. }\end{array}$ & 447 & & & & $\begin{array}{l}\text { Water at } 223 \text { feet; brine at } \\
282 \text { feet. }\end{array}$ \\
\hline Do. ${ }^{21} \ldots \ldots \ldots \ldots$ & 1,200 & $\ldots \ldots$ & & $\ldots \ldots \ldots \ldots$ & \\
\hline Calhoun County: & 2,200 & $\ldots \ldots \ldots$ & & $\ldots \ldots$ & \\
\hline Albion.............. & & & & & Several wells. \\
\hline Battlecreek $: . .$. & 440 & & & -16 & Water at 116 feet only. \\
\hline & 460 & $\ldots \ldots \ldots$ & & $\ldots \ldots$ & \\
\hline Marshall $\leqslant 3 \ldots$ & 440 & $\ldots \ldots \ldots$ & & Flows. & \\
\hline Cass County: & & & & & \\
\hline $\begin{array}{r}\text { Dowagiac } \ldots \ldots \ldots \ldots \ldots \ldots \\
\quad \text { Do } \ldots \ldots \ldots \ldots \ldots \ldots\end{array}$ & $\begin{array}{l}1,500 \\
2,200\end{array}$ & $\ldots$ & & & $\begin{array}{l}\text { Unsuccessful. } \\
\text { Water at } 87 \text { feet; brine at }\end{array}$ \\
\hline Bo. ${ }^{24}$ & 1,760 & & & & \\
\hline Do... & 2,300 & ........ & & ........ & Water at 90 feet; brine at \\
\hline Charlevoix 25 .. & $400-483$ & 8 & & Flow. & Temp., $46^{\circ}$ \\
\hline
\end{tabular}

1 Record, Mich. Geol. Surv. Rept., 1881-1893, vol.

5 , part 2, pp. 44-45, pl. 4 .

slbid, pp. 46-47, pl. 5 .

3 Mich. Geol. Surv. Rept., 1873-1876, vol. 3, part

1. p. 40.

4 Analysis, ibid., p. 18:

5 Record, ibid., 1881-1893, vol. 5, part 2, p. 50, pl. 6.

Ibid., 1900-1903, vol. 8 , part 2 , p. 170

I Ibjd, 1881-1893, vol. 5, part 2, p. 58 .

8 Ann. Rept. State Board of Geol. Surv. of Mich., 1901, p. 224.

9 Record, Mich. Geol. Surv. Rept., 1881-1893, vol.

5 , part 2, p. 65; 1873-1876, vol. 3, part 1, p.96.

10Ibid., 1900-1903, vol. 8 , part 2 , p. 169 .

11 Analysis, ibid, $1873-1876$, vol. 3 , part 1, p. 182.

12 Record, Ann. Rept. State Board of Geol. Surv. of Mich., 1901, pp. 224-226.

14 Analysis, ibid., p. 59

15 Record, ibid., p. 51, pl. 7 .

16 Ann. Rept. State Board of Geol. Surv. of Mich., 1901, p. 213.

17 Record, Mich. Genl. Surv. Rept., 1881-1893, vol. 5 , part 2 , p. 73 . pl. 44 .

18 Ann. Rept. State Board of Geol. Surv. of Mich., 1901, pp. 213-214.

19 Record, Mich. Geol. Surv. Rept., 1873-1876, vol. 3, part 1, p. 93 .

9Ibid., pp. $87-88$.

m lbid., 18ol-1893, vol. 5 , part 2, p. 5t, pl. 10.

221 bid., p: 50.

23 lbid., p. 67 .

2+ Ibid., p. 55 , pl. 16

i5 L. S. Geol. Surv. Water-Sup. and Irr. Paper No. 30, p. 87 .

.

5 , part 2, p. 59 , pl. 18 .

$$
\text { IRR } 149-05-5
$$


MICHIGAN-Continued.

\begin{tabular}{|c|c|c|c|c|c|}
\hline Location. & Depth. & $\begin{array}{l}\text { Diame- } \\
\text { ter. }\end{array}$ & $\begin{array}{l}\text { Yield per } \\
\text { minute. }\end{array}$ & $\begin{array}{l}\text { Height of } \\
\text { water. }\end{array}$ & Remarks. \\
\hline $\begin{array}{c}\text { Cheboygan County: } \\
\text { Cheboygan }\end{array}$ & Fect. & Inches. & Gallons. & Fert. & \\
\hline Do $\ldots \ldots \ldots$ & 452 & $10-8$ & & Tosuriace. & \\
\hline $\begin{array}{r}\text { Do. } \\
\text { Indian River } \ldots \ldots \ldots \ldots\end{array}$ & 2,750 & & & $\cdots \cdots \cdots$ & \\
\hline Chippewa County: & & & & & . \\
\hline $\begin{array}{l}\text { Neebish Island }{ }^{3} \text {.. } \\
\text { Clinton County: }\end{array}$ & 565 & & & & \\
\hline $\begin{array}{l}\text { St. Johns } \ldots \ldots \ldots \ldots \ldots \\
\text { Do. }{ }^{4} \ldots \ldots \ldots \\
\end{array}$ & $\begin{array}{r}1,200 \\
608\end{array}$ & & & & $\begin{array}{l}\text { Unsuccessful. } \\
\text { Waterworks well. }\end{array}$ \\
\hline $\begin{array}{l}\text { Crawford County: } \\
\text { Grayling...... }\end{array}$ & & & & & \\
\hline 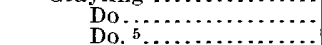 & 2,560 & 6 & & & ramy wens. \\
\hline $\begin{array}{l}\text { Delta County: } \\
\text { Escanaba }{ }^{\circ} \ldots \ldots \ldots \ldots \ldots \ldots \\
\end{array}$ & & & & & \\
\hline $\begin{array}{l}\text { Escanaba }{ }^{\circ} \cdot \ldots \ldots \ldots \\
\text { Eaton County: }\end{array}$ & 640 & & & & \\
\hline $\begin{array}{r}\text { Charlotte }{ }^{\top} \ldots \ldots \ldots \ldots \\
\text { Do } \ldots \ldots \ldots \ldots\end{array}$ & $\begin{array}{r}2,209 \\
730\end{array}$ & 6 & & -20 & \\
\hline $\begin{array}{l}\text { Emmet County: } \\
\text { Petoskey } \ldots . . . \ldots \ldots\end{array}$ & 100 & $10-8$ & 450 & \pm 18 & T amp $500^{\circ}$ \\
\hline Genesee County: & 56 & $10-5$ & $\$ 30$ & $\perp_{18}$ & $1 \geq$ mp., 50. \\
\hline Flint $8, \ldots \ldots \ldots$ & 1,200 & & & & $\begin{array}{l}\text { Salt well; fresh water at } \\
260 \text { feet. }\end{array}$ \\
\hline $\begin{array}{l}\text { Gladwin County: } \\
\text { Gladwin...... }\end{array}$ & 400 & 4 & & & \\
\hline Do....... & 400 & 6 & 100 & +24 & \\
\hline $\begin{array}{l}\text { Gratiot County: } \\
\text { Alma } 4 . \ldots . .\end{array}$ & 2,863 & & & -2 & \\
\hline $\begin{array}{l}\text { Ithaca } 10 \\
\text { St. Louis } i 1 . . .\end{array}$ & $\begin{array}{r}.637 \\
1,314\end{array}$ & 8 & 50 & -72 & $\begin{array}{l}\text { Several wells; good water. } \\
\text { Dep well. }\end{array}$ \\
\hline Hillsdale County: & & & & & \\
\hline $\begin{array}{l}\text { Hillsdale } 12 . \ldots \\
\text { Houghton Count } y:\end{array}$ & $1,350-1,550$ & & & & $B$-ine at 1,100 feet. \\
\hline $\begin{array}{l}\text { Houghton County: } \\
\text { Lake Linden ... }\end{array}$ & $1,502-1,508$ & $12-8$ & 100 & & \\
\hline $\begin{array}{l}\text { Huron County: } \\
\text { Caseville }\end{array}$ & $1,750-1,770$ & & & & Salt wells. \\
\hline $\begin{array}{r}\text { Do. }{ }^{13} \ldots \ldots \\
\text { Grindstone }\end{array}$ & $1,760-2,270$ & & & & Do. \\
\hline $\begin{array}{c}\text { Grindstone } \ldots \ldots \ldots \ldots \\
\text { Do. }{ }^{13} \ldots \ldots \ldots \ldots \\
\end{array}$ & (?) $\begin{array}{r}1,080 \\
1,000\end{array}$ & & & & $\begin{array}{l}\text { Abandoned. } \\
\text { Salt well. }\end{array}$ \\
\hline Harbor Beach $13 . . .$. & +702 & & & & Do. \\
\hline $\begin{array}{l}\text { New River }{ }^{13} \ldots \ldots \ldots \\
\text { Old Bay Port is } \ldots \ldots . . . .\end{array}$ & 1,029 & & & $\cdots$ & Do. \\
\hline Old Bay Port ${ }^{13} \ldots \ldots \ldots$ & 2,000 & & & & $\begin{array}{l}\text { Salt welt; never in opera- } \\
\text { tion. }\end{array}$ \\
\hline Pigeon River ${ }^{13}$.. & 1,760 & & & & $\begin{array}{l}\text { Pigeon River Furnace } \\
\text { Co.'s salt well (later } \\
\text { Lake Huron Iron Co.). }\end{array}$ \\
\hline Port Austin ${ }^{14}$. & $1,198-1,225$ & & & & $\begin{array}{l}\text { Salt wells; sweet water at } \\
336 \text { to } 1,100 \text { feet. }\end{array}$ \\
\hline $\begin{array}{l}\text { Port Crescent }{ }^{13} . \\
\text { Port Hope } 15\end{array}$ & 1,250 & & & & salt well. \\
\hline $\begin{array}{l}\text { Port Hope }{ }^{15} \ldots \ldots \ldots \ldots \ldots \\
\text { Sandbeach } 16 \ldots \ldots \ldots \ldots\end{array}$ & 787 & & … & …..... & Do. \\
\hline $\begin{array}{l}\text { Sandbeach }{ }^{16} \ldots \ldots \ldots \ldots \ldots \\
\text { Do. }{ }^{17} \ldots \ldots \ldots \ldots \ldots\end{array}$ & 702 & & & & Do. \\
\hline Verona Milils (neari is... & $\begin{array}{r}1,920 \\
400\end{array}$ & 55 & & $\cdots$ & For gas; unsuccessful. \\
\hline $\begin{array}{l}\text { Whiterock }{ }^{19} \ldots \ldots \ldots \\
\text { Ingham County: }\end{array}$ & $555-1,311$ & & & ... & Several salt wells. \\
\hline $\begin{array}{l}\text { Ingham County: } \\
\text { Lansing " } \\
\text { well." }\end{array}$ & 1,400 & & 1 & Flows. & S.aline water; temp., $58 \frac{1}{2}^{\circ}$. \\
\hline $\begin{array}{l}\text { Lansing Hotel........... } \\
\text { Lansing Reform School }\end{array}$ & 740 & & & & \\
\hline Mason (near) & 401,409 & & & & \\
\hline Meridian (near) 22 & 514 & & & & \\
\hline
\end{tabular}

${ }^{1}$ Mich. Geol. Surv. Rept., 1881-1898, vol. 5, part 2, p. 53.

Record, Ann. Rept. State Board of Geol. Surv. of Mich., 1901, pp. 230-231.

3 Record, ibid. p. 227.

4 Record, Mich. Geol. Surv. Rept., 1900-1903, vol. 8, part 2, p. 196.

5 Record, state Board of Geol. Surv. of Mich. 1901, pp. 231-232.

6 Ibid., pp. 228-229.

7 Record, Mich. Geol. Surv. Rept., 1881-1893, vol. 5 , part 2 , p. 53, pl. 8 .

8 Ibid., p. 58; 1873-1876, vol. 3, part 1, p. 97.

Gnalysis, ibid., pp. 45-16: [†. S. Geol. Surv.

Water-Sup. and Irr. Paper No. 31, p. 83; record,

Mich. Geol. Surv. Rept., 1900-1903, vol. 8, part 2, p. 175.

10 Record. ibid., pp. 63-64.

11 Mich. Geol. Surv. Rept., 1900-1903, vol. 8, part 2, p. 174
12 Record, ibid., 1881-1 993 , vol. 5, part 2, p. 62 : 1873-1876, vol. 3 , part 1 , F. 81

${ }^{13}$ Mich. Geol, Surv. Rept., 1896-1900, vol. 7, part $2, \mathrm{p}, 224$

14 Record, ibid., 1881-1893, vol. 5, part 2, pp. $75-$ 76 ; 1873-1876, vol. 3 , part 1 , pp. 77-78; analysis, p. 183.

16 Ibid., p. 76.

${ }_{16}$ Analysis, ibid. 1873-1876, vol. 3, part 1, p. 184

17 Record ibid., 1891-1893, vol. 5 , part 2 , pp. $81-82$ 18 Ibid., 1896-1900, vol. 7, part 2, pp. 175-176. 19 Mich. Geol. Surv. Rept., 1873-1876, vol. 3, part 1, pp. 76-77; analysis, p. 194; record, 1881-1893, vol. 5, part 2, p. 86; 1896-1900, vol. 7, part 2, p. 160 . ${ }_{20}$ Record, ibid., pp. $117-118$.

21 Ibia., 1900-1903, vol. 8, part 2, pp. 216, 217. 22 Ibid., p. 207. 
MICHIGAN-Continued,

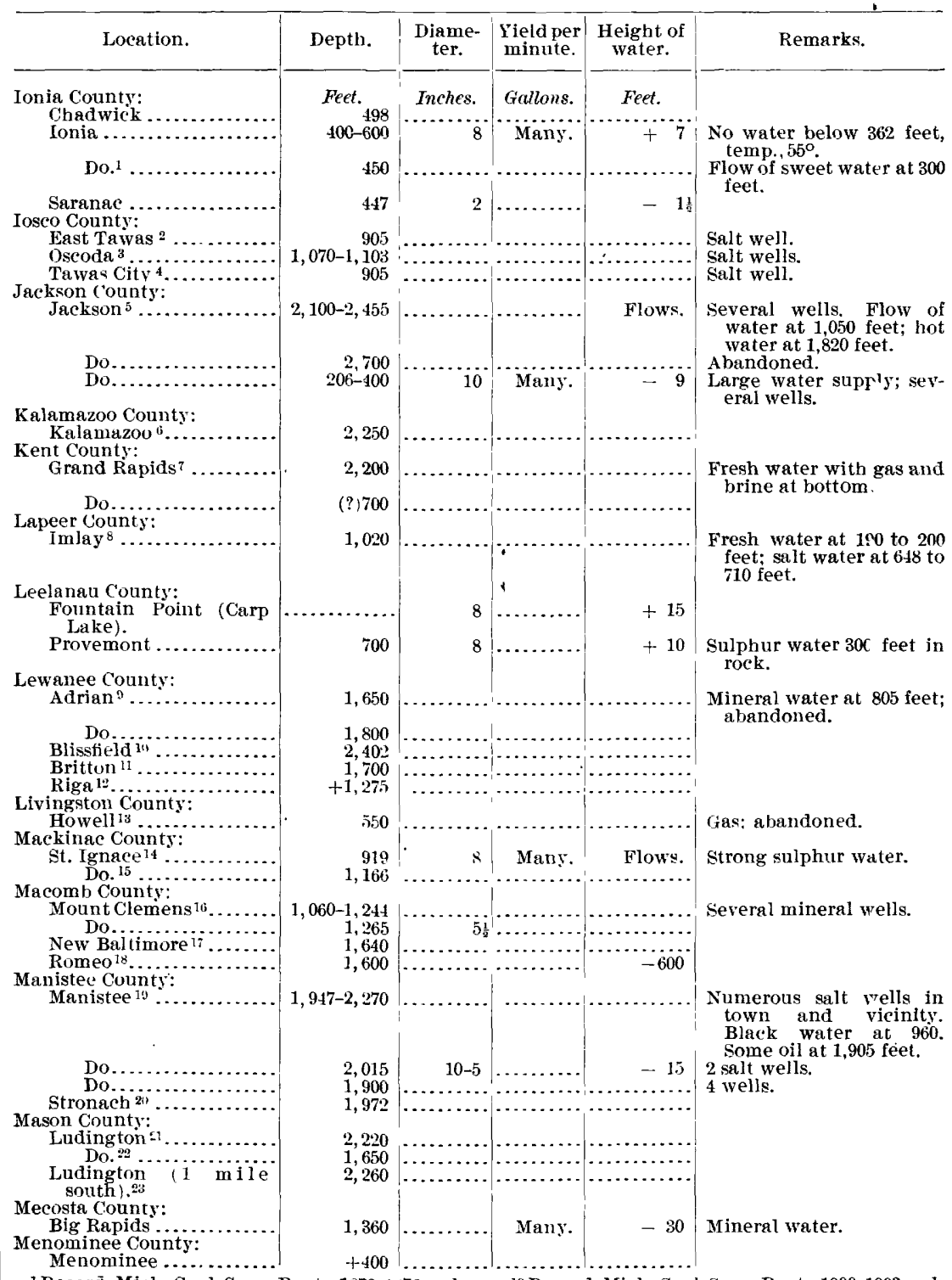

${ }^{1}$ Recorā, Mich. Geol. Surv. Rept., 1873-1876, vol.

3 , part 1, pp. 134-135.

Ibid., 1881-1893, vol. 5, part 2, p. 57; analysis, 1873-1876, vol. 3 , part 1 , p. 184.

3 Analysis, ibid., 1873-1876, vol. 3, part 1, p. 186.

4 Record, ibid., p. 79.

5 Ibid., 1881-1893, vol. 5, part 2, p. 65, pls. $23-25$.

Ibid., p. 65 , pl. 26.

7 Ibid., p. 61, pl. 20 .

8 Ibid., p. 63, pl. 22

9 Ibid., p. 44, pl. 1.

10 Record, Ann. Rept. State Board of Geol. Surv. of Mich., 1901, p. 219.

11 Ibid., pp. 219-220.

12 Ann. Rept. State Board of Geol, Surv. of Mich., 1901, p. 219.

${ }^{13}$ Record. Mich. Geol. Surv. Rept., 1900-1903, vol. 8 , part 2, p. 218

14 Ibid., 1881-1893, vol. 5, part 2, p. 79, pl. 63.

15 Record. Ann. Rept. State Board of Ge ol. Surv. of Mich., 1901, p. 228.

${ }_{16}$ Record and Analysis, Mich. Geol. Sur"7. Rept., 1881-1893, vol. 5, part 2, pp. 70-71, pl. 42 .

17 Record, Ann. Rept. State Board of Geol. Surv. of Mich., 1901, pp. 221-222.

${ }^{18}$ Record, Mich. Geol. Surv. Rept., 1881-189;,

voi. 5 , part 2 , p. 78 , pl. 59 .
${ }_{19}$ Ibid., p. 66 , pls. $30-32$ : Ann. Rept. State Board of Geol. Surv. of Mich., 1901, p. 235.

20 p. 84, pl. 65 .

21 Ibid., p. 66, pl. 27.

22 Ibid., p. 66 , pl. 29

23 Ibid., p. 66, [1. 28. 
MICHIGAN--Continued.

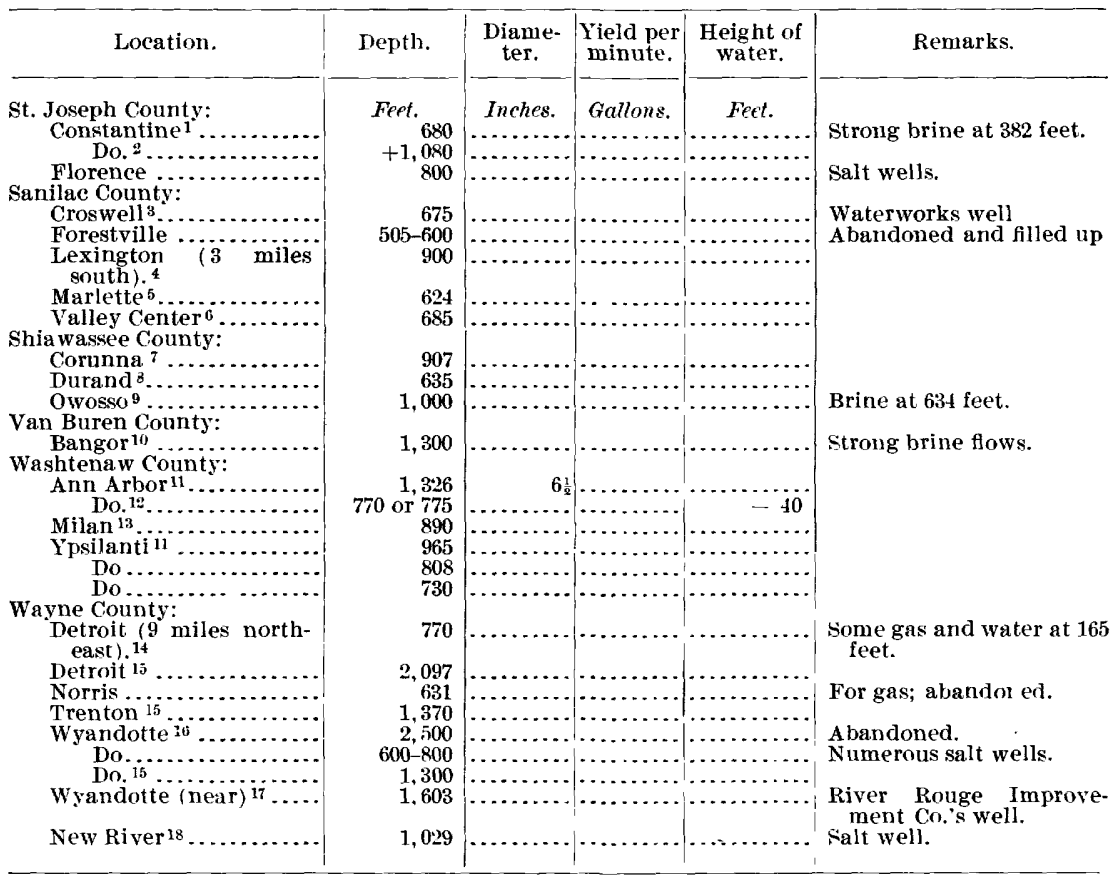

1 Record, Mich. Geol. Surv. Rept., 1873-1876, vol. 3, part 1, p. 93 .

'Ibid., 1881-1893, vol. 5, part 2, p. 54, pl. 11.

3 Ibid., 1896-1900, vol. 7, part 3, p. 11.

4 Ibid., p. 12.
5 Mich. Geol. Surv. Rept., 1896-1900, vol. 7, part 3, p. 30.

Record, ibid., p. 11

7 Ibid., 1881-1893, vol. 5, part 2, p. 54, pl. 12.

8 Ibid., 1900-1903, vol. 8, part 2, p. 199.

9 Ibid., 1873-1876, vol. 3, part 1, p. 97; 1881-1893, vol. 5, part 2, p. 78, pl. 45

${ }^{11}$ Ann. Rept. State Board of Geol. Surv. of Mich. 1901, p. 214 .
11 Record, ete., ibid., pp. 214-215.

12 Record, Mich. Geoil. Surv, Rept., 1881-1893, vol. 5 , part 2 , pp. 47-49; 1873-1876, vol. 3, part 1 , p. 92 . is Record, Ann. Rept. State Board of Geol. Surv. of Mich., 1901 , p. 219.

14 Record, Mich. Geol. Surv. Rept., 1881-1893, vol. 5 , part 2, p. 54, pl. 15 .

15 Record, Ann. Rept. State Board of Geol. Surv. 1901, p. 217.

10 Record, Mich. Geol. Surv. Rept., 1881-1893, vol. 5 , part 2, p. 87, pl. 66 .

17 Ibid., p. 218.

18 Record, Mich. Geol. Surv. Rept.. 1881-1893, vol. 5, part 2, p. 73; 1873-1876, vol.3, part 1, p. 77 .

\section{PUBLICATIONS RELATING TO DEEP BORINGS IN MICHIGAN.}

Geology of the lower Peninsula of Michigan, by C. Rominger: Michigan Geological Survey, vol. 3, part 1, 225 pages, New York, 1876.

The Geology of lower Michigan with reference to deep borings, etc., by A. C. Lane: Michigan Geological Survey, vol. 5, part 2, 100 pages, plates, Lansing, 1895.

Analyses of many of the well waters are to be found in "Lower Michigan I"ineral Waters," by A. C. Lane: U. S. Geological Survey Water-Supply and Irrigation Papers No. 31, Washington, 1899.

Water resources of the lower Peninsula of Michigan, by A. C. Lane: U. S. Geological Survey Water-Supply and Irrigation Papers No. 30, 97 pages, plates, Washington, 1899.

Geological report on Huron County, Michigan, by A. C. Lane: Geological Survey : Michigan, 1896-1900, vol. 7, part 2.

Coal of Michigan, by A. C. Lane: Geological Survey of Michigan, 1900-19 3, vol. ', part 2 .

Report of the State Board of Geological Survey of Michigan, for 1901, by A. C. ane. 
MINNESO'TA.

\begin{tabular}{|c|c|c|c|c|c|}
\hline Location. & Depth. & $\begin{array}{l}\text { Diame- } \\
\text { ter. }\end{array}$ & $\begin{array}{c}\text { Yield per } \\
\text { minute. }\end{array}$ & $\begin{array}{l}\text { Height of } \\
\text { water. }\end{array}$ & Remarks. \\
\hline $\begin{array}{l}\text { Bigstone County: } \\
\text { Graceville............ }\end{array}$ & Feet. ${ }_{460}$ & $\begin{array}{r}\text { Inches. } \\
8-6\end{array}$ & $\begin{array}{r}\text { Gallons. } \\
40\end{array}$ & Fect. 50 & 2 wells; granite at 510 feet. \\
\hline $\begin{array}{l}\text { Do } \\
\text { Blue Earth County: }\end{array}$ & 522 & & Several. & No flow. & \\
\hline Lake Crystal .............. & & & & -71 & \\
\hline Mankato ... & 2,204 & & & -90 & Unsuccessful. \\
\hline Do........... & 650 & $10,8,6$ & 500 to 80 & +40 & $\begin{array}{l}\text { Several wells; water fer- } \\
\text { ruginous. }\end{array}$ \\
\hline Mankato and vicinity... & $570-2,240$ & $6-8$ & & & $\begin{array}{l}\text { Several wells; in one the } \\
\text { water rises to }+28 \text { feet. }\end{array}$ \\
\hline Minneopa Falls ${ }^{1}$......... & 1,000 & $8-6$ & Many. & . & $\begin{array}{l}\text { Flow at } 540 \text { feet, and salty } \\
\text { water at } 940 \text { feet; granite } \\
\text { at } 940 \text { feet. }\end{array}$ \\
\hline $\begin{array}{l}\text { Carver Ciunty: } \\
\text { New Germany..... }\end{array}$ & 410 & & & & \\
\hline Chisago County: & $\$ 10$ & 5 & & & water at 100 teet only. \\
\hline $\begin{array}{l}\text { Wyoming..... } \\
\text { Clay County: }\end{array}$ & 505 & $8-6$ & Many. & -12 & \\
\hline Moorhead $2 . . .$. & 1,901 & & & & Water at 120,135 , and 370 \\
\hline Do. ${ }^{3} \ldots \ldots \ldots \ldots$ & 1,425 & & & & Water at 120 and 1,425 feet. \\
\hline 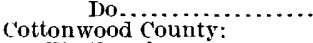 & 820 & & & +4 & \\
\hline Westbrook & 600 & & & & \\
\hline Crow Wing Coun & & & & & \\
\hline $\begin{array}{l}\text { Brainerd } \\
\text { Dakota County: }\end{array}$ & 647 & & & & \\
\hline Hastings ${ }^{4} \ldots \ldots \ldots \ldots$ & 1,160 & & 100 & +14 & Water slightly salty. \\
\hline $\begin{array}{l}\text { Lakeville } \ldots \ldots \ldots \ldots \ldots \ldots \\
\text { Mendota }{ }^{5}, \ldots \ldots \ldots \ldots\end{array}$ & $\begin{array}{r}1,085 \\
857\end{array}$ & & 10 & +10 & \\
\hline Dodge County: & oin & 4 & 10 & +10 & \\
\hline $\begin{array}{l}\text { Dodge Center......... } \\
\text { Hayfield ............. }\end{array}$ & 504 & 8 & & -88 & Railroad well. \\
\hline $\begin{array}{c}\text { Hayfield } \ldots \ldots \ldots \ldots \ldots \\
\text { Do................. }\end{array}$ & 530 & & None. & & \\
\hline Faribault County: & 515 & 10 & & & \\
\hline Blue Earth ...... & 1,300 & & & -30 & \\
\hline Do........ & 1,240 & & Many: & $\begin{array}{r}-30 \\
\times 200\end{array}$ & $\begin{array}{l}\text { First fiow at } 420 \text { feet: sec- } \\
\text { ond flow at } 425 \text { feet. }\end{array}$ \\
\hline $\begin{array}{l}\text { Fillmore County: } \\
\text { Fountain }\end{array}$ & & & & & \\
\hline Freeborn County: & 579 & 6 & 20 & -225 & \\
\hline Albert L & +660 & & & & \\
\hline Freebor & 950 & & & & Unsuccessful. \\
\hline $\begin{array}{l}\text { Goodhue County: } \\
\text { Red Wing } 6 \text {... }\end{array}$ & & & & +75 & \\
\hline Do.............. & $\begin{array}{r}500 \\
1,018\end{array}$ & 6 & 100 & $+7 b$ & Fows from $190-450$ feet. \\
\hline $\begin{array}{l}\text { Hennepin Cou } \\
\text { East Minn }\end{array}$ & 1,421 & & & & \\
\hline 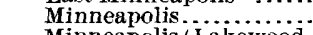 & 1,431 & & & & Seyeral wells unsuccess- \\
\hline $\begin{array}{l}\text { Minneapolis (Lakewood } \\
\text { Cemetery). } 8\end{array}$ & 2,150 & & & & fil \\
\hline $\begin{array}{l}\text { Minneapolis (West Ho- } \\
\text { tel). }{ }^{9}\end{array}$ & 622 & & 300 & -24 & Water at 168 feet. \\
\hline $\begin{array}{l}\text { Minneapolis (C.,"M. and } \\
\text { S.P. R. R. shops). }\end{array}$ & & & & & \\
\hline $\begin{array}{l}\text { Minneapolis (Soldiers' } \\
\text { Home). }\end{array}$ & & & & & \\
\hline $\begin{array}{l}\text { Home). } \\
\text { Minneapolis (Winslow }\end{array}$ & 1,421 & & & No flow. & Abandoned. \\
\hline $\begin{array}{l}\text { House) } \\
\text { Minneapolis .............. }\end{array}$ & & & & & \\
\hline $\begin{array}{r}\text { Minneapolis........ } \\
\text { Do............ }\end{array}$ & 60.2 900 & & Manv & -15 to -50 & \\
\hline Houston County: & & & Many. & $-15 t 0-50$ & \\
\hline & 590 & & 1,000 & +13 & \\
\hline Isanti County: & & & & & \\
\hline Dandiyo & 558 & & 200 & & \\
\hline Atwater .......... & 453 & $8-6$ & 100 & & Water-bearing strata at \\
\hline Kandiyohi . & 450 & & & & U'isuccessful. \\
\hline
\end{tabular}

1 Record, Minn. Geol. Surv. Bull. 5, Gas in Minnesota, pp. 23-24.

2 Report on Irrigation, 52d Congress, 1st session, Senate Ex. Doc. No. 41, part 2, 1893, pp. 72-74.

3 Record, Rept. Spec. Comm. U. S. Senate on Irrigation and Reclamation of Arid Lands, vol. 4, 1890, p. 48; Minn. Geol. Surv. Bull. 5, Gas in Minnesota, pp. $27-31$.

${ }^{4}$ Record, Minn. Geol. Surv., 13th Rept., 1884, pp. 56-57; analysis and record, Minn. Acad. Natural Seiences Bull., vol. 3, No. 1, pp. 137-141.

${ }^{5}$ Record, Minn. Acad. Natural Sciences Bull., vol. 3, No. 1, p. 141; Minn. Geol. Surv., 13th Rept., 1884, pp. 55, 56 .
${ }^{6}$ Ibid., p. 142; Minn. Geoi. Surv., 13th Rept., 1884, pp. 57-58.

${ }^{7}$ Record, Minn. Geol. Enrv. Rept., vol. 5, 1876, pp. 154-156.

Record, Minn. Acad. Natural Sciences Bull., vol. 3, No.1, pp. 137-138; Minn. Geol. Surv., 13th Rept., 1881, pp. 50, 54 .

9Analysis, ibid., p. 137; record, Minn. Geol. Surv., 14th Rept., 1885, p. 11.

${ }_{10}$ Record, Minn. Geol. Surv., 13th Rept., 1884, p. 59; Rept. Spec. Comm. U. S. Senate on Irrigation and Reclamation of Arid Lands, 1890, vol. 4, p. 48; Minn. Acad. Natural Sciences Bull., vol. 3, No. 1, p. 142 . 
MIN NESOTA-Continued.

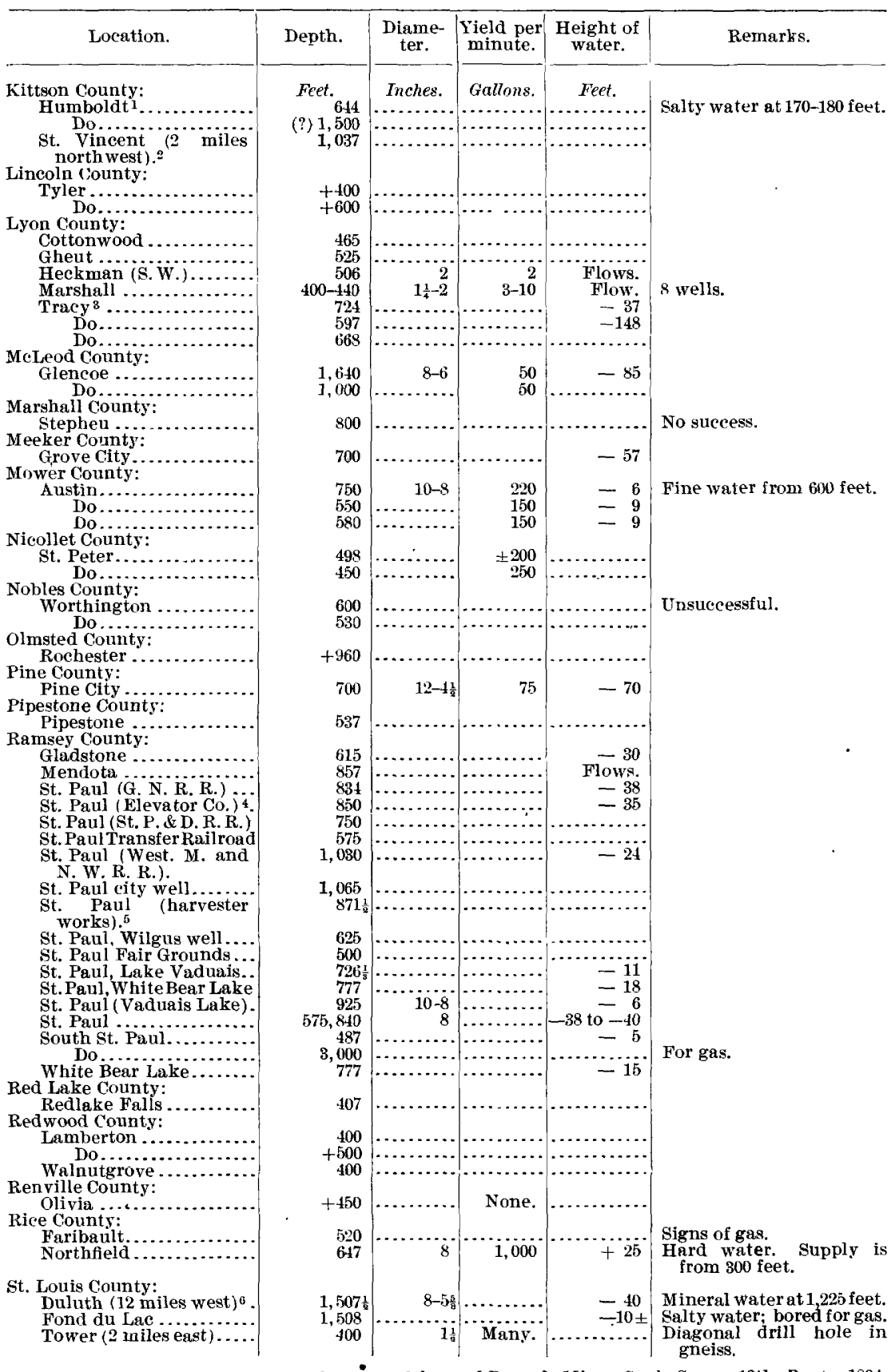

1 Record and analysis, Minn. Geol. Sưve, 13th Rept., 1884 , pp. $42-47$.

2 Record, ibid., 14th Rept., 1885, p. 15.

3 Ibid., pp. 351-352.

4 Ibid., 13th Rept., 1884, p. 63; Minn. Acad. Natural Sciences Bull., vol. 3, No. 1, p. 140.
5 Record, Minn. Geol. Surv., 13th R эpt., 1884, pp. 59-63; Minn. Acad. Natural Scienes Bull., vol. 3 No. 1, p. 140.

6 Ibid., Bull. 5, Gas in Minnesota, pp. 31-35. 
MIN NESO'TA-Continued.

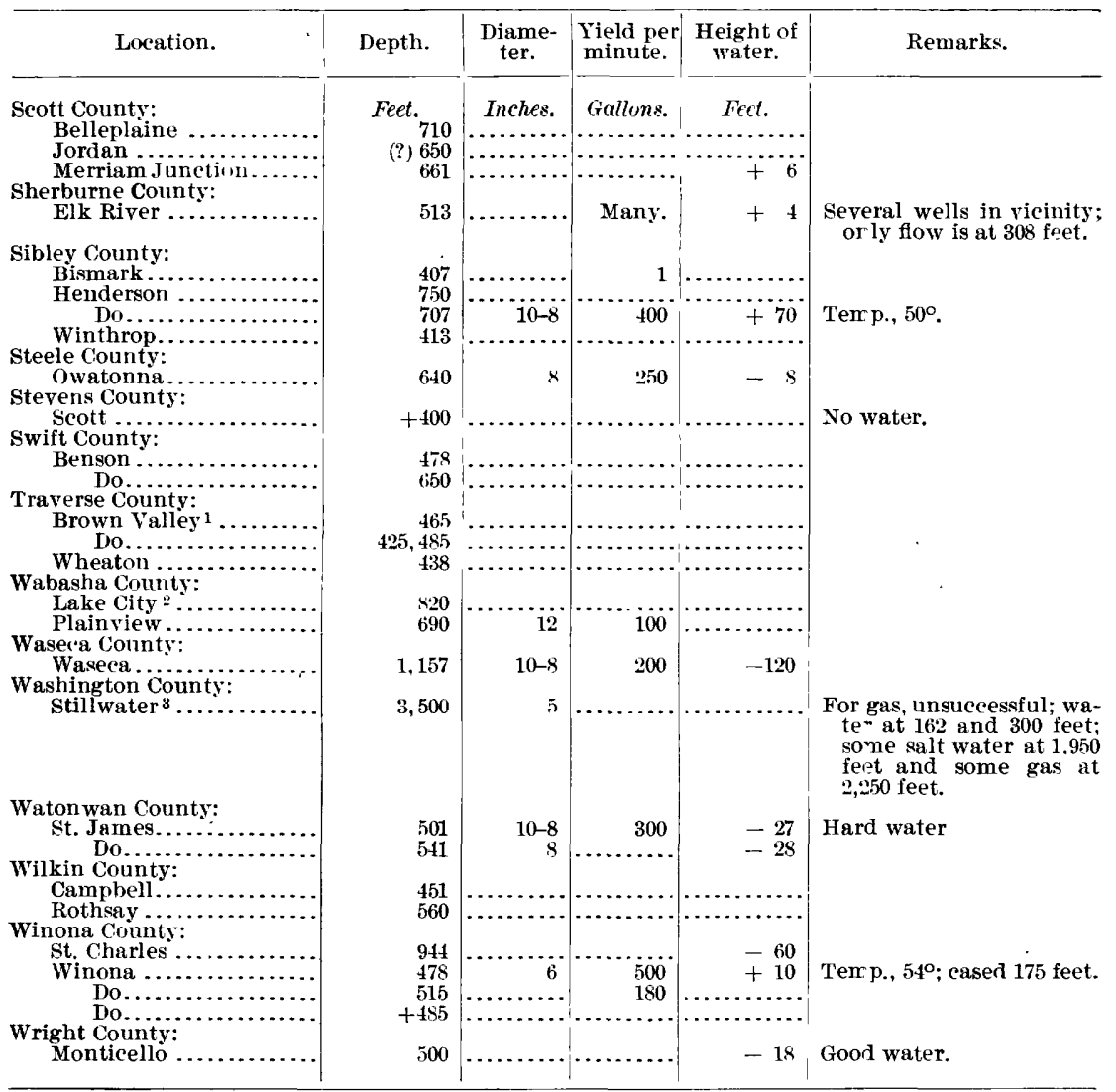

1 Record, Minn. Geol. Surv., 14th Rept., 1885. p. 14; Rept. Spec. Comm. U. S. Senate on Irrigation and Reclamation of Arid Lands, vol. 4, 1890, p. 48.
2 Ibid., 13th Rept., 1884, p. 58; Minn. Acad. Natural Sciences Bull, yol, 3 , No. 1, p. 142,

3 Ibid., Bull. 5, Gas in Minnesota, pp. 25-27; Am. Geol., vol. 3, p. 343 .

\section{PUBLICATIONS RELATING TO DEEP BORINGS IN MINNESOTA.}

Minnesota Geological Survey, Thirteenth Annual Report, for 1884, by N. H. Winchell, 196 pages, plates, St. Paul, 1884.

Minnesota Geological Survey, Fourteenth Annual Report, for 1885, part 1, by N. H. Winchell, 165 pages, St. Paul, 1886.

Minnesota Academy of Natural Sciences Bulletin, vol. 3, No. 1, Proceedings and Accompanying Papers, 1883-1886, by C. W. Hall, 160 pages, plates, Minneapolis, 1889.

Natural gas in Minnesota, by N. H. Winchell: Minnesota Geological Survey Bulletin No. 5, 39 pages, St. Paul, 1889.

Report of the Special Committee of the Tnited States Senate on the Irrigation and Reclamation of Arid Lands, vol. 4, 386 pages, Washington, 1890. 
MISSISSIPPI.

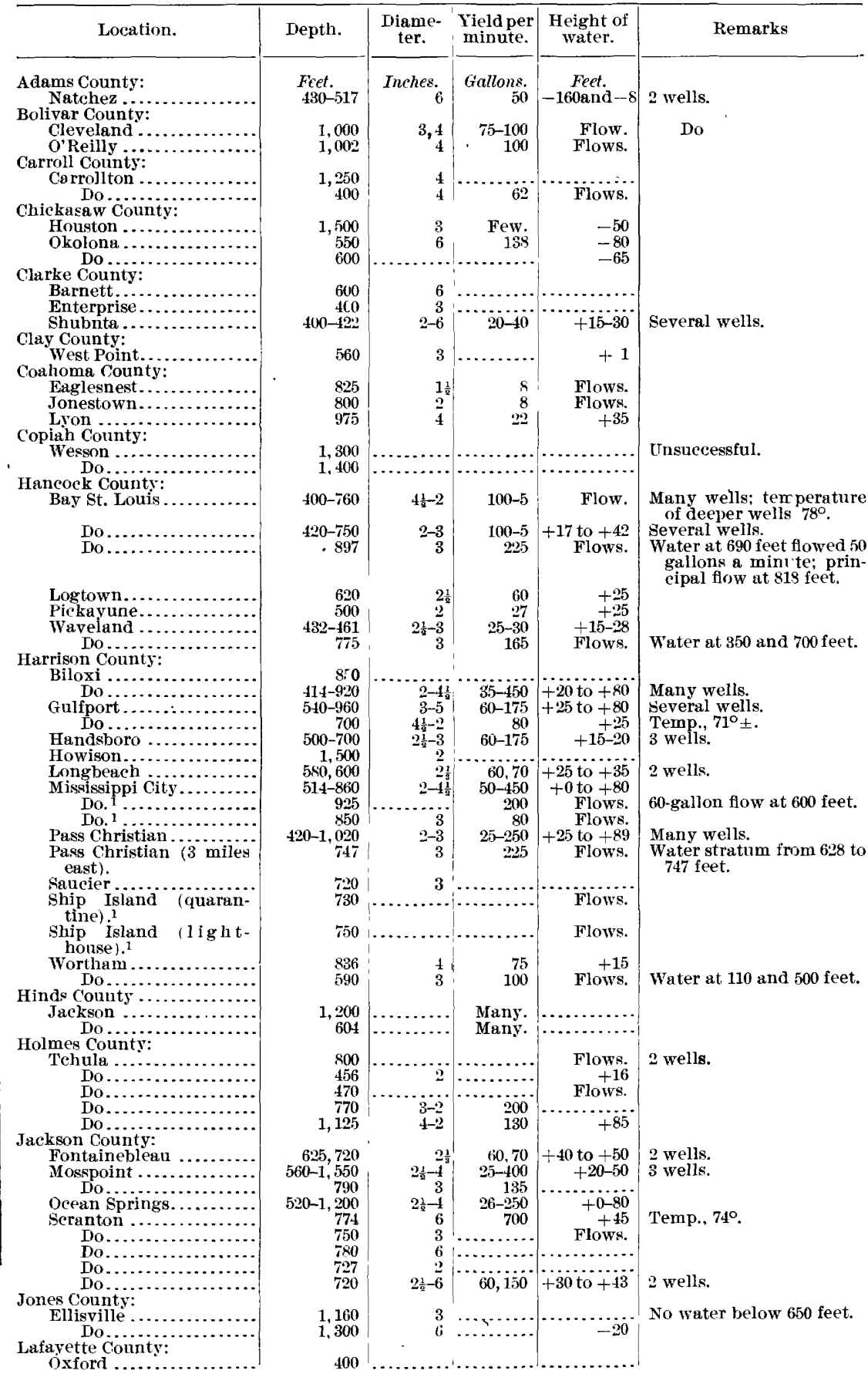

${ }^{1}$ La. Genl. Surv. Rept., 1902, p. 220. 
MISAISAIPPI - Continued.

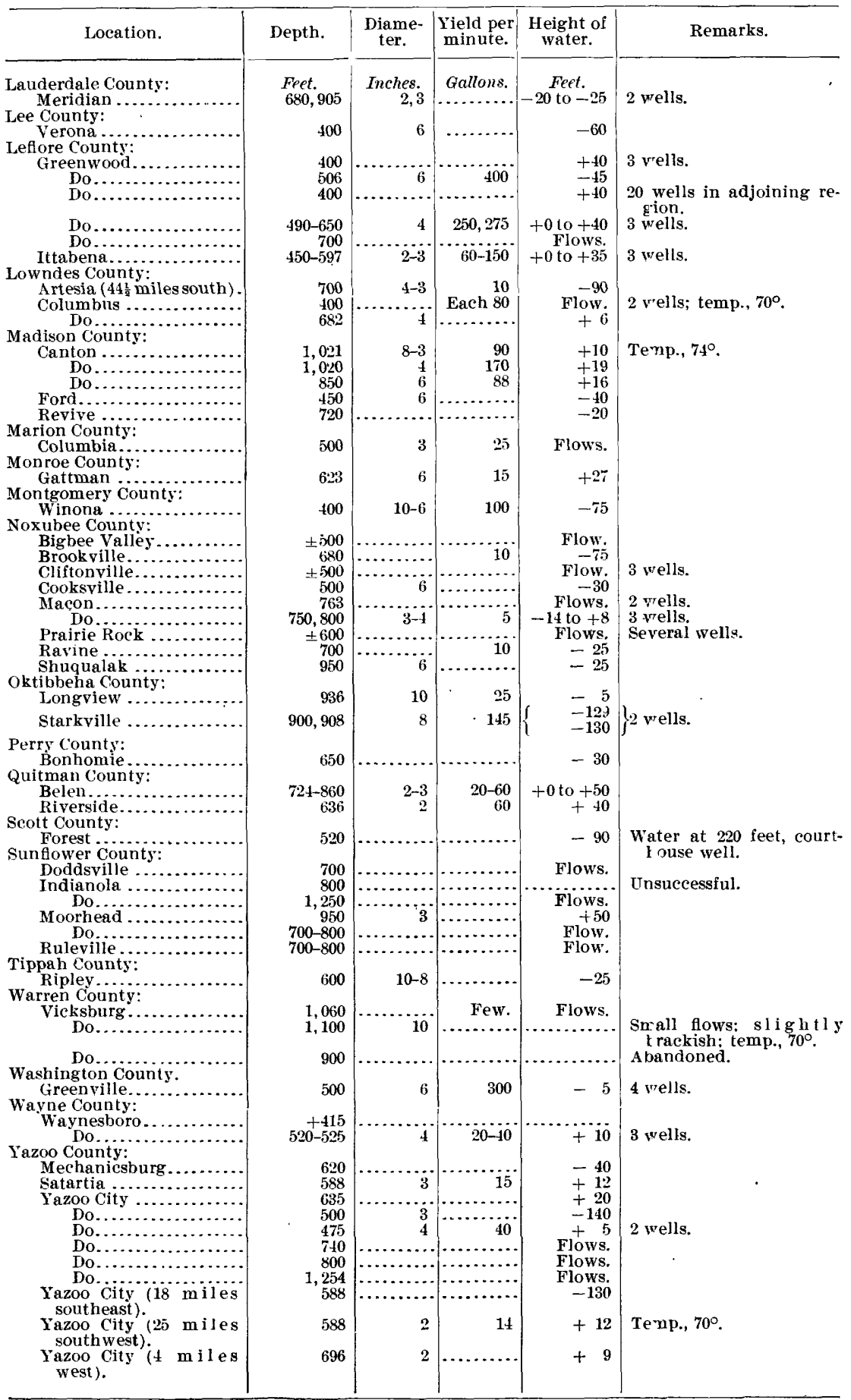


MISSOURI.

\begin{tabular}{|c|c|c|c|c|c|}
\hline Location. & Depth. & $\begin{array}{l}\text { Diame- } \\
\text { ter. }\end{array}$ & $\begin{array}{l}\text { Yield per } \\
\text { minute. }\end{array}$ & $\begin{array}{l}\text { Height of } \\
\text { water. }\end{array}$ & Remerks. \\
\hline $\begin{array}{l}\text { Adair County: } \\
\text { Kirksville.... }\end{array}$ & $\begin{array}{l}\text { Feet. } \\
\quad 1,300\end{array}$ & Inches. & Gallons. & Feet. & \\
\hline $\begin{array}{l}\text { A tehison Connty: } \\
\text { Roekport ...... }\end{array}$ & 1,300 & $\ldots \ldots \ldots$ & & $\rightarrow 16$ & $\begin{array}{l}\text { Prospect hola for coal; } \\
\text { water at } 143 \text { feet. }\end{array}$ \\
\hline 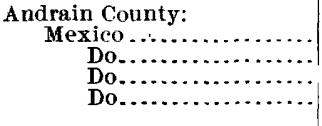 & $\begin{array}{r}588 \\
1,125 \\
1,100 \\
\pm 1,800\end{array}$ & $\begin{array}{l}8 \\
8 \\
5 \\
5\end{array}$ & $\begin{array}{r}10 \\
70 \\
\cdots\end{array}$ & $\begin{array}{l}-100 \\
-80 \\
-8\end{array}$ & $\begin{array}{l}\text { For oil or gas, unsuccess- } \\
\text { ful. Salt water. }\end{array}$ \\
\hline $\begin{array}{l}\text { Barry County: } \\
\quad \text { Monett } \ldots \ldots \ldots \ldots \ldots \\
\text { Barton County: }\end{array}$ & 415 & & $\cdots$ & -155 & \\
\hline 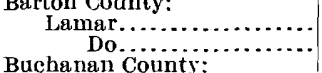 & $\begin{array}{r}1,000 \\
+2,000\end{array}$ & 6 & Many. & $\begin{array}{l}-150 \\
-\cdots+1\end{array}$ & Good water; abandoned. \\
\hline 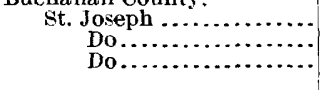 & $\begin{array}{l}1,600 \\
1,300 \\
1,805\end{array}$ & $\begin{array}{l}6 \\
6 \\
6\end{array}$ & ( & & $\begin{array}{l}\text { Prospect for coal. } \\
\text { Do. } \\
\text { Temp., } 82^{\circ} \text {; water min- } \\
\text { eral. }\end{array}$ \\
\hline $\begin{array}{l}\text { St. Joseph (5 miles east) - } \\
\text { Butler County: }\end{array}$ & 500 & 6 & Few. & & \\
\hline $\begin{array}{l}\text { Poplarbluff .................. } \\
\text { Caldwell County: }\end{array}$ & 600 & $8-6$ & ......... & -10 & \\
\hline 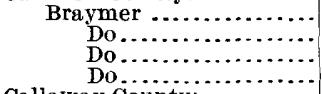 & $\begin{array}{r}457 \\
+1,350 \\
? 500 \\
1,100\end{array}$ & $\begin{array}{ll}\cdots \cdots \\
\cdots \cdots\end{array}$ & Many. & - 30 & \\
\hline $\begin{array}{l}\text { Callaway County: } \\
\text { Cedar City } \ldots \ldots \ldots \ldots \ldots \ldots \\
\text { Fulton } \ldots \ldots \ldots \ldots \ldots \ldots\end{array}$ & $\begin{array}{r}1,282 \\
750\end{array}$ & $\begin{array}{r}10 \\
8\end{array}$ & Many, & $\begin{array}{l}\text { Flows. } \\
-70\end{array}$ & . \\
\hline $\begin{array}{l}\text { Cape Girardeau County: } \\
\text { Appleton } \ldots \ldots \ldots \ldots \ldots \\
\text { Jackson } \ldots \ldots \ldots \ldots \ldots\end{array}$ & $\begin{array}{r}1,295 \\
531\end{array}$ & $4 \frac{1}{2}$ & Many. & $-\cdots$ & Sulphur water; not in use. \\
\hline $\begin{array}{l}\text { Carroll County: } \\
\quad \text { Ludlow } \ldots \ldots \ldots \ldots \ldots \ldots \ldots \\
\quad \text { Tina } \ldots \ldots \ldots \ldots \ldots \ldots \ldots\end{array}$ & $\begin{array}{l}495 \\
675\end{array}$ & & & & \\
\hline $\begin{array}{l}\text { Cass County: } \\
\text { Lonetree .... }\end{array}$ & 1,000 & & & & \\
\hline $\begin{array}{l}\text { Cedar County: } \\
\text { Eldorado Springs.... }\end{array}$ & 1,400 & 8 & & -28 & Sulphur water. \\
\hline $\begin{array}{l}\text { Chariton County: } \\
\text { Brunswick }{ }^{1} \ldots \ldots \ldots .\end{array}$ & 1,505 & $6-4$ & 7 & Flows. & Mineral water. \\
\hline $\begin{array}{l}\text { Clay County: } \\
\text { Excelsior Springs.. }\end{array}$ & $1,370-1,460$ & & & & \\
\hline $\begin{array}{l}\text { Cole County: } \\
\text { Jefferson City ..... }\end{array}$ & 1,365 & & & & \\
\hline $\begin{array}{l}\text { Cooper County: } \\
\text { Booneville } . . . \ldots \ldots \ldots \ldots . . .\end{array}$ & 403 & 6 & & -78 & $\begin{array}{l}\text { Water strongly mineral; } \\
\text { abandoned. }\end{array}$ \\
\hline $\begin{array}{l}\text { Crawford County: } \\
\text { Sullivan (5 miles south). }\end{array}$ & 1,200 & & & Tosurface. & $\begin{array}{l}\text { Water also at } 20,240 \text {, and } \\
800 \text { feet. }\end{array}$ \\
\hline $\begin{array}{l}\text { Dunklin County: } \\
\text { Campbell.... }\end{array}$ & 910 & 4 & 7 & +10 & con \\
\hline $\begin{array}{l}\text { Greene County: } \\
\text { Springfield }\end{array}$ & 755 & 6 & 750 & & Water at $610-620$ feet. \\
\hline $\begin{array}{l}\text { Grundy County: } \\
\text { Trenton ....... }\end{array}$ & 740 & & Many. & & \\
\hline $\begin{array}{l}\text { Harrison County: } \\
\text { Bethan } y . . . . .\end{array}$ & 654 & $3 \frac{1}{8}$ & 5 & Flows. & Temp., $47^{\circ}$. \\
\hline 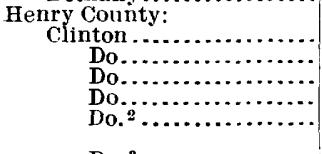 & $\begin{array}{l}650 \\
850 \\
900 \\
900 \\
800\end{array}$ & $\begin{array}{r}8 \\
8 \\
10 \\
6 \\
8-5 \\
8\end{array}$ & $\begin{array}{l}200 \\
175 \\
400 \\
125 \\
400\end{array}$ & $\begin{array}{l}+20 \\
+20 \\
+20 \\
+20 \\
+10\end{array}$ & $\begin{array}{l}\text { Water also at } 310 \text { and } 425 \\
\text { feet. }\end{array}$ \\
\hline $\begin{array}{c}\text { Do. }^{3} \ldots \ldots \ldots \ldots \ldots \ldots \\
\text { Howard County: } \\
\text { Boonslick }{ }^{4} \ldots \ldots \ldots \ldots \ldots \ldots\end{array}$ & $\begin{array}{r}913 \\
1,008 \\
900\end{array}$ & $\begin{array}{c}3 \\
\cdots\end{array}$ & $\begin{array}{r}2,700 \\
\text { Many. }\end{array}$ & $\cdots$ & Temp., $64^{\circ}$ \\
\hline $\begin{array}{l}\text { Howell County: } \\
\text { Mountainview .............. }\end{array}$ & 645 & 6 & & -509 & - \\
\hline $\begin{array}{l}\text { Westplains } \\
\text { Iron County: } \\
\text { Annapolis (near) } . . . \ldots \ldots\end{array}$ & $\begin{array}{r}575 \\
663-400\end{array}$ & 10 & 100 & -40 & Several prospect holes. \\
\hline $\begin{array}{l}{ }^{1} \text { Analysis, Mo. Geol. Surv. } \\
2 \text { Ibid., pp. 85-87, 118-119. }\end{array}$ & vol. 3 & & $\begin{array}{l}\text { s Ibid., } \\
4 \text { Ibid., }\end{array}$ & op. $120-121$. & . \\
\hline
\end{tabular}


MISSOURI-Continued.

\begin{tabular}{|c|c|c|c|c|c|}
\hline Location. & Depth. & $\begin{array}{l}\text { Diame- } \\
\text { ter. }\end{array}$ & $\begin{array}{l}\text { Yield per } \\
\text { minute. }\end{array}$ & $\begin{array}{l}\text { Height of } \\
\text { water. }\end{array}$ & Remarks. \\
\hline $\begin{array}{l}\text { Jackson County: } \\
\text { Kansas City } \\
\end{array}$ & $\begin{array}{l}\text { Feet. } \\
1,000-425\end{array}$ & $\begin{array}{l}\text { Inches. } \\
\text {.......... }\end{array}$ & $\begin{array}{l}\text { Gallons. } \\
\text {............ }\end{array}$ & $\begin{array}{l}\text { Feet. } \\
\quad \mathbf{3} 0\end{array}$ & $\begin{array}{l}\text { Several test borings for } \\
\text { gas: water from } 380-390 \\
\text { feet, } 590 \text { feet, and } 995 \\
\text { feet; braekdish and sul- } \\
\text { ph"r water. }\end{array}$ \\
\hline 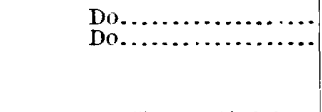 & $1,000-1,6222$ & & & & $\begin{array}{l}\text { Temo., } 65^{\circ} \text {; principal wa- } \\
\text { ter supply at } 815 \text { feet; } \\
\text { wa ter also at } 86 \text { and } 900 \\
\text { feet. }\end{array}$ \\
\hline Kansas City (Swift & & & & -119 & \\
\hline $\begin{array}{l}\text { Lisle.................... } \\
\text { Jasper County: }\end{array}$ & 405 & & & ........... & No vater. \\
\hline $\begin{array}{r}\text { Carterville } . . . \\
\text { Do......... } \\
\text { Do..... }\end{array}$ & $\begin{array}{l}643 \\
800 \\
799\end{array}$ & $\begin{array}{l}6 \\
5 \\
5\end{array}$ & $\begin{array}{r}\text { Many. } \\
10 \\
15\end{array}$ & $\begin{array}{l}-70 \\
-140 \\
-115\end{array}$ & \\
\hline Carthage ${ }^{-. .}$ & 2,005 & $S_{\frac{6}{8}}$ & & & To granite. \\
\hline Do......... & 1,800 & 8 & & & \\
\hline Joplin .......... & 1,375 & 6 & $\begin{array}{l}30 \\
80\end{array}$ & $\begin{array}{l}-80 \\
-80\end{array}$ & Ferruginous water. \\
\hline $\begin{array}{l}\text { Do............ } \\
\text { Do........ }\end{array}$ & $\begin{array}{r}1,400 \\
908\end{array}$ & $\begin{array}{l}b \\
6 \frac{5}{4}\end{array}$ & 170 & $\begin{array}{l}-80 \\
-120\end{array}$ & \\
\hline Prosperity...... & 998 & $10-6$ & 50 & -115 & \\
\hline Webb City.... & 500 & 78 & $\cdots \cdots$ & -20 & Several water horizons. \\
\hline 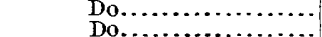 & 827 & 10 & +8 & $\begin{array}{l}-75 \\
-100\end{array}$ & \\
\hline Laclede County: & & & & & \\
\hline Lebanon ${ }^{3}$... & 1,002 & 8 & 1 & -200 & Water at 135 and 750 feet. \\
\hline Do.......... & 453 & $6 \frac{1}{4}$ & $\begin{array}{l}35 \\
35\end{array}$ & $\cdots, \cdots$ & Water at 380 and 420 feet. \\
\hline Lafayette County: & 1,000 & 6 & Many. & -360 & \\
\hline Concordia & +200 & & & & \\
\hline $\begin{array}{l}\text { Higginsville. } \\
\text { Lewis County: }\end{array}$ & 1,512 & $12-5$ & 30 & -80 & \\
\hline Lagrange 4 .. & 840 & & 60 & & Brackish. \\
\hline Do....... & 850 & 8 & Several. & Flows. & \\
\hline $\begin{array}{l}\text { Linn County: } \\
\text { Brooktield.... }\end{array}$ & 451 & & & -200 & \\
\hline Do........ & 570 & & Many. & & \\
\hline Livingston County: & & & & & \\
\hline A valon ........ & 406 & $\cdots \cdots$ & Few. & -60 & \\
\hline $\begin{array}{l}\text { Avalon (northeast of ) } \ldots \\
\text { Cavendish............... }\end{array}$ & $\begin{array}{l}700 \\
400\end{array}$ & (n....... & $\begin{array}{l}\text { Few. } \\
\text { None. }\end{array}$ & n........ & \\
\hline Chillicothe .......... & 700 & $\cdots \cdots$ & & & No water. \\
\hline Do...... & 539 & & Many. & -90 & \\
\hline Do. & 481 & & 2 & Flows. & \\
\hline Do. & 1,101 & $\cdots \cdots$ & $\cdots \ldots \ldots$ & -70 & \\
\hline Do......... & $\begin{array}{r}515 \\
+700\end{array}$ & & & ............ & Very little water. \\
\hline 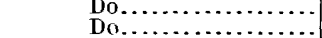 & $\begin{array}{r}+700 \\
469\end{array}$ & (n...... & $\begin{array}{l}\text { Many. } \\
\text { Many. }\end{array}$ & $\begin{array}{l}-8 \\
\ldots 90\end{array}$ & \\
\hline Dawn ................ & +433 & & Many. & -65 & \\
\hline Dawn (near) ..... & 421 & (n....... & Few. & Flows. & \\
\hline Springhill (near)......... & 414 & ….......ii & e........ & -70 & \\
\hline McDonald County: & 42 & & several. & & \\
\hline Galbraith $S_{1}$ iring 5 & 804 & & Many. & & \\
\hline Lanahan ..... & 1,428 & 6 & ธิ0 & Flows. & sulphur water. \\
\hline Madison County: & & & & Flows & \\
\hline $\begin{array}{l}\text { Mine Lamotte. } \\
\text { Maries County: }\end{array}$ & 670 & 2 & 4 & Flows. & \\
\hline $\begin{array}{l}\text { Maries county: } \\
\text { Steen Prairie }\end{array}$ & & & & & \\
\hline $\begin{array}{l}\text { Marion County: } \\
\quad \text { Philadelphia ............. }\end{array}$ & $470,55 \%$ & & 300 & -6 & 2 we'ls; much water, little \\
\hline Hannibal... & 1,340 & & & & \\
\hline Mercer County: & 537 & & None & & \\
\hline Princeton ................... & $\begin{array}{l}101 \\
501\end{array}$ & ......... & $\begin{array}{l}\text { None. } \\
\text { None. }\end{array}$ & & \\
\hline Topsy $\ldots \ldots \ldots \ldots \ldots \ldots$ & +400 & & & & \\
\hline Miller County: & & & & & \\
\hline 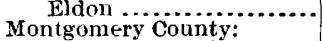 & 595 & & & -80 & \\
\hline Montgomery City ....... & 1,500 & $10-5 \frac{5}{6}$ & & -30 & \\
\hline $\begin{array}{l}\text { Do.................................. } \\
\text { Newton County: }\end{array}$ & 600 & 6 & 70 & & Temo., $58^{\circ}$. \\
\hline Diamond.... & & & & & \\
\hline Granby (sec. 6)... & 876 & 8 & 600 & -40 & \\
\hline Racine (4 miles $\mathrm{n}$ & 1,244 & 9 & & -80 & \\
\hline
\end{tabular}

1 Analysis, U. S. Geol. Surv., 17th Ann. Rept., part $2,1895-96$, p. 827 .

2 Record, Mo. Genl. Surv. Rept., vol 7, p. 405.

${ }^{3}$ Record, Geol. Mo., by Broadhead, part 2, p. 86.
${ }^{4}$ Analysis, Mo. Geol. Surv. Rept., vol. 3, pp. 141-143.

Ilbid., pp. 117-118. 
MISSOURI-Continued.

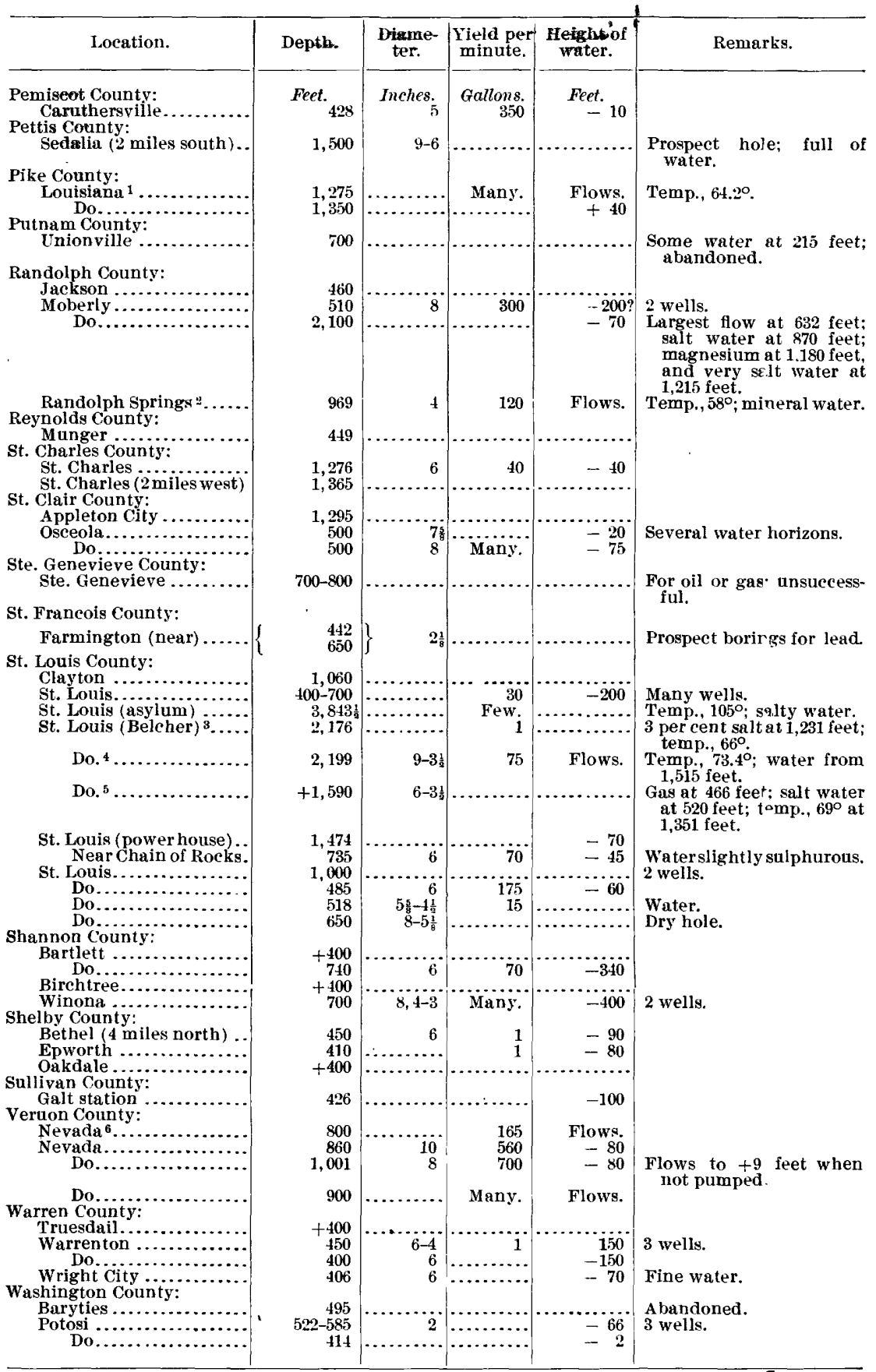

1 Record and analysis, Geol. Mo., by Broadhead, part 2, p. 86.

2 Analysis, Mo. Geol. Surv. Rept., vol. 3, pp. 73-74.

3 Ibid., pp. 79-81.
4 Analysis and record, St. Louis Acad. Sci. Trans., vol. 1, pp. 80-86, pl. 5 .

5 Record,Am.Jour.Sci, 2d ser., vol.15, pp.460-461. 6 Analysis, Mo. Geol. Surv. Rept., vol. 3, pp. 121- 


\section{PRINCIPAL PUBLICATIONS RELATING TO DEEP BORINGS IN MISSOURI.}

Report on the mineral waters of Missouri, by Paul Schweitzer: Missouri Geological Survey, 1890-1892, vol. 3, 256 pages, Jefferson City, 1892.

MONTANA.

\begin{tabular}{|c|c|c|c|c|c|}
\hline Lociation. & Depth. & $\begin{array}{l}\text { Diame- } \\
\text { ter. }\end{array}$ & $\begin{array}{l}\text { Tield per } \\
\text { minute. }\end{array}$ & $\begin{array}{l}\text { Height of } \\
\text { water. }\end{array}$ & Remarks. \\
\hline $\begin{array}{l}\text { Carbon County: } \\
\quad \text { Bridger (near) ...... }\end{array}$ & $\begin{array}{l}\text { Feet. } \\
\qquad 1,500\end{array}$ & $\begin{array}{l}\text { Inches. } \\
11-4 \frac{8}{4}\end{array}$ & Gallons. & $\begin{array}{l}\text { Fєt. } \\
\text {. }\end{array}$ & $\begin{array}{l}\text { In progress: b rackish } \\
\text { water at } 450 \text { feet that } \\
\text { came to top of well; } \\
\text { flows at } 1,000 \text { and } 1,500 \\
\text { feet, which come to top } \\
\text { o well; water at } 1,500 \\
\text { feet; strongly charged } \\
\text { with sulphuretted hy- } \\
\text { drogen gas. }\end{array}$ \\
\hline $\begin{array}{l}\text { Cascade County: } \\
\text { Great Falls... }\end{array}$ & +500 & & & & $\begin{array}{l}\text { In progress; gas at } 300 \\
\text { feet; indications of oil } \\
\text { farther down. }\end{array}$ \\
\hline $\begin{array}{l}\text { Chouteau County: } \\
\text { Chinook }{ }^{1} \ldots \ldots \ldots \ldots \ldots\end{array}$ & 956 & & & -50 & $\begin{array}{l}\text { Water also at } 112,220,540, \\
\text { and } 620 \text { feet. }\end{array}$ \\
\hline Fort Assinniboine ........ & 1,950 & & & & $\begin{array}{l}\text { Sma.l flow of gas; no } \\
\text { water below } 65 \text { feet; all } \\
\text { clay. }\end{array}$ \\
\hline Fort Benton ............... & 502 & & & & $\begin{array}{l}\text { Small flow of gas at } 300 \\
\text { feet: indications of oil } \\
\text { at } 502 \text { feet. }\end{array}$ \\
\hline Miles City & 472 & $4-2 \frac{1}{2}$ & 13 & $\begin{array}{l}\text { Flows. } \\
\text { Flows. }\end{array}$ & \\
\hline Do.................... & 481 & $4-2 \frac{1}{2}$ & .... & Flows. & \\
\hline $\begin{array}{r}\text { Do... } \\
\text { Miles City (court-houne). }\end{array}$ & $\begin{array}{l}456 \\
509\end{array}$ & $\begin{array}{l}4-2 \frac{1}{4} \\
4-2 \frac{1}{1}\end{array}$ & : & Flows. & \\
\hline Miles City & 456 & & 5 & $\begin{array}{r}\text { S10ws. } \\
+16\end{array}$ & Temp., $57^{\circ}$. \\
\hline Do.......... & 535 & & 2 & & \\
\hline $\begin{array}{l}\text { Miles City ( } 35 \text { miles west) } \\
\text { Miles City . .............. }\end{array}$ & 420 & $4-2 \frac{1}{2}$ & & Flows. & \\
\hline $\begin{array}{l}\text { Miles City } \\
\text { Do } \ldots \ldots\end{array}$ & $\begin{array}{r}452-514 \\
179\end{array}$ & $\dddot{9-2} \frac{i}{2}$ & & $\begin{array}{l}\text { Flow. } \\
\text { Flow. }\end{array}$ & 5 wells. \\
\hline $\begin{array}{l}\text { Miles City }(10 \mathrm{n} \\
\text { Miles City }\end{array}$ & 553 & ..... & ........ & Flows. & \\
\hline $\begin{array}{l}\text { Miles City (Re form } \\
\text { School). }\end{array}$ & 507 & $\cdots \cdots$ & & Flows. & \\
\hline $\begin{array}{l}\text { Rosebud.............................. } \\
\text { Dawson County: }\end{array}$ & $4 \times 5-502$ & $4-2 \frac{1}{2}$ & & Flows. & 3 wells. \\
\hline Dawson County: & 500 & & & & Unsuccessful. \\
\hline $\begin{array}{l}\text { Flathead County: } \\
\text { Kintla Lake (near) ....... }\end{array}$ & 1,405 & & & & $\begin{array}{l}\text { Strong flow of water and } \\
\text { gas necessitated discon- } \\
\text { tnuance of drilling un- } \\
\text { ti heavier tools could } \\
\text { ke procured. }\end{array}$ \\
\hline $\begin{array}{l}\text { Gallatin County: } \\
\quad \text { Bozeman ............... }\end{array}$ & 600 & & & & Bomed for oll; unsuccess- \\
\hline 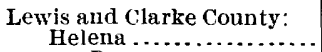 & 1,002 & & & & \\
\hline Do..... & 1,023 & & & & Good flow; abandoned. \\
\hline Teton County. & 900 & & & -100 & \\
\hline , Chief Mountain Lake... & 1,200 & & & & $\begin{array}{l}\text { Lubricating oil well, } 30 \\
\text { karrels a day; just north } \\
\text { cf United States bound- } \\
\text { ary line. }\end{array}$ \\
\hline 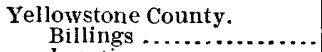 & $\mathrm{I}, 000$ & & & & All in shale \\
\hline Junction & 500 & & & Flows. & Small flow also at 144 feet. \\
\hline
\end{tabular}

${ }^{1}$ Report on Irrigation, $52 d$ Cong., 1st sess., Senate $\quad z$ Record, ibid., pp. $73,94$. Ex. Doc. 41, part 2, 1893, pp. 72-73. 
NEBRASKA.

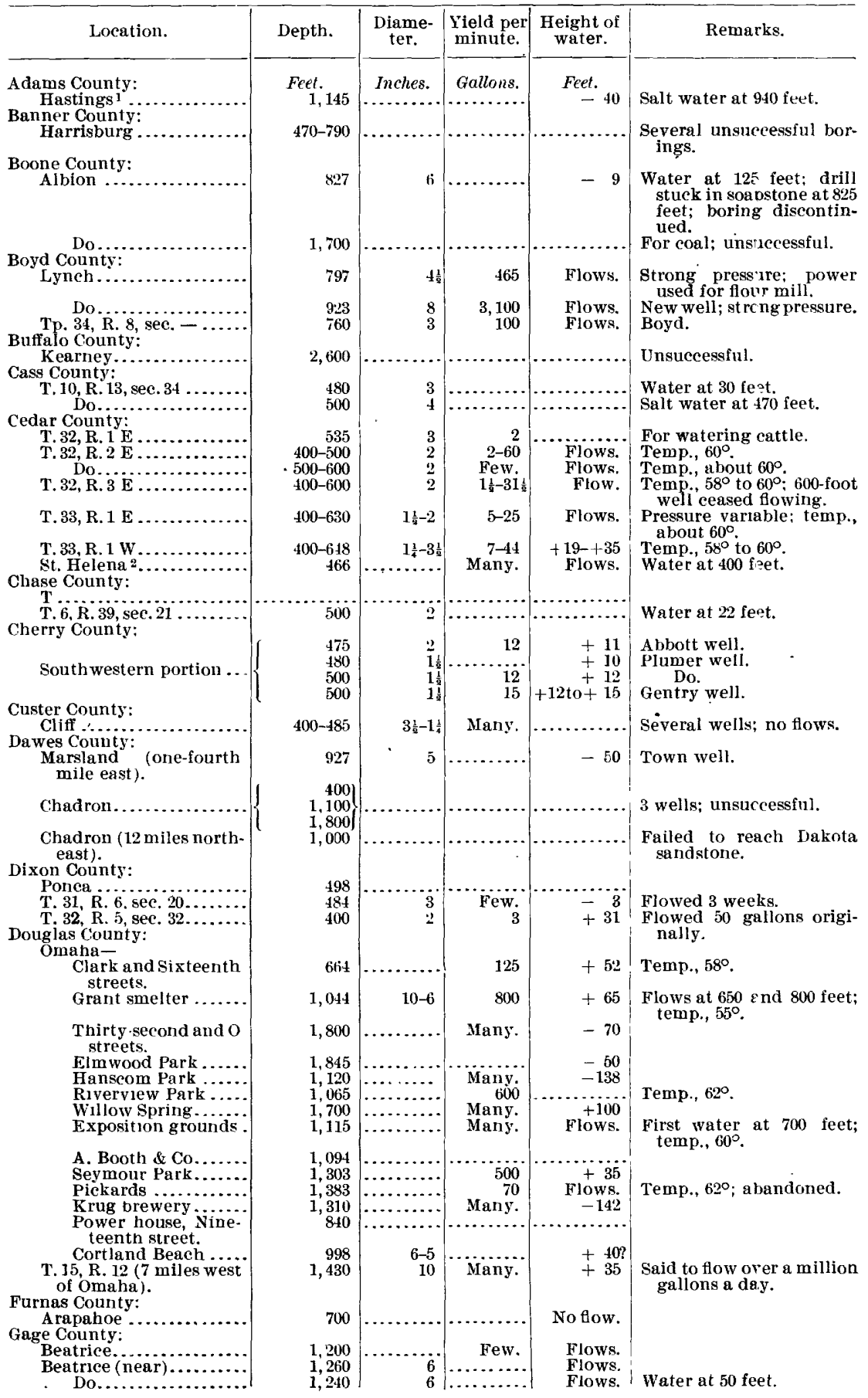

1 Record, U. S. Geol. Surv. Water-Sup. and Irr. Paper No. 12, pp. 37-38.

2 Record, Am. Assoc, Adv. Sei. Proc., vol. 35, 1886, pp. 217-219. 
NEBRASKA-Continued.

\begin{tabular}{|c|c|c|c|c|c|}
\hline Location. & Depth. & $\begin{array}{c}\text { Diame- } \\
\text { ter. }\end{array}$ & $\begin{array}{l}\text { Yield per } \\
\text { minute. }\end{array}$ & $\begin{array}{l}\text { Height of } \\
\text { water. }\end{array}$ & Remarks. \\
\hline $\begin{array}{l}\text { Grant County: } \\
\text { Hyannis... }\end{array}$ & Feet. ${ }_{400}$ & Inches. & Gallons. & Feet. & 2 wells \\
\hline Holt Count y: & & & & & \\
\hline o'Neill ....... & 1,300 & & & & ¿nsuccessful. \\
\hline $\begin{array}{l}\text { Hooker County: } \\
\text { Farm of E. Demerit.. }\end{array}$ & 1,200 & & & Flows. & \\
\hline Howard County: & & & & & \\
\hline Jefferson County: & 1,011 & & & & Co successiul. \\
\hline T. 2, R. 2 , sec. 4 & 500 & 1 & & + & $\begin{array}{l}\text { Sexen borings for coal; } \\
\text { strong salt water at } 22 \% \\
\text { to } 238 \text { feet; temp., } 70^{\circ} \text {. }\end{array}$ \\
\hline $\begin{array}{r}\text { Johnson County: } \\
\text { Tecumseh ... }\end{array}$ & 520 & & & & Boring made for coal, un- \\
\hline $\begin{array}{l}\text { Keith County: } \\
\text { T.12, R. } 37 \text {, sec. } 8 .\end{array}$ & & & & & $\begin{array}{l}\text { ported. } \\
\text { Water at } 176 \text { and } 305 \text { feet; }\end{array}$ \\
\hline T. 13, R. 35, sec. 5 ....... & 525 & 6 & 500 & & $\begin{array}{l}137 \text { feet of water in well. } \\
\text { Water at } 7 \text { feet. }\end{array}$ \\
\hline T. 14 , R. 40 , sec. $18^{2}$. & 421 & 3 & 0 & & Ursuccessful on account \\
\hline $\begin{array}{r}\text { T. I4, R. } 41, \text { sec. } 2 \ldots \ldots \ldots \\
\text { Do }^{2} \ldots \ldots \ldots \ldots \ldots \ldots\end{array}$ & $\begin{array}{l}407 \\
40^{\prime}\end{array}$ & $3 \frac{1}{7}$ & 2 & & Water at 385 feet. \\
\hline & & & & & $\begin{array}{l}\text { Bad workmanship render- } \\
\text { ed well useless; water } \\
\text { medium hard. }\end{array}$ \\
\hline $\begin{array}{l}\text { Kimball County: } \\
\text { T.9, R. } 8 \text {, sec.29 }\end{array}$ & 460 & & Many. & & No flow. \\
\hline $\begin{array}{l}\text { Knox County: } \\
\text { T. } 31, \text { R. } 6 \text {, sec. } 29\end{array}$ & $\mathbf{7 7 0}$ & 2 & 14 & +78 & Prossure greatly dimin- \\
\hline & & & & & ished. \\
\hline T. 32, R. 6 , sec. 12 & $\begin{array}{l}520 \\
548\end{array}$ & 2 & $\begin{array}{r}50 \\
240\end{array}$ & +188 & Largest flow at 520 feet. \\
\hline Niobrara Mili .... & 656 & 8 & 1,900 & +218 & $\begin{array}{l}\text { Pressure } 120 \text { pounds in } \\
\text { 1896. }\end{array}$ \\
\hline T. 32, R. 6 , sec. $16 \ldots$ & 656 & 8 & 2,500 & & 2 vells; water at 575 and \\
\hline Do......... & 656 & 8 & Many. & & Water at 625 feet. \\
\hline Packing house ........... & 600 & 2 & & +246 & Pressure diminished, ow- \\
\hline T. 32, R. 7 , sec. 21 & 500 & 2 & & & In progress; no flows ex- \\
\hline T. 33, R. 2, sec. 13 .. & 700 & 2 & Many. & & No flow; 200 feet above \\
\hline T. 33, R. 2, sec. $15, \ldots \ldots \ldots$ & 405,425 & 2 & 9 & +32 & 2 vells; considerable leak- \\
\hline T. 33, R. 2, sec. 16 & 400 & 2 & 9 & +25 & age. \\
\hline T. 33, R. 2 & 400 & 2 & 3 & +57 & Leaks. \\
\hline $\begin{array}{l}\text { T. } 33 \text {, R. } 2 \text {, sec. } 19 \ldots \ldots \ldots . . \\
\text { T. } 33, \text { R. } 2 \text {, sec. } 20 \ldots \ldots \ldots .\end{array}$ & $\begin{array}{l}5,0 \\
650\end{array}$ & $2 \underset{4}{4}$ & $\begin{array}{l}10 \\
30\end{array}$ & +137 & Leaks; present pressure \\
\hline T. 33, R. 3 , sec. 13 & 504 & 2 & 2 & Flows. & $\begin{array}{l}\text { low. } \\
\text { Or high land. }\end{array}$ \\
\hline T. 33, R. 3, sec. $15 \ldots$ & 400 & 2 & & Flows. & \\
\hline $\begin{array}{l}\text { T. 33, R. 3, sec. } 16 \ldots \ldots \ldots \ldots \\
\text { Santee Agency ........... }\end{array}$ & $\begin{array}{r}400 \\
+600\end{array}$ & $\frac{2}{6}$ & 8 & Flows. & Leaks. \\
\hline $\begin{array}{l}\text { Santee Agency } \\
\text { Santee Agency Mission } 3 \text {. }\end{array}$ & $\begin{array}{r} \pm 600 \\
603\end{array}$ & $2 \frac{1}{8}$ & 20 & Flows. & Do. \\
\hline Santee Agency school... & 604 & 3 & & Flows. & 143 feet above Missouri \\
\hline Do..................... & 740 & 8 & 1,699 & +126 & $\begin{array}{l}105 \text { feet above Missouri } \\
\text { River: pressure and } \\
\text { yield diminished. }\end{array}$ \\
\hline T. 33, R. 8 , sec. $18 \ldots \ldots$ & 700 & 2 & 420 & +172 & $\begin{array}{l}3 \text { Hows; pressure greatly } \\
\text { diminished, owing to }\end{array}$ \\
\hline Do......... & 760 & 3 & 420 & Flows. & leakrge. \\
\hline $\begin{array}{l}\text { Lancaster County: } \\
\text { Lincoln }{ }^{4}-\end{array}$ & 985 & & & -100 & Salt water at 244 and 544 \\
\hline Sanitarium ${ }^{5} \ldots$ & 570 & & & +34 & feet. \\
\hline Public square. & 1,050 & & Many. & Flows. & Salt water at 560 and 1,050 \\
\hline $\begin{array}{l}\text { Burlington Beach... } \\
\text { Madison County: }\end{array}$ & 2,463 & & Many. & Flows. & Salt water at 828 feet. \\
\hline Nortolk $\ldots \ldots \ldots \ldots \ldots$ & 472 & & & -100 & \\
\hline T. 23, R. $4 \ldots \ldots \ldots \ldots \ldots$ & 335 & 6 & Many. & -275 & \\
\hline Merrick County: & +400 & 4 & …........ & -90 & \\
\hline Silver Creek. & 1,700 & & & -19 & \\
\hline \multicolumn{3}{|c|}{$\begin{array}{l}{ }^{1} \text { Record, U. S. Geol. Surv. Water-Sup. and Irr. } \\
\text { Paper No. 12, p. 47. } \\
2 \text { U. S. Geol. Surv. Bull. No. 131, 1895, p. } 96 . \\
{ }^{3} \text { Record, 51st Cong., 1st session, Senate Ex. Doc. } \\
\text { No. 222, pl. op. p. } 55 \text {. }\end{array}$} & \multicolumn{3}{|c|}{$\begin{array}{l}4 \text { Record, Am. Assoc. Adv. Sci. Proc., vol. 35, p. } \\
218 \text {. } \\
\text { o Descriptions, records, etc., U. S. Geol. Surv. } \\
\text { Water-Sup, and Irr. Pape No. 12, pp. 28-30; Aw. } \\
\text { Assoc. Adv. Sci. Proc., vol. 35, p. 218; Physical } \\
\text { Geog. and Geol. Nebr. (Aughey), 1880. }\end{array}$} \\
\hline
\end{tabular}


NEBRASKA-Continued.

\begin{tabular}{|c|c|c|c|c|c|}
\hline Location. & Depth. & $\begin{array}{l}\text { Diame- } \\
\text { ter. }\end{array}$ & $\begin{array}{l}\text { Yield per } \\
\text { minute. }\end{array}$ & $\begin{array}{l}\text { Height of } \\
\text { water. }\end{array}$ & Remarks. \\
\hline $\begin{array}{l}\text { Nemaha County: } \\
\text { Brownville } 1 . .\end{array}$ & $\begin{array}{l}\text { Fect. } \\
\quad 1,001\end{array}$ & $\begin{array}{l}\text { Inches. } \\
\ldots . . . . .\end{array}$ & Gallons. & $\begin{array}{l}\text { Fet. } \\
\cdots\end{array}$ & Test boring for \\
\hline Nuckolis County: & & & & & of salty water at 242 feet. \\
\hline $\begin{array}{l}\text { Mount Clare....... } \\
\text { toe County: }\end{array}$ & 535 & & & No flow. & \\
\hline 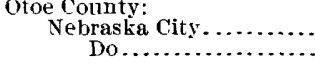 & $\begin{array}{r}448 \\
1,000-1,200\end{array}$ & 4 & $\frac{1}{2}$ & +6 & $\begin{array}{l}\text { Mineral water. } \\
\text { Several deep well } \text { in prog- }\end{array}$ \\
\hline Do........ & 570 & & & & $\begin{array}{l}\text { rese. } \\
\text { Salt water. }\end{array}$ \\
\hline Pawnee County: & & & & & \\
\hline $\begin{array}{l}\text { Duboise ........... } \\
\text { Platte County: }\end{array}$ & 562 & 6 & & & Cnsuccessful. \\
\hline Monroe........... & 580 & 4 & & & [nsuccessful. \\
\hline $\begin{array}{l}\text { Redwillow County: } \\
\text { MeCook .......... }\end{array}$ & 405 & 6 & & & Some water at 375 feet. \\
\hline $\begin{array}{l}\text { Richardson County: } \\
\text { Falls City .......... }\end{array}$ & 1,300 & & & & \\
\hline $\begin{array}{l}\text { Rulo ( } 2 \text { miles west) } . . . . \\
\text { Garny County }\end{array}$ & 1,370 & & & & Coal prospect. \\
\hline 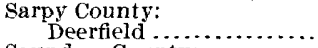 & 1,450 & 10 & & -760 & Pressure, 15 pour. ds. \\
\hline $\begin{array}{l}\text { Saunders County } \\
\text { Malmo (nort) }\end{array}$ & 451 & & & & \\
\hline $\begin{array}{l}\text { Scotts Bluff County: } \\
\text { Gering ............. }\end{array}$ & 300 & & & & $\begin{array}{l}\text { Vigorous fiow for short } \\
\text { time, but soon choked } \\
\text { up. }\end{array}$ \\
\hline $\begin{array}{l}\text { Seward County: } \\
\text { Seward } 2 \ldots \ldots . .\end{array}$ & 610 & & & & No flow; abandored. \\
\hline 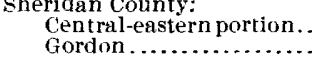 & $\begin{array}{l}300 \\
582\end{array}$ & $1 \frac{1}{2}$ & 10 & $\begin{array}{l}+10 \\
+\ldots\end{array}$ & $\begin{array}{l}\text { Richard's well. } \\
\text { Failure; water at } 180 \text { to }\end{array}$ \\
\hline $\begin{array}{l}\text { Tha ver County: } \\
\text { Hubbell ....... }\end{array}$ & 725 & & & & Some water; no flow. \\
\hline $\begin{array}{l}\text { Webster County: } \\
\text { Rosemont ........ }\end{array}$ & 409 & & & & Iron ore at 375 feet; oil at \\
\hline $\begin{array}{l}\text { Wheeler County: } \\
\text { Erricson............ }\end{array}$ & 905 & & & & $\begin{array}{l}379 \text { feet. } \\
\text { Failure. }\end{array}$ \\
\hline $\begin{array}{l}\text { York County: } \\
\text { York (just south of })^{3} .\end{array}$ & 590 & 4 & & +16 & $\begin{array}{l}\text { Russian mill well; aban. } \\
\text { doned. }\end{array}$ \\
\hline
\end{tabular}

${ }^{1}$ Am. Assoe. Adv. Sci. Proc., vol. 35, pp. 217-219.

2 Record, U. S. Geol. Survey Water-Sup. and Irr.Paper No. 12, p. 31.

3 Ibid., pp. 33-34.

\section{PRINCIPAL PUBLICATIONS RELATING TO DEEP BORINGS IN NEBRASKA.}

Underground waters of a portion of southeastern Nebraska, by N. H. Darton: United States Geological Survey, Water-Supply and Irrigation Paper No. 12, 56 pages, maps, plates, Washington, 1898.

A preliminary report on the geology and water resources of Nebraska west of the one hundred and third meridian, by N. H. Darton: United States Geological Survey, Eighteenth Annual Report, 1896-1897, part 4, pages 719-785, Washington, 1899.

Nebraska Geological Survey, Report State Geologist E. H. Barbour, vol. 1, Lincoln, 1903.

United States Geological Survey Bulletin No. 131, page 96, Washington, 1895.

Preliminary report on the geology and underground water resources of the central Great Plains, by N. H. Darton: United States Geological Survey Professional Paper No. 32, Washington, 1905.

IRR $149-05-6$ 


\section{NEVAD́A.}

\begin{tabular}{|c|c|c|c|c|c|}
\hline Location. & Depth. & $\begin{array}{l}\text { Diam- } \\
\text { eter. }\end{array}$ & $\begin{array}{c}\text { Yield } \\
\text { per } \\
\text { minute. }\end{array}$ & $\begin{array}{c}\text { Height } \\
\text { of } \\
\text { water. }\end{array}$ & Remarks. \\
\hline $\begin{array}{l}\text { Lander County: } \\
\text { Battle Mountain }{ }^{1} \ldots \ldots . .\end{array}$ & Fcet. 800 & Inches. & $\begin{array}{l}\text { Gallons. } \\
\text { a......... }\end{array}$ & Fcet. & Etrong flow. \\
\hline Lincoln County: & 650 & & & & Severalflowsatlessdepths. \\
\hline Dalamar ...... & 800 & & & & Unsuccessful. \\
\hline $\begin{array}{l}\text { Ormsby County: } \\
\end{array}$ & 400 & $6-7$ & 5 & & Several wells. \\
\hline White Pine County: & $\mathrm{con}$ & & Soverol & & \\
\hline $\begin{array}{l}\text { Ely } \\
\text { Churchili county: }\end{array}$ & 600 & & Several & & \\
\hline $\begin{array}{l}\text { Vail Ranch } \\
\text { Sierra Valley }{ }^{2}(?) \ldots\end{array}$ & $\begin{array}{r}400 \\
1,132\end{array}$ & 3 & 30 & $\begin{array}{l}\text { No flow. } \\
\text {. }\end{array}$ & F'ot Water. \\
\hline
\end{tabular}

NEW HAMPSHIRE.

\begin{tabular}{|c|c|c|c|c|c|}
\hline 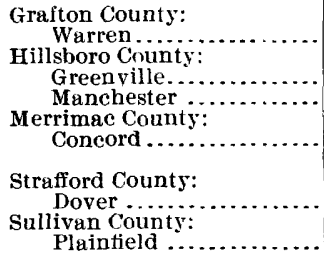 & $\begin{array}{r}492 \\
410 \\
630 \\
1,325 \\
\\
400 \\
1,104\end{array}$ & $\begin{array}{l}6 \\
8\end{array}$ & $\begin{array}{r}3 \\
20 \\
\text { Few. } \\
\text { Few. } \\
100 \\
\ldots . . .\end{array}$ & $\begin{array}{r}-90 \\
\text { No flow. } \\
-16 \\
\text { No flow. } \\
-6\end{array}$ & $\begin{array}{l}\text { Well ahandoned; water at } \\
935 \text { feet }\end{array}$ \\
\hline
\end{tabular}

\section{NEW JERSEY.}

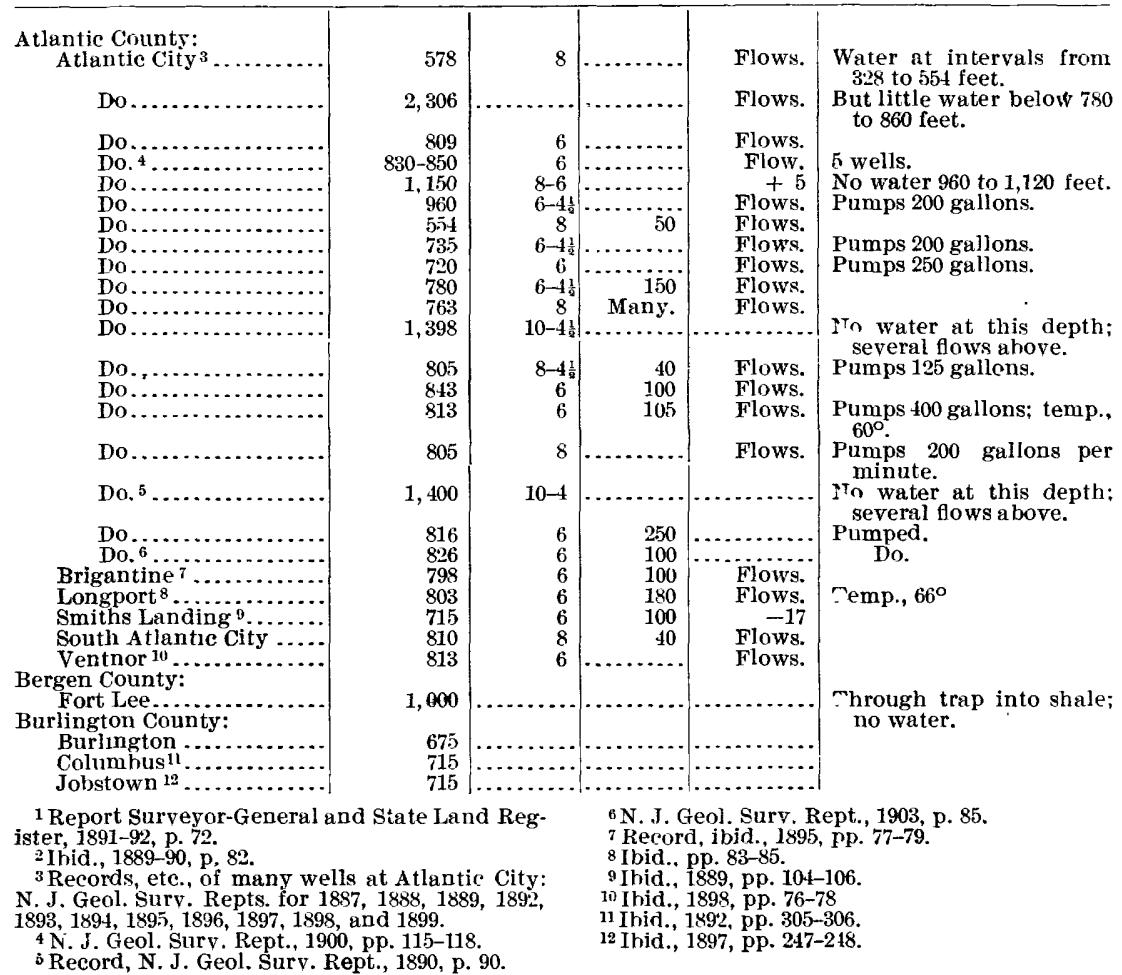


NEW JERSEY-Continued.

\begin{tabular}{|c|c|c|c|c|c|}
\hline Location. & Depth. & $\begin{array}{l}\text { Diame- } \\
\text { ter. }\end{array}$ & $\begin{array}{c}\text { Yield per } \\
\text { minute. }\end{array}$ & $\begin{array}{l}\text { Height of } \\
\text { water. }\end{array}$ & Remarks \\
\hline Burlington County-Cont'd. & Feet. & Inches. & Gallons. & Feet. & \\
\hline Moorestown 1 . & 457 & & & & \\
\hline $\begin{array}{l}\text { Mount Holly }{ }^{2} \ldots \ldots \ldots \ldots \\
\text { Seven Islands } 3 \ldots \ldots \ldots \ldots\end{array}$ & $\begin{array}{l}562 \\
408\end{array}$ & $\cdots \cdots \cdots_{6-3}$ & $\cdots \cdots$ & Flows. & Small supply. \\
\hline Camden County: & & & & Fluws. & \\
\hline $\begin{array}{l}\text { Asyla } 4 . . . . . . . . \\
\text { Cape May County: }\end{array}$ & 457 & $8-6$ & 200 & -25 & Pumped. \\
\hline $\begin{array}{l}\text { Cape May County: } \\
\text { Avalon }{ }^{5} \ldots \ldots \ldots \ldots \ldots \ldots\end{array}$ & 925 & $10-4 \frac{1}{2}$ & 75 & & \\
\hline Cape May ${ }^{6} . \ldots \ldots \ldots \ldots \ldots$ & 1,313 & $10-2 \frac{1}{2}$ & $\sigma_{0}$ & -4 & $\begin{array}{l}\text { Large supply, } 90 \text { to } 130, \\
285 \text { to } 300 \text {, and } 585 \text { to } 600 \\
\text { feet; no water below } 600 \\
\text { feet. }\end{array}$ \\
\hline Cape May Point ${ }^{7} \ldots \ldots \ldots$ & $\begin{array}{l}700 \\
800\end{array}$ & & 140 & Flows & \\
\hline Do. ${ }^{9} \ldots \ldots \ldots \ldots \ldots$ & 821 & $\ddot{8}$ & Many. & $\begin{array}{l}\text { Flows. } \\
\text { Flows. }\end{array}$ & \\
\hline Do. ${ }^{10} \ldots \ldots \ldots \ldots \ldots$ & 760 & & Many. & Flows. & \\
\hline Do $\ldots \ldots \ldots \ldots \ldots \ldots \ldots$ & 830 & $8-6$ & Many. & Flows. & \\
\hline 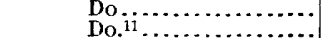 & $\begin{array}{l}816 \\
812\end{array}$ & 6 & $\begin{array}{r}250 \\
150\end{array}$ & & $\begin{array}{l}\text { Pumped. } \\
\text { Do. }\end{array}$ \\
\hline Sea Isle City $12 . . . .$. & 464 & & & Flows. & \\
\hline Do. ${ }^{13} \ldots \ldots$ & 854 & 6 & 160 & +14 & \\
\hline Wild wood $\ldots . . . .$. & 655 & $\cdots$ & 300 & Flows. & Temp., $63^{\circ}$. \\
\hline $\begin{array}{l}\text { Do. } 14 \\
\text { Cumberland County: }\end{array}$ & 1,244 & $\cdots$ & 10 & Flows. & Temp., $67^{\circ}$; watior at 625 , \\
\hline $\begin{array}{l}\text { Cumberiand county: } \\
\text { Bridgeton }{ }^{15} \ldots . . . .\end{array}$ & 990 & 8 & & & $\begin{array}{l}750,843, \text { and } 1,185 \text { feet. } \\
\text { Large supply. }\end{array}$ \\
\hline Green wich 16 ........ & 690 & $4-2 \frac{1}{2}$ & & & No water found. \\
\hline Millville $17 . . . . . .$. & 685 & & & & No water below 212 feet. \\
\hline Essex County: & & & & & \\
\hline $\begin{array}{l}\text { Brookdale }{ }^{18} \ldots \ldots \ldots \ldots \\
\text { Caldwell } \ldots \ldots \ldots \ldots\end{array}$ & $\begin{array}{l}712 \\
875\end{array}$ & $4 \frac{1}{2}$ & 174 & & \\
\hline Franklin $19, \ldots \ldots \ldots$ & 400 & 8 & $125^{\circ}$ & & \\
\hline Harrison...$\ldots \ldots \ldots \ldots$ & 400 & & 100 & & In soft shale. \\
\hline Milburn $\ldots \ldots \ldots \ldots \ldots$ & 800 & 8 & 100 & …..... & \\
\hline $\begin{array}{l}\text { Montclair (Mount Pros- } \\
\text { pect). }\end{array}$ & 510 & $7 \frac{3}{4}$ & 45 & & Soft water. \\
\hline Newark (Balentine's) ... & 529 & & $\mathbf{3} 50$ & & \\
\hline $\begin{array}{l}\text { Do. }{ }^{20} \\
\text { Newark (Ceiluioid Co.)... }\end{array}$ & 450 & 8 & 200 & Nottow? & \\
\hline Newark (Citizens' Gas & 600 & 10 & $\begin{array}{r}200 \\
50\end{array}$ & No flow? & 9 \\
\hline Co.) & & & & & - \\
\hline Newark $\ldots \ldots \ldots \ldots \ldots \ldots$ & 615 & 8 & 556 & & \\
\hline $\begin{array}{l}\text { Newark (smelter) } 21 \ldots \ldots \\
\text { Gloucester County: }\end{array}$ & 500 & 8 & 500 & & \\
\hline $\begin{array}{l}\text { Gloucester County: } \\
\text { Glassboro } 22 \ldots \ldots \ldots \ldots\end{array}$ & 511 & & & & \\
\hline Harrisonville & $40^{\circ}$ & & & & \\
\hline Pitman $24 \ldots \ldots \ldots \ldots$ & 507 & & & -140 & Good supply. \\
\hline Sewell......$\ldots \ldots$ & 420 & $\dddot{3}$ & & & Water also at 72,381 , and \\
\hline Hudson County: & & & Fow & & 395 feet. \\
\hline 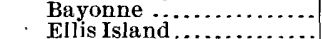 & $\begin{array}{r}600 \\
1,400\end{array}$ & $\ddot{8}$ & Few. & & Water brackish. \\
\hline Hoboken $25, \ldots \ldots \ldots \ldots$ & $\begin{array}{r}1,400 \\
400\end{array}$ & & & & Bored in 1828; rock at 40 \\
\hline Jersey City (Limbeck's & $776 \frac{1}{2}$ & 8 & 33 & & \\
\hline $\begin{array}{l}\text { brewery) }{ }^{2 j} \\
\text { Jersey City (Malone \& }\end{array}$ & 500 & & 50 & & \\
\hline $\begin{array}{l}\text { Co.). } \\
\text { Jersey City (stock yards) }\end{array}$ & 455 & $8-6 \frac{1}{2}$ & & & \\
\hline $\begin{array}{l}\text { Jersey City (Communi- } \\
\text { paw). }\end{array}$ & 500 & & & & Salt water. \\
\hline $\begin{array}{l}\text { Jersey City (sugar refin- } \\
\text { ery) } .26\end{array}$ & 1,000 & $8-4$ & 50 & & \\
\hline $\begin{array}{c}\text { Jersey City (Cox's brew- } \\
\text { ery) } .26\end{array}$ & 400 & 5 & Few. & & \\
\hline Jersey City (Dixon Co.). & 1,205 & & 22 & & \\
\hline Jersey City (Colgate \& & 1,500 & & 15 & & Rock 35 to 1,500 feet. \\
\hline Jersey City (Hudson Ca- & 650 & & Few. & & \\
\hline Jersey City (Traction Co.) & 2,200 & & & & No water. \\
\hline
\end{tabular}
414.

1 Record,' N. J. Geol. Surv. Rept., 1893, pp. 413-

15 N. J. Geol. Surv. Rept., 1903, p. 86.

16 Record, tbid., 1885, p. 131: 1894, pp. 190-193.

17 Ibid., 1901, pp. 64-65; 1902, p. 80.

18 Ibid., 1897, pp. 227-229.

19 Ibid., 1894, p. 127; 1885, p. 133.

20 Ibid., 1879, p. 126; 1882, p. 142; 1885, p. 115.

21 Ibid., 1879, p. 126; 1882, p. 142; 1885, p. 114.

22 Ibid., 1894, pp. 407-409.

23 Ibid., 1896, pp. 126-127.

24 Ibid., 1901, pp. \5-86.

25 Ibid., 1879, p. 132: 1882, p. 139; 1885. p. 111.

26 Ibid,, 1879, pp. 130-132; 1882, pp. 138-140; 1885, p. 118.

${ }_{27}$ Ibid., 1880, p. 172; 1882, p. 139, 1885, p. 111.

11 Ibid., 1902, p. 94.

13 Ibid., 1896, pp. 175-177; 1886, p. 211; 1899, p. 109.

14 Ibid., 1897, pp. 247-248. 
NEW JERSEY-Continued.

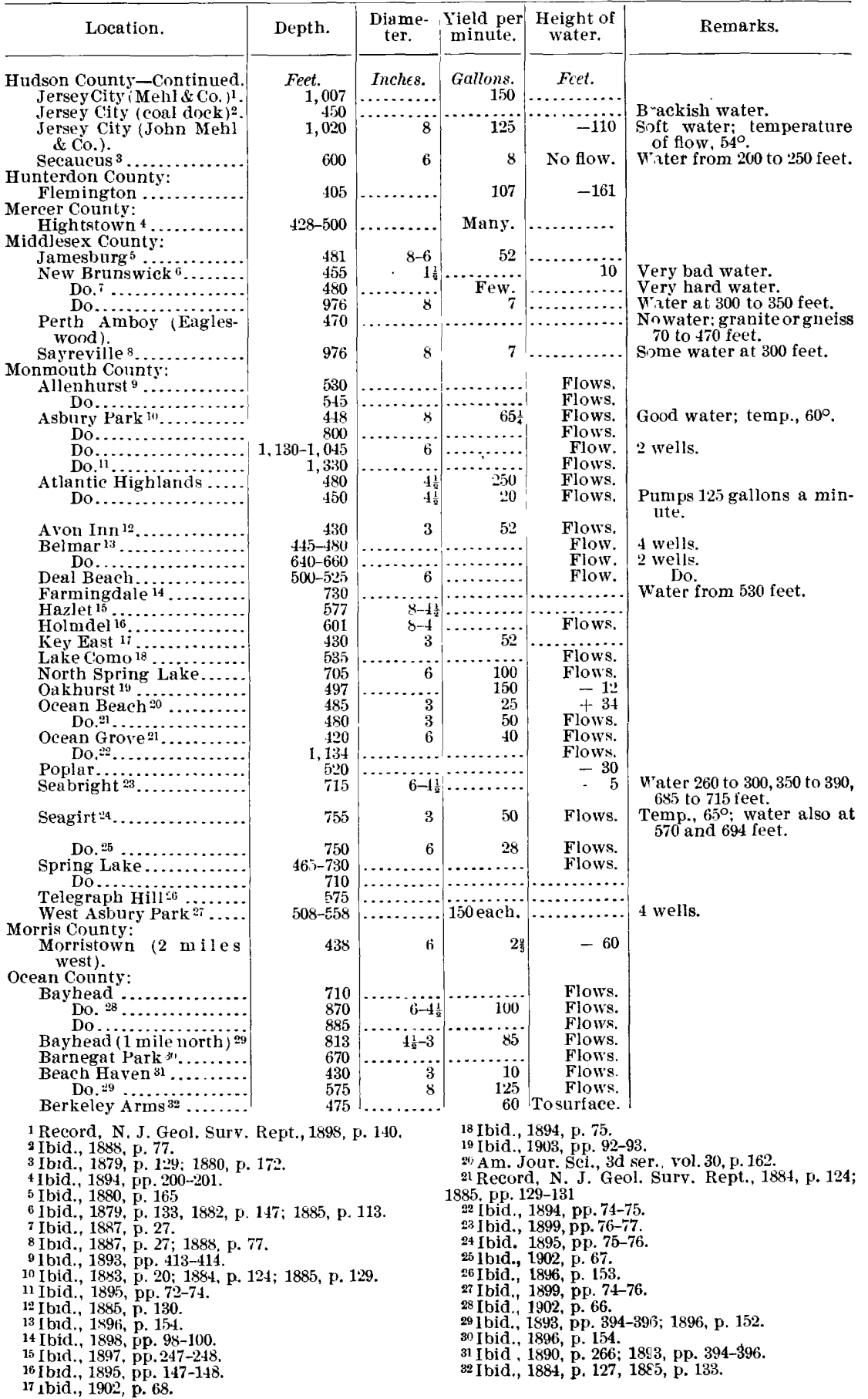


NEW JERSEY-Continued.

\begin{tabular}{|c|c|c|c|c|c|}
\hline Location. & Depth. & $\begin{array}{c}\text { Diame- } \\
\text { ter. }\end{array}$ & $\begin{array}{c}\text { Yield per } \\
\text { minute. }\end{array}$ & $\begin{array}{c}\text { Height of } \\
\text { water. }\end{array}$ & Remarks. \\
\hline 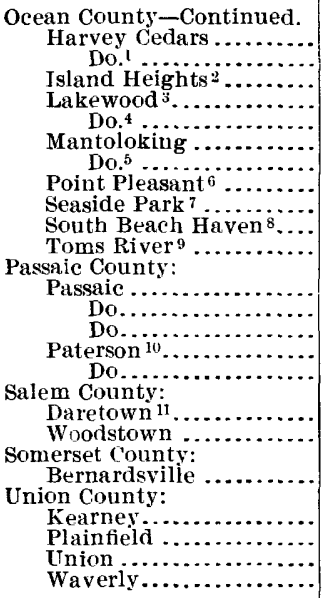 & $\begin{array}{r}\text { Fcet. } \\
500 \\
500 \\
1,145 \\
475 \\
600-625 \\
790 \\
922 \\
806 \\
515 \\
425 \\
745 \\
402 \\
558 \\
1,000 \\
2,100 \\
900 \\
\\
405 \\
776\end{array}$ & 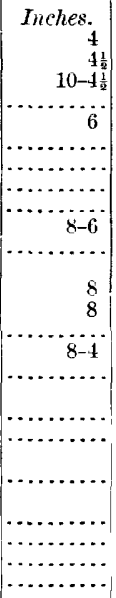 & $\begin{array}{r}\text { Gallons. } \\
100 \\
120 \\
\ldots \ldots \\
100 \\
3 \frac{1}{2} \\
25 \\
60 \\
45 \\
16 \\
10\end{array}$ & $\begin{array}{l}\text { Fect. } \\
\text { Flows. } \\
+6 \\
+\quad 3 \\
+17 \\
+200 \\
+33 \\
+42 \\
\text { Flows. } \\
\text { Flows. } \\
+14 \\
\ldots . . . . .\end{array}$ & $\begin{array}{l}\text { Water from } 368 \text { feet. } \\
\text { Several wells. } \\
\text { Temp., } 58^{\circ} \text {. }\end{array}$ \\
\hline
\end{tabular}

${ }^{1}$ Record, N. J. Geol. Surv. Rept,, 1896, pp. 166168.

Ibid., 1901, pp. 66-68

3 Ibid., 1885, p. 131; 1884, p. 125; 1895, pp. 148149: 1900 , pp. $148-150$.

4 Ibid., 1898 , pp. $96-98 ; 1899$, pp. $73-74$.

5 Ibid., 1895, p. 77.
6 Ibid., $1 \times 95$, pp. $76-77$.

7 Ibir., 1898, pp. 101-102

8 Ibid., 1896. pp. 175-177; 1886, p. 211; 1899, p. 109. 9 [bid., 1893, pp. 399-400; 1894, pp. 159-180; 1898, pp. 10:-103.

${ }^{10}$ Ibid., 1879, p. 128; 1882, p. 143; 1885, pา. 115, 117. ${ }^{11}$ Ibid., 1897, pp. 250-253.

\section{PUBLICATIONS RELATING TO DEEP BORINGS IN NEW JERSEY.}

New Jersey Geological Survey, Reports of the State Geologist for 1868, 1879, 1882 to 1885,1887 to $1884,1890,1892$ to $1899,1900,1901-2,1903$.

Artesian well prospects in the Atlantic Coastal Plain region, by N. H. Darton: United States Geological Survey Bulletin No. 138, pp. 39-115, plates, Washington, 1896.

\section{NEW MEXICO.}

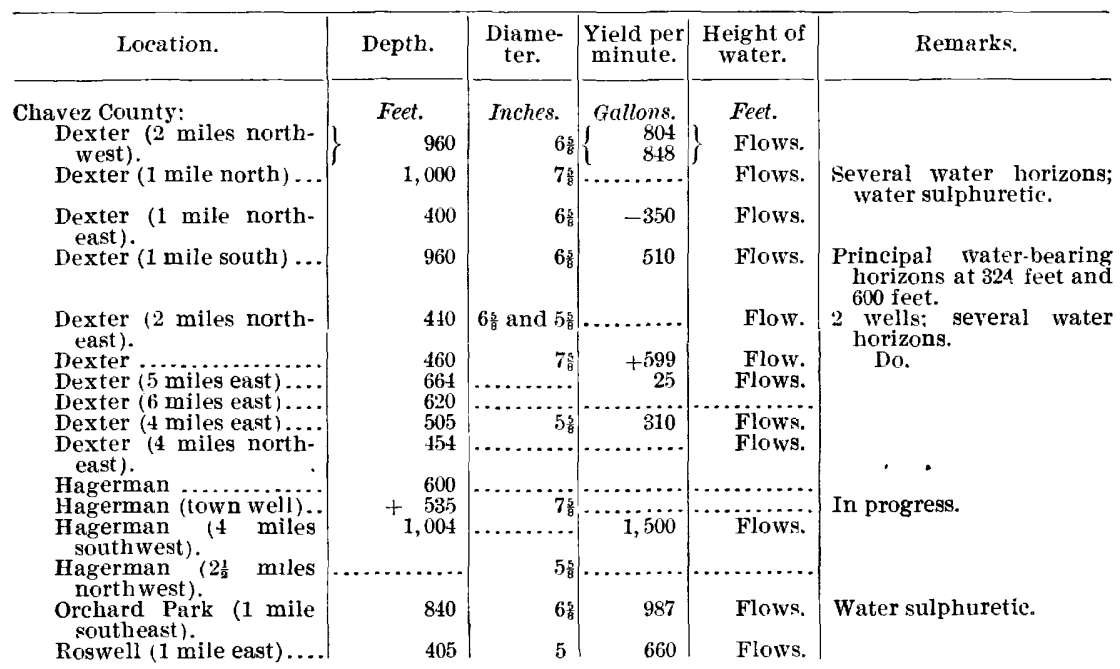


NEW MEXICO-Continued.

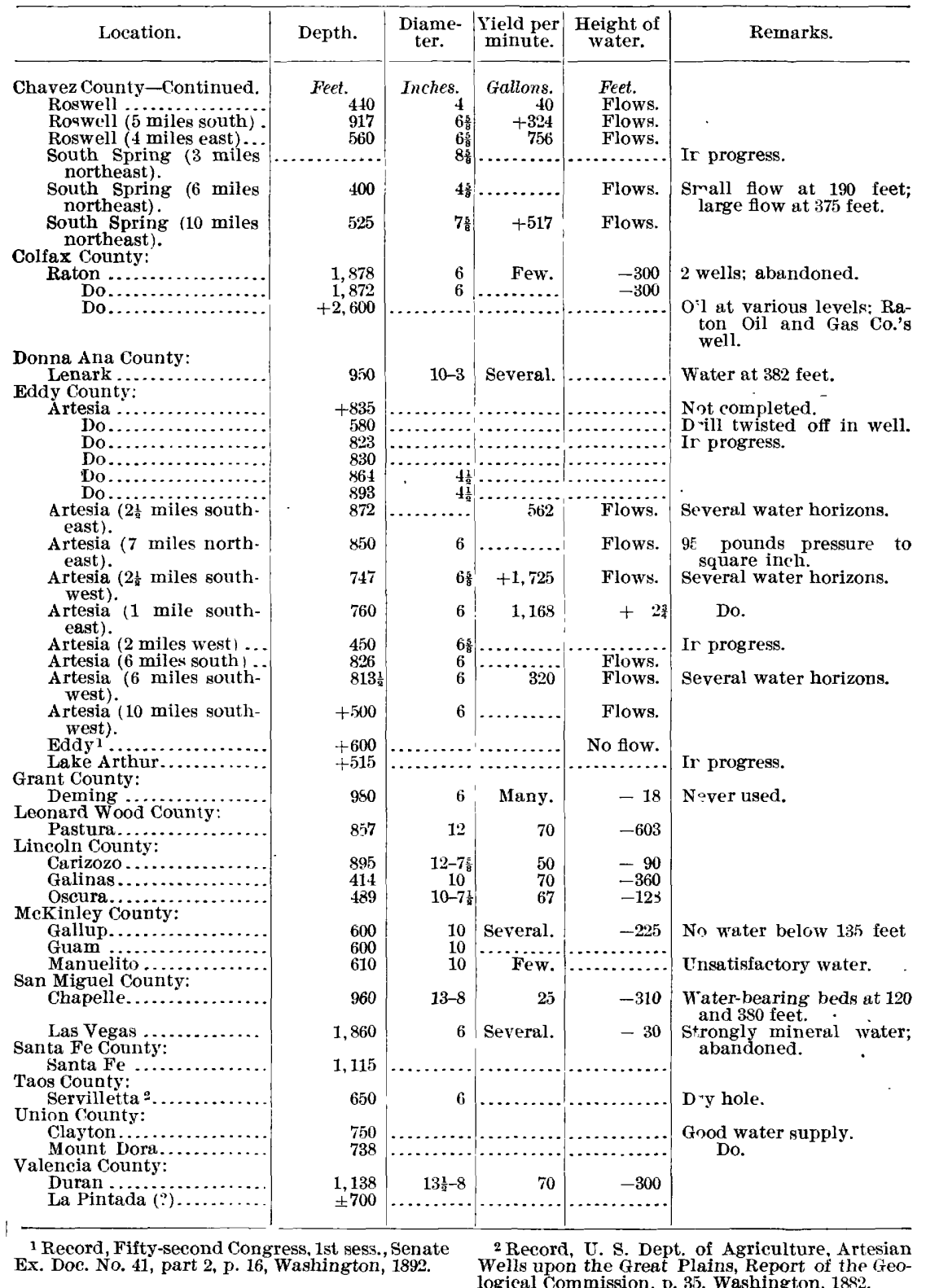

\section{PUBLICATIONS RELATING TO DEEP BORINGS IN NEW MEXICO.}

Report on New Mexico, by L. G. Carpenter: Fifty-first Congress, first session, Senate Ex. Doc., No. 222, pp. 233-241, Washington, 1890.

Report of P. H. Van Diest, on the geological conditions of artesian basins in eastern Colorado and New Mexico: Fifty-first Congress, first session, Senate Ex. Doc., No. 222, pp. 233-241, Washington, 1890. 
On the occurrence of artesian and other underground waters in Texas, eastern New Mexico, and Indian Territory west of the ninety-seventh meridian, by Robert T. Hill: Fifty-second Congress, first session, Senate Ex. Doc., No. 41, part 3, pp. 41-166, Washington, 1892.

Report on irrigation, etc., by R. J. Hinton: Fifty-second Congress, first session, Senate Ex. Doc. No. 41, part 1, pp. 5-159, Washington, 1892.

NEW YORK.

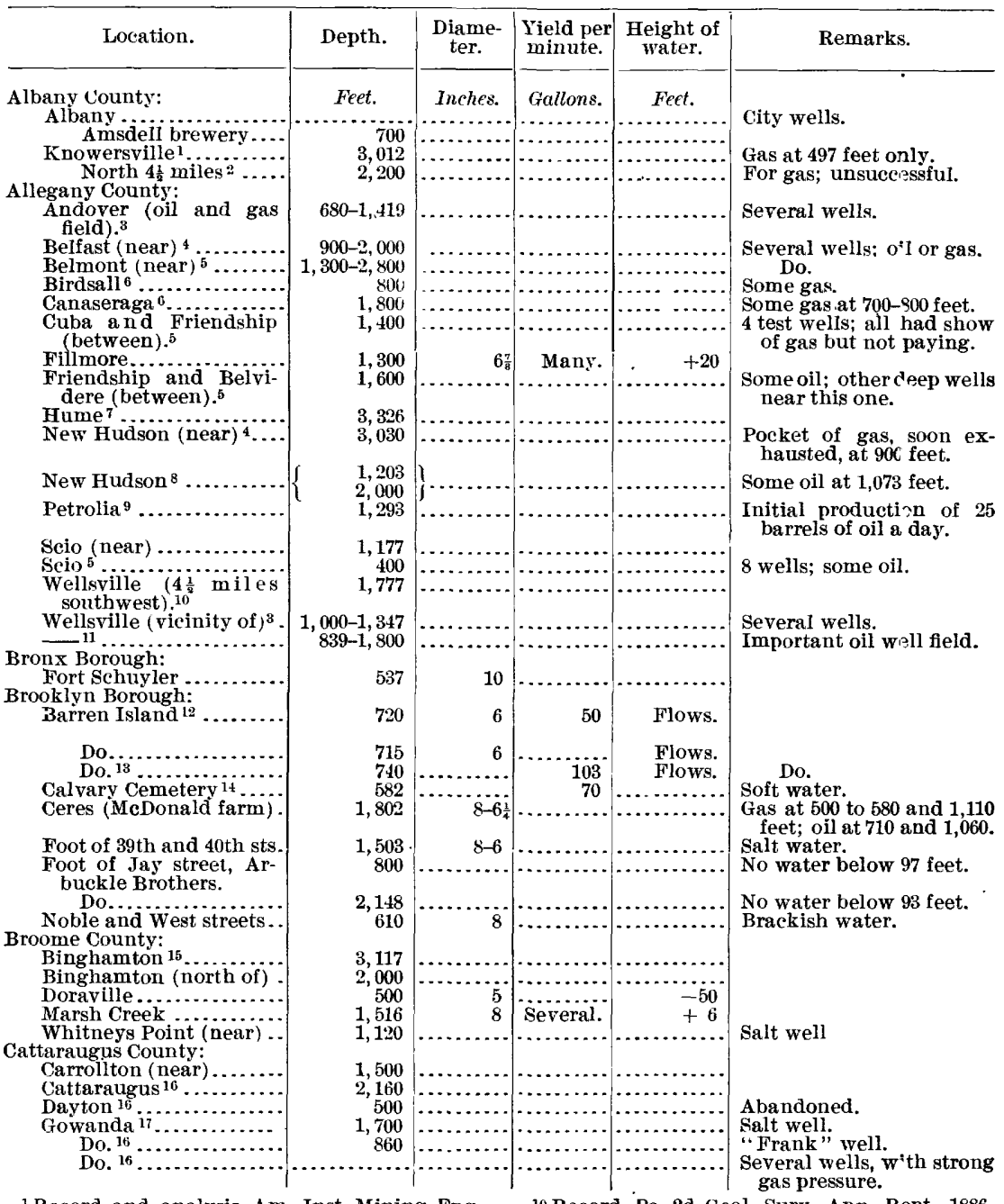

1 Record and analysis, Am. Inst. Mining Eng. Trans., vol. 16, pp. 951-952.

${ }_{2}$ Am. Inst. Mining Eng. Trans., vol. 16, pp. 953954.

${ }^{3}$ Record, N. Y. State Museum Rept., 1899, pp. r111-113.

4 Ibid., p. r109.

5 Ibid., p. r110.

Ibid., p. r107.

7 Ibid., p. r108.

8 Ibid., pp. r108-109.

9 Ibid., pp. r110-111.
${ }^{10}$ Record, Pa. 2d Geol. Surv. Ann. Rept., 1886, part 2, pp. 774-775.

11 Reeord, etc., Ám. Inst. Mining En $\zeta$. Trans., vol. 16, pp. 930-934.

12 Record, N.J.Geol.Surv. Rept., 1896, p э. 155-156. 13 Ibid., pp. 156-157.

14 Record, U. S. Geol. Surv. Bull. 138, p. 34.

15 Record, Geol. Soc. Am. Bull., vol. 4, pp. 93-94.

10 N. Y. State Museum Rept., 1899, pp. r115-117.

1 i Record, Rept. Supt. Onondaga Sal' Springs, 188 , pl. 2 . 
NEW YORK-Continued.

\begin{tabular}{|c|c|c|c|c|c|}
\hline Loeation. & Depth. & $\begin{array}{l}\text { Diame- } \\
\text { ter. }\end{array}$ & $\begin{array}{c}\text { Yield per } \\
\text { minute. }\end{array}$ & $\begin{array}{l}\text { Height of } \\
\text { waiter. }\end{array}$ & Remarks. \\
\hline Cattaraugus County-Cont'd. & Fcet. & Inches. & fictlluns. & , Fe'et. & \\
\hline Hinsdale (near i $1 \ldots \ldots \ldots$ & $+1,200$ & & & & UTsucessful. \\
\hline $\begin{array}{l}\text { Dimestone } \\
\text { Olean }^{3} \ldots\end{array}$ & $\begin{aligned} 1,500 \\
734-1,417\end{aligned}$ & & & & $\begin{array}{l}\text { For gas or oll. } \\
\text { Several wells. }\end{array}$ \\
\hline Do. $3 \ldots$ & 1,050 & & & & small a mount of oil. \\
\hline $\begin{array}{r}\text { Do. }{ }^{4} \ldots \ldots \\
\text { Otto }{ }^{5} \ldots \ldots\end{array}$ & 1,230 & & & & Gas well. \\
\hline Rock city inearji & $1,471-1,546$ & & & & o'l wells. \\
\hline Versailles $^{1} \ldots$ & $\begin{array}{l}1,3 \times 3 \\
1,543\end{array}$ & & & & For gas; un-atisfactory. \\
\hline Cayuga County: & & & & & \\
\hline Auburn $7 . .$. & 3,570 & & & & Gis well. \\
\hline $\begin{array}{c}D, \\
\text { Aurora }\end{array}$ & $\begin{array}{l}3,400: \\
1,068\end{array}$ & & & & Salty water. \\
\hline $\begin{array}{l}\text { Chautauqua County: } \\
\text { Charlotte Center }\end{array}$ & 2,332 & & & & For oil: unsuccessful. \\
\hline 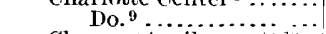 & 2,262 & & & & Do. \\
\hline Clymer (4 miles east) ${ }^{\prime \prime} .$. & 1,975 & & & & Gas well. \\
\hline Fredonia $11 . . . \ldots \ldots \ldots$ & 1,207 & & & & $\begin{array}{l}\text { Much salty water; several } \\
\text { gas wells in vicinity. }\end{array}$ \\
\hline $\begin{array}{l}\text { Jamestown } \\
\text { Mayville }\end{array}$ & 1,807 & & & & Fir oil: unsuccessful. \\
\hline Chemung County: & $1,200-1,800$ & & & & Several wells; oll or gas. \\
\hline Breesport....... & 1,875 & 5 & & -14 & \\
\hline $\begin{array}{l}\text { Chenango County: } \\
\text { Norwich........ }\end{array}$ & & & & & \\
\hline $\begin{array}{r}\text { Norwich........ } \\
\text { Do. } 14, \ldots .\end{array}$ & $\begin{array}{r}900 \\
\end{array}$ & & & & Small amounts of gas. \\
\hline Columbia County: & 2,304 & & & & \\
\hline Burden .... & 900 & & & +2 & \\
\hline Hudson ............ & 500 & 6 & 40 & +22 & \\
\hline Do............. & 696 & 6 & 40 & -110 & \\
\hline $\begin{array}{l}\text { Do } \ldots \ldots \ldots \ldots \\
\text { Do............. }\end{array}$ & 602 & 6 & $\begin{array}{l}1 \\
35\end{array}$ & -60 & \\
\hline Delaware county: & 500 & & & $+\frac{1}{4}$ & \\
\hline Sic & 416 & & & & \\
\hline Dutchess Cou & & & & & \\
\hline $\begin{array}{l}\text { Barrytown } \\
\text { Fishkill-on-the-Hudson...... }\end{array}$ & 620 & 6 & 3 & -60 & \\
\hline $\begin{array}{l}\text { Fishkill-on-the-Hudson } \\
\text { Poughkeepsie ........... }\end{array}$ & 3,100 & 10 & 10 & -125 & \\
\hline $\begin{array}{l}\text { Poughkeepsie } . . . . . \\
\text { Tivoli }\end{array}$ & $\begin{array}{l}940 \\
405\end{array}$ & $\begin{array}{l}6 \\
6\end{array}$ & $\begin{array}{r}50 \\
2\end{array}$ & $\begin{array}{l}+50 \\
-30\end{array}$ & \\
\hline Erie County: & $\$ 20$ & & & & \\
\hline Alden $15 .$. & 1,308 & & & & Gas well. \\
\hline Buffalo $\ldots . . . \ldots \ldots \ldots$ & 490 & 6 & & $\cdots$ & Do. \\
\hline Do. ${ }^{16} \ldots \ldots \ldots \ldots \ldots$ & 1,305 & $5 \frac{5}{9}$ & & & Do. \\
\hline Collins $17 \ldots \ldots \ldots \ldots \ldots$ & 1,150 & & & & Gas at 1,106 feet. \\
\hline $\begin{array}{l}\text { Collins ( } 1 \frac{1}{2} \text { miles north- } \\
\text { east). }\end{array}$ & 1,548 & & & & Gas well. \\
\hline Depew................ & $1,685-1,700$ & & & & $\begin{array}{l}4 \text { wells; small supply of } \\
\text { gas. }\end{array}$ \\
\hline East Aurora ${ }^{19} \ldots$. & 1,465 & & & & Salt wells. \\
\hline $\begin{array}{l}\text { East Aurora and Orchard } \\
\text { Park (between) }:=\end{array}$ & $1,000-3,000$ & & & & For gas; unsuccessful. \\
\hline - Eden Valley $19 \ldots \ldots \ldots \ldots$ & 1,750 & & & & Salt well. \\
\hline n well $=2 . \ldots \ldots \ldots$ & & & & & \\
\hline New Oregon $23 . \ldots \ldots \ldots$ & 2,100 & & & & U7successful. \\
\hline North Collins $24 . . . \ldots \ldots$ & 1,250 & & & & Do. \\
\hline $\begin{array}{l}\text { Port Colborne } \\
\text { Springville }\end{array}$ & $770-1,500$ & & & & Several small gas wells. \\
\hline $\begin{array}{l}\text { Springvin } \\
\text { Do... }\end{array}$ & 2,300 & & & & $\begin{array}{l}2 \text { gas wells. } \\
\text { Unsuccessful. }\end{array}$ \\
\hline Williamsville.... & (Av.) 875 & $5 \frac{5}{8}$ & & No flow. & 3 wells; 2 unauccessful. \\
\hline
\end{tabular}

1 N. Y. State Museum Rept., 1899, p. rl18

2 Record, Pa. 2d Geol. Surv. Rept, Vol. II, p. 272. 119 .

3 N. Y. State Museum Rept., 1899, pp. r118-

${ }^{4}$ Am. Inst. Mining Eng. Trans., vol. 16, pp. 939-940.

5 N. Y. State Museum Rept., 1899, pp. r115-117.

6 Record, Pa. $2 d$ Geol. Surv. Rept., Voi. I4, p. 100.

7 Record, Am. Geol., vol. 25, pp. 156-160.

$\varepsilon$ Record, Pa.2d Geol. Surv. Kept., Vol. $\mathrm{I}^{\mathbf{b}}, \mathrm{p} .325$.

I Ibid., pp. 325-326.

10 Ibid., p. 228

11 Analysis, Am. Inst. Mining Eng. Trans., vol. 16, pp. 918-923.

${ }_{12}$ Record, Pa. $2 d$ Geol. Surv. Rept., Vol. I4, p. 126.

13 Record, N. Y. State Museum Rept., 1899, p. r120.

${ }_{14}$ Record, Geol. Soc. Am. Bull., vol. 4, p. 95.
15 N. Y. State Museum Rept., 1899, p. r121.

16 Record, Am. Inst. Mining Eng. Trans., vol. 16 , pp. $924-925$.

i7 Record, N. Y. State Museum Rept., 1899, p. r122.

13 Ibid., p. r123.

${ }_{19}$ Record, Rept. Supt. Onondaga Salt Springs, 1888 , pl. 2; 1885, p. 15.

20 N. Y. State Museum Rept., 1899, p. r121.

a1 Record, Rept. Supt. Onondaga salt Springs, 1888, pl. 2.

22 Record, N. Y. State Museum Rept., 1899, p. $\mathrm{r} 117$.

${ }_{23}$ N. Y. State Museum Rept., 1899, p. r116.

${ }^{24}$ Record, Am. Inst. Mining Eng. Trans, vol. 17, p. 401.

:6 N. Y. State Museum Rept., 1899, p. r122. 
NEW YORK-Contịnued.

\begin{tabular}{|c|c|c|c|c|c|}
\hline Location. & Depth. & $\begin{array}{c}\text { Diame- } \\
\text { ter. }\end{array}$ & $\begin{array}{c}\text { Yield per } \\
\text { minute. }\end{array}$ & $\begin{array}{l}\text { Height of } \\
\text { water. }\end{array}$ & Remark \\
\hline 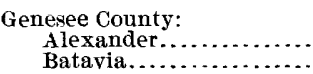 & Fect. & $\begin{array}{c}\text { Inches. } \\
\ldots \ldots \\
\ldots \ldots\end{array}$ & lons. & $\begin{array}{c}\text { Feet. } \\
\cdots \cdots \cdots \\
\cdots \cdots\end{array}$ & Salt well. \\
\hline Corfu ( 2 miles west)..... & $\begin{array}{l}1,208 \\
1,248\end{array}$ & $8-6 \frac{1}{4}$ & & $\left\{\begin{array}{l}-15 \text { and } \\
-135\end{array}\right.$ & Several gas wel's. \\
\hline $\begin{array}{r}\text { Darien }^{1} \ldots \ldots \ldots \ldots \\
\text { Leroy }\end{array}$ & $\begin{array}{r}+1,300 \\
878-1,003\end{array}$ & & & …........ & Salt wells. \\
\hline $\begin{array}{l}\text { Greene County: } \\
\text { Cairo ( } 3 \frac{1}{2} \text { miles south- } \\
\text { west) }{ }^{3}\end{array}$ & 2,200 & $5 \frac{5}{8}$ & & -310 & For oil or gas: abandoned. \\
\hline 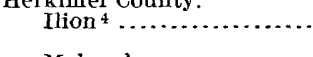 & 1,135 & & & & $\begin{array}{l}\text { Gas in small quantities at } \\
800,950 \text {, and } 1.000 \text { feet. }\end{array}$ \\
\hline $\begin{array}{l}\text { Mohawk.............. } \\
\text { Jefferson County: }\end{array}$ & 420 & 6 & & -30 & Sulphurous water. \\
\hline Watertown $5 . .$. & 530 & & & & Some gas at 253 feet. \\
\hline $\begin{array}{l}\text { Lewis County: } \\
\text { Greig } \ldots . . . . . . .\end{array}$ & 700 & & & & Bored for oil. \\
\hline $\begin{array}{l}\text { Livingston County: } \\
\text { Caledonia .......... }\end{array}$ & 1,100 & $8-6 \frac{1}{4}$ & & -25 & Salty, sulphurous water. \\
\hline $\begin{array}{r}\text { Do. } 6 \ldots \ldots \ldots \\
\text { Cuylerville } 6 \ldots \ldots\end{array}$ & $\begin{array}{r}760 \\
1,145\end{array}$ & & & 20 & $\begin{array}{l}\text { Salt well. } \\
\text { Do. }\end{array}$ \\
\hline Dansville.................... & 1,800 & & & ........ & Du. \\
\hline Dansville (near) ${ }^{7} \ldots \ldots$ & $\begin{array}{r}+508 \\
2,240\end{array}$ & & & & $\begin{array}{l}\text { Gas at } 295 \text { and } 508 \text { feet. } \\
\text { No gas reported. }\end{array}$ \\
\hline Greigsville ${ }^{8} \ldots \ldots \ldots$ & $1,138-1,145$ & & & & Salt wells. \\
\hline Do.1 ${ }^{1} \ldots \ldots \ldots \ldots$ & 1,800 & & & & $\begin{array}{l}\text { For gas: un zuccessful ; } \\
\text { black sulphir water at } \\
1,315 \text { feet. }\end{array}$ \\
\hline $\begin{array}{l}\text { Lakeville }{ }^{8} \ldots \ldots \ldots \ldots \ldots \ldots \\
\text { Leicester } . . . \ldots \ldots \ldots \ldots\end{array}$ & $\begin{array}{l}1,053 \\
1,165\end{array}$ & & & & $\begin{array}{l}\text { Salt well. } \\
\text { Do. }\end{array}$ \\
\hline Livonia $^{0} \ldots \ldots$ & 1,432 & Shaft. & & $\cdots$ & Salt mine. \\
\hline Do $\ldots \ldots$................. & 1,100 & & & & Salt well. \\
\hline $\begin{array}{l}\text { Mount Morris }{ }^{8} \ldots \ldots \ldots \ldots \\
\text { Nunda }{ }^{8} \ldots \ldots \ldots \ldots \ldots \ldots\end{array}$ & $1,130-1,422$ & & & (... & $\begin{array}{l}\text { Several salt wells. } \\
\text { Do. }\end{array}$ \\
\hline Piffard ${ }^{10} \ldots \ldots \ldots \ldots$ & $961-1,141$ & & & & \\
\hline $\begin{array}{l}\text { York } \\
\text { Madison County: }\end{array}$ & 828 & & & & Salt well. \\
\hline Canastota ...... & 648 & & & & Bitter brines. \\
\hline Chittenango ${ }^{11}$........... & 3,026 & & & & Gas well. \\
\hline $\begin{array}{l}\text { Eagleville } . . . \ldots \ldots \ldots \\
\text { Eaton }\end{array}$ & $\begin{array}{r}1,889 \\
400\end{array}$ & 5 & 20 & -3 & \\
\hline Morrisville $12 . . .6 . . .6$. & 1,889 & & & $\rightarrow \infty$ & Do. \\
\hline Uniontown $\ldots \ldots \ldots \ldots \ldots$ & & & & & Do. \\
\hline $\begin{array}{l}\text { Manhattan Borough: } \\
\text { Governors Island.. }\end{array}$ & 1,822 & $12-6$ & 18 & Flows. & Flow of 15 gallons at 1,715 \\
\hline & & & & & $\begin{array}{l}\text { feet was increased by } \\
\text { torpedoing; salty. }\end{array}$ \\
\hline $\begin{array}{l}\text { Tenth and Washington } \\
\text { streets. }\end{array}$ & 500 & 6 & 600 & No flow. & \\
\hline Fifth Avenue Hotel..... & 1,108 & & & & No water. \\
\hline $\begin{array}{l}\text { Greenwich and ilth } \\
\text { streets. }\end{array}$ & 1,047 & 8 & Comanol & No flow. & \\
\hline $\begin{array}{l}\text { United States Hotel.... } \\
\text { Twenty-eighth st., near }\end{array}$ & $\begin{array}{r}629 \text { ( or } 900 \text { ) } \\
500\end{array}$ & 8 & $\begin{array}{r}\text { Several. } \\
100\end{array}$ & No flow. & \\
\hline $\begin{array}{l}\text { Broadway } \\
\text { Avenue D, foot of East }\end{array}$ & 1,194 & & Several. & & \\
\hline Tenth street. & & & & & \\
\hline $\begin{array}{l}\text { Fourth avenue and } 47 \text { th } \\
\text { street. }\end{array}$ & 600 & 8 & 100 & No flow. & \\
\hline Foot of 47 th st.................. & $\begin{array}{l}402 \\
700\end{array}$ & 8 & 100 & No flow. & \\
\hline $\begin{array}{l}\text { Eleventh avenue and } \\
59 \text { th street. }\end{array}$ & & & & & \\
\hline $\begin{array}{l}\text { Fourth avenue and 51st } \\
\text { street. }\end{array}$ & 1,194 & & Few. & & \\
\hline $\begin{array}{l}\text { Eighth avenue and } 72 \mathrm{~d} \\
\text { street. }\end{array}$ & 1,200 & 8 & 8 & No flow. & \\
\hline $\begin{array}{l}\text { Fifth avenue and 59th } \\
\text { street. }\end{array}$ & 500 & & 80 & No flow. & \\
\hline Third avenue and $92 \mathrm{~d}$ & 685 & 9 & 300 & No flow. & \\
\hline $\begin{array}{l}\text { Eighth avenue and 145th } \\
\text { street. }\end{array}$ & 605 & $10-8$ & & No flow. & \\
\hline
\end{tabular}

1 N. Y. State Museum Rept., 1899, p. r121.

2 Record, Rept. Supt. Onondaga Salt Springs,

1888, pl. 2: 1884, pp. 19-20.

3 Record, Am. Inst. Mining Eng. Trans., vol.

16 , p. 956 .

4 Record, Am. Geol., vol. 25, pp. 132-135.

5 Record, Geol. Soc. Am. Bull., vol. 4, p. 107.

${ }^{6}$ Record, Rept. Supt. Onondaga Salt Springs,

1888 , pl. $2 ; 1885$, p. 15 .

7 N. Y. State Museum Rept., 1899, p. r128.

${ }^{8}$ Record, Rept. Supt. Onondaga Salt Springs, $1888, \mathrm{pl} .2$.

9 Am. Geol., vol. 15, p. 379; N. Y. State Geol. Rept., 1893, vol. 1, p. 13.

10 Record, Rept. Supt. Onondaga Salt Springs, 1884, pp. 20-21.

11 Record, Geol. Soc. Am. Bull., vo' 4, p. 101.

12 Ibid., pp. 96-97; Rept. Supt. Onondaga Salt

Springs, 1888, pl. 2. 
NEW YORK-Continued.

\begin{tabular}{|c|c|c|c|c|c|}
\hline Location. & Depth. & $\begin{array}{l}\text { Diame- } \\
\text { ter. }\end{array}$ & $\begin{array}{c}\text { Yield per } \\
\text { minute. }\end{array}$ & $\begin{array}{l}\text { Height of } \\
\text { water. }\end{array}$ & Remarks. \\
\hline $\begin{array}{l}\text { Manhattan Borough-Con. } \\
\text { Washington Building ... }\end{array}$ & $\begin{array}{l}\text { Feet. } \\
1,000\end{array}$ & $\begin{array}{l}\text { Inches. } \\
\text {........... }\end{array}$ & Gallons. & $\begin{array}{l}\text { Feet. } \\
\text { No flow. }\end{array}$ & \\
\hline $\begin{array}{c}\text { Manhattan insurance } \\
\text { Building. }\end{array}$ & 1,056 & 8 & 75 & No flow. & \\
\hline $\begin{array}{c}\text { Liberty and Nassau } \\
\text { streets. }\end{array}$ & 720 & $\ldots . .$. & 80 & No flow. & \\
\hline $\begin{array}{l}\text { New York Life Insur- } \\
\text { ance Building. }\end{array}$ & 500 & & & No flow. & \\
\hline Fulton Market .......... & 626 & & & No flow. & \\
\hline $\begin{array}{l}\text { Broadway and Bleecker } \\
\text { street. }\end{array}$ & 448 & 7 & 80 & No flow. & \\
\hline $\begin{array}{l}\text { Lafayette and Barnard } \\
\text { streets. }\end{array}$ & 700 & 8 & 80 & No flow. & \\
\hline Boulevard and $72 \mathrm{~d}$ street & 700 & & 25 & & Hard water \\
\hline $\begin{array}{l}\text { Eighth avenue and } 146 \text { th } \\
\text { street. }\end{array}$ & 1,035 & 8 & 500 & No flow. & \\
\hline $\begin{array}{l}\text { Eighth avenue and } 55 \mathrm{th} \\
\text { street (Y. M. C. A. } \\
\text { Building), }\end{array}$ & 1,000 & & & & \\
\hline Ninety-ninth street....... & $\begin{array}{r}609 \\
1,505\end{array}$ & $\begin{array}{l}8 \\
8\end{array}$ & 11 & $\begin{array}{l}\text { No flow. } \\
\text { No flow. }\end{array}$ & $\begin{array}{l}\text { Akandoned. } \\
\text { Do. }\end{array}$ \\
\hline $\begin{array}{l}\text { Sixty-seventh st., near } \\
\text { Third ave. }\end{array}$ & 1,504 & 8 & 11 & -32 & Do. \\
\hline NearSecond ave..... & 1,502 & 8 & 50 & -38 & Do. \\
\hline $\begin{array}{l}\text { Morris and Greenwich } \\
\text { streets. }\end{array}$ & 625 & 8 & 40 & No flow. & Do. \\
\hline Dunwoodie................... & 775 & $\begin{array}{c}8 \\
\ldots\end{array}$ & & No flow. & $\begin{array}{l}\text { Do. } \\
\text { Good supply. }\end{array}$ \\
\hline Monroe County: & & & & & \\
\hline $\begin{array}{l}\text { Brockport } \ldots \ldots \ldots \ldots \\
\text { Honeove Falls } 1\end{array}$ & 2,000 & & & & Fo"gas; unsuccessful. \\
\hline $\begin{array}{l}\text { Honeoye Falls }{ }^{1} \ldots \ldots \ldots \ldots \\
\text { Nassau County: }\end{array}$ & 1,500 & & & & Gas well. \\
\hline Brookville.......................... & 400 & 6 & & & Akandoned; quicksand. \\
\hline Hewletts Point ........... & 512 & 8 & & & Rock below 230 ; no water. \\
\hline 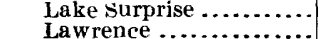 & 755 & $8-4 \frac{1}{2}$ & 300 & -135 & \\
\hline $\begin{array}{l}\text { Lawrence } \ldots . . . \ldots \ldots \ldots . . . . . \\
\text { Lynbrook (one-half mile }\end{array}$ & $\begin{array}{l}416 \\
504\end{array}$ & $\begin{array}{l}3 \\
8\end{array}$ & $\begin{array}{l}13 \\
\mathbf{3 0}\end{array}$ & $\begin{array}{r}-15 \\
+\quad 2\end{array}$ & $\begin{array}{l}\text { Salt water. } \\
\text { Flows at } 76 \text { and } 500 \text { feet. }\end{array}$ \\
\hline $\begin{array}{l}\text { west). } \\
\text { Lynbrook (1 mile east } \\
\text { Brooklyn Waterworks } \\
\text { test well No. 25). }\end{array}$ & 587 & 5 & 5 & +2 & Flows at 578 and 587 feet. \\
\hline Oyster Bay ................ & 465 & 6 & & Flows. & Atandoned; pipe broke. \\
\hline $\begin{array}{l}\text { Valley Stream (Brook- } \\
\text { lyn Waterworks test } \\
\text { well No. 21).2 }\end{array}$ & 410 & 5 & $\ldots$ & ......... & $\begin{array}{l}\text { At } 290 \text { feet slightly water } \\
\text { bearing. }\end{array}$ \\
\hline Wheatley Hills.......... & 434 & 8 & 150 & -245 & \\
\hline $\begin{array}{l}\text { Do } \\
\text { Niagara County: }\end{array}$ & 400 & 10 & 35 & -230 & \\
\hline 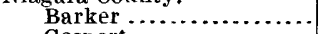 & 2,175 & & & $\cdots \cdots \cdot$ & Salt, oil, and gas. \\
\hline Gasport................... & 2,007 & & & & Gas at 1,080 feet. \\
\hline $\begin{array}{l}\text { Getzville } \ldots \ldots \ldots \ldots \ldots \ldots \\
\text { Lockport } \ldots \ldots \ldots \ldots \ldots\end{array}$ & 1,400 & & & & $\begin{array}{l}\text { Several good gas wells. } \\
\text { Salt well. }\end{array}$ \\
\hline Oneida County:.......... & & & & & 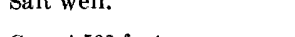 \\
\hline New Iork Mills ${ }^{3}$ & 2,000 & & & & Gas at 500 feet. \\
\hline Rome 4 ............ & 1,632 & & & & Gas wells. \\
\hline Do. ${ }^{5} \ldots$ & 832 & & & & Gas well. \\
\hline Utica ${ }^{2}, \ldots . . . .$. & 860 & & & & Do. \\
\hline Do. ${ }^{7} \ldots \ldots \ldots$ & 1,720 & & $\cdots$ & $\cdots$ & \\
\hline $\begin{array}{l}\text { Utica (Bagg's Hotel) } \ldots \ldots \\
\text { Vernon }{ }^{8} . . . \ldots \ldots\end{array}$ & $\begin{array}{r}460 \\
1,968\end{array}$ & & & & Do. \\
\hline Onondaga County: & & & & & \\
\hline Baldwinsville..$\ldots \ldots \ldots$ & 2,358 & $6 \frac{1}{4}$ & & & Do. \\
\hline $\begin{array}{l}\text { Baldwinsville ( } 1 \text { mile } \\
\text { south).9}\end{array}$ & 2,250 & & & & \\
\hline $\begin{array}{c}\text { Baldwinsville }(1 \mathrm{mile} \\
\text { north). } 10\end{array}$ & 2,795 & & & & Do. \\
\hline Cardiff $11 \ldots \ldots \ldots \ldots \ldots$ & 844 & & $\cdots \cdot \cdot$ & & Di \\
\hline $\begin{array}{l}\text { Cedarville } \\
\text { Greenpoint } 12 \ldots \ldots \ldots \ldots\end{array}$ & $\begin{array}{l}1,157 \\
1,600\end{array}$ & & & & Do. \\
\hline
\end{tabular}

${ }^{1}$ Record, Pa. 2d Geol. Surv. Rept., Vol. 15, p. 326.

Record, Ann. Rept. Dept. City Works, BrookIyn, 1896, p. 302

${ }^{8}$ Am. Inst. Mining Eng. Trans., vol. 16, pp. 958-959.

4 Record, Am. Geol., vol. 25, pp. 137-143.

6 Ibid., p. 145.
${ }^{6}$ Am. Geol., vol. 25, p. 137.

7 Record, Geol. Soc. An. Bull., vol. 4, p. 100.

8 Record, Am. Geol., vci. 25, pp. 145-149.

9 Ibid., pp. 150-152.

10 Ibid., p. 154.

1 Record, Rept. Supt. Onondaga Salt Springs, 1888 , pl. 2; 1885, p. 15 .

12 Ibid., 1884, pp. 12-15; 1888, pl. 2 . 
NEW YORK-Continued.

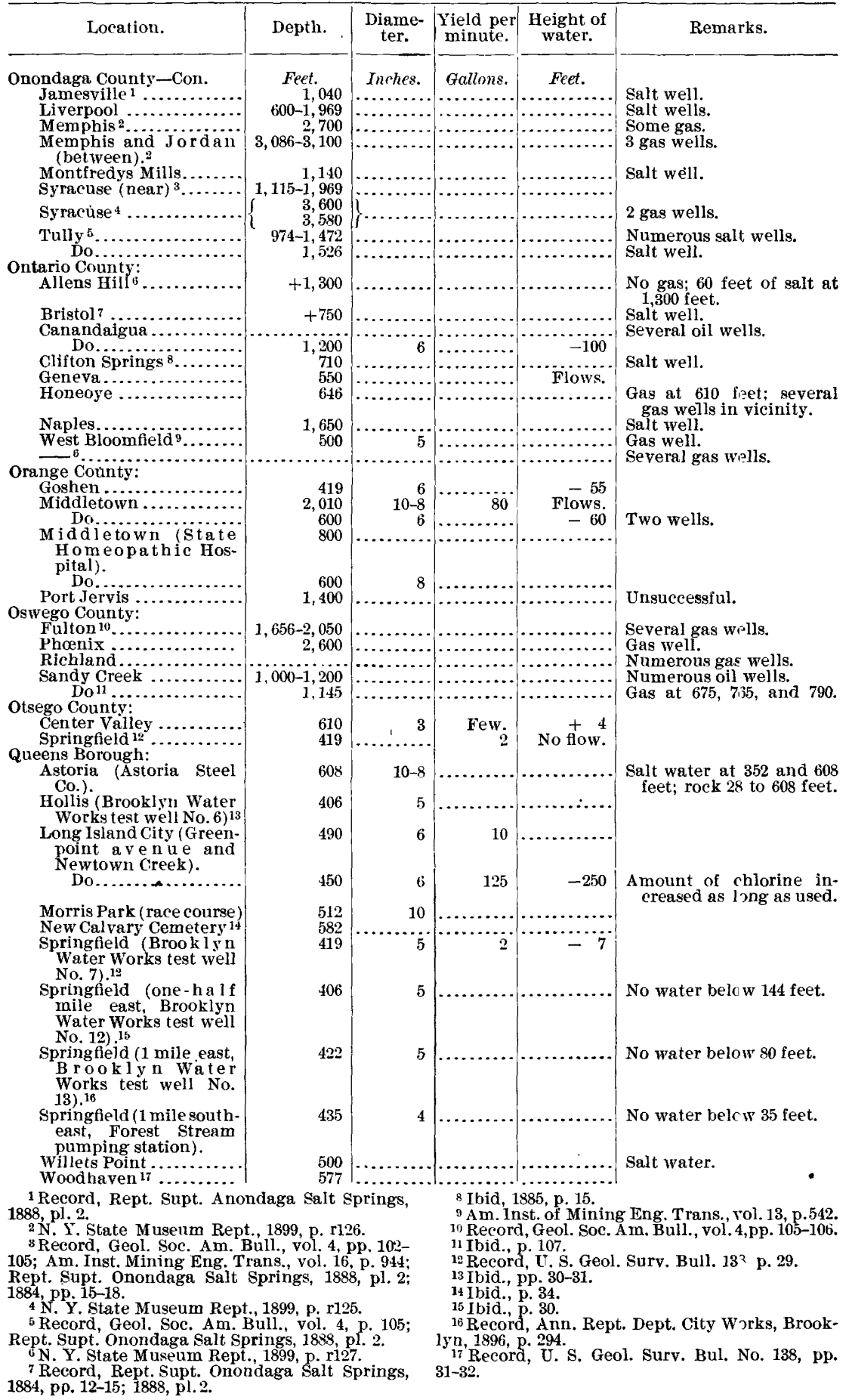

1884, p p. 12-15; 1888, pl.2. 
NEW YORK-Continued.

\begin{tabular}{|c|c|c|c|c|c|}
\hline Location. & Depth. & $\begin{array}{l}\text { Diame- } \\
\text { ter. }\end{array}$ & $\begin{array}{c}\text { Yield per } \\
\text { minute. }\end{array}$ & $\begin{array}{l}\text { Height of } \\
\text { water. }\end{array}$ & Remarks. \\
\hline $\begin{array}{l}\text { Rensselaer County: } \\
\text { Shodack Landing. }\end{array}$ & $\begin{array}{l}\text { Feet. } \\
1,000 ?\end{array}$ & & & & Salt well. \\
\hline Richmond County: & & & & & Nowater \\
\hline $\begin{array}{l}\text { New Dorp } \ldots \ldots \ldots \ldots \ldots \\
\text { Hoffmans Island } \ldots \ldots \ldots\end{array}$ & $\begin{array}{r}600 \\
1,000\end{array}$ & 8 & & 33 & $\begin{array}{l}\text { No water. } \\
\text { Salt water to } 900 \text { feet. }\end{array}$ \\
\hline Saratoga County: & & & & & \\
\hline $\begin{array}{r}\text { Ballston } \ldots \ldots \ldots \ldots \ldots \\
\text { Do } \ldots \ldots \ldots\end{array}$ & $\begin{array}{l}560 \\
778\end{array}$ & 6 & & $\begin{array}{l}+60 \\
-3\end{array}$ & Mineral water. \\
\hline Saratoga Springs ........... & 400 & 6 & $3 \frac{1}{2}$ & & \\
\hline Do............. & 1,006 & $2 \frac{7}{8}$ & 2 & +75 & \\
\hline Do........... & $\begin{array}{l}600 \\
440\end{array}$ & 6 & $\frac{1}{3}$ & Flows. & \\
\hline Do............ & $\begin{array}{r}440 \\
520\end{array}$ & $\begin{array}{l}6 \\
6\end{array}$ & $\begin{array}{l}\frac{1}{3} \\
\frac{1}{3}\end{array}$ & $\begin{array}{l}+40 \\
+40\end{array}$ & \\
\hline Do.......... & 425 & 6 & $\begin{array}{l}3 \\
\frac{1}{3}\end{array}$ & -16 & \\
\hline Do.......... & $478 ?$ & & & +40 & Do. \\
\hline $\begin{array}{l}\text { Do............ } \\
\text { Schuvlervilie... }\end{array}$ & 422 & & & -16 & \\
\hline schenectady County & & & & & \\
\hline & 400 & 6 & 75 & -20 & \\
\hline $\begin{array}{l}\text { chuyler County: } \\
\text { Glen Springs. }\end{array}$ & 1,500 & & & & For oil: unsuceessful. \\
\hline Watkins..... & $2,100 \pm$ & & & & $\begin{array}{l}\text { For oll; unsuccessful. } \\
\text { Several salt wells. }\end{array}$ \\
\hline Do 1. & 1,100 & & & & A bandoned. \\
\hline Do $^{1} \ldots \ldots \ldots$ & 800 & & & & \\
\hline $\begin{array}{l}\text { Do } 1 \ldots \ldots \ldots \\
\text { seneca County: }\end{array}$ & 1,715 & & & & Gas, at 1,350 feet. \\
\hline Seneca Falls.... & 3,560 & & & & Gas well. \\
\hline Do.......... & $400-500$ & & & Flow. & $\begin{array}{l}\text { Several salt wells in vicin. } \\
\text { ity. }\end{array}$ \\
\hline $\begin{array}{r}\text { Do } 2 . . . . . . \\
\text { Steuben Counts: }\end{array}$ & 1,500 & & & & Gas well. \\
\hline $\begin{array}{l}\text { Steuben County: } \\
\text { Addison and corning }\end{array}$ & 1,148 & & & & \\
\hline (between). ${ }^{3}$ & 2050 & & & & Gas well \\
\hline Bloods ${ }^{4} \ldots \ldots \ldots$ & $\begin{array}{l}2,000 \\
1,495\end{array}$ & & & & $\begin{array}{l}\text { Gas well. } \\
\text { Showing of gas. }\end{array}$ \\
\hline Campbell Township $5 . .$. & 2,800 & & & & For gas; unsuccessful. \\
\hline Campbell ${ }^{6} \ldots \ldots \ldots \ldots \ldots$ & 2,250 & $\cdots$ & & & For oit or gas. \\
\hline Canisteo (and vicinity) & $735-1,300$ & & & & $\begin{array}{l}\text { Sev aral unsuccessful. } \\
\text { Several gas wells. }\end{array}$ \\
\hline Corning 5 ................. & 3,000 & & & & Salt water prevented far- \\
\hline Cohocton ( & & & & & For oil. \\
\hline $\begin{array}{l}\text { Howard (one-half mile } \\
\text { west). }\end{array}$ & 2,000 & & & & $\begin{array}{l}\text { For oil or gas; unsuccess- } \\
\text { ful. }\end{array}$ \\
\hline $\begin{array}{l}\text { Hornby Township (near } \\
\text { south line) }\end{array}$ & 1,528 & & & & Gas well. \\
\hline Hornellsville ${ }^{3} . \ldots \ldots \ldots$. & 3,200 & & & & Good veins of gas at 700 , \\
\hline Do......... & 1,500 & $6 \frac{1}{2}$ & & & $\begin{array}{l}\text { Gas at } 650,940 \text {, and } 1,200 \\
\text { feat, } 3 \text { wells of same } \\
\text { depth. }\end{array}$ \\
\hline $\begin{array}{l}\text { Do............. } \\
\text { Lavona } 8 . . . . .\end{array}$ & $\begin{array}{l}1,522 \\
3,005\end{array}$ & $6 \frac{1}{4}$ & & & Gas well. \\
\hline Prattsburg ( $1 \frac{1}{s}$ miles & & & & & in boih. \\
\hline southwest).$^{\frac{1}{2}}$ miles & 1,800 & & & & \\
\hline$\underset{\text { Rexville }}{{ }^{5}} \ldots \ldots$ & 1,200 & & & & \\
\hline $\begin{array}{l}\text { Rexville } 5 \text {. } \\
\text { Rheims }{ }^{8} \text {. }\end{array}$ & $1,635-1,181$ & … & & & Do. \\
\hline $\begin{array}{l}\text { Rhe } \\
\text { Spr }\end{array}$ & 2,000 & & & & Showing \\
\hline Troup & $\begin{array}{r}1,030 \\
632\end{array}$ & & & & $\begin{array}{l}\text { Small amount } \\
\text { Gas well. }\end{array}$ \\
\hline Urbana $\ldots \ldots \ldots$ & 2,000 & 6 & 8 & -30 & \\
\hline Woodhull ................ & 3,000 & & & +50 & Unsuceessful oil well, flow \\
\hline Wyleys & 2,010 & & & & Gas well. \\
\hline Suffolk County. & & & & & \\
\hline $\begin{array}{l}\text { Cold Spring Harbor (1 } \\
\text { mile north). }\end{array}$ & 410 & 6 & 10 & +1 & \\
\hline Do....... & 400 & 8 & 75 & No flow. & $\begin{array}{l}\text { Water-bearing beds at } 276 \\
\text { an } 303 \text { feet. }\end{array}$ \\
\hline Fishers Island ........... & 485 & 6 & & & Sal! water. \\
\hline $\begin{array}{l}\text { Huntington (2 miles } \\
\text { northwest). }\end{array}$ & 498 & 3 & & & $\begin{array}{l}\text { Incomplete; no water be- } \\
\text { low } 88 \text { feet. }\end{array}$ \\
\hline$\underset{\text { Point). }}{\text { Orient (Long Beach }}$ & +406 & 6 & & & $\begin{array}{l}\text { Salt water } 225 \text { to } 555 \text { feet; } \\
\text { small fow of fresh water } \\
\text { at } 665 \text { feet, bed rock at } \\
670 \text { feet. } \\
\text { Salt water. }\end{array}$ \\
\hline
\end{tabular}

1N. I. State Museum Rept., 1899, p. r127.

2 Record, Am. lnst. Mining Eng. Trans., vol. 16, p. 949 .

${ }^{3}$ Record, N. I. State Museum Rept., 1899. p. r130.

${ }^{4}$ N. Y. State Museum Rept., 1849, p. r128.
5 Ibid., p. r132.

o Record, Geol. Soc, Am. B 'll, vol, 4 pp, 97-100. 7 Record, N. Y. State Muserm Rept., 1899, p. r131. Ibid., p. ri29. 
NEW YORK-Continued.

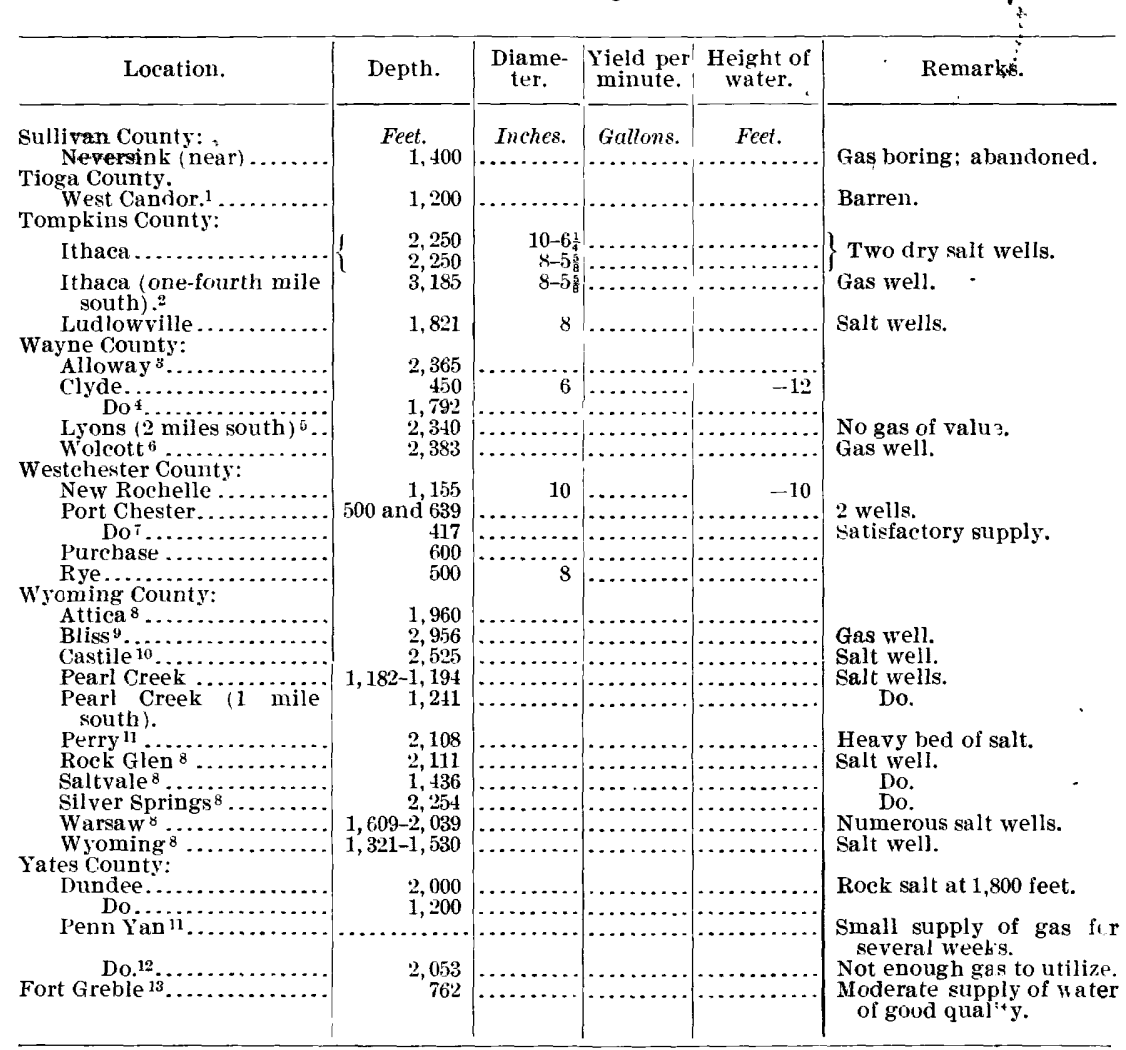

${ }^{1}$ N. Y. State Museum Rept., 1899, p. r132.

2 Record and analysis, Am. Inst. Mining Eng.

Trans., vol. 16, p. 941; Rept. Supt. Onondaga Salt

Sprungs, 1888, pi. 2 .

a kecord, Am. Geol., vol. 25, 1900, pp. 353-355.

4 Record, Am. Inst. Mining Eng. Trans, vol. 16,

p. 94'. 1899 , p. r133

Am Inst. Mining Eng. Trans, vol. 13, .p. 943.

7 N. J, Geol. Surv. Ann, Rept., 1900, p. 156.
${ }^{8}$ Record, Rept. Supt. Onondaga salt Springs, $1888, \mathrm{pl} .2$.

${ }^{9}$ Record, N. Y. State Museum Rept., 1897, p. r133.

"Record, Rept. Supt Onondaga Salt Springs, 1888, pl. 2; Rept , 1885, p. 15.

11 Am. Inst. Mining Eng. Trans., vol. 16, pp. 939-940

12 Partial record, N. Y. State Museum Rept., 1899, p. r134.

13 . J. Geol. Surv. Ann. Rept., 1900, pp. 155-156.

\section{PRINCIPAL PUBLICATIONS RELATING TO DEEP BORIIGS IN NEW YORK.}

Annual Report of Superintendent of Onondaga Salt Springs for 1888, 26 pages, plates, Albany, 1889.

Thickness of the Devonian and Sllurian rocks of central New York, by G. S. Prosser: American Geological Society Bulletın, volume 4, pages 91-118, Fochester, 1893.

United States Geological Survey Bulletin No. 138, 232 pages, Washington, 1896.

Gas well sections in the upper Mohawk Valley and central New York, by C. S. Prosser: American Geologist, volume 25, pages 131-162, March, 1900.

Petroleum and natural gas in New York State, by C. A. Ashburner: American Institute of Mining Engmeers Transactions, volume 16, pages 906-953.

Section of the Alloway (New York) well, by C. S. Prosser: American Geologist, volume $25,1900$.

Fifty-third Annual Report of the New York State Museum for 1899. 


\section{NORTH CAROLINA.}

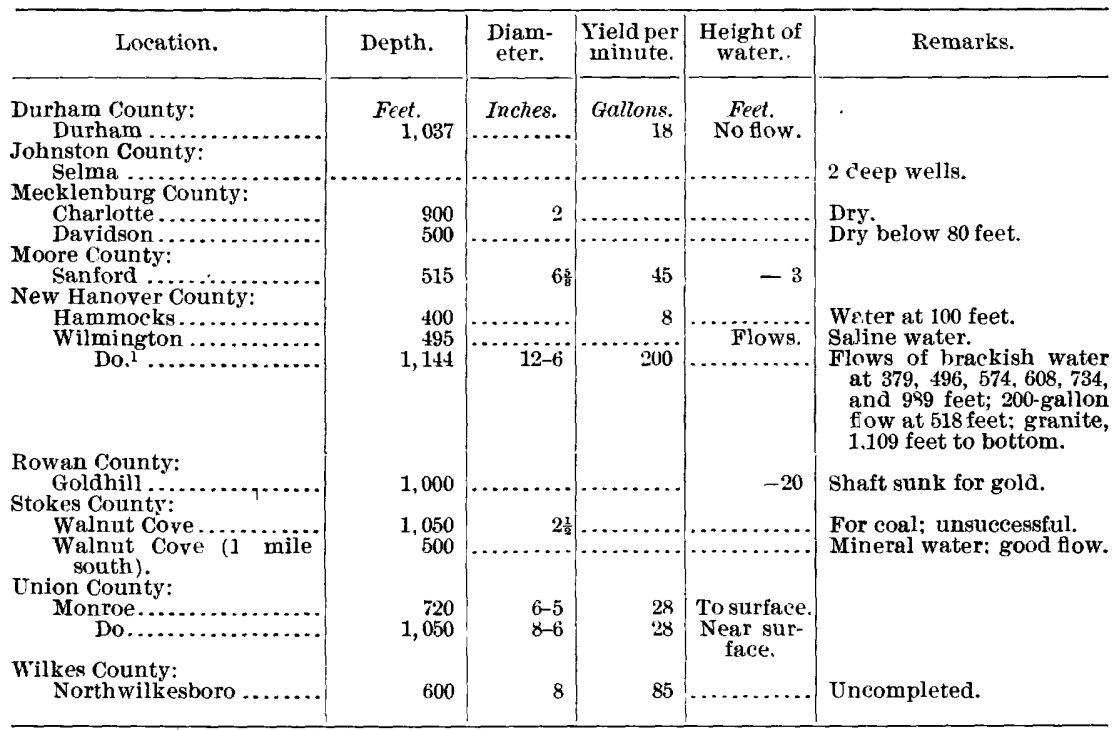

1 Science, new ser., vol. 11, 1900, pp. 128-130.

\section{PUBLICATIONS RELATING TO DEEP BORINGS IN NORTH CAROLINA.}

Artesian well prospects in the Atlantic Coastal Plain region, by N. H. Darton: U. S. Geological Survey Bulletin No. 138, 232 pages, plates, Washington, 1896.

Science, new series, volume 11, 1900.

\section{NORTH DAKOTA.}

\begin{tabular}{|c|c|c|c|c|c|}
\hline Location. & Depth. & $\begin{array}{l}\text { Diam- } \\
\text { eter. }\end{array}$ & $\begin{array}{l}\text { Yield per } \\
\text { minute. }\end{array}$ & $\begin{array}{l}\text { Height of } \\
\text { water. }\end{array}$ & Remarks. \\
\hline $\begin{array}{l}\text { Barnes County: } \\
\text { Ashtabula ( } 2 \frac{1}{2} \text { miles west } \\
\text { of). }\end{array}$ & $\begin{array}{l}\text { Feet. } \\
\quad 1,340\end{array}$ & $\begin{array}{l}\text { Inches. } \\
\text {......... }\end{array}$ & Gallons. & $\stackrel{\text { Feet. }}{-11}$ & $\begin{array}{l}\text { Prin aipal water horizon at } \\
1,325 \text { feet. }\end{array}$ \\
\hline Wimbleton ${ }^{1} \ldots \ldots \ldots \ldots \ldots$ & 1,557 & & 200 & +184 & \\
\hline 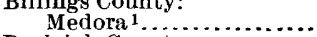 & 941 & 4 & 33 & $+34 \frac{1}{2}$ & \\
\hline $\begin{array}{l}\text { Burleigh County: } \\
\text { Bismarck }\end{array}$ & 1,315 & $8-4$ & & & No flow. \\
\hline $\begin{array}{l}\text { Cass County: } \\
\text { Buffalo ( } 6 \text { miles north- }\end{array}$ & 514 & & 25 & +115 & Stap'e's well. \\
\hline 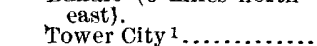 & 716 & $6-4 \frac{2}{2}$ & $20-25$ & & \\
\hline $\begin{array}{c}\text { Dickey County: } \\
\text { northeast) }\end{array}$ & 1,022 & 1 & 25 & Flows. & \\
\hline $\begin{array}{l}\text { Ellendale (15 miles } \\
\text { northeast). }\end{array}$ & 1,036 & $2-1$ & 18 & Flows. & \\
\hline $\begin{array}{l}\text { Ellendale } \\
\text { Ellendale (west of } \ldots \ldots\end{array}$ & $\begin{array}{l}860 \\
600\end{array}$ & & $\ldots$ & $\begin{array}{r}+138 \\
\ldots \ldots\end{array}$ & No water. \\
\hline $\begin{array}{l}\text { Ellendale (12 miles } \\
\text { northwest). }\end{array}$ & 1,015 & 1 & & & \\
\hline $\begin{array}{l}\text { Ellendale } 1 \ldots \ldots \ldots \ldots \ldots \\
\text { Glover (near) } \ldots \ldots \ldots \ldots\end{array}$ & 1,087 & $\begin{aligned} 4 \frac{2}{8}-3 \\
1 \frac{3}{4}\end{aligned}$ & $\begin{array}{r}700 \\
37\end{array}$ & +260 & Water at 1,042 feet. \\
\hline & 1,000 & & & $+1 i i$ & \\
\hline Ludden (south of) $\ldots \ldots$. & 940 & & & & : \\
\hline $\begin{array}{l}\text { Ludden (north of) } \ldots \ldots \ldots \\
\text { Do } \ldots \ldots \ldots \ldots \ldots \ldots \ldots\end{array}$ & $\begin{array}{r}1,050 \\
980\end{array}$ & & 10 & $\cdots \cdots \cdots+6{ }^{2}$ & \\
\hline Oakes 1 .......................... & 977 & & & & $\begin{array}{l}\text { Wate at } 790,845,870, \text { ard } \\
937 \text { feet. }\end{array}$ \\
\hline
\end{tabular}

1 U. S. Geol. Surv., 17th Ann. Rept., 1895-96, part 2, pp. 59-63. 
NORTH DAKOTA-Continued.

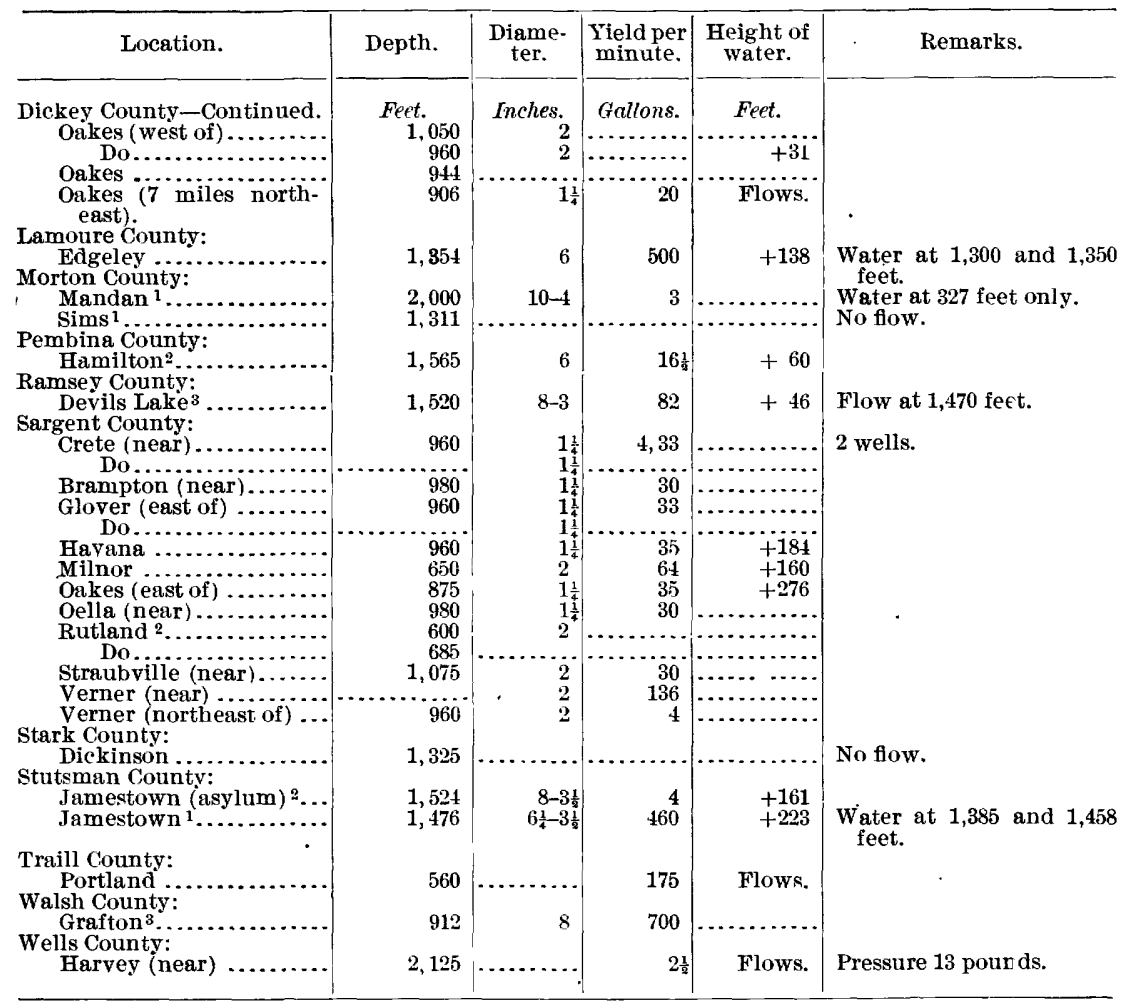

1 U. s. Geol. Surv., 17th Ann. Rept., 1895-96, part 2, pp. 59-63.

2 51st Cong., 1st sess., Senate Ex. Doc. No. 222, 1890, p. 322.

3 Record, ibid., 1890, pp. 107-108.

\section{PRINCIPAL PUBLICATIONS RELATING TO DEEP BORINGS IN NORTH DAKOTA.}

Report of F. S. Underhill for North Dakota: Fifty-first Congress, first session, Senate Ex. Doc. No 222, pages 105-109, Washington, 1890.

Report on Irrigation, Fifty-second Congress, first session, Senate Ex. Doc. No. 41, part 2, pages 66-72, 87-94, Washington, 1893.

Preliminary report on artesian waters of a portion of the Dakotas, by N. H. Darton: United States Geological Survey, Seventeenth Annual Report, 1895-96, part 2, pages 609-694, Washington, 1896. 


\section{OHIO.}

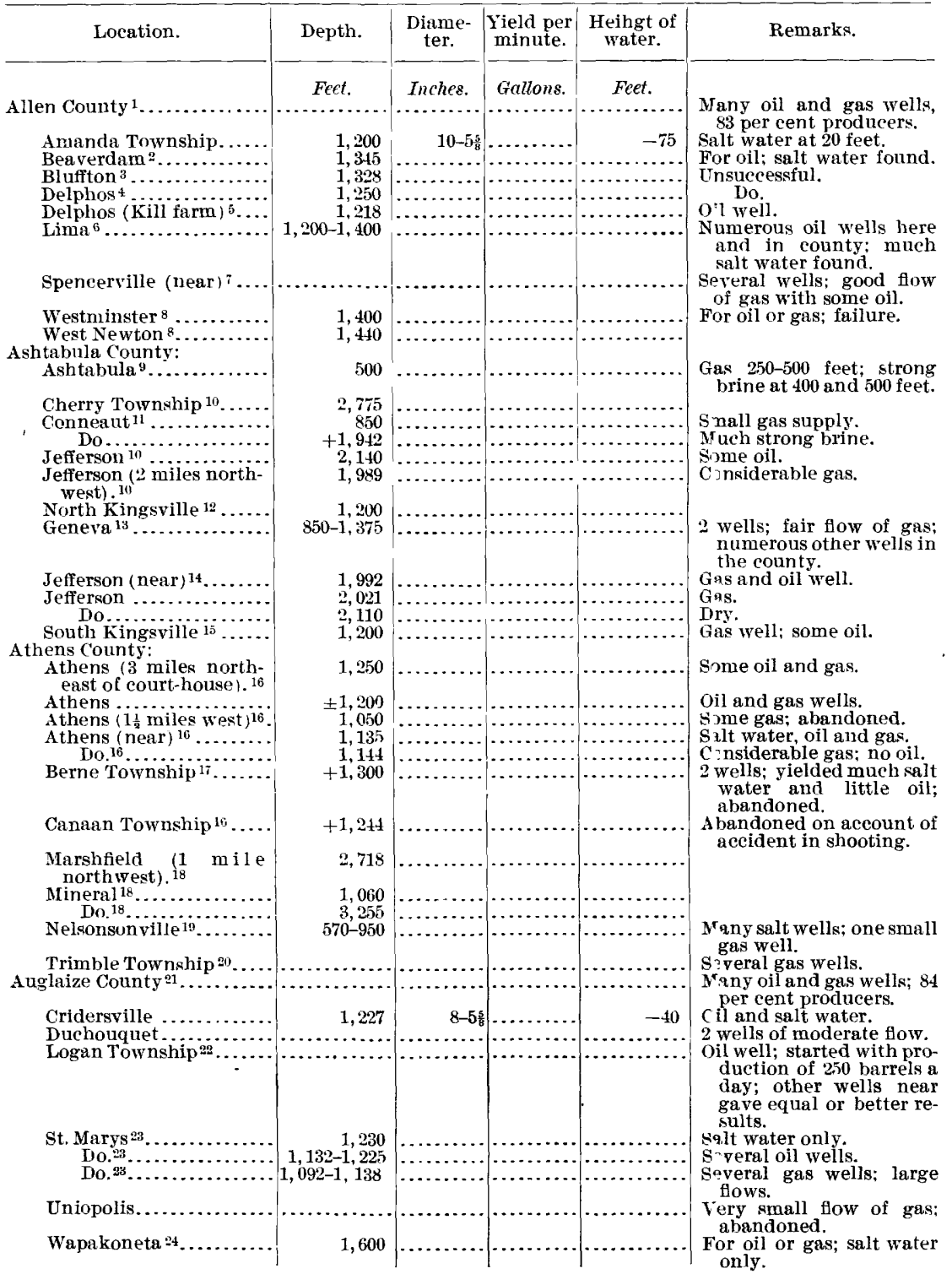

1 Ohio Geol. Surv. Bull. No. 1, 4th ser., 1903, pp. 78-85.

2 Ibid., p. 79. Abandoned at 1,309 feet in 1886 new casing inserted in 1899 , and pumping caused well to produce 25 barrels of oil per day, but this rapidly decreased to a very small amount. Other productive wells near.

3 Ibid., Rept. 1888, vol. 6, p. 216

4 Record, ibid., p. 240.

5 Ibid., 1890, p. 217.

${ }^{6}$ Ibid., 1888, vol. 6, pp. 165-168

7 Ohio Geol. Surv. Buli. No. 1, 4 th ser., 1903, p. 82

8 Record, ibid., Rept. 1888, vol. 6, p. 220.

9 Ibid., pp. 424-425.

303.
11 Ibid., Rept. 1888 , vol. 6 , pp. $422-423$.

12 Ibid,, Bull, No. 1, 4tl ser., p. 302.

13 Record, ibid., Rept. 1888, vol. 6, pp. 425-426.

14 Ibid., Bull. No. 1, 4th ser., 1903, p. 21.

15 Ibid., Rept. 1888, vol. 6, pp. 423-424.

16 Ohio Geol. Surv. Bull. No. 1, tth ser., 1903, pp. 269-270.

17 Ibid., p. 139

18 Ibid., pp. 271-272

19 Ibid., Rept. 1888, vol. 6, p. 398.

20 Ibid., Bull. No. 1, 4th ser., 1903, p. 263

21 Ibid, pp. 85-89.

22 Ibid., p. 85.

${ }^{23}$ Ibid., Rept. 1888, vol. 6, pp. 255-258.

24 Ibid., p. 254. 
OHIO-Continued.

\begin{tabular}{|c|c|c|c|c|c|}
\hline Location. & Depth. & $\begin{array}{l}\text { Diame- } \\
\text { ter. }\end{array}$ & $\begin{array}{l}\text { Yield per } \\
\text { minute. }\end{array}$ & $\begin{array}{l}\text { Height of } \\
\text { water. }\end{array}$ & Remark? \\
\hline $\begin{array}{l}\text { Belmont County: } \\
\text { Barnesville } 1 .\end{array}$ & $\begin{array}{l}\text { Feet. } \\
2,700\end{array}$ & & & & Gas wells. \\
\hline Bellaire $2 \ldots \ldots \ldots \ldots \ldots$ & $\begin{array}{l}1,550 \\
2700\end{array}$ & & & & Small gas wells. \\
\hline $\begin{array}{l}\text { Flushing (I mile north- } \\
\text { east). }\end{array}$ & 1,680 & & & & Salt water only. \\
\hline $\begin{array}{l}\text { Goshen } \\
\text { Martins Ferry } \ldots \ldots \ldots \ldots\end{array}$ & $\begin{array}{l}1,707 \\
2,300\end{array}$ & & & & \\
\hline 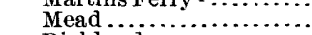 & 2,325 & & & & \\
\hline Richland ............... & $1,237-1,900$ & & & & Several wells. \\
\hline 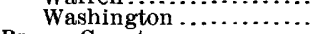 & 1,125 & & & & Gas. \\
\hline $\begin{array}{l}\text { Brown County: } \\
\text { Mount Orab... }\end{array}$ & $800-1,200$ & $55^{5}$ & & & Gas wells. \\
\hline Ripley......... & & & & & No product. \\
\hline $\begin{array}{l}\text { Butler County: } \\
\text { Hamilton }{ }^{5} \ldots \ldots \ldots \ldots \\
\text { Middletown }{ }^{6} \ldots \ldots \ldots \ldots \ldots \\
\text { Oxford }{ }^{6} \ldots \ldots \ldots \ldots \ldots\end{array}$ & $\begin{array}{r}550-700 \\
1,060 \\
1,365\end{array}$ & & & & $\begin{array}{l}\text { Gas wells; smal flow. } \\
\text { Some gas and sq.lt water. } \\
\text { Shale gas and sulphur }\end{array}$ \\
\hline $\begin{array}{l}\text { Sevenmile } \\
\text { Carroll County: }\end{array}$ & 1,220 & 8 & & 6 & $\begin{array}{l}\text { Water only. } \\
\text { Salt water and some gas. }\end{array}$ \\
\hline $\begin{array}{c}\text { Amsterdum (east of })^{7} \ldots \\
\text { West of } 7\end{array}$ & $\begin{array}{r}953-1,040 \\
1,135\end{array}$ & & & & 4 wells. \\
\hline Northwest of $7 . . . . .$. & 1,177 & & & & \\
\hline Augusta Township ${ }^{8} \ldots$.... & 1,500 & & & & Dry hole. \\
\hline Germano (north of $)^{7} \ldots$ & $\begin{array}{r}928 \\
1,032\end{array}$ & & & & Good show of oll. \\
\hline $\begin{array}{l}\text { London Township }{ }^{9} \ldots \ldots \\
\text { Sherrodsville (west) }{ }^{8} \ldots\end{array}$ & $\begin{array}{r}1,130-1,240 \\
+900\end{array}$ & & & & $\begin{array}{l}4 \text { wells; } 3 \text { produred oil. } \\
\text { Gas and salt water: well }\end{array}$ \\
\hline Union Township ${ }^{2} . . . .$. & 1,500 & & & & some oil. \\
\hline $\begin{array}{l}\text { Do.......................... } \\
\text { Champaign County: }\end{array}$ & 2,000 & & & & Large flow of salt water. \\
\hline $\begin{array}{l}\text { St. Paris }^{10} \ldots \ldots \\
\text { Urbana }{ }^{11} \ldots \ldots\end{array}$ & $\begin{array}{r}+1,000 \\
1,307-1,350\end{array}$ & & & & $\begin{array}{l}\text { Two unsuccessfe' borings. } \\
\text { Very small showing of gas }\end{array}$ \\
\hline $\begin{array}{l}\text { Clark County: } \\
\text { New Carlisle } 12 . \ldots \ldots \ldots \ldots\end{array}$ & 1,060 & & & & For gas: unsuccessful. \\
\hline Pike Township $12 \ldots$ & 1,380 & & & & $\begin{array}{l}\text { For gas; } \\
\text { Do. }\end{array}$ \\
\hline $\begin{array}{l}\text { Springfield } 12 . \ldots \ldots \ldots \\
\text { Clermont County: }\end{array}$ & $1,140-1,200$ & & & & Several wells; failures. \\
\hline Felieity ${ }^{13} \ldots \ldots \ldots \ldots \ldots$ & 400 & & & & Gaswell. \\
\hline Williamsburg........ & 660 & 6 & ... & & Small flow of gas. \\
\hline $\begin{array}{l}\text { Do } \\
\text { Clinton County: } \\
\text { Sabina } \ldots \ldots \ldots \ldots \ldots\end{array}$ & 660 & 6 & & & Unsuceessful. \\
\hline $\begin{array}{l}\text { New Vienna } 17 . . . \\
\text { Columbiana County: }\end{array}$ & 1.785 & & & & Salt water at 1,785 feet. \\
\hline $\begin{array}{l}\text { olumbiana County: } \\
\text { Corning } 15 . . . \ldots \ldots . . . .\end{array}$ & & & & & Several gas well \\
\hline Do.16 & 1,008 & & & & \\
\hline Corning (south of $)^{17} \ldots$. & 1,507 & & & & $\begin{array}{l}\text { Much salt water; some oil, } \\
\text { well closed. }\end{array}$ \\
\hline $\begin{array}{l}\text { East Liverpool }{ }^{18} \ldots \ldots \ldots \\
\text { On Dry Run } 19 . \ldots \ldots \\
\text { Knowles well } \ldots \ldots \ldots\end{array}$ & $\begin{array}{r}425-450 \\
\pm 3,000 \\
2,954\end{array}$ & & & & $\begin{array}{l}\text { Several gas well } \\
\text { Dry. }\end{array}$ \\
\hline East Palestine (near) ${ }^{2 i}$.. & 1,700 & & & & \\
\hline $\begin{array}{l}\text { East Rochester } 21 \ldots \ldots \\
\text { Homeworth (near) }\end{array}$ & $\begin{array}{l}+725 \\
+618\end{array}$ & & & & Oil well \\
\hline $\begin{array}{l}\text { Homeworth (near) } \\
\text { Island Run } 22 . . . \ldots \ldots\end{array}$ & $\begin{array}{r}+618 \\
600\end{array}$ & & & & Onl well. \\
\hline 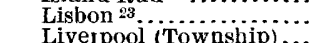 & 1,582 & & & & \\
\hline $\begin{array}{l}\text { Liverpool (Township) } \ldots \\
\text { Madison Township } 24 \ldots\end{array}$ & 426 & & & & Brine. \\
\hline $\begin{array}{l}\text { Madison Township } 24 \ldots \ldots \\
\text { Monroe Township }{ }^{25} \ldots \ldots\end{array}$ & $\begin{array}{r}1,600-3,000 \\
1,012\end{array}$ & & & & 3 wells. \\
\hline New Lisbon ${ }^{26} \ldots \ldots \ldots$ & $1,350-1,370$ & & & & Gas wells. \\
\hline $\begin{array}{l}\text { (Township unknown) } . . \\
\text { Do }\end{array}$ & 1.600 & & & & 3 wells \\
\hline
\end{tabular}

1 Ohio Geol. Surv. Rept., 1890, p. 254.

2 Ibid., 1888, vol, 6 , p. 406 .

3 Ibid., 1890 , pp. 253-254.

4 Ibid., 1888 , vol. 6 , pp. $404-406$.

6 Record, ibid., p. 292-293.

6 Jbid., p. 294-295.

7 U. S. Geol. Surv. Bull. No. 198, 1902, pp. 25-33. 8 Ohio Geol. Surv. Bull. No. 1, 4th ser., 1903, p.293. 9 Ibid., p. 294. in Record, ibid., Rept., 1888, vol. 6, pp. 276-277. 11 Ibid., p. 275.

12 Ibid., pp. 278-280.

${ }^{13}$ Ohio Geol. Surv. Rept., 1888, vol. 6, p. 301.

14 Ibid., pp. 296-297.
${ }^{16}$ Record, ibid., pp. 261-262. 258.

17 Ohio Geol. Surv. Bull. No. 1, 4th se»., 1903, p.

18 Record, ibid., Rept., 1888, vol. 6, pp. 331-334. 19 Ibid., pp. 322-323.

o" Ohio Geol. Surv. Bull. No. 1, 4th se*., 1903, p. 256.

1 Ibid., p. 257.

22 Record, Pa. 2d Geol. Surv. Ann. Rept., 1886, part 2 , pp. $781-785$.

23 Ohio Geol. Surv. Rept., 1888, vol. 6, p. 322

24 Ibid., Buli. No. 1, th ser., 1903, p. 2 .

25 Ibid., p. 259.

${ }^{26}$ Record, ibid., Rept. 1888, vol. 6, p. 404. 
OHIO-Continued.

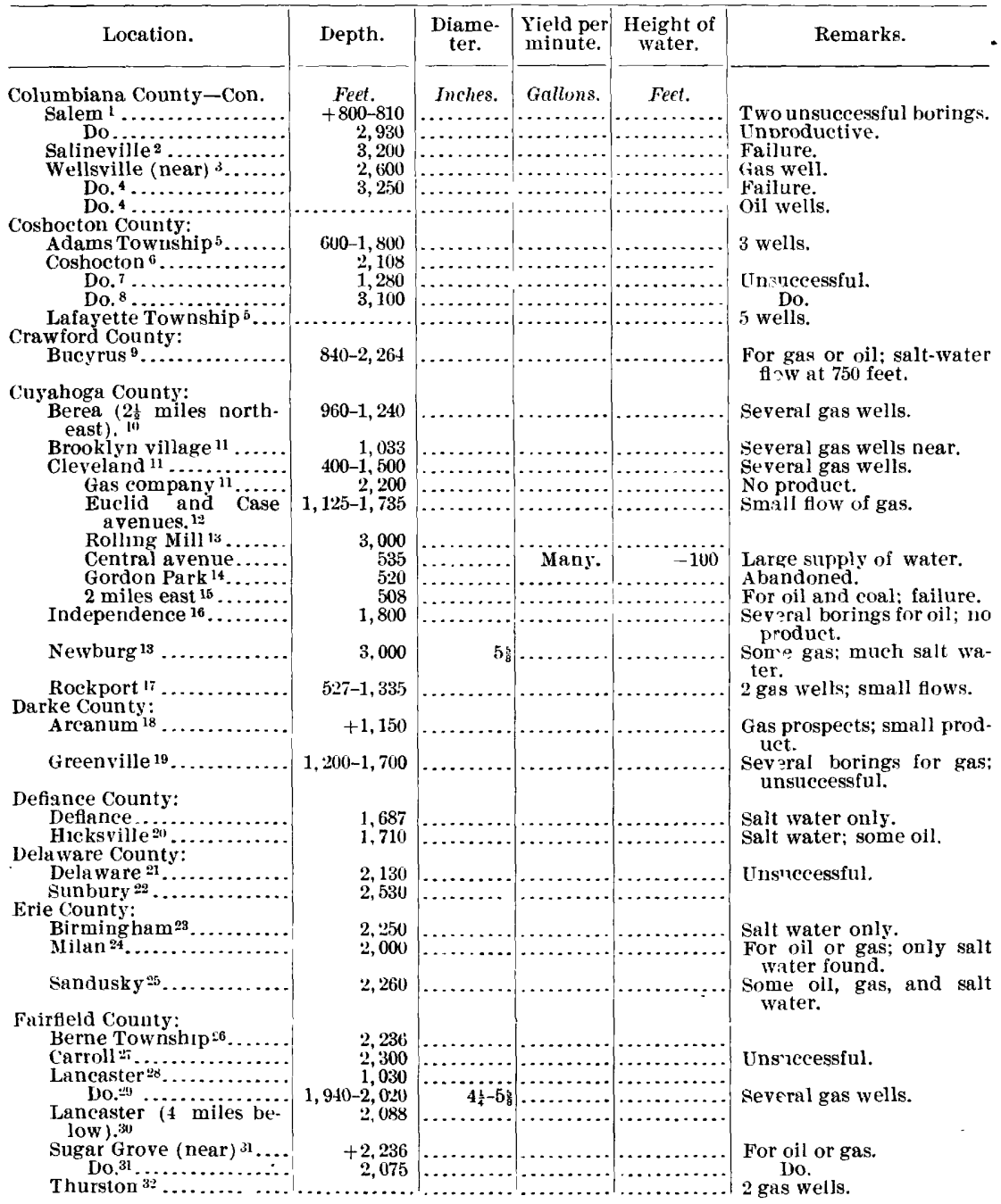

${ }^{1}$ Ohio Geol. Surv. Rept., 1888, vol. 6, pp. 403404,452 .

"Ibid., Bull. No. 1, 4th ser., 1908, p. 257.

s Ibid., p. 22.

4 Ibid., pp. 251-252

5 Ibid., p. 292.

${ }^{6}$ Record, ibid., Rept., 1888, vol 6, p. 324.

I Ibid., p. 364 .

8 Ibld., p. 367 , 1890 . pp. 245-246

9 Ibld., pp. $360-364$

10 Ibud.' pp. $438-436$

11 Ibid, pp. 489-43!

12 Geol. Soc. Am. Bull. vol. 8, p. 10.

13 Record, Mich. Geol. Surv. Rept., 1881-1893, vol. 5, part 2 p. 73, Onio Geol. Surv. Rept., 1888, vol. $6, \mathrm{pp} .351-355$

14 Geol. Soc. Am., Bull., vol. 8, p. 10.

is Economic Geol., Ill.. vol. 3, pp 195-196.

16 Ohio Geol. Surv. Rept., 1888, vol. 6, p. 431.
17 Record, ibid., pp. 432-131.

18 Ohio Geol. Surv. Rept., 1888, vol. 6, pp. 272-273. 19 Ibid., pp. 271-272

20) Record, ibid., pp. 250-251.

21 Ohio Geol. Surv. Rept., 1888, vol. 6, p. 270

22 Ibid., p. 283

23 Ibid., pp. 346-347.

24 Ibid., p. 346 .

${ }^{25}$ Record, Mich. Geol. Surv. Rept., 1881-1893, p. 83, Ohio Geol. Surv Rept. 1888, vol.6, pp. 194-196. ${ }^{26}$ Partial record, Ohio Genl. Surv, Bull. No. I, 4th ser., 1903, p. 118.

${ }_{27}$ Ohio Geol. Surv. Rept., 1888, vol. 6, p. 388 28 Record, ibid., p. 318.

29 Ibid., pp. $382-388,7 \times 3$

30 Ibid., Bull. No. 1. 4th ser., 1903, pp. 117-118.

31 Partial record, ibid., pp. 20-21

Onio Geol. Surv. Bull. No. 1, 4th ser., 1903, pp. 107-108. 
OHIO-Continued.

\begin{tabular}{|c|c|c|c|c|c|}
\hline Location. & Depth. & $\begin{array}{l}\text { Diame- } \\
\text { ter. }\end{array}$ & $\begin{array}{l}\text { Yield per } \\
\text { minute. }\end{array}$ & $\begin{array}{l}\text { Hei } \\
\text { wa }\end{array}$ & Remarks. \\
\hline $\begin{array}{l}\text { Fayerte County: } \\
\text { Washington } 1 \text {. }\end{array}$ & $\begin{array}{l}\text { Feet. } \\
1,850\end{array}$ & & & & For gas or oil; fornd salt \\
\hline $\begin{array}{l}\text { Franklin County: } \\
\quad \text { Columbus }{ }^{2} \ldots \ldots \ldots \ldots\end{array}$ & 2,020 & & & & No gas or oil. \\
\hline Columbus (st & 2,775 & $6-4$ & & +5 & $\begin{array}{l}\text { Saline water be'ow } 175 \\
\text { feet; temp., } 91^{\circ} \text {. }\end{array}$ \\
\hline $\begin{array}{l}\text { Groveport (ne } \\
\text { Harrisburg } 5 \\
\text { Westerville }\end{array}$ & $\begin{array}{r}2,675 \\
405 \\
+2,300\end{array}$ & 6 & Many. & Flows. & \\
\hline $\begin{array}{l}\text { Fulton Co } \\
\text { Delta? }\end{array}$ & 10 & & & & [nsuccessful. \\
\hline on 8 & $\begin{array}{r}2,100 \\
+2,158\end{array}$ & & & & Oil at 2,158 feet. \\
\hline $\begin{array}{l}\text { Gallia Connty: } \\
\text { Adamsville............. }\end{array}$ & 800 & & & & $\begin{array}{l}\text { Considerable gas at } 400 \\
\text { feet. }\end{array}$ \\
\hline $\begin{array}{l}\text { Gallipolis }{ }^{9} \ldots \ldots . . . . . . . \\
\text { Huntington Township }{ }^{10} \\
\text { Raccoon Township }{ }^{11} \ldots \\
\text { Township unknown..... }\end{array}$ & $\begin{array}{l}2,910 \\
1,765 \\
1,417 \\
2,910\end{array}$ & & & & $\begin{array}{l}\text { For oil; nnsuceesstul. } \\
\text { Failure. } \\
\text { Much salt water; failure. } \\
\text { Dry well. }\end{array}$ \\
\hline Geaug & & & & & \\
\hline ip $13 \ldots \ldots$ & $\begin{array}{l}2,472 \\
1,500\end{array}$ & & & & $\begin{array}{l}\text { Only a showing of oil. } \\
\text { Somegas; well corsidered } \\
\text { a failure. }\end{array}$ \\
\hline 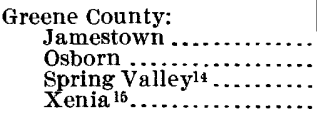 & $\begin{array}{r}1,500 \\
990 \\
1,500 \\
1,200\end{array}$ & & & & $\begin{array}{l}\text { Salt water only. } \\
\text { Unsuccessful. } \\
\text { Do. } \\
\text { For oil or gas; unsuccess- } \\
\text { ful }\end{array}$ \\
\hline $\begin{array}{l}\text { Gnernsey County: } \\
\text { Cambridge }{ }^{16} . .\end{array}$ & $1,090-2,000$ & & & & Gas and oil well v yield \\
\hline Center (Tor & 690 & & & & n. \\
\hline Kimbol & 1,087 & & & & \\
\hline $\begin{array}{l}\text { Millers } \\
\text { Quaker }\end{array}$ & $\begin{array}{r}430 \\
1.347\end{array}$ & & & & Salt \\
\hline 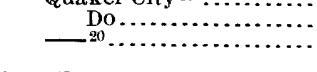 & $\begin{array}{l}1,347 \\
1,352\end{array}$ & & & & $\begin{array}{l}\text { A number of oil and gas } \\
\text { wells reported. }\end{array}$ \\
\hline $\begin{array}{l}\text { Hamilton Cou } \\
\text { Cincinnat }\end{array}$ & & & & & $\begin{array}{l}\text { Numerous oil or gas } \\
\text { wells; unsuccessful. }\end{array}$ \\
\hline Cincinnati . & $\begin{array}{l}2,400 \\
1,200\end{array}$ & & & & \\
\hline $\begin{array}{r}\text { North Bend } \ldots \ldots \ldots \ldots \\
\text { Hancock County: }{ }^{21} \ldots \ldots \ldots \ldots\end{array}$ & 1,350 & 5 & 200 & +30 & $\begin{array}{l}\text { Good water. } \\
\text { Many oil wells; } 84 \text { per }\end{array}$ \\
\hline $\begin{array}{l}\text { Arcadia }{ }^{22} \ldots \ldots \ldots \ldots . . . \\
\text { Arcadia (near) }{ }^{23} . . . . . . .\end{array}$ & $\begin{array}{r}1,365 \\
+1,200\end{array}$ & & & & Gas at 1,180 feet. \\
\hline Arlington $22 \ldots \ldots \ldots \ldots$ & 1,304 & & & & $\begin{array}{l}\text { Some oil and gas at } 1,304 \\
\text { feet; abandoned. }\end{array}$ \\
\hline $\begin{array}{c}\text { Beaverdam } \\
\text { east). } 24\end{array} \quad$ miles & $1,288-1,290$ & & & & Gas wells. \\
\hline $\begin{array}{l}\text { Cannonsburg }{ }^{26} \ldots \ldots \ldots \ldots \\
\text { Cass Township } 23 \ldots \ldots \ldots \ldots\end{array}$ & $\begin{array}{r}1,300 \\
+1,150\end{array}$ & & & & Several oil wells. \\
\hline Findlay ${ }^{26}, \ldots \ldots \ldots \ldots$ & $1,116-1,334$ & & & & $\begin{array}{l}\text { Many gas wells: some oil } \\
\text { in several wells. }\end{array}$ \\
\hline Do. ${ }^{27} \ldots \ldots \ldots \ldots \ldots$ & 1,648 & & & & Gas well; oil at 1,092 feet; \\
\hline $\begin{array}{l}\text { Findlay (1 mile north- } \\
\text { west). } 28\end{array}$ & 1,334 & & & & \\
\hline \multirow{3}{*}{\multicolumn{3}{|c|}{ 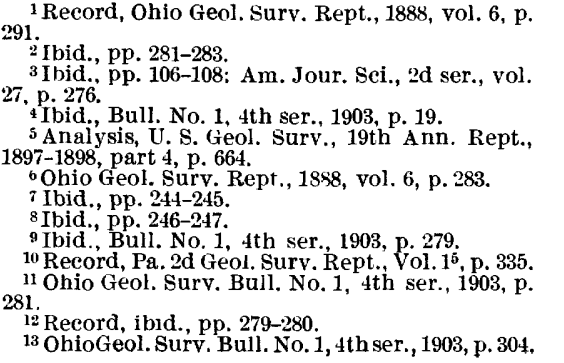 }} & \multicolumn{3}{|c|}{$\begin{array}{l}14 \text { Ibid., Rept, } 1888, \text { vol. 6, p. } 291 . \\
15 \text { Ibid., pp. } 289-290 . \\
16 \text { Ibid., pp. } 320,377-378 . \\
17 \text { Ibid,, pp. } 380-381 . \\
18 \text { Ibid., pp. } 654-655 . \\
19 \text { Record, ibid., pp. } 324,381-382 \text {. } \\
20 \text { Ohio Geol. Surv. Bull. No. 1, 4th ser., 1903, pp. } \\
201-203\end{array}$} \\
\hline & & & \multicolumn{3}{|c|}{$\begin{array}{l}221-223 . \\
21 \text { Ibid., pp. } 65-71 . \\
22 \text { Ibid., Rept. } 1888, \text { vol. 6, p. } 218 . \\
23 \text { Ibid., Bull. No. 1, 4th ser., 1903, p. } 69 . \\
21 \text { Ibid., pp. } 215-216 . \\
25 \text { Ibid,, p. } 217 . \\
20 \text { Ibid., Rept. } 188 \text {, vol. 6, pp. 122-133, 146; 1890; }\end{array}$} \\
\hline & & & \multicolumn{3}{|c|}{$\begin{array}{l}\text { p. } 125 . \\
27 \text { Ibid., pp. 111-117. } \\
28 \text { Ibid., pp. 131-132. }\end{array}$} \\
\hline
\end{tabular}


OHIO-Continued.

\begin{tabular}{|c|c|c|c|c|c|}
\hline Location. & Depth. & $\begin{array}{l}\text { Diame- } \\
\text { ter. }\end{array}$ & $\begin{array}{l}\text { Yield per } \\
\text { minute. }\end{array}$ & $\begin{array}{l}\text { Height of } \\
\text { water. }\end{array}$ & Remarks. \\
\hline $\begin{array}{l}\text { Hancock County-Cont'd. } \\
\text { Findlay ..................... }\end{array}$ & $\begin{array}{l}\text { Feet. } \\
\quad 1,158\end{array}$ & 68. & & & $\begin{array}{l}\text { Water at } 50 \text { and } 60 \text { feet: } \\
\text { b-ine at } 540 \text { feet; small } \\
\text { amount of gas; well } \\
\text { abandoned. } \\
\text { Gas well. }\end{array}$ \\
\hline $\begin{array}{l}\text { Marion } \\
\text { MeCom }\end{array}$ & 1,495 & & & & $\begin{array}{l}\text { Gas well. } \\
\text { Gas well with salt water. }\end{array}$ \\
\hline Mount & & & & & $\begin{array}{l}\text { Moderate flow of oil and } \\
\text { gas. }\end{array}$ \\
\hline $\begin{array}{r}\text { Portage Township } 4 . . . \\
\text { Do........................ }\end{array}$ & $\begin{array}{r}+1,201 \\
1,414\end{array}$ & & & & Smith farm well No. 8; \\
\hline Rawson 5 & 1,337 & & & & For gas or oil; found salt \\
\hline Stuartsville Township ${ }^{6}$. & 450 & & & & Oil wells. \\
\hline & $+1,232$ & & & & Oil well. \\
\hline Hardin County: & $1004 t^{2}$ & & & & Small tow of gas. \\
\hline Ada ${ }^{7} \ldots \ldots$ & $1,384-1,820$ & & & & $\begin{array}{l}\text { Several wells for gas; } \\
\text { some successful; others } \\
\text { yंeld only tlows of salt } \\
\text { water. }\end{array}$ \\
\hline Dunkirk ${ }^{8} \ldots \ldots \ldots$ & 1,865 & & & & $\begin{array}{l}\text { For gas; only salt water } \\
\text { found. }\end{array}$ \\
\hline $\begin{array}{r}\text { Do }{ }^{9} \ldots \ldots \ldots \ldots \ldots \ldots \\
\text { Forest }{ }^{8}, \ldots \ldots \ldots \ldots \ldots\end{array}$ & $\begin{array}{l}1,370 \\
1,470\end{array}$ & & & & $\begin{array}{l}\text { Large flow of oil. } \\
\text { Unsuccessful. }\end{array}$ \\
\hline $\begin{array}{l}\text { Forest ( } 3 \text { miles south- } \\
\text { west). }\end{array}$ & $\begin{array}{r}1,470 \\
480\end{array}$ & & Many. & ws. & White sulphur water. \\
\hline $\begin{array}{c}\text { Kenton }{ }^{10} \ldots \ldots \ldots \ldots \ldots \\
\text { Do } \ldots \ldots \ldots \ldots \ldots\end{array}$ & $\begin{array}{l}1,600 \\
\ldots \ldots\end{array}$ & & & & $\begin{array}{l}\text { Cnsucessful. } \\
\text { Do. }\end{array}$ \\
\hline Paterson ( 2 miles south) ${ }^{i i}$ & 1,330 & & & & Gas at 835 feet; large flow \\
\hline Paterson ( 2 miles west) ${ }^{12}$. & 1,300 & & & & W of gas; also \\
\hline $\begin{array}{l}\text { Harrison County: } \\
\text { A rcher Township. }\end{array}$ & & & & & \\
\hline (n....... & $\begin{array}{l}1,308-1,418 \\
1,400-1,567\end{array}$ & & & & Several wells; some gas. \\
\hline $\begin{array}{l}\text { Cadiz }(1 \text { mile north of } \\
\text { court-house) }{ }^{13} \\
\text { Cadiz (east of }{ }^{14} . \ldots \ldots \ldots\end{array}$ & $\begin{array}{l}1,464 \\
1,400\end{array}$ & & & & $\begin{array}{l}\text { Strong fiow of brine: no } \\
\text { ol. } \\
\text { Small fiow of oil, and con- }\end{array}$ \\
\hline Cadiz (1 mile north) ${ }^{15} \ldots$ & 1,151 & & & & $\begin{array}{l}\text { siderable gas. } \\
\text { Dry hole; flrst well near }\end{array}$ \\
\hline $\begin{array}{l}\text { Cadiz (one-half to } 1 \text { mile } \\
\text { east).15 }\end{array}$ & $1,036-1,072$ & & & & $\begin{array}{l}\text { Cadiz. } \\
3 \text { wells; } 2 \text { produce gas. }\end{array}$ \\
\hline $\begin{array}{l}\text { Cadiz (i to } 2 \text { miles south- } \\
\text { east).15 }\end{array}$ & $1,022-1,14 t$ & & & & Do. \\
\hline $\begin{array}{l}\left.\text { Cadiz ( } 1 \frac{1}{3} \text { to } 2 \text { miles east }\right)^{15} \\
\text { Cadiz } 11 \frac{1}{2} \text { to } 2 \text { miles }\end{array}$ & $\begin{array}{l}1,133-1,220 \\
1,032-1,216\end{array}$ & & & & $\begin{array}{l}3 \text { unproductive wells, } \\
30 \text { viells; some gas and oil. }\end{array}$ \\
\hline t) 15 & 150 & & & & Dry. \\
\hline & & & & & Gas. \\
\hline & 1,411 & & & & Do. \\
\hline $\begin{array}{r}\text { Fife (vicinity) }{ }^{15} \ldots \ldots \ldots \\
\text { Do. }{ }^{15} \ldots \ldots \ldots \ldots\end{array}$ & & & & & 3 wells. \\
\hline $\begin{array}{l}\text { Fife (1 to } 1 \frac{1}{2} \text { miles west } \\
\text { and northwest) } 15\end{array}$ & $1,081-1,285$ & & & & Many wells. \\
\hline p..... & & & & & \\
\hline & $\begin{array}{r}1,191 \\
1,306-1,419\end{array}$ & & & & \\
\hline & $\begin{array}{r}1,000-1,15 \% \\
1,152\end{array}$ & & & & \\
\hline $\begin{array}{l}\text { Ger } \\
\text { so }\end{array}$ & & & & & \\
\hline $\begin{array}{l}\text { Germano ( } 2 \text { miles south- } \\
\text { west). }\end{array}$ & 1,041 & & & & M \\
\hline & $1,353-1,680$ & & & & Many wells; some gas. \\
\hline $\begin{array}{l}\text { Greenough ( } 1 \text { to } 1 \frac{1}{2} \text { miles } \\
\text { south). } 16\end{array}$ & & & & & \\
\hline $\begin{array}{l}\text { Greenough (1 mile } \\
\text { west).15 }\end{array}$ & $1,096-1,195$ & & & & $3 \mathrm{~d}$ 'y wells. \\
\hline colot & & & & & \\
\hline $\begin{array}{l}\text { Greenough (i to } 1 \frac{1}{2} \text { miles } \\
\text { north).15 }\end{array}$ & & & & & 19 wells: some oil. \\
\hline \multicolumn{3}{|c|}{$\begin{array}{l}1 \text { Ohio Geol. Surv. Rept., 1888, vol. 6, p. } 236 . \\
\text { 2 Ibid., p. 219. } \\
\text { 2 Ibid., p. 218. } \\
\text { 4 Ibid., Bull. No, 1, 4th ser., 1903, p. } 69 . \\
\text { 5 Ibid., Rept.., 1888, vol. 6, p. 217. } \\
\text { 6 Ibid., 1890, pp. 219-220. } \\
\text { ' Ibid., p. 219; 1890, pp. 184-186. } \\
8 \text { Ibid., p. 223. }\end{array}$} & \multicolumn{3}{|c|}{$\begin{array}{l}9 \text { Ibid., 1890, p. } 186 . \\
10 \text { Ibid., p. 220. } \\
\text { 11 Record, ibid., Rept. 1889. vol. 6, pp. 221-222. } \\
12 \text { Ibid., p. } 222 . \\
13 \text { OhioGeol. Surv. Bull. No.1, 4th ser., 1903, p. } 226 . \\
14 \text { Ibid., pp. 227,228. } \\
15 \text { U. S. Geol. Surv. Bull. No. 198, 1902, pp. 25-33. }\end{array}$} \\
\hline
\end{tabular}


OHIO-Continued.

\begin{tabular}{|c|c|c|c|c|c|}
\hline Location. & Depth. & $\begin{array}{l}\text { Diame- } \\
\text { ter. }\end{array}$ & $\begin{array}{l}\text { Yield per } \\
\text { minute. }\end{array}$ & $\begin{array}{l}\text { Height of } \\
\text { water. }\end{array}$ & Remarks. \\
\hline $\begin{array}{l}\text { Harrison County-Cont'd. } \\
\text { Greenough (1mile east) })^{1}\end{array}$ & Feet. & Inches. & Gallons. & & \\
\hline Greenough (1 or $1 \frac{1}{2}$ miles & & & & & \\
\hline $\begin{array}{l}\text { northeast) } \\
\text { Greenough (1 mile }\end{array}$ & & & & & \\
\hline northwest). 1 & & & & & \\
\hline Hopedale (1 mile south)' & 1,190 & & & & \\
\hline $\begin{array}{l}\text { Hopedale (southwest } \\
\text { of).2 }\end{array}$ & 1,512 & & & & \\
\hline 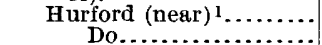 & $\begin{array}{r}1,148 \\
1,110-1,152\end{array}$ & & & & $\begin{array}{l}\text { Dry. } \\
2 \text { wells; some oi. }\end{array}$ \\
\hline Jewett $\left(1\right.$ to $1 \frac{2}{2}$ miles & $1,030-1,212$ & & & & 12 wells. \\
\hline $\begin{array}{l}\text { southeast). }{ }^{1} \\
\text { Means ( } 1 \text { mile north- }\end{array}$ & 1,071 & & & & \\
\hline $\begin{array}{l}\text { east) } .1 \\
\text { Miller Station (1 mile } \\
\text { north) } 1\end{array}$ & 1,025 & & & & \\
\hline Monroe Township... & $1,038-1,250$ & & & & Several wells. \\
\hline North Township ........... & $1,100-1,540$ & & & & Many gas and oil wells. \\
\hline Nottingham Township.. & 1,278 & & & & Gas. \\
\hline Ohio Township $\ldots . . . . .$. & & & & & 4 wells \\
\hline $\begin{array}{l}\text { Rumley Township ....... } \\
\text { Scio (near) }{ }^{3} \ldots \ldots \ldots \ldots\end{array}$ & $\begin{array}{r}1,178-1,300 \\
1,190\end{array}$ & & & & 4 wells. \\
\hline Short Creek Township.. & $1,435-1,580$ & & & & Do. \\
\hline Unionvale (vicinity) ${ }^{i} \ldots$ & 1,036 & & & & \\
\hline $\begin{array}{l}\text { Unionvale (11 miles } \\
\text { southwest). }{ }^{1}\end{array}$ & $1,107-1,213$ & & & & $\begin{array}{l}\text { Some oil with large quan- } \\
\text { tjties of salt water. }\end{array}$ \\
\hline $\begin{array}{l}\text { Unionvale (1 mile } \\
\text { north). }\end{array}$ & 1,011 & & & & \\
\hline Washington Township.. & 1,154 & & & & \\
\hline $\begin{array}{l}\text { Henry Connty: } \\
\text { Deshler }{ }^{4} \ldots \ldots \ldots \ldots \ldots\end{array}$ & 1,600 & & & & Only small flow of gas. \\
\hline Napoleon ${ }^{6} \ldots \ldots \ldots$ & 1,889 & & & & For gas; salt water at 1,889 \\
\hline $\begin{array}{l}\text { Highland County: } \\
\text { Hillsboro } 6 . . . . .\end{array}$ & & & & & \\
\hline $\begin{array}{l}\text { Hillsbo } \\
\text { Hocking C }\end{array}$ & 1,750 & & & & Good water at 1,750 feet. \\
\hline $\begin{array}{l}\text { Hocking County: } \\
\text { Bloomingville } 7 \text {... }\end{array}$ & 628 & & & & Small flow of oil. \\
\hline Do ${ }_{8} \ldots \ldots$ & 0.0 & & & & Two borings. \\
\hline $\operatorname{Logan}^{8} \ldots \ldots \ldots \ldots \ldots \ldots$ & $625-689$ & & & & Several wells; some oil, \\
\hline Do...... & $1,00^{\circ}$ & & & & Some oil. \\
\hline $\begin{array}{l}\text { Holmes County: } \\
\text { Kilbuck (near) }{ }^{9} \ldots \ldots\end{array}$ & $6^{9} 6-1,000$ & & & & ( \\
\hline $\begin{array}{l}\text { Kulbuck (near) } \\
\text { Millersburg }{ }^{10} \ldots \ldots \ldots \ldots\end{array}$ & $\begin{array}{r}626-1,000 \\
2,100\end{array}$ & & & & severan wens. \\
\hline $\begin{array}{l}\text { Millersburg (4 miles } \\
\text { from) }\end{array}$ & $900-1,000$ & & & & Gas and oil well. \\
\hline Millersburg ${ }^{11} \ldots \ldots \ldots \ldots$ & 2,100 & & & & Oil and gas; free from salt \\
\hline Huron County: & & & & & \\
\hline & 1,700 & & & & For gas; unsucessful. \\
\hline $\begin{array}{l}\text { Chicago Junc } \\
\text { Monroeville }\end{array}$ & 1,250 & & & & \\
\hline New London $15 . . . \ldots . . .$. & $\dddot{998-1,030}$ & & & & $\begin{array}{l}\text { Small tlow of gar only. } \\
\text { Three wells; rothing }\end{array}$ \\
\hline Norwalk ${ }^{1}$ & 2,304 & & & & found except sq.it water. \\
\hline $\begin{array}{l}\text { Do......... } \\
\text { Wakeman... }\end{array}$ & 2,725 & 5 s & & & For oil or gas; vnsuccess- \\
\hline wakeman... & 3,000 & & & & water only at 1,950 feet. \\
\hline $\begin{array}{l}\text { Jackson County: } \\
\text { Jackson }{ }^{17} \ldots \ldots\end{array}$ & & & & & Small fow of ogs \\
\hline 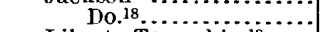 & $\begin{array}{l}1,600 \\
1,636\end{array}$ & & & & Somegas; muchsalt water. \\
\hline Liberty & 2,155 & & & & Abandoned. \\
\hline Wellst & 800 & & & & Small show of oil and gas. \\
\hline $\begin{array}{l}\text { Jefferson County: } \\
\text { Amsterdam (1 n }\end{array}$ & 961 & & & & Salt water. \\
\hline southeast). 1 (1 & & & & & Sall water. \\
\hline $\begin{array}{l}\text { A msterdam (1 to } 1 \frac{1}{2} \\
\text { miles solthwest). } 1\end{array}$ & $945-1,070$ & & & & 3 wells. \\
\hline Amsterdam (vicinity) ${ }^{1}$ & 933 & & & & \\
\hline $\begin{array}{l}\text { Bloomfield station (vi- } \\
\text { cinity) l }\end{array}$ & 1,067 & (2) & & & \\
\hline
\end{tabular}

1 U. S. Geol. Surv. Bull. No. 198, 1902, pp. 25-33. 2 Record, Ohio Geol. Surv. Bull. No. 1, 4th ser., 1903 p. 226.

3 İbid., p. 238.

4 Ibid., Rept. 1888, vol. 6, p. 253.

6 Ibid., pp. 252-253.

6 Analysis, ibid., p. 297.

7 Record, ibid., pp. 393-394.

8 Ibid., pp. 318, 392-393.

9 Ohio Geol. Surv. Buli, No. 1, 4th ser., 1903, pp.
10 Ibid., Rept., 1888. vol. 6, pp. 367-368.

11 Record, ibid., Bull. No, 1, 4th ser., 1903, p. 288. 12 Ohio Geol. Surv. Rept., 1888, vol. 6, p`. 214-215. 13 Ibid., pp. 350-351 14 Ibid., pp. 439-440. 15 Ibid., pp. 348-350, 440.

36 Ibid., pp. 440-441.

17 [bid., pp. 319-394.

18 Ibid., Bull. No, 1, 4th ser., 1903, p. 275. 
OHIO-Continued.

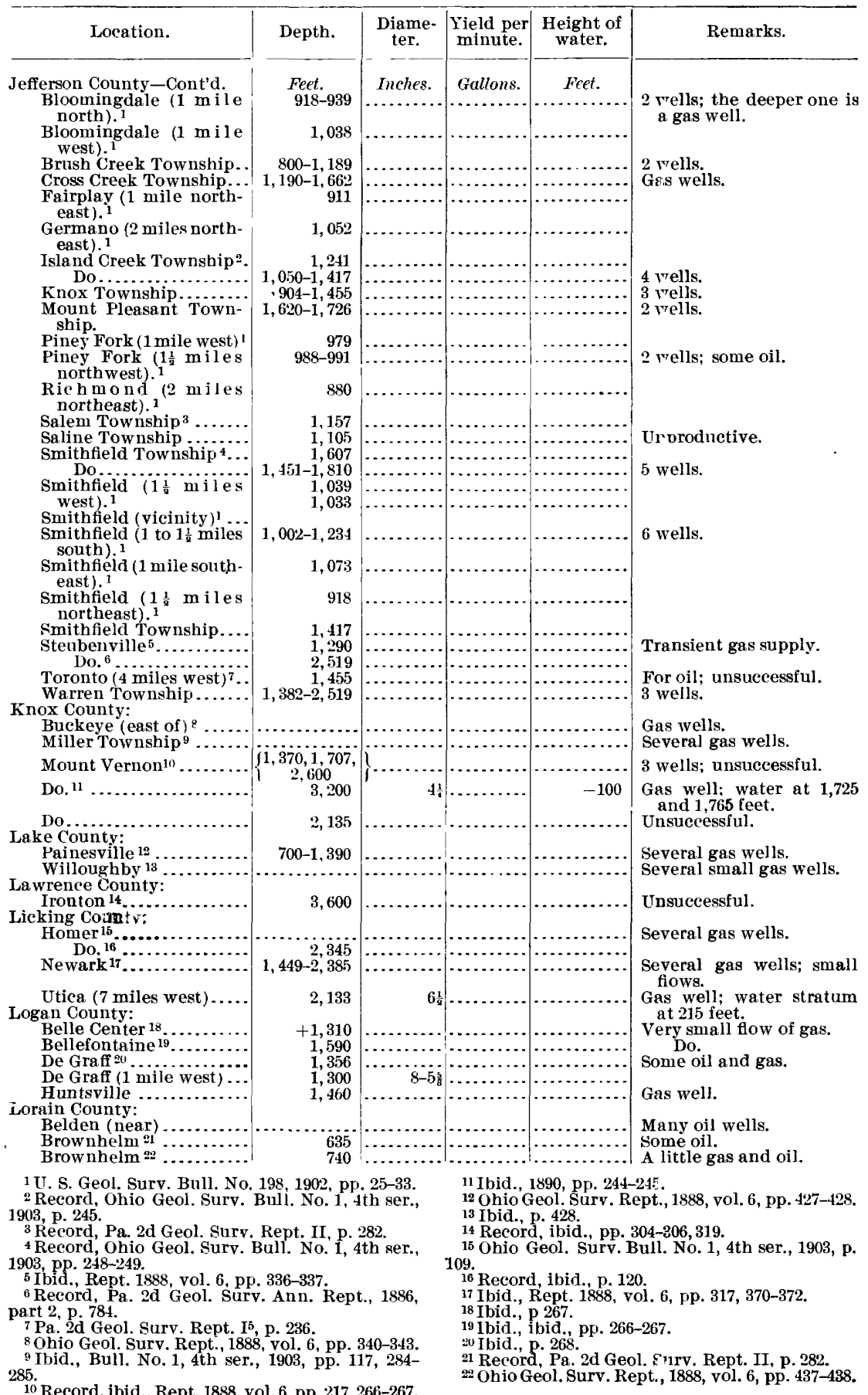


OHIO-Continued.

\begin{tabular}{|c|c|c|c|c|c|}
\hline Location. & Depth. & $\begin{array}{l}\text { Diame- } \\
\text { ter. }\end{array}$ & $\begin{array}{l}\text { Yield per } \\
\text { minute. }\end{array}$ & $\begin{array}{l}\text { Height of } \\
\text { water. }\end{array}$ & Remarks. \\
\hline $\begin{array}{l}\text { Lorain County-Continued. } \\
\text { Brownhelm Township .. }\end{array}$ & Feet. 635 & Inches. & Gallons. & Feet. & \\
\hline Elyria $1 . . . .$. & 987 & & & & $\begin{array}{l}\text { Small gas su pply a nd } \\
\text { heavy flow of salt and } \\
\text { sulphur water. }\end{array}$ \\
\hline $\begin{array}{l}\text { Lorain }{ }^{2} \ldots \ldots \ldots \ldots \ldots \ldots \\
\text { Sheffield }{ }^{3} \ldots \ldots \ldots \ldots \ldots \ldots\end{array}$ & $\begin{array}{r}+600 \\
720\end{array}$ & & & -50 & $\begin{array}{l}\text { Mineral water; some gas. } \\
\text { Bored for oil; some gas }\end{array}$ \\
\hline Wellington $4 . . .$. & $1,030-1,050$ & & & & $\begin{array}{l}\text { found; unstrccessful. } \\
\text { Several small gas wells. }\end{array}$ \\
\hline $\begin{array}{l}\text { Lucas County: } \\
\text { Oregon Township }\end{array}$ & & & & & Several unsat'sfactory oil \\
\hline $\begin{array}{l}\text { South Toledo }{ }^{6} \ldots \ldots \ldots \\
\text { Toledo }{ }^{7} \ldots \ldots \ldots \ldots\end{array}$ & $\begin{array}{r}+1,012 \\
1,125\end{array}$ & & & & $\begin{array}{l}\text { Wells. } \\
\text { Several borires for gas }\end{array}$ \\
\hline Waterville $^{6} \ldots \ldots \ldots$ & 1,153 & & & & Small flow of gas. \\
\hline $\begin{array}{l}\text { Madison County: } \\
\text { Lafayette } 8 \text {.... }\end{array}$ & & & & & Unsuccessful. \\
\hline London ${ }^{9} \ldots .$. & 1,585 & & & & Severa] wells for oil or gas. \\
\hline Plain City ${ }^{10}, \ldots \ldots$. & $1,530-2,000$ & 8 & & +13 & $\begin{array}{l}\text { Two wells; large flows of } \\
\text { fine water from } 350,600 \text {, } \\
\text { and } 900 \text { feet. }\end{array}$ \\
\hline $\begin{array}{l}\text { Mahoning County: } \\
\text { Brier Hill } 11 \ldots . . . . . .\end{array}$ & 500 & & & & $\begin{array}{l}\text { Gas at } 420 \text { feet. but not in } \\
\text { paying quartities. }\end{array}$ \\
\hline $\begin{array}{l}\text { Canfleld (near) }{ }^{12} \ldots \ldots \ldots \\
\text { Lowellsville }{ }^{12} \ldots \ldots \ldots\end{array}$ & $\begin{array}{r}600 \\
1,800\end{array}$ & & & & $\begin{array}{l}\text { Only a show of ofl. } \\
\text { Neither oil or gas. }\end{array}$ \\
\hline West Austintown $\div 2$ & 400 & & & & Several wells; small quan- \\
\hline Youngstown ${ }^{13} \ldots \ldots \ldots$. & 2,480 & & & & For gas or oil: unsuccess- \\
\hline $\begin{array}{l}\text { Youngstown (3 miles } \\
\text { southwest). } 12\end{array}$ & 2,075 & & & & $\begin{array}{l}\text { Neither oil or gas in com- } \\
\text { mercial guantities. }\end{array}$ \\
\hline $\begin{array}{l}\text { Youngstown (1 mile } \\
\text { west). } 12\end{array}$ & 500 & & & & Unsuecèssful. \\
\hline arion County: & & & & & \\
\hline ( & 1,790 & & & & Abandoned. \\
\hline & 1,650 & & & & No product. \\
\hline $\begin{array}{l}\text { Medina County: } \\
\text { Lodi (near) }{ }^{16} \ldots \ldots .\end{array}$ & 1,670 & & & & \\
\hline $\begin{array}{l}\text { Medina } 17 \\
\text { Meigs County: }\end{array}$ & 917 & & & & Small flow of gas. \\
\hline Middletown $\ldots \ldots \ldots \ldots$ & $950-1,250$ & 3 and 4 & Av. 25 & & $\begin{array}{l}\text { Great number of salt- } \\
\text { water wells in county. }\end{array}$ \\
\hline Milan ${ }^{18} \ldots \ldots \ldots \ldots . . . . .$. & 1,500 & & & & Small amount of oil from \\
\hline New Lima (near) ........ & 1,000 & & & & Several wells; all made \\
\hline Olive Township ${ }^{19} \ldots$ & 2,500 & & & & Showing of cil and gas: \\
\hline Pomeroy ... & 1,550 & & 20 & -500 & Salt well: so'ne oil and \\
\hline Do $20, \ldots \ldots \ldots \ldots \ldots$ & $\begin{array}{r}1,100 \\
767\end{array}$ & & & & $\begin{array}{l}\text { Several salt wells; flowed } \\
\text { originally. }\end{array}$ \\
\hline Salisbury Township 2 ... & 1,780 & & $\cdots$ & ... & Some gas, small show of \\
\hline $\begin{array}{l}\text { Rutland ( } 1 \frac{1}{4} \text { miles north- } \\
\text { west }) .2\end{array}$ & 830 & & & & $\begin{array}{l}\text { oil in very snall quanti- } \\
\text { ties: not saved. }\end{array}$ \\
\hline $\begin{array}{l}\text { Rutland (near)²1 .......... } \\
\text { Rutland Township....... }\end{array}$ & $\begin{array}{l}1,971 \\
1,560\end{array}$ & & $10-25$ & -500 & $\begin{array}{l}\text { Unsuccessful. } \\
\text { Salt water only. }\end{array}$ \\
\hline Mercer County ${ }^{22}$.............. & $1.147-1.168$ & & & & $\begin{array}{l}\text { Many oil and gas wells: } \\
81 \text { per cert are pro- } \\
\text { ducers. }\end{array}$ \\
\hline Celina (southwest of ) & $1,147-1,100$ & & & & $\begin{array}{l}\text { Oil well; produced } 500 \text { bar- } \\
\text { rels of oil a day at first: } \\
\text { one month later it yield- } \\
\text { ed salt wate- only. }\end{array}$ \\
\hline
\end{tabular}

1 Ohio Geol. Surv. Rept., 1888, vol. 6, pp. 347-348.

2 Ibid., pp. $438-439$.

3 Record, ibnd., p. 437.

4 Ibid., pp. $348-349$.

SOhio Geol. Surv. Buil. No. 1, 4th ser., 1903, pp. 92-93.

${ }^{6}$ Record, Rept. 1888 , vol. 6, p. 225

${ }^{7}$ Record, inid., pp. 208-209; Mich. Geol. Surv., 1881-1893, p. 85.

${ }^{8}$ Ohio Geol. Surv. Rept., 1888, vol. 6, p. 219

9 Ibid., pp. 280-281.

10 Ibid., 1890 , p. 246 ; U. S. Geol. Surv., 19th Ann.

Rept., 1897-98, p. 663 .

${ }_{11}$ Ibld., Bull. No. 1, 4th ser., 1903, p. 299
12 Ibid., p. 300.

13 Ibid., Rept. 1888, vol. 6, pp. 321, 402-103.

14 Record, ibid., pp. 201-202.

15 Analysis, ibid., pp. 270-271.

16 Ohio Geol. Surv. Buil. No. 1, 4th ser., 1903, p. 306

${ }_{17}$ Ibid., Rept. 1888, vol. 6, p. 360 .

18 Ibid., Rept. 1888, vol. 6, p. 346 .

19 Ibid., Bull. No. 1, 4th ser., 1903, p. 283

20 Ibid., Rept. 1888 , vol. 6 , p. 397 .

21 Ibid., p. 282

22 Ibid., Bull. No. 1, 4th ser., 1903, p). 89-92.

${ }_{23}$ Record, ibid., Rept. 1888, vol. 6, F. 259-260.

${ }_{24}$ Ohio Geol. Surv. Buil. No. 1, 4th se"., 1903, p. 90. 
OHIO-Continued.

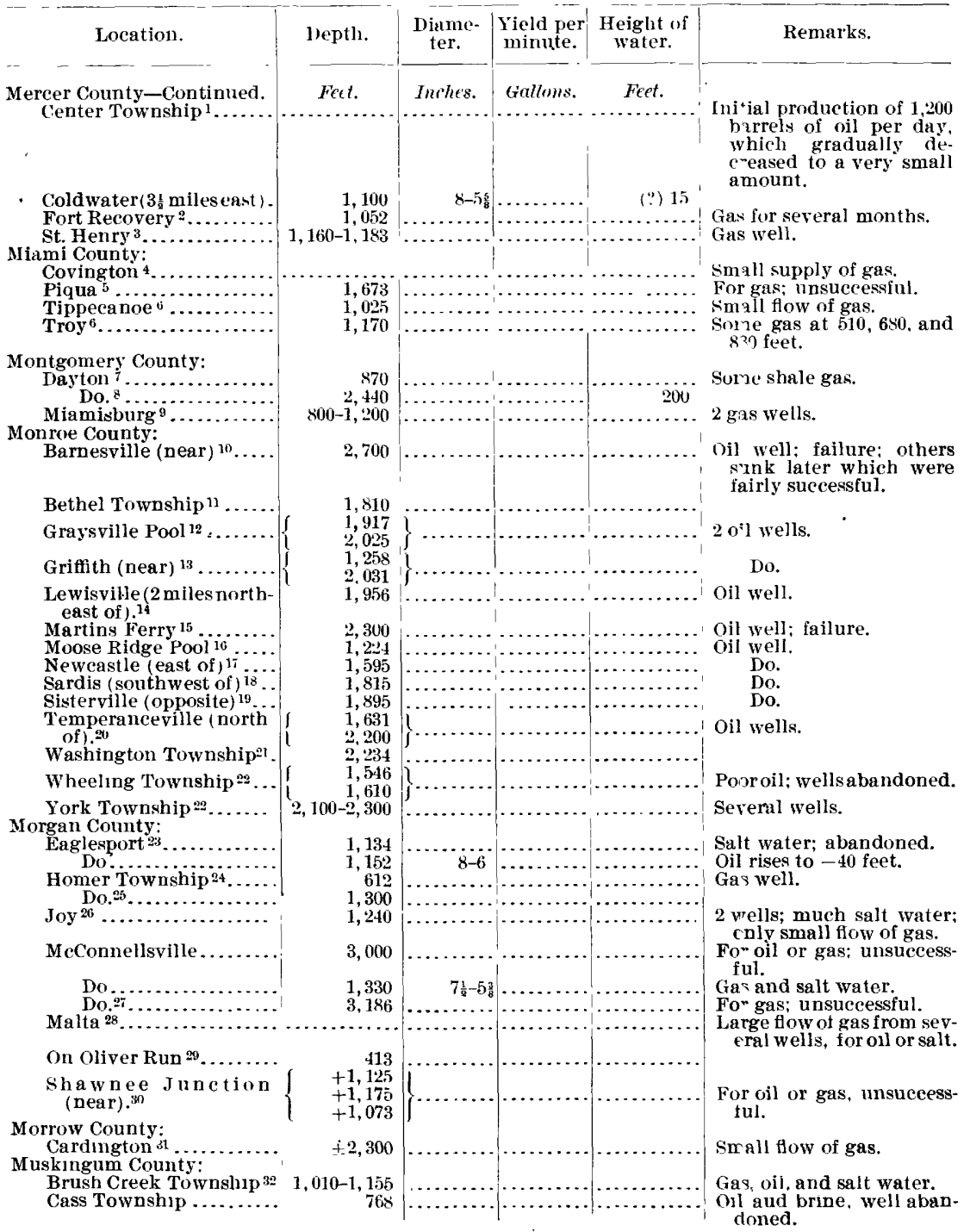

1 Ohio Geol. Surv. Bull. No. 1, 4th ser, 1903, pp 91-92

2 Ibid., Rept., 1888, vol. 6, pp. 263-264.

3 Ibid., pp. 260-262.

4 bid., 1890, p. 74

GIbıd., Rept., 1888, vol. 6, p. 273.

Ibid., p. 274

? Record, ibid., p. 288.

8 Ibid., p. 256

9 lbid, pp, 288-289.

10 OhioGeol.Surv. Bull. No. 1, 4th ser., 1903, p. 214

II Record, ibid., p. 208 .

12 Ibid., p. 203.

13 Ibrd., p. 201

14 Ibid., pp. 212-213.

161 lbid, $\mathrm{p}, 219$

16 Ibıd., pp. 205-206.

17 Ibid., p. 210 .

${ }^{16}$ Record, W. Va. Geol. Surv. Rept., vol. 1, pp.
19 Record, Ohio Geol. Surv. Bull, No, 1, 4th ser. 1903. p. 196 20 Ibid, pp. 216-217.

21 lbid., p. 220.

22 Ohio Geol. Surv. Bull ITn. 1,4th ser. 1903, p. 221. 23 Ibid, Rept. 1888, vol. 6, pp. 389-390.

24 Record, ibid., Bull. No. 1, 4th ser., 1903, pp. 133-134.

25 Ohio Geol. Surv. Bull No.1,4th ser., 1903, p. 139. 20 Ibid , Rept. 1888 vol. 6, p. 390.

2: Record, ibid. Bull. Iro. 1, 4th ser., 1903, pp. 145-146.

${ }^{28}$ Ohio Geol. Sury. Rept., 1888. vol. 6, p 389 . ${ }^{20}$ Record, ibid. Bull. No 1, 4th ser., 1903 p. 142.

${ }^{30}$ Ohio Geol. Surv. Bull. No. 1, 4th ser., 1903, pp. 147-148

31 Ibtd., Rept., 1888, vol. 6, pp. 283-284

3 Ibid., Bull. No. 1, 4th ser., 1903, p. 267. 356-357. 
OHIO-Continued.

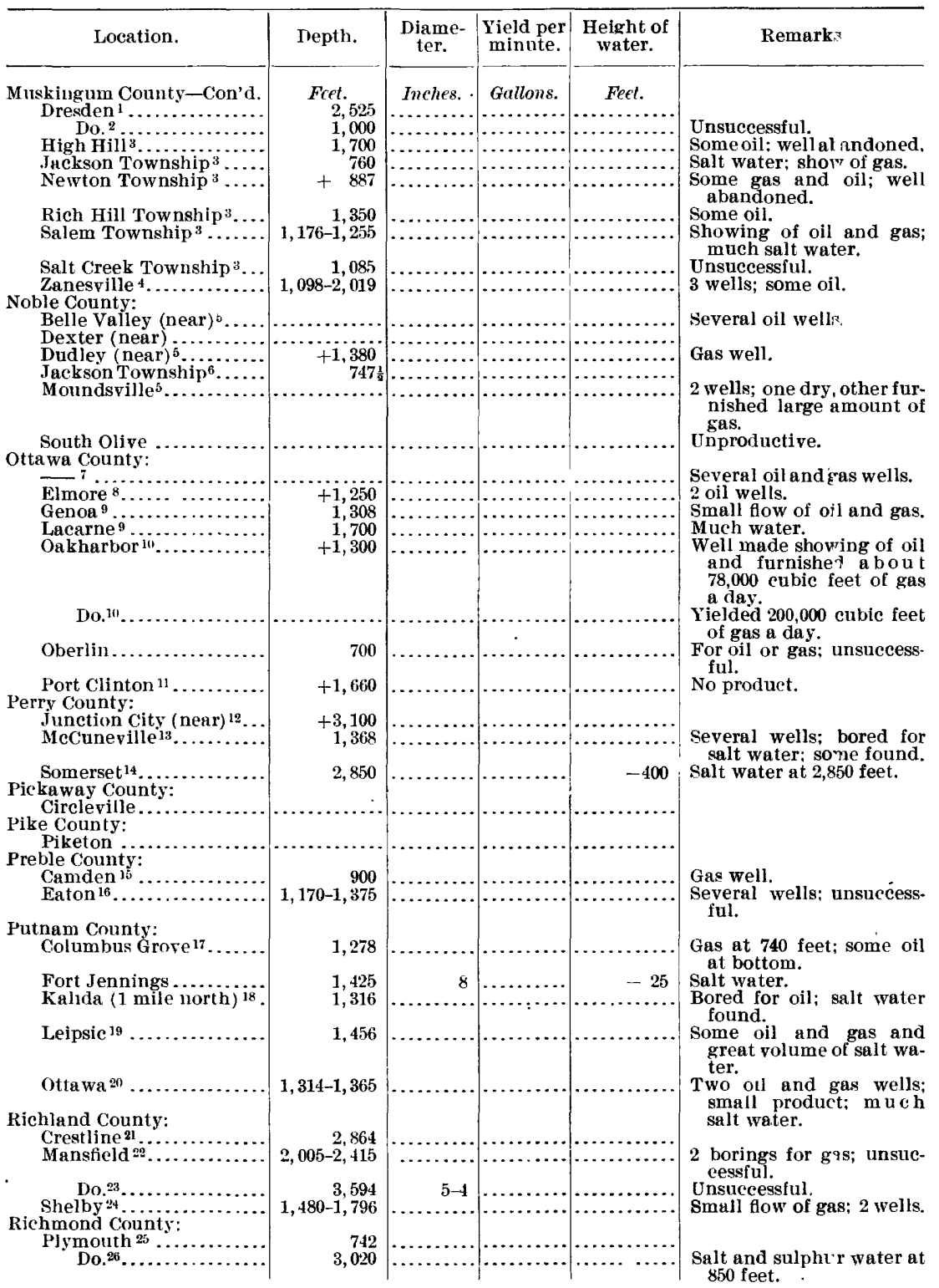

:Ohio Geol Surv Rept.. 1890, vol. 6, p. 246.

2 Ibid., 1888, vol 6, p. 376 .

8 Ibid., pp 268-269.

4 Ibid., pp. $372-375$.

o Ibid., Buil. No. 1, 4th ser., 1903, p. 225.

${ }^{6}$ Record, ibid., 1903, pp. 160-161 7
$94-95$

io Geol. Surv. Bull. No 1, 4th ser., 1903, pp.

Ibid., Rept 1888, vo1. 6, pp. 211-212.

9 Ibid., p. 213

1 Ibid., Bull. No. 1, 4th ser., 1903. p. 94, 1888, vol 6, p. $210-211$.

il Ibid, Rept 1888, vol 6, p, 212

12 Record ibid., Bull. No. 1, 4th ser, 1903, pp 118-119.
${ }^{13}$ Ohio Geol. Surv. Rept. for 1888, vol, 6, pp. $388-389$

${ }^{14}$ Ibld, , 1890, p. 247

15 lbid". 1885. vol. 6, p. 285.

16 Ibid , pp. 108, 284

17 Ibid., p. 242.

is Record, ibid., p. 243.

19 Ibid., p. 242 .

20 Ibid., p. 241

21 Ibid., pp. 303-304.

22 Ibld., pp. 318, 365-366.

23 Ibid., 1890, p, 245.

24 l bid., 1888, vol. 6, pp. 316, 364-365.

25 I bid., p. 315

56 Ibid,, pp. 302-303. 
OHrO-Continued.

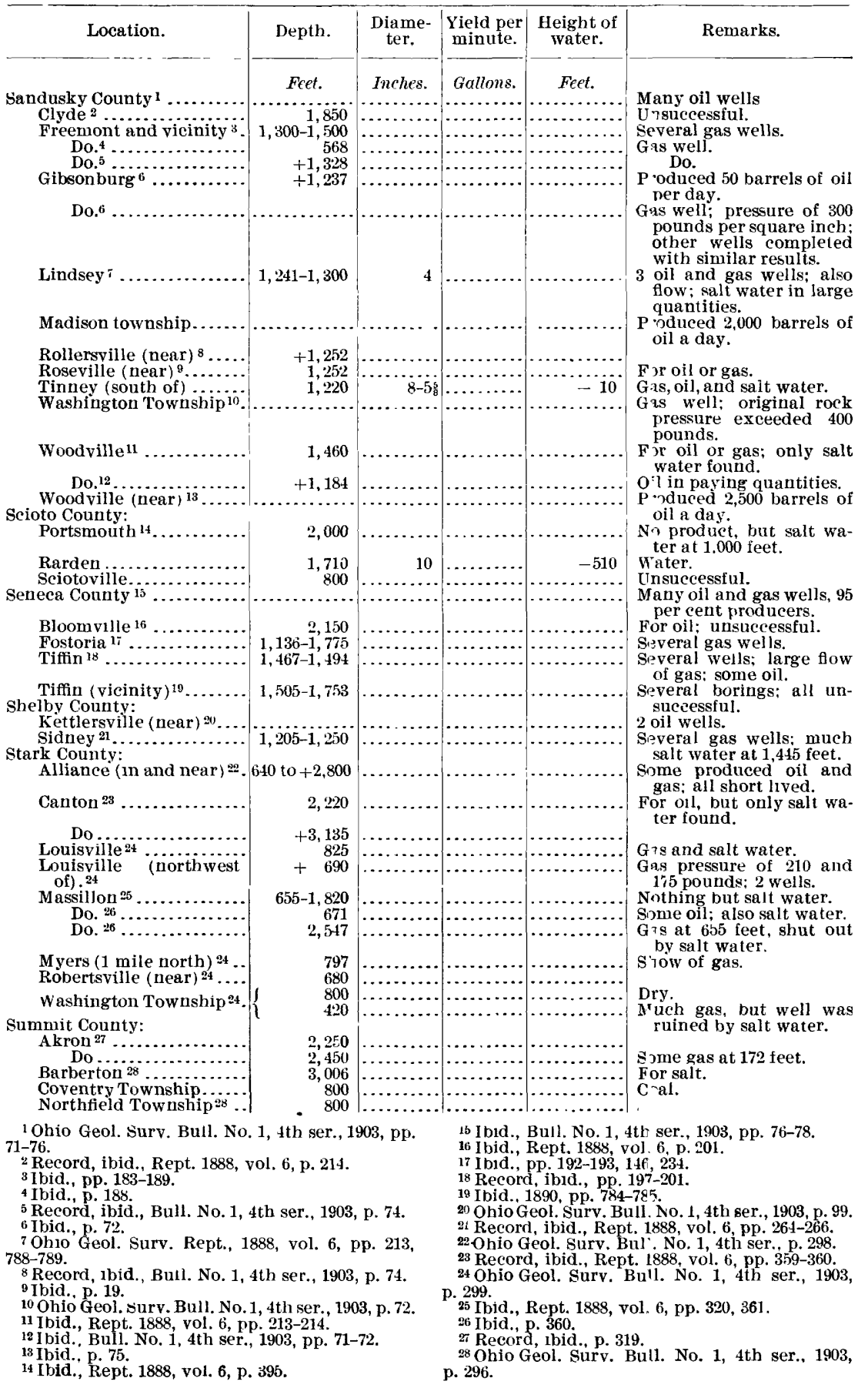


OHIO-Continued.

\begin{tabular}{|c|c|c|c|c|c|}
\hline Location. & Depth. & $\begin{array}{l}\text { Diame- } \\
\text { ter. }\end{array}$ & $\begin{array}{c}\text { Yield per } \\
\text { minute. }\end{array}$ & $\begin{array}{l}\text { Height of } \\
\text { water. }\end{array}$ & Remarks. \\
\hline $\begin{array}{l}\text { Trumbull County: } \\
\text { Brookfield }{ }^{1} \ldots . .\end{array}$ & $\begin{array}{l}\text { Feet. } \\
\quad 1,800\end{array}$ & Inches. & & & \\
\hline Cortland & 3,710 & & & & $\begin{array}{l}\text { Little oil, ges, and salt } \\
\text { water at } 2,995 \text { feet; top } \\
\text { of salt at } 3,239 \text { feet. } \\
2 \text { borings for gas; unsuc- }\end{array}$ \\
\hline West Mecca (near) ${ }^{1}$. & $\begin{array}{l}1,100 \\
1,300\end{array}$ & & & & $\begin{array}{l}\text { cessful. } \\
\text { 3 wells; unsuccessful. }\end{array}$ \\
\hline Tuscarawas County: & & & & & \\
\hline wnship.. & $\begin{array}{r}891 \\
2760\end{array}$ & & & & Coal and brine. \\
\hline $\begin{array}{l}\text { Canal Dove } \\
\text { Dennison }\end{array}$ & $\begin{array}{l}2,760 \\
1,400\end{array}$ & & & & $\begin{array}{l}\text { Little gas and salt water. } \\
\text { Small show of gas. }\end{array}$ \\
\hline Gilmore (near & 1,200 & & & & Several wells \\
\hline $\begin{array}{l}\text { Mill To } \\
\text { Salem T }\end{array}$ & $\begin{array}{r}460 \\
1,50 y\end{array}$ & & & & Some oil and gas. \\
\hline Union County: & & & & & \\
\hline $\begin{array}{l}\text { Magnetic Springs } \\
\text { Marysville?...... }\end{array}$ & $\begin{array}{l}1,600 \\
1,743\end{array}$ & & & & $\begin{array}{l}\text { Salt well. } \\
\text { For gas or oil: found only } \\
\text { water at } 30 \text { c feet. }\end{array}$ \\
\hline $\begin{array}{l}\text { Van Wert County: } \\
\text { Vanwert........ }\end{array}$ & & & & & Several oil and gas wells. 8 \\
\hline Do. & 1,240 & & & & Very small flcw of gas. \\
\hline $\begin{array}{r}\text { Vinton Co } \\
\text { Brown }\end{array}$ & 1,000 & $10-5$ & & & Oil, gas, and sqlt water. \\
\hline Eng & 600 & & & & Salt water. \\
\hline $\begin{array}{l}\text { Ha. } \\
\text { Lor }\end{array}$ & $\begin{array}{r}780 \\
1,100\end{array}$ & & & & $\begin{array}{l}\text { Nothing but sqlt water. } \\
\text { Salt water, scme oil. }\end{array}$ \\
\hline & $900-1,000$ & & & & Fresh and sal' waters. \\
\hline Madison Townshi & 1,017 & $10-5 \frac{5}{8}$ & & & Very little oil and salt \\
\hline $\begin{array}{l}\text { Sugar Grove }(25 \text { miles } \\
\text { south }) .10\end{array}$ & 2,860 & & & & \\
\hline on Township" & 2,449 & & & & \\
\hline $\begin{array}{l}\text { Radeliff } \\
\text { Richland Township } 19 . . .\end{array}$ & $\begin{array}{r}700 \text { or } 800 \\
2,540\end{array}$ & & & & $\begin{array}{l}\text { Water and gas } \\
\text { Gas well. }\end{array}$ \\
\hline Swan Township ${ }^{13} \ldots \ldots$ & $\begin{array}{l}2,900 \\
2,811\end{array}$ & & & & 2 wells. \\
\hline $\begin{array}{r}\text { Vinton Township }{ }^{14} \ldots \ldots \\
\text { Do }{ }^{15}, \ldots \ldots \ldots\end{array}$ & $\begin{array}{r}490-1,057 \\
1,052\end{array}$ & $10-5 \frac{3}{3}$ & & & $\begin{array}{l}\text { Gas, oil, and salt water. } \\
\text { Salt water and gas. }\end{array}$ \\
\hline $\begin{array}{c}\text { Warren Coun } \\
\text { Lebanon }\end{array}$ & $700-1,300$ & & & & Small flow of gas; much \\
\hline Washing & (120 1,000 & & & & salt water. \\
\hline Township $\ldots \ldots$ & $\begin{array}{r}1,114 \\
+1.740\end{array}$ & & & & \\
\hline $\begin{array}{l}\text { Browns Mills (3 miles } \\
\text { southwest). } 18\end{array}$ & $\begin{array}{r}473 \\
447\end{array}$ & & & & 2 wells. \\
\hline Cow Run 19 ............... & $+1,375$ & & & & $\begin{array}{l}\text { For oil or gas; unsuccess- } \\
\text { ful. }\end{array}$ \\
\hline $\begin{array}{l}\text { Do. }{ }^{20} \ldots \ldots \ldots \ldots \\
\text { Do. }{ }^{21} \ldots \ldots \ldots \ldots\end{array}$ & $\begin{array}{r}594 \\
+\quad 423\end{array}$ & & & & $\begin{array}{l}\text { Oil well (schoolhouse). } \\
\text { Oil well. }\end{array}$ \\
\hline Elk Run Pool $22 . . . \ldots$. & 2,138 & & & & Do. \\
\hline Flint's Mills Pool ${ }^{23} . .$. & 1,400 & & & & \\
\hline Lawrence Tow nship ${ }^{24}$. & $1,650-1,800$ & & & & 3 wells, procuced small \\
\hline $\begin{array}{r}\text { Do........... } \\
\text { Macksburg } 25 .\end{array}$ & $\begin{array}{r}1,017 \\
400-1,700\end{array}$ & & & & Large oil fielc about here. \\
\hline Do. 26 & 2,100 & & & & $\begin{array}{l}\text { Numerous successful } \\
\text { wells; gas found also. }\end{array}$ \\
\hline $\begin{array}{r}\text { Do. }{ }^{27} \ldots \ldots \\
\text { Macksburg (near) } 28 \ldots \\
\text { Do. }{ }^{28} \ldots \ldots \ldots\end{array}$ & $\begin{array}{r}2,500 \\
702 \\
905\end{array}$ & & & & $\begin{array}{l}\text { Oil and gas. } \\
\text { For gas or oil } \\
\text { Do. }\end{array}$ \\
\hline
\end{tabular}

1 Ohio Geol. Surv. Bull. No. 1, th ser, 1903, p. 302.

2 Ohio Geol. Surv. Rept., 1888, vol. 6, p. 401.

3 Ibid., Buli. No, i, 4th ser., 1903, pp. 320, 369-370.

4 Ibid., p. 289.

5 Ibid., p. 290.

6 Record, Ibid., Rept. 1888, vol. 6, p. 269.

7 Ibid., pp. 269-270.

8 Ohio Geol. Surv. Buil. No.1, 4th ser., 1903, pp. 96-99.

9 Record, ibid., Rept. 1888, vol.6, pp. 239-240.

10 Skeleton record, ibid., Bull. No. 1, 4th ser. 1903, p. 120.

11 Record, ibid., p. 287

12 OhioGeol. Surv. Buli. No. 1, 4th ser., 1903, p. 277.

13 Ibid., pp. 278-279.

1 Ibid., Rept. 1888, vol. 6, p. 394.

15 Record, 1bid., Bull. No. 1, 4th ser., 1903, pp. 276-277.

16 Ohio Geol. Surv. Rept., 1888, vol. £, pp. 295-296. 17 Ibid., p. 218.

18 Recora, 1bid., Bull. No. 1, 4th ser., 1903, pp. 135-136.

19 Ibid., pp. 168-169.

20 Ibid., pp. 165-166.

21 Ibid., p. 27.

22 Skeleton record, ibid., p. 186.

${ }^{23}$ Record, ibid., p. 190.

24 Ibid., pp, 170-171.

25 Ohio Geol. Surv. Rept., 1888, vol. €, pp. 450-464. 26 Ibid, p. 453. 334.

${ }^{7}$ Record, Pa. Geol. Surv. Rept., Vo', I5, pp. 333${ }_{28}$ Ibid., p. 28. 
OHIO-Continued.

\begin{tabular}{|c|c|c|c|c|c|}
\hline Location. & Depth. & $\begin{array}{l}\text { Diame- } \\
\text { ter. }\end{array}$ & $\begin{array}{l}\text { Meld per } \\
\text { minute. }\end{array}$ & & Remarks. \\
\hline $\begin{array}{l}\text { ashington County-Co }-\mathrm{Co} \\
\text { Macksburg (near) }\end{array}$ & Feft. & & & & Many oil wells \\
\hline & 1,695 & & & & \\
\hline Mariett & $1,740-2,940$ & & & & Oil wells. \\
\hline$\underset{\text { low }) .4}{\text { Marietta }}(4$ miles be- & 1,440 & & & & Grs well. \\
\hline Marietta (near) ${ }^{5} \ldots \ldots \ldots$ & 3,015 & & & & Much salt water at 1,790 \\
\hline Do. ${ }^{6} \ldots \ldots \ldots \ldots$ & +546 & & & & For oil or gas. \\
\hline Marietta ${ }^{7} \ldots \ldots \ldots \ldots$ & & & & & Do. \\
\hline & & & & & Oil well. \\
\hline $\begin{array}{l}\text { Newport Tow } \\
\text { Wingett }{ }^{9} \ldots . .\end{array}$ & $\begin{array}{r}601 \\
+1,687\end{array}$ & & & & Gas well. \\
\hline Township unknown..... & & & & & 2 oil wells. \\
\hline ayne $\mathrm{C}$ & & & & & \\
\hline $\begin{array}{l}\text { Orrville } \\
\text { Wooster in }\end{array}$ & $\begin{array}{r}604 \\
1,805-2,000\end{array}$ & $4 \frac{1}{4}$ & & & $\begin{array}{l}\text { Brine at } 237 \text { and } 588 \text { feet. } \\
3 \text { borings for oil or gas; }\end{array}$ \\
\hline Sterl & +400 & & & & $\begin{array}{l}\text { unsuccessful. } \\
\text { Gas-well boring. }\end{array}$ \\
\hline $\begin{array}{l}\text { Williams County: } \\
\text { Bryan } 12 . . . \ldots . .\end{array}$ & & & & & \\
\hline & & & & & $\begin{array}{l}\text { small; salt water at } 2,037 \\
\text { feet. }\end{array}$ \\
\hline $\begin{array}{r}\text { Stryker } \ldots \ldots \ldots \ldots \ldots \ldots \\
\text { Wood county is } \ldots \ldots \ldots \ldots \ldots\end{array}$ & 860 & & & & $\begin{array}{l}\text { Mineral water at } 230 \text { feet. } \\
\text { Many oil wells: } 88 \text { per }\end{array}$ \\
\hline 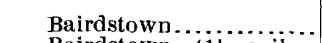 & 1,058 & & & & vells. \\
\hline $\begin{array}{c}\text { Bairdstown } \\
\text { north }) .14\end{array}$ & 1,154 & & & & \\
\hline (near) ${ }^{15} \ldots$. & 1,154 & & & & Fo \\
\hline een $17 \ldots \ldots$. & $\begin{array}{r}1,110 \\
\pm 1,300\end{array}$ & & & & \\
\hline & & & & & $\mathrm{I}$ \\
\hline & & & & & \\
\hline $\mathrm{rg} 2 \mathrm{z}_{1} \ldots \ldots \ldots$ & & & & & low of oil. \\
\hline g & & & & & \\
\hline$p$ & & & & & welis; \\
\hline Jerry City $24 \ldots \ldots \ldots \ldots$ & $\begin{array}{r}1,212-1,295 \\
1,155\end{array}$ & & & & fair sup. \\
\hline Liberty Town & & & & & $\begin{array}{l}\text { ply of o1, } \\
\text { Produced } 10,000 \text { barrels of }\end{array}$ \\
\hline more 26 & $-1,295$ & & & & $\begin{array}{l}\text { er day. } \\
\text { nd oil wells. }\end{array}$ \\
\hline & 1,190 & & & & \\
\hline . & & & & & \\
\hline inity $29 . . .$. & $\begin{array}{r}+1,600 \\
1,177\end{array}$ & & & & ells. \\
\hline (n) & & & & & \\
\hline Portage (near) $\ldots \ldots$ & 1,262 & $8 \frac{1}{4}-6 \frac{1}{4}$ & & & P oduces 5 barrels of oil a \\
\hline & & & & & o fly small \\
\hline $\begin{array}{l}\text { Tontogany ( } 2 \frac{1}{2} \text { miles } \\
\text { southeast). }\end{array}$ & 1,425 & $8-5$ & & & $\begin{array}{l}\text { Some salt water, oil, and } \\
\text { gas. }\end{array}$ \\
\hline 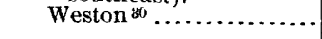 & 1,575 & & & …......... & 0.1 , gas, and sul \\
\hline Wyandot & & & & & Several oil and gas wells. \\
\hline Carey and vicinity ${ }^{32} \ldots$ & $1,326-1,500$ & & & & \\
\hline Little Sa & 1,450 & $8-5 \frac{5}{8}$ & & -40 & \\
\hline \multicolumn{3}{|c|}{ 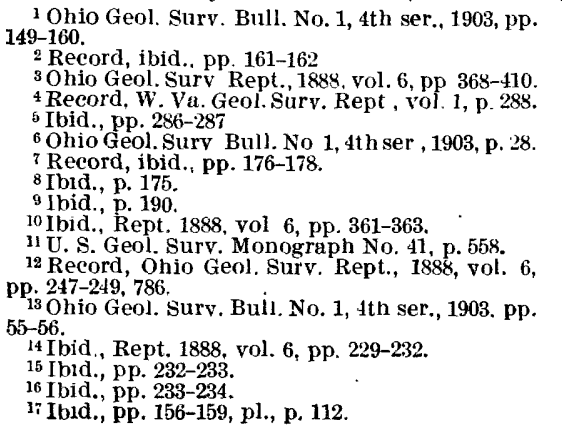 } & \multicolumn{3}{|c|}{ 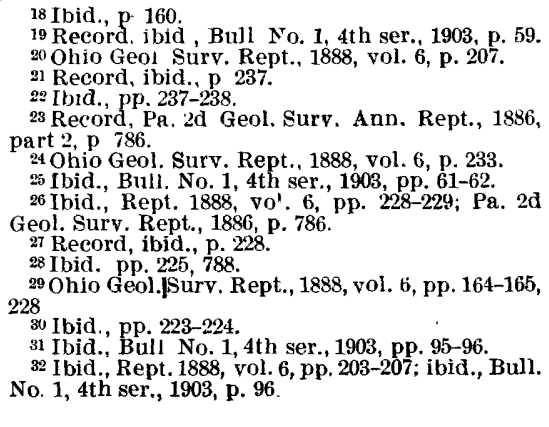 } \\
\hline
\end{tabular}


OHIO-Continued.

\begin{tabular}{|c|c|c|c|c|c|}
\hline Location. & Depth. & $\underset{\text { ter. }}{\text { Diame- }}$ & $\begin{array}{l}\text { Yield per } \\
\text { minute. }\end{array}$ & $\begin{array}{l}\text { Height of } \\
\text { water. }\end{array}$ & Remarks. \\
\hline $\begin{array}{l}\text { Wyandot County-Cont'd. } \\
\text { Nevada }{ }^{1} \ldots \ldots \\
\text { Salem Township }{ }^{2} \ldots \ldots \ldots \\
\text { Upper Sandusky }{ }^{3} \ldots \ldots \ldots \\
\text { Miscellaneous: } \\
\text { Oakharbor }{ }^{4} \ldots \ldots \ldots \ldots \ldots \\
\text { Whartonsburg } 1 \ldots \ldots \ldots \\
\text { Wilmington }{ }^{5} \ldots \ldots \ldots \ldots \ldots\end{array}$ & $\begin{array}{r}\text { Feet. } \\
2,000 \\
1,323 \\
1,340-1,347 \frac{1}{2} \\
1,326-1,335 \\
1,427\end{array}$ & \begin{tabular}{c} 
Inches. \\
$\ldots \ldots \ldots$ \\
\hdashline$\ldots \ldots$ \\
$\ldots \ldots \ldots$
\end{tabular} & $\begin{array}{c}\text { Gallons } \\
\ldots \ldots \ldots \\
\ldots \ldots \ldots\end{array}$ & \begin{tabular}{c} 
Feet. \\
$\cdots \cdots$ \\
\hdashline$\cdots \cdots$ \\
$\cdots \cdots$ \\
$\cdots$
\end{tabular} & $\begin{array}{l}\text { Nothing but salt water. } \\
\text { Small flow of oil. } \\
\text { Two borngs for cil or gas; } \\
\text { unsuccessful. } \\
\text { 3 gas wells. } \\
\text { For oil or gas; unsuccess- } \\
\text { ful. }\end{array}$ \\
\hline $\begin{array}{l}\text { 1 Ohio Geol. Surv. Rept. } 18 \\
\text { 2 Record, Pa. 2d Geol. Sul } \\
\text { part 2, pp. 785-786. }\end{array}$ & vel. & 1886 & $\begin{array}{l}3 \text { Ohio G } \\
4 \text { Ibid., } \\
5 \text { Ibid., }\end{array}$ & $\begin{array}{l}\text { ol. Surv. R } \\
210-211 . \\
296-297 \text {. }\end{array}$ & pt., 1888, vol. 6, p 202. \\
\hline
\end{tabular}

\section{PRINCIPAL PUBLICATIONS RELATING TO DEEP BORINGS IN OHIO.}

Report of the Geological Survey of Ohio, volume 6, Economic Geology, 831 pages, plates, Columbus, 1888.

First Annual Report of the Geological Survey of Ohio (third organization), by Edward Orton, State geologist, 323 pages, plates, Columbus, 1890.

Water resources of Indiana and Ohio, by Frank Leverett: U. S. Geological Survey, Eighteenth Annual Report, 1896-97, part 4, pp. 423-559, plates, Washington, 1897.

Rock waters of Ohio, by Edward Orton: U. S. Geological Survey, Nineteenth Annual Report, 1897-98, part 4, pp. 633-717, plates, Washington, 1899.

Oil and gas, by Bownocker: Ohio Geological Survey, Bulletin 1, 4th series, 1903.

Berea grit oil sand in Cadiz quadrangle, Ohio, by W. T. Griswold: U. S. Geological Survey Bulletin No. 198, pages 25-33, 1902.

Glacial formations of Erie and Ohio basins, by Frank Leverett: U. S. Geological Survey Monograph, No. 41, Washington, 1902.

\section{OKLAHOMA.}

\begin{tabular}{|c|c|c|c|c|c|}
\hline Location. & Depths. & $\begin{array}{l}\text { Diame- } \\
\text { ter. }\end{array}$ & $\begin{array}{l}\text { Yield per } \\
\text { minute. }\end{array}$ & $\begin{array}{l}\text { Height of } \\
\text { water. }\end{array}$ & Remarks. \\
\hline $\begin{array}{l}\text { Beaver County: } \\
\text { Optima ............... }\end{array}$ & Feet. ${ }_{498}$ & $\begin{array}{l}\text { Inches. } \\
\text {.......... }\end{array}$ & Gallons. & Feet. & No water. \\
\hline $\begin{array}{l}\text { Canadian County: } \\
\text { Fort Reno }\end{array}$ & 1,200 & & & & \\
\hline Do......................... & 1,370 & & & & Fresh water at 441 feet. \\
\hline $\begin{array}{r}\text { Do } \ldots \ldots \ldots \ldots \ldots \ldots \\
\text { Comanche County: }\end{array}$ & 1,445 & $12-7$ & & No flow. & Alkaline and salty. \\
\hline $\begin{array}{l}\text { Lawton (T. } 2 \text {, R. } 11 \text {, sec. } \\
22 \text { ). }\end{array}$ & 600 & $10-8$ & & & $\begin{array}{l}\text { No water: natural gas at } \\
350 \text { and } 575 \text { feet. }\end{array}$ \\
\hline $\begin{array}{l}\text { Lawton (T. 2, R. 11, sec. } \\
\text { '23). }\end{array}$ & 504,520 & & & & $\begin{array}{l}\text { Not completed; water } \\
\text { sand at } 638 \text { and } 950 \text { feet } \\
\text { no flow; gas at } 600 \text { feet } \\
\text { water at } 950 \text { fe would } \\
\text { rse about } 500 \text { feet; top } \\
\text { water soft and fresh, } \\
\text { lower is brackish; tem- } \\
\text { perature at mout h, } \\
\text { about } 60^{\circ} \text {. } \\
\text { Bored for oil. }\end{array}$ \\
\hline $\begin{array}{l}\text { Garfield County: } \\
\text { Garber ( } \mathrm{T} .23, \mathrm{R} .3 \text {, sec } \\
\text { 18). }\end{array}$ & 600 & 10 & & & $\begin{array}{l}\text { Not completed; ro water } \\
\text { excellent samp'es of oil } \\
\text { passed through. }\end{array}$ \\
\hline $\begin{array}{l}\text { Greer County. } \\
\text { Granite (T } 5, \text { R. } 21 \text {, see. } \\
33 \text { ). }\end{array}$ & 900 & $10-6$ & & No flow. & $\begin{array}{l}\text { Water found in sand } \\
\text { prmeipal supplies at } 15 \\
\text { and } 750 \text { feet. }\end{array}$ \\
\hline$\underset{\text { Do }}{\text { Mangum }} \ldots \ldots \ldots \ldots \ldots \ldots$ & $\begin{array}{l}500 \\
400\end{array}$ & & & & $\begin{array}{l}\text { For oil, unsuccessful. } \\
\text { A bandoned. }\end{array}$ \\
\hline $\begin{array}{l}\text { Kay County: } \\
\text { B lack ell cone-half } \\
\text { mile east from post- } \\
\text { office). }\end{array}$ & 1,630 & $4 \frac{1}{4}$ & & -10 & $\begin{array}{l}\text { Water salty: vein of salt } \\
\text { water at } 1,630 \text { feet pro- } \\
\text { ducing } 30 \text { per cent of } \\
\text { dry salt of remarkable } \\
\text { purity. }\end{array}$ \\
\hline
\end{tabular}


OKLAHOMA-Continued.

\begin{tabular}{|c|c|c|c|c|c|}
\hline Location. & Depth. & $\begin{array}{l}\text { Diame- } \\
\text { ter. }\end{array}$ & $\begin{array}{l}\text { Yield per } \\
\text { minute. }\end{array}$ & $\begin{array}{l}\text { Height of } \\
\text { water. }\end{array}$ & Remarks. \\
\hline $\begin{array}{l}\text { Kay County-Continued. } \\
\text { Blackw ell (50 rods } \\
\text { northwest). }\end{array}$ & $\begin{array}{l}\text { Feet. } \\
\text { - . . . }\end{array}$ & $\begin{array}{l}\text { Inches. } \\
\text {.......... }\end{array}$ & $\begin{array}{l}\text { Gallons. } \\
\text {............ }\end{array}$ & $\begin{array}{c}\text { Feet. } \\
\cdots \cdots\end{array}$ & Gas at 500 and 860 feet. \\
\hline Newkirk .................... & 1,115 & & & & Som ${ }^{\circ}$ il, but not in paying \\
\hline $\begin{array}{c}\text { Kingfisher County: } \\
\text { Kingfisher...... }\end{array}$ & 600 & & & -8 & $\begin{array}{l}\text { quantities: salt water at } \\
\text { various depths } \\
\text { Larce supply of strong } \\
\text {. }\end{array}$ \\
\hline $\begin{array}{l}\text { Okla homa County: } \\
\text { Oklahoma }\end{array}$ & 780 & & & & For oil or gas; unsuccess- \\
\hline $\begin{array}{l}\text { Osage County: } \\
\text { Pawhuska..... }\end{array}$ & 1,700 & & & & $\begin{array}{l}\text { ful. } \\
\text { oil well. }\end{array}$ \\
\hline Pawnee County: & & & & & \\
\hline $\begin{array}{l}\text { Cleveland } \\
\text { Pottawatomie County: }\end{array}$ & 520 & & & -40 & For oil or gas; salt water \\
\hline Shawnee ........... & 672 & & & & For oil or gas. \\
\hline $\begin{array}{l}\text { Woods County: } \\
\quad \text { Alva...................... }\end{array}$ & 491 & & & & $\begin{array}{l}\text { Hard water, useless for } \\
\text { boiler purposes (at } \\
\text { depot). }\end{array}$ \\
\hline Jet........ & 975 & & & & $\begin{array}{l}\text { At } 280 \text { feet is an } 8 \text {-foot } \\
\text { layer of sand, producing } \\
1 \text { to } 3 \text { barrels of oil daily; } \\
\text { so't water at } 180 \text { feet. }\end{array}$ \\
\hline
\end{tabular}

\section{OREGON.}

\begin{tabular}{|c|c|c|c|c|c|}
\hline Baker County: & & & & & \\
\hline Baker City ................. & 400 & $\cdots$ & Many. & ….... & \\
\hline Clatsop County: & & & & & \\
\hline Fort Stevens............. & 400 & & $\cdots$ & - & Uns"1ccessful. \\
\hline 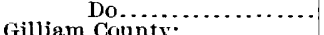 & 800 & $\ldots \ldots \ldots$ & ........... & $\ldots \ldots \ldots \ldots$ & Do. \\
\hline $\begin{array}{l}\text { Gilliam County: } \\
\text { Blalock........ }\end{array}$ & 400 & & & & Do. \\
\hline Harney County: & & & & & \\
\hline Burns . . . . . . . . . . & 750 & 8 & & & $\begin{array}{l}\text { Abandoned; only a very } \\
\text { sn'all flow at } 300 \text { feet. }\end{array}$ \\
\hline $\begin{array}{l}\text { Morrow County: } \\
\text { Heppner ......... }\end{array}$ & 650 & & & i & \\
\hline Multnomab County: & & & & & \\
\hline $\begin{array}{l}\text { Portland } \\
\text { Wasco County: }\end{array}$ & 1,850 & & & & \\
\hline The Dalles............... & 1,020 & $4 \frac{1}{4}-1 \frac{3}{4}$ & & & $\begin{array}{l}\text { Bored for oil: no water } \\
\text { below } 350 \text { feet. }\end{array}$ \\
\hline A. M. Kelsay's farm..... & $+1,002$ & …...... & & & Not completed. \\
\hline Bliss water station ........... & 418 & $4-3 \frac{3}{4}$ & 42 & +10 & Wator tepid. \\
\hline Cleft water station ........... & 425 & 3 & +28 & +10 & Do. \\
\hline
\end{tabular}

PENNSYLVANIA.

\begin{tabular}{|c|c|c|c|c|c|}
\hline \multicolumn{6}{|l|}{$\begin{array}{l}\text { Adams County-Continued. } \\
\text { Littlestown } . . . . . . . . . .\end{array}$} \\
\hline & 500 & & $\cdots$ & $\ldots \ldots \ldots \ldots$ & \\
\hline Allegheny............... & 1,760 & $\ldots$ & - ..... & & Salt well. \\
\hline Do (?) $\ldots \ldots$ & $555-561$ & (......... & $\ldots \ldots$. & & 2 wells. \\
\hline Bridgeville (vicinity) ${ }^{1}$.. & 2,250 & ......... & & & \\
\hline Brushton Station....... & 1,615 & $\ldots \ldots \ldots$ & $\therefore \ldots \ldots$ & $\ldots \ldots \ldots \ldots$ & Uns xccessful. \\
\hline Carnegie (near) ............ & 2,305 & $\ldots \ldots \ldots$ & $\ldots \ldots \ldots$ & $\ldots \ldots \ldots \ldots$ & Gas well. \\
\hline Collier Township ${ }^{2} \ldots \ldots$ & $2,019-2,400$ & ........ & & $\cdots \ldots \ldots \ldots$ & 3 wells; 2 gas wells. \\
\hline Crescent Townshtp $^{\circ} \ldots$. & 2,106 & & & & $\begin{array}{l}\text { For oil or gas; unproduc- } \\
\text { tive. }\end{array}$ \\
\hline Dana Township . . . . & 1,300 & & & & Gas. \\
\hline Demmler......... & 1,000 & & & $\cdots$ & For oil or gas; abandoned. \\
\hline Dixmont $4 \ldots \ldots \ldots \ldots \ldots$ & $1,80^{2}$ & .. & .. & $\ldots$ & Oil and gas well. \\
\hline East Deer Township .... & $1,610-2,334$ & $\ldots \ldots \ldots$ & $\ldots \ldots$ & $\ldots \ldots \ldots \ldots$ & 11 wells, some gas and oil. \\
\hline Do. ${ }^{5} \ldots \ldots \ldots \ldots \ldots$ & $1,194-1,243$ & (....... & $\ldots \ldots$ & $\ldots \ldots \ldots$ & $\begin{array}{l}\text { Several gas wells: one } \\
\text { abandoned. }\end{array}$ \\
\hline Elrod...... & $\pm 1,500$ & & & & For oll or gas, abandoned. \\
\hline Do. ${ }^{6} \ldots$ & 1,186 & ........ & ........ & Flows. & $\begin{array}{l}\text { For oul or gas; unsuccess- } \\
\text { fui }\end{array}$ \\
\hline $\begin{array}{l}{ }^{1} \text { Record, Pa. 2d Geol. Surv } \\
2 \text { Ibid., pp. 261-262. } \\
\text { 3 Ibid., pp. 264-265. }\end{array}$ & Rept., Vol. & & $\begin{array}{l}4 \text { Ibid., } \\
\text { 5 Ibid., } \\
\text { 'Ibid., }\end{array}$ & $\begin{array}{l}\text { p. } 257-258 \text {. } \\
\text { p. } 237-238 \text {. } \\
886, \text { pt. } 2, \text { p }\end{array}$ & $667-668$ \\
\hline
\end{tabular}


PENNSYLVANIA-Continued.

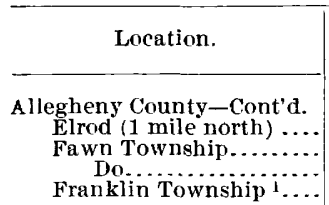

$$
\text { Do. }{ }^{2} \text {. }
$$

Forward Township (southern part).

Forward Township (near headwaters of Sunfish Run). ${ }^{3}$

Gerties Run 4 ..

Gibsonia (one-half mile west) .5

Hampton Township

Harmar Township

Harrison Township 6

Do...................

Hulton Station (near)

Indiana Township....... Do

Jacks Run 8 .

Jefferson Township 9

Lower Burrell Township LowerSt.Clair Township McCandless Township 10 McDonald Oil Field ${ }^{1}$. McKeesport Borough. Marshall Township 12. Mifflin Township Millvale ${ }^{13}$

Monroeville ( $1 \mathrm{mile}$ southeast). 14

Moon Township ${ }^{15}$

Neville Island 16

North Versailles (township).

Oakdale Station ( 3 miles north). 17

O'Harra Township ...... Do ..................

Do. 18

Ohio Township 19

Patton Township

Penn Township $: 0$

Pine Township 21

Pittsburg(12miles southeast). 22

Pjttsburg (Lang avenue and Grazier street). 23

Pittsburg (Twenty-first Ward).

ittsburg (Twenty-fifth

Ward). 24

Pitts burg (Twenty-

${ }^{1}$ Record, Pa. 2d Geol. Surv. Rept., Vol. 15, pp. 251-254.

2 Ibid., Vol. I4, p. 144

3 Record, U. S. Geol. Surv. Follo No. 94, 1903.

${ }^{4}$ Record, Pa. 2d Geol. Surv. Ann. Rept., 1886,

pt. 2 , pp. $742-744$.

5 Ibid., Vol, $1^{5}$, p. 242

${ }^{6}$ Ibid. pp. 684-686.

7 Ibid., pp. $744-746$.

8 Ibid., pp. 748-749.

Ibid., pp. 752-753.

10 Ibid., Vol. I5, p. 254

11 Record, W. Va. Geol. Surv. Rept., vol. 1, 1899, pp. 214-226; vol. 1 (a), 1904, pp. 112-114.

is Record, Pa. 2d. Geol. Surv. Ann. Rept, 1886 part 2, pp 242-213.

13 Ibid., pp. 741-742.

\begin{tabular}{|c|c|c|c|c|}
\hline Depth. & $\begin{array}{l}\text { Diame- } \\
\text { ter. }\end{array}$ & $\begin{array}{l}\text { Yield per } \\
\text { minute. }\end{array}$ & $\begin{array}{l}\text { Height of } \\
\text { water. }\end{array}$ & Remarks. \\
\hline $\begin{array}{l}\text { Feet. } \\
\quad 1,510\end{array}$ & & & & For gas. abandoned \\
\hline $1,639-1,975$ & & & & 19 wells: some gas and oil. \\
\hline $2,000-3,118$ & & & & 6 wells; some gas and oil. \\
\hline $\begin{array}{l}1,905-2,150 \\
1,492 \text { to }\end{array}$ & & & & Several oil or gas wells. \\
\hline$\left\{\begin{array}{r}1,492 \text { to } \\
\pm 1,500\end{array}\right.$ & & & & For oil or gas. \\
\hline $2,030-2,385$ & & & & Many wells; for oil or gas. \\
\hline 2,960 & & & & Gas well. \\
\hline $\begin{array}{r} \pm 1,600 \\
2,017\end{array}$ & & & & $\begin{array}{l}\text { For oil or gas; a bardoned. } \\
\text { For oil or gas. }\end{array}$ \\
\hline $1,300-2,106$ & & & & 6 gas wells. \\
\hline $1,852-2,300$ & & & & 5 gas and oil wells \\
\hline $1,109-1,200$ & & & & several gas wells. \\
\hline $1,205-2,300$ & & & & 4 wells; some gas. \\
\hline 1,744 & & & & For oil or gas. \\
\hline $1,541-1,991$ & & & & 20 gas and oil wells. \\
\hline $2,002-2,418$ & & & & 12 gas and oil wells. \\
\hline 1,724 & & Many. & Ws. & Fresh water at 1,600 feet. \\
\hline $\begin{array}{l}2,014 \\
1,914\end{array}$ & & & & $\begin{array}{l}\text { Gas well. } \\
\text { Do. }\end{array}$ \\
\hline $\begin{array}{l}1,914 \\
1,403\end{array}$ & & & & Do. \\
\hline 2,110 & & & & For oil or gas. \\
\hline $\begin{array}{l}2,342 \\
1,640\end{array}$ & & & & Gas well. \\
\hline 1,830 & & & & Gas wein. \\
\hline 2,471 & & & & Unproductive. \\
\hline 1,655 & & & & $\begin{array}{l}\text { For oil or gas: un } \\
\text { fulceess- }\end{array}$ \\
\hline 1,798 & & Many. & Flows. & Fresh water. \\
\hline $1.800-2,337$ & & & & SeveraJ oil and gas wells. \\
\hline $\begin{array}{r}1,686-1,837 \\
1,850\end{array}$ & & & & Do. \\
\hline 2,164 & & & & For oil or gas. \\
\hline $1,686-1,950$ & & & & Gas and oil. \\
\hline $\begin{array}{r}2,182 \\
1,950-2,060\end{array}$ & & & & For oil or gas; unoroduc- \\
\hline $1,715-2,240$ & & & & $\begin{array}{l}\text { twe. } \\
\text { Numerous gas and oil }\end{array}$ \\
\hline 1,799 & & & & weins. \\
\hline 1,750 & & & & $\begin{array}{l}\text { For oil or gas: unproduc- } \\
\text { tive. }\end{array}$ \\
\hline $\begin{array}{l}2,010 \\
5,575 \\
4,700 ?\end{array}$ & $60^{2}$ & & & $\begin{array}{l}2 \text { gas and oil wells } \\
\text { No water below } 1,100 \text { feet; } \\
\text { deepest well in the } \\
\text { United States. } \\
\text { For oil or gas; abandoned. }\end{array}$ \\
\hline 1,616 & & & & Gas well. \\
\hline $\begin{array}{l}1,620 \\
3,000\end{array}$ & $5 \frac{6}{8}-5 \frac{i}{2}$ & & & $\begin{array}{l}\text { For oll or gas; a bandoned. } \\
\text { Large gas well. }\end{array}$ \\
\hline 1,826 & & & & Gas well. \\
\hline
\end{tabular}

14 Ibid., pp. 746-747.

15 Ibid., Vol. I5 pp. 263-268.

16 lbud., pp. 258-260.

17 Ibid., pp. 262-263.

18 Ibid., pp. 239-241.

19 Ibid., pp. 244-25i - W. Va. Geol. Surv. Rept.' vol. 1 (a), 1904, pp. 97-98.

20) Ibid., 1886, part 2 , pp. 749-750

Il Ibid., Vol. $I^{5}$, pp. 243-244.

22 Record, W. Va. Geol. Surv. Rept., vo'. 1 (a), 1904, pp. 103-107.

${ }_{23}$ Record, Pa. 2d Geol. Surv. Rept, Vo' $I^{5}$, pp. 276-277.

24 Ibid., 1886, part 2, pp. 730-732; W. Va. Geol.

Surv. Rept., vol. 1 (a), 1904, pp. 99-101.

25 Ibid., pp. 733-736 
PENNSYLVANIA-Continued.

\begin{tabular}{|c|c|c|c|c|c|}
\hline Location. & Depth. & $\begin{array}{l}\text { Diame- } \\
\text { ter. }\end{array}$ & $\begin{array}{l}\text { Yield per } \\
\text { minute. }\end{array}$ & $\begin{array}{l}\text { Height of } \\
\text { water. }\end{array}$ & Remarks. \\
\hline $\begin{array}{l}\text { llegheny County-Cont'd. } \\
\text { Pittsburg (Fourteenth }\end{array}$ & $\begin{array}{l}\text { Fect. } \\
\quad 2,007\end{array}$ & & & & Dr: hole. \\
\hline $\begin{array}{l}\text { Ward). }{ }^{1} \\
\text { Pittsburg (near steel }\end{array}$ & 2,360 & & & & Fo" oil or gas. \\
\hline $\begin{array}{l}\text { works). } \\
\text { Pittsburg (just outside } \\
\text { of eity). }\end{array}$ & 1,901 & & & & Gas well. \\
\hline $\begin{array}{l}\text { Do.... } \\
\text { Pittsburg (Thirty-fourth }\end{array}$ & $\begin{array}{l}1,600 \\
2,014\end{array}$ & & & & $\begin{array}{l}\text { Small flow of gas. } \\
\text { Forgas: unsuccesfu }\end{array}$ \\
\hline $\begin{array}{l}\text { Ward } \\
\text { Pittsbu }\end{array}$ & & & & & ing to salt wate \\
\hline Ward ). 4 & & & & & \\
\hline $\begin{array}{l}\text { Pittsburg (Twenty-third } \\
\text { Wardi. }\end{array}$ & 1,600 & & & & $\begin{array}{l}\text { Fo"gas; flooded with salt } \\
\text { vater. }\end{array}$ \\
\hline $\begin{array}{l}\text { Pittaburg (Thirty-third } \\
\text { Ward).5 }\end{array}$ & 1,577 & & & & $\begin{array}{l}\text { Fo' oil or gas; abandoned } \\
\text { on account of salt water. }\end{array}$ \\
\hline Pittsburg $_{\text {Ward). }}$ (Fifteenth & 1,576 & & & & Fo" oil or gas; abandoned. \\
\hline $\begin{array}{l}\text { Pitt-burg ('Twenty-first } \\
\text { Ward). }\end{array}$ & 1,575 & & & & $\begin{array}{l}\text { For gas; flooded with wa- } \\
\text { tor. }\end{array}$ \\
\hline (Twenty-sixth & 1,535 & & & & $\begin{array}{l}\text { For oil or gas; abandoned } \\
\text { on account of salt water. }\end{array}$ \\
\hline Pittsbu & 2,518 & & & & \\
\hline ownship ...... & $\begin{array}{l}7-1,866 \\
-2,085\end{array}$ & & & & $5 \mathrm{~g}$ \\
\hline Robiu & 1,7 & & & & wells. \\
\hline $\begin{array}{l}\text { Ross T } \\
\text { Sewick }\end{array}$ & $\begin{array}{l}1,9 \\
2,0\end{array}$ & & & & \\
\hline Shaler ? & 1,39 & & & & ned. \\
\hline$\ldots \ldots \ldots$ & 1 & & & & \\
\hline (n....... & $\begin{array}{l}5-1,949 \\
0-2,250\end{array}$ & & & & oil. \\
\hline Sharps & 2,01 & & & & $\begin{array}{l}\text { orgas: abandoned. } \\
\text { orgas: }\end{array}$ \\
\hline Snow & 2,3 & & & & \\
\hline Sodom (near) ${ }^{13} \ldots \ldots \ldots$ & $2,275-2,502$ & & & & Se \\
\hline $\begin{array}{l}\text { South Fayette Town- } \\
\text { ship. 14 }\end{array}$ & 2,140 & & & & Oi well. \\
\hline $\begin{array}{l}\text { South Versailles Town- } \\
\text { ship. }\end{array}$ & $1,500-1,724$ & & & & 3 wells. \\
\hline & 1,550 & & & & \\
\hline Do. ${ }^{15} \ldots \ldots \ldots \ldots \ldots$ & $1,510-1,624$ & & & & \\
\hline Spence & 1,990 & & & & \\
\hline $\begin{array}{l}\text { Springdale Station } \\
\text { (near). }\end{array}$ & & & & & \\
\hline $\begin{array}{l}\text { Tarentum } \ldots \ldots \ldots \ldots \ldots \\
\text { Tarentum (vicinity) }{ }^{17} \ldots\end{array}$ & $\begin{array}{r}+1,160 \\
482-1,705\end{array}$ & & & & $\begin{array}{l}\text { Fer gas or oil } \\
\text { Several gas a }\end{array}$ \\
\hline$\underset{\text { northeast })}{\text { Taren }}(18$ miles & 2,010 & & & & $\begin{array}{l}\text { small production. } \\
\text { Fcr oll or gas; unproduc- } \\
\text { tive. }\end{array}$ \\
\hline Toby Township ......... & 1,400 & & & & \\
\hline $\begin{array}{l}\text { Cpper St. Claír Town- } \\
\text { ship. } 19\end{array}$ & & & & & Ges well. \\
\hline & $2,250-2,502$ & & & & \\
\hline Wall Station (near) ..... & 1,850 & & Many. & Flows. & $\begin{array}{l}\text { Water charged with soda; } \\
\text { temp., } 65^{\circ}-70^{\circ} \text {; also gas } \\
\text { well. }\end{array}$ \\
\hline West Deer Township .... & $1,425-1,971$ & & & & 26 wells: principally gas \\
\hline & $2,004-2,243$ & & & & $\begin{array}{l}\text { and onl } \\
8 \text { wells; } s\end{array}$ \\
\hline & & & & & For oll o \\
\hline Towns] & & & & & \\
\hline & $1,520-1,837$ & & & & 12 wells; \\
\hline & $2,007-2,4: 25$ & & & & 5 wells; some gas; 3 un- \\
\hline & $3,000-4,618$ & & & & 2 wells: 1 gas, 1 unpro- \\
\hline $\begin{array}{l}\text { mstrong Co } \\
\text { Bethel To }\end{array}$ & & & & & 3 well \\
\hline Do.................. & & & & & \\
\hline Do................ & $2,223-2,273$ & & & & ells; 1 unproductive, 1 \\
\hline \multicolumn{3}{|c|}{$\begin{array}{l}1 \text { Record, Pa. 2d Geol. Surv. Ann. Rept., 1886, } \\
\text { pt. } 2 \text { pp. 736-737. } \\
\text { 2 Ibid., Vol. III, pp. 398-400. } \\
3 \text { Ibid., 1886, part 2, pp. 739-741: W. Va. Geol. }\end{array}$} & \multicolumn{3}{|c|}{ 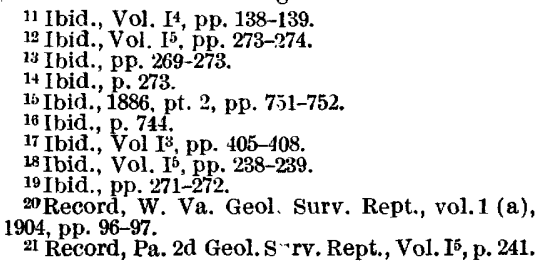 } \\
\hline
\end{tabular}


PENNSYLVANIA-Continued.

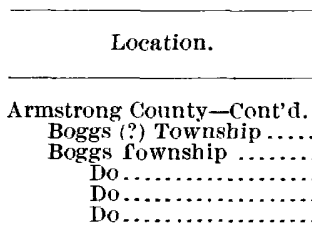

Bradys Bend Bradys Bend Township ${ }^{i}$

Burrell Township ..........

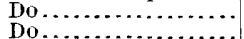
Do.

Cowanshannock Township. Do

Criswell (vicinity)

East Franklin Township.

Do..................

Do

Farrentown ${ }^{3}$

Fawn Township....

Foxburg 4 . wnship (?) ...

Kiskiminitas Township Kittanning Township... Do

Do

Lawrenceburg (southof) ${ }^{5}$ Limestone Township (?). Madison Township..... Do.

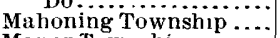

Manor Township...

North Buffalo Township

Park Township.

Parker City 6

erry Township $7 . . . . .$. Do. ${ }^{8}$

$$
\text { Do }
$$

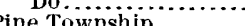

$$
\text { Do.................. }
$$
Do 9

Plum Creek Township.

Rayburn Township.

Redbank Township....

South Bend Township.

$$
\text { Do }
$$

South Buffaio

Sugar Creek Township.

Valley Township. Washington Township.

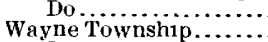
Do .....................

West Franklin.............. Do ..................

Beaver County:

Baden (1 mile north) ${ }^{11}$.

Beaver Falls ${ }^{12}$............

Beaver Falls (2 miles above) ${ }^{13}$

Bridgewater (near)

${ }_{1}^{1}$ Reeord, Pa. $2 d$ Geol. Surv. Rept., Vol. II, pp. 258-259.

2 Ibid., pp. 253-258

3 Ibid., pp. 242-243.

4 Ibid., pp. 237-238.

5 Ibid., p. 243.

6 Ibid., p. 242.

7 Ibid., pp. 240-241.

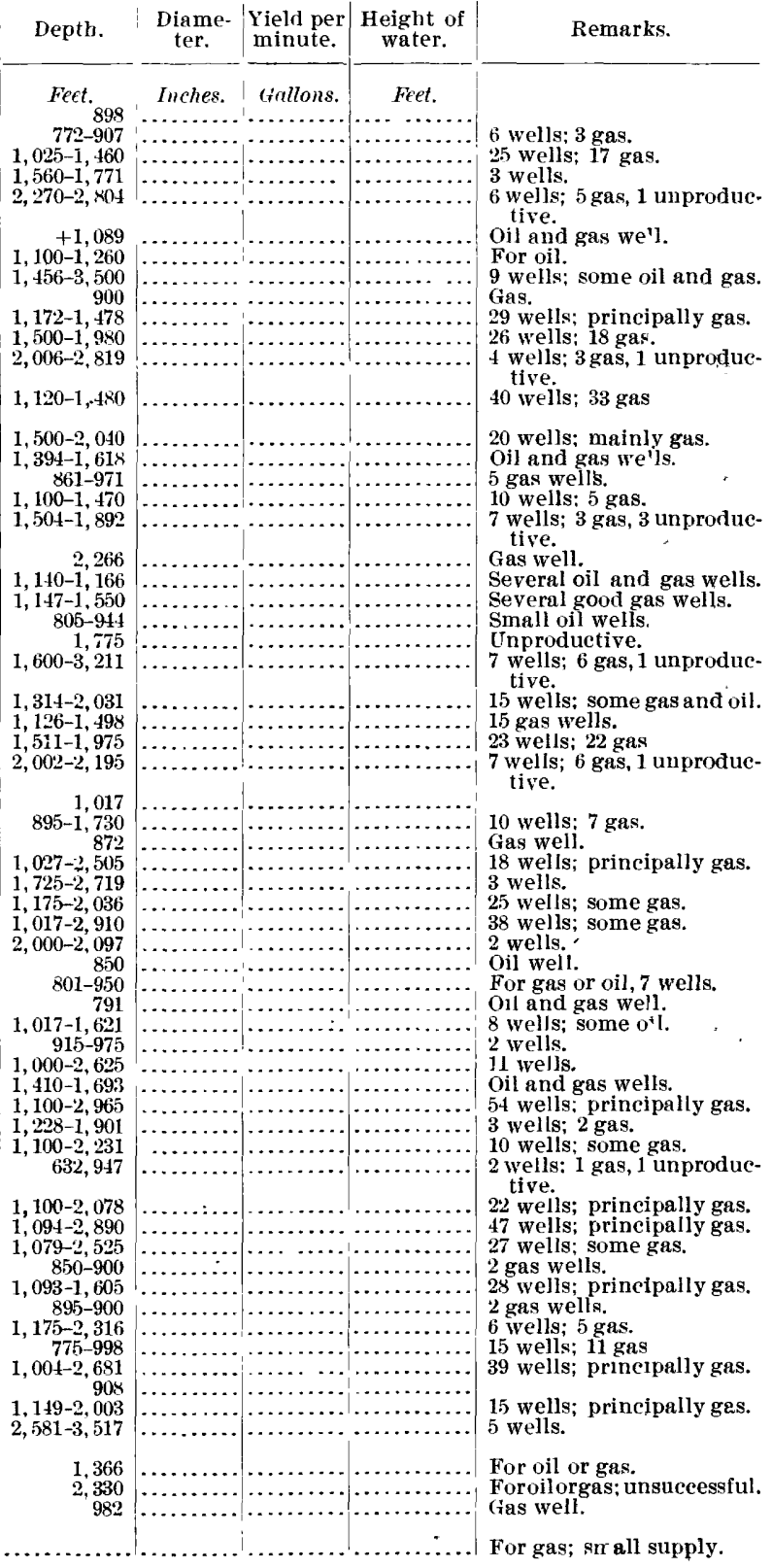

8 Ibid., Vol. III, pp. 416-417.

10 Record, W. Va. Geol. Surv. Rept., vol. 1 (a), 1904, pp. 108-112.

11 Record. Pa. 2d Geol. Surv. Rept., Vcl. 15, p. 232

12 Ibid., Vol. III, pp. 401-404.

13 Ibid., Vol. I4, pp. 142-143.

IRR $149-05-8$ 
PENNSYLVANIA-Continued.

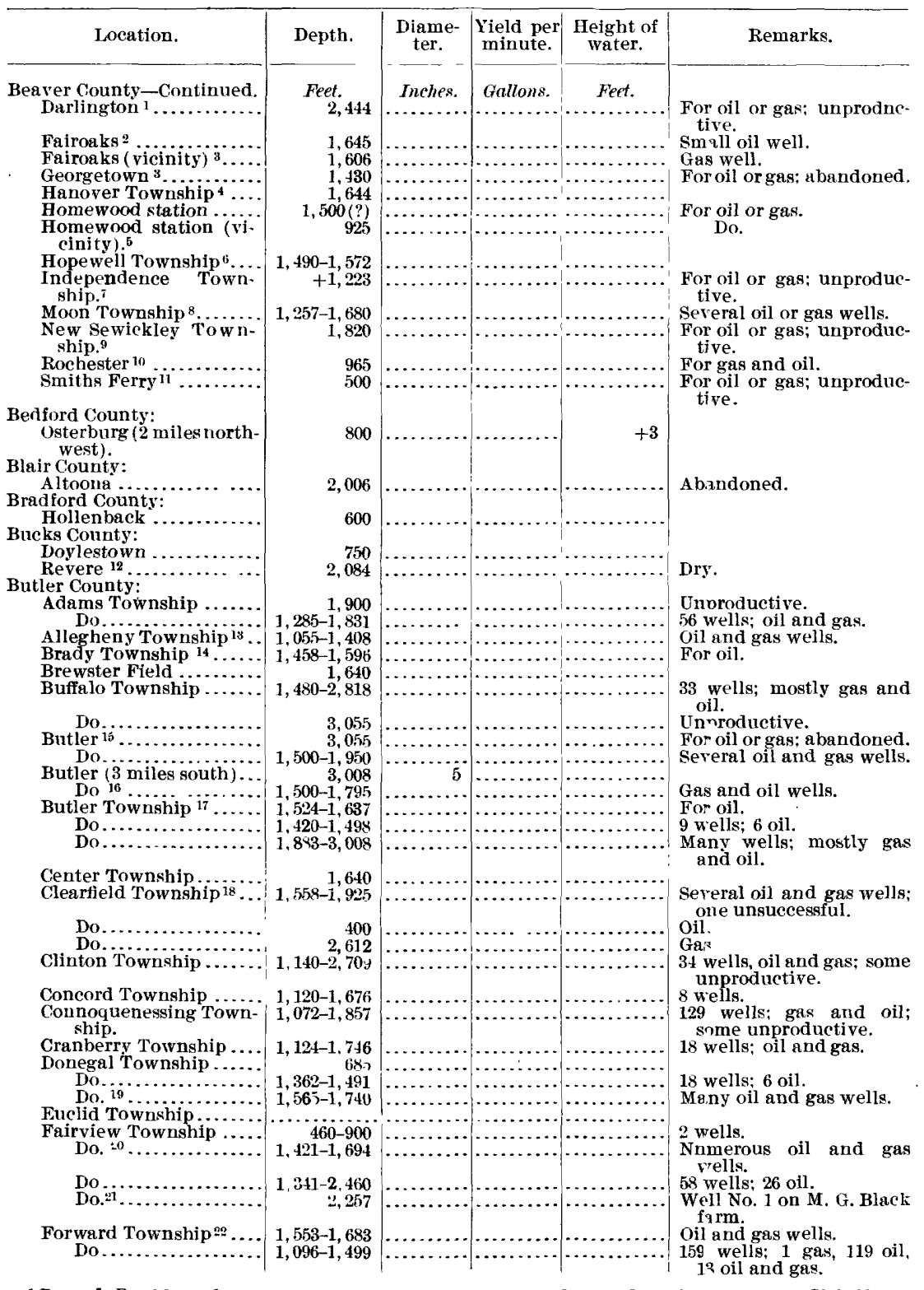

${ }^{1}$ Record. Pa. 2d Geol. Surv. Ann. Rept., 1886, part 2, pp. 780-781.

"Ibid., Vol. I', pp. 232-233.

3 Ibid., p. 233.

4 Ibid., pp. 235-236.

5 Ibid., Vol. QQ, pp. 250-251.

6 Ibid., Vol. $\mathrm{I}^{5}$, pp. 234-235.

7 Ibid., 1886, part 2, pp. 779-780.

8 Ibid., pp. 688-689.

${ }^{9}$ Ibid., Vol. ${ }^{5}$, pp. 231-232.

1o Ibid., Vol. II, pp. 279-280

11 Ibid., pp. 281-282.

12 Record,Änn. Phil. Soc. Trans., vol. 29, pp.21-24.
13 Record, Pa. 2d Geol. Surv. Rept., Vol. II, pp. 238-240.

${ }^{14}$ Ibid., Vol. G4, pp. 150-151; Vol III, pp. 418-419. 15 Ibid., Vol, $\mathrm{I}^{5}$, pp. 193-194.

16 Ibid., pp. 209-210

17 Ibid., 1886, part 2 , pp. 711-718.

18 Ibid., p. 178; Vol. II, Fp. 266-268.

19 Ibid., Vol. I', pp. 199-203; Vol. II, pp. 263-265.

${ }^{30}$ Ibid., Vol. II, pp. $246-262$

${ }^{21}$ Record, W. Va. Geol. Surv. Rept., vol. 1 (a),

1904, p. 94.

${ }_{22}$ Record, Pa. $2 d$ Geol. Surv. Rept., Vol. $1^{5}$, p. 208. 
PENNSYLVANIA-Continued.

\begin{tabular}{|c|c|c|c|c|c|}
\hline Location. & Depth. & $\begin{array}{l}\text { Diame- } \\
\text { ter. }\end{array}$ & $\begin{array}{c}\text { Yield per } \\
\text { minute. }\end{array}$ & $\begin{array}{l}\text { Height of } \\
\text { water. }\end{array}$ & Remarks. \\
\hline $\begin{array}{l}\text { Butler County-Continued. } \\
\text { Forward Township...... }\end{array}$ & $\begin{array}{l}\text { Feet. } \\
1,500-1,809\end{array}$ & & & & 88 wells; 2 gas 51 oil, 4 \\
\hline${ }_{\text {Great Beit City (vicin- }}^{\text {Do }}$ & 2,625 & & & & $\begin{array}{l}\text { oil and gas. } \\
\text { oil and gas. }\end{array}$ \\
\hline $\begin{array}{l}\text { Great Belt City (vicin- } \\
\text { ity). } 1\end{array}$ & & & & & \\
\hline $\begin{array}{l}\text { Greece City (3 miles } \\
\text { west). }{ }^{2}\end{array}$ & 1,500 & & & & $\begin{array}{l}\text { For oil or gas; unproduc- } \\
\text { tive. }\end{array}$ \\
\hline $\begin{array}{l}\text { Greece City (vicinity) }{ }^{3} . . \\
\text { Harrisville (vicinity) } \\
4{ }^{4} . .\end{array}$ & $\begin{array}{r}1,423-1,530 \\
880-1,367\end{array}$ & & & & $\begin{array}{l}\text { Several oil and gas wells. } \\
\text { For gas or oil. }\end{array}$ \\
\hline 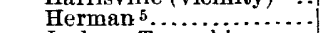 & $1,784-1,901$ & & & & Several oil and gas wells. \\
\hline Jackson Township & $1,088-1,756$ & & & & $\begin{array}{l}80 \text { wells; princirally gas } \\
\text { and oil. }\end{array}$ \\
\hline $\begin{array}{l}\text { Jefferson Center } \mathbf{6} . . \\
\text { Jefferson Township }\end{array}$ & $\begin{array}{r}1,732 \\
1,494-1,959\end{array}$ & & & & $\begin{array}{l}\text { Oil well. } \\
59 \text { wells; gas and oil. }\end{array}$ \\
\hline $\begin{array}{l}\text { Karns city (one-half } \\
\text { mile south) } .^{7}\end{array}$ & 1,454 & & & & \\
\hline Lardens Mills ${ }^{8} \ldots$ & 1,140 & & & & Gas well. \\
\hline $\begin{array}{l}\text { (?) Lower Burrell Town- } \\
\text { ship. } \\
\text { Marion Township } 9 . . . .\end{array}$ & $\begin{array}{r}1,779 \\
765\end{array}$ & & & & \\
\hline Mars station & 1,900 & & & & $\begin{array}{l}\text { For oil or gas; unpro- } \\
\text { ductive. }\end{array}$ \\
\hline $\begin{array}{l}\text { Mercer Township . } \\
\text { Do............. }\end{array}$ & $\begin{array}{r}880-948 \\
1,367\end{array}$ & & & & 3 wells. \\
\hline Middle & $1,785-1,930$ & & & & Several oil and gas wells. \\
\hline & $1,248-2,027$ & & & & 17 wells; gas and oil. \\
\hline $\begin{array}{l}\text { Oneida station ( } 1 \frac{1}{2} \text { miles } \\
\text { east). } 12\end{array}$ & 2,135 & & & & well. \\
\hline $\begin{array}{l}\text { Parker Township }{ }^{13} \ldots \ldots \ldots \\
\text { Do.................. }\end{array}$ & $\begin{array}{l}1,183-1,418 \\
2,073-2,356\end{array}$ & & & & For oil; 3 wells. \\
\hline Penn Towi & $1,164-1,482$ & & & & 13 wells; princir a.lly oil. \\
\hline Do. ${ }^{14}$ & $1,528-1,825$ & & & & $\begin{array}{l}\text { Numerous oil and gas } \\
\text { wells; some good pro- } \\
\text { ducers. }\end{array}$ \\
\hline Petrolia (vicinity) ${ }^{15}$ & $1,400-1,631$ & & & & Numerous gas and oil \\
\hline Reibold 10 & $1,707-1,711$ & & & & 2 oil wells. \\
\hline & 1,738 & & & & \\
\hline Renfrew (ne & 1,780 & $8 \frac{1}{4}-6 \frac{1}{4}$ & & & $\begin{array}{l}\text { Produces } 11 \text { barrels of oil } \\
\text { a day: water-bearing } \\
\text { strata at } 170 \text { and } 600 \text { feet. }\end{array}$ \\
\hline $\begin{array}{l}\text { Rough Run District..... } \\
\text { St. Joe (vicinity) }{ }^{17} \ldots . . .\end{array}$ & $\begin{array}{r}1,380 \\
1,445-1,577\end{array}$ & & & & $\mathrm{cos}^{-3}$ \\
\hline Sarve & $\begin{array}{r}3,055 \\
1,930\end{array}$ & & & & For oil or gas; abandoned \\
\hline Saxo & $\begin{array}{l}1,980 \\
1,857\end{array}$ & & & & Gas well \\
\hline & 1.825 & & & & For oil or \\
\hline Slippe & 1,411 & & & & Do. \\
\hline & $\begin{array}{r}1,400-1,436 \\
2,135\end{array}$ & & & & For oil; unproductive. \\
\hline Summit $24 \ldots \ldots \ldots$ & 1,822 & & & & Gas we \\
\hline Summit Township ${ }^{25} . .$. . & 1,735 & & & & \\
\hline Do................... & $1,080-2,527$ & & & & Many wells; oi and gas \\
\hline & & & & & \\
\hline & 1,956 & & & & Gas well. \\
\hline $\begin{array}{l}\text { Winfield Township. } \\
\text { Do. }{ }^{26} \ldots \ldots \ldots \ldots \ldots\end{array}$ & 400 & & & & \\
\hline Do.................. & $\begin{array}{r}1,030-2,680 \\
1,680\end{array}$ & & & & rincipally gas: \\
\hline $\mathrm{ml}$ & & & & & \\
\hline & 1,000 & & & & \\
\hline $\begin{array}{l}\text { Cambria Mill }{ }^{27} \ldots \ldots \ldots \\
\text { Cherry Tree Borough } 28\end{array}$ & $\begin{array}{l}653 ? \\
653\end{array}$ & & & & $\begin{array}{l}\text { Gas well. } \\
\text { Do. }\end{array}$ \\
\hline
\end{tabular}

1 Record, Pa. 2d Geol. Surv. Rept., Vol. I4, p. 138.

2 Ibid., p. 141.

3 Ibid., Vol. II, pp. 247-248.

4 Ibid., 1886, part 2, pp. 718-719.

5 Ibid., Vol. I5, pp. 195-197.

6 Ibid., 1886, part 2, pp. 716-717.

7 Ibid., Vol. II, pp. 262-263.

8 Ibid., pp. 270-271.

9 Ibid., 1886 , part 2, p. 720.

10 Ibid., Vol. $\mathrm{I}^{5}$, p. 210

11 Ibid,' Vol. II, p. 271; Vol. $\mathbf{I}^{6}$, pp. 197-198; Vol.

III pp. 404-405.

12 Ibid., 1886, part 2, pp. 717-718.

${ }^{13}$ Ibid., Vol. II, pp. 243-246.

14 Ibid., 1886, part 2, pp. 713-716; Vol. I5, pp. 203208; W. Va. Geol. Surv. Rept., vol.1 (a), 1904, pp. 95-96.
15 Ibid., Vol. II, pp. 260-261, 283-296; W. Va.Geol. Surv. Rept., vol. 1 (a), 1904, pp. 89-93.

16 Ibid., Vol. $\mathrm{I}^{5}$, pp. 194-195.

17 Ibid., 1886, part 2, pp. 713-714; Vol. I', p. 138.

18 Ibid., Vol. $1^{5}$, pp. 198-194.

19 Ibid., p. 194.

20 Ibid., Vol. II, p. 269.

21 Ibid., p. 270

22 Ibid., Vol. QQ , p. 154.

23 Ibid., Vol. I4, pp. 143-144; Vol. I3, 417-418.

24 Ibid., Vol. I8, p. 404.

25 Ibid., Vol. II, pp. 268-269.

26 Ibid., p. 716.

27 Ibid., Vol. HH, pp. 176-180.

28 Ibid., Vol. I4, p. 146. 
PENNSYLVANIA-Continued.

\begin{tabular}{|c|c|c|c|c|c|}
\hline Location. & Depth. & $\begin{array}{l}\text { Diame- } \\
\text { ter. }\end{array}$ & $\begin{array}{l}\text { Yield per } \\
\text { minute. }\end{array}$ & $\begin{array}{l}\text { Height of } \\
\text { wate.s. }\end{array}$ & Remarks, \\
\hline $\begin{array}{l}\text { Cambria County-Cont'd. } \\
\text { Cresson }{ }^{1} \ldots \ldots \ldots \ldots \ldots . . . . .\end{array}$ & Feet. & & Gal & & \\
\hline 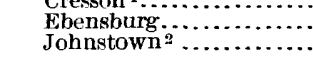 & $\begin{array}{l}1,000 \\
2,856\end{array}$ & $5 \frac{3}{4}$ & & No flow. & Fo* oil or gas; unproduc- \\
\hline Johnstown ( 4 miles west) & 2,500 & & & & $\begin{array}{l}\text { tive. } \\
\text { Do. }\end{array}$ \\
\hline $\begin{array}{l}\text { Taylor Township } \ldots \ldots \ldots \\
\text { Cameron County: }\end{array}$ & 2,500 & & & & Unproductive. \\
\hline $\begin{array}{l}\text { Cameron siation (one- } \\
\text { half mile northeast). } 4\end{array}$ & 971 & & & & Fon oil. \\
\hline $\begin{array}{r}\text { Emporium }^{5}, \ldots \ldots \\
\text { Do..... }\end{array}$ & $\begin{array}{r}1,410 \\
+400\end{array}$ & & & & Do. \\
\hline$\underset{\text { northwest) } 6}{\text { Emporium }}(4 \mathrm{miles}$ & 1,607 & & & & $\begin{array}{l}\text { Fo" oil or gas; unprotuc- } \\
\text { tive. }\end{array}$ \\
\hline $\begin{array}{l}\text { Chester Cou } \\
\text { Parkesb }\end{array}$ & 522 & & & & \\
\hline $\begin{array}{c}\text { Clarion } \\
\text { Ashl }\end{array}$ & & & & & Do. \\
\hline $\begin{array}{l}\text { Ashli } \\
\text { Beav }\end{array}$ & $1,001-1$ & & & & For oil or gas. \\
\hline & 636 & & & & Oil and gas wells. \\
\hline Clarion 11 ................ & $1,238-1,367$ & & & & $\begin{array}{l}\text { Several oil wells; one un- } \\
\text { productive. }\end{array}$ \\
\hline Clarion (near) $\ldots \ldots \ldots \ldots$ & $1,3 ! 1$ & & & & \\
\hline (nity) ${ }^{12}$. & $843-2,050$ & & & & $\begin{array}{l}\text { For oil or gas; one unpro- } \\
\text { ductive. }\end{array}$ \\
\hline $\begin{array}{l}\text { Crown Township.... } \\
\text { Edenburg }{ }^{13} \ldots . . . .\end{array}$ & 1,082 & & & & \\
\hline $\begin{array}{l}\text { Edenb } \\
\text { Edenb }\end{array}$ & $\begin{array}{l}1,268 \\
1,046\end{array}$ & & & & Good oil well. \\
\hline $\begin{array}{l}\text { east). }{ }^{14} \\
\text { Elk Township }{ }^{15} \ldots \ldots \ldots\end{array}$ & $977-1,450$ & & & & Several oil or \\
\hline Do & 2,025 & & & & unproductive. \\
\hline Farm & 2,050 & & & & \\
\hline & 1,207 & & & & \\
\hline $\begin{array}{l}\text { Madison Township ...... } \\
\text { Mill Creek Township } 10 . .\end{array}$ & $\begin{array}{r}1,052-3,513 \\
2,323\end{array}$ & & & & $\begin{array}{l}6 \text { vrells; some gas. } \\
\text { For oil or gas; unproduc- }\end{array}$ \\
\hline Do......... & 1,367 & & & & \\
\hline Millville ${ }^{17} \ldots$. & $\begin{array}{l}2,280 \\
992\end{array}$ & & & & Oil and gas well. \\
\hline Piney Township & 1,151 & & & & \\
\hline $\begin{array}{l}\text { Riehland Township } 18 \ldots \\
\text { Salem Township } 19 . \ldots \ldots\end{array}$ & $1,040-1,700$ & & & & Sereral oil wells. \\
\hline & $\begin{array}{r}-1,200 \\
2,378\end{array}$ & & & & \\
\hline asville ( 1 miles & 2,025 & & & & $\begin{array}{l}\text { For oil or gas; unproduc- } \\
\text { tive. }\end{array}$ \\
\hline & 1,151 & & & & of well. \\
\hline & & & & & \\
\hline & & & & & D \\
\hline & 1,150 & & & & For oil or gas. \\
\hline $\begin{array}{r}\text { Township unknown } \ldots \ldots \\
\text { Do........................ }\end{array}$ & 944 & & & & 3 vells \\
\hline (n........ & $\begin{array}{r}1,040-1,427 \\
1,636\end{array}$ & & & & 3 vells. \\
\hline & $2,130-2,280$ & & & & 2 vells. \\
\hline ....... & 2,712 & & & & \\
\hline uth- & & & & & For oil \\
\hline & & & & & For on \\
\hline & 3,020 & & & & \\
\hline hip $\ldots \ldots \ldots$ & $\begin{array}{r}3,006 \\
454-617\end{array}$ & & & & $\mathbf{F}$ \\
\hline Clinto & & & & & \\
\hline$p \ldots$. & 458 & & & & \\
\hline ip $\ldots$. & 3,525 & & & & \\
\hline & $-1,800$ & & & & \\
\hline & & & & & tive. \\
\hline Lockhaven ............. & 3,525 & & & & $\begin{array}{l}\text { Fcr oil or gas; unsuccess- } \\
\text { ful. }\end{array}$ \\
\hline \multicolumn{3}{|c|}{ 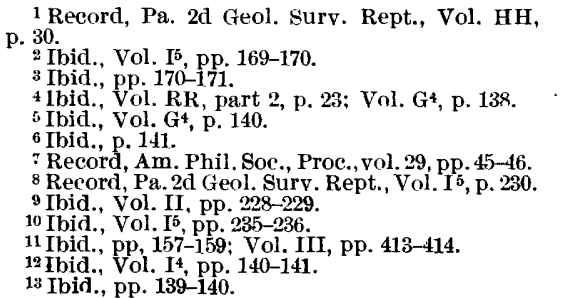 } & \multicolumn{3}{|c|}{ 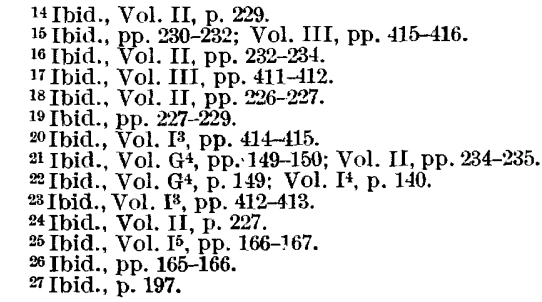 } \\
\hline
\end{tabular}


PENNSYLVANIA-Continued.

\begin{tabular}{|c|c|c|c|c|c|}
\hline Location. & Depth. & $\begin{array}{l}\text { Diame- } \\
\text { ter. }\end{array}$ & $\begin{array}{c}\text { Yield per } \\
\text { minute. }\end{array}$ & $\begin{array}{l}\text { Height of } \\
\text { water. }\end{array}$ & Remarks. \\
\hline 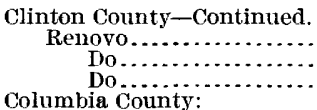 & $\begin{array}{r}\text { Feet. } \\
4,000 \\
3,460 \\
450-1,350\end{array}$ & $\begin{array}{l}\text { In } \\
\cdots \\
\cdots\end{array}$ & $\begin{array}{l}G a \\
\cdots \\
\cdots \\
\cdots\end{array}$ & $\begin{array}{l}\text { Feet. } \\
-600\end{array}$ & \multirow{9}{*}{$\begin{array}{l}\text { For oil; unsuccessiul. } \\
\text { Gas well. } \\
\text { For oil or gas. } \\
\text { For oil or gas; abandoned. } \\
\text { Several oil wells } \\
\text { Do. } \\
3 \text { wells. } \\
\text { Oil and gas well. } \\
\text { For oil or gas. } \\
\text { Oil well. } \\
\text { Several oil wells in this } \\
\text { vicinity. }\end{array}$} \\
\hline $\begin{array}{l}\text { Columbia County: } \\
\text { Montana } \ldots \ldots \ldots \ldots \ldots \ldots\end{array}$ & $717-722$ & 2 & & & \\
\hline $\begin{array}{l}\text { Crawford County: } \\
\text { Black Ash } 1 \text {. }\end{array}$ & 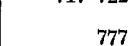 & & & & \\
\hline 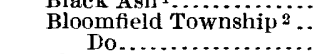 & $\begin{array}{r}590-1,000 \\
975\end{array}$ & & & & \\
\hline Chureh Run ${ }^{3} . \ldots \ldots$. & $415-700$ & & & & \\
\hline Coneord Township....+ & $\begin{array}{r}098-814 \\
845\end{array}$ & & & & \\
\hline $\begin{array}{l}\text { Conneautyille (1 mile } \\
\text { below). }{ }^{5}\end{array}$ & 750 & & & & \\
\hline $\begin{array}{l}\text { Dicksonburg } \ldots \ldots \ldots \ldots \ldots \\
\text { Meadville }^{6} \ldots \ldots \ldots\end{array}$ & $\begin{array}{l}680 ? \\
900\end{array}$ & & & & \\
\hline $\begin{array}{l}\text { Meadville (near) }{ }^{\top} \ldots . . . \\
\text { Oil Creek Townsip.... }\end{array}$ & $\begin{array}{r}+475 \\
3.500\end{array}$ & & & & \\
\hline Do...... & $550-971$ & & & & \multirow{13}{*}{$\begin{array}{l}\text { For oil. } \\
3 \text { wells. } \\
\text { Several oil wells } \\
\text { For oil or gas; abandoned. } \\
\text { Oil and gas well. } \\
\text { Oil well. } \\
\text { Several oil and gas wells; } \\
\text { some productive. } \\
\text { Gas well. } \\
\quad \text { Do. } \\
\text { For oil or gas. } \\
\text { Numerous oil and gas } \\
\text { wells. } \\
\text { Several oil and gas wells; } \\
\text { some unproductive. } \\
\text { Oil and gas wells. } \\
\text { Several oil and gas wells. } \\
\text { For oil; unsuceesful. }\end{array}$} \\
\hline $\begin{array}{l}\text { Randolpl } \\
\text { Reeds Co }\end{array}$ & $\begin{array}{r}565-950 \\
500\end{array}$ & & & & \\
\hline Richmo & 900 & & & & \\
\hline $\begin{array}{l}\text { South shenango Town- } \\
\text { ship.ic }\end{array}$ & 1,065 & & & & \\
\hline Sparta Township ${ }^{11} \ldots . .$. & $465-1,507$ & & & & \\
\hline $\begin{array}{l}\text { Spartansburg }\left(2 \frac{1}{2} \text { miles }\right. \\
\text { southeast }) .12\end{array}$ & 745 & & & & \\
\hline vnship ......... & 512 & & & & \\
\hline $\begin{array}{l}\text { Titu } \\
\text { Titu }\end{array}$ & $\begin{array}{r}600 \\
3,553\end{array}$ & 10 & & & \\
\hline Titusville (vicinity) $14 \ldots$ & $400-806$ & & & & \\
\hline Troy Township..... & $500-1,700$ & & & & \\
\hline Tryon & $600-1,000$ & & & & \\
\hline $\begin{array}{l}\text { Wayne Township } \\
\text { Woodeock Townsh }\end{array}$ & $\begin{array}{r}600-1,100 \\
+600\end{array}$ & & & & \\
\hline \multicolumn{5}{|l|}{ Cumberland County: } & \\
\hline 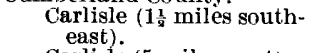 & 864 & $5-1 \frac{1}{2}$ & & & \\
\hline $\begin{array}{l}\text { Carlisle (5 miles v } \\
\text { Riverton }(?) . . . .\end{array}$ & $\begin{array}{l}420 \\
485\end{array}$ & $5-4 \frac{1}{2}$ & & & \\
\hline \multicolumn{6}{|r|}{ Abandoned. } \\
\hline Fort Hun & 2,675 & 6 & & & Abandoned. \\
\hline $\begin{array}{l}\text { Harrisburg } \ldots \ldots \ldots \ldots \\
\text { Do } \ldots \ldots \ldots \ldots \ldots\end{array}$ & $\begin{array}{l}2,800 \\
+400\end{array}$ & 6 & & & For gas; abando"ied. \\
\hline & 2,440 & & & & Gas accompanied \\
\hline \multirow{2}{*}{\multicolumn{6}{|c|}{$\begin{array}{l}\text { Delaware County: } \\
\text { Eagle Station.. }\end{array}$}} \\
\hline & 1,700 & & Few. & & 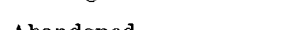 \\
\hline $\begin{array}{r}\text { Radnor Sta } \\
\text { Do..... }\end{array}$ & $\begin{array}{l}500 \\
975\end{array}$ & $\begin{array}{r}12 \\
12-8\end{array}$ & $\cdots 40-50$ & Pumped. & $\begin{array}{l}\text { Abandoned. } \\
\text { Probably surface water. }\end{array}$ \\
\hline \multicolumn{6}{|l|}{ Elk County: } \\
\hline & $\begin{array}{r}721 \\
424-632\end{array}$ & 3 & & & $\begin{array}{l}\text { For oll or gas; abandoned. } \\
13 \text { wells. }\end{array}$ \\
\hline Highland Township is... & $2,095-2448$ & & & & $\begin{array}{l}\text { Many oil and gas wells: } \\
\text { some abandoned. }\end{array}$ \\
\hline $\begin{array}{l}\text { Johnsonburg Station } 19 \\
\text { Jones Township } 20\end{array}$ & $\begin{array}{r}2,510 \\
, 335-1,756\end{array}$ & & & & $\begin{array}{l}\text { Large gas well. } \\
2 \text { oil wells; } 1 \text { abandoned. }\end{array}$ \\
\hline Maxwell & 2,445 & & & & \\
\hline $\begin{array}{l}\text { Millstone Township...... } \\
\text { Ridgway 21 }\end{array}$ & $1,805-2,326$ & & & & 3 wells; some gas. \\
\hline $\begin{array}{l}\text { Ridgway } \\
\text { Do.2 }\end{array}$ & $\begin{array}{r}1,820 \\
772\end{array}$ & & & & \\
\hline Ridg $\mathrm{u}$ & & & & & unsuccessful. \\
\hline & & & & & \\
\hline
\end{tabular}

1 Record, Pa. 2d Geol. Surv. Rept., Vol. $I^{5}$, p. 186. 2 Ibid, Vol. Q, pp. 224-226; Vol. II, pp. 273-274;

Vol. I 4 , p. 119

3 Ibid., Vol. II, pp. 66-69.

4 Ibid., Vol. Q4, p. 212.

5 Ibid., pp. 216, 234-236.

${ }_{6} \mathrm{~Pa} .2 \mathrm{~d}$ Geol. Surv., Reports, Vol. Q4, p. 175.

7 Record, U. S. Geol. Surv. Monograph No. 41 pp. 457-458.

8 Record, Pa. 2d Geol. Surv. Rept., Vol. Q4, pp.

\section{8-179.}

9 Ibid., p. 212

10 Ibid., p. 153.

11 Ibid., Vol. I ${ }^{5}$, pp. 186-187; Vol. Q4, p. 227.

12 Ibid., Vol. Ii, p. 69; Am. Philos. Soc. Proc. vol, 16, p. 493 284.

13 Ibid., Vol. $Q^{4}$, p. 184; Vol. $I^{3}$, p. 154; Vol. I4, p. 14 Ibid. Vol. I4, pp. 118-119; Am. Philos. Soc. Proc., vol. 16, pp. $490-493$. 15 Ibid., Vol. Q4, pp. 122-125.

16 Record, U. S. Geol. Surv. Folio No. 82.

17 Record, Pa. 2d Geol. Surv. Rept., Vol. I*, pp. 133-134: Vol. RR., p. 248.

18 Ibid., 1886, part 2, pp. 707-709; Vol. $\mathrm{I}^{5}$, p. 155. 19 Ibid., pp. 710-711.

so Ibid., Vol. I4, pp. 127-128.

21 Ibid., 1886, pt. 2, p. 711

22 Ibid, Vol. G4, pp. 142-143.

«3 Ibid,, pp. 129-131. 
PENNSYLVANIA-Continued.

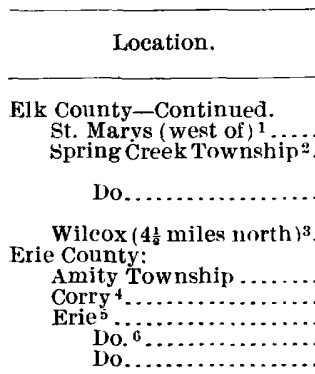

Fairview Township :... Girard Township 8 . Greenfield

Leboeuf

Springfieid Township...................

Summit Township.

Wayne Township ........

Union City 9

Union Township

Waterford ( 2 miles west)

Fayette County:

Belle Vernon 10

Brownsville11

Township $1 \% . .$.

Do 13

Haddenvilie $14 . . . \ldots . . . .$.

Layton station 15

McClellandtown ( 1 mile southeast). ${ }^{16}$

Masolitown 17

Do. 18

Menallen Township

New Geneva $\left(2 \frac{1}{2}\right.$ miles southeast) 10

Oldtrame ( 1 mile west) 19

Redstone Trownship ....

smithteld (1 mile north) 19

South Unıon Township.

Tyrone Township .....

Uniontown (3 miles northwest). 20

Upper Middletown 21 .

Washington Township lownship unknown. Forest County:

Barnet Township 22

$$
\text { Do }
$$

Barnet Township (40 rods from Clarion River).

\section{Brookston}

\section{Cooksburg 23}

Delight (near)

Howe Township 24

$$
\text { Do. (?) }{ }^{25} \text {............ }
$$

\begin{tabular}{r} 
Depth. \\
\hline Feet. \\
2,010 \\
880 \\
1,302 \\
2,25 \\
2,72 \\
1,850 \\
$500-630$ \\
2,340 \\
4,460 \\
$1,250-1,418$ \\
$470-800$
\end{tabular}

$700-1,000$

1,418

980
780

780
780

400
400

600
1,523

1,600

650

2,005

$+2,106$

1,196

2,525

2,907

1,712

2,100

1,196

2,525

870-2, 327

1,712

2,050

1,265

1,858

744

2,100

2,001

2,440

2,005

2,106

2,428

$1,778-2,725$

2,726

2,200

$2,100-2,726$
1,225

$1,475-1,985$

2,233

1 Record, Pa. 2d Geol. Surv. Rept., Vol. ${ }^{\mathbf{4}}$, pp.

\section{1-132.}

2 Ibid., pp. 132-133.

I Ibid., Vol. $\mathrm{G}^{4}$, pp. 143-146.

4 Ibid., Vol. I", p. 228.

s Ibid., Vol. Is, pp. 187-192.

6 Ibid., Vol. It pp. 122, 290

TIbid., Vol. $Q^{4}$, pp. 262-263.

8 Ibid., p. 259

Ibid., Vol. I', p. 121

1u Ibid., 1886, part 2, pp. 778-779.

"Ibid., Vol. It, pp. 317-318.

12 Ipld., pp. 321-322

1s Record, W. Va. Geol. Surv. Rept., vol. 1 (a),

\begin{tabular}{|c|c|c|c|}
\hline $\begin{array}{c}\text { Diame- } \\
\text { ter. }\end{array}$ & $\begin{array}{c}\text { Yield per } \\
\text { minute. }\end{array}$ & $\begin{array}{l}\text { Height of } \\
\text { water. }\end{array}$ & Remarks. \\
\hline Inches. & Gallons. & $\begin{array}{r}\text { Feet. } \\
\text { ren. }\end{array}$ & $\begin{array}{l}\text { Gas well. } \\
\text { For oil; unsuccessful. }\end{array}$ \\
\hline & & & S mall oil well. \\
\hline
\end{tabular}
1904, pp. 115-116.
$\mathrm{S}$ veral oil and gas wells. Gas and oil well.

For oil or gas; abandoned.

Gas wells.

Numerous gas and oil wells.

Several gas wells.

For oil; unsuccessful.

Large gas well

oil and gas well.

For oll; unsuccessful.

Gas well.

Gas and oil well.

For oil or gas; unsuccessful.

For oil; unsuccessful.

Oil and gas wells.

S rall gas well.

Gas well.

Do.

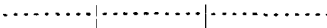

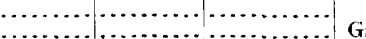

Gas well: only small amount of gas.

For oil or gas; unproductive. Gas well.

Do.

N"any wells; gas, oil, and brine.

Show of gas at bottom of well.

Unproductive.

Gas well.

For oll or gas; unproductive.

Gas well. Do.

For oll or gas, unsuccessful. 3 wells.

For oil or gas; unsuccessful.

Gas well; hard water at 80 feet.

Several oll wells.

Gas well.

14 Record, U. S. Geol. Surv. Folıo No. 82, p. 18. 15 Record, Pa. 2d Geol. Surv. Rept., Vol. 15, pp. 318-319.

16 Record, U.S. Geol. Sr rv. Folıo No. 82, pp. 18-19. ${ }_{17}$ Record, Pa. 2d Geol. Surv. Rept., Vol. $1^{5}, \mathrm{pp}$. 322-323.

18 U. S. Geol. Surv. Fol $\cap$ No. 82,1902, p. 20.

${ }^{19}$ Record, ibid., p. 19.

2) Record, Pa. 2d Geol. Surv. Rept., Vol. $1^{b}, \mathrm{pp}$. 320-321.

21 Ibid., p. 319.

22 Ibid., p. 154.

23 Ibid., pp. 159-161

24 Ibid., Vol. I4, pp. 79-81; 1886, part 2, p. 700.

25 Ibid., 1886, part 2, pF . 700-701. 
PENNSYLVANIA-Continued.

\begin{tabular}{|c|c|c|c|c|c|}
\hline Location. & Depth. & $\begin{array}{l}\text { Diame- } \\
\text { ter. }\end{array}$ & $\begin{array}{l}\text { Yield per } \\
\text { minute. }\end{array}$ & $\begin{array}{l}\text { Height of } \\
\text { water. }\end{array}$ & Remar'ss. \\
\hline $\begin{array}{l}\text { Forest County-Continued. } \\
\text { Jenks Township } 1 \ldots \ldots \ldots \ldots\end{array}$ & $\begin{array}{l}\text { Feet. } \\
400-1,003\end{array}$ & & & & Several gas or \\
\hline Do. ${ }^{2} \ldots$ & $1,310-2,505$ & & & & $\begin{array}{l}\text { unproductiv' } \\
\text { Several wells; mainly un- }\end{array}$ \\
\hline Do.: $\ldots \ldots$ & 2,630 & & & & productive. \\
\hline Kingsley Township ${ }^{3} .$. & 2,200 & & & & For oil or gas; unproduc- \\
\hline Marienville (near) ${ }^{4} \ldots$ & 1,305 & & & & tive. \\
\hline Neilltown (vicinity) ${ }^{5}$ & . $780-995$ & & & & $\begin{array}{l}\text { Numerous oil and gas } \\
\text { wells; some unproduc- } \\
\text { tive. }\end{array}$ \\
\hline Tionesta Township 7 & $554-2,177$ & & & & For oil or gas; unproduc- \\
\hline Do............... & $2,055-2,425$ & & & & 3 wells. \\
\hline $\begin{array}{l}\text { Franklin Coun } \\
\text { Chambersb }\end{array}$ & +400 & & & & 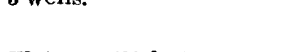 \\
\hline $\begin{array}{l}\text { Chambersburg ( } 2 \text { miles } \\
\text { west). }\end{array}$ & 600 & 6 & & -17 & Water at 420 feet. \\
\hline $\begin{array}{l}\text { Greene County: } \\
\text { Aleppo Township }{ }^{8} \ldots \ldots\end{array}$ & $3,030-3,343$ & & & & 6 wells; gas an ; oil. \\
\hline Blacksville $9 . . . .$. & $0,000-0,500$ & & & & $\begin{array}{l}\text { For oil. } \\
\text { Fon ant } 011 .\end{array}$ \\
\hline $\begin{array}{l}\text { Carmichaels (vicinity) } \\
\text { Center Township }\end{array}$ & $\begin{array}{r}2,432 \\
805\end{array}$ & & & & $\begin{array}{l}\text { For oil or gas. } \\
\text { Gas well. }\end{array}$ \\
\hline Do $\ldots \ldots \ldots \ldots$ & 2,980 & & & & oil well. \\
\hline Do $\ldots \ldots \ldots \ldots \ldots \ldots$ & $3,046-3,267$ & & & & 2 gas wells. \\
\hline Cumberland Township.. & 2,432 & & & & \\
\hline Deep Valley (near) ${ }^{11}$ & $\left\{\begin{array}{l}3,398 \\
3,478\end{array}\right.$ & & & & 2 wells. \\
\hline Dunkard Township.. & $798-2,620$ & & & & Many oil and gas wells; \\
\hline Franklin Township & $400-888$ & & & & 8 wells; 5 gas, 2 unproduc- \\
\hline $\begin{array}{l}\text { Do } \ldots \ldots \ldots \ldots \ldots \\
\text { Greene Township .......... }\end{array}$ & $1,931-3,353$ & & & & $\begin{array}{l}50 \text { wells; principally gas, } \\
\text { Oil and gas we }\end{array}$ \\
\hline & 2,165 & & & & On and gas we . \\
\hline $\begin{array}{l}\text { Gree } \\
\text { Gree }\end{array}$ & 668 & & & & Oil well. \\
\hline $\begin{array}{l}\text { Greensburg } \\
\text { southwest). }{ }_{13}^{4} \text { miles }\end{array}$ & 769 & & & & $D_{0}$ \\
\hline Higbee (near) .......... & 3,337 & $10-5$ & & & $\begin{array}{l}\text { F or oil; ursuccessful; } \\
\text { Pittsburg conl at } 1,0222\end{array}$ \\
\hline Do................ & 3,076 & $13-5$ & & & For oil; Pittsb'arg coal at \\
\hline $\begin{array}{l}\text { Jackson Township ...... } \\
\text { Jefferson } 14 \ldots \ldots \ldots\end{array}$ & $\begin{array}{r}3,125-3,211 \\
2,658\end{array}$ & & & & 3 wells; unproductive. \\
\hline 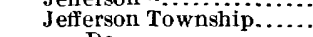 & 2,050 & & & & \\
\hline & $2,920-3,182$ & & & & \\
\hline $\begin{array}{c}\text { Jollyt own } \\
\text { northeast). } 15\end{array}$ & $3 \cdot 2$ & & & & \\
\hline $\begin{array}{l}\text { Jollyto wn } \\
\text { west }) \text {. } 35 \text { miles }\end{array}$ & 3,477 & & & & \\
\hline Mount Morris (near) ${ }^{16} \ldots$ & 1,772 & & & & $\begin{array}{l}\text { Oil well. } \\
\text { For oil. }\end{array}$ \\
\hline Morgan Township..... & $\begin{array}{r}1,909 \\
750\end{array}$ & & & & Gas well. \\
\hline Do & $2,606-3,278$ & & & & 11 wells; mostl-gas. \\
\hline Morris Townshly & $825-980$ & & & & $\begin{array}{l}3 \text { wells; } 2 \text { oil, } 1 \text { unproduc- } \\
\text { tive. }\end{array}$ \\
\hline Do.................... & $1,010-3,290$ & & & & 22 wells: ofl an 1 gas, some \\
\hline Do.... & 2,965 & $13-6$ & & & Gas well: Pittsburg coal at \\
\hline New Freeport ( $3 \frac{1}{2}$ miles & 3,466 & & & & \\
\hline Nineveh (vicinity) ${ }^{19} \ldots .$. & $2,970-3,221$ & & & & Several wells. \\
\hline Perry Township .......... & $1,730-3,261$ & & & & 6 wells; gas an 1 oil. \\
\hline Richhill Townsh & $2,424-3,413$ & & & & $\begin{array}{l}9 \text { wells: gas ant oil, } 1 \text { un- } \\
\text { productive. }\end{array}$ \\
\hline
\end{tabular}

${ }_{1}^{1}$ Record, Pa. 2d Geol. Surv. Rept., Vol. $1^{4}$, pp. 81-83.

2 Ibid., pp. 83-86; 1886, part 2, pp. 702-705.

3 Ibid., 1886, part 2, pp. 703-704.

I Ibid., Vol. G4, pp. 146-147.

5 Ibid., Vol. I4, pp. 69-77.

6 Record, Am. Philos. Soc. Proc., vol. 16, p. 488.

7 Pa. $2 d$ Geol. Surv. Rept., Vol. I4, pp. 77-79; 1886 , part 2, pp. 705-707.

${ }^{8}$ Record, W. Va. Geol. Surv. Rept., vol. 1 (a), 1904, p. 129.

9 Record, Pa. 2d Geol. Surv. Rept., Vol. K, pp. 108-109.

${ }^{10}$ Ibid., Vol. I5, pp. 315-316.

11 Record, W. Va. Geol. Surv. Rept., vol. 1 (a), 1904, p. 128-129.
12 Record, Pa. 2d Geol. Surv. Ann. Rept., 1886, part 2, p. 774 .

13 Ibid., Vol. $I^{4}$, p. 145.

14 Ibid., Vol. I', pp. 314-315.

15 Record, W. Va. Geol. Surv. Rept., vol. 1 (a), 1904, p. 127.

${ }_{16}$ Record, Pa. $2 d$ Geol. Surv. Rept., Vol. $1^{5}$, pp. 316-317.

17 Record, Bull. Geol. Soe. Am., vol. 3, p. 189; U. S. Geol. Surv. Folio No. 82, p. 19.

18 Record, W. Va. Geol. Surv. Rept., vol. 1 (a), 1904, pp. 129-130.

${ }_{19}$ Record. Pa. $2 d$ Geol. Surv. Rept., Vol, $\mathbf{I}^{5}, \mathrm{pp}$. 308-312; W. Va. Geol. Surv. Rept., vol. 1 (a), 1904, pp. 130-131. 
PENNSYLVANIA - Continued.

\begin{tabular}{|c|c|c|c|c|c|}
\hline Location. & Depth. & $\begin{array}{l}\text { Diame- } \\
\text { ter. }\end{array}$ & $\begin{array}{l}\text { Yield per } \\
\text { minute. }\end{array}$ & $\begin{array}{l}\text { Height of } \\
\text { water. }\end{array}$ & Remarks. \\
\hline $\begin{array}{l}\text { Greene Couniy-Continued. } \\
\text { Ryerson station (north } \\
\text { of). } 1\end{array}$ & $\underset{=, 716}{\text { Feet. }}$ & Inches. & & & For oil or gas. \\
\hline $\begin{array}{l}\text { Springfield Township... } \\
\text { Spring Hill Township.. }\end{array}$ & $\begin{array}{l}3,146 \\
3,434\end{array}$ & $10-5$ & & & $\begin{array}{l}\text { Gas } \\
\text { Gas at } 3,369 \text { feet; pressnre } \\
900 \text { pounds. }\end{array}$ \\
\hline 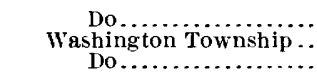 & $\begin{array}{r}3,234 \\
962 \\
2,871-3,441\end{array}$ & $10-5$ & & & $\begin{array}{l}\text { Gas at } 3,183 \text { and } 3,228 \text { feet. } \\
\text { Oil. } \\
7 \text { wells; } 1 \text { oil, } 3 \text { gas, } 3 \text { un- }\end{array}$ \\
\hline Wayne Township........ & $605-852$ & & & & 8 walls; 1 gas, 4 unpro- \\
\hline 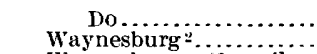 & $\begin{array}{r}2,020-3,780 \\
2,745\end{array}$ & & & & $\begin{array}{l}18 \text { vells; principally gas. } \\
\text { oil well; abandoned. }\end{array}$ \\
\hline $\begin{array}{l}\text { Waynesburg } \\
\text { northeast). } 3\end{array}$ & 3,260 & & & & \\
\hline $\begin{array}{l}\text { Waynesburg ( } \\
\text { northeast). } 3\end{array}$ & 3,004 & & & & \\
\hline $\begin{array}{l}\text { Waynesburg (4 miles } \\
\text { southeast). } 4\end{array}$ & 2,965 & 4 & & & \\
\hline $\begin{array}{l}\text { Waynesburg (several } \\
\text { miles southwest). } 5\end{array}$ & $\left\{\begin{array}{l}3,008 \\
3,780 \\
3,298\end{array}\right.$ & & & & 3 wells. \\
\hline Waynesburg (vicinity $)^{b}$. & $2,675-2,900$ & & & & $\begin{array}{l}2 \text { oil and gas wells; } 1 \text { un- } \\
\text { productive. }\end{array}$ \\
\hline Whiteley Township. & $\begin{array}{l}2,922 \\
3,399\end{array}$ & & & & $\begin{array}{l}12 \text { wells; mostly gas; } 2 \text { un- } \\
\text { productive. }\end{array}$ \\
\hline Willow Tree $7 . . . . .$. & $\begin{array}{l}0,095 \\
2,165\end{array}$ & & & & For vil or gas; abandoned. \\
\hline known..... & $\begin{array}{r}835 \\
\end{array}$ & & & & Oil well. \\
\hline (n) & $3,030-3,272$ & & & & $\begin{array}{l}5 \text { wells; } 1 \text { gas, } 3 \text { unpro- } \\
\text { ductive. }\end{array}$ \\
\hline $\begin{array}{l}\text { Huntingdon County: } \\
\text { Huntingdon......... }\end{array}$ & 400 & & & & Several wells. \\
\hline Hyner Station (near) ${ }^{8} \ldots$ & 1,187 & & & & For oil. \\
\hline icinity) ${ }^{9} \ldots$ & 1,728 & & & & For oil or gas; abandoned \\
\hline & $\begin{array}{r}2,160-2,357 \\
2,125\end{array}$ & & & & 2 wells; 1 dry. \\
\hline wnship .. & $1,545-1,734$ & & & & 2 gas wells. \\
\hline $\begin{array}{l}\text { Indiana Township ....... } \\
\text { North Mahoning Town- }\end{array}$ & $\begin{array}{l}2,054 \\
2,615\end{array}$ & & & & $\begin{array}{l}\text { Gas well. } \\
\text { Do. }\end{array}$ \\
\hline $\begin{array}{l}\text { ship. } \\
\text { Punxsutawney (vicin- } \\
\text { ity).10 }\end{array}$ & 2,745 & & & & Gas well. \\
\hline Saltsburg (near) ${ }^{11} \ldots \ldots$. & 2,014 & & & & $\begin{array}{l}\text { For oil or gas; unproduc- } \\
\text { ti }{ }^{\text {re. }}\end{array}$ \\
\hline $\begin{array}{l}\text { Saltsburg district........ } \\
\text { Washington Township .. }\end{array}$ & $\begin{array}{r}2,216 \\
1,100-1,620\end{array}$ & & & & $\begin{array}{l}\text { Gas well. } \\
8 \text { wells; } 7 \text { gas, } 1 \text { unpro- }\end{array}$ \\
\hline $\begin{array}{l}\text { West Mahoning Town- } \\
\text { ship. }\end{array}$ & 1,605 & & & & Gas \\
\hline White Township .. & 433 & & & & Coal. \\
\hline $\begin{array}{l}\text { Do.... } \\
\text { Township }\end{array}$ & $\begin{array}{l}3,246 \\
3,220\end{array}$ & & & & \\
\hline & 414 & & & & \\
\hline & $1,190-1,200$ & & & & \\
\hline $\begin{array}{l}\text { Do } \ldots \ldots \ldots \ldots \ldots \ldots \\
\text { Jefferson County: }\end{array}$ & $1,839-1,930$ & & & & 2 wells; 1 unproductive. \\
\hline Barnett Township....... & 1,845 & & & & Brine. \\
\hline 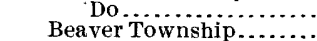 & $\begin{array}{r}2,170 \\
2,705-2,716\end{array}$ & & & & 2 wells. \\
\hline Brookville ${ }^{12} . . . . . . . .$. & 3,100 & & & & For oil or gas; unproduc- \\
\hline $\begin{array}{r}\text { Do. }{ }^{13} \ldots \ldots \ldots \ldots \ldots \\
\text { Brookvilie Borough }{ }^{14} \ldots\end{array}$ & $\begin{array}{l}1,700 \\
2,430\end{array}$ & & & & $\begin{array}{l}\text { Gas well. } \\
\text { Do. }\end{array}$ \\
\hline Eldred Township......... & $\begin{array}{l}2,400 \\
2,850\end{array}$ & & & & \\
\hline $\begin{array}{l}\text { Falls Creek station } \\
\text { (near).15 }\end{array}$ & 3,040 & & & & Do. \\
\hline Heath Township ....... & $1,870-2,955$ & & & & 2 wells. \\
\hline $\begin{array}{l}\text { Horatio } \ldots \ldots \ldots \ldots \\
\text { Knox Township } 6 \ldots \ldots\end{array}$ & $\begin{array}{r}543 \\
1,608-2,000\end{array}$ & & & & \\
\hline \multicolumn{3}{|c|}{ 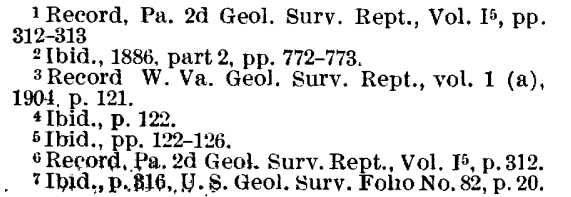 } & \multicolumn{3}{|c|}{$\begin{array}{l}8 \text { Ibid., Vol. G4, pp. 131-134. } \\
9 \text { Ibid., Vol. I5, p. 168. } \\
10 \text { Ibid., 1886, part 2, pp. } 776-777 . \\
11 \text { Ibid., Vol. I', pp. 167-168. } \\
12 \text { Ibid., pp. 163-164. } \\
13 \text { Ibid., Vol. I4, p. } 139 . \\
14 \text { Ibid., 1886, part } 2, \text { p. } 778 . \\
15 \text { Ibid., Vol. I5, p. 164. } \\
16 \text { Ibid., pp. 162-163. }\end{array}$} \\
\hline
\end{tabular}


PENNSYLVANIA - Continued.

\begin{tabular}{|c|c|c|c|c|c|}
\hline Location. & Depth. & $\begin{array}{l}\text { Diame- } \\
\text { ter. }\end{array}$ & $\begin{array}{l}\text { Yield per } \\
\text { minute. }\end{array}$ & $\begin{array}{l}\text { Height of } \\
\text { water. }\end{array}$ & Remarks, \\
\hline Jefferson County-Cont'd. & Feet. & Inches. & & & \\
\hline $\begin{array}{l}\text { Oliver Township ..... } \\
\text { Polk Townshin }\end{array}$ & $1,734-2,720$ & & & & 3 wells; 1 gas. \\
\hline Rose Townshi & 1,951 & & & & \\
\hline & 1,105 & & & & Unproductive. \\
\hline Tnion ? & 2,359 & & & & \\
\hline Washir & 3,040 & & & & Gas. \\
\hline $\begin{array}{c}\text { Township unk } \\
\text { Do............ }\end{array}$ & $\begin{array}{l}1,734 \\
2,015\end{array}$ & & & & Dry (?). \\
\hline Do......... & 2,985 & & & & Gas. \\
\hline Do....... & $3,100-3,200$ & & & & 2 wells; 1 dry. \\
\hline a County: & 780 & 6 & 25 & & \\
\hline $\begin{array}{l}\text { Scranton (i mile south- } \\
\text { east). }\end{array}$ & 2,050 & 6 & & & Abandoned. \\
\hline $\begin{array}{l}\text { Scranton (2 miles north- } \\
\text { west). }\end{array}$ & +700 & 6 & 30 & Flows. & \\
\hline Scranton ( 3 miles $w$ & $\pm 1,000$ & 6 & 40 & & \\
\hline $\begin{array}{l}\text { Seranton ( } 6 \text { miles } n \\
\text { east). }\end{array}$ & & $8-6$ & & & \\
\hline Throo & 2,380 & & & & Water in small quantity. \\
\hline $\begin{array}{l}\text { Lawrence County: } \\
\text { Newcastle }{ }^{1} . . . .\end{array}$ & 2,700 & $5 \frac{5}{8}$ & & & For oil or gis; unpro- \\
\hline Newcastle (vicinity & 1,912 & & & & $\begin{array}{l}\text { ductive. } \\
\text { Gas and oil well. }\end{array}$ \\
\hline Do............ & $700-900$ & & & & Several wells. \\
\hline Robinson crossing..... & 3,830 & $x-6 \frac{1}{2}$ & & & $\begin{array}{l}\text { Oil and water at } 240 \text { feet; } \\
\text { gas at 500, } 575 \text {, and } 825 \\
\text { feet; abandoned, with } \\
\text { two sets of tools in well. } \\
\text { For oil; unsueressful. }\end{array}$ \\
\hline $\begin{array}{l}\text { Luzerne } \\
\text { Hazle }\end{array}$ & $482-690$ & 2 & & & \\
\hline (Diamond wa & $\begin{array}{r}482-690 \\
800\end{array}$ & $\frac{2}{8}$ & & & $\begin{array}{l}\text { Coal prospee } \\
2 \text { wells. }\end{array}$ \\
\hline Pilts & $464-511$ & 2 & & & 2 wells. \\
\hline Wilke & $\begin{array}{r}404-511 \\
536\end{array}$ & 2 & & & 2 weils. \\
\hline & 466 & & & & For water; unsuccessful. \\
\hline Ckean C & 1,085 & & & & For oil. \\
\hline Bradford (vicinity) ${ }^{4} \ldots$ & $1,010-1,719$ & & & & $\begin{array}{l}\text { Numerous oil and gus } \\
\text { wells. }\end{array}$ \\
\hline Corydon ( 1 mile from $)^{5}$ & $1,532-1,601$ & & & & Gas weils. \\
\hline Degoli & 1,404 & & & & For oil or gas. \\
\hline $\begin{array}{l}\text { Hamiton Township } 7 . . \\
\text { Hamlin Township }{ }^{8} . . .\end{array}$ & $2,315-2,400$ & & & & $\begin{array}{l}\text { Oll well. } \\
\text { Several oil wells; some }\end{array}$ \\
\hline Do. ${ }^{9} \ldots$ & $1,613-1,768$ & & & & $\begin{array}{l}\text { unproductive. } \\
\text { Several oil wells; one }\end{array}$ \\
\hline Lafayette Township ${ }^{10} \ldots$ & $2,111-2,490$ & & & & Several oil and gas wells. \\
\hline $\begin{array}{l}\text { Limestone }(3 \mathrm{~m} \text { iles } \\
\text { south }) \text {. }\end{array}$ & & & & & Oil well. \\
\hline Miam Hollow ${ }^{11}, \ldots \ldots \ldots$ & 1,390 & & & & $\begin{array}{l}\text { For oil or gas; unpro- } \\
\text { ductive. }\end{array}$ \\
\hline Sergeant station (near) & $\begin{array}{l}2,000 \\
2,263\end{array}$ & & 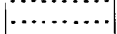 & & Dry hole. \\
\hline $\begin{array}{l}\text { Do. }{ }^{14} \ldots \ldots \ldots \\
\text { Sergeant Townsip }{ }^{15} .\end{array}$ & $\begin{array}{l}2,000 \\
2,004\end{array}$ & & & & .0r \\
\hline Do.16... & 1,850 & & & & \\
\hline & 1,785 & & & & For oil or gas; abandoned. \\
\hline & & $\cdots$ & & & as well. \\
\hline & 1,802 & & & & Good gas well. \\
\hline $\begin{array}{l}\text { Do. } \\
\text { Do. }\end{array}$ & $\begin{array}{r}2,000-2,380 \\
1,943\end{array}$ & & & & Several oil and gas wells. \\
\hline Smethport (v & 2,004 & $\cdots$ & & & For oil: abanconed. \\
\hline Smethport (vicinity & $1,293-1,900$ & & & & $\begin{array}{l}\text { Several oil and gas wells; } \\
\text { small produrtion. }\end{array}$ \\
\hline $\begin{array}{l}\text { Sugar Run } 23 . . . \\
\text { Tuna Valley } 24 . .\end{array}$ & $\begin{array}{r}970 \\
1,035-1,919\end{array}$ & & & & $\begin{array}{l}\text { Oil well. } \\
\text { Several oil and gas wells. }\end{array}$ \\
\hline
\end{tabular}

1 Record, Pa. 2d Geol. Surv. Rept., Vol. G4, pp.

13 Ibid., pp. 243-245.

151-152; Vol. II, pp. 275-276.

2 Ibid., Vol. QQ, p. 89.

8 Ibid., Vol. I" pp. $97-103$

4 Ibid., p. 89; Vol R, pp. 287-290.

5 Ibid., pp. 259-261.

6 Ibid., p. 90

I Ibid., Vol. R, pp. 266-267.

8 Ibid, Vol. $1^{5}$, pp. 151-152.

9 Ibid., Vol. R, pp. 179-182; Vol. I4, pp. 111-113.

${ }^{10}$ Ibid., Vol. $1^{5}$, pp. 152-153.

11 Ibid,, vol. 14, p. 97.

12 Analysis, ibid., vol. R, p. 92.

14 ibid., pp. $245-248$

${ }_{15}$ Record, ibrd., Vol 14, pp. 106-108.

16 Ibid., pp. 108-111.

37 Ibid., pp. 104-106.

18 Ibid., 1886 , pt. 2, pp. 695-696.

19 Ibid., p. 698.

20 Ibid., pp. 696-698, Vol. I4, p. 117

21 Ibid., Vol. R, pp. 271-272.

22 Ibid., pp. 272-276.

$2 a$ Ibid., Vol. I4 p. 91 .

24 Ibid., pp. 87-92. 
PENNSYLVANIA-Continued.

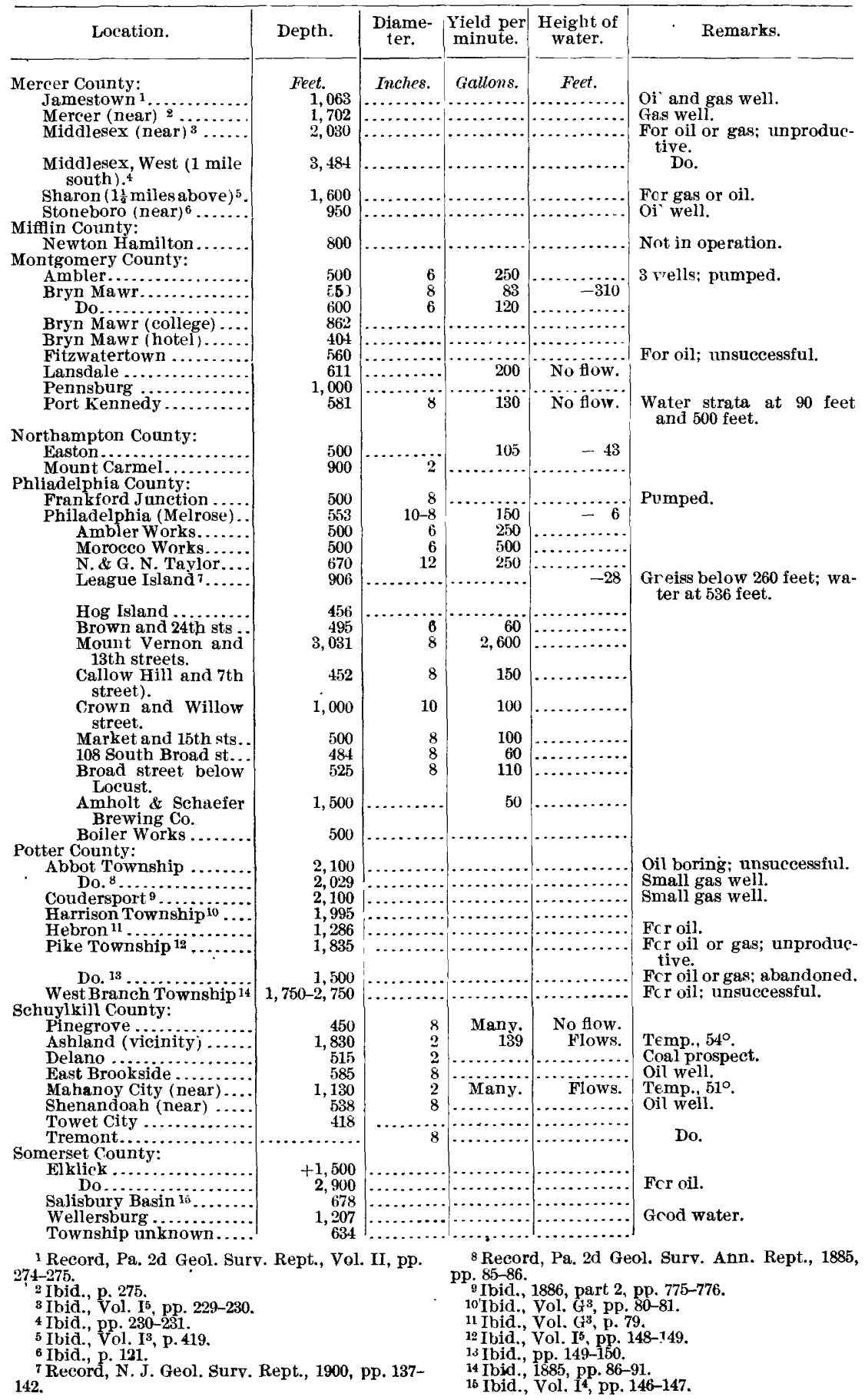


PENNSYLVANIA-Continued.

\begin{tabular}{|c|c|c|c|c|c|}
\hline Location. & Depth. & $\begin{array}{l}\text { Diame- } \\
\text { ter. }\end{array}$ & $\begin{array}{c}\text { Yield per } \\
\text { minute. }\end{array}$ & $\begin{array}{l}\text { Height of } \\
\text { water. }\end{array}$ & Remarks. \\
\hline $\begin{array}{l}\text { Tioga County: } \\
\text { Elkland... }\end{array}$ & Feet. & & & & For oil or gas. \\
\hline $\begin{array}{l}\text { Gaines } \\
\text { Gaines oil tield }\end{array}$ & $\begin{array}{r}1,345 \\
565-1,320\end{array}$ & & & & $\begin{array}{l}\text { For oil or gas; } \text { abandoned. } \\
90 \text { wells for oil. }\end{array}$ \\
\hline $\begin{array}{l}\text { Wellsboro } \ldots \ldots \ldots \ldots \\
\text { Union County: }\end{array}$ & $\ldots \ldots \ldots \ldots$ & & & & \\
\hline Foresthill ............ & ' 480 & & & Flows. & Sulphur water. \\
\hline $\begin{array}{l}\text { Venango County: } \\
\text { Alleghany Township }{ }^{3} . .\end{array}$ & 850 & & & & For oil: unproductive. \\
\hline $\begin{array}{l}\text { Do } \\
\text { Black's siding }\end{array}$ & $\begin{array}{r}619-9225 \\
1,65 \theta\end{array}$ & & & & $\begin{array}{l}3 \text { wells. } \\
\text { For oil or gas; unproduc- }\end{array}$ \\
\hline 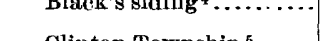 & 1,050 & & & & tive. \\
\hline Clinton Township ${ }^{5} \ldots \ldots$ & $836-1,266$ & & & & $\begin{array}{l}\text { Several oil we'ls; mainly } \\
\text { productive. }\end{array}$ \\
\hline $\begin{array}{l}\text { Cornplanter Township } 6 \\
\text { Cornplanter Township(?) }\end{array}$ & $\begin{array}{l}451-924 \\
780-835\end{array}$ & & & & $\begin{array}{l}\text { For oil or gas. } \\
4 \text { wells. }\end{array}$ \\
\hline $\begin{array}{l}=(\text { bluff between Pe- } \\
\text { troleum Center and } \\
\text { Pioneer }) .\end{array}$ & & & & & \\
\hline Cornplanter Township.. & $\begin{array}{r}651-802 \\
702\end{array}$ & & & & 43 wells. \\
\hline 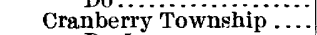 & $\begin{array}{r}1,002-1,018 \\
450-600\end{array}$ & & & & Several wells. \\
\hline Do. ${ }^{7} \ldots \ldots \ldots \ldots$ & $600-1,506$ & & & & $\begin{array}{l}\text { Numerous oil and gas } \\
\text { wells; mainly produc- } \\
\text { tive. }\end{array}$ \\
\hline Emelton (vicinity) ${ }^{8} \ldots$. & $720-1,000$ & & & & $\begin{array}{l}\text { Numerous oil wells; } \\
\text { mainly prod"xctive. }\end{array}$ \\
\hline $\begin{array}{l}\text { Franklin (one-half mile } \\
\text { northeast). } 9\end{array}$ & 490 & & & Flows. & Good oil well. \\
\hline Franklin ( 8 miles south) ${ }^{10}$ & 3,880 & & & & $\begin{array}{l}\text { For oil or gas unproduc- } \\
\text { tive. }\end{array}$ \\
\hline Jackson Township $11 . . .$. & $\begin{array}{r}688 \\
583-688\end{array}$ & & & & Oil well. \\
\hline Mineral Township ....... & $\begin{array}{l}005-000 \\
893-986\end{array}$ & & & & $\begin{array}{l}3 \text { wells. } \\
5 \text { wells. }\end{array}$ \\
\hline Do................. & $1,015-1,350$ & & & & 3 wells. \\
\hline Oakland Township ${ }^{12} \ldots$ & 640 & & & & \\
\hline $\begin{array}{l}\text { Oil Gity }{ }^{13} \ldots \ldots \ldots \ldots \ldots \\
\text { Do. }{ }^{14} \ldots \ldots \ldots \ldots \\
\end{array}$ & $\begin{array}{r}1,070 \\
540-818\end{array}$ & & & & Several oil wells. \\
\hline Oil Creek Townshipis ... & $902-1,000$ & & & & Do. \\
\hline 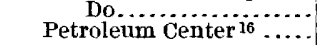 & $\begin{array}{l}415-936 \\
500-900\end{array}$ & & & & $\begin{array}{l}22 \text { wells. } \\
\text { Numerous oil wells; }\end{array}$ \\
\hline & 1,010 & & & & mainly productive. \\
\hline Pinegrove Township ${ }^{17} .$. & $\begin{array}{r}1,869-2,060 \\
912-1,070\end{array}$ & & & & $\begin{array}{l}\text { Several oil wells. } \\
\text { For oil. }\end{array}$ \\
\hline Pioneer (vicinity) ig..... & $437-980$ & & & & Numerous oil wells; large \\
\hline Pithole City ${ }^{20}, \ldots \ldots$. & 747 & & & & For oil or gas unprodue- \\
\hline 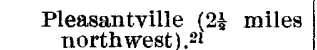 & 415 & & & & Oil well. \\
\hline $\begin{array}{l}\text { Pleasantville ( } 4 \frac{1}{2} \text { miles } \\
\text { southeast) }{ }_{22}\end{array}$ & 1,000 & & & & Gas and oil well. \\
\hline $\begin{array}{l}\text { Pleasantville }(2 \text { miles } \\
\text { northeast } \text {. }^{28}\end{array}$ & 885 & & & & Do. \\
\hline Pleasantville Borough ${ }^{24}$. & $693-1,044$ & & & & $\begin{array}{l}\text { Numerous } o^{i 1} \text { and gas } \\
\text { wells. }\end{array}$ \\
\hline $\begin{array}{c}\text { Pleasantville } \ldots \ldots \ldots \ldots \\
\text { Do } \ldots \ldots \ldots \ldots \ldots \ldots \\
\end{array}$ & $\begin{array}{r}633-955 \\
1,020-1,050\end{array}$ & & & & $\begin{array}{l}66 \text { wells. } \\
2 \text { wells. }\end{array}$ \\
\hline Pleasantv & $840-870$ & & & & Do. \\
\hline $\begin{array}{l}\text { Pleasantville (?) } \ldots \ldots \ldots \\
\text { Plumer }(?) \ldots \ldots \ldots\end{array}$ & $\begin{array}{r}607-620 \\
930\end{array}$ & & & & \\
\hline
\end{tabular}

1 Record, Pa.2d Geol.Surv. Ann. Rept., Vol. I $^{5}$, pp. 147-148; U.S. Geol. Surv., 22d Ann. Rept., 19001901, part 3, pp. $583-584$.

2 U. S. Geol. Surv., $22 d$ Ann. Rept., 1900-1901, pp. 585-591.

3 Record, Pa. $2 d$ Geol. Surv. Rept., Vol. I ${ }^{4}$, pp. 58-59.

4 Ibid., Vol. I ${ }^{5}$, pp. 184-185.

5 Tbid.' Vol. II, pp. 219-222.

6 Ibid., Vol. I4, pp. 59-61.

7 Ibid., Vol. II, pp. 203-207, 210-214; Vol. I4, pp. 62-63.

8 Ibid., Vol. II, pp. 222-225.

9 Ibid.', Vol. I 4 , p. 65 .

${ }^{10}$ Ibid.,', Vol. I', pp. 185-186; W. Va. Geol. Surv.

Rept., vol. 1 (a), 1904, pp. 86-87.

11 Ibid., Vol. II, p. 201.

12 Ibid., p. 202

13 Ibid., Vol. III, p. 416.
14 Record, Am. Philos. Soc. Proc. vol. 16, pp. 482-487; Pa. 2d Geol. Surv. Rept., Vol. II, pp. 204 205.

${ }_{15}$ Record, Pa. $2 d$ Geol. Surv. Rept., Vol. I ${ }^{4}, p p$. 53-54.

${ }_{16}$ Record, Am. Philos. Soc. Proc. vol. 16, pp. $470-477$.

${ }_{17}$ Record, Pa. 2d Geol. Surv. Rert., Vol. $\mathbf{I}^{5}$, p. 184.

${ }^{18}$ Ibid., Vol. I4, p. 64

19 Ibid., Vol. II, pp. 43-64; Am. Philos. Soc. Proc., vol. 16, pp. 468-471.

21) Ibid., Vol. $I^{5}$, p. 179

${ }_{21}$ Ibid., p. 175 .

22 Record, Am. Philos. Soc. Proc., vol. 16, p. 497. ${ }^{23}$ Record, Pa. $2 d$ Geol. Surv. Rept., Vol. I4, pp. $54-55$.

${ }^{44}$ Ibid, Vol. II, pp. 9-34; Vol. III, p. 420: Vol. I4 p. 55; Am. Philos. Socz Proc., vol. 1s, pp. 435-460. 
PENNSYLVANIA-Continued.

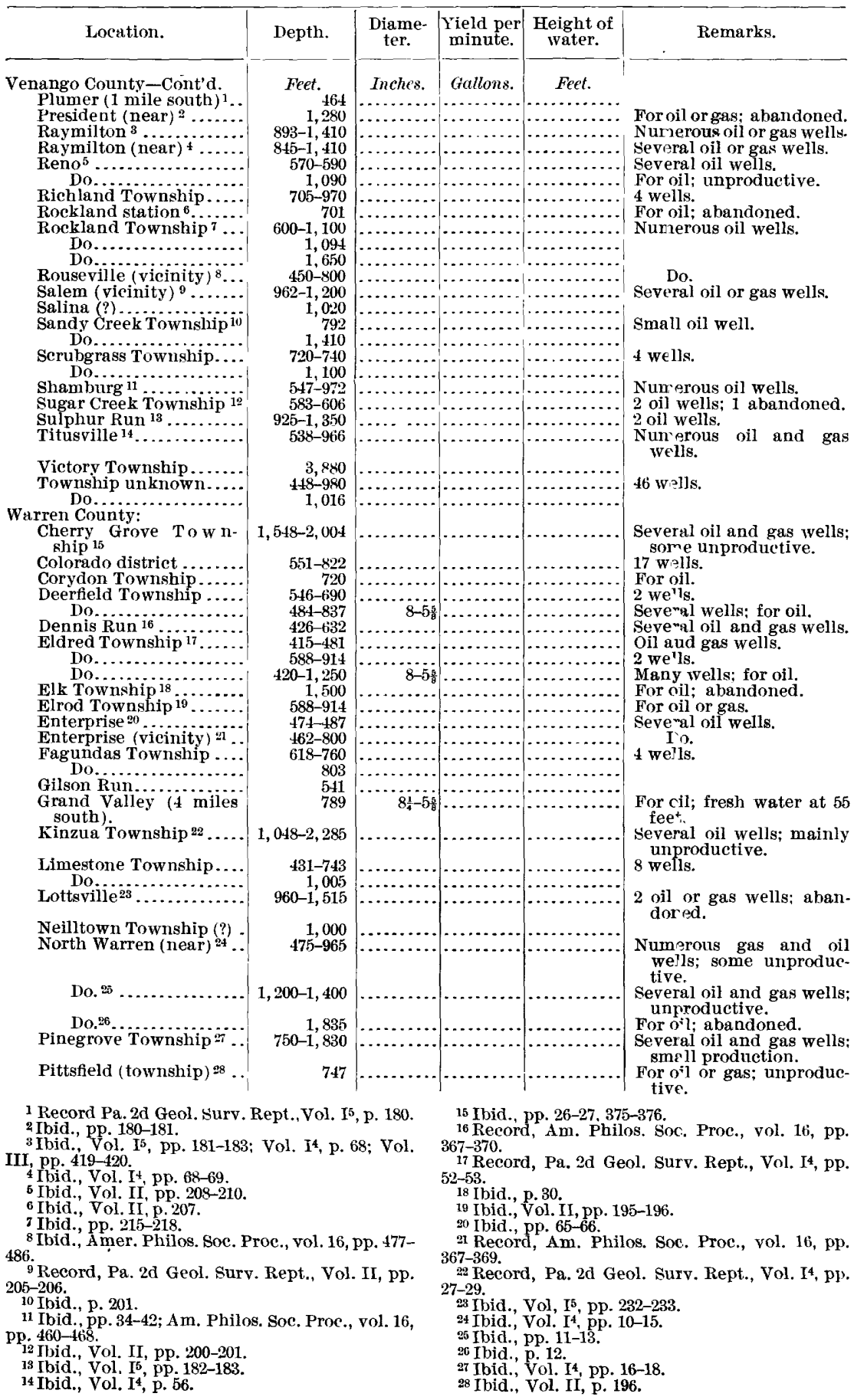


PENNSYLVANIA-Continued.

\begin{tabular}{|c|c|c|c|c|c|}
\hline Location. & Depth. & $\begin{array}{l}\text { Diame- } \\
\text { ter. }\end{array}$ & $\begin{array}{l}\text { Yield per } \\
\text { minute. }\end{array}$ & $\begin{array}{l}\text { Height of } \\
\text { water. }\end{array}$ & Remarks \\
\hline $\begin{array}{l}\text { Warren County-Cont'd. } \\
\text { Pittsfield (township) }{ }^{1} \ldots\end{array}$ & $\begin{array}{l}\text { Feet. } \\
\quad 1.500\end{array}$ & Inches. & Gallons. & Feet. & For oil or gas; unsuccess- \\
\hline Pleasant Township ${ }^{2} \ldots$ & 1,586 & & . & $\cdots \cdots$ & For oil or gas; unproduc- \\
\hline Do. ${ }^{3} \ldots$. & $818-900$ & & & & Several small oil wells. \\
\hline Do. ${ }^{5} \ldots \ldots \ldots \ldots$ & $\begin{array}{l}1,645 \\
1,565 ?\end{array}$ & & & $\begin{array}{ll}\cdots \\
\cdots\end{array} \ldots \ldots \ldots$ & $\begin{array}{l}\text { For oil or gas; unsuccess- } \\
\text { ful. }\end{array}$ \\
\hline & 825 & & & & For oil or gas; abandoned. \\
\hline Do ${ }^{6} \ldots \ldots \ldots$ & $961-1,200$ & & & & For oil or gas. \\
\hline Sheffield Township ${ }^{7} \ldots$ & $1,435-2,016$ & & & $\cdots$ & $\begin{array}{l}\text { Numerous oil and gas } \\
\text { wells. }\end{array}$ \\
\hline Spring Creek Township 8 & $600-1,061$ & & & & Several oil and gas wells; \\
\hline Do............... & 484 & $8-5 \frac{5}{8}$ & & & $\begin{array}{l}\text { For oil; fresh water flowed } \\
10 \text { gallons a nainute at } \\
198 \text { feet; oil and gas } \\
\text { strata at } 224 \text { and } 463 \text { feet; } \\
\text { abandoned. }\end{array}$ \\
\hline Southwest Township ${ }^{9} .$. & $500-1,550$ & & & & $\begin{array}{l}\text { Numerous oil and gas } \\
\text { wells. }\end{array}$ \\
\hline Stoneham (vicinity) ${ }^{10} \ldots$ & $1,025-1,600$ & & & & Several oil and gas we]ls; \\
\hline Tidioute (vicinity) ${ }^{11} \ldots$ & $403-715$ & & & & $\begin{array}{l}\text { Numerous oil and gas } \\
\text { wells; none large pro- } \\
\text { ducers, and many aban- } \\
\text { doned. }\end{array}$ \\
\hline $\begin{array}{l}\text { Do } \ldots \ldots \ldots \ldots \ldots \ldots \\
\text { Triumph } 12 \ldots \ldots \ldots \ldots \ldots\end{array}$ & $\begin{array}{r}803 \\
+472\end{array}$ & & & & For oil; unsuccersful. \\
\hline Triumph (vicinity) $13 . \ldots$ & $739-815$ & & & & Several oil wells \\
\hline Triumph Township ${ }^{14} . .$. & $2,464-2,700$ & & & . & For oil or gas; unsuccess- \\
\hline Do. ${ }^{15} \ldots \ldots \ldots \ldots$ & $805-90 x$ & & & & $\begin{array}{l}\text { Numerous oil and gas } \\
\text { wells. }\end{array}$ \\
\hline Do $\ldots \ldots \ldots \ldots \ldots \ldots$ & 543-961 & & & & 13 wells. \\
\hline Warren (near) ${ }^{16} \ldots$ & $521-1,065$ & & & & $\begin{array}{l}\text { Numerous oil and gas } \\
\text { wells; some grod pro- } \\
\text { ducers. }\end{array}$ \\
\hline Warren Township (?) .... & 2,016 & & & & \\
\hline Watson Townshi & 1,936 & & & & For oil or gas; unproduc- \\
\hline $\begin{array}{c}\text { Wrightsville } \\
\text { northeast }) .18\end{array}$ & 1,200 & & & & Abandoned as dry hole. \\
\hline $\begin{array}{l}\text { Ne a r Warren-M c K e a } n \\
\text { county line. }\end{array}$ & 2.254 & & & & \\
\hline $\begin{array}{l}\text { Washington County: } \\
\text { Allen Township io ....... }\end{array}$ & 2,060 & & & & Gas well. \\
\hline Amwell Township $20 . .$. & 2,385 & & & & $\begin{array}{l}\text { For oil or gas; unproduc- } \\
\text { tive. }\end{array}$ \\
\hline Do................ & 2,390 & & & & Gas. \\
\hline Do............. & $\begin{array}{r}460-602 \\
3,200\end{array}$ & $10-4$ & $\ldots$ & & 3 wells. \\
\hline $\begin{array}{l}\text { Beallsville (10 miles } \\
\text { west).22 }\end{array}$ & 2,774 & & & - & \\
\hline Buffalo Township ....... & 510 & & & & \\
\hline 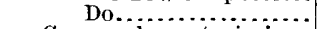 & $2,350-2,760$ & $\cdots$ & $\ldots$ & $\ldots$. & 21 wells; some oi and gas. \\
\hline $\begin{array}{l}\text { Cannonsburg ( vicin- } \\
\text { ity). }\end{array}$ & $1,763-2,502$ & .... & $\ldots . .$. & $\ldots$. & $\begin{array}{l}\text { Numerous oil and gas } \\
\text { wells; some unproduc- }\end{array}$ \\
\hline Canton Township 24 & 2,727 & & & & For oil or gas. \\
\hline Do................. & 2,068 & & & & Gas well. \\
\hline Do............. & 1,977 & & & $\ldots \ldots$ & Do. \\
\hline Carroll Township & $\begin{array}{l}2,152 \\
2,218\end{array}$ & & & & 2 gas wells. \\
\hline
\end{tabular}

1 Record, Pa. 2 d Geol. Surv. Rept., Vol.II, p. 197. 2 Ibid., Vol. $\mathrm{I}^{\mathrm{5}}$, p. 174.

3 Ibid., Vol. I4, p. 19.

4 Ibid., pp. 23, 379-380.

5 Ibid., pp. 24, 38C-381.

6 Ibid., Vol. II, pp, 194-195.

TIbid., pp. 193-194: Vol, I4, pp. 24-26; Vol. $I^{5}$, pp. 174-175: 1886, part 2, pp. 698-700.

8 Ibid., Vol. I4, pp. 252-263.

Ibid., pp. 49-52; Vol. I5, p. 855; Am. Philos. Soc. Trans, vol. $16, \mathrm{pp}, 346-367$.

10 Ibid.,pp. 20-23.

11 Ibid., pp. 31-48: Am. Philos. Soc. Proc., vol. 16 , pp. 372-374.

12 Record, Am. Philos. Soc. Proc., vol. 16, p. 494.
13 Ibid., pp. 370-372.

14 Record, Pa. 2d Geol. Surv. Rept., Vol. I4, pp. 280-283.

15 Ibid., Vol. I5, pp. 173-174; Vol. I3, pp. 283-286.

16 Ibid., Vol. I4, pp. 1-9.

17 Ibid., p. 20.

18 Ibid., p. 236

${ }^{19}$ Ibid., Vol. I ${ }^{5}$, pp. 301-302.

20 Ibid., pp. 307-308.

a Record., etc., W. Va. Geol. Surv. Rept., vol. 1(a), 1904, pp. 116-119

${ }^{23}$ Record, Pa. $2 d$ Geol, Surv. Rept., Vcl. ${ }^{5}$, pp. 281-297.

24 Ibid., pp. 279-280. 
PENNSYLVANIA-Continued.

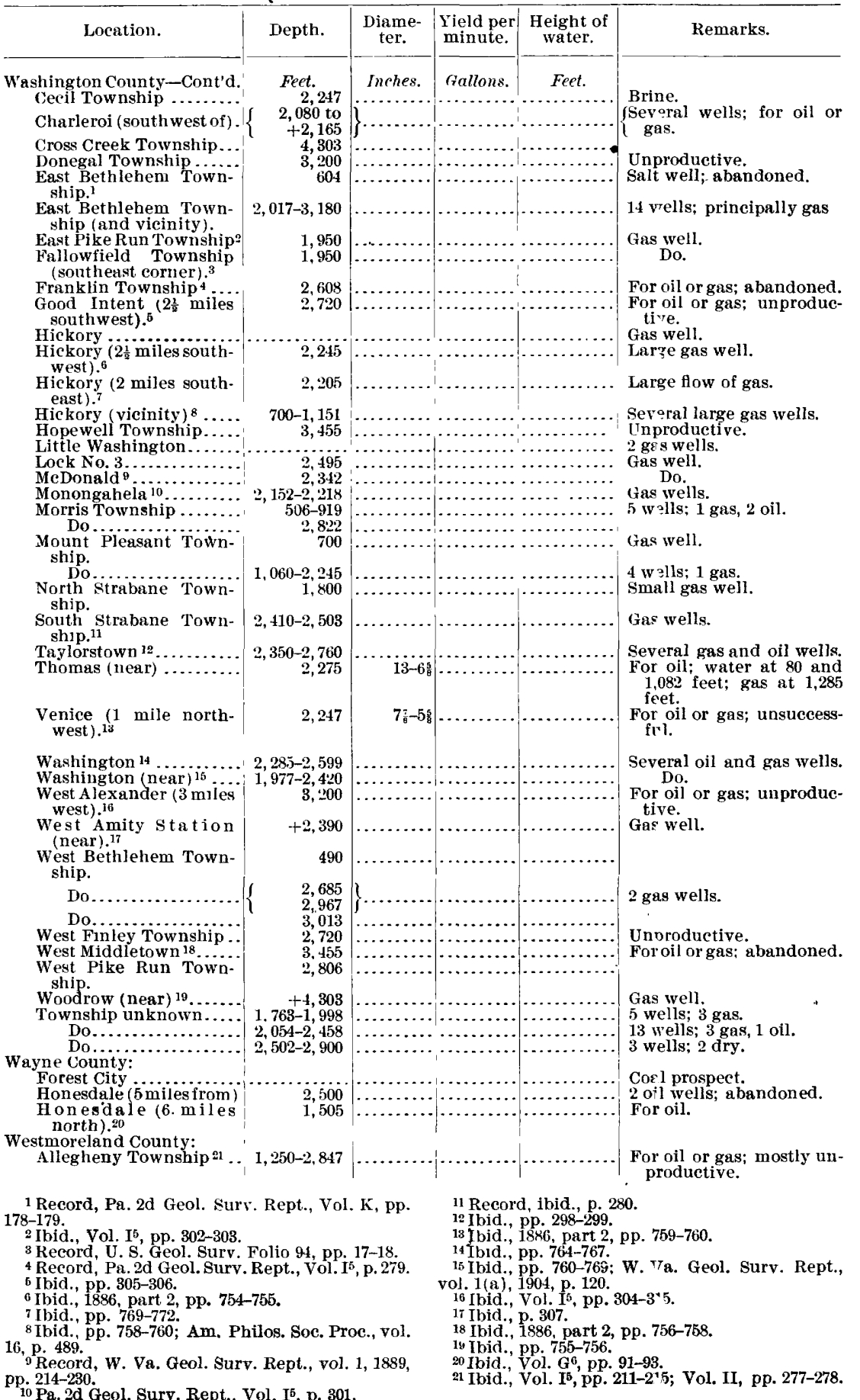


PENNSYLVANIA-Continued.

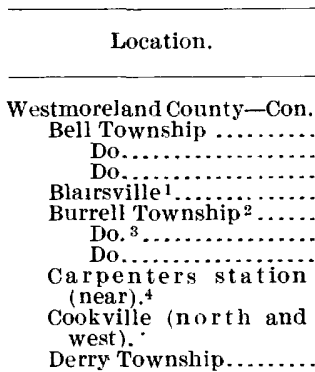

$$
\text { Do. }
$$

East Huntingdon Township.

Franklin Township ...... Gibsonton (three-fourths mile north . $^{6}$

Hemptield Township ${ }^{6} .$. rwin. Do. 7 .

\section{Latrobe 8}

Lower Burrell Township. Loyalhanna Township. Do.

Mount Pleasant Township.

Murrysville 9

Murrysville (vicinity) ${ }^{10}$.

North Huntingdon Township.

North Washington Township.

Oakland Cross Roads..

Pennsylvania Tow llship. 11 Do. 12

Pleasant Unity (2⿺辶) northwest) 13

Reagantown ( south of ${ }^{14}$

Rostraver Township ...

Sewickley Township ....

Webster Township (northeast, east, and southeast).

Tarentum (1 $\frac{1}{2}$ miles south east).

Unity Township.

Ipper Burrell Township

Waltz Mill (near)

Washington Township ${ }^{16}$ Do..................

Township unknown...

W yoming County:

Lovelton (near)

York County:

Manchester 17.

Miscellaneous:

Allegheny River

Boydstown Township

Eulalia Township.

Grimes Township

Hooks Run .............

West Hickory Creek....
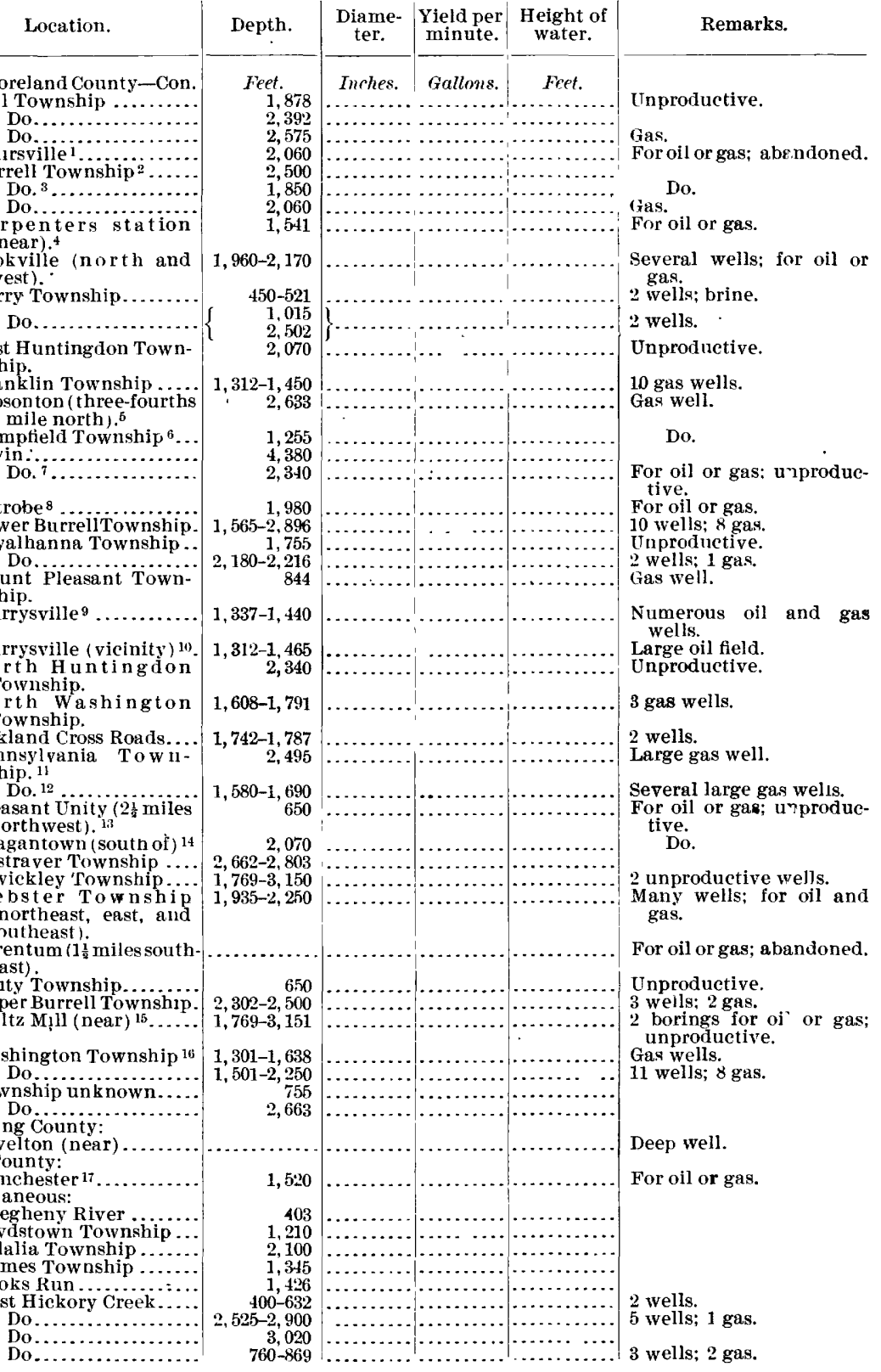

${ }^{1}$ Record, Pa. $2 d$ Geol. Surv. Rept., Vol. $\mathbf{I}^{5}$, pp. $224-225$.

2Ibid.;pp. 212-213.

3 Ibid., 1886 , part 2, pp. 686-687.

4 Ibid., pp, 725-726.

5 Record, U. S. Geol. surv. Folio No. 94, p. 18.

- Record, Pa. $2 d$ Geol. Surv. Rept., Vol. I5, p. 223.

7 Ibid., pp. 221-222.

8 Ibid., pp. 223-224.
9 Ibid., pp. 215-218.

10 Ibid., 18s6, part 2, pp. 673-674, 721-72c

13 Ibid., Vol. II, pp. 280-281.

14 Ibid., Vol. $\mathrm{I}^{5}$, pp. 227-228.

15 Ibid., pp. 225-227.

16 Ibid., 1886 , part 2 , pp. $726-730$.

17 Ibid., Vol. II, pp. 278-279.
11 Ibid., Vol. $1^{5}$, pp. $219-220$.

12 Ibid., pp. 218-219; 1886, part 2, pp. 724-725 
PENNSYLVANIA-Continued.

\begin{tabular}{|c|c|c|c|c|c|}
\hline Location. & Depth. & $\begin{array}{c}\text { Diame- } \\
\text { ter. }\end{array}$ & $\begin{array}{l}\text { Yield per } \\
\text { minute. }\end{array}$ & $\begin{array}{l}\text { Height of } \\
\text { water. }\end{array}$ & Remarks. \\
\hline 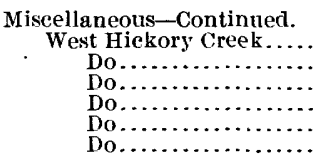 & $\begin{array}{c}\text { Feet. } \\
1,040-1,460 \\
1,505-1,980 \\
2,000-2,405 \\
2,665-3,375 \\
1,325-1,475 \\
1,504-1,635\end{array}$ & 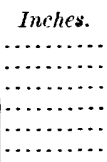 & 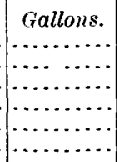 & 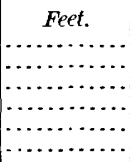 & $\begin{array}{l}14 \text { wells; } 6 \text { gas. } \\
19 \text { wells; } 6 \text { gas; } 1 \text { oil. } \\
7 \text { vells; } 1 \text { gas; } 1 \text { oil. } \\
2 \text { vells; } 1 \text { gas; } 1 \text { dry. } \\
3 \text { vells; } 2 \text { gas. } \\
8 \text { vells; } 4 \text { gas. }\end{array}$ \\
\hline
\end{tabular}

PUBLICATIONS RELATING TO DEEP BORINGS IN FENNSYLVANIA.

Oil well records, selected from the collections of Mr. J. F. Carll, by J. P. Lesley: American Philosophical Society Proceedings, volume 16, pages 346-380, Philadelphia, 1877.

On the first systematic collection and discussion of the Venang) County oil wells of western Pennsylvania, by E. S. Nettleton, prepared for publicetion by J. F. Carll: American Philosophical Society Proceedings, Nos. 97-99, for 1876-1877, volume 16, pages 429-495, Philadelphia, 1877.

Oil well records and levels, by J. F. Carll: Pennsylvania Second Geological Survey, Report of Progress, 1876-1877, Volume II, 398 pages, Harrisburg, 1877.

The geology of the oil regions of Warren, Venango, Clarion, and Butler counties, by J. F. Carll: Pennsylvania Second Geological Survey, Report for 1875-1879, Volume III, 482 pages, Harrisburg, 1880.

The geology of Erie and Crawford counties, by I. C. White: Fennsylvania Second Geological Survey, Report of Progress, 1879, Volume QQQQ, 406 pages, Harrisburg, 1881 .

Geological report on Warren County and neighboring oil regions, by J. F. Carll: Pennsylvania Second Geological Survey, Report for $1880-1883$, Volume $I^{4}, 439$ pages, Harrisburg, 1883.

O. S. C. Carter, artesian water supplies for Philadelphia: Franklin Institute Journal, 1893 , volume 135 , page 58 ; volume 136 , pages $230-239,298-i 05$.

United States Geological Survey Folio No. 82, 1902, by M. R. Campbell.

United States Geological Survey Folio No. 94, 1903, by M. R. Campbell.

Gaines oil field of northern Pennsylvania, by M. L. Fuller: Twenty-second Annual Report of the United States Geological Survey, 1900-1901, pages 579-627.

\section{RHODE ISLAND.}

\begin{tabular}{|c|c|c|c|c|c|}
\hline Location. & Depth. & $\begin{array}{c}\text { Diame- } \\
\text { ter. }\end{array}$ & $\begin{array}{l}\text { Yield per } \\
\text { minute. }\end{array}$ & $\begin{array}{c}\text { Height of } \\
\text { water. }\end{array}$ & Remarks. \\
\hline 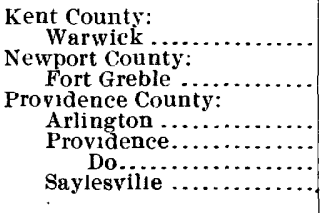 & $\begin{array}{rr}\text { Feet } \\
502 \\
762 \\
402 \\
400 \\
460 \\
1,436\end{array}$ & 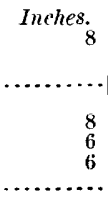 & $\begin{array}{r}\text { Gallons } \\
120 \\
\\
\\
\cdots\end{array}$ & $\begin{array}{l}\text { Feet } \\
\text { No flow. } \\
\text { No flow. } \\
\text { No flow. } \\
\text { No flow. }\end{array}$ & $\begin{array}{l}\text { Hard water. } \\
\text { Grod supply of water. }\end{array}$ \\
\hline
\end{tabular}

\section{SOUTH CAROLINA.}

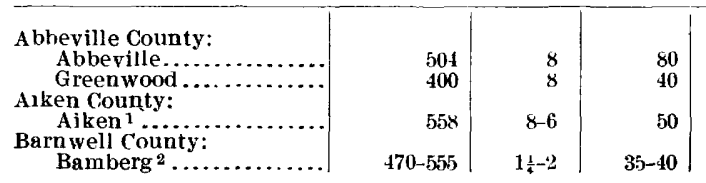

1 Record, U. S. Geol. Surv. Bull, No. 138, p. 220.

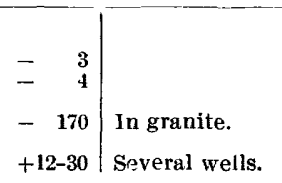

2 I jid., p. 221. 
SOUTH CAROLINA-Continued.

\begin{tabular}{|c|c|c|c|c|c|}
\hline Location. & Depth. & $\begin{array}{l}\text { Diame- } \\
\text { ter. }\end{array}$ & $\begin{array}{c}\text { Yield per } \\
\text { minute. }\end{array}$ & $\begin{array}{l}\text { Height of } \\
\text { water. }\end{array}$ & Remarks. \\
\hline $\begin{array}{l}\text { Beaufort County: } \\
\text { Beaufort } 1 . . . .\end{array}$ & Feet. ${ }_{800}$ & $\begin{array}{l}\text { Inches. } \\
\text {......... }\end{array}$ & Gallons. & Feet. & \\
\hline Mays River Neck & 800 & & $\cdots$ & -1 & Very sulphurous water. \\
\hline Charleston County: & & & & & \\
\hline $\begin{array}{c}\text { Charleston }^{2} \ldots \\
\text { Do. }{ }^{3} \ldots \ldots\end{array}$ & $\begin{array}{l}1,970 \\
1,260\end{array}$ & (n......... & $\begin{array}{r}250 \\
30\end{array}$ & $\begin{array}{l}+4 \\
+25\end{array}$ & $\begin{array}{l}\text { Temp., } 99.5^{\circ} \text {. } \\
\text { Saline water; temp. } 87^{\circ} \text {. }\end{array}$ \\
\hline Do... & 1,950 & $3 \frac{1}{4}$ & 167 & $+\ldots .$. & $\begin{array}{l}\text { Sanne water; temp., } 87 . \\
\text { Temp., } 99^{\circ} \text {. }\end{array}$ \\
\hline Do...... & 1,970 & $\begin{array}{l}0 \frac{1}{16} \\
26\end{array}$ & 104 & ?....... & Do. \\
\hline Do... & 2,050 & $4^{100}$ & 451 & & \\
\hline Do............... & 1,945 & 5 & 695 & .............. & Do. \\
\hline Charleston (vicinity) ${ }^{4} \ldots$ & $425-475$ & $\cdots$ & $\cdots$ & n........... & Several wells. \\
\hline $\begin{array}{l}\text { Charleston........... } \\
\text { Johns Island }\end{array}$ & 2,000 & ... & & $\ldots \ldots$ & Tonn 700 \\
\hline $\begin{array}{l}\text { Johns Island } . . . . . \\
\text { Chester County: }\end{array}$ & 500 & 6 & 11 & Flows. & Temp., $70^{\circ}$. \\
\hline Chester .......... & 760 & & & & In granite; unsuccessful. \\
\hline $\begin{array}{l}\text { Do............ } \\
\text { Colleton County: }\end{array}$ & 500 & 8 & & & Unsuccessful. \\
\hline Green Pond ..... & 503 & 3 & 1 & Flows. & Temp., $70^{\circ}$. \\
\hline Jacksonboro... & 420 & 3 & 4 & Flows. & Temp., $72^{\circ}$. \\
\hline $\begin{array}{l}\text { Walterboro.... } \\
\text { Florence County: }\end{array}$ & 490 & 6 & Many. & -30 & Soft water. \\
\hline $\begin{array}{l}\text { Florence County: } \\
\text { Florence } 5\end{array}$ & 1,335 & $10-8$ & 100 & -20 & Lowest water at 1,215 to \\
\hline Do........... & 420 & & Many. & & $\begin{array}{l}1,220 \text { feet. } \\
\text { Fine water. }\end{array}$ \\
\hline Georgetown County: & & & & & \\
\hline $\begin{array}{l}\text { Georgetown ...... } \\
\text { Hampton County: }\end{array}$ & $400 ?$ & & Not any. & & \\
\hline Hampton..... & 800 & & & Flows. & \\
\hline $\begin{array}{l}\text { Do......... } \\
\text { Peoples..... }\end{array}$ & 583 & 6 & Many. & -9 & Soft, irony water. \\
\hline 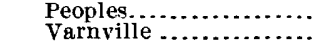 & 850 & 6 & 100 & Flows. & Temp., $76^{\circ}$. \\
\hline $\begin{array}{l}\text { Varnville } \\
\text { ershaw County: }\end{array}$ & 983 & 6 & Many. & -12 & \\
\hline $\begin{array}{l}\text { hersuaw county: } \\
\text { Camden....... }\end{array}$ & $618-625$ & & Many. & -20 & 2 wells. \\
\hline Laurens County: & & & & & Tos 0 \\
\hline $\begin{array}{l}\text { Sullivans Island } \\
\text { Marion County: }\end{array}$ & 1,308 & $12-3$ & 10 & & Temp., $87^{\circ}$. \\
\hline Marion ............. & 1,244 & $8-6$ & $\frac{1}{2}$ & Flows. & \\
\hline $\begin{array}{l}\text { Orangeburg County: } \\
\text { Orangeburg } 6 \text {...... }\end{array}$ & 1,160 & $6-27$ & Many. & -52 & Pumped at 300 feet. \\
\hline
\end{tabular}

${ }^{1}$ Analysis, U. S. Geol. Surv. Bull. No. 138 , p. 220.

2 Record, Artesian Wells Report of Scientific Committee: Municipal Rept. Charleston, 1881,

${ }^{3}$ A nalysis, U. S. Geol. Surv. Bull. No. 13S, p. 212. 4 Ibid., pp. $214-216$.

5 Record and analysis, ibid., 218-219.

6 Record, ibid., p. 220.

\section{PUBLICATIONS RELATING TO DEEP BORINGS IN SOUTH CAROLINA.}

Artesian wells report of scientific committee, etc.: Municipal Report of the City of Charleston, S. C., 1881, 61 pages, plates, Charleston, 1882.

Artesian well prospects in the Atlantic Costal Plain region, by N. H. Dartor: U. S. Geological Survey Bulletin No. 138, 232 pages, plates, Washington, 1896.

SOU'TH DAKO'TA.

\begin{tabular}{|c|c|c|c|c|c|}
\hline Location. & Depths. & $\begin{array}{l}\text { Diam- } \\
\text { eter. }\end{array}$ & $\begin{array}{l}\text { Yield per } \\
\text { minute }\end{array}$ & Pressure. & Remarks \\
\hline 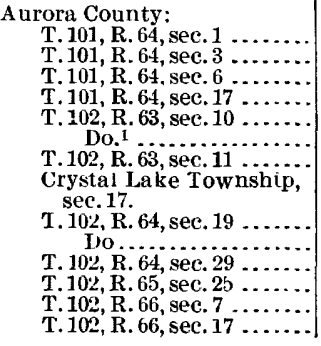 & $\begin{array}{l}\text { Feet } \\
630 \\
800 \\
730 \\
960 \\
536 \\
613 \\
460 \\
850 \\
\\
800 \\
800 \\
600 \\
795 \\
800 \\
835\end{array}$ & $\begin{array}{rr}\text { Inches. } \\
2 \\
2 \\
2 \\
2 \\
2 \\
2 \\
4-1 \\
3-2 \\
3-2 \\
2 \\
2 \\
2 \\
4 \frac{1}{2}\end{array} \mid$ & \begin{tabular}{|r|} 
Gallons. \\
50 \\
30 \\
60 \\
$\cdots$ \\
3 \\
600 \\
40 \\
40 \\
8 \\
10 \\
120 \\
400
\end{tabular} & 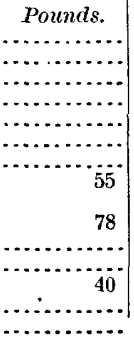 & $\cdot$ \\
\hline
\end{tabular}

IRR $149-05-9$ 
SOUTH DAKOTA-Continued.

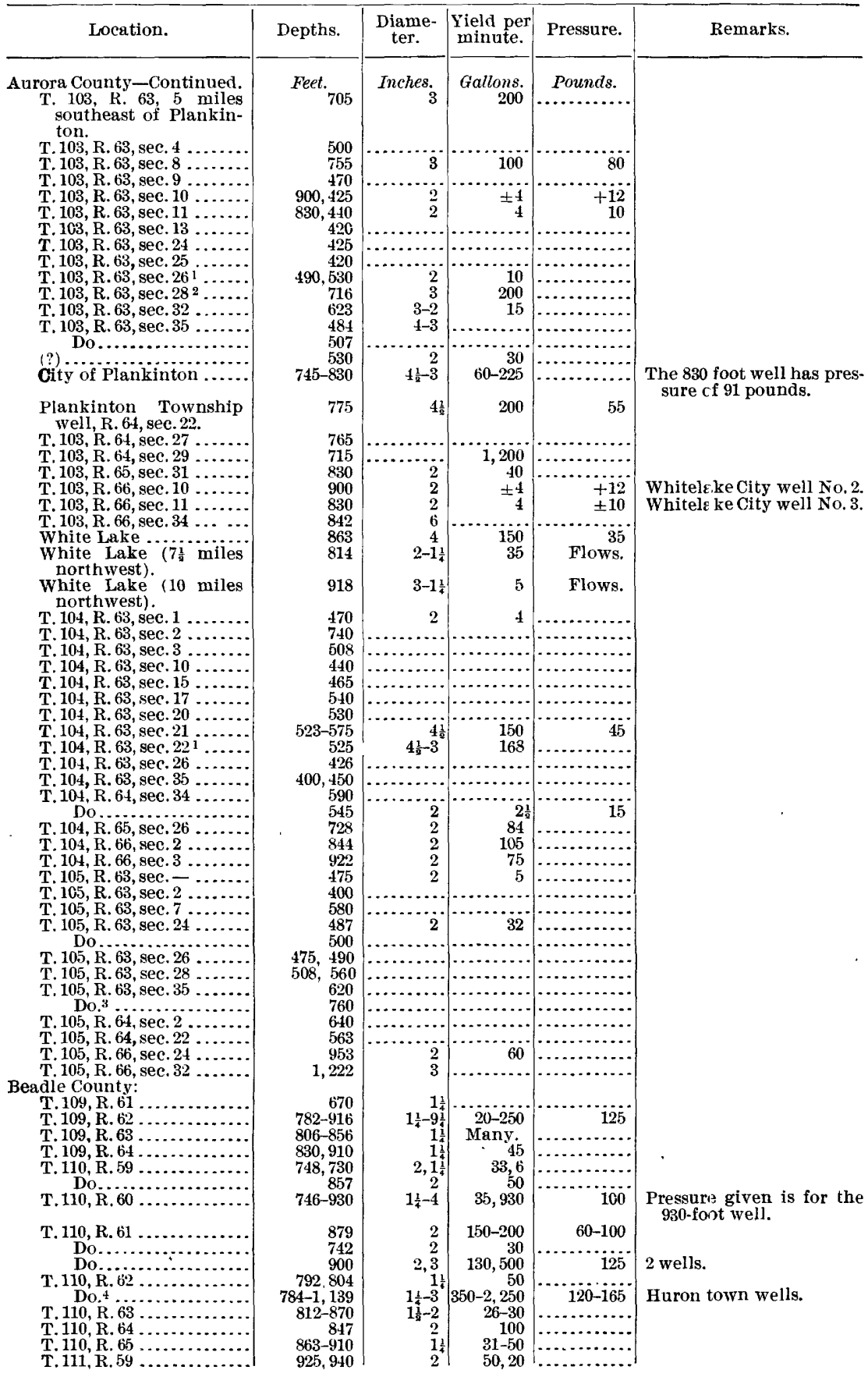

1 Record, U. S. Geol, Surv,, 18th Ann. Rept, part 4, pl, 40 .

2 Ibid., Mitchell folio No. 99, p. 3.

3 Ibid., p. 2.

4 U. S. Geol. Surv., 17th Ann. Rept., part 2, pp. 22-23. 
SOUTH DAKO'TA-Continued.

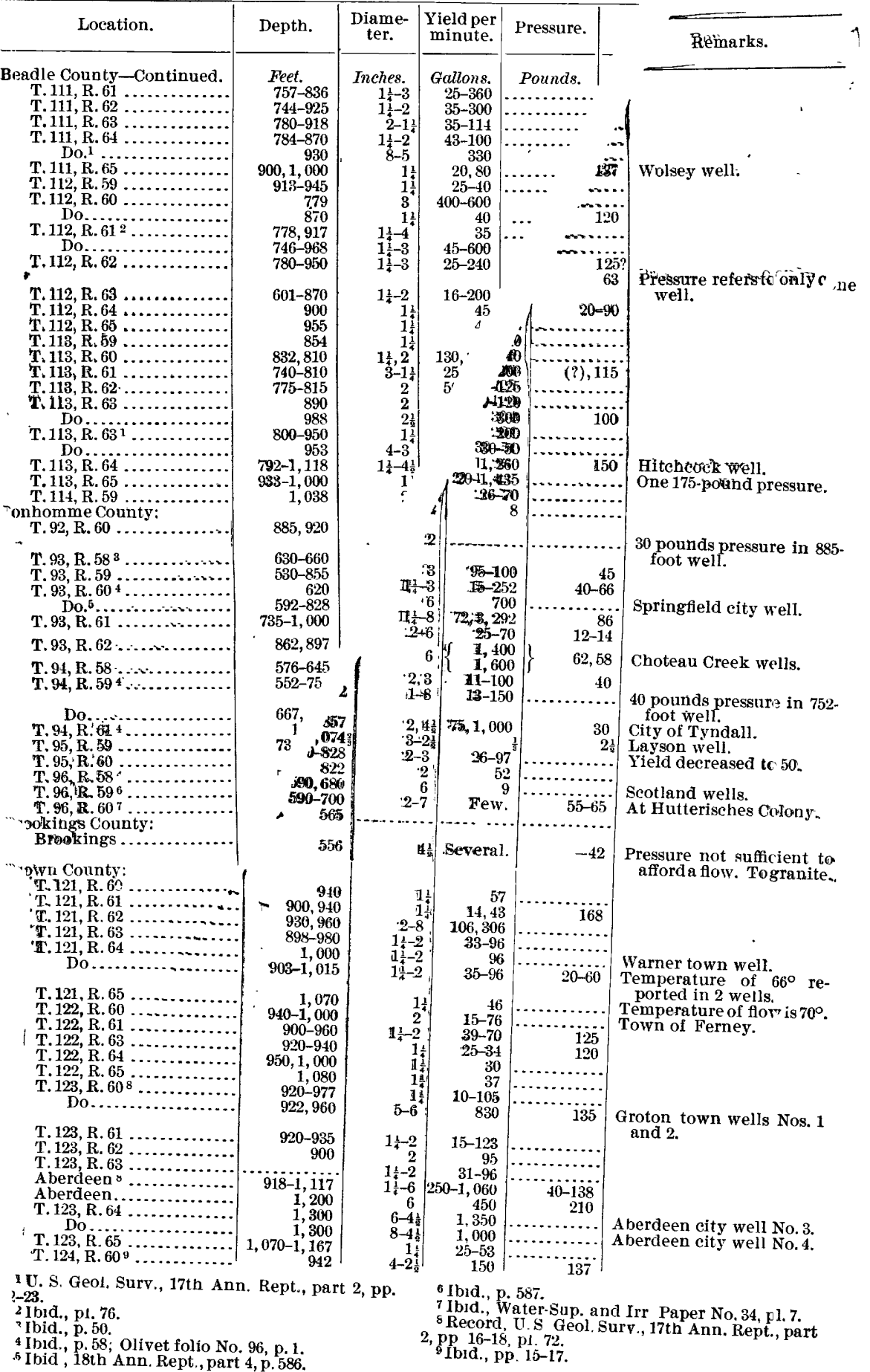


SOUTH DAKO'TA-Continued.

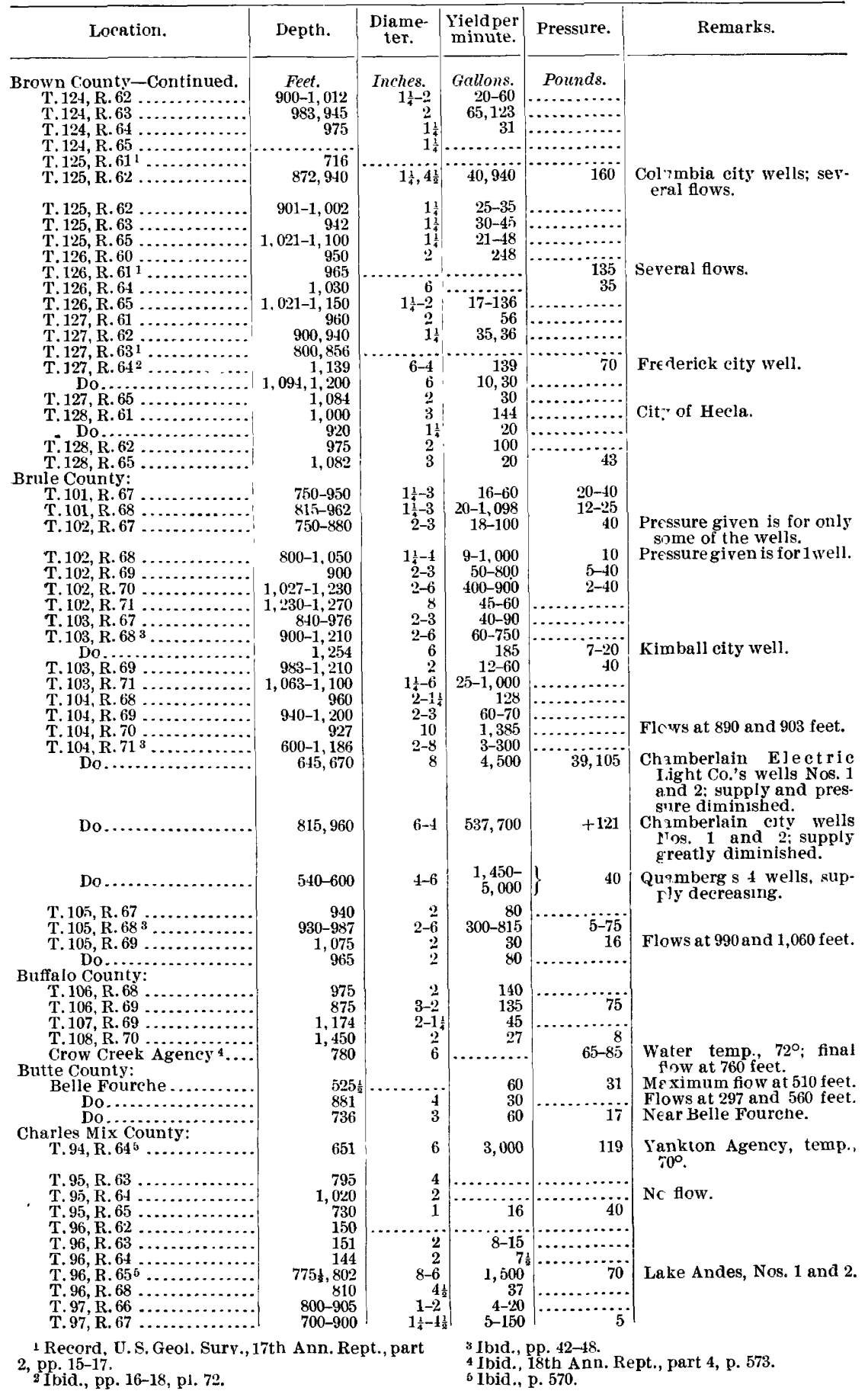


SOUTH DAKOTA-Continued.

\begin{tabular}{|c|c|c|c|c|c|}
\hline Location. & Depth. & $\begin{array}{l}\text { Diame- } \\
\text { ter. }\end{array}$ & $\begin{array}{l}\text { Yield per } \\
\text { minute. }\end{array}$ & Pressure. & Remarks. \\
\hline $\begin{array}{r}\text { Charles Mix County-Con. } \\
\text { T. } 98 \text {, R. } 64 \ldots \ldots \ldots \ldots \ldots \\
\text { T. } 98 \text {, R. } 65 \ldots \ldots \ldots \ldots \ldots \ldots \\
\text { T. } 98 \text {, R. } 66 \ldots \ldots \ldots \ldots \ldots \\
\text { T. } 98 \text {, R. } 67 \ldots \ldots \ldots \ldots \ldots\end{array}$ & $\begin{array}{l}\text { Feet. } \\
772 \\
920,940 \\
820-950 \\
800-991\end{array}$ & $\begin{array}{r}\text { Inches. } \\
2 \\
2 \\
2-3 \\
1-3\end{array}$ & $\begin{array}{r}\text { Gallons. } \\
200 \\
6,11 \\
50-65 \\
6-65\end{array}$ & \begin{tabular}{|r} 
Pounds. \\
52 \\
$2-8$ \\
$24-30$ \\
$\ldots . .$.
\end{tabular} & $\begin{array}{l}\text { Various pressires given, } \\
\text { the greatest being } 63 \\
\text { pounds. }\end{array}$ \\
\hline $\begin{array}{r}\text { T. } 98, \text { R. } 68 \ldots \ldots \ldots \ldots \ldots \\
\text { Do } \ldots \ldots \ldots \ldots \ldots \ldots\end{array}$ & $\begin{array}{r}800-1,110 \\
1,220\end{array}$ & $\begin{array}{r}1 \frac{1}{4}-3 \\
6\end{array}$ & $\begin{array}{r}10-150 \\
\ldots . . \ldots \ldots\end{array}$ & $3-80$ & No flow. \\
\hline T. 98, R. 69 & 644 & 6 & 50 & +24 & \\
\hline T. 99, R. $66 \ldots \ldots \ldots \ldots \ldots$ & $\begin{array}{r}810 \\
730-950\end{array}$ & $1 \frac{1}{4}$ & 20 & +24 & Greatest pressure reported. \\
\hline 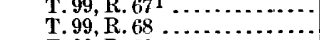 & $\begin{array}{r}730-950 \\
720-1,006\end{array}$ & $\begin{array}{r}1 \frac{1}{4}-3 \\
1-3\end{array}$ & $\begin{array}{l}1-50 \\
2-78\end{array}$ & $\begin{array}{l}-50 \\
-40\end{array}$ & $\begin{array}{l}\text { Greatest pressure reported. } \\
\text { Do. }\end{array}$ \\
\hline T. 99, R. $69 \ldots \ldots \ldots \ldots \ldots$ & 944,966 & 3,2 & 60 & 50 & \\
\hline -T. 99, R. $70 \ldots \ldots \ldots$ & $840-1,000$ & $1 \frac{1}{4}-3$ & $\begin{array}{r}10-30 \\
.0-120\end{array}$ & $20-26$ & \\
\hline $\begin{array}{c}\text { T. } 100, \text { R. } 67 \\
\text { T. } 100, \text { R. } 68 \ldots \ldots \ldots \ldots \ldots\end{array}$ & $\begin{array}{l}734-875 \\
720-930\end{array}$ & $\begin{array}{r}1 \frac{1}{4}-3 \\
1-2\end{array}$ & $\begin{array}{r}20-120 \\
7-31 \frac{1}{2}\end{array}$ & $\begin{array}{l}-87 \\
-13\end{array}$ & $\begin{array}{l}\text { Do. } \\
\text { Do. }\end{array}$ \\
\hline T. 100, R. 69 . & $856-1,030$ & 2 & $15-125^{2}$ & 15 & Pressure given is for 1 well. \\
\hline T. 100, R. $70 \ldots \ldots \ldots$ & 890.900 & $1 \frac{1}{4}, 2$ & 16 & 30 & \\
\hline $\begin{array}{l}\text { T. 100, R. } 71 \\
\text { Clark County: }\end{array}$ & $600-868$ & 8 & $500-3,000$ & $\ldots \ldots \ldots \ldots$ & \\
\hline T.113, R. $58 \ldots \ldots \ldots \ldots \ldots$ & 990 & 2 & 17 & ........ & \\
\hline T. 114, R. $59 \ldots \ldots$ & $1,100,1,038$ & 2 & 6,8 & .............. & \\
\hline 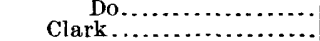 & $\begin{array}{r}866-946 \\
1,200\end{array}$ & $1 \frac{1}{4}$ & $\cdots$ & $\begin{array}{ll}\ldots \ldots \ldots \\
\ldots \ldots \ldots \ldots\end{array}$ & 2 unsuccessful wells, \\
\hline T, 117, R. $59^{2} \ldots \ldots \ldots$ & $1,020-1,200$ & $1 \frac{1}{4}-6$ & $15-35$ & (n...... & \\
\hline T.118, R. $59, \ldots \ldots \ldots \ldots \ldots$ & $1,013-1,080$ & $1 \frac{1}{4}-2$ & $25-150$ & $\ldots \ldots$ & \\
\hline T. 92, R. 51 , sec. $33 \ldots \ldots \ldots$ & 400 & $3-2$ & Few. & ........... & $\begin{array}{l}\text { Water rises a few feet } \\
\text { above the surface. }\end{array}$ \\
\hline Vermilion $\ldots . . . \ldots \ldots \ldots$ & 507 & 3 & Few. & & Flouw derroging \\
\hline ec. $29 \ldots \ldots \ldots$ & 400 & $1 \frac{1}{4}$ & & $\ldots$ & Flow decreasing. \\
\hline $\begin{array}{l}\text { T. } 93 \text {, R. } 51 \text {, sec. } 31 \ldots \ldots . \\
\text { T. } 93 \text {, R. } 52 \text {, sec. } 28\end{array}$ & 410 & $\begin{array}{l}1 \\
2\end{array}$ & 1 & $\cdots \cdots$ & Do. \\
\hline T. 94, R. 52 , sec. $11 \ldots \ldots \ldots$ & $\begin{array}{l}400 \\
402\end{array}$ & $\begin{array}{l}2 \\
2\end{array}$ & & $\cdots \cdots$ & Do. \\
\hline T. 94, R. 52, sec. $15 \ldots \ldots$ & 400 & $1 \frac{1}{4}$ & Many. & & Do. \\
\hline T. $94, \mathrm{~F}$ & 500 & $2+$ & Feiv. & & Irony; flow decreasing. \\
\hline sec. 9 ......... & 500 & $3-2$ & & $\ldots$ & Soft; flow decreasing. \\
\hline $\begin{array}{l}\text { T. } 95, \text { R. } 52, \text { sec. } 17^{3} \ldots \ldots \\
\text { Custer County: }\end{array}$ & 507 & …..... & ........... & & \\
\hline Buffalo Gap ............ & 700 & & & & 2 unsuccessful borings. \\
\hline $\begin{array}{l}\text { Davicon County: } \\
\quad \text { T. } 101, \text { R. } 60^{4} \ldots \ldots \ldots\end{array}$ & $413-525$ & 2 & $25-45$ & & Very hard rock bottom in \\
\hline T. 101, R. $61 \ldots$ & $425-640$ & $1 \frac{1}{4}-2$ & $15-48$ & & $\begin{array}{l}\text { Depths increase regularly } \\
\text { from northeast to south- } \\
\text { west in this tow nship. }\end{array}$ \\
\hline T. 101, R. $62^{5} \ldots \ldots \ldots \ldots$ & $480-775$ & & 60 & $\ldots \ldots$ & \\
\hline $\begin{array}{l}\text { T. } 102, \text { R. } 61 \\
\text { T. } 10^{\circ}, \text { R. } 62\end{array}$ & $\begin{array}{r}500 \\
449-642\end{array}$ & $\ddot{2}-\bar{i}$ & $20-90$ & & \\
\hline T. 103, R. $60^{6} \ldots \ldots \ldots \ldots$ & $431-550$ & $2-1 \overline{4}$ & 35 & 13 & $\begin{array}{l}\text { Yield and pressure for } 550 \text { - } \\
\text { foot well sur } \mathrm{k} \text { in } 1896 \text {. }\end{array}$ \\
\hline T. 103, R. $60^{7} \ldots \ldots \ldots$ & 765 & & & & $\begin{array}{l}\text { In Mitchell; fows at } 285 \text {, } \\
376,445 \text {, an } 1540 \text { feet; } \\
\text { quartzite from } 540 \text { to } 765 \\
\text { feet. }\end{array}$ \\
\hline Do $\ldots \ldots \ldots \ldots \ldots \ldots$ & $433-586$ & $2-8$ & $20-600$ & $13-28$ & In Mitchell ard vicinity. \\
\hline T. 103, R. $61 \ldots$ & $410-500$ & 2 & $110-120$ & $\ldots \ldots \ldots \ldots$ & \\
\hline T. 103, R. $62 \ldots$ & $\begin{array}{r}400-495 \\
646\end{array}$ & $\begin{array}{r}2-4 \frac{1}{2} \\
4 \frac{1}{4}\end{array}$ & $\begin{array}{r}35-70 \\
700\end{array}$ & (n. & $\begin{array}{l}\text { Flows at } 350,470 \text {, and } 620 \\
\text { feet. }\end{array}$ \\
\hline T. 104, R. $60^{8}$ & $400-507$ & $3-4 \frac{1}{9}$ & $10-100$ & & \\
\hline T. $104, R, 61 \ldots \ldots \ldots \ldots$ & $400-653$ & $2-3$ & $22-210$ & $\ldots \ldots \ldots \ldots$ & Several flows. \\
\hline T. 104, R. $62^{8} \ldots \ldots \ldots \ldots$ & $405-601$ & $2-4 \frac{1}{2}$ & $5-156 ?$ & $\ldots \ldots \ldots \ldots$ & \\
\hline Webster ............... & 1,716 & & +69 & $\ldots \ldots$. & Water rises to -220 feet. \\
\hline Do......................... & 1,550 & & & & Unsuccessful. \\
\hline Andover ${ }^{9} \ldots \ldots$ & 1,075 & $6 \frac{1}{2}$ & 300 & 90 & Saline. \\
\hline T. 122, R. 59 , sec. 4 . & 1,080 & $1 \frac{1}{4}$ & 40 & 85 & \\
\hline T. 124, R. $58 \ldots \ldots \ldots$ & 1,240 & & & & Water just flows. \\
\hline T. 124, R. 58 , sec. $6 \ldots \ldots$ & 930 & $1 \frac{1}{4}$ & 28 & & \\
\hline T. 124, R. $58 \ldots \ldots \ldots \ldots \ldots$ & 1,200 & $1 \frac{1}{4}$ & 15 & 40 & \\
\hline T. 124 , R. 59 , sec. $2 \ldots \ldots$. & 930 & $1 \frac{1}{4}$ & 40 & 75 & \\
\hline T. 124, R. 59 , sec. $36 \ldots \ldots$. & 970 & $1 \frac{1}{4}$ & 35 & 90 & \\
\hline $\begin{array}{l}\text { Dewey County: } \\
\text { Cheyenne Agency } 10 \text {. }\end{array}$ & 1,337 & $8-4$ & 500 & 205 & Temp., $90^{\circ}$ or $92^{\circ}$. \\
\hline
\end{tabular}

1 Record U.S. Geol. Surv., 17th Ann. Rept., part 2, pp. 44-45.

Ibid., 18th Ann. Rept., 1897, part 4, pp. 18, 21

3 Ibid., Parker folio No. 97, p. 21.

4 Ibid., Alexandria folio No. 100, p. 2

'Ibid, 17th Ann. Rept., part 2, pp. 39-40, 44.

7 U. S. Geol. Surv. Mitchell folio No 99.

8 Record, ibid., 18th Ann. Rept., part 4, p. 575.

9 Ibid., 17th Ann. Rept., part 2, p. 19.

5 Ibid., Mitchell folio No. 99, pp, 2-3.

10 Ibid., 18th Ann. Rept, part 4, p. 588. 
SOUTH DAKOTA-Continued.

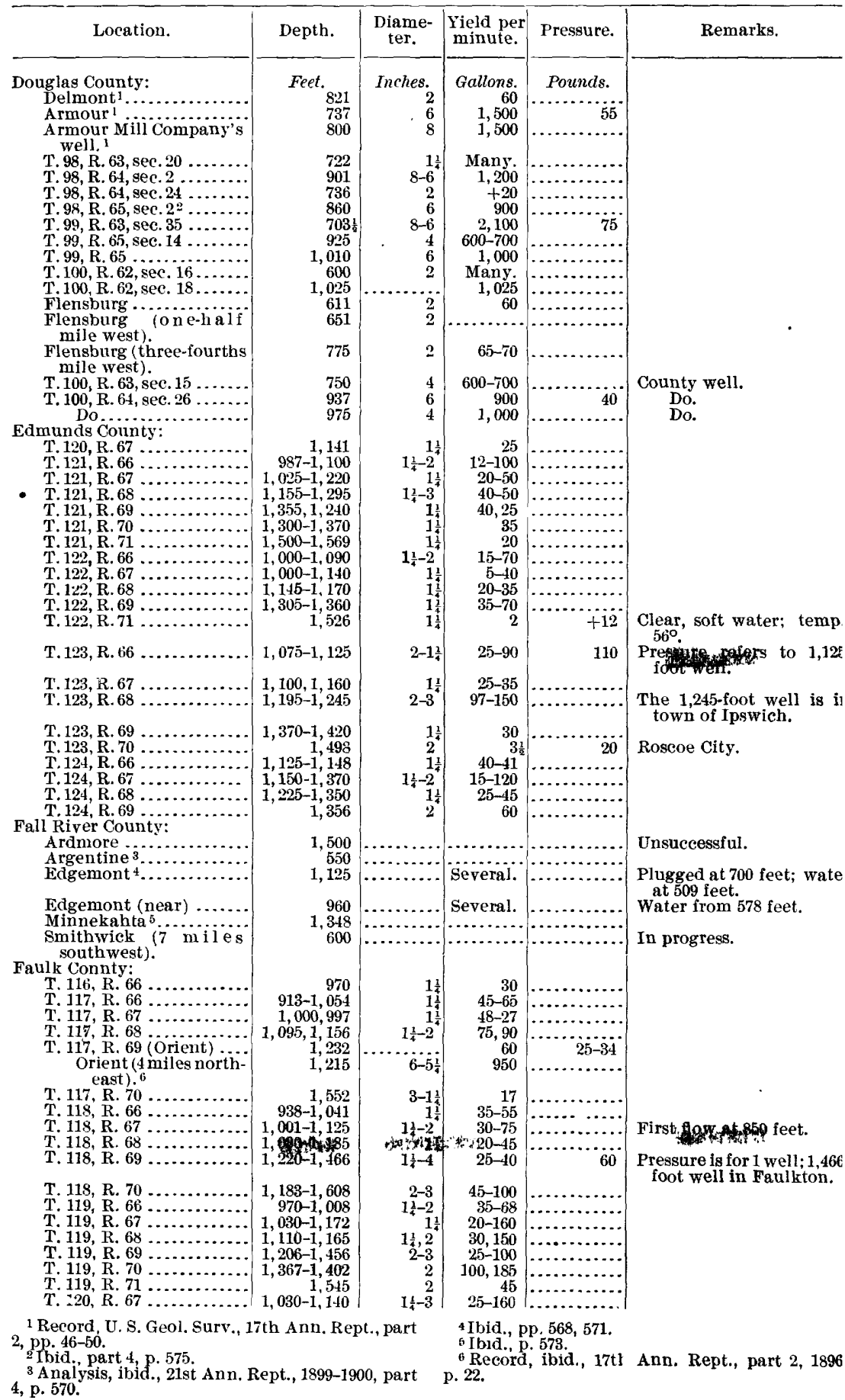


SOUTH DAKOTA-Continued.

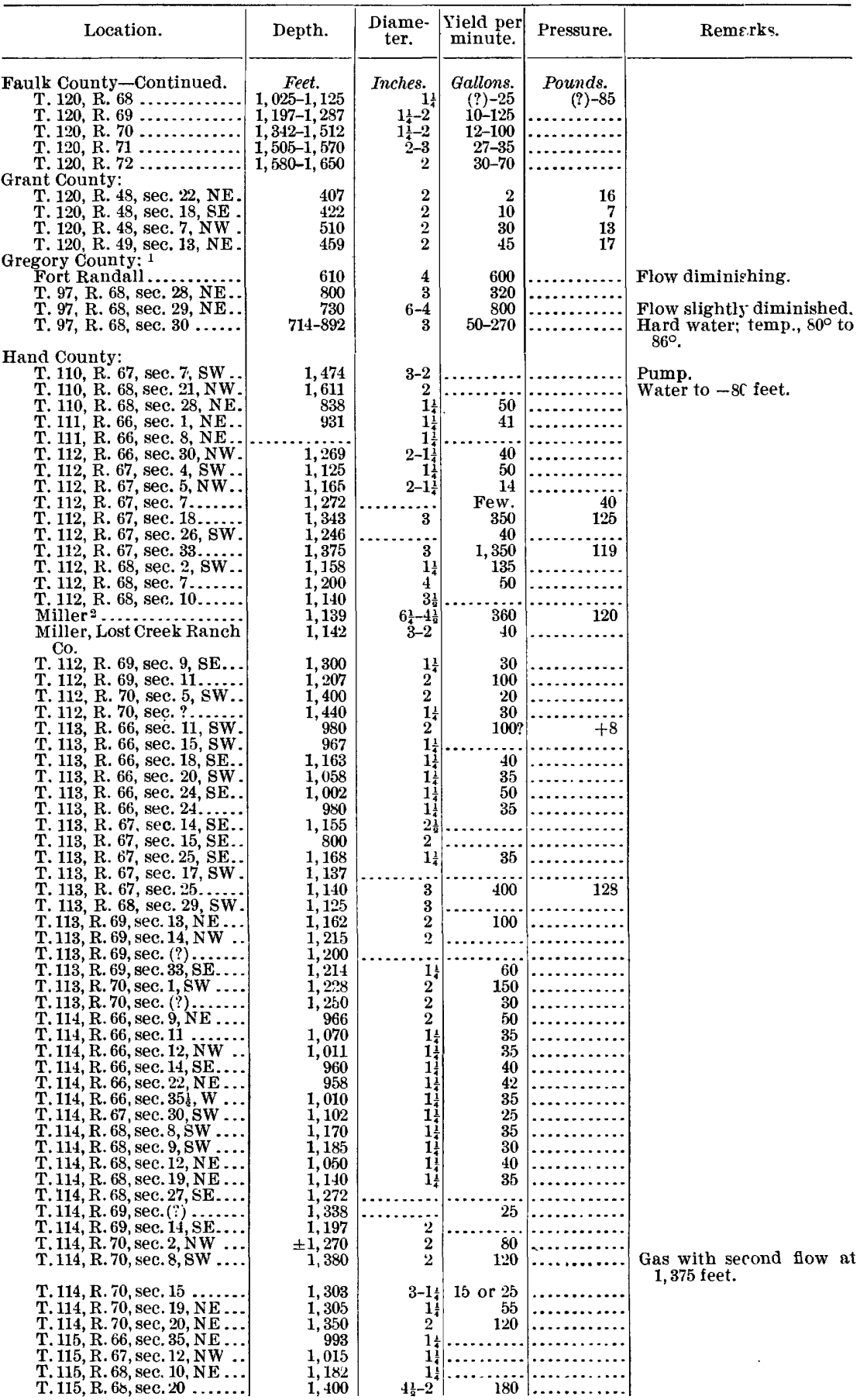

1 Record, U. S. Geol. Surv., 17th Ann. Rept., z Ibld., p. 26. part 2,1896 , p. 58 . 
SOUTH DAKOTA-Continued.

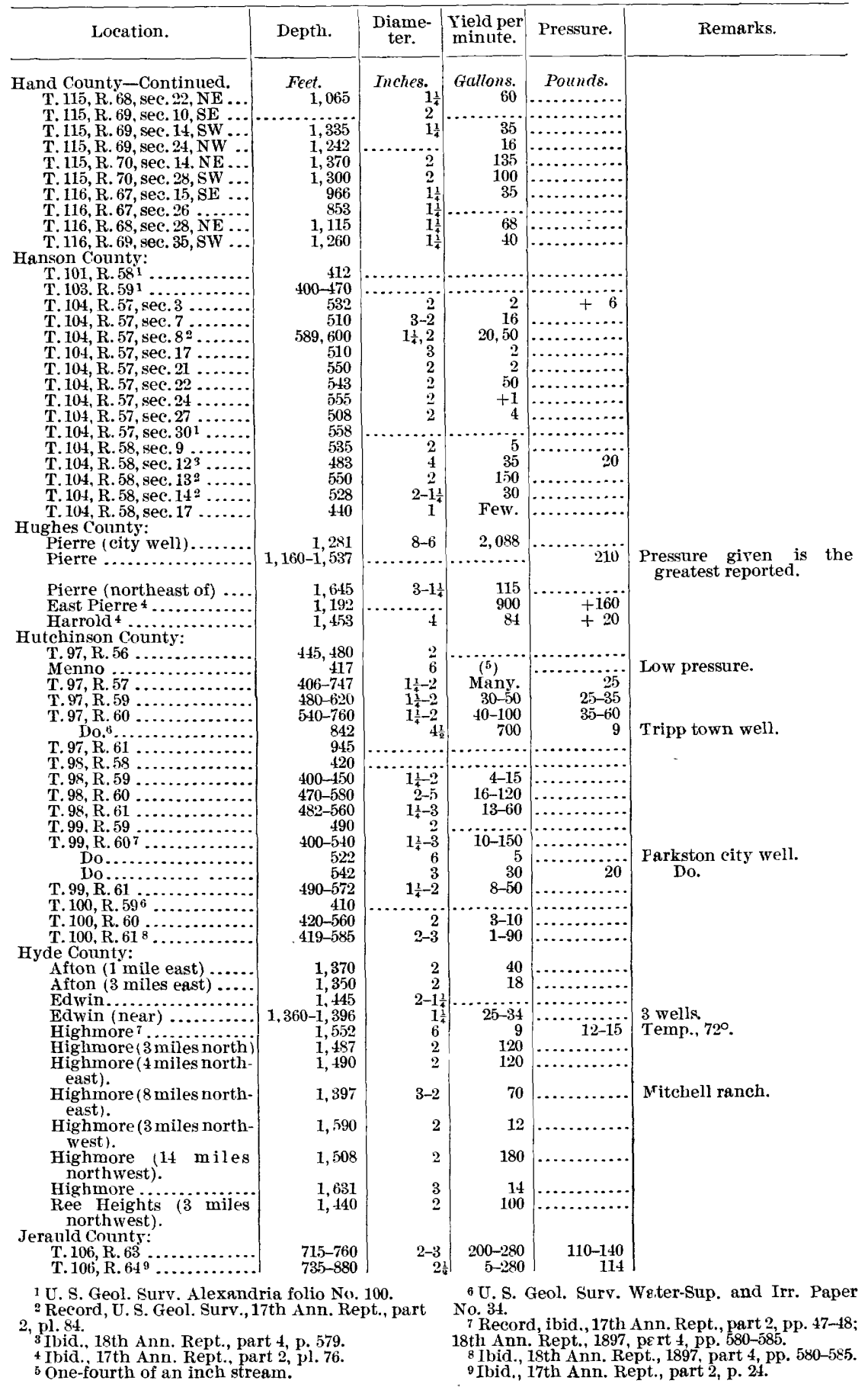


SOUTH DAKOTA-Continued.

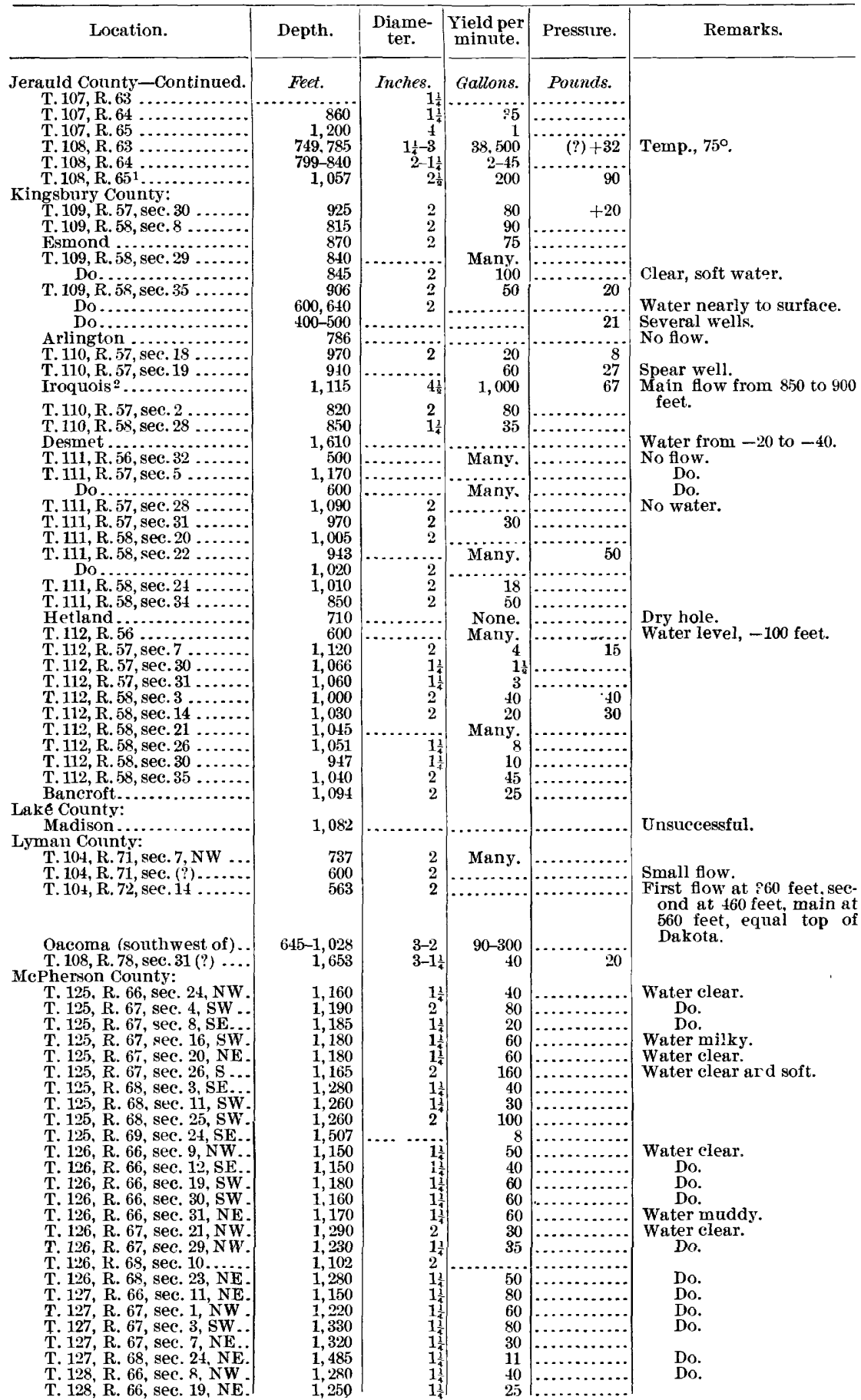

1 Record, U. S. Geol. Surv., 17th Ann. Rept. part 2, pp. 29-30. 
SOUTH DAKO'TA-Continued.

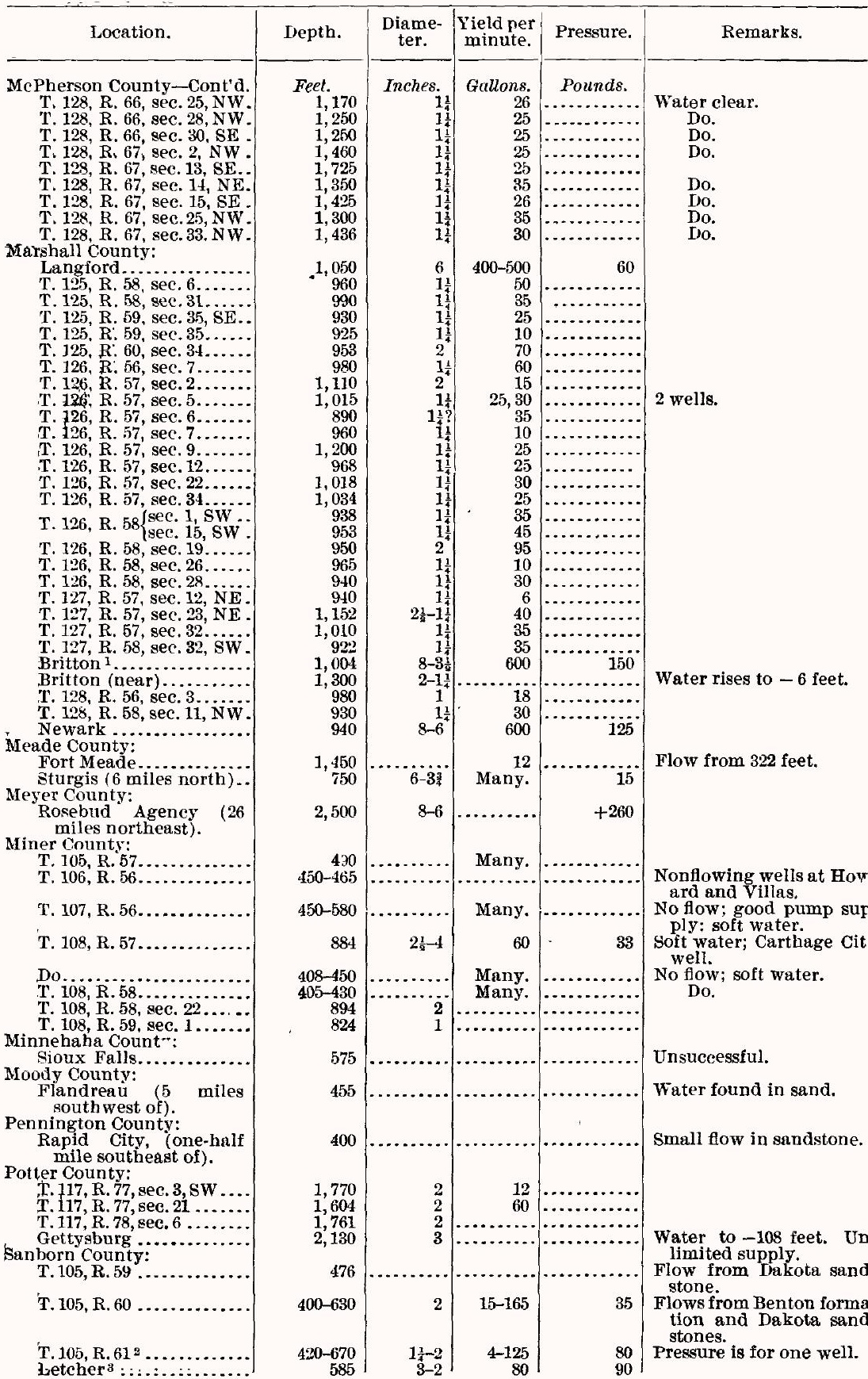

1 Record, U. S. Geol. Surv., 17th Ann. Rept.,part 2, p. 181.

2 Ibid., pp. 631-633; Mitchell folio No. 99 .

I Ibid., pp. 631-633. 
SOUTH DAKOTA-Continued.

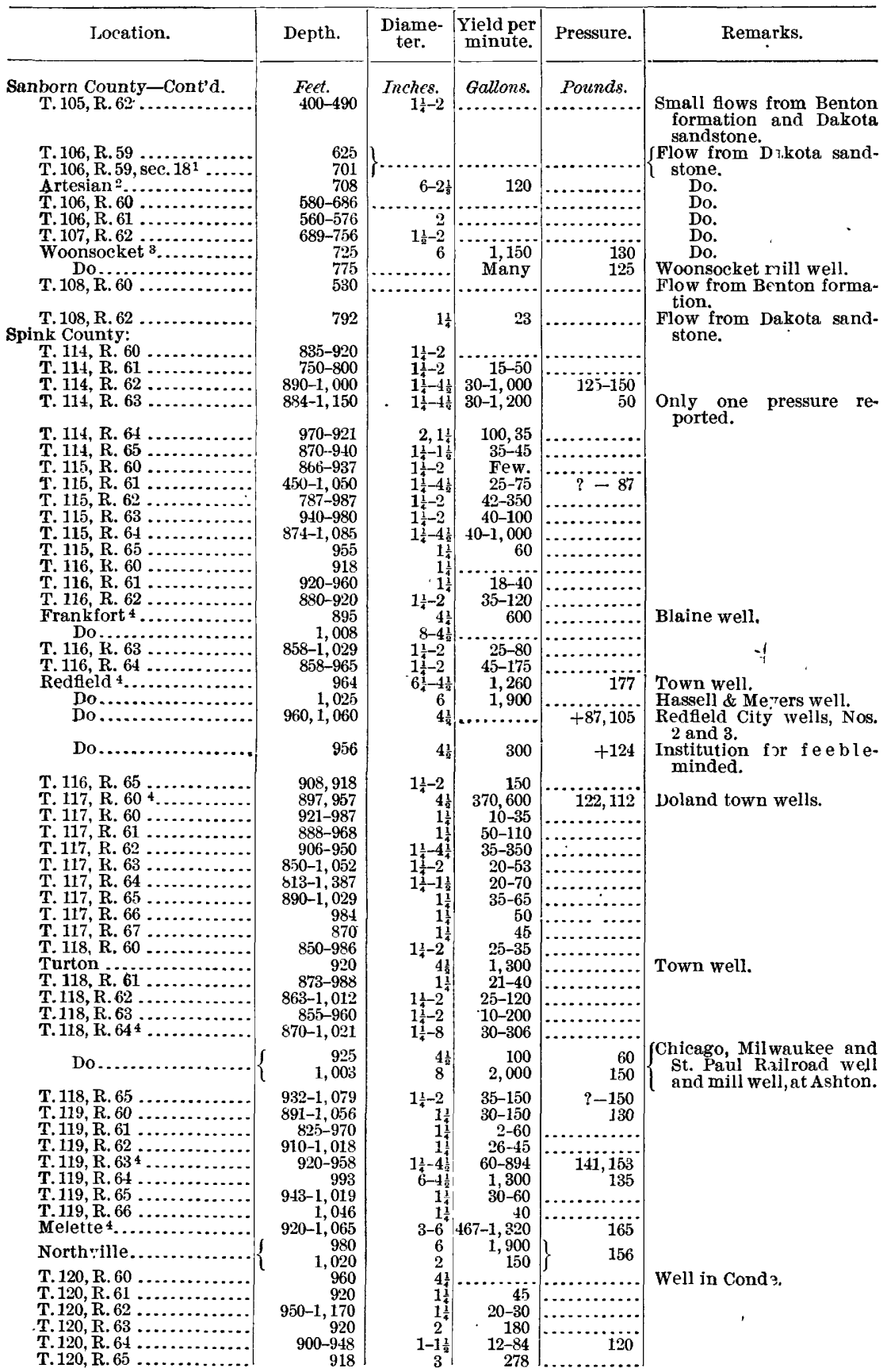

1 U. S. Geol. Surv. Alexandria folio No. $100 ;$ p. 2. 575.

Record, ibid., 18th Ann. Rept., 1897, part 4, $\mathrm{p}$.

3 Ibid., 17th Ann. Rept., 1896, part 2, pp. 631-683. 4 Ibid., pp. 19-20. 
SOUTH DAKOTA-Continued.

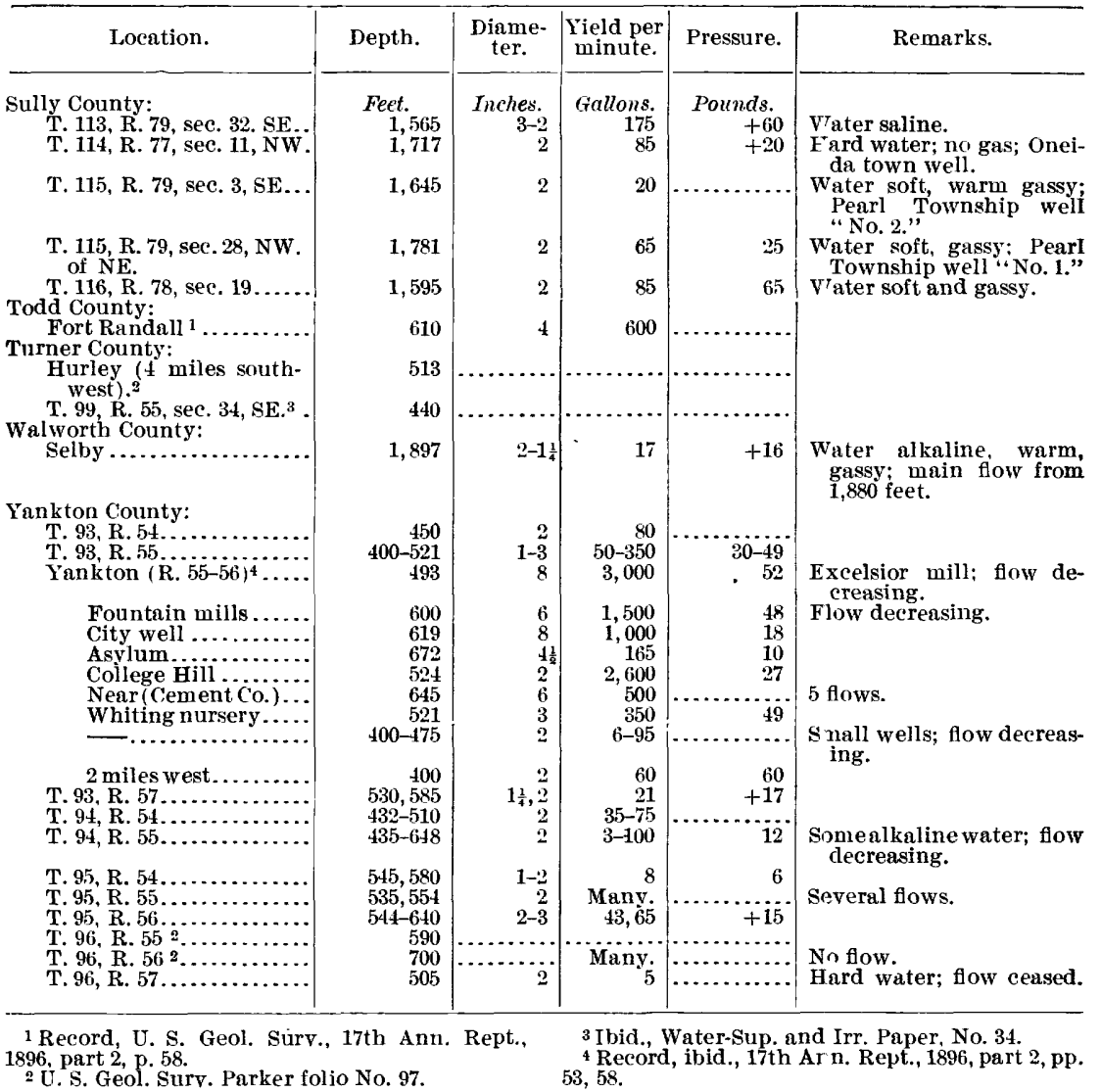

\section{PUBLICATIONS RELATING TO DEEP BORINGS IN SOUTH DAKOTA.}

Report on Irrigation, 52d Congress, 1st session, Senate Ex. Doc. No. 41, part 2, pp. 40-65, Washington, 1893.

Preliminary report on the artesian waters of a portion of the Dakotas, by N. H. Darton: United States Geological Survey, Seventeenth Annual Report, 1895-96, part 2, pp. 609-694, Washington, 1896.

New development in well boring and irrigation in South Dako'a, by N. H. Darton: United States Geological Survey, Eighteenth Annual Report, 1896-97, part 4, pp. 567-615, Washington, 1897.

Geology and water resources of a portion of eastern South Dakota, by J. E. Todd: United States Geological Survey, Water-Supply and Irrigatior Paper, No. 34, 34 pages, plates and maps, Washington, 1900.

United States Geological Survey, Olivet, Parker, Mitchell, ard Alexandria folios (Nos. 96, 97, 99, and 100).

Preliminary report on the geology and underground water resources of the Central Great Plains, by N. H. Darton: United States Geological Survey Professional Paper No. 32, Washington, 1905. 
TENNESSEE.

\begin{tabular}{|c|c|c|c|c|c|}
\hline Location. & Depth. & $\begin{array}{l}\text { Diame- } \\
\text { ter. }\end{array}$ & $\mid \begin{array}{c}\text { Yield per } \\
\text { minute. }\end{array}$ & $\begin{array}{l}\text { Height of } \\
\text { water. }\end{array}$ & Remarks. \\
\hline $\begin{array}{l}\text { Benton County: } \\
\text { Eva } \ldots \ldots \ldots \ldots \ldots \ldots \ldots\end{array}$ & Feet. ${ }_{727}$ & $\begin{array}{r}\text { Inches. } \\
6\end{array}$ & $\begin{array}{r}\text { Gallons. } \\
5\end{array}$ & Fret. & \\
\hline Cheatham county: & & & & & \\
\hline $\begin{array}{l}\text { Kingston Springs......... } \\
\text { Coffee County: }\end{array}$ & 1,000 & & & & Unsuccessful. \\
\hline Tullahoma........... & 700 & & & & Oil well. \\
\hline $\begin{array}{l}\text { Crockett County: } \\
\text { Bells } \ldots \ldots \ldots \ldots\end{array}$ & 1,100 & & & & $\begin{array}{l}\text { Prospect well; unsuccess- } \\
\text { ful. }\end{array}$ \\
\hline 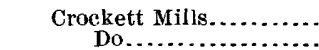 & $\begin{array}{r}+900 \\
420\end{array}$ & $\begin{array}{l}3 \\
3\end{array}$ & Many. & $\begin{array}{r}\text { No flow. } \\
-30\end{array}$ & Abandoned. \\
\hline Dickson County: & & & & & \\
\hline $\begin{array}{r}\text { Dull (2 miles from) } \ldots \ldots \\
\text { Do } \ldots \ldots \ldots\end{array}$ & $\begin{array}{r}565 \\
2,000\end{array}$ & $\begin{array}{l}4 \frac{1}{2} \\
4 \frac{1}{2}\end{array}$ & & & $\begin{array}{l}3 \text { oil wells. } \\
\text { Oil well. }\end{array}$ \\
\hline $\begin{array}{l}\text { Dyer County: } \\
\text { Dyersburg }{ }^{1} \ldots \ldots \ldots \ldots \ldots\end{array}$ & 600 & & 140 & Flows. & encose \\
\hline Do................... & 600 & & 130 & Fows. & Do. \\
\hline $\begin{array}{l}\text { Do.............. } \\
\text { Fentress County: }\end{array}$ & 591 & 6 & 100 & +11 & \\
\hline Little Crab²... & 2,185 & & & & $\begin{array}{l}\text { For oil; not fornd in pay- } \\
\text { ing quantities. }\end{array}$ \\
\hline $\begin{array}{l}\text { Hamilton County: } \\
\text { Chattanooga .. }\end{array}$ & 600 & $10-8$ & 50 & -45 & \\
\hline $\begin{array}{l}\text { Hardin County: } \\
\text { Lexington............ }\end{array}$ & 700 & & & & \\
\hline Saltillo $\ldots . . . . . .$. & 950 & $36-6$ & Many. & Flows. & $\begin{array}{l}\text { Sulphur: temp., } 45^{\circ} \text {; bored } \\
\text { in } 1830 \text {. }\end{array}$ \\
\hline $\begin{array}{l}\text { Knox County: } \\
\text { Knoxville } . . . \ldots \ldots \ldots \ldots\end{array}$ & 2,100 & & & & Temp., $57^{\circ}$ \\
\hline Lawrence County: & & & & & \\
\hline $\begin{array}{r}\text { Iron City } \ldots \ldots \ldots \ldots \ldots \\
\text { Do } \ldots \ldots \ldots\end{array}$ & $\begin{array}{l}400 \\
480\end{array}$ & 12 & (n. & & $\begin{array}{l}\text { For oil or gas. } \\
\text { For gas; not in use. }\end{array}$ \\
\hline $\begin{array}{l}\text { Morgan County: } \\
\text { Rugby ........... }\end{array}$ & & & & & Several wells for oil. \\
\hline $\begin{array}{l}\text { Obion County: } \\
\text { Rives......... }\end{array}$ & 500 & & & -30 & \\
\hline $\begin{array}{l}\text { Overton County: } \\
\text { Livingston (just south- } \\
\text { west).2 }\end{array}$ & 2,080 & & & & For oil. \\
\hline $\begin{array}{l}\text { Putnam County: } \\
\text { Cookeville } \\
\text { southwest). }\end{array}$ & 1,990 & & & & Do. \\
\hline $\begin{array}{l}\text { Cookeville } \\
\text { northeast).2 }\end{array}$ & 1,549 & & & & Do. \\
\hline $\begin{array}{l}\text { Scott County: } \\
\text { Elgin ( } 2 \frac{1}{2} \text { miles north- } \\
\text { west })^{2}\end{array}$ & & & & & Do. \\
\hline 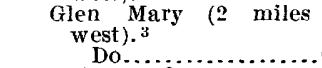 & $\begin{array}{r}1,236-1,340 \\
600\end{array}$ & & & & $\begin{array}{l}\text { Oil wells: several others } \\
\text { in scott Courty. }\end{array}$ \\
\hline Helenwood $(?) \ldots \ldots \ldots \ldots$ & 1,500 & & & & For oil; unsuccessful. \\
\hline $\begin{array}{l}\text { Shelby County: } \\
\text { Memphis ... }\end{array}$ & $450-400$ & $8-6$ & $200-100$ & & Several wells. \\
\hline Do. ${ }^{4} \ldots \ldots \ldots \ldots$ & $+1,156$ & & ........... & & \\
\hline Do $\ldots . . . \ldots \ldots$ & $3,000-2,000$ & & & & $\begin{array}{l}\text { Several wells for oil; aban- } \\
\text { doned. }\end{array}$ \\
\hline $\begin{array}{l}\text { Uniou County: (?) } \\
\text { Hurricane Creek }{ }^{1} \ldots\end{array}$ & 530 & & & & Oil well. \\
\hline
\end{tabular}

1 Tenn. Com. Ag. Oil Region Rept., 1877, pp. 54, 73 2 Record. U. S. Geol. Surv. Folio No. 53 , pp. $4-5$. 3 U. S. Geol. Surv., 17th Ann. Rept., 1895-96, part 3 , pp. 699-700.

\section{PUBLICATIONS RELATING TO DEEP BORINGS IN TENNESSEE.}

United States Geological Survey, Seventeenth Annual Report, 1896, parts 2 and 3. "Oil region," Tennessee: Commissioner of Agriculture Report, 1877.

Tennessee State Board of Health Bulletin, volume 5, 1890.

United States Geological Survey Folio No. 53, by M. R. Campbell, 1899. 


\section{TEXAS.}

\begin{tabular}{|c|c|c|c|c|c|}
\hline Location. & Depth. & $\begin{array}{l}\text { Diam- } \\
\text { eter. }\end{array}$ & $\begin{array}{l}\text { Yield per } \\
\text { minute. }\end{array}$ & $\begin{array}{c}\text { Height of } \\
\text { water. }\end{array}$ & Remarks. \\
\hline $\begin{array}{l}\text { Anderson County: } \\
\text { Palestine ........... }\end{array}$ & Feet. 650 & & $\begin{array}{l}\text { Gallons. } \\
\text { Few. }\end{array}$ & Feet. & \\
\hline Palestine ( $1 \frac{1}{2}$ miles) ...... & $400-444$ & $8-6$ & $1: 21$ & No flow. & several wells. \\
\hline $\begin{array}{l}\text { Do } \\
\text { Angelina County: }\end{array}$ & 560 & 6 & 100 & -80 & \\
\hline $\begin{array}{l}\text { Angelina County: } \\
\text { Burke .......... }\end{array}$ & 500 & & & & Salt water; abandoned. \\
\hline $\begin{array}{l}\text { Lufkin ......... } \\
\text { Archer County: }\end{array}$ & 1,300 & & & & $\begin{array}{l}\text { Salt water; abandonea. } \\
\text { No we.ter; abandoned. }\end{array}$ \\
\hline $\begin{array}{l}\text { Archer County: } \\
\text { Archer city ........... }\end{array}$ & 550 & 6 & Few, & -50 & Alkuli water. \\
\hline Do. ${ }^{1} \ldots \ldots$ & 736 & & c.en..... & No fiow. & \\
\hline $\begin{array}{l}\text { Do.................. } \\
\text { Atascosa County: }\end{array}$ & 500 & & & & Salt water only. \\
\hline $\begin{array}{l}\text { Atascosa County: } \\
\text { Tobey ............ }\end{array}$ & $1,200-1,300$ & & & & \\
\hline $\begin{array}{l}\text { Bastrop County: } \\
\text { Bastrop................ }\end{array}$ & & & & & \\
\hline $\begin{array}{l}\text { Bastrop....................... } \\
\text { Bell County: }\end{array}$ & +900 & $\cdots$ & & & No we.ter. \\
\hline Belton (9 miles west) & 700 & & & Flows. & \\
\hline $\begin{array}{l}\text { Belton (10 miles south- } \\
\text { east). }\end{array}$ & 1,800 & & Many. & Flows. & \\
\hline $\begin{array}{l}\text { Belton ( } 2 \text { miles north- } \\
\text { east). }\end{array}$ & 1,000 & & & Flows. & \\
\hline $\begin{array}{l}\text { Belton (19 miles west) } \\
\text { Belton (9 miles south- }\end{array}$ & $\begin{array}{l}\text { 530 } \\
772\end{array}$ & & 70 & $\begin{array}{l}\text { Flows. } \\
\text { Flows. }\end{array}$ & \\
\hline $\begin{array}{c}\begin{array}{c}\text { west) } \\
\text { Belton }\end{array}{ }^{2} \ldots \ldots \ldots \ldots \ldots \ldots \\
\text {. }\end{array}$ & 975 & 4 & 173.6 & F] ows & Anft water \\
\hline $\begin{array}{l}\text { Belton (1 mile south- } \\
\text { west). }\end{array}$ & 1,060 & . & $\begin{array}{r}173.0 \\
347\end{array}$ & $\begin{array}{l}\text { Flows. } \\
\text { Flows. }\end{array}$ & $\begin{array}{l}\text { Soft water. } \\
\text { Dio. }\end{array}$ \\
\hline $\begin{array}{l}\text { Belton (1 mile south) } \\
\text { Holland (10miles south })\end{array}$ & 1,000 & & & Flows. & \\
\hline & $\begin{array}{r}1,800 \\
606\end{array}$ & & 10 & $\begin{array}{l}\text { Flows. } \\
-60\end{array}$ & Salt vater. \\
\hline 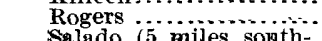 & $+1,600$ & & $\cdots$ & Flows. & \\
\hline $\begin{array}{l}\text { Salado (5 miles south- } \\
\text { east). }\end{array}$ & 412 & & & -397 & \\
\hline 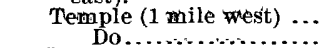 & $\begin{array}{l}1,850 \\
1,800\end{array}$ & & $\begin{array}{l}\text { Many. } \\
\text { Few. }\end{array}$ & $\begin{array}{l}\text { Flows. } \\
\text { Flows. }\end{array}$ & Temp., $91^{\circ}$ \\
\hline 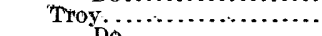 & 1,472 & 8 & & $\begin{array}{l}\text { FTows. } \\
\text { Flows. }\end{array}$ & Soft water. \\
\hline Do & 1,474 & $\cdots$ & 14 & Flows. & \\
\hline 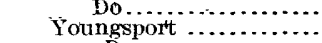 & $\begin{aligned} 1,464 \\
404\end{aligned}$ & & $\begin{array}{r}243 \\
1\end{array}$ & Flows. & D). \\
\hline Do...................... & $\begin{array}{l}404 \\
417\end{array}$ & (n....... & $1_{\frac{1}{3}}$ & $\begin{array}{l}\text { Flows. } \\
\text { Flowe. }\end{array}$ & \\
\hline $\begin{array}{l}\text { Youngsport ( } 1 \frac{1}{4} \text { miles } \\
\text { east }) \text {. }\end{array}$ & 433 & & $\frac{1}{4}$ & Flows. & \\
\hline $\begin{array}{l}\text { Youngsport (one - half } \\
\text { mile north). }\end{array}$ & 444 & $\ldots \ldots$ & 1 & Flows. & \\
\hline $\begin{array}{l}\text { Bexar County: } \\
\text { Aul }{ }^{3} \ldots \ldots \ldots \ldots \ldots \ldots \ldots\end{array}$ & 673 & & & & \\
\hline 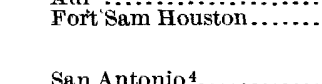 & 726 & & 200 & -5 & $\begin{array}{l}\text { Wate-bearing beds at } 351 \\
\text { and } 398 \text { feet; water at } \\
398 \text { feet being salty. }\end{array}$ \\
\hline $\begin{array}{r}\text { San }{ }_{\text {Do }}^{\text {Dontonio }}{ }^{4} \ldots \ldots \ldots \ldots \\
\ldots\end{array}$ & $\begin{array}{r}822-1,200 \\
1,250\end{array}$ & ......... & $55-200$ & ......... & Numerous wells. \\
\hline Do & 1,465 & & 55 & (n............... & \\
\hline $\begin{array}{l}\text { 'San Antonio (1 mile west) } \\
\text { San Antonio............. }\end{array}$ & 835 & $\cdots \cdots$ & 55 & $\mid \cdots \ldots \ldots \ldots$ & \\
\hline 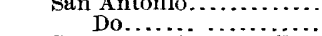 & 870 & & 861 & . & \\
\hline $\begin{array}{l}\text { San Antonio ( } 3 \text { miles } \\
\text { southeast). }\end{array}$ & 1,100 & & & (n) & Hot sulphur water. \\
\hline $\begin{array}{l}\text { San Antonio ( } 3 \text { miles } \\
\text { south). }\end{array}$ & 1,900 & & $5 \overline{55}$ & & \\
\hline $\begin{array}{l}\text { San Antonio ( } 6 \text { miles } \\
\text { southeast). }\end{array}$ & 2,215 & & & & Water at 1,800 feet. \\
\hline $\begin{array}{l}\text { San Antonio ( } 2 \text { miles } \\
\text { south). }\end{array}$ & 1,900 & ....... & 555 & -84 & \\
\hline San Antonio $\ldots \ldots \ldots \ldots \ldots$ & $\begin{array}{r}500 \\
650-715\end{array}$ & & & & Several wells. \\
\hline 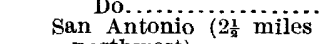 & $\begin{array}{r}650-715 \\
540\end{array}$ & & $500-700$ & $\ldots \ldots$ & D). \\
\hline 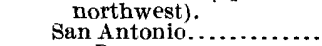 & 630 & & & & \\
\hline $\begin{array}{l}\text { Do } \ldots \ldots \ldots \ldots \ldots \ldots \ldots \\
\text { Do. } \ldots \ldots \ldots \ldots \ldots\end{array}$ & $\begin{array}{r}750-780 \\
450\end{array}$ & & 1,000 & 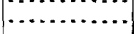 & Do. \\
\hline Do $(\ldots \ldots \ldots \ldots$ & $\begin{array}{l}450 \\
657\end{array}$ & $\cdots$ & 250 & (n......... & Do. \\
\hline $\begin{array}{l}\text { San Antonio ( } 3 \text { miles } \\
\text { north). }\end{array}$ & 583 & & & -50 & Dי \\
\hline Bosque County: & & & & & \\
\hline $\begin{array}{l}\text { Cayote ( } 3 \text { miles north- } \\
\text { east). }\end{array}$ & 439 & & & No flow. & \\
\hline $\begin{array}{r}\text { Chifton } \ldots \ldots \ldots \\
\text { Do } \ldots \ldots \ldots \ldots\end{array}$ & $\begin{array}{l}640 \\
700\end{array}$ & $\ldots$ & $\begin{array}{r}170 \\
\text { Many. }\end{array}$ & $\begin{array}{l}\text { Flows. } \\
\text {........... }\end{array}$ & Temp. $70^{\circ}$ \\
\hline
\end{tabular}

${ }^{1}$ Record, 51st Cong., 1st sess., Senate Ex. Doc. No. 222, p. 262.

2 Record, Artesian waters of Texas west of the

${ }^{3}$ Record, U. S. Geol. Surv., 18th Ann. Rept. 1896-97, part 2 , p. 272 .

97th meridian, by R. T. Hill: 52d Cong., 1st sess., 4 Ibid., pp. 290-297.

Senate Ex. Doc. No. 41, part 3, 1893 p. 116. 
TEXAS-Continued.

\begin{tabular}{|c|c|c|c|c|c|}
\hline Location. & Depth. & $\begin{array}{l}\text { Diame- } \\
\text { ter. }\end{array}$ & $\begin{array}{c}\text { Yield per } \\
\text { minute. }\end{array}$ & $\begin{array}{l}\text { Height of } \\
\text { water. }\end{array}$ & Remarks, \\
\hline $\begin{array}{l}\text { ar ue County-Continued. } \\
\text { Clifton ( } 3 \text { miles north) }\end{array}$ & Feet. & & $\begin{array}{r}\text { Gallons. } \\
220\end{array}$ & Feet. & Temp $84^{\circ}$. soft water. \\
\hline Clifton ( 1 mile west) .... & $\begin{array}{l}062 \\
715\end{array}$ & & $\begin{array}{r}230 \\
60\end{array}$ & Flows. & Soft water. \\
\hline Clifton ( $3 \frac{1}{2}$ miles north). & 670 & & 170 & Flows. & \\
\hline $\begin{array}{l}\text { Clifton (8 miles south- } \\
\text { east). }\end{array}$ & 840 & & & Flows. & \\
\hline Clifton ( 3 miles west) $\ldots .$. & 612 & & & Flows. & Do. \\
\hline Clifton ( 1 mile west)...... & 687 & & & Flows. & Do. \\
\hline $\begin{array}{l}\text { Clifton - (three-fourths } \\
\text { Clifton }\end{array}$ & $\begin{array}{l}700 \\
700\end{array}$ & & & Flows. & $\begin{array}{l}\text { Temp., } 70^{\circ} \text {. } \\
\text { Soft water. }\end{array}$ \\
\hline mile west). & & & & & \\
\hline Cyrus ( 1 mile east) ....... & 1,000 & & Many; & Flows. & \\
\hline 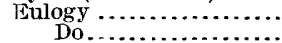 & $\begin{array}{l}780 \\
529\end{array}$ & & $\begin{array}{l}34 \\
30\end{array}$ & $\begin{array}{l}\text { Flows. } \\
\text { Flows. }\end{array}$ & \\
\hline Tulogy (i mile north)... & 475 & & & Flows. & Do. \\
\hline $\begin{array}{l}\text { Eulogy (three - fourths } \\
\text { mile north). }\end{array}$ & 460 & & 10 & Flows. & \\
\hline $\begin{array}{l}\text { Dulogy (one-fourth mile } \\
\text { west). }\end{array}$ & 430 & & 68 & Flows. & Do. \\
\hline owler ( $1 \frac{1}{2}$ miles north). & 735 & & 123 & Flows. & Do. \\
\hline rimball ............... & $550-630$ & & & Flows. & Several.wells. \\
\hline Kimball ( 6 miles west).. & 564 & & 60 & +20 & Soft water. \\
\hline Kopperl …........ & 400 & & $800^{\frac{1}{9}}$ & Flows. & \\
\hline $\begin{array}{l}\text { Kopperl (three-fourths } \\
\text { mile east). }\end{array}$ & 600 & & & Flows. & Do. \\
\hline Kopperl $\ldots$ opperl $(3 i$ miles west) & $\begin{array}{l}625 \\
609\end{array}$ & & 150 & Flows. & Slightly brackish. \\
\hline Kopperl $\ldots \ldots \ldots \ldots \ldots \ldots$ & 525 & & 200 & Flows. & \\
\hline 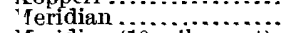 & $450-580$ & & $25-45$ & Flows. & Several wells; soft water. \\
\hline Teridian ( 10 miles east) & 850 & & 16 & Flows: & 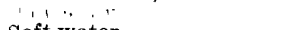 \\
\hline $\begin{array}{l}\text { Teridian }(12 \text { miles east }) \text {. } \\
\text { Jorgan } 1 . \ldots \ldots \ldots \ldots \ldots \ldots \ldots\end{array}$ & $\begin{array}{r}875 \\
600\end{array}$ & & jö & Flows & $\begin{array}{l}\text { Soft water. } \\
\text { Do. }\end{array}$ \\
\hline Do & $580-620$ & & $20-150$ & Flow: & 'Several wells; soft water. \\
\hline Forgan (1 mile south- & 575 & & 170 & Flows. & Soft water. \\
\hline $\begin{array}{l}\text { east) } \\
\text { Iorgan } . . . \ldots \ldots \ldots \ldots \ldots \ldots\end{array}$ & 800 & & 50 & Flows. & \\
\hline Torgan ( 5 miles east) & 780 & & 40 & Flows. & \\
\hline $\begin{array}{l}\text { Torgan (12 miles east) .- } \\
\text { Torse (4 miles south- }\end{array}$ & 501 & 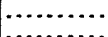 & 100 & Flows. & \\
\hline $\begin{array}{l}\text { Torse ( } \\
\text { west) }\end{array}$ & 622 & & $\cdots$ & No flow. & Do. \\
\hline 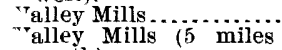 & 805 & & & Flows. & Do \\
\hline $\begin{array}{l}\text { alley Mils (b mules } \\
\text { north). } \\
\text { alley Mills ( } 1 \text { mile }\end{array}$ & 870 & & & Flows. & Do. \\
\hline "alley Mills (1 mile & 706 & & & Flows. & \\
\hline $\begin{array}{l}\text { glley Mills (5 miles } \\
\text { north) }\end{array}$ & 877 & & & Flows. & Do. \\
\hline $\begin{array}{l}\text { "e County: } \\
\text { ?ekalb (13 miles north }\end{array}$ & 425 & 2 & & -2 & Ahendined \\
\hline $\begin{array}{l}\text { of, at mouth of Mill } \\
\text { Creek). }\end{array}$ & +20 & & & & ADandonea. \\
\hline$\nabla^{\top} \mathrm{ew}$ Boston ................ & 1,200 & & & -75 & \\
\hline Do $\ldots \ldots \ldots \ldots \ldots$ & 536 & $3 \frac{3}{4}$ & $\cdots$ & $\cdots \cdots$ & Salt water at 500 feet. \\
\hline $\begin{array}{l}\text { Do } \ldots \ldots \ldots \\
\text { Do } \ldots \ldots \ldots\end{array}$ & 1,200 & $\ddot{5}$ & & $\begin{array}{l}-20 \\
-60\end{array}$ & Salty water; used for stock. \\
\hline roria County: & & & & & \\
\hline$\therefore \operatorname{lvin} \ldots$ & $\begin{array}{l}550 \\
502\end{array}$ & 2 & 70 & & \\
\hline $\begin{array}{l}\text { lvin (4 miles north) } \ldots \\
\text { ngleton }{ }^{2} . \ldots \ldots \ldots \ldots \ldots\end{array}$ & $600-1,500$ & $\mathbf{2}$ & 70 & & \\
\hline Columbia ( 2 mileswest) ${ }^{3}$ & 600 & & & & $\begin{array}{l}\text { Strong pressure of gas at } \\
600 \text { feet: large flow of } \\
\text { water with small quen- } \\
\text { tities of oil. }\end{array}$ \\
\hline Tamon (northwest of $)^{4}$. & 1,160 & & & & $\begin{array}{l}\text { Herndon well; rock salt } \\
\text { from } 587 \text { to } 1,160 \text { fest; } \\
\text { considerable quantites } \\
\text { of sulphur water; no } \\
\text { traces of oil. } \\
\text { Well No. } 1 \text { of the } \mathrm{J} . \mathrm{M} \text {. }\end{array}$ \\
\hline amon (southwest of) 4 .. & 1,230 & & & & Damond Mound oil and \\
\hline & & & & & $\begin{array}{l}\text { Pipe Line Company's } \\
\text { well. }\end{array}$ \\
\hline rlintana ........ & 650 & & & & \\
\hline Iandy Point..... & 1,500 & & & & $\begin{array}{l}\text { Prospect for oil; artesian } \\
\text { water stratum at } 1,000 \\
\text { feet. }\end{array}$ \\
\hline$\therefore$ rfside. & 1,070 & 4 & 215 & Flows. & \\
\hline $\begin{array}{l}\text { Do... } \\
\text { elasco.. }\end{array}$ & $\begin{array}{l}1,000 \\
1,100\end{array}$ & $\ddot{8}$ & 694 & Flows. & \\
\hline
\end{tabular}

ecord, 51st Cong., 1st sess., Senate Ex. Doc. .22, p. 269.

S. Geol. Surv. Bull. No. 212, p. 41.
3 Record, ibid., p. 40. 4 Ibid., pp. 37-39.
Temp., $84^{\circ}$; soft water.

Do.

Temp., $70^{\circ}$.

Soft water.

Do.

Do.

Deral.wells.

Do.

Slightly brackish.

Several wells; soft water. Soft water.

Several wells; soft water. Soft water.

Do.

Do. Herndon well; rock salt fom 58 t to 1,160 fest races of oil

Well No. 1 of the J. M. . well Line Company's

Prospect for oil; artesian water stratum at 1,000 feet. 
TEXAS-Continued.

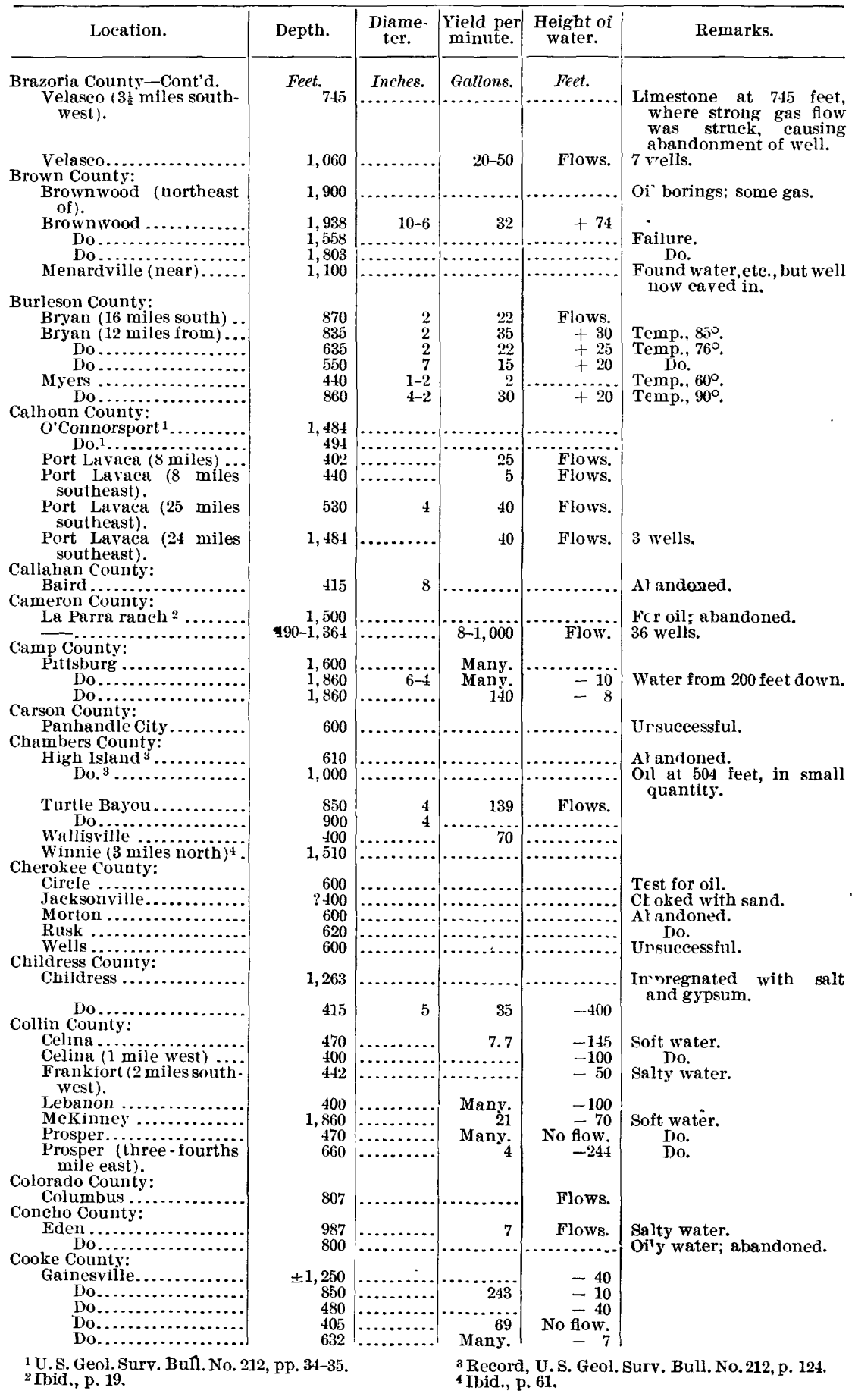


TEXAS-Continued.

\begin{tabular}{|c|c|c|c|c|c|}
\hline Location. & Depth. & $\begin{array}{l}\text { Diame- } \\
\text { ter. }\end{array}$ & $\begin{array}{l}\text { Yield per } \\
\text { minute. }\end{array}$ & $\begin{array}{l}\text { Height of } \\
\text { water. }\end{array}$ & Remarks. \\
\hline $\begin{array}{c}\text { Cooke County-Continued. } \\
\text { Gainesville } . . . \ldots \ldots \ldots \ldots . .\end{array}$ & Feet. 700 & & Gallons. & $\begin{array}{l}\text { Feet. } \\
-30\end{array}$ & \\
\hline Do...................... & 850 & & & & \\
\hline Hemming $\ldots \ldots \ldots \ldots$ & 426 & & 100 & Flows. & Soft water. \\
\hline $\begin{array}{l}\text { Pilotpoint ( } 8 \text { miles north- } \\
\text { west). }\end{array}$ & 426 & & 1 & .......... & Do. \\
\hline Coryell County: & & & & & \\
\hline $\begin{array}{l}\text { Coperas Cove. } \\
\text { Coperas Cove miles }\end{array}$ & $\begin{array}{r}1,865 \\
500\end{array}$ & & Many. & $\begin{array}{l}-100 \\
\text { No flow. }\end{array}$ & $\begin{array}{l}\text { Brackish water. } \\
\text { Salty water. }\end{array}$ \\
\hline $\begin{array}{l}\text { north) } \\
\text { Coperas Cove............. }\end{array}$ & 1,875 & & many. & -475 & \\
\hline Coryell ( 3 miles east) ..... & 940 & & Many. & -50 & Soft water. \\
\hline $\begin{array}{c}\text { Gatesville } \ldots \ldots \ldots \ldots \\
\text { Do } \ldots \ldots \ldots \ldots\end{array}$ & $\begin{array}{r}500-550 \\
700\end{array}$ & 6 & $\begin{array}{r}2-20 \\
175\end{array}$ & Flow. & Several wells. \\
\hline Do.................. & 475 & & & No flow. & Soft water. \\
\hline Gatesville ( 8 miles west). & 612 & & & & Do. \\
\hline $\begin{array}{l}\text { Gatesville ( } 6 \text { miles south- } \\
\text { east). }\end{array}$ & 558 & & 4 & Flows. & \\
\hline Hurst Lake ................ & 500 & & & & \\
\hline $\begin{array}{l}\text { Mound ( } 2 \text { miles north- } \\
\text { east). }\end{array}$ & 697 & & & -5 & Mineral water. \\
\hline $\begin{array}{l}\text { Oglesby ( } 2 \frac{1}{3} \text { miles north- } \\
\text { west). }\end{array}$ & 500 & & & No flow. & Soft water. \\
\hline Pecangrove ............. & 590 & & & Flows. & \\
\hline $\begin{array}{l}\text { The Grove } \\
\text { Waldo (2 miles south })\end{array}$ & 900 & & $680^{\circ}$ & -13 & \\
\hline $\begin{array}{l}\text { Waldo (2 miles south)... } \\
\text { Dallas County: }\end{array}$ & 423 & & & -85 & Saline water. \\
\hline $\begin{array}{l}\text { Cedar Hill (19 miles } \\
\text { southwest). }\end{array}$ & 750 & & Many. & -300 & Soft water. \\
\hline Dallas (1 mile east) ..... & 850 & & 70 & Flow. & 2 wells. \\
\hline $\begin{array}{l}\text { Dallas (6 miles west- } \\
\text { northwest). }\end{array}$ & +400 & & Many. & Flows. & \\
\hline Dallas............................ & $790-1,000$ & & Many. & Flows. & Numerous wells \\
\hline Do.................... & $\begin{array}{l}718 \\
700\end{array}$ & & $\cdots \cdots$ & Flows. & Much soda in water. \\
\hline Dallas (City Park) ........ & $\begin{array}{l}700 \\
672\end{array}$ & & $\begin{array}{l}12 \\
15\end{array}$ & $\begin{array}{l}\text { Flows. } \\
\text { Flows. }\end{array}$ & \\
\hline 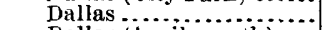 & $\pm 2,500$ & & & & \\
\hline Dallas ( 1 mile south) $\ldots$ & 850 & & & Flow. & 2 wells. \\
\hline $\begin{array}{l}\text { Dallas (6 miles west- } \\
\text { northwest). }\end{array}$ & \pm 400 & & Many. & Flows. & \\
\hline Eagleford ................ & 417 & & 800 & +35 & Soft water. \\
\hline 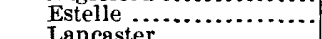 & 970 & & & Flow. & Do. \\
\hline Lancaster $\ldots . . \ldots \ldots \ldots \ldots$ & 1,057 & & & Flows. & Do. \\
\hline $\begin{array}{l}\text { Orphans' Home Station } \\
\text { (2 miles southeast). }\end{array}$ & 685 & & & No flow. & Very salty water. \\
\hline Orphans' Home Station.. & 1,230 & & 20 & -40 & Mineral water. \\
\hline Trinity Mills ( 4 miles & \pm 468 & & & -25 & \\
\hline $\begin{array}{l}\text { east }) . \\
\text { Do. } \ldots \ldots \ldots \ldots \ldots \ldots \ldots\end{array}$ & 415 & & & -25 & \\
\hline Denton County: & & & & & \\
\hline Argyle ( $1 \frac{1}{3}$ miles east) ... & 500 & & & Flows. & Soft water. \\
\hline $\begin{array}{l}\text { Bolivar ........................... } \\
\text { Denton }\end{array}$ & 1,176 & & ... & Flows. & \\
\hline $\begin{array}{r}\text { Denton } \ldots \ldots \ldots \ldots \ldots \ldots \\
\text { Do } \ldots \ldots \ldots \ldots\end{array}$ & $\begin{array}{l}460 \\
550\end{array}$ & 6 & 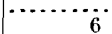 & $\begin{array}{l}+15 \\
+20\end{array}$ & \\
\hline 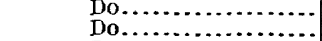 & $\begin{array}{l}500 \\
600\end{array}$ & & Few. & & \\
\hline Do $\ldots \ldots \ldots . . .$. & 620 & & 8 & Flows. & \\
\hline (- & 600 & & & Flows. & \\
\hline a.......... & 606 & & 28 & Flows. & \\
\hline $\begin{array}{l}\text { Do } \\
\text { Krum }\left(2 \frac{1}{2} \text { miles south }\right)\end{array}$ & $\begin{array}{l}592 \\
450\end{array}$ & $6-4$ & 12 & No flow. & \\
\hline Pilotpoint .................. & 937 & & 17 & $\begin{array}{r}10010 \% \\
-25\end{array}$ & Do. \\
\hline Roanoke (west) ........... & 476 & & & -33 & \\
\hline Roanoke ................ & $400-600$ & & $40-50$ & Flows. & Several wells. \\
\hline $\begin{array}{l}\text { Roanoke (one-half mile } \\
\text { south). }\end{array}$ & 505 & & & & \\
\hline Stony ( $1 \frac{1}{2}$ miles south) ... & 447 & & 3 & Flows. & Soft water. \\
\hline $\begin{array}{l}\text { Duval County: } \\
\text { Benavides (near) }{ }^{2} \ldots \ldots . .\end{array}$ & 1,200 & & & & Small quantities of oil at \\
\hline Dimmit Cou & & & & & \\
\hline Carrizo Springs (near) & $400-690$ & $4-10$ & $100-1,400$ & Flows. & Several wells. \\
\hline $\begin{array}{l}\text { Eastland County: } \\
\text { Cisco } \ldots \ldots \ldots \ldots \ldots \ldots\end{array}$ & & & & & \\
\hline $\begin{array}{l}\text { Cisco } \\
\text { Eastland }{ }^{3} \ldots \ldots \\
.\end{array}$ & $\begin{array}{r}1,680 \\
500\end{array}$ & 8 & & -25 & $\begin{array}{l}\text { Salt water. } \\
\text { Abandoned. }\end{array}$ \\
\hline Do..... & 1,300 & 6 & & No flow. & Salt water. \\
\hline Do............... & 400 & & & Flows. & Mineral water. \\
\hline $\begin{array}{l}\text { tor County: } \\
\text { Odessa...... }\end{array}$ & 800 & 8 & & & A hondongd \\
\hline Edwards & 850 & 8 & & & Apandoned. \\
\hline Rocksprings.... & $\begin{array}{l}400 \\
450\end{array}$ & ...... & Many. & No flow. & 2 wells. \\
\hline & & & & No flow. & Do \\
\hline
\end{tabular}

1 Record, 51st Cong., 1st sess., Senate Ex. Doc. No. 222, p. 283 .

2 U. S. Geol. Surv. Bull. No. 212, p. 19.

${ }^{3}$ Record, 51st Cong., 1st sess., Senate Ex. Doc. No. 222 , pp. $268,269$. IRR 149-05-10 
TEXAS-Continued.

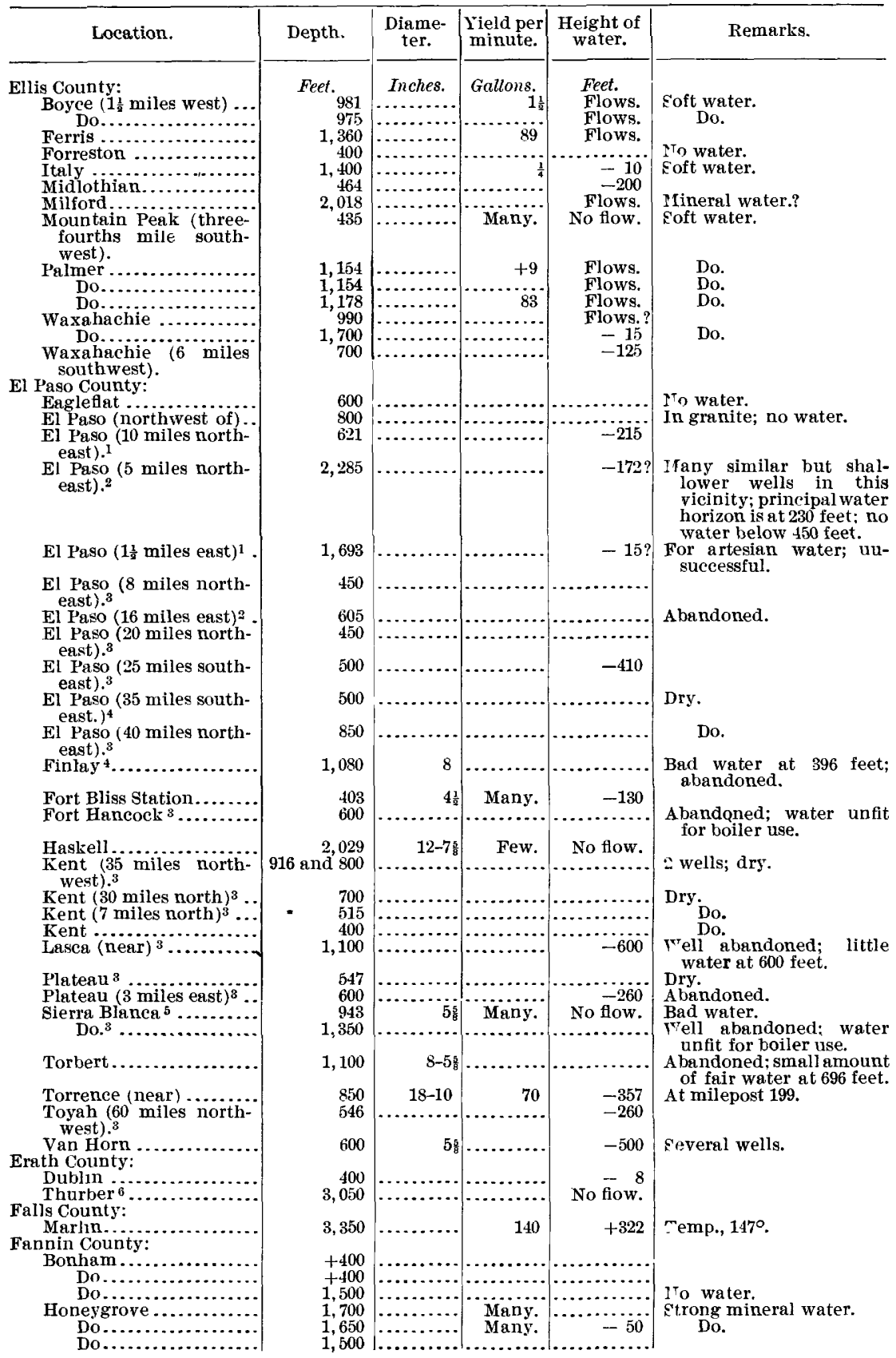

${ }^{1}$ Record, 51st Cong., 1st sess., Senate Ex. Doc. No. 222, p. 297.

2 Record, Texas Univ. Mineral Survey Bull. No. 9,1904 , pp. $96-97$.

3 Texas Unv. Mineral Survey Bull. No. 9, 1904, pp. 109-111.
${ }^{4}$ Analysis, 51st Cong., 1st sess., Senate Ex. Doc. No. 222, p. 272.

${ }^{5}$ Record, ibid., p. 296.

${ }^{6}$ Ibid., p. 270. 
TEXAS-Continued.

\begin{tabular}{|c|c|c|c|c|c|}
\hline Location. & Depth. & $\begin{array}{l}\text { Diame- } \\
\text { ter. }\end{array}$ & $\begin{array}{l}\text { Yield per } \\
\text { minute. }\end{array}$ & $\begin{array}{l}\text { Height of } \\
\text { water. }\end{array}$ & Remarks. \\
\hline 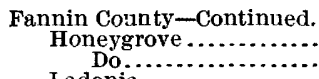 & $\begin{array}{r}\text { Feet. } \\
1,000 \\
1,200\end{array}$ & $\begin{array}{l}\text { Inches. } \\
\text { an. }\end{array}$ & $\begin{array}{l}\text { Gallons. } \\
\text { a.............. }\end{array}$ & $\begin{array}{l}\text { Feet. } \\
\text { No flow. }\end{array}$ & Salty water; not, in use. \\
\hline 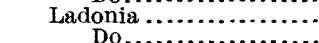 & & & & & \\
\hline $\begin{array}{l}\text { Do } \ldots \ldots \ldots \ldots \ldots \ldots \\
\text { Fort Bend county: }\end{array}$ & 1,033 & & & & Never completeન. \\
\hline 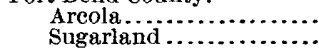 & $\begin{array}{r}+910 \\
600-1,550\end{array}$ & & 300 & Flows. & Severgl wells \\
\hline Do........................ & $\begin{array}{r}1,550 \\
1,500\end{array}$ & $\begin{array}{l}3-4 \\
8-4\end{array}$ & 104 & $\begin{aligned} & +10 w 5 \\
+ & 9\end{aligned}$ & Several wells. \\
\hline $\begin{array}{l}\text { Do........................... } \\
\text { Franklin County: }\end{array}$ & 1,760 & ...... & 7 & Flows. & \\
\hline Mount Vernon..$\ldots \ldots \ldots$ & 400 & & & No flow. & Large supply of water. \\
\hline $\begin{array}{l}\text { Freestone County: } \\
\text { Bonner } \ldots \ldots \ldots \ldots \ldots \ldots\end{array}$ & & & & & Not completed. \\
\hline $\begin{array}{l}\text { Fairfield (8 miles north- } \\
\text { west). }\end{array}$ & 1,350 & & & & \\
\hline $\begin{array}{l}\text { Fairfield (10 miles north- } \\
\text { east). } \\
\text { Worthain ................ }\end{array}$ & 1,200 & & & & $\begin{array}{l}\text { Sulphur water at } 800 \text { feet. } \\
\text { Salt water. }\end{array}$ \\
\hline Frio County: & & & & & \\
\hline $\begin{array}{l}\text { Derby } \\
\text { Pearsall }\end{array}$ & $\begin{array}{l}540 \\
600\end{array}$ & & $\underset{15}{\text { Many. }}$ & Flows. & \\
\hline Do.... & 400 & & 30 & Flows. & \\
\hline Do.... & $\begin{array}{l}650 \\
620\end{array}$ & & 30 & Flows. & . \\
\hline Pearsall (15 miles east).. & & & $\cdots \cdots$ & Flows. & Several wells. \\
\hline $\begin{array}{l}\text { Pearsall (20 miles south- } \\
\text { east). }\end{array}$ & (?) & & & & \\
\hline $\begin{array}{l}\text { Galveston County: } \\
\text { Alta Loma } . . . \ldots \ldots \ldots \ldots\end{array}$ & $875-950$ & 9 & 310 & 22 & $\begin{array}{l}\text { Numerous wells; temp., } \\
75^{\circ}-78^{\circ} \text {. }\end{array}$ \\
\hline Do..... & $726-868$ & $5-7$ & & & 13 wells. \\
\hline Dickinson ${ }^{1} \ldots \ldots \ldots \ldots$ & 600 & 3 & 14 & Flows. & \\
\hline $\begin{array}{l}\text { Do.................... } \\
\text { Dickinson (3 miles west) }\end{array}$ & $\begin{array}{l}624 \\
700\end{array}$ & $\begin{array}{l}3 \\
3\end{array}$ & $\begin{array}{l}40 \\
31.7\end{array}$ & $\begin{array}{l}\text { Flows. } \\
\text { Flows. }\end{array}$ & \\
\hline $\begin{array}{l}\text { Dickinson (one-fourth } \\
\text { mile west). }\end{array}$ & 588 & 1 & (............ & Flows. & \\
\hline Fairwood ${ }^{2} \ldots \ldots \ldots \ldots$ & 575 & 3 & 50 & Flows. & Temp., 7810. \\
\hline Galveston $^{3}$... & 3,070 & $22-6$ & Many. & Flows. & $\begin{array}{l}\text { Brackish water at various } \\
\text { depths to bot }{ }^{+} \text {om. }\end{array}$ \\
\hline Do & $\begin{array}{r}1,346 \\
810-973\end{array}$ & & $\begin{array}{l}400 \\
\text { Many. }\end{array}$ & $\begin{array}{l}\text { Flows. } \\
\text { Flows. }\end{array}$ & $\begin{array}{l}\text { Salty water. } \\
\text { Several wells; water too }\end{array}$ \\
\hline 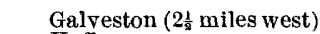 & 1,365 & & 250 & Flows. & $\begin{array}{l}\text { salty. } \\
\text { Temp., } 84^{\circ} \text {. }\end{array}$ \\
\hline Heffron.................. & 480 & 3 & 52 & +16 & Temp., $60^{\circ} \pm$. \\
\hline Hitcheock 4 ............. & 726 & & 66 & Flows. & $\begin{array}{l}\text { Temp., } 77^{\circ} \text {; many wells in } \\
\text { vicinity. }\end{array}$ \\
\hline $\begin{array}{l}\text { Hiteheock ( } 1 \frac{1}{9} \text { mil es } \\
\text { northwest). }\end{array}$ & 710 & & 100 & Flows. & Temp., $77^{\circ}$ \\
\hline Do.................... & 768 & & 48 & Flows. & Temp., $78^{\circ}$. \\
\hline $\begin{array}{l}\text { Hitchcock } \\
\text { League Cit }\end{array}$ & $700-750$ & $3-4 \frac{1}{2}$ & $20-75$ & Flows. & \\
\hline North Galveston ........... & $\begin{array}{r}410-750 \\
575-1,590\end{array}$ & $\dddot{3}$ & 70 each. & Flows. & $\begin{array}{l}6 \text { wells. } \\
\text { Several wells. }\end{array}$ \\
\hline Texas City .............. & 725 & & +104 & +16 & \\
\hline Do $\ldots \ldots \ldots \ldots \ldots \ldots$ & 900 & & +104 & +16 & \\
\hline $\begin{array}{l}\text { Gillespie Count } \\
\text { Morris Ran }\end{array}$ & $1100+2>$ & & & -55 & \\
\hline Grayson Cou & 1,100 & & & $-\infty 0$ & . \\
\hline Denison (1 mile south) ${ }^{6}$ & 1,800 & $2 \frac{1}{2}$ & & & Abandoned. \\
\hline Pottsbore ( 7 miles west). & \pm 500 & & Many. & Flows. & Pure water. \\
\hline Sherman ................... & 632 & & & c........ & Fine water. \\
\hline Do...................... & 915 & & & $\cdots \ldots \ldots \ldots$ & \\
\hline $\begin{array}{l}\text { Do... } \\
\text { Do... }\end{array}$ & $\begin{array}{r}2,500 \\
660\end{array}$ & (n....... & $\begin{array}{l}\text { Many. } \\
\ldots . . . . . .\end{array}$ & $\begin{array}{r}-40 \\
\ldots \ldots \ldots\end{array}$ & Several wells. \\
\hline Sherman (18miles north) & 480 & & (n) & No flow. & \\
\hline Whitesboro..... & +800 & & $\ldots \ldots \ldots$ & No flow. & \\
\hline $\begin{array}{l}\text { Gregg County: } \\
\text { Long view ...... }\end{array}$ & 500 & & 80 & & Lignitic. \\
\hline Grimes County: & & & & & \\
\hline Navasota $7 \ldots \ldots \ldots \ldots$ & 830 & & & To surface. & \\
\hline $\begin{array}{l}\text { Navasota (16 miles north) } \\
\text { Guadalupe county: }\end{array}$ & 999 & & Many. & Flows. & \\
\hline $\begin{array}{l}\text { Guadarupe conthy: } \\
\text { Davenport...... }\end{array}$ & 810 & & & -180 & Good water. \\
\hline $\begin{array}{l}\text { Hall County: } \\
\text { Newlin Station }\end{array}$ & 550 & 6 & & & $\begin{array}{l}4 \text { layers of salt water; } \\
\text { abandoned. }\end{array}$ \\
\hline
\end{tabular}

1 Analysis, Texas Geol. Surv. 4th Ann. Rept., 1892, p. 104 .

I Ibld., p. 102.

3 Record, etc., ibid., pp. 87-101: U. S. Geol. Surv., 21st Ann. Rept., 1899-1900, part 7, pp. $402-$ 406.
4 Analysis, etc., ibid., pp. 102-103.

5 Record, U. S. Geol. Snrv., 18th Ann. Rept. 1896-97, part 2 , p. 272 .

${ }^{6}$ Ibid., 21st Anu. Rept., 1899-1900, part 7, p. 197.

7 Record, 5lst Cong., 1st sess., Senate Ex. Doc. No. 222, p. 265 . 
TEXAS-Continued.

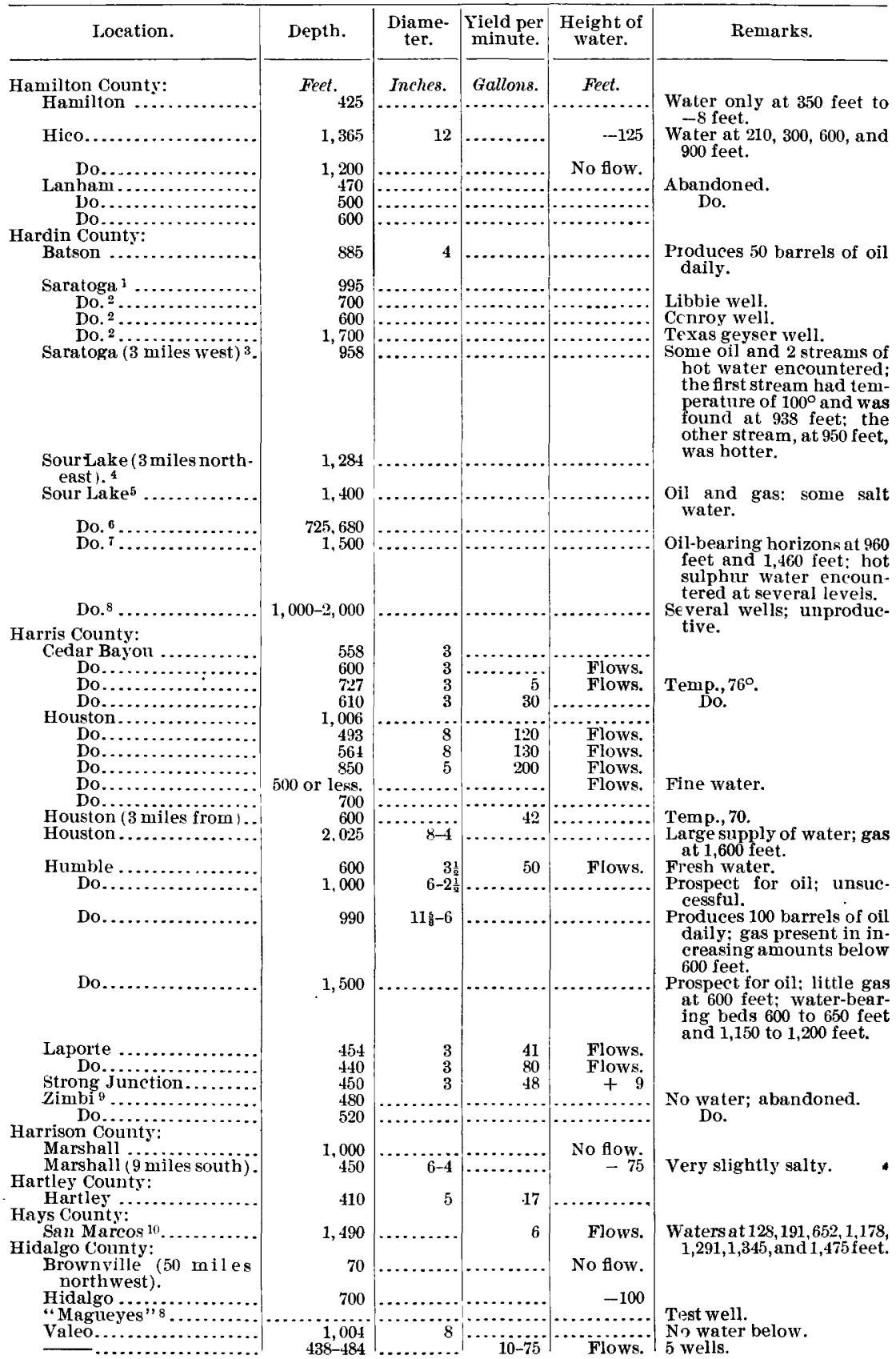

1 Record, U.S.Geol.Surv. Bull.No.212,pp.120-121. 2 U.S. Geol. Sury. Bull. No. 212, p. 121 3 Record, bid., p. 59 . 4 Ibid., p. 60.

5 Partial record, ibid., p. 116

${ }^{6}$ Record, ibid., p. 117.
IU. S. Geol. Surv, Bull. No. 212, pp. 117-118.

8 Ibid., p. 118.

${ }^{9}$ Record, etc., Texas Geol. Surv. 4th Ann. Rept., 1892, p. 107.

10 Record, U. S. Geol. Surv., 18th Ann. Rept., $1896-97$, pp. $287-290$. 
TEXAS-Continued.

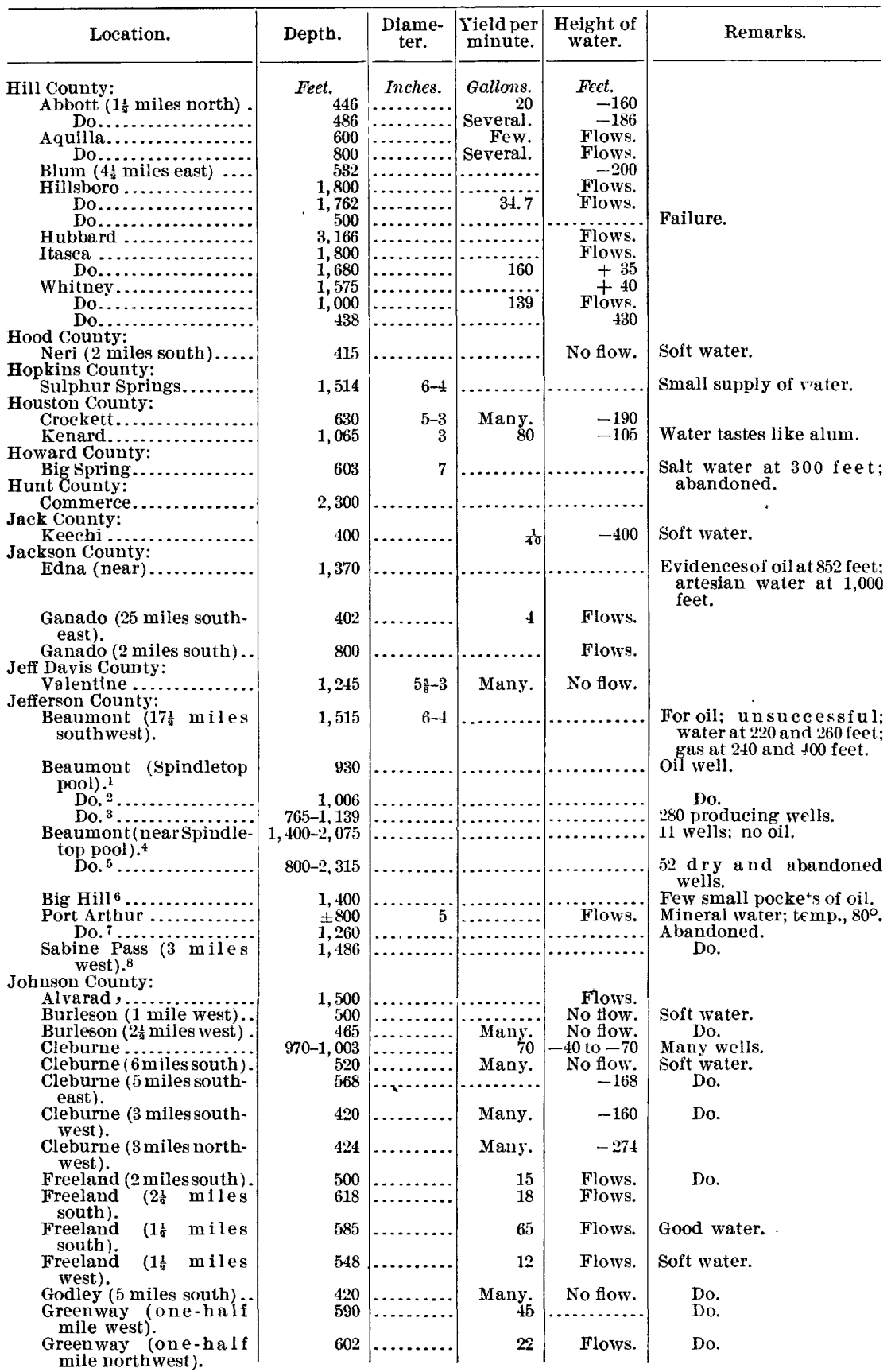

1 Record, U. S. Geol. Surv. Bull. No. 212, pp. 74-75. 2 Ibid., pp. 76-77.

3 U. S.'Geol. Surv. Bull. No. 212, pp. 77-85.

4 Record, ibid., pp. 88-102.

5 U. S. Geol. Surv. Bull. No. 212, pp. 103-104.

6 Ibid., p. 126.

? Record, jbid., p. 112.

8 Ibid., p. 113. 
TEXAS-Continued.

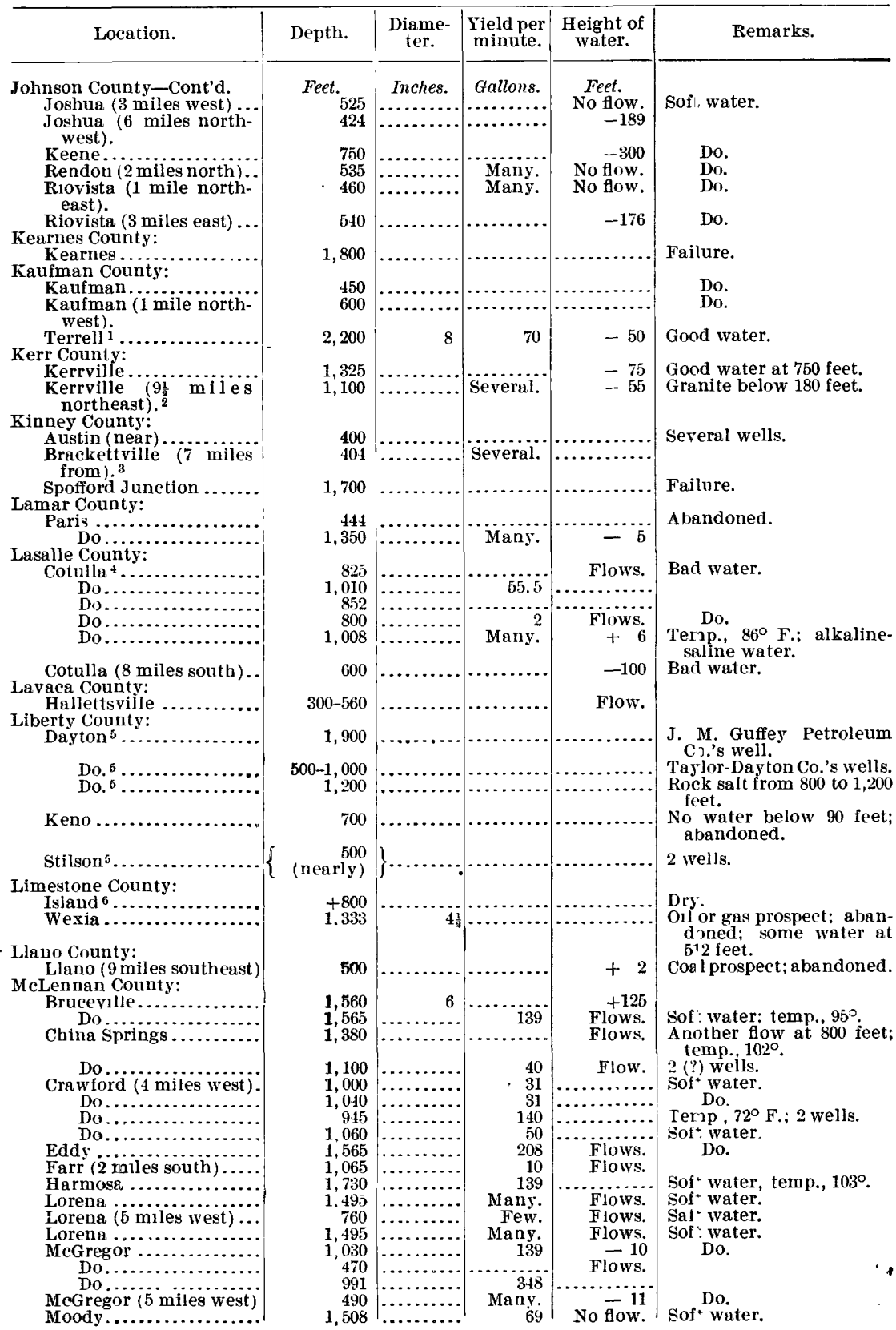

1 Record, Artesian waters in Texas west of 97 th meridian, by R. T. Hill. 52 Cong., 1st sess., Senate Ex. Doc. No. 41, part 3, p. 99. Anotber authority gives ' 2,700 feet as depth

2U. S. Geol. Surv,, 18th Ann. Rept., 1896-97. part 2, p. 271 .
${ }^{3}$ Record, ibid., p. 278.

4 Texas Geol. Surv. 2d Ann. Rept., 1891, p. 71; analysis, 51st Cong., 1st sess., Senate Ex. Doc. No. 222 , p. 272.

5 Record, U. S. Geol. Surv. Bull. No. 212, pp. 4o'-47. 6 U. S. Geol. Surv. Bull. NTo. 212, p. 24. 
TEXAs-Continued.

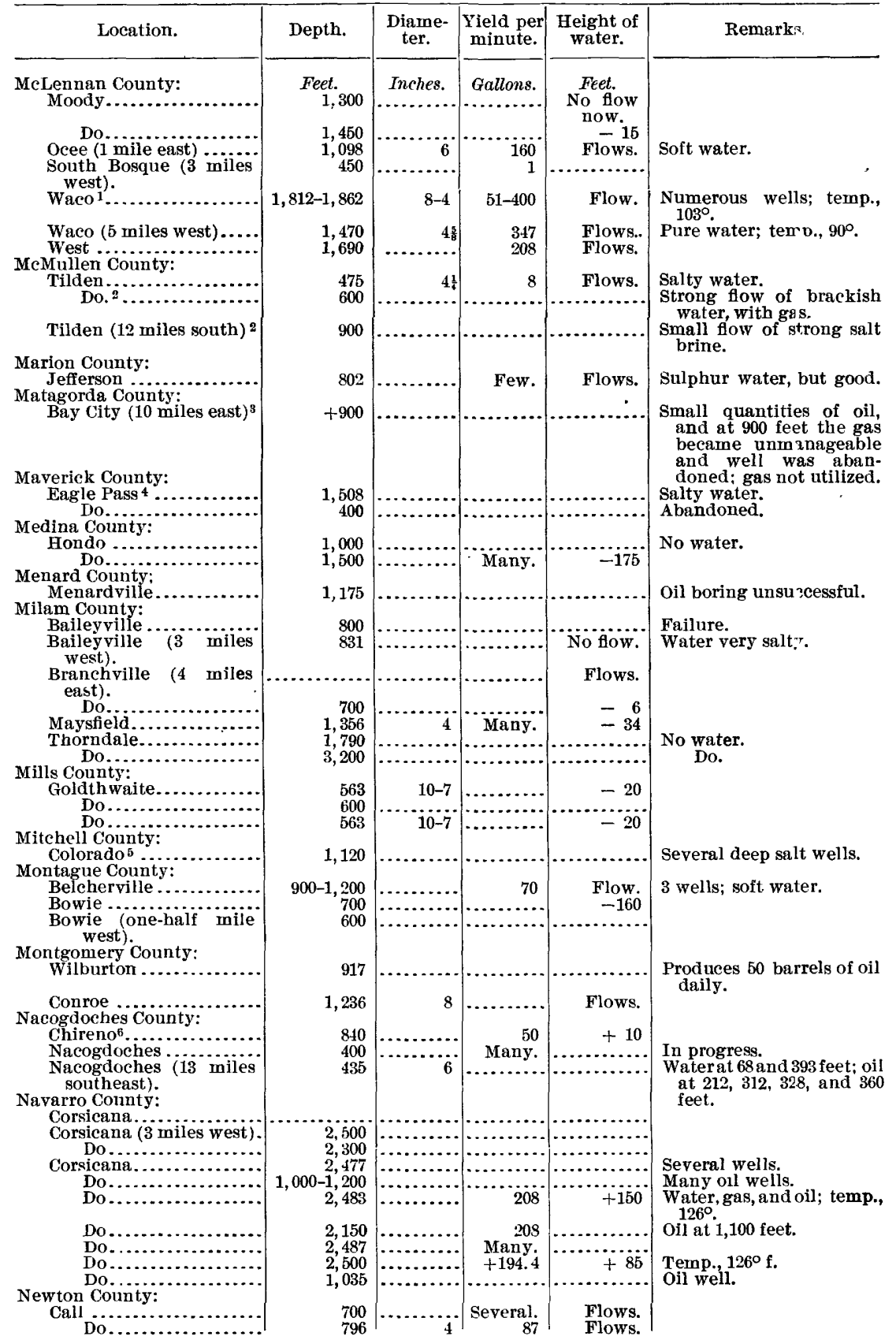

1 Record, 51st Cong., 1st sess., Senate Ex. Doc. No. 222, pp. 265, 269; analysis, p. 271 .

2 U. S. Geol. Surv. Bull. No. 212, p. 18.

3 Ibid., p. 127.
4 Record, 51st Cong., 1st sess., Senati Ex. Doc. No. $222, p, 266$.

5 Record, U.S. Geol. Surv., 18th Ann. Fept., 189697, part 2, p. 265

6 Record, La.Geol. Surv. Rept., 1902, p. 126. 
TEXAS-Continued.

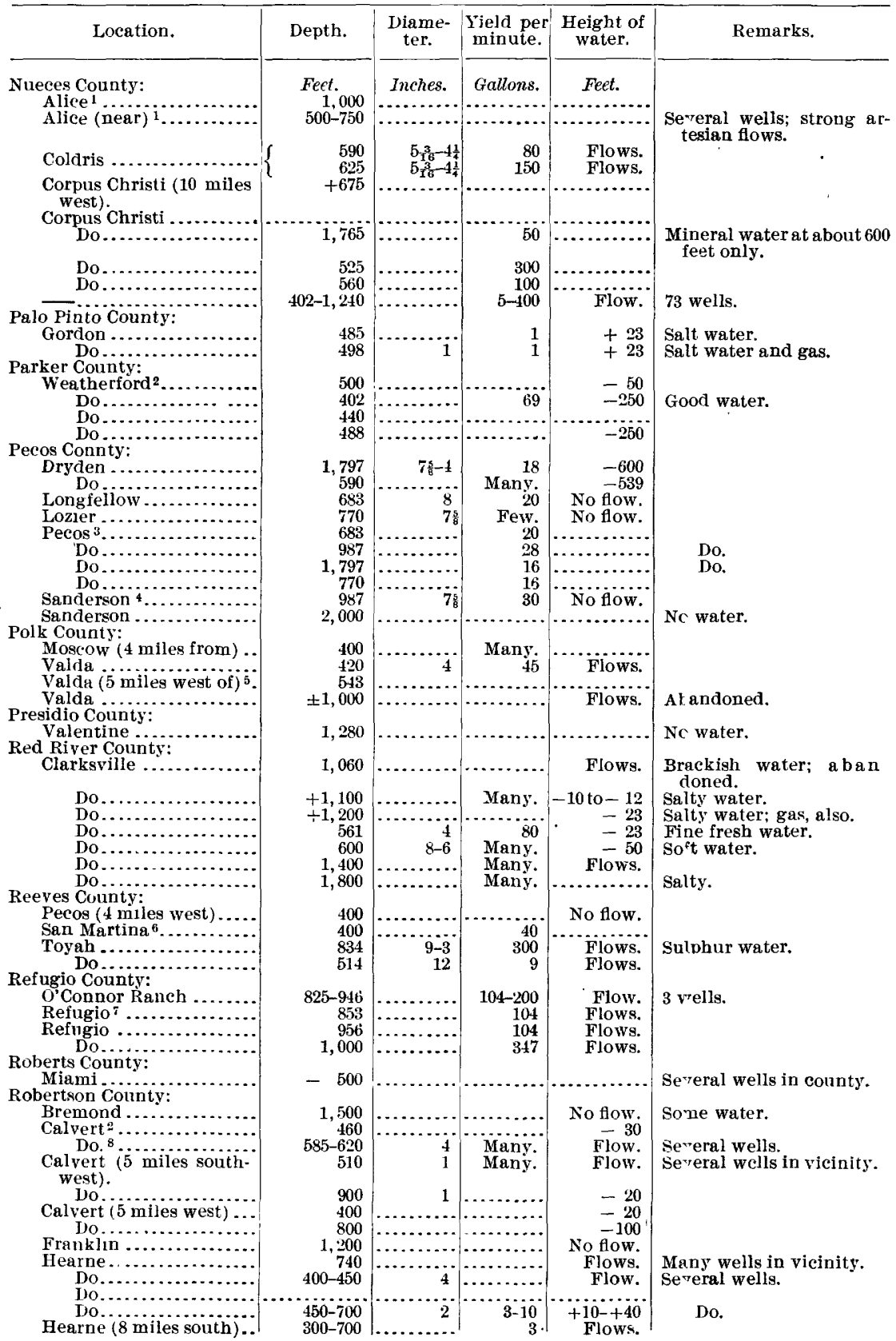

1 U. S. Geol. Surv. Bull. No. 212, p. 18.

${ }^{2}$ Record, 51st Cong., 1st sess., Senate Ex. Doc. No. 222 , p. 266 .

3 Record, etc., U.8. Geol. Surv., 18th Ann. Rept. 1896-97, part 2, p. 267.

4 Ibid., p. 274

b Record, U. S. Geol. Surv. Bull. No. 212, p. 54.
6 Texas Univ. Mineral survey Bull. No. 9, 1904, pp, 109-111.

${ }^{7}$ Record, 51st Cong., 1st sess., Senate Ex. Doc. No. 2222 , pp. $266-267$.

$\checkmark$ Record, Texas Geol. Surv., 4th Ann. Rept. 1892, p. 109 
TEXAS-Continued.

\begin{tabular}{|c|c|c|c|c|c|}
\hline Location. & Depth. & $\begin{array}{l}\text { Diame- } \\
\text { ter. }\end{array}$ & $\begin{array}{c}\text { Yield per } \\
\text { minute. }\end{array}$ & $\begin{array}{l}\text { Height of } \\
\text { water. }\end{array}$ & Remarkฯ. \\
\hline $\begin{array}{l}\text { Robertaon County-Cont'd. } \\
\text { Hearne (12 miles north- } \\
\text { west). }\end{array}$ & $\begin{array}{l}\text { Feet. } \\
\text { s00-700 }\end{array}$ & ches. & $\underset{3}{\text { Gallons. }}$ & $\begin{array}{l}\text { Feet. } \\
\text { Flows. }\end{array}$ & 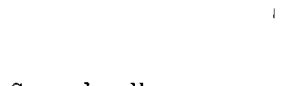 \\
\hline $\begin{array}{l}\text { Mumford ..................... } \\
\text { San Augustine County: }\end{array}$ & $300-1,000$ & & $2-12$ & n.......... & Several wells. \\
\hline $\begin{array}{l}\text { San Augustine ( } 6 \text { miles } \\
\text { south). }\end{array}$ & 415 & 6 & Few. & +30 & Good water. \\
\hline $\begin{array}{l}\text { San Augustine (2 miles } \\
\text { west). }\end{array}$ & 700 & & Many. & Flows. & Oil test well. \\
\hline $\begin{array}{l}\text { San Patricio County: } \\
\text { Sinton } . . . \ldots \ldots \ldots \ldots \ldots\end{array}$ & 983 & & 60 & Flows. & \\
\hline $\begin{array}{l}\text { Sabine County: } \\
\text { Hemphill ( } 15 \text { miles east- } \\
\text { southeast of }) \text {. }\end{array}$ & 1,975 & $10-6$ & & Flows. & $\begin{array}{l}\text { Artesian water } \varepsilon . t 1,030 \text { and } \\
1,215 \text { feet; oil well in } \\
\text { progress. }\end{array}$ \\
\hline $\begin{array}{l}\text { Shackelford County: } \\
\text { Albany .................. } \\
\text { Shelby County: }\end{array}$ & 400 & & Few. & 80 & \\
\hline $\begin{array}{l}\text { Timpson } \\
\text { Smith County: }\end{array}$ & 900 & & & -80 & . \\
\hline 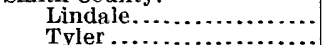 & +500 & 4 & 3 & +10 & \\
\hline 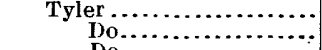 & $\begin{array}{l}1,150 \\
1,207\end{array}$ & & & -100 & In progress, $190^{\prime}$. \\
\hline $\begin{array}{r}\text { Do............................ } \\
\text { Starr County: }\end{array}$ & +500 & & Many. & ........... & \\
\hline & $526-800$ & & $15-250$ & Flow. & 7 wells. \\
\hline Breckenridge & 1,400 & & & & Failure. \\
\hline $\begin{array}{l}\text { Sutton County: } \\
\text { Sonora }\end{array}$ & & & & & \\
\hline 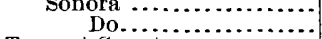 & $\begin{array}{l}480 \\
800\end{array}$ & & & & $\begin{array}{l}\text { Several wells. } \\
\text { Oil. }\end{array}$ \\
\hline $\begin{array}{l}\text { Tarrant County: } \\
\text { Arlington }\end{array}$ & 1,480 & & 21 & & Strong mineral water. \\
\hline Bedford $(2$ miles south $\}$ & 1, $602 \frac{1}{2}$ & & & Flows. & Soft water. \\
\hline Birdville $\ldots \ldots \ldots \ldots \ldots$ & 406 & & $\cdots$ & No flow. & Do. \\
\hline $\begin{array}{l}\text { Birdville ( } 1 \text { mile north) } \\
\text { Birdville (one-half mile }\end{array}$ & $\begin{array}{l}486 \\
420\end{array}$ & & Many. & $\begin{array}{r}-20 \\
\text { Flowed }\end{array}$ & Do. \\
\hline 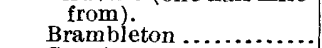 & 485 & & & $\begin{array}{l}\text { once. } \\
-130\end{array}$ & Do. \\
\hline Crowley ................. & 486 & & 3 & No flow. & Do. \\
\hline $\begin{array}{l}\text { Crowley ( } 3 \text { miles north- } \\
\text { west). }\end{array}$ & 446 & & & -150 & Do. \\
\hline $\begin{array}{l}\text { Crowley ( } 7 \text { miles south- } \\
\text { west). }\end{array}$ & 430 & & & No flow. & Do. \\
\hline Crowley ( 2 miles from)... & 484 & 2 & & -134 & Do. \\
\hline Enon $\ldots \ldots \ldots \ldots \ldots \ldots$ & 442 & & .......... & -142 & \\
\hline $\begin{array}{l}\text { Enon (1 mile west) ....... } \\
\text { Enon ( } 3 \text { milesnortheast). }\end{array}$ & $\begin{array}{l}430 \\
460\end{array}$ & & $\begin{array}{r}5 \\
\text { Many. }\end{array}$ & $\begin{array}{l}-60 \\
-90\end{array}$ & Do. \\
\hline Fort Worth 1 ................. & & & & & \\
\hline Do.................. & 484 & $\cdots \ldots$ & (n) & -50 & \\
\hline 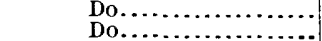 & $\begin{array}{l}450 \\
465\end{array}$ & & 30 & Fjows. & \\
\hline Do.................... & $950-1,400$ & $10-4$ & 140 & Flow. & Several wells. \\
\hline Do.................. & 4,000 & & -.............. & ........... & No flow below 1,200 feet: \\
\hline Do $\ldots \ldots \ldots \ldots \ldots$ & 760 & & & Flows. & \\
\hline $\begin{array}{l}\text { Fort Worth ( } 3 \mathrm{miles} \\
\text { north). }\end{array}$ & 1,200 & & & & \\
\hline $\begin{array}{l}\text { Fort Worth (10 miles } \\
\text { east). }\end{array}$ & 480 & $4 \frac{1}{2}$ & +208 & 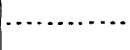 & \\
\hline $\begin{array}{l}\text { Fort Worth (12 miles } \\
\text { southeast). }\end{array}$ & 534 & & & -450 & \\
\hline $\begin{array}{l}\text { Fort Worth } \\
\text { south }) .2\end{array}$ & +400 & & & & \\
\hline Grapevine $. . . \ldots \ldots \ldots . .$. & 423 & & & No flow. & Soft water. \\
\hline $\begin{array}{l}\text { Handley } \\
\text { Haslett }(1 \text { mile south }) . .\end{array}$ & $\begin{array}{l}509 \\
430\end{array}$ & & & $\begin{array}{l}-25 \\
-255\end{array}$ & $\begin{array}{l}\text { Do. } \\
\text { Do. }\end{array}$ \\
\hline $\begin{array}{l}\text { Haslett ( } 3 \text { miles south- } \\
\text { east). }\end{array}$ & 480 & & 3 & -258 & \\
\hline 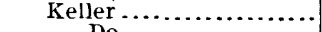 & 400 & & & & - \\
\hline 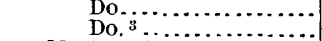 & $\begin{array}{l}457 \\
430\end{array}$ & & 50 & -50 & \\
\hline $\begin{array}{l}\text { Marine (one-half mile } \\
\text { northeast). }\end{array}$ & 1,200 & & 545 & Flows. & Temp., $78^{\circ}$; sof $!$ water. \\
\hline Oak Grove (1 mile south). & 500 & & $3 \frac{1}{4}$ & -72 & Soft water. \\
\hline $\begin{array}{l}\text { Randol ( } 1 \text { mile north- } \\
\text { east). }\end{array}$ & 546 & & & -10 & Sulphur water. \\
\hline $\begin{array}{l}\text { Randol (one-half mile } \\
\text { southwest). }\end{array}$ & 525 & .... & 156 & Flows. & \\
\hline
\end{tabular}

1 Record, Artesian waters of Texas west of $97 \mathrm{th}$ meridian, by R. T. Hill: $52 \mathrm{~d}$ Cong., 1 st sess, Benate Ex. Doc. No. 41, part 3, pp. 105-106.

- FIfty-first Cong., Ist sess., Senate Ex. Doc. No. 222 , p. 270 .
3 Record, Artesian waters of Texas west of 97 th meridian. by R. T. HJIl: 52d Cong., 1st sess., Senute Ex. Doc. No. 41 , part 3, p. 104. 
TEXAS-Continued.

\begin{tabular}{|c|c|c|c|c|c|}
\hline Location. & Depth. & $\begin{array}{l}\text { Diame- } \\
\text { ter. }\end{array}$ & $\begin{array}{l}\text { Yield per } \\
\text { minute. }\end{array}$ & $\begin{array}{l}\text { Height of } \\
\text { water. }\end{array}$ & Remarks. \\
\hline $\begin{array}{l}\text { Tarrant County-Continued. } \\
\text { Randol (3 miles south- }\end{array}$ & Feet. ${ }_{420}$ & Inches. & Gallons. & $\begin{array}{l}\text { Feet. } \\
\text { Flows. }\end{array}$ & Sof; water. \\
\hline $\begin{array}{l}\text { west). } \\
\text { Randol (one-half mile }\end{array}$ & & & & & \\
\hline $\begin{array}{l}\text { Randol (one-half mile } \\
\text { north). }\end{array}$ & 505 & 4 & & Flows. & Do. \\
\hline Timber ..................... & 576 & & $2 \frac{1}{2}$ & & Sal $y$ water. \\
\hline $\begin{array}{l}\text { Webb.............................. } \\
\text { Taylor County: }\end{array}$ & 800 & & & -160 & Poor water. \\
\hline 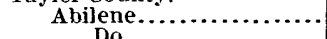 & 2,500 & & & & \\
\hline $\begin{array}{r}\text { Do } \ldots \ldots \ldots \ldots \ldots \ldots \\
\text { Merkel } \ldots \ldots \ldots \ldots\end{array}$ & $\begin{array}{r}2,223 \\
+2,000\end{array}$ & & & (n) & \\
\hline Tom Green County: & & & & & \\
\hline $\begin{array}{l}\text { San Angelo....... } \\
\text { Travis County: }\end{array}$ & 960 & & & & \\
\hline $\begin{array}{l}\text { Travis County: } \\
\text { Austin (Fifth and Ja- }\end{array}$ & 2,020 & & 175 & Flows & \\
\hline & & & 180 & Flows. & \\
\hline $\begin{array}{l}\text { Austin (asylum) ............ } \\
\text { Austin (poorhouse) ...... }\end{array}$ & $\begin{array}{l}1,280 \\
1,300\end{array}$ & & & No flow & \\
\hline Austin ..................... & 471 & $\cdots$ & $\begin{array}{l}0 \\
5\end{array}$ & $\begin{array}{l}\text { No How. } \\
\text { n............. }\end{array}$ & \\
\hline Do................ & 1,450 & & 5 & & \\
\hline$\underset{\text { street). }}{\text { Austin }}$ (East Fif th & 700 & & 14 & Flows. & $\begin{array}{l}\text { In progress 1897; sulphur } \\
\text { water. }\end{array}$ \\
\hline Austin (natatorium) ${ }^{2} \ldots$ & 2,025 & $\begin{array}{c}10-8 \text { and } \\
7-6 \text {. }\end{array}$ & 175 & Flows. & $\begin{array}{l}\text { Main flow at } 1,875 \text { feet; } \\
\text { temp., } 100^{\circ} \text {. }\end{array}$ \\
\hline Austin (asylum) ${ }^{3} \ldots \ldots$. & 1,975 & & +104 & +40 & \\
\hline $\begin{array}{c}\text { Austin }{ }^{3} \ldots \ldots \ldots \\
\text { Do............. }\end{array}$ & $\begin{array}{l}2,053 \\
1,280\end{array}$ & & & -5 & \\
\hline Manor ${ }^{4} \ldots \ldots \ldots \ldots$ & 2,220 & 6 & 69 & +30 & Temp., $93^{\circ}$. \\
\hline Roundrock...$\ldots \ldots \ldots \ldots$ & 400 & & 1 & No flow. & \\
\hline $\begin{array}{l}\text { Walters..................... } \\
\text { Trinity County: }\end{array}$ & 700 & & & ................. & \\
\hline Trinity $\ldots \ldots \ldots \ldots \ldots$ & +900 & & Few. & & Sal'y, sulphur water. \\
\hline $\begin{array}{l}\text { Tyler County; } \\
\text { Kountze (15 miles west). }\end{array}$ & 1,737 & $6-4$ & & & Dr: hole. \\
\hline$-^{5}, \ldots \ldots \ldots \ldots \ldots$ & 824 & & & & $\begin{array}{l}2 \text { miles from Neches River, } \\
\text { between Rush and Wolf } \\
\text { creeks. }\end{array}$ \\
\hline $\begin{array}{l}\text { Uvalde County: } \\
\text { Sabinal........ }\end{array}$ & & & & & \\
\hline $\begin{array}{l}\text { Sabinal } \ldots \ldots \ldots \\
\text { Uvalde } \ldots \ldots \ldots\end{array}$ & 529 & & & & \\
\hline $\begin{array}{r}\text { Do } \\
\text { Yalyerde County }\end{array}$ & 1,000 & & Few. & No flow. & - \\
\hline $\begin{array}{l}\text { Valverde county: } \\
\text { Comstock }\end{array}$ & & & & & \\
\hline $\begin{array}{c}\text { Comstock } \\
\text { from }) .6\end{array} \quad(20$ miles & 569 & & & & \\
\hline Del Rio ${ }^{7} \ldots \ldots \ldots \ldots \ldots$ & 760 & & & -60 & Mineral waters. \\
\hline Del Rio ( 30 miles north). & 475 & & * & -300 & \\
\hline $\begin{array}{l}\text { Del Rio (3 miles south).. } \\
\text { Van Zandt County: }\end{array}$ & 460 & & & Flows. & Sulphur water. \\
\hline $\begin{array}{l}\text { Van Zandt County: } \\
\text { Myrtle Springs ............ }\end{array}$ & 650 & & & & Unauccessful. \\
\hline Wills Point ................. & 1,100 & 6 & & To sur- & \\
\hline Victoria County: & & & & & \\
\hline Victoria ....... & $815-956$ & & $70-200$ & Flow. & 3 wells. \\
\hline Do. $8 \ldots$ & 953 & & & & \\
\hline $\begin{array}{l}\text { Do } \\
\text { Do.......................... }\end{array}$ & 1,045 & $\dddot{m}$ & 80 & Flows. & \\
\hline Victoria ( 17 miles south). & $\begin{array}{l}716 \\
592\end{array}$ & $\begin{array}{l}2 \\
3\end{array}$ & $\begin{array}{l}10 \\
10\end{array}$ & $\begin{array}{l}\text { Flows. } \\
\text { Flows. }\end{array}$ & \\
\hline Victoria (20 miles south- & 704 & $\cdots$ & 30 & Flows. & \\
\hline $\begin{array}{l}\text { east). } \\
\text { Walker County: }\end{array}$ & & & & & \\
\hline Huntsville... & 2,210 & $9-3$ & Many. & -100 & \\
\hline $\begin{array}{l}\text { Ward County: } \\
\text { Barstow .......... }\end{array}$ & +500 & & & & \\
\hline $\begin{array}{l}\text { Barstow .............. } \\
\text { Washington County: }\end{array}$ & +500 & & . & No flow. & \\
\hline Brenham....... & 600 & & & & Failure. \\
\hline Webb county: & & & & & \\
\hline Encinal ... & 900 & ... & $\cdots$ & -200 & Good water. \\
\hline Laredo ......... & 1,200 & & & No flow. & \\
\hline Wharton County: & & & & & \\
\hline Pierce $\ldots . . . \ldots \ldots$ & $\begin{array}{r}1,509 \\
850 \text { or } 900\end{array}$ & 2 & & Flows. & \\
\hline $\begin{array}{l}\text { Pierce Station.: } \\
\text { Wilbarger County: }\end{array}$ & & & & & \\
\hline Vernon ${ }^{9} . . . .$. & (?) & & & & \\
\hline & & & & & \\
\hline
\end{tabular}

1 Record, U. S. Geol. Surv., 18th Ann. Rept., 1896-97, part 2, pp. 280-283.

2 U. S. Geol. Surv., 18th Ann. Rept,, 1896-97, part 2 , pp. $280,284$.

3 Ibid., pp. $280,284$.

4 Record, 1bid., pp. 285-286.

5 Record, U. S. Geol. Surv. Bull. No. 212, p. 57.

${ }^{6}$ Record 51st Cong, 1st sess, Senate Ex. Doc. No. 222, p. 284

氵 U. S. Geol. Surv., 18th A nn. Rept., 1896-97, part 2 , pp. 265,299 .

Record, U. S. Geol. Sur . Bull. No. 212, p. 33.

"Analysis, Texas Geol. Surv., 4tn Ann. Rept 1892, p. 105. 
TEXAS-Continued.

\begin{tabular}{|c|c|c|c|c|c|}
\hline Location. & Depth. & $\begin{array}{l}\text { Diame- } \\
\text { ter. }\end{array}$ & $\begin{array}{l}\text { Yield per } \\
\text { minute. }\end{array}$ & $\begin{array}{l}\text { Height of } \\
\text { water. }\end{array}$ & Remark: \\
\hline $\begin{array}{l}\text { Williamson County: } \\
\text { Cornhill .............. }\end{array}$ & Feet. ${ }_{404}$ & Inches. & Gallons. & Feet. & \multirow{8}{*}{$\begin{array}{l}\text { Sulphur water. } \\
2 \text { wells; poor water. } \\
\text { Several wells. } \\
\text { Flows at } 650,950,1,300 \text {, } \\
\text { and } 1,400 \text { feet. }\end{array}$} \\
\hline $\begin{array}{l}\text { George to wn ( } 2 \text { miles } \\
\text { east). }\end{array}$ & $\begin{array}{l}407 \\
520\end{array}$ & (n.... & 15 & 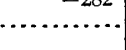 & \\
\hline $\begin{array}{l}\text { Gravis ( } 1 \frac{1}{2} \text { miles sonth)... } \\
\text { Roundrock }\end{array}$ & $\begin{array}{r}412 \\
400\end{array}$ & & 3 & $\begin{array}{l}-96 \\
-\quad 4\end{array}$ & \\
\hline Taylor.................... & 1,400 & & 104 & Flows. & \\
\hline 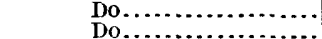 & 2,800 & ........... & 27 & Flow. & \\
\hline Wilson County: & 1,000 & & 15 & +40 & \\
\hline Gonzales...$\ldots \ldots \ldots \ldots$ & 1,400 & $\cdots \cdot$ & 15 & +60 & \\
\hline $\begin{array}{l}\text { Do................. } \\
\text { Gonzales (i mile north). }\end{array}$ & $\begin{array}{r}625 \\
1,135\end{array}$ & $\begin{array}{l}10-8 \\
1 \ldots \ldots\end{array}$ & $\begin{array}{r}30 \\
\text { Many. }\end{array}$ & $\begin{array}{r}\text { Flows. } \\
-60\end{array}$ & \\
\hline $\begin{array}{l}\text { Sutherland } \ldots \ldots \ldots \ldots \\
\text { Wise County: }\end{array}$ & 1,500 & & & & \multirow{5}{*}{$\begin{array}{l}\text { For oil; unsuccessful. } \\
\text { Temp., } 65^{\circ} \text {. }\end{array}$} \\
\hline 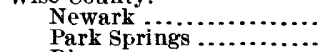 & $\begin{array}{l}410 \\
400\end{array}$ & $\begin{array}{l}5 \\
6\end{array}$ & $\begin{array}{r}1 \\
\text { Many. }\end{array}$ & $\begin{array}{l}+14 \\
-60\end{array}$ & \\
\hline Rhome $\ldots \ldots \ldots \ldots \ldots \ldots$ & 1,400 & ...... & (2) & ........ & \\
\hline $\begin{array}{l}\text { Wood County: } \\
\text { Mineola } 1 . . .\end{array}$ & 1,200 & $6-3$ & & -40 & \\
\hline $\begin{array}{l}\text { Zavalla County: } \\
\text { Batesville } . . . \ldots \ldots \ldots \ldots\end{array}$ & 700 & & & -300 & \\
\hline & & & & & \\
\hline
\end{tabular}

${ }^{1}$ Brown coal and lignite: Texas Geol. Surv. Rept. 1892, pp. 132-135.

\section{PRINCIPAL PUBLICATIONS RELATING TO THE UNDERGPOUND WATERS OF TEXAS.}

Report of F. E. Roesler, division field agent for Texas, letter from the Socretary of Agriculture transmitting a report on the preliminary investigations to determine the proper location of artesian wells within the area of the ninety-seventh meridian and east of the foothills of the Rocky Mountains, Fifty-first Congress, first session: Senate Ex. Doc. No. 222, pages 243-319, Washington, 1890.

Report of E. T. Dumble on the existence of artesian waters west of the ninetyseventh meridian, etc., Fiity-first Congress, first session: Senate Ex. Doc. No. 222, pages 99-102, Washington, 1890.

Preliminary reports on the artesian wells of the Gulf coastal slope, 1 y J. A. Singley: Texas Geological Survey Fourth Annual Report, 1892, pages 85-113, Austin, 1893.

On the occurrence of artesian and other underground waters in Texas, etc., west of the ninety-seventh meridian, by R. T. Hill, report on irrigation, Fifty-second Congress, first session: Senate Ex. Doc. No. 41, part 3 (Final Geological Peports), pages 41-166, plates, Washington, 1893.

Geology of the Edwards Plateau and Rio Grande Plain adjacent to Austin and San Antonio, Tex., with reference to the occurrence of underground waters, by Pobert $T$. Hill and T. Wayland Vaughan: United States Geological Survey, Eighteentr Annual Report, 1896-1897, part 2, pages 193-321 and plates, Washington, 1898.

Geography and geology of the Black and Grand prairies, Texas, with detailed descriptions of the Cretaceous formations and special reference to artesian waters, by R. T. Hill: United States Geological Survey, Twenty-first Annual Report, 1899-1900, part 7 , pages 1-649, Washington, 1901.

Oil Fields of Texas-Louisiana Gulf Coastal Plain, by C. W. Hayes and William Kennedy, United States Geological Survey Bulletin No. 212, Washington, 1903.

Geology and water resources of northern Louisiana and southern Arksnsas, by A. C. Veatch: Prof. Paper U. S. Geol. Survey No. 46. (In preparation.) 
UTAH.

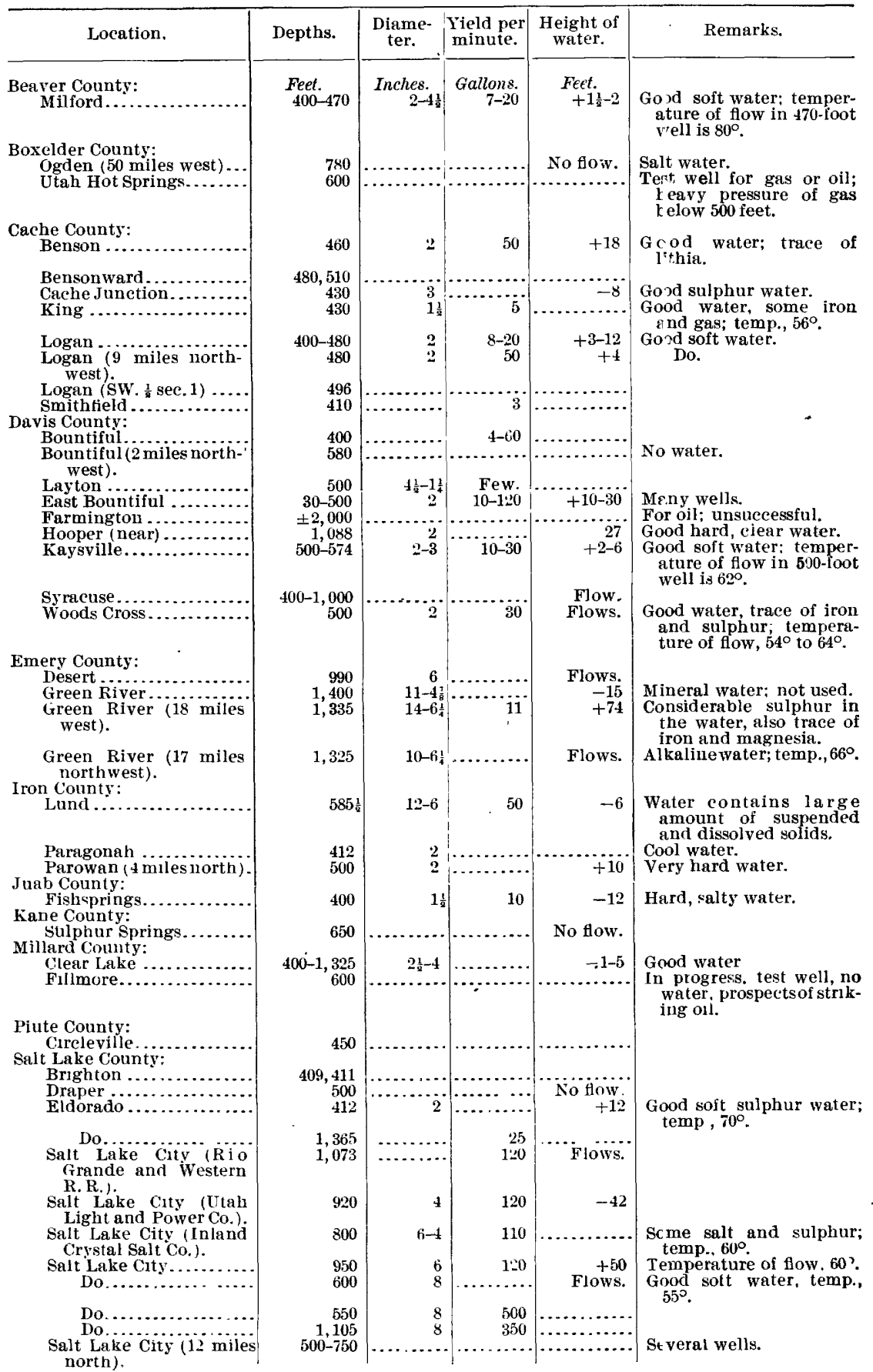


UTA H - Continued.

\begin{tabular}{|c|c|c|c|c|c|}
\hline Location. & Depth. & $\begin{array}{c}\text { Diame- } \\
\text { ter. }\end{array}$ & $\begin{array}{l}\text { Yield per } \\
\text { minute. }\end{array}$ & $\begin{array}{c}\text { Height of } \\
\text { water. }\end{array}$ & Remarks. \\
\hline 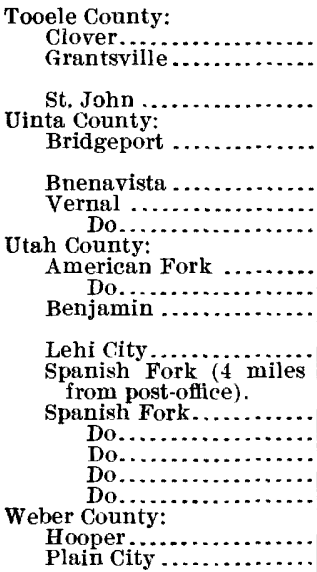 & $\begin{array}{r}\text { Feet. } \\
1,004 \\
432 \\
400,1,000 \\
2,700 \\
500 \\
979 \\
900 \\
500 \\
543 \\
560 \\
400 \\
404 \\
404 \\
420 \\
400 \\
400 \\
410 \\
\\
400-1,000 \\
450\end{array}$ & $\begin{array}{r}2-\frac{1}{2} \\
\cdots\end{array}$ & 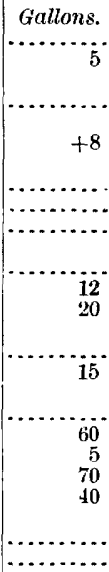 & 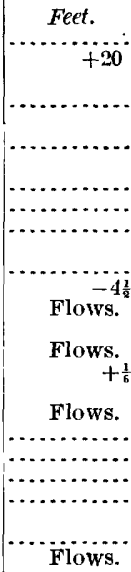 & $\begin{array}{l}\text { Slight amount of sulphur } \\
\text { and iron in water. } \\
\text { Water soft. sliphtly alka- } \\
\text { line. } \\
\text { Abundant supplyof water. } \\
\text { Abandoned. } \\
\text { Surface water only. } \\
\text { Mauy wells of sane depth. } \\
\text { Good water. } \\
\text { Softwaterwith slight trace } \\
\text { of sulphur; tomp., } 72^{\circ} \text {. } \\
\text { Good soft water. }\end{array}$ \\
\hline
\end{tabular}

VERMONT.

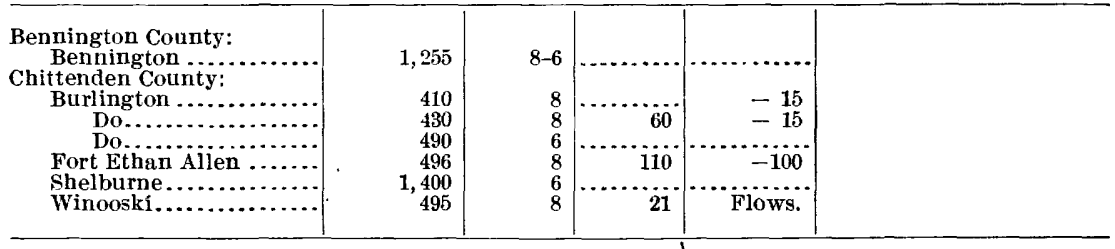

VIRGINIA.

Alexandria County: Alexandria (brewery) Alexandria (ice works) Alleghany County: Covington....

Augusta County Middlebrook Staunton (asyium).......... Staunton (mile east)... Botetourt County: Blueridge Springs

Elizabeth city County Buckroe Beach
Fort Monroe 1

Do. ${ }^{2}$

Do. ${ }^{3}$

Northend Point 4

Fairlax County: Ditchley....

Sandy Point

Glokcester County: Claybank

Gloucester.

Roanes ${ }^{6}$...

1 Record, Geology of the Virginias, by W. B. Rogers, New York, 1884, pp. 731-736: Am. Inst. Mining Eng. Trans., vol. 24, pp. 380-384; U. S. Geol. Surv. Bull. No. 138, p. 167.

2 Record, etc., N. J. Geol. Surv. Rept., 1898, pp.

122-126; IT. S. Geol. Survey Folio No. 80.

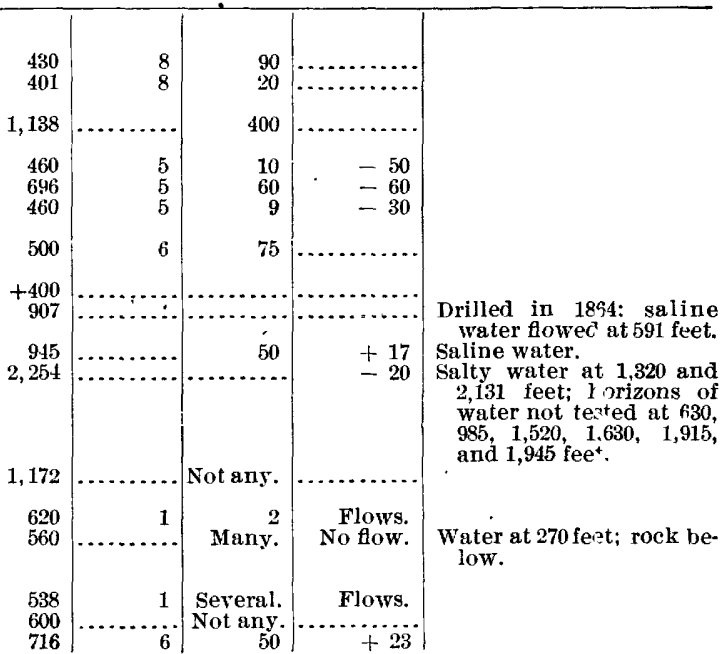

3 Record, U. S. Geol. Surv, Folio No. 80.

4 Record, Am. Inst. Mining Eng. Trø ns, vol. 24, pp. 384-386.

5 Record, U. S. Geol. Surv. Bull. No 138, p. 178.

6 N. J. Geol. Surv., Rept., 1899, pp. 8t-87. 
VIRGINIA-Continued.

\begin{tabular}{|c|c|c|c|c|c|}
\hline Location. & Depth. & $\begin{array}{l}\text { Diame- } \\
\text { ter. }\end{array}$ & $\begin{array}{c}\text { Yield per } \\
\text { minute. }\end{array}$ & $\begin{array}{l}\text { Height of } \\
\text { water. }\end{array}$ & Remarks. \\
\hline $\begin{array}{l}\text { Greene County: } \\
\text { Stanardsvilie... }\end{array}$ & Feet. & Inches. & Gallons. & Feet. & For oil: no success \\
\hline $\begin{array}{l}\text { Henrico County: } \\
\text { Cotman.... }\end{array}$ & & & & Noflow & For on, ho success. \\
\hline Richmond (paper mili) .. & $\begin{array}{l}730 \\
400\end{array}$ & & $\begin{array}{r}40 \\
\text { Several. }\end{array}$ & No How. & In granite. \\
\hline $\begin{array}{l}\text { Richmond (Sherwood } \\
\text { Park). }\end{array}$ & 900 & ....... & Not any. & & \\
\hline $\begin{array}{l}\text { Richmond (Ginter } \\
\text { Farm). }\end{array}$ & 400 & & Many. & & \\
\hline $\begin{array}{l}\text { Richmond } \\
\text { James City County: }\end{array}$ & 445 & & & & $\begin{array}{l}\text { Small supply of water at } \\
102 \text { feet. }\end{array}$ \\
\hline 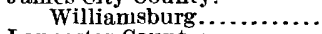 & 876 & & Not any. & & \\
\hline $\begin{array}{l}\text { Lancaster County: } \\
\text { Lancaster...... }\end{array}$ & +400 & & & Nofloy & \\
\hline Windmill Point & $\begin{array}{r}T+900 \\
450\end{array}$ & & & No flow. & At andoned. \\
\hline $\begin{array}{l}\text { Norfolk County: } \\
\text { Lambert Point } 1\end{array}$ & 616 & 6 & & +23 & \\
\hline Norfolk (Money Point).. & $\begin{array}{l}010 \\
562\end{array}$ & 0 & $\begin{array}{r}65 \\
\text { Many. }\end{array}$ & $\begin{array}{l}+23 \\
\text { Flows. }\end{array}$ & $\begin{array}{l}\text { Temperature about } 70^{\circ} \text {. } \\
\text { Ferruginous water. }\end{array}$ \\
\hline Norfolk (waterworks). 2 . & 1,760 & $12-4 \frac{1}{2}$ & 150 & Flows. & $\begin{array}{l}\text { Saline waters at several } \\
\text { horizons. }\end{array}$ \\
\hline $\begin{array}{l}\text { Northumberland County: } \\
\text { Dymer Creek }{ }^{3} . \ldots \ldots \ldots \ldots\end{array}$ & 507 & & & & + \\
\hline Fuirport $4 . \ldots \ldots \ldots$ & 662 & $8-6$ & 75 & Flows. & \\
\hline $\begin{array}{l}\text { Reedville....... } \\
\text { Nottoway County: }\end{array}$ & 680 & $8-6$ & 85 & +3 & Temp., 780. \\
\hline $\begin{array}{l}\text { Nottoway County: } \\
\text { Crewe ......... }\end{array}$ & 500 & & Few & Flow. & \\
\hline Allisonia .......... & $400-1,200$ & & Few. & Flow. & Sereral wells. \\
\hline Delton........... & +400 & & Notany. & $\cdots \cdots$ & At andoned. \\
\hline I & 475 & 6 & 25 & $->0$ & \\
\hline Pulaski & $\begin{array}{r}400-600 \\
1,200\end{array}$ & 6 & 100 & -10 & Several wells. \\
\hline $\begin{array}{l}\text { Princess Anne County: } \\
\text { Virginia Beach } 5\end{array}$ & 600 & & & & Or?y small amount of \\
\hline Rockingham County: & & & & & \\
\hline Harrisonburg.... & 420 & 8 & & -10 & \\
\hline $\begin{array}{l}\text { Roanoke County: } \\
\text { Roanoke ........ }\end{array}$ & 1.200 & 6 & & -4 & Not in use. \\
\hline Warwick County: & & & & & \\
\hline $\begin{array}{l}\text { Newport News }{ }^{5} . . \\
\text { Wise County: }\end{array}$ & 600 & & Few. & No flow. & \\
\hline Stonega ..... & 503 & 8 & 55 & -16 & \\
\hline $\begin{array}{l}\text { Toms Creek... } \\
\text { Wythe County: }\end{array}$ & & 6 & 100 & No flow. & \\
\hline $\begin{array}{l}\text { Wythe County: } \\
\text { Foster Falls }\end{array}$ & 808 & & 100 & 9 & \\
\hline Miscellaneous: & & & 100 & -2 & \\
\hline Oak Springs . & 400 & 1 & Several. & Flows. & \\
\hline
\end{tabular}

1 Record, U. S. Geol. Surv. Folio No. 80: No. 138, p.172; N. J. Geol. Surv. Rept., 1899, pp. 87-92

2 Record, ete, N. J. Geol. Surv, Rept., 1899 , pp.

3 Record, U. S. Geol. Surv. Bull. No. 138, p. 176. ${ }^{4}$ N. J. Geol, Surv. Rept., 1898, pp. 121-122. 92-102; U. S. Geol. Surv. Folio No. 80.

\section{PRINCIPAL PUBLICATION RELATING TO DEEF WELLS IN VIRGINIA.}

Artesian well prospects in the Atlantic Coastal Plain region, by N. H. Darton: United States Geological Survey Bulletin No. 138, 232 pages, 19 plates, Washington, 1896.

United States Geological Survey Folio No. 80, by N. H. Darton.

WASHINGTON.

\begin{tabular}{|c|c|c|c|c|c|}
\hline Location. & Depths. & $\begin{array}{c}\text { Diame- } \\
\text { ter. }\end{array}$ & $\begin{array}{l}\text { Yield per } \\
\text { minute. }\end{array}$ & $\begin{array}{l}\text { Height of } \\
\text { water. }\end{array}$ & Remarks. \\
\hline $\begin{array}{l}\text { Adams County: } \\
\text { Cunningham .......... }\end{array}$ & Feet. ${ }_{426}$ & $\begin{array}{r}\text { Inches. } \\
6\end{array}$ & $\begin{array}{l}\text { Gallons. } \\
\text { G......... }\end{array}$ & $\begin{array}{l}\text { Feet. } \\
\qquad-356\end{array}$ & Soft water; \\
\hline $\begin{array}{l}\text { Eureka Flat (southeast } \\
\text { of Snake River). }\end{array}$ & $200-900$ & & & & Several wells. \\
\hline $\begin{array}{l}\text { Franklin County: } \\
\text { Connell ........................ }\end{array}$ & 676 & 5 & & -640 & $\begin{array}{l}\text { Farm supply; soft water; } \\
\text { temperature of water at } \\
\text { mouth, } 51^{\circ} \text {. }\end{array}$ \\
\hline
\end{tabular}


WASHINGTON-Continued.

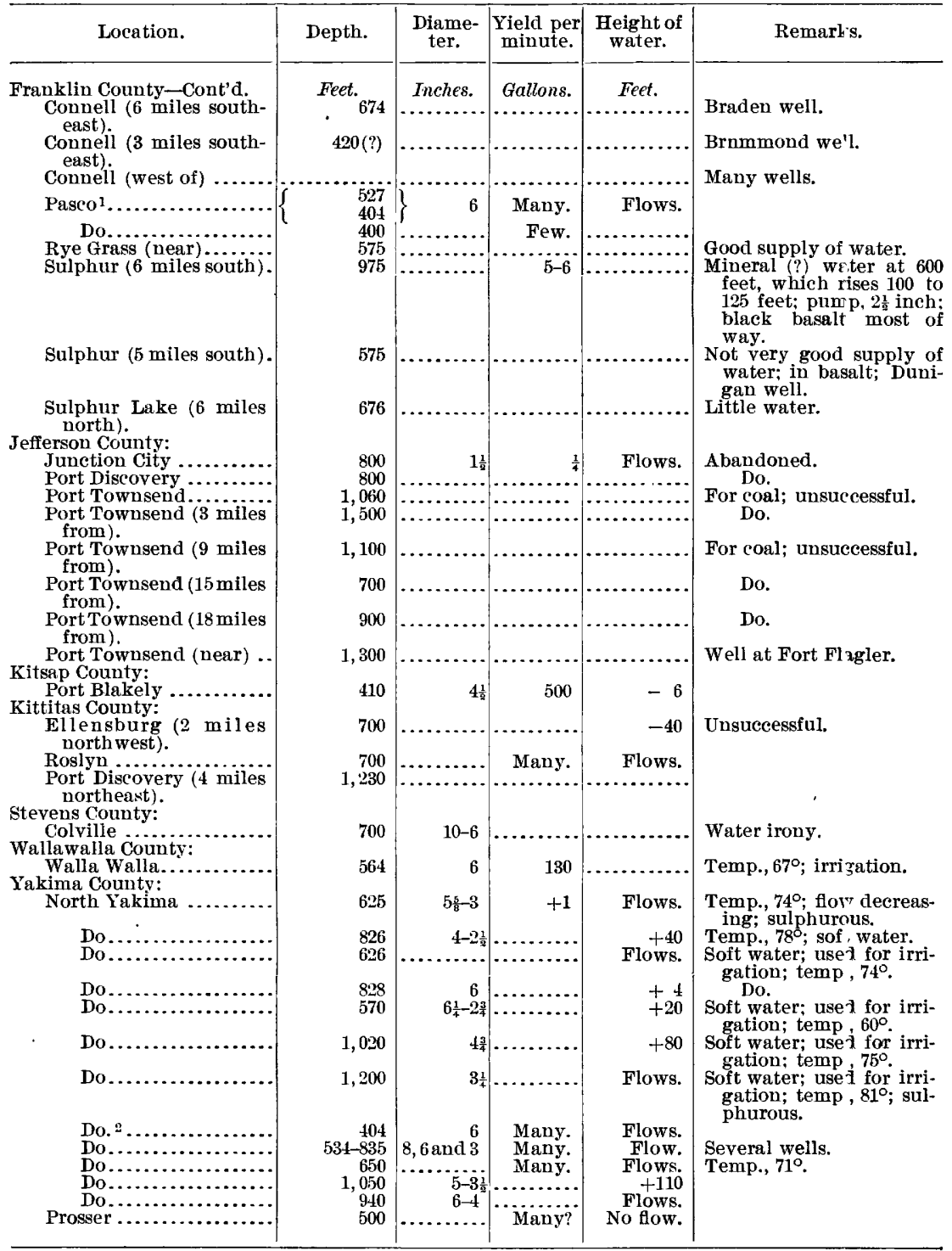

\section{WEST VIRGINIA.}

Barbour County:

Elk Creek (below Philippi). 3

Philippi (4 miles west) 4

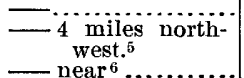

2,725

1 Record, U. S. Geol. Surv. Bull. No. 108, p. 39

2 Ibid., pp. 56-58.

3 Record, W. Va. Geol. Surv. Rept., vol. 1 (a), I904, p. 348 .

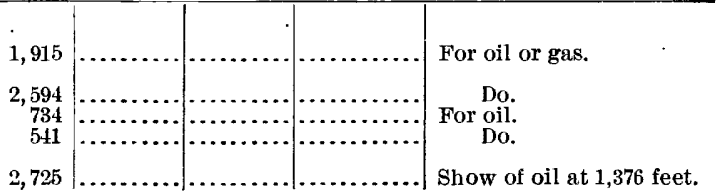

4 Ibid., pp. 346-348.

5 Ibid., vol. 2, pp. 357-358.

6 Ibid., vol. 1 (a), 1904, pp. 344-346. 
WEST VIRGINIA-Continued.

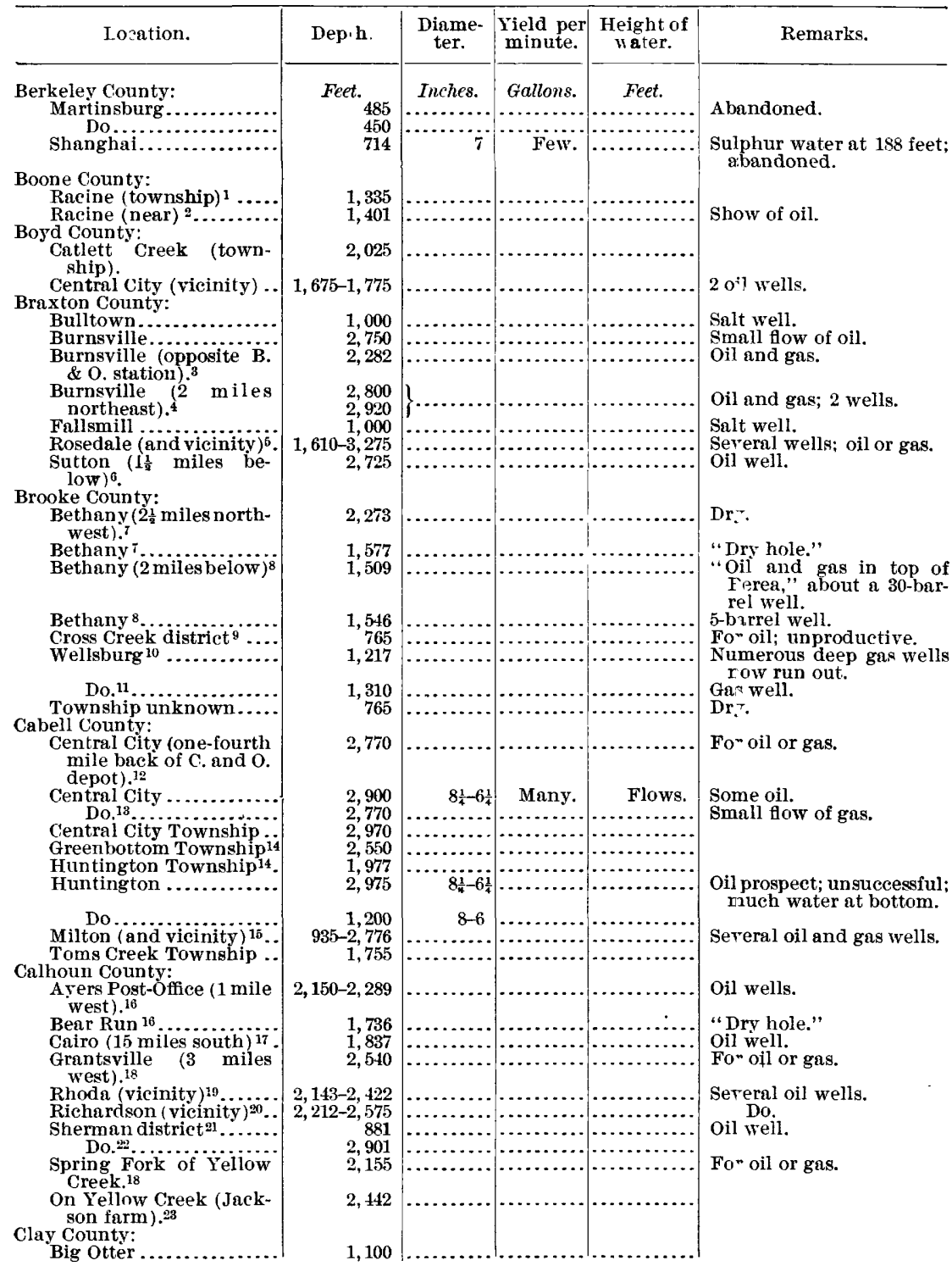

1 U. S. Geol. Surv. Folio No. 72, p. 4.

2 Record, W. Vq. Geol. Surv. Rept., vol. 1 (a), 1904, pp, 499-500.

3 Ibid., p. 391 .

4 Ibid., pp. 392-393.

5 Ibid., pp. 388-390.

o Ibid., vol. 1, 1899, pp. 269-270.

7 Ibid., vol. 1 (a), 1904, p. 233.

8 Ibid., p. 232.

${ }^{9}$ Record, Pa. 2d Geol. Surv. Rept., vol. $1^{5}$, pp. $327-328$.

10 Record, Ohio Geol. Surv. Rept., 1888, vol. 6, pp. 337-339.

11 Record, Pa. 2d Geol. Surv. Rept., 1886, part 2. pp. 783-784; W. Va. Geol. Surv. Rept., vol, 1, p. 367.

12 Record, W. Va. Geol. Surv, Rept., vol, 1(a), 1904, pp. 495-496; U. S. Geol surv. Folio No. 69, p. 3. 13 Ibid., vol. 1, pp. 275-276.

14 U. S. Geol. Surv, Folio No. 69, p. 3.

15 Record, W. Va. Geol. Surv. Rept., vol. 1(a), 1904, pp. 484-195.

16 Ibid., p. 395.

17 Ibid., pp. $394-395$

18 Ibid., p. 397

19 Ibid., pp, 398-401.

20 Ibid., pp. 401-402.

21 Ibid., vol. 2 , p. 396.

22 Ibid., vol. 1(a), 1904, pp. 396-397.

23 Ibid., vol. 2 , pp. 395-396. 
WEST VIRGINIA-Continued.

\begin{tabular}{|c|c|c|c|c|c|}
\hline Location. & Depth. & $\begin{array}{l}\text { Diame- } \\
\text { ter. }\end{array}$ & $\begin{array}{l}\text { Yield per } \\
\text { minute. }\end{array}$ & $\begin{array}{l}\text { Height of } \\
\text { water. }\end{array}$ & Remarks \\
\hline Clay County-Continued. & Feet. & & & & \multirow{12}{*}{$\begin{array}{l}\text { Produced } 2 \text { barrels of oil a } \\
\text { day; well abardoned. } \\
\text { For oil or gas. } \\
\text { Gas well. } \\
\text { Gas, } 1,869 \text { feet; oil, } 1,905 \\
\text { feet; gas, } 2,835 \text { feet. } \\
\text { Oil well. } \\
\text { Gas and oil. } \\
\text { Gas, } 1,890 \text { to } 1,895 \text { feet; gas } \\
\text { and oil, } 1,902 \text { foet. } \\
\text { Several oil wells. } \\
\text { Sulphur water. } \\
7 \text { wells; for oil o" gas. }\end{array}$} \\
\hline $\begin{array}{c}\text { Clay and Clendenin } \\
\text { (half way between }\end{array}$ & 2,614 & & & & \\
\hline Near Roan County line? & 2,422 & & & & \\
\hline Doddridge County: & & & & & \\
\hline Alpha Post-Office ( $1 \frac{1}{2}$ and & 2,795 & & & & \\
\hline $\begin{array}{l}1 \text { mile southwest and } \\
\text { west). } .^{3}\end{array}$ & 2,843 & & & & \\
\hline $\begin{array}{l}\text { Big Flint Creek ( } 2 \text { miles } \\
\text { southeast from mouth) }\end{array}$ & 2,520 & & & & \\
\hline Cascara (near) $5 . . . . .$. & 2,760 & & & & \\
\hline $\begin{array}{l}\text { Center Point (1 mile } \\
\text { west). }\end{array}$ & 1,950 & & & & \\
\hline Center Point (near) ${ }^{7} \ldots$ & $1,910-2,880$ & & & & \\
\hline 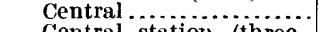 & 460 & & & & \\
\hline $\begin{array}{l}\text { Central station } \\
\text { fourths three- } \\
\text { from) } .^{8} \text { to } 2 \text { miles }\end{array}$ & $1,879-3,085$ & & & & \\
\hline Cove district ${ }^{9}, \ldots \ldots \ldots$ & $2,595-2,782$ & & & & \multirow{10}{*}{$\begin{array}{l}5 \text { wells; for oil o" gas. } \\
2 \text { wells; for oil o" gas. } \\
13 \text { wells; for oil or gas. } \\
8 \text { wells; for oil or gas. } \\
\text { " Good Injun ga? well." } \\
\text { For oil or gas. } \\
\text { " } 30 \text {-barrel well." } \\
\text { Fo to } 20 \text { barrel well." } \\
\text { For oil or gas. }\end{array}$} \\
\hline Doddridge-Lewis County & 2,186 & & & & \\
\hline line (near) 10 & $\left\{\begin{array}{r}2,207 \\
2,257-3,314\end{array}\right.$ & & & & \\
\hline $\begin{array}{l}\text { Grant district } 11 \\
\text { Greenbrier district } 12 \ldots \ldots\end{array}$ & $\begin{array}{l}2,257-3,314 \\
\mathbf{2}, 750-3,193\end{array}$ & & & & \\
\hline $\begin{array}{l}\text { Greenwood Post-office } \\
\text { (4 miles southeast).13 }\end{array}$ & 2,081 & & & & \\
\hline . Kelley Post-Office ( 2 & 2,500 & & & & \\
\hline Kenton (?) (vicinity) ${ }^{15}$. & 2,115 & & & & \\
\hline Leopold Post-Office (11 & 2,587 & & & & \\
\hline $\begin{array}{l}\text { and Imile northwest). } \\
\text { Long Run stat it in }\end{array}$ & 2,564 & & & & \\
\hline$\underset{\text { (near). } .^{17}}{\text { Long }}$ sutation & 2,701 & & & & \\
\hline $\begin{array}{l}\text { MeClellan district }{ }^{18} \ldots \ldots \\
\text { Do }\end{array}$ & $\begin{array}{l}2,158-3,206 \\
2,791-3,131\end{array}$ & & & & \multirow{5}{*}{$\begin{array}{l}9 \text { wells; for oil or gas. } \\
4 \text { gas wells. } \\
\text { Gas at } 2.771,2,778, \text { and } 2,800 \\
\text { feet, so strong that drill- } \\
\text { ing had to be s1'spended. } \\
\text { For oil or gas. } \\
\text { Gas well. } \\
\text { For oil or gas. }\end{array}$} \\
\hline Do.10.................. & $\begin{array}{r}2,191-3,151 \\
2,773\end{array}$ & & & & \\
\hline Miletus (near) ${ }^{20} \ldots$. & 2,930 & & & & \\
\hline Do & 2,670 & & & & \\
\hline$\underset{\text { northwest) }}{\text { Morganswille }}$ (1 mile & 2,723 & & & & \\
\hline New Milton district ${ }^{22} \ldots$ & $2,047-2,906$ & & & & \multirow{9}{*}{$\begin{array}{l}6 \text { wells; for oil } o^{*} \text { gas. } \\
\text { For oil or gas. } \\
\text { Oil well. } \\
\text { For oil or gas. } \\
\text { Large gas well. } \\
6 \text { wells: for oil om gas. } \\
\text { For oil; unsuccessiul on } \\
\text { acconnt of wa ter. } \\
\text { Practically dry hole. } \\
\text { "Big gas, } 1,750 \text { f зet." }\end{array}$} \\
\hline $\begin{array}{l}\text { Oxford (2 miles north- } \\
\text { east) }{ }^{23}\end{array}$ & & & & & \\
\hline $\begin{array}{l}\text { Oxford ( } 7 \text { miles above })^{24} \text {. } \\
\text { St. Clara }(21 \text { miles north- }\end{array}$ & 2,484 & & & & \\
\hline $\begin{array}{l}\text { St. Clara ( } 2 \frac{1}{4} \text { miles north- } \\
\text { east }) .26\end{array}$ & 2,770 & & & & \\
\hline $\begin{array}{c}\text { Sedatia (near) }{ }^{26} \ldots \ldots \ldots \ldots \\
\text { Do. }{ }^{27} \ldots \ldots \ldots \ldots \ldots\end{array}$ & $\begin{array}{r}2,800 \\
2,800-3,295\end{array}$ & & & & \\
\hline Vadis $28, \ldots \ldots \ldots \ldots \ldots \ldots \ldots$ & $\begin{array}{r}2,000 \\
2,207\end{array}$ & & & & \\
\hline $\begin{array}{l}\text { West Union ( } 3 \text { and } 3 \frac{1}{2} \\
\text { miles southwest) } 29\end{array}$ & 2,493 & & & & \\
\hline $\begin{array}{l}\text { miles southwest). }{ }^{29} \\
3 \frac{1}{2} \text { miles nor th - }\end{array}$ & $+1,745$ & & & & \\
\hline${ }_{\text {west. } 30}^{3 \frac{1}{2}}$ miles orth - & 2,479 & & & & \\
\hline Fayette cour & & & & & \\
\hline $\begin{array}{l}\text { Oak Hill } 31 \\
\text { Powellton } 32\end{array}$ & $\begin{array}{r}541 \\
+813\end{array}$ & & & & \\
\hline $\begin{array}{c}\text { Powellton }{ }^{32} \ldots \ldots \ldots \\
\text { Do. }{ }^{33} \ldots \ldots \ldots \ldots\end{array}$ & $\begin{array}{l}+813 \\
2,895\end{array}$ & & & & For oil or gas. \\
\hline Gilmer County: & & & & & \\
\hline Butcher Fork of Sand & 2,825 & & & & \\
\hline $\begin{array}{l}\text { Fork creek (n e a r } \\
\text { Lewis County line). } .34\end{array}$ & & & & & \\
\hline
\end{tabular}

1 Record, W. Va. Geol. Surv. Rept., vol. 1(a), 1904, pp. 474-475.

2 Ibld., pp. 473-474.

3 Ibid., pp. 287-288.

4 W. Va. Geol. Surv. Rept, vol, 1, pp. 332-334.

5 Record, ibid., vol. 1(a), 1904, pp. 282-283.

6 Ibid., pp. 281-282.

7 Ibid., voi. 1, pp. 328-332.

8 Ibid., vol. 1 (a), 1904, pp. 302-304.

9 Ibid., pp. 297-300.

10 Ibid., p. 298.

11 Ibid., pp. 288-292.

12 Ibid., pp. 292-294.

13 Ibid., p. 303 .

14 Ibid., p. 300.

15 Ibld., vol. 1, p. 335

16 Ibid., vol. 1(a), 1904, p. 297.

17 Ibid., vol. 1, pp. 325-326.
18 Ibid., vol. 1(a), 1904. pp. 285-287.

${ }^{19}$ Ibid , p. 282

${ }^{20}$ Ibid., vol 1, pp. 323-324

21 Ibid, vol. 1(a), 1904, p. 301.

22 I bid.. pp. 295-297.

23 I tid, p 304

24 1bid., vol. 1, 322-323.

2o lbid., vol. 1(a), 1904, p. 298

261 bid., vol. 1 . pp. 326-327.

27 Ibid, vol, 1(a), 1904, pp 282-284.

28 W. Va. Geol. Surv. Rept, vol 1, pp. 259-259.

29 Recorr, ibıd., vol. I (a), 1904, pp. 300-301.

30 Ibid.. p. 301.

31 Partjal record, ibid., vol. 2 , pp. 661-66:2.

32 Ibid., p. ti22.

${ }^{33}$ Record, ibid., vol. 1 (a) : 1904, pp 50ะ-503

34 Ibid., pp 380-381. 
WEST VIRGINIA-Continued.

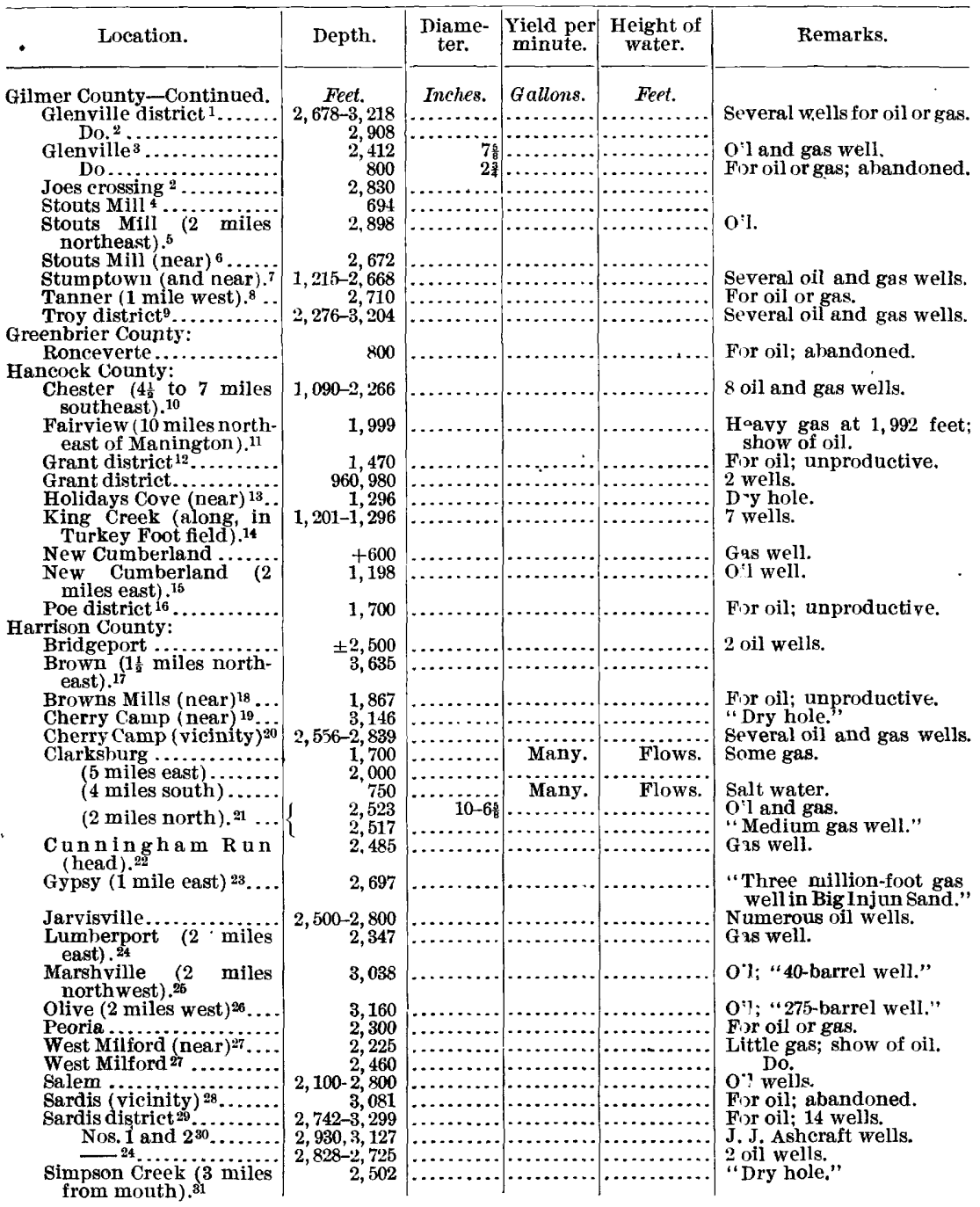

1 Record, W. Va. Geol. Surv. Rept., vol. 1 (a), 1904, pp. 376-377.

2 Ibid., p. 381 .

3 Ibid., vol. 1, pp. 259-260.

4 Ibid., vol. 2 , p. 243

5 Ibid., vol. 1(a), 1904, pp. 377-378.

6 Ibid., pp. $378-380$.

7 Ibid., pp. 383-386.

8 Ibid., pp. 386-388.

9 Ibid., pp. 382-383.

Ibid., pp. $382-383$.
10 Ibid., pp. 236-237.

11 Geol. Soc. Am. Bull., vol. 3, pp. 191-192, 1892.

12 Record, Pa. 2d Geol Śurv. Rept., Vol. $I^{5}, 328$.

13 Record, W. Va. Geol, Sürv. Rept., vol. 1 (a),

$1904, p .237$

14 Ibid., $234-235$.

15 Ibid., vol. 1, p. 369

16 Record, Pa. 2d Geol. Surv. Rept., Vol. $1^{5}$, p. 327.
${ }^{17}$ Record, W. Va. Geol. Surv. Rept., vol. 1 (a), 1904, p. 311.

$18 \mathrm{~W}$. Va. Geol. Surv. Rept., vol. 1, 1899, pp. 249-250.

19 Ibid., vol, 1 (a), 1904, pp. 317-318.

20 Ibid., vol. 1, 1899, pp. 252-255.

21 Ibid., vol. 1 (a), 1904, pp. 328-330.

221 bid., p. 328.

I Ibid., pp. 330-331.

24 Ibid., p. 327.

25 Ibid., p. 315 .

26 Ibid, p. 310.

27 Ibid., pp. 334-335.

${ }^{28}$ Ibid., vol. 1, 1899, pp. 248-249.

29 Ibid., vol. 1 (a), 1901, pp. 305-311.

30 Ibid., p. 309; authority, South Penn. Oil Co.

81 lbid,, p. 330 . 
WEST VIRGINIA -Continued.

Location.
$\begin{gathered}\text { Harrison Connty-Cont'd. } \\ \text { Ten Mile district }{ }^{1} \ldots \ldots . \\ \text { Vicinity of Sedalia } \\ \text { and Salem. }\end{gathered}$

Union district 4 .

Jackson County :

Cottageville 5

Kentuck Post-ôffice (southeast of ). ${ }^{6}$

Kenna Post-Office ?

Ravenswood (near) 8

Sandyville (near) ${ }^{9}$

Jefferson County:

Harpers Ferry

Kanawha County:

Cabin Creek Township

Charleston (waterworks), 10

8 miles above 11

9 miles above 12

13 miles sout hwest 13

5 miles below

-15........

Cool Spring Fork Burning spring Branch.17

Fork of Little Sandy (on simmons farm).

Kanawha (and vicinity). 18

Kana wha River at head of Witehers Creek 19

Lens Creek Township i7

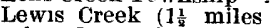
from KanawhaRiver) ${ }^{10}$

Malden Township .......

Malden .

Simpsons Creek ${ }^{19}, \ldots . . .$.

Winifrede 19

Lewis County

Camden (near) 20

Court-House district $2 \mathrm{i}$

FreemansCreek district 2

Lightburn (vicinity)

Vadis (near) 23

2 miles below 24

10 miles southeast

Hospital for the Insane. 26

1 W. Va. Geol. Surv. Repts., vol. 1, 1899, p. 251. 2 Ibid., vol. 1 (a), 1904, pp. 311-316.

3 Ibid,, pp. 319-326.

4 Ibid,, pp. 331-337.

6 Record, ibid., pp. 476-477.

6 Ibid., p. 477.

7 Ibid., pp. 477-478.

8 W. Va. Geol. Surv, Rept., vol. 1, pp. 283-284.

9 Record, 1 bid., vol. 1 (a), 1904, p. 476.

${ }^{10}$ Record, Pa. $2 d$ Geol. Surv. Rept., vol. $I^{5}$, pp. $331-332$

11 Ibid., p. 330.

12 Record, W. Va. Geol. Surv. Rept, vol. 1, pp. 271-272.

13 Record, Pa. 2d Geol. Surv. Rept, Vol. $\mathrm{I}^{5}$, pp. 32-333.

${ }^{14}$ Record, W. Va. Geol. Surv. Rept, vol. 2, p. 400.
Remarks.

For oil or gas; unproduc16. wells, for oil or gas.

24 wells; covering the region where the Fifth Sand is productive of cil or gas.

16 gas and oil wells; the 2,160 -foot well is the largest gas well in the state at present.

For oil or gas.

"Big gas pressure at 1,420 feet; show of oil at 1,430." "Dry hole."

For oil or gas.

Gas, water, and little oil at 1,787 feet.

For oil or gas; unproductive.

Moderate flow of gas.

Small flow of gas.

For oil or gas; unproductive.

For oil or gas.

Do.

Gas well, water at 60 and 155 feet; hole fllied with salt water, 940-990 feet: gas at 938 feet.

Numerous salt aud gas wells.

Gas well.

Do.

15 oil and gas wells.

33 oil and gas well

For oil or gas: abardoned.

Oll well.

For oil: unsuccessful.

small flow of oil.

Gas well.

Oil well.

Gas well.
${ }^{15}$ Ibid., vol. 1 (a), 1904, pp. 500-501.

16 Ibid., p. 501

37 U. S. Geol. Surv. Folio No. 72, p. 3

18 Record, Pa. 2d Geol. Surv. Rept., Vol. $I^{5}$, pp. 329-333; W: Va. Board of Centennial Manager: Resources Report by Maury and Fontaine, pp. $287-290$.

19 U. S. Geol. Surv. Folio No. 72, p. 4.

20 Record, W. Va. Geol. Surv. Rept., vo', 1 (a), 1904. pp. 357-358.

21 Ibid., pp. 369-373.

2* Ibid., pp. 360-368.

23 W. Va. Geol. Surv. Rept, vol. 1, pp, 257-258.

24 Record, sbid., vol. 1 (a). 1904, pp. 354-355.

25 Ibid, vol. 1 pp. 255-256.

26 Ibid., vol. 1 (a), 1904, pp. 355-356. 
WEST VIRGINIA-Continued.

\begin{tabular}{|c|c|c|c|c|c|}
\hline Location. & Depth. & $\begin{array}{l}\text { Diame- } \\
\text { ter. }\end{array}$ & $\begin{array}{c}\text { Yield per } \\
\text { minute. }\end{array}$ & $\begin{array}{l}\text { Height of } \\
\text { water. }\end{array}$ & Remarks. \\
\hline $\begin{array}{l}\text { Lewis County-Continued. } \\
\text { Weston (4 miles from) }\end{array}$ & Feet. & Inches. & Gallons. & Feet. & \\
\hline $\begin{array}{l}\text { Weston (4 miles from) }{ }^{1} . \\
10 \text { miles southwest }\end{array}$ & 2,202 & & & & Oil and gas. \\
\hline $\begin{array}{l}10 \text { miles southwest }{ }^{2} . \\
16 \text { miles south }{ }^{3} \ldots . .\end{array}$ & $\begin{array}{r}2,645 \\
2,936-2,517\end{array}$ & & & & Oil well. \\
\hline \multicolumn{6}{|c|}{$\begin{array}{l}16 \text { mines south } 3 \ldots \ldots \\
\text { Lincoln County: }\end{array}$} \\
\hline $\begin{array}{l}\text { Big Hart Creek }{ }^{4} \ldots \ldots \ldots \\
\text { Hart (near) })^{5} \ldots \ldots \ldots \ldots \ldots\end{array}$ & $\begin{array}{l}3,261 \\
3,260\end{array}$ & & & & For oil or gas. \\
\hline \multicolumn{6}{|l|}{$\begin{array}{c}\text { Hart (near) } \\
\text { Logan County: }\end{array}$} \\
\hline \multicolumn{6}{|l|}{$\begin{array}{l}\text { (Township unknown)... } \\
\text { MeDowell County: }\end{array}$} \\
\hline \multicolumn{6}{|l|}{$\begin{array}{l}\text { Mewoweh } \\
\text { Welch..................... } \\
\text { Marion County: }\end{array}$} \\
\hline \multirow{2}{*}{\multicolumn{6}{|c|}{$\begin{array}{l}\text { Barrackville } \\
\text { northwest) }{ }^{7}\end{array}$}} \\
\hline & & & & & \\
\hline \multicolumn{6}{|l|}{ Brink Post-office (1 mile } \\
\hline \multicolumn{6}{|l|}{1 mile east ${ }^{2} \ldots \ldots \ldots$} \\
\hline \multicolumn{6}{|r|}{ For oil or gas; 4 wells. } \\
\hline $\begin{array}{l}\text { Dunkard Mill Run (near } \\
\text { head waters). } 11\end{array}$ & $2,7172,750$ & & & & \& wells. \\
\hline \multicolumn{6}{|l|}{$\begin{array}{l}\text { neanwaters) } \\
\text { Fairview (southwest) }{ }^{12} . \text {. }\end{array}$} \\
\hline \multirow{3}{*}{$\begin{array}{l}2 \text { miles northeast }{ }^{13} \ldots \\
2 \text { miles south, }{ }^{14} \ldots\end{array}$} & 1,997 & & & & For o1l; unproductive. \\
\hline & $\begin{array}{l}1,970 \\
\mathbf{3}, 028\end{array}$ & & & & Gas well. \\
\hline & $3,333 \frac{1}{4}$ & & & & $\begin{array}{l}\text { Some gas at } 3,293 \text { feet; } 25 \\
\text { barrels of oil daily from } \\
3,315 \text { feet. }\end{array}$ \\
\hline \multicolumn{6}{|l|}{ Fairview (near) ${ }^{14} .}$. \\
\hline & 3,150 & & & & $\begin{array}{l}\text { daily, in July, } 1903 \text {, and } \\
\text { still yields } 68 \text { barrels } \\
\text { daily. }\end{array}$ \\
\hline $\begin{array}{c}\text { Farmington station }(2 \\
\text { miles eqst) }\end{array}$ & 2,811 & & & & For oil or gas: abandoned. \\
\hline Flat $\operatorname{Run}^{16} \ldots \ldots \ldots$ & $3,064-3,374$ & & & & 6 wells; for oil or gas. \\
\hline \multicolumn{6}{|l|}{$\begin{array}{l}\text { Glovers Gap ( } 1 \mathrm{mile} \\
\text { east). } 17\end{array}$} \\
\hline \multirow{2}{*}{\multicolumn{6}{|c|}{ Glovers Gap (near) ${ }^{18} \ldots$}} \\
\hline & & & & & \\
\hline \multicolumn{6}{|l|}{ Joetown ( 1 mile west) ${ }^{19}$. } \\
\hline \multicolumn{6}{|l|}{ Joetown (near) 20} \\
\hline \multicolumn{6}{|l|}{ Manington Township ... } \\
\hline \multicolumn{6}{|l|}{ Manington (near) $21 . \cdots$} \\
\hline 1 mile above $22 . . .$. & 3,144 & & & …. & Do. \\
\hline 3 miles south west 23 . & 3,042 & & & & Do. \\
\hline $\begin{array}{l}3 \text { miles north } 24 \\
6 \text { miles north west } 25 .\end{array}$ & $\begin{array}{l}2,895 \\
3,010\end{array}$ & & & & $\begin{array}{l}\text { Oil well. } \\
\text { Do. }\end{array}$ \\
\hline 3 to 4 miles east $26 . .$. & $\begin{array}{l}0,010 \\
3,025\end{array}$ & & & & Gas at 2,420 feet below the \\
\hline Near ${ }^{2} \ldots . .$. & 1,877 & & & & $\begin{array}{l}\text { Pittsburg coal. } \\
\text { For oll or gas. }\end{array}$ \\
\hline$-27 \ldots$. & $\stackrel{5}{2,631}$ & & & & Do. \\
\hline 2 miles west $27 \ldots$ & 1,965 & & & & Do. \\
\hline Near ${ }^{27}$ & 2,400 & $10^{4}-4$ & & & Do. \\
\hline 3 miles southwest $27 .$. & $\begin{array}{lr}2,630 \\
2,903\end{array}$ & & & & Gas. \\
\hline Near ${ }^{27}$. & $2,255-3,020$ & & & & 11 wells, oil and gas. \\
\hline
\end{tabular}

1 Record, W. Va. Geol Surv. Rept., vol. 1 (a), pp. 356-357.

Ibid., p. 369.

3 Ibld., p. 374 .

4 U.S. Geol. Sur v. Folio No. 69, p. 4.

5 Record, W. Va. Geol. Surv. Rept. vol. 1, pp. 280-281.

6 Ibid., vol. 2, pp. 694

7 Ibld., vol. 1 (a), 1904, pp. 152-154

8 Ibid., p. 165 .

9 Ibid., pp. 173-174.

10 Ibid., pp. 167-168.

11 1bid., pp. 151-155.

12 W. Va. Geol. Surv. Rept., vol. 1, pp. 239-241.

13 lbid., pp. $238-239$.

14 Recort, ibid., vol. 1 (a), 1904, pp. 156-157.
16 Record, Pa. 2d Geol. Surv. Ann. Rept. 1886 , part 2, pp. 782-783.

${ }_{16}$ Record, W. Va. Geol. Surv. Rept., vol 1 (a), 1904, pp. 169-173.

17 ibid 161.

18 Ibid.', pp. 165-167.

19 Tbid., vol. 1, pp. 345-347.

20 Ibid., vol. 1 (a), 19C4, pp. 174-176.

21 Ibid., vol. 1, pp. 241-242.

22 Ibid., pp. 242-243.

23 Ibid., pp. 243-244.

24 Ibid., pp. 244-246; vol. 2, pp. 129-130

25 Ibid., pp. 246-247.

26 Ibid., vol. 1 (a), 19C1, pp. 155-156.

27 Ibid., pp. 158-164. 
WEST VIRGINIA-Continued.

\begin{tabular}{|c|c|c|c|c|c|}
\hline Location. & Depth, & $\begin{array}{l}\text { Diame- } \\
\text { ter. }\end{array}$ & $\begin{array}{l}\text { Yield per } \\
\text { minute. }\end{array}$ & $\begin{array}{l}\text { Height of } \\
\text { water. }\end{array}$ & Remarks. \\
\hline $\begin{array}{l}\text { Marion County-Continued. } \\
\text { M a ing ton district } \\
\text { (west of Campbells } \\
\text { Run). } 1\end{array}$ & $\begin{array}{l}\text { Feet. } \\
\qquad 3,218\end{array}$ & ehes. & Gallons. & & Oil at 3,113 feet. \\
\hline Metz (near) ${ }^{2} \ldots \ldots \ldots \ldots$ & 2,992 & & & & For oil or gas. \\
\hline Township unknown..... & 2,811 & & & & Dry. \\
\hline Whiteday (near) ${ }^{3} \ldots \ldots$. & 2,539 & & & & For oil or gas. \\
\hline $\begin{array}{l}\text { Marshall County: } \\
\text { Adaline ( } 3 \text { miles north- }\end{array}$ & 2,970 & & & & \\
\hline $\begin{array}{l}\text { east). }{ }^{4} \\
2 \text { miles southwest } 5\end{array}$ & 2,869 & & & & Good oil well. \\
\hline $\begin{array}{l}3 \text { to } 4 \text { miles south- } \\
\text { west. } \\
\text { Aduline }(2 \text { miles north })^{\circ}\end{array}$ & 3,085 & & & & $\begin{array}{l}\text { Oil at } 3,075 \text { feet; gas at } \\
3,085 \text { feet. }\end{array}$ \\
\hline $\begin{array}{l}\text { Adaline ( } 2 \text { miles north)" } \\
\text { Belleton (one-half mile } \\
\text { west). } 7\end{array}$ & $\begin{array}{l}2,798 \\
3,225\end{array}$ & & & & Oil and gas. \\
\hline Cameron (near) ${ }^{8} \ldots \ldots$ & 3,249 & & & & For oil or gas. \\
\hline $\begin{array}{l}2 \text { miles south west }{ }^{9} \ldots \\
1 \text { mile west }{ }^{9} \ldots \ldots\end{array}$ & $\begin{array}{l}2,810 \\
2,913\end{array}$ & & & & \\
\hline Elmgrove Post-office ( $3 \frac{i}{2}$ & 904 & & & & "Gas on top; best well in \\
\hline $\begin{array}{c}\text { miles southeast) }{ }^{10} \\
\text { Do. }{ }^{10} \ldots \ldots \ldots \ldots \ldots \ldots\end{array}$ & 970 & & & & $\begin{array}{l}\text { this field." } \\
\text { "Struck oil at about } 945 \\
\text { feet, and shot with } 60 \\
\text { quarts below thi depth } \\
\text { which shut off the oil } \\
\text { and opened up the gas." } \\
\text { "Use gas for drilling pur- }\end{array}$ \\
\hline & & & & & $\begin{array}{l}\text { poses, piped to Elm- } \\
\text { grove, probably } 2,000,000 \\
\text { feet, with rock , Fressure } \\
\text { of } 260 \text { pounds." }\end{array}$ \\
\hline $\begin{array}{l}3 \text { miles southeast } 11 \text {.. } \\
\text { Franklin district } 12\end{array}$ & $\begin{array}{l}1,050 \\
2,616\end{array}$ & & & & \\
\hline Garret (near) $7 . . . . . . .$. & 3,249 & & & & \\
\hline Liberty Township ${ }^{13} \ldots .$. & 2,984 & & & & $\begin{array}{l}\text { For oil or gas; unoroduc- } \\
\text { tive. }\end{array}$ \\
\hline $\begin{array}{l}\text { Liberty Distriet } 14 \ldots \ldots . . . \\
\text { Loudensville }(5 \text { miles }\end{array}$ & $\begin{array}{r}2,656-3,108 \\
1,935\end{array}$ & & & & For oil or gas. \\
\hline north) 15 & & & & & 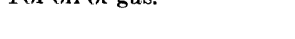 \\
\hline $\begin{array}{l}\text { Majorsville (near) }{ }^{16} \ldots \ldots \\
\text { Do. }{ }^{17} \ldots \ldots \ldots \ldots \ldots\end{array}$ & $\begin{array}{l}2,603 \\
1,055\end{array}$ & & & & Gas well. \\
\hline Meade district ${ }^{18} . \ldots \ldots \ldots$ & $2,477-2,949$ & & & & For oil or gas. \\
\hline Moundsville (east edge) ${ }^{19}$ & $\left\{\begin{array}{l}2,579 \\
1,165\end{array}\right.$ & & & & Do. \\
\hline near $=\ldots \ldots \ldots \ldots$ & $\begin{array}{r}1,465 \\
1,470\end{array}$ & & & & For oil or gas. \\
\hline vicin & $1,400-1,413$ & & & & Several oil wells. \\
\hline theast ${ }^{21}$.. & 578 & & & & Numerous oil well: \\
\hline 5 miles east ${ }^{2} \ldots \ldots \ldots$ & 2,707 & & & & Dry. \\
\hline Pioneer (1mile west) ${ }^{12} .$. & 2,999 & & & & Gats, 2,980 to 2,990 feet. \\
\hline $\begin{array}{l}\text { Rosebys Rock station } \\
\text { (near). } 23\end{array}$ & 2,920 & & & & \\
\hline St.Joseph Post-Office 5 ... & 2,945 & & & & \\
\hline 2 miles northeast $23 \ldots$ & $\begin{array}{l}2,974 \\
2,747\end{array}$ & & & & 2 wells. \\
\hline$\underset{\text { west. } 24}{\text { one-half mile north- }}$ & 2,875 & & & & \\
\hline Webster District ${ }^{25} \ldots \ldots$ & 2,756 & & & & \\
\hline Mason County: & & & & & \\
\hline $\begin{array}{l}\text { Brighton (mile } 1 \text { south). }{ }^{26} \\
\text { Clutton }\end{array}$ & 2,400 & $8 \frac{1}{4}-4 \frac{7}{8}$ & & & For oil or gas. \\
\hline $\begin{array}{l}\text { Clitton }(\text { near) } \\
\text { Letart }\end{array}$ & $\begin{array}{l}1,800 \\
2,139\end{array}$ & & & & Do. \\
\hline $\begin{array}{l}\text { Point Pleasant }(6 \text { miles } \\
\text { below })^{28}\end{array}$ & 2,942 & & & & Do. \\
\hline $2 \mathrm{mi}$ & $1, \in 77$ & $13-4_{8}^{7}$ & & & Do. \\
\hline
\end{tabular}

1 Record, W. Va, Geol. Surv, Rept., vol. 1 (a), 1904, p. 167.

2 W. Va. Geol. Surv. Rept., vol. 1, 348.

3 Record, ibid., vol. 1 (a), 1904, pp. 151-152.

4 Ibud., pp. 215-216.

slbid., p. 218 .

Ibid., p. 219.

ilbid., p. 214.

8 W. Va. Geol. Surv. Rept., vol. 1, p. 350.

9 Record, ibid., vol, 1(a), 1104, p. 215.

10 Ibid., 225.

11 lbid., p. 226.

12 Ibid., p. 222

${ }_{13}$ Record, Pa. $2 d$ Geol. Surv. Rept., vol. $1^{5}$, pp. $328-329$.

14 Record, W. Va. Geol. Surv. Rept., vol.1(a), pp. 216-217.
$15 \mathrm{~W}$. Va. Geol, Surv. Rept., vol. 1, pp. 351-352. 16 Record, ibid., vol, 1(a), 1904, pp. 227-229.

17 Ibid, , p. 230.

18 Ibid., pp. 220-222.

19 Ibid., pp. 223-224.

20 Ibid., vol 1, 1899, pp. 362-363.

21 lbid, p. 364 .

22 Ibid., p, 223

23Ibid., pp. 218-219.

24 Ibid, pp. 219-220.

25 Ibid., p. 224

26 Ibid., pp. 481-482.

27 Ibid. vol. 1, 1899, pp. 281-282; vol. 1 (a), 1904, pp. $479-481$.

28 Ibid., pp. 273-274

29 Ibld., vol., 1(a), 1904, p. 481. 
WEST VIRGINIA-Continued.

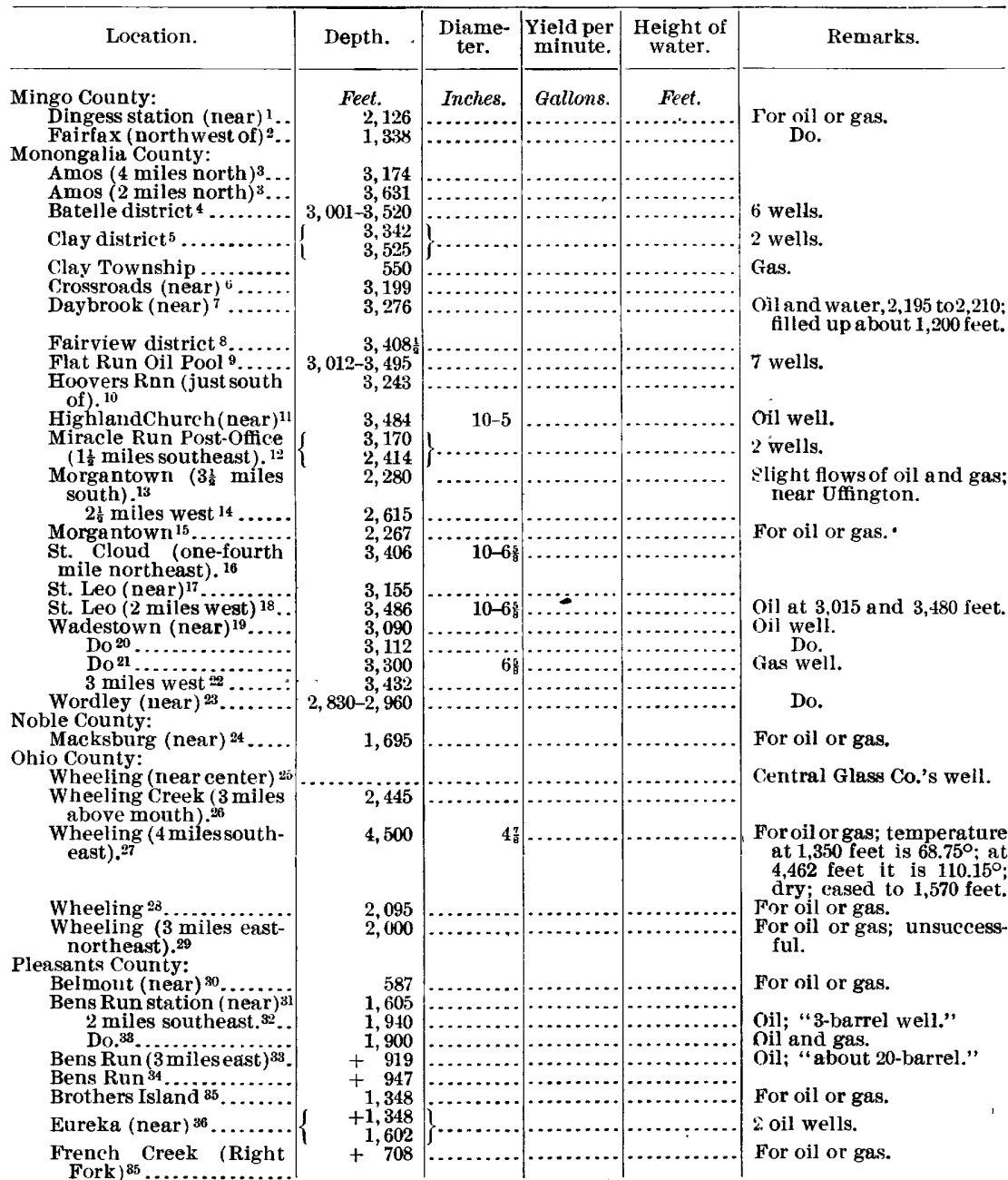

1 Record, W. Va. Geol Surv, Rept., vol. 1, 1899 ,

pp. 278-280; U. S. Geol. Surv. Follo No. 69, p. 4.

Ibid., pp. $276-277$.

3 Ibid., vol. 1 (a), 1904, pp. 140-141.

4 Ibid., pp. 143-150.

5 Ibid., p. 140.

6 Ibid., pp. 142-143.

7 Ibid., pp. 135-136.

8 Ibid., p. 141

9 Ibid., p. 136-139.

10 Ibid , p. 146.

11 Ibid., vol. 1, 1899, pp. 231-232

12 Ibid., vol. 1 (a), 1904, p. 139 .

13 Ibid., pp. 133-134.

14 Ibid., pp. 134-135.

16 Record, Pa. $2 d$ Geol. Surv. Rept., Vol. I5, p. 329.

16 Record, W. Va. Geol. Surv. Rept., vol. 1 (a), 1904, p. 150.

17 Ibid., pp. 147-148.

18 Ibid., p. 148.

19 Ibid., vol. 1, pp. 233-234.

20 Ibld., pp. 232-233.
21 Ibid., pp. 230-231; vol. 1 (a), 1904, p. 147.

22 Ibid., vol: 1 (a), 1904, pp. 148-149.

23 Ibid., vol. 1, pp. 234-237.

24 Ibid., pp. 298-299.

25 W. Va. Geol. Surv. Ropt., vol. 1 (a), 1904, p. 230

20 Record, ibid., p. 231.

27 W. Va. Geol. Surv. Rept., vol. 1, pp. 364-365 record of temperatures, Am. Assoc. Adv. Sci. Proc., 1891 , p. 258 (description pp. 446-457); W. Va. Geol Surv. Rept., vol. 1 (a), 1 vi, p. 230.

28 Record, ibid , p. 366. vol. 1 (a), 1904, p. 94.

29 Record, Pa 2 d̀ Geol. Surv. Ann. Rept., 1886 part 2, pp. 781-782.

3" Record, W. Va. Geo'. Surv. Rept., vol. 1 (a) 1904 , p. 277.

31 Ibid., p. 269.

32 Ibid., p. 272 .

3s Ibid., p. 273.

34 Ibid., p. 279.

35 Ibid., p. 280.

36 W. Va. Geol. Surv. Rept, vol. 1, pp. 351-352; vol. 1 (a), 1904, pp. 280-281. 
WEST VIRGINLA-Continued.

\begin{tabular}{|c|c|c|c|c|c|}
\hline Location. & Depth. & $\begin{array}{c}\text { Diame- } \\
\text { ter. }\end{array}$ & $\begin{array}{l}\text { Yield per } \\
\text { minute. }\end{array}$ & $\begin{array}{l}\text { Height of } \\
\text { water. }\end{array}$ & Remarks, \\
\hline Pleasants County-Cont'd. & Feet. & $I_{7}$ & & & \\
\hline Grant district ${ }^{1} \ldots .$. & $\begin{array}{l}1,481 \\
2,000\end{array}$ & & & & 2 wells, for oil. \\
\hline $\begin{array}{r}\text { Hebron }(\text { near })^{2} \ldots \ldots \ldots \ldots \\
\text { Do. }^{3}\end{array}$ & $\begin{array}{l}2,080 \\
2,012\end{array}$ & & & & $\begin{array}{l}\text { For oil or gas. } \\
\text { Do. }\end{array}$ \\
\hline Jefferson district 1. & $\begin{array}{l}+\quad b 76 \\
+\quad 636\end{array}$ & & & & 3 wells, for oil. \\
\hline Do. ${ }^{1} \ldots$ & $\begin{array}{r}623 \\
1,470\end{array}$ & & & & Oil and gas. \\
\hline Lafayette district 4 & $+2,181$ & & & & 2 wells; for oil or gas. \\
\hline Lytton (near) ${ }^{5} \ldots \ldots \ldots \ldots$ & $\begin{array}{l}2,100 \\
1,770 \\
2,090\end{array}$ & & & & For oil or gas. \\
\hline $\begin{array}{r}1 \text { mile east }{ }^{3} \\
\text { Middle Island Creek }\end{array}$ & $\begin{array}{l}2,0 \leq 0 \\
1,779 \\
1,932\end{array}$ & & & & $\begin{array}{l}\text { " } 5 \text { to } 10 \text {-barrel well;" oil. } \\
\text { For oil or gas (C. B. Bar- }\end{array}$ \\
\hline Iron Bridge ${ }^{7} \ldots \ldots \ldots$ & $+\quad 614$ & & & & $\begin{array}{l}\text { ker well No. } 1) \\
\text { For oil or gas. }\end{array}$ \\
\hline $\begin{array}{l}7 \text { miles from mouth } 7 \text {. } \\
\text { Parkersburg }\{5 \text { mil es }\end{array}$ & $+\begin{array}{r}530 \\
2,075\end{array}$ & & & & $\begin{array}{l}\text { Do. } \\
\text { No oil or gas. }\end{array}$ \\
\hline $\begin{array}{l}\text { Raven Rock ( } 3 \mathrm{miles} \\
\text { east). } 7\end{array}$ & +814 & & & & For oil or gas. \\
\hline St. Marys ( 6 miles east $)^{\top}$. & +826 & & & & \\
\hline St. Marys (2 miles south $)^{7}$ & $\begin{array}{l}+\quad 468 \\
+\quad 480\end{array}$ & & & & 2 wells, Dotsor farm, Nos. \\
\hline 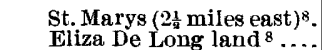 & $\begin{array}{r}600-1,000 \\
649-996\end{array}$ & $\begin{array}{l}8 \frac{1}{4}-6 \frac{1}{4} \\
8 \frac{1}{4}-6 \frac{1}{4}\end{array}$ & & & $\begin{array}{l}\text { Many wells; for oil or gas. } \\
\text { Several wells. }\end{array}$ \\
\hline $\begin{array}{l}\text { Sugar Creek (3-4 miles } \\
\text { from mouth) } .^{7}\end{array}$ & $\begin{array}{r}+686 \\
+680\end{array}$ & & & & For oil or gas. \\
\hline Union District ${ }^{9} \ldots \ldots \ldots$ & 1,871 & & & & Do. \\
\hline Waverly ( $1 \frac{1}{8}$ miles east $)^{1}$ & 1,438 & & & & $\begin{array}{l}\text { Water, } 1,180 \text { to } 1,220 \text { feet; } \\
\text { gas, } 1,413 \text { feet; oil, } 1,423 \\
\text { and } 1,428 \text { feet. }\end{array}$ \\
\hline Township unknown..... & 2,309 & & & & Dry. \\
\hline $\begin{array}{l}\text { Preston County: } \\
\quad \text { Bretz (near) }{ }^{10} \ldots \ldots \ldots \ldots\end{array}$ & 2,000 & & & & For oil or gas; failure. \\
\hline Henry ...................... & 703 & $4 \frac{1}{9}$ & & & \\
\hline $\begin{array}{r}\text { Newburg }{ }^{11} \ldots \ldots \ldots \\
\text { Do } \ldots \ldots \ldots\end{array}$ & $\begin{array}{r}3,004 \\
865\end{array}$ & & & & For gas; unsuceessful. \\
\hline Putnam County: & 8000 & & & & \\
\hline $\begin{array}{l}\text { Buffalo (near) ............ } \\
\text { Hurricane (near) } 12 . . . .\end{array}$ & $\begin{array}{r}400 \\
2,198\end{array}$ & & & & Gas and oil; neither in \\
\hline$\underset{\text { north })_{.12}^{\text {House }}}{\text { Red }}$ (3 miles & 1,875 & $10-4 \frac{7}{8}$ & & & Small show of oil. \\
\hline Winfield................... & 500 & & & & 2 wells \\
\hline Winfield (1 mile below) is & 1,670 & & & & Oil well. \\
\hline eld (1 mile south) 14 & 2,603 & & & & For oil or gas. \\
\hline $\begin{array}{l}\text { Winfield (2 miles south) } \\
\text { Randoiph County: }\end{array}$ & 2,603 & & & & Do. \\
\hline $\begin{array}{l}\text { Randoiph County: } \\
\text { Beaver Creek (1 mile }\end{array}$ & 431 & & & & \\
\hline $\begin{array}{l}\text { north). } 15 \\
\text { Ritchie County: }\end{array}$ & & & & & \\
\hline Auburn (near) $16 \ldots \ldots$ & 1,940 & & & & Do. \\
\hline $\begin{array}{l}\text { Berea ( } 1 \text { to } 2 \text { miles north- } \\
\text { east) } 17\end{array}$ & $1,775-2,062$ & & & & Several oil wells. \\
\hline$\underset{\text { well). } 18}{\text { Cabin }}$ Run (tollgate & 2,712 & & & & For oil or gas. \\
\hline Cairo ${ }^{19} \ldots \ldots \ldots \ldots$ & 2,060 & & & & Do. \\
\hline $1 \frac{1}{2}$ miles northwest 20 & 1,735 & & & & Do. \\
\hline 4 miles northeast $21 .$. & 2,142 & & & & Do. \\
\hline $\begin{array}{l}8 \text { miles sothth }{ }^{23} \ldots \ldots \ldots \\
\text { Vicinity } 23\end{array}$ & $\begin{array}{r}1,652 \\
1,469-2,045\end{array}$ & & & & $\begin{array}{l}\text { Small supply of oil. } \\
\text { Many wells: fo-oil and gas. }\end{array}$ \\
\hline Corn wallis (vicinity) 24. & $1,473-1,657$ & & & & 5 wells; for oil or gas. \\
\hline $\begin{array}{l}\text { Ellenboro } \\
\text { north). }\end{array}$ & 1,788 & & & & Oil well; "5-barrel well." \\
\hline $\begin{array}{l}3 \frac{1}{2} \text { miles from } 26 \\
\text { Flannagan Field } 27, \ldots\end{array}$ & $\begin{array}{l}1,782-1,828 \\
1,770-2,120\end{array}$ & & & & $\begin{array}{l}\text { Several oil and gas wells. } \\
\text { Many oil and fas wells. }\end{array}$ \\
\hline
\end{tabular}

1 Record, W. Va. Geol. Surv. Rept., vol. 1 (a), 1904, p. 278.

2 W. Va. Geol. Surv, Rept., vol. 1, p. 360.

3 Record, ibid., vol. 1 (a), 1904, p. 275 :

4 Ibid., p. 276

5 Ibid., p. 272.

Ibid., pp. 273-274.

7 Ibid., p. 279.

8 W. Va. Geol. Surv. Rept., vol. 2. p. 276, 277

${ }^{9}$ Record, ibid., vol. 1 (a), 1904, p. 273.

${ }^{10}$ W. Va. Geol. Surv. Rept., vol. 1 (a), 1904, p. 342.

11 Record, ibid., pp. 342-344.

12 Ibid., p. 483 .

13 W. Va. Geol. Surv. Rept., vol. 2, p. 401; U, S

Geol. Surv, Folio No. 72, p. 3 .
14 Recor d,ibid., vol. 1 (a), 1904, p. 482.

15 W. Va. Geol. Surv. Rept., vol. 2 , pp. 360-361.

16 Record, ibid, vol. 1 (a), 1904, p. 425 .

17 Ibid., pp. 422-424.

18 Ibid. 406

19 W. Va. Geol. Surv. Rept., vol. 1, 1899, p. 302.

20 Ibid., pp. 303-304.

21 Ibid., pp. 305-307.

22 Ibid., pp. 308-309

${ }^{23}$ Record, ibid., vol. 1 (a), 1904,pp. 480-430.

24 Ibid., pp. 428-429.

25 Ibid., p 409.

26 Ibid, , vol. 1, pp. 311-315.

27 Ibid., vol. 1 (a) , 1904, pp. $420-422$. 
WEST VIRGIN IA-Continued.

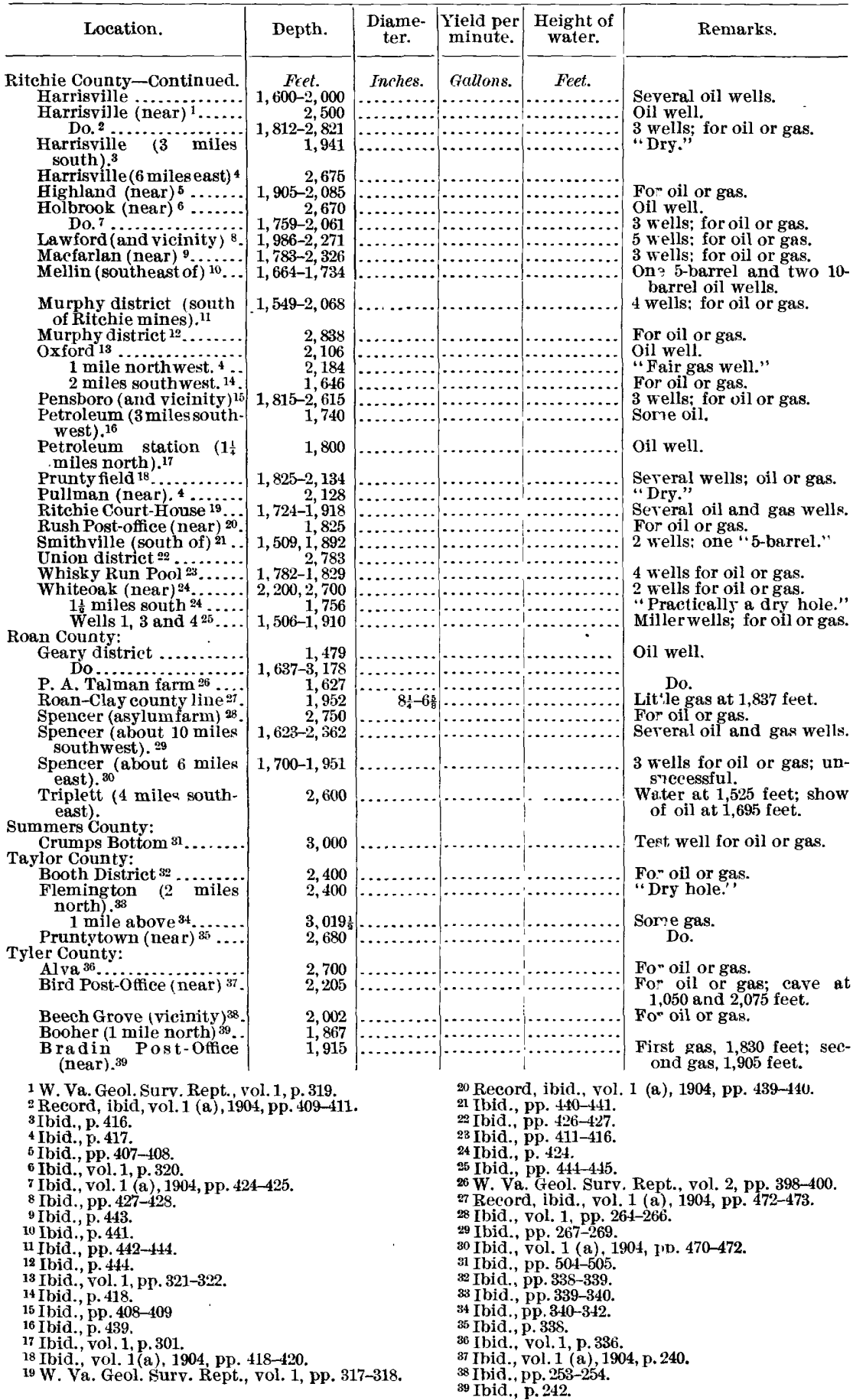


WEST VIRGINIA - Continued.

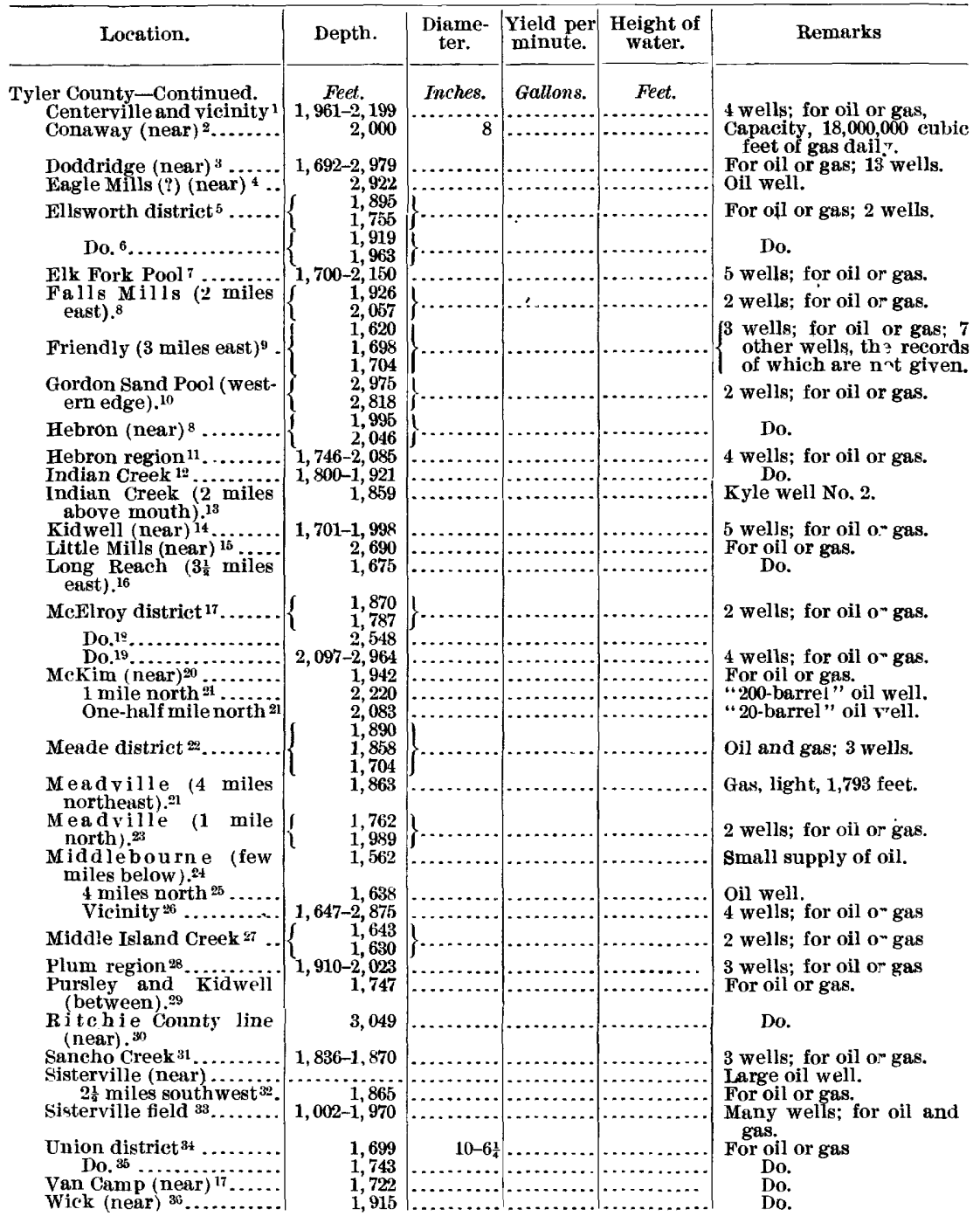

1 Record, W. Va. Geol. Surv. Rept., vol. 1 (a), 1904, pp. 252-253.

2 Ibid., p. 250.

3 Ibid,, pp. 242-245.

4 Ibid., vol. 1, pp. 334-335.

5 Ibid., vol. 1 (a), 1904, pp. 240-241.

6 Ibid., pp. 249-250.

I Ibid., pp. 250-252.

8 Ibid., p. 256.

9 Ibid., pp. 266-267.

10 Ibid., pp. $246-247$.

11 Ibid., pp. 261-262.

12 Ibid., pp. 241-242.

13 Ibid., vol. 1, p. 358.

14 Ibid., vol. 1 (a), 1904, pp. 249-250, 252

15 W. Va. Geol. Surv. Rept., vol. 1, p. 335.

16 Record, ibid., vol. 1 (a), 1904, p. 266.

17 Ibid., p. 240.

18 Ibid., p. 241 .
19 Ibid., pp. 244,246 and 247.

20 Ibid., vol. 1, p. 359.

21 Record, ibid., vol. 1 (a), 1904, p. 253.

22 Ibid., pp. 260-261.

23 Ibid., p. 257

24 W. Va. Geol. Surv. Rept., vol. 1, p. : 261 .

25 Ibid., p. 360.

20 Record, ibid., vol. 1 (a), 1904, p. 248.

27 Ibid., pp. 255-256.

28 Tbid., p. 254.

29 Ibid., p. 268.

80 Ibid., p. 259.

31 Ibid., p. 255.

33 Ibid., vol. 1, p. 357.

33 Ibid., vol. 1 (a), 1904, pp. 262-265.

34 Ibid., p. 250.

35 Ibid., pp. 267-268.

36 W. Va. Geol. Surv. Rept., vol. 1, p. 359. 
WEST VIRGINIA-Continued

\begin{tabular}{|c|c|c|c|c|c|}
\hline Location. & Depth. & $\begin{array}{c}\text { Diame- } \\
\text { ter. }\end{array}$ & $\mid \begin{array}{c}\text { Yield per } \\
\text { minute. }\end{array}$ & $\begin{array}{l}\text { Height of } \\
\text { water. }\end{array}$ & Remarks. \\
\hline Tyler County-Continued, & Feet. & & Gallon & & \\
\hline $\begin{array}{l}\text { miles south) }{ }^{1} \ldots \\
\text { ear) }{ }^{2} \ldots \ldots \ldots \ldots \ldots\end{array}$ & $\begin{array}{r}2,101 \\
1,254-1,932\end{array}$ & & & & $\begin{array}{l}\text { Oil well. } \\
3 \text { vells; for oil or gas. }\end{array}$ \\
\hline Wilbur (one-half mile & 1,972 & & & & Fcr oil or gas. \\
\hline $\begin{array}{l}\text { south) } \\
\text { South Penn Oil Co. }\end{array}$ & & & & & \\
\hline $\begin{array}{l}\text { Upshur County: } \\
\text { Buckhannon }\end{array}$ & & & & & \\
\hline $\begin{array}{l}\text { non } \ldots \ldots \ldots \ldots \\
\text { rtheast }{ }^{5} \ldots \ldots \ldots \ldots\end{array}$ & 2,530 & & & & $\begin{array}{l}\text { For oil. } \\
\text { Some oil and gas shows. }\end{array}$ \\
\hline ear station ${ }^{6} . . . .$. & & & & & Showing of gas. \\
\hline Wayne County: & & & & & \\
\hline $\begin{array}{l}\text { Big Sandy River (near } \\
\text { Blaine Creek mouth).7 }\end{array}$ & 1,845 & & & & Gr.s. \\
\hline $\begin{array}{l}\text { Catlettsburg (1 } 1 \frac{1}{2} \text { miles } \\
\text { south).8 }\end{array}$ & 2,132 & & & & Fcr oil or gas. \\
\hline $\begin{array}{l}\text { Twelvepole Creek } \\
\text { (Arkansas Branch } \\
\text { mouth).9 }\end{array}$ & 1,968 & & & & \\
\hline ity: & 1,807 & & & & Fcr oil or gas; salt water \\
\hline & 1,000 & 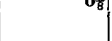 & & & at 1,125 feet. \\
\hline $\begin{array}{l}\text { Witzel Cor } \\
\text { Brash }\end{array}$ & 3,053 & & & & Ge,s. \\
\hline ear) ${ }^{11}, \ldots \ldots \ldots$ & 2,611 & & & & Water at 2,080 feet; gas at \\
\hline & 2,753 & & & & For oil o \\
\hline $\begin{array}{l}\text { iles east } \\
13\end{array}$ & $2,263-3$ & & & & r oil or gas. \\
\hline Center distriet 14 & 3,083 & & & & 45 barrel well. \\
\hline ict.......... & $2,265-2,971$ & & & & dry. \\
\hline southeast). & $\begin{array}{r}2,016-3,375 \\
3,157\end{array}$ & & & & \\
\hline Dulany ( & & & & & 207 to 300 barrels of oil. \\
\hline Eastern Wetzel $17 . . . \ldots$. & $2,050-3,273 \frac{1}{2}$ & & & & lls. \\
\hline Do. ${ }^{18} \ldots \ldots \ldots$ & $\left\{\begin{array}{l}2,043 \\
2,847\end{array}\right\}$ & & & & $\left\{\begin{array}{l}\text { wells: authority, South } \\
\text { Penu oil Co. }\end{array}\right.$ \\
\hline Folsom & 3,560 & $10-5$ & & & Deepest producing well \\
\hline $\begin{array}{r}1 \text { to } 2 \text { miles from } 19 \\
\text { Grant district } 20 . . . . . . .\end{array}$ & $\begin{array}{r}3,053-3,451 \\
3,195\end{array}$ & & & & $\begin{array}{l}\text { For oil and gas. } \\
\text { Gr. well. }\end{array}$ \\
\hline Do. ${ }^{21} \ldots \ldots \ldots \ldots \ldots$ & $\left\{\quad 2,939 \frac{1}{2}\right.$ & & & & 2 wells. \\
\hline Do. $22 \ldots \ldots$ & 2,859 & & & & \\
\hline Do. $₫ 3 \ldots \ldots$ & 3,159 & & & & Do. \\
\hline Do. ${ }^{24} \ldots \ldots$ & $\cdot \quad 3,044$ & & & & Gàs well. \\
\hline & $2,808-3,540$ & & & & Gas anid oil. \\
\hline$[\ldots \ldots \ldots \ldots \ldots \ldots, \ldots$ & $2,146-3,317 \frac{1}{2}$ & & & & $\begin{array}{l}\text { For oil or'gas! } \\
\text { Do. }\end{array}$ \\
\hline triet & $\begin{array}{l}2,140-3,317 \\
2,772-3,136\end{array}$ & & & & 3 gas wंells; 1 well dry. \\
\hline & $3 \quad 3,249$ & & & & Gas well. \\
\hline $\begin{array}{c}\text { Jacksonburg }(3 \mathrm{mil} \text { es } \\
\text { northeast) } 28\end{array}$ & $1,838-3,067$ & & & & $\therefore \ldots$ \\
\hline 1 mile southeast 29 & $\begin{array}{r}2,297-2,697 \\
2,590\end{array}$ & & & & 5 wells. \\
\hline Near $31, \ldots \ldots . . . . . .$. & $\left\{\begin{array}{l}2,571 \\
2,605\end{array}\right.$ & & & & 2 wells. \\
\hline 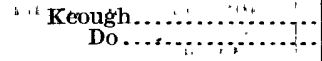 & $\begin{array}{l}2,6035 \\
3,200\end{array}$ & $\begin{array}{l}13-6 \\
10-6 \frac{5}{6}\end{array}$ & & & Gas well; \\
\hline 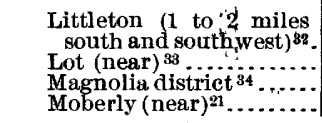 & $\begin{array}{r}2,972-3,377 \\
2,588 \\
2,843 \\
2,002\end{array}$ & & & & $\begin{array}{l}5 \text { wells; for oil or gas. } \\
\text { For oil or gas. } \\
\text { Gas. }\end{array}$ \\
\hline \multicolumn{3}{|c|}{ 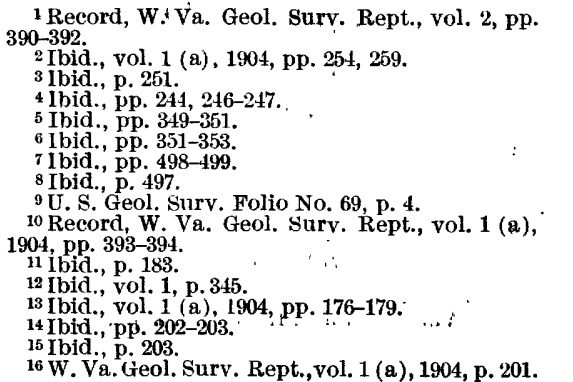 } & \multicolumn{3}{|c|}{ 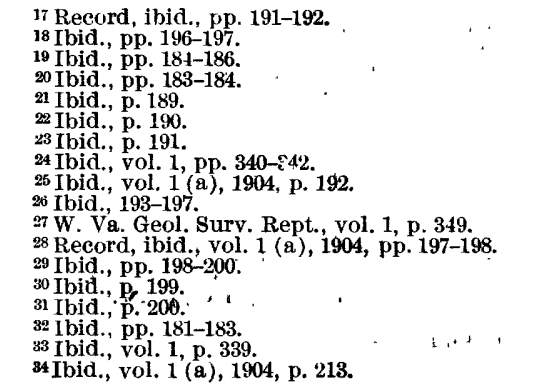 } \\
\hline
\end{tabular}


WEST VIRGINIA - Continued.

\begin{tabular}{|c|c|c|c|c|c|}
\hline Location. & Depth. & $\begin{array}{l}\text { Diame- } \\
\text { ter. }\end{array}$ & $\begin{array}{l}\text { Yield per } \\
\text { minute. }\end{array}$ & $\begin{array}{l}\text { Height of } \\
\text { water. }\end{array}$ & Remarłs. \\
\hline $\begin{array}{l}\text { Witzel County-Continued. } \\
\text { Pine Grove (3 miles }\end{array}$ & $\begin{array}{l}\text { Fect. } \\
3,011\end{array}$ & & & & Oil; 150-barrel well. \\
\hline northeast). 1 & & & & & Oil, low-diarel wen. \\
\hline $\begin{array}{l}4 \text { miles northeast }{ }^{1} . . \\
\text { Near }^{1} \ldots \ldots \ldots \ldots \ldots \ldots\end{array}$ & $\begin{array}{l}3,460 \\
2,822\end{array}$ & & & & \\
\hline Piney Fork $2 \ldots \ldots \ldots \ldots$ & 2,640 & & & & For oil or gas. \\
\hline $\begin{array}{r}\text { Do. } \\
\text { Proctor district } 4 \ldots \ldots \ldots\end{array}$ & $\begin{array}{l}2,040-3,187 \\
2,100-2,980\end{array}$ & & & & $\begin{array}{l}20 \text { wells; for oil and gas. } \\
5 \text { wells; for oil or gas. }\end{array}$ \\
\hline $\begin{array}{l}\text { Reader Post-Ofice } \\
\text { miles southwest }) .\end{array}$ & 3,037 & & & & \\
\hline $\begin{array}{l}\text { Robinsons Mill ( } 1 \frac{1}{9} \text { miles } \\
\text { east) } 6\end{array}$ & 3,105 & & & & \\
\hline Silver Hill (near) ${ }^{7} \ldots \ldots \ldots$ & 2,710 & & & & $\begin{array}{l}\text { Upper Freepcrt coal at } \\
575 \text { feet. }\end{array}$ \\
\hline $\begin{array}{l}\text { Sincerity ( } 1 \text { mile north- } \\
\text { west). } 8\end{array}$ & 3,211 & & & & Good gas well. \\
\hline $\begin{array}{l}1 \text { mile south west } 8 . \\
1 \frac{1}{2} \text { miles southeast } 8 . .\end{array}$ & $\begin{array}{l}3,064 \\
3,496\end{array}$ & & & & Dry hole. \\
\hline $1 \frac{1}{3}$ miles north $8 . .$. & $\begin{array}{l}3,496 \\
3,386\end{array}$ & & & & Oil and gas. \\
\hline$\underset{\text { northeast }) .9}{\text { Smithfield }}(1$ mile & $3 ; 092$ & & & & \\
\hline Smithfield region ${ }^{9} \ldots .$. & $1,120-3,106$ & & & & \\
\hline Smithfield (near) ${ }^{10} \ldots \ldots$ & 3,282 & & & & Oil well. \\
\hline $\begin{array}{l}2 \text { miles northeast } 11 . . \\
\text { Uniontown }\end{array}$ & $\begin{array}{r}3,106 \\
\\
\end{array}$ & & & & Do. . \\
\hline $\begin{array}{l}\text { east). } 12 \\
\text { Willey Fork (between }\end{array}$ & J, & & & & Faiv gas well. \\
\hline $\begin{array}{l}\text { Sincerity and Co- } \\
\text { burn). } 13\end{array}$ & 2,781 & & & & Fair gas well. \\
\hline $\begin{array}{c}\text { Wileyville }(2 \text { miles } \\
\text { northeast }) .14\end{array}$ & 3,067 & & & & $\begin{array}{l}\text { Gas and oil at } 3,048 \text { feet; } \\
\text { second pay at } 3,059 \text { feet. }\end{array}$ \\
\hline $2 \frac{1}{2}$ miles east 14 & 3,358 & & & & 12-barrel well; oil. \\
\hline $1 \frac{1}{3}$ miles northeast 15 & $\begin{array}{l}3,157 \\
3,116\end{array}$ & & & & $\begin{array}{l}\text { 15-barrel well; oll. } \\
\text { 20-barrel well; oil. }\end{array}$ \\
\hline 3 miles east ${ }^{16}$. & $\begin{array}{l}3,228 \\
3,270\end{array}$ & & & & 10-barrel well: oil. \\
\hline 4 miles northeast $17 .$. & 3,162 & & & & 20-barrel well; oil. \\
\hline Township unknown ... & $2,777-3,010$ & & & & 3 wells; gas and oil. \\
\hline 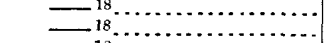 & $\begin{array}{r}2,900 \\
2,720-2,801\end{array}$ & & & & 3 wells. \\
\hline Wirt County: ${ }^{18} \ldots \ldots \ldots \ldots$ & 3,392 & & & & \\
\hline $\begin{array}{c}\text { Burning Springs (near) is } \\
\text { Do. }{ }^{20} \ldots \ldots \ldots \ldots \ldots\end{array}$ & $\begin{array}{r}2,010 \\
428-1,128\end{array}$ & & & & $\begin{array}{l}\text { Oil well. } \\
3 \text { oil wells. }\end{array}$ \\
\hline Devers Forks 1 . & 1,480 & & & & \\
\hline Elizabeth ( $4 \frac{1}{2}$ mileseast) 22 & 2,380 & & & & \\
\hline $\begin{array}{l}6 \text { miles west-south- } \\
\text { west). }{ }^{23}\end{array}$ & 2,806 & & & & Dry. \\
\hline 9 miles west-south- & 2,802 & & & & Do. \\
\hline $\begin{array}{c}\text { Munday }\left(1 \frac{1}{3} \text { miles south- }\right. \\
\text { west }) .22\end{array}$ & 2,205 & & & & Oil well. \\
\hline $\begin{array}{c}\text { Northwest corner of } \\
\text { Wirt.26 }\end{array}$ & $\begin{array}{l}1,902 \\
1,795\end{array}$ & . & & & 2 oil wells. \\
\hline Wood County: & & & & & \\
\hline $\begin{array}{l}\text { Chesterville (near) }{ }^{26} \\
\text { Hendershot field }{ }^{27} \ldots\end{array}$ & $\begin{array}{r}2,172 \\
2,145-2,332\end{array}$ & & & & $\begin{array}{l}\text { For oil or gas. } \\
\text { fany yells for oil or gas. }\end{array}$ \\
\hline Kanawha Station (neat) & $\begin{array}{r}2,1+3-2,002 \\
2,206 \frac{1}{2}\end{array}$ & .... & & & For oil or gas. \\
\hline Murphytown (vicinity) ${ }^{29}$ & 2,177 & & & & Do. \\
\hline $\begin{array}{c}\text { Do. }{ }^{30} \ldots \ldots \ldots \ldots \ldots \\
\text { Parkersburg (near) }\end{array}$ & $2,200-2,365$ & & & & Several welly for oill or gas. \\
\hline iles northeast $3 \$$ & $\begin{array}{l}2,000 \\
3,016\end{array}$ & & & & $\begin{array}{l}\text { For out or gas. } \\
\text { Do. }\end{array}$ \\
\hline & & & & & \\
\hline
\end{tabular}

1 Record, W. Va. Geol. Surv. Rept., vol. 1 (a)

18 Ibid. pp. 189-193: authority, South Penn Oil Co. 1904, pp. 205-206.

2 W. Va. Geol. Surv., Rept., vol. 1, p. 337.

3 Record, ibid,, vol. 1(a), 1904, pp, 206-211

4 Ibid., pp. $212-213$.

5 Ibid., p. 211

6 Ibid, p. 184

7 Ibid., pp. 200-201.

8 Ibid., pp. 180-181.

9 Ibid., pp. 186-189.

${ }^{10} \mathrm{~W}$. Va. Geol. Surv., Rept., vol. 1, p 343.

11 Ibid., pp. 343-344.

19 W. Va. Geol. Surv. Rept., vol.-1, pp. 262-263; vol. 1 (a), 1904, pp. 463-464.

${ }_{20}$ Record, ibid., yol. 1 (a), 1904, p. 464

21 Ibid, pp. 465-466.

22 Ibid., p. 467.

23 Ibid., pp. 467-468.

24 Ibid., p. 468.

25 Ibid., pp. 466-467.

26 Ibid., p. 462.

27 Ibid., pp. 452-455.

28 Ibid., pp. 447-448.

29 W. Va. Geol. Surv. Rept., vol. 1, pp. 292-294.

30 Record, ibid., vol. 1 (a), 1904 , pp. 456-457.

31 W. Va. Geol. Surv. Rept., vol. 1, p. 285.

13 Ibid.. p. 201.

14 Ibid., p. 202

15 Ibid., p. 203.

16 Ibid., p. 204

32 Ibid, pp. 296-298.

17 Ibid., pp. 204-205.

33 Record, ibid., vol. 1(a), 1904, pp. 460-461. 
WEST VIRGINIA-Continued.

\begin{tabular}{|c|c|c|c|c|c|}
\hline Location. & Depth. & $\begin{array}{c}\text { Diame- } \\
\text { ter. }\end{array}$ & $\begin{array}{l}\text { Yield per } \\
\text { minute. }\end{array}$ & $\begin{array}{l}\text { Height of } \\
\text { water. }\end{array}$ & Remarks. \\
\hline 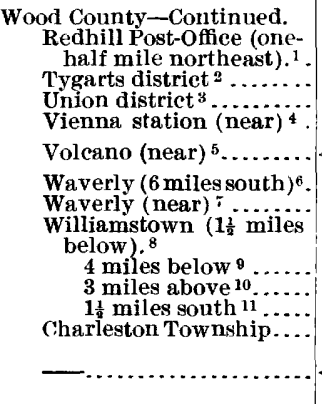 & 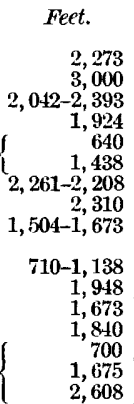 & Inches. & Gallons. & Feet. & $\begin{array}{l}\text { For oil or gas. } \\
\text { Do. } \\
\text { Many wells for oil or gas. } \\
\text { For oil or gas. } \\
2 \text { wells for oil or gas. } \\
\text { Two oil wells. } \\
\text { For oil or gas. } \\
\text { Do. } \\
2 \text { oil wells. } \\
\text { For oil or gas. } \\
\text { Do. } \\
3 \text { wells. }\end{array}$ \\
\hline
\end{tabular}

1 Record, W. Va., Geol. Surv. Rept., vol. 1 (a), 1904 , pp. $459-460$.

2 Ibid., pp. 461-162.

3 Ibid., pp. 448-452.

4 Ibid., p. 459.

5 Ibid., pp. 446-447.

${ }^{6}$ W. Va. Geol. Surv. Rept., vol. 1, pp. 292-294. 7 Ibid., vol. 1 (a), 1904, p. 452.

8 W. Va. Geol. Surv. Rept, vol. 1, pp. 290-291. 9 Ibid., p. 289

10 Record, ibid., vol. 1 (a), 1904, pp. 457-458.

11 Ibid., pp. 458-459.

\section{PRINCIPAL PUBLICATIONS RELATING TO DEEP BORINGS IN WEST VIRGINIA.}

West Virginia Geological Survey Reports, Volume I, by I. C. White, 392 pages. Morgantown, 1899.

Seventh report on the oil and gas fields of western Pennsylvenia for 1887-1888, by J. F. Carll: Pennsylvania Second Geological Survey, Volume $I^{5}, 356$ pages, Harrisburg, 1890.

West Virginia Geological Survey Reports, volume 2, Morgantown, 1903.

Oil and gas levels, by I. C. White, state geologist: West Virginia Geological Survey Reports, volume 1 (a), 1904, Morgantown, W. Va.

United States Geological Survey Atlas, folios Nos. 69 and 72, by M. R. Campbell.

WISCONSIN.

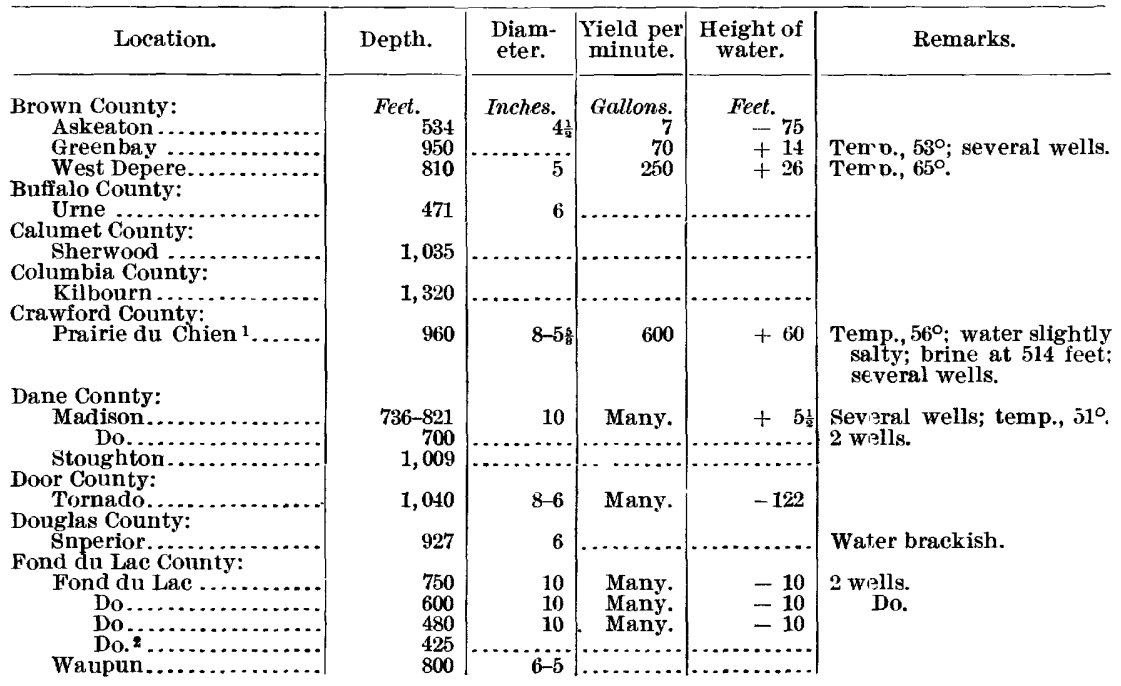

1 Record, Wis. Geol. Surv. Rept., 1873-1879, vol.4,

2 Ibid., 1873-1877, vol. 2, p 153. pp. 61-62. 
WISCONSIN-Continued.

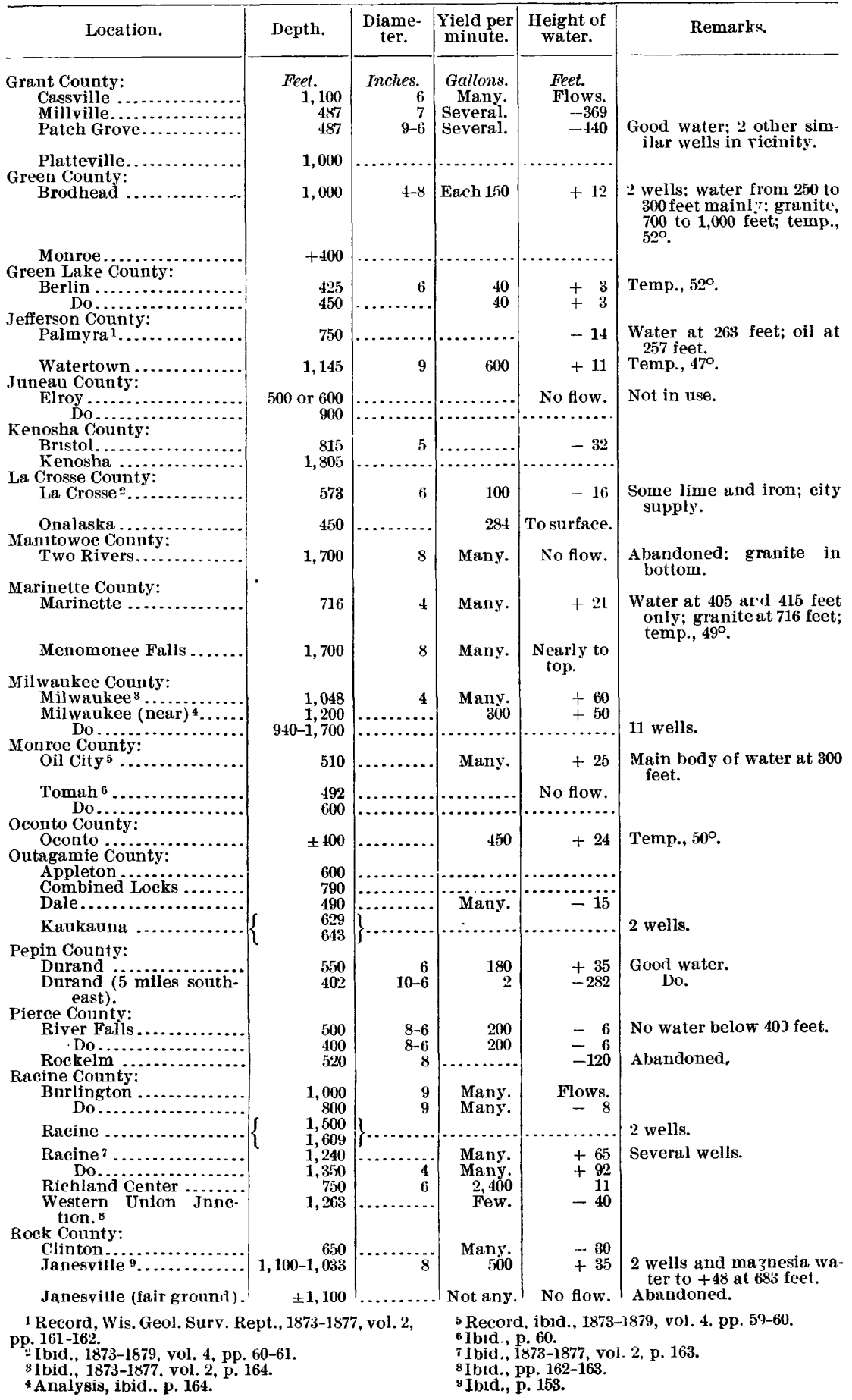


WISCONSIN-Continued.

\begin{tabular}{|c|c|c|c|c|c|}
\hline Location. & Depth. & $\begin{array}{c}\text { Diame- } \\
\text { ter. }\end{array}$ & $\begin{array}{c}\text { Yield per } \\
\text { minute. }\end{array}$ & $\begin{array}{c}\text { Height of } \\
\text { water. }\end{array}$ & Remarks. \\
\hline 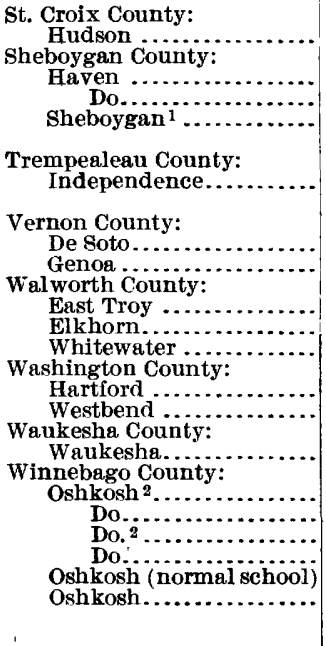 & $\begin{array}{r}466 \\
460 \\
\\
2,200 \\
1,050 \\
950 \\
\\
920 \\
1,500 \\
1,000-1,500 \\
961 \\
700 \\
695 \\
537 \\
613 \\
505\end{array}$ & $\begin{array}{l}\text { Inches. } \\
. . . . . . . .\end{array}$ & $\begin{array}{l}\text { Many. } \\
\text { Many. } \\
\text { Many. } \\
\text { Mauy. } \\
\text { Many. }\end{array}$ & $\begin{array}{c}\text { Feet. } \\
-40 \\
-11 \\
+104 \\
-12 \\
+26 \\
-30 \\
\text { No flow. } \\
-155 \\
+20 \\
\ldots . . . \\
-4 \\
-35 \\
-4 \\
\cdots \\
=1 \\
=4 \\
-\quad 1\end{array}$ & $\begin{array}{l}\text { To be deepened. } \\
\text { Seve" ll wells. } \\
\text { Granite below } 700 \text { feet. } \\
\text { Granite below } 665 \text { feet. } \\
\text { Sevenal other similar } \\
\text { wells. }\end{array}$ \\
\hline
\end{tabular}

1 Record and analysis, Wis. Geol. Surv. Rept., $\quad 2$ Record, ibid., p. 156. 1873-1877, vol. 2, , p. 164 .

\section{PUBLICATIONS RELATING TO DEEP BORINGS IN WISCONSIN.}

Wisconsin Geological Survey Reports, 1873-1877, volume 2, part 2, pages 97-405. Wisconsin Geological Survey Reports, 1873-1879, volume 4, part 1, 98 pages.

WYOMENG.

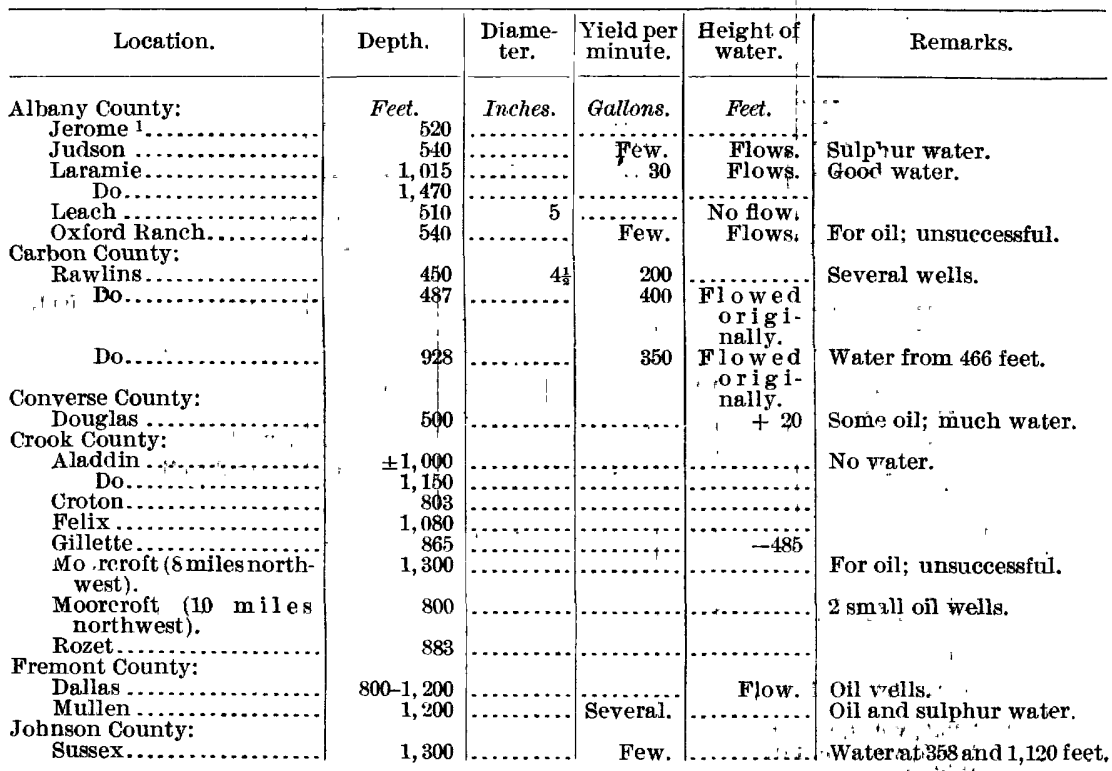

${ }^{1}$ Analysis, U. S. Geol. Survey, 21st Ann. Rept., 1889-1890, part 4, p. 571. 
WYOMING-Continued.

\begin{tabular}{|c|c|c|c|c|c|}
\hline Location. & Depth. & $\begin{array}{l}\text { Diame- } \\
\text { ter. }\end{array}$ & $\begin{array}{c}\text { Yield per } \\
\text { minute. }\end{array}$ & $\begin{array}{l}\text { Height of } \\
\text { water. }\end{array}$ & Remark? \\
\hline $\begin{array}{l}\text { Laramie County: } \\
\text { Cheyenne ........ }\end{array}$ & Feet. & Inches. & Gallons. & Feet. & \\
\hline Fort D. A. Russeli. & & & & & No water below surface \\
\hline $\begin{array}{l}\text { Natrona County: } \\
\text { Oil City }{ }^{1} \ldots \ldots \ldots \ldots \ldots\end{array}$ & & & & & \\
\hline $\begin{array}{l}\text { Oil City }{ }^{1} \\
\text { Salt Creek Oil Field } 2 . . .\end{array}$ & $\begin{array}{r}1,130 \\
809-1,200\end{array}$ & & & (n) & $\begin{array}{l}\text { Oil and gas. } \\
\text { Oil wells. }\end{array}$ \\
\hline $\begin{array}{l}\text { Sheridan County: } \\
\text { Glearmont............. }\end{array}$ & (20) & & & -100 & Modergte sunnly of water \\
\hline sheridan ........ & 500 & & & -100 & mouerate suppy or water. \\
\hline $\begin{array}{l}\text { Verona } \\
\text { Sweetwater coint........ }\end{array}$ & 540 & & & -100 & Do. \\
\hline $\begin{array}{l}\text { Sweetwater County: } \\
\text { Almond } \ldots \ldots \ldots \ldots \ldots\end{array}$ & 1,000 & & & & Strong sulphur water. \\
\hline $\begin{array}{l}\text { Rock Springs }(6 \text { miles } \\
\text { south). }\end{array}$ & 2,400 & 13 & & & $\begin{array}{l}\text { Water-bearing beds at } 30 \\
\text { and } 90 \text { feet; snall show } \\
\text { ing of oil at } 625 \text { feet. }\end{array}$ \\
\hline $\begin{array}{l}\text { Wamsutter... } \\
\text { Uinta County: }\end{array}$ & 1,363 & & & & \\
\hline $\begin{array}{l}\text { Uinta County: } \\
\text { Evanston..... }\end{array}$ & 1,200 & $14-10$ & & $+\frac{1}{6}$ & \\
\hline $\begin{array}{l}\text { Hilliard ........ } \\
\text { Weston County: }\end{array}$ & 484 & & & & For oil; unsuccessful. \\
\hline $\begin{array}{l}\text { Weston County: } \\
\text { Cambria }{ }^{3} \ldots \ldots \ldots \ldots \ldots . . . . .\end{array}$ & 2,345 & & & & \\
\hline $\begin{array}{l}\text { Clifton (north of) } 4 \ldots . \\
\text { erome Siding (on Bur- } \\
\text { lington and Missouri } \\
\text { River R.R.). }\end{array}$ & $\begin{array}{r}1,002 \\
520\end{array}$ & & Few. & Flows. & Mineral water. \\
\hline $\begin{array}{r}\text { Newcastle } \ldots \ldots \ldots \ldots \ldots \ldots \ldots \\
\text { Do } \ldots \ldots \ldots \ldots \ldots \ldots\end{array}$ & 1,950 & & Several. & Flows. & For oil; unsuccessful. \\
\hline $00, \ldots \ldots \ldots$ & $\begin{array}{r}1,340 \\
420\end{array}$ & & & & $\begin{array}{l}\text { Some oil at abort, } 400 \text { feet. } \\
\text { Some oil. }\end{array}$ \\
\hline $\begin{array}{l}\text { Newcastle ( } 3 \frac{1}{2} \text { miles } \\
\text { southwest). }\end{array}$ & 720 & & & & No product. \\
\hline $\begin{array}{l}\text { Newcastle ( } 1 \frac{1}{2} \text { miles } \\
\text { southwest). }\end{array}$ & 650 & & & & Large supply of water. \\
\hline Thornton.............. & 980 & & & No flow. & $\begin{array}{l}\text { Satisfactory supply for } \\
\text { railroad use. }\end{array}$ \\
\hline
\end{tabular}

1 Record, etc., Wyo. Geol. Ann. Rept., 1898, p. 32. 2 Record, Wyo. Üniv. Bull. No. 1 (Petroleum series), 1896, pp. 18-19.
${ }^{3}$ Record, U. S. Geol. Surv., 21st Ann. Rept., 18891900 , pt. 4, p. 572 .

4 Ibld., p. 571 .

\section{PUBLICATIONS RELATING TO DEEP BORINGS IN WYOMING.}

Petroleum of Salt Creek, Wyoming, by W. C. Knight: University of Wyoming Bulletin No. 1 (Petroleum series), 47 pages, June, 1896.

Petroleum of the Shoshone anticlinal, by W. C. Knight: University of Wyoming Bulletin No. 2 (Petroleum series), 34 pages, January, 1897.

Oil fields of Crook and Uinta counties, Wyoming, by W. C. Knight: University of Wyoming Bulletin No. 3 (Petroleum series), 31 pages, November, 1899.

Preliminary report on the artesian basins of Wyoming, by W. C. Knight: University of Wyoming Experiment Station Bulletin No. 45, 251 pages, plates, map, June, 1900.

Preliminary description of the geology and resources of the southern helf of the Black Hills and adjoining regions in South Dakota and Wyoming, by N. H. Darton: United States Geological Survey, Twenty-first Annual Report, 1899-1900, pages 489599, plates, maps, Washington, 1901.

Preliminary report on the geology and underground water resources of the Central Great Plains, by N. H. Darton: United States Geological Survey Professional Paper No. 32, Washington, 1905. 



\section{PUBLICATIONS OF UNITED STATES GEOLOGICAL SURVEY.}

[Water-Supply Pape r No. 149.]

The serial publications of the United States Guological Survey consist of (1) Annual Reports, (2) Monographs, (3) Professional Papers, (4) Bulletins, (5) Mineral Resources, (6) Water-Supply and Irrigation Papers, (7) Topographic Atlas of United States-folios and separate sheets thereof, (8) Geologic Atlas of United States-folios thereof. The classes numbered 2, 7, and 8 are sold at cost of publication; the others are distributed free. A circular giving complete lists may be had on application.

Most of the above publications may be obtained or consulted in the following ways:

1. A limited number are delivered to the Director of the Survey, from whom they may be obtained, free of charge (except classes 2,7 , and 8), on application.

2. A certain number are allotted every member of Congress, from whom they may be obtained, free of charge, on application.

3. Other copies are deposited with the Superintendent of Documents, Washington, D. C., from whom they may be had at prices slightly above cost.

4. Copies of all Government publications are furnished to the princifal public libraries in the large cities throughout the United States, where they may be consulted by those interested.

The Professional Papers, Bulletins, and Water-Supply Papers treat of a variety of subjects, and the total number issued is large. They have therefore been clasrified into the following series: A, Economic geology; B, Descriptive geology; C, S-stematic geology and paleontology; D, Petrography and mineralogy; $\mathrm{E}$, Chemistry and physics; F, Geography; G, Miscellaneous; H, Forestry; I, Irrigation; J, Water storage; K, Pumping water; L, Quality of water; M, General hydrographic invertigations; $\mathrm{N}$, Water power; $\mathrm{O}$, Underground waters; $\mathrm{P}, \mathrm{Hydrographic}$ progress reports. This paper is the forty-eighth in Series $O$, the complete list of which follows ( $P P=$ Professional Paper; $\mathrm{B}=$ Bulletin; WS $=$ Water-Supply Paper):

\section{SERIES O, UNDERGROUND WATERS.}

WS 4. A reconnaissunce in southeastern Washington, by I. C. Russell. $1897.96 \mathrm{pp} ., 7$ pls.

WS 6. Underground waters of southwestern Kansas, by Erasmus Haworth. 1897.65 pp., 12 pls.

WS 7. Seepage waters of northern Utah, by Samuel Fortier. 1897.50 pp., 3 pls.

WS 12. Underground waters of southeastern Nebraska, by N. H. Darton. 1898. 56 pp., 2 pls.

WS 21. Wells of northern Indiana, by Frank Leverett. $1899.82 \mathrm{pp} ., 2 \mathrm{pls.}$

WS 26. Wells of southern Indiana (continuation of No. 21), by Frank Leverett. 1899. $64 \mathrm{pp.}$

WS 30. Water resources of the Lower Peninsula of Michigan, by A. C. Lane. 1899. 97 pp., 7 pls.

WS 31. Lower Michigan mineral waters, by A. C. Lane. 1899.97 pp., 4 pls.

WS 34. Geology and water resourees of a portion of southeastern South Dakota, by J. E. Todd. 1900. 34 pp., 19 pls.

WS 53. Geology and water resources of Nez Perces County, Idaho, Pt. J, by I. C. Russell. 1901.86 pp., 10 pls.

WS 54. Geology and water resources of Nez Perces County, Idaho, Pt. II, by I. C. Rursell. 1901. 87-141 pp.

WS 55. Geology and water resources of a portion of Yakima County, Wash., by G. O. Srith. 1901. $68 \mathrm{pp} ., 7 \mathrm{pls}$.

WS 57. Preliminary list of deep borings in the United States, Pt. I, by N. H. Darton. $1902.60 \mathrm{pp.}$

WS 59. Development and application of water in southern Californı, Pt. I, by J. B. Lippincott. 1902. 95 pp., 11 pls.

WS 60. Development and application of water in southern California, Pt. II, by J. B. Lippincott. 1902. 96-140 pp.

IRR $149-05-12$ 
WS 61. Preliminary list of deep borings in the United States, Pt. II, by N. H. Darton. $1902.67 \mathrm{pp}$.

WS 67. The motions of underground waters, by C. S. Slichter. $1902.106 \mathrm{pp} ., 8 \mathrm{pls}$.

B 199. Geology and water resources of the Snake River Plains of Idaho, by I. C. Russell. 1902.192 pp., 25 pls.

WS 77. Water resources of Molokai, Hawaiian Islands, by W. Lindgren. $1903.62 \mathrm{pp.,} 4 \mathrm{pls.}$

WS 78. Preliminary report on artesian basin in southwestern Idaho and southeastern Oregon, by I. C. Russell. 1903. 53 pp., 2 pls.

PP 17. Preliminary report on the geology and water resources of Nebraska west of the one hundred and third meridian, by N. H. Darton. $1903.69 \mathrm{pp} ., 43 \mathrm{pls}$.

WS 90. Geology and water resources of a part of the lower James River Valley, Sc uth Dakota, by J. E. Todd and C. M. Hall, 1904. 47 pp., 23 pls.

WS 101. Underground waters of southern Louisiana, by G. D. Harris, with discussions of their uses for water supplies and for rice irrigation, by M. L. Fuller. $1904.98 \mathrm{p}$ \%, $11 \mathrm{pls}$.

Ws 102. Contributions to the hydrology of eastern United States, 1903, by M. L. Fuller. $1904.522 \mathrm{pp.}$

WS 104. Underground waters of Gila Valley, Arizona, by W. T. Lee. 1904. 71 pF ., 5 pls.

Ws 110. Contributions to the hydrology of eastern United States, 1904; M. L. Fuller, geologist in charge. 1904. 211 pp., 5 pls.

PP 32. Geology and underground water resources of the central Great Plains, by N. H. Darton. 1904. $433 \mathrm{pp} ., 72 \mathrm{pls}$.

WS 111. Preliminary report on underground waters of Washington, by Henry Landes. $1904.85 \mathrm{pp}$., $1 \mathrm{pl}$.

KS 112. Underflow tests in the drainage basin of Los Angeles River, by Homer Hamlin. 1904.55 pp., 7 pls.

Ws 114. Underground waters of eastern United States: M. L. Fuller, geologist in charge. 1904.285 pp., 18 pls.

WS 118. Geology and water resources of east-central Washington, by F. C. Calkins. 1905.96 pp., 4 pIs.

B 252. Preliminary report on the geology and water resources of central Oregon, by l. C. Russell. 1905. 138 pp., 24 pls.

Ws 120. Biblingraphic review and index of papers relating to underground waters published by the United States Geological survey, 1879-1904, by M. L. Fuller. 1905. 12? pp.

WS 122. Relation of the law to underground waters, by D. W. Johnson. $1905.55 \mathrm{pp}$.

WS 123. Geology and underground water conditions of the Jornada del Muerto, New Mexico, by C. R. Keyes. 1905. 42 pp., 9 pls.

WS 136. Underground waters of the Salt River Valley, by W. T. Lee. 1905. - Fp., 24 pls.

B 264. Record of deep-well drilling for 1904, by M. L. Fuller, E. F. Lines, and A. C. Veatch. 1905. $106 \mathrm{pp}$.

PP 44. Underground water resources of Long Island, New York, by A. C. Veatch and others. 1905.

WS 137. Development of underground waters in the eastern coastal plain region of southern California, by W. C. Mendenhall. 1905. $140 \mathrm{pp} ., 7 \mathrm{pls}$.

WS 138. Development of underground waters in the central coastal plain region of southern California, by w. C. Mendenhall, 1905. $162 \mathrm{pp} ., 5 \mathrm{pls}$.

WS 139. Development of underground waters in the western coastal plain region of southern California, by W. C. Mendenhall. 1905. $105 \mathrm{pp} ., 7 \mathrm{pls}$.

WS 140. Field measurements of the rate of movement of underground water, by C. S. Slichter. 1905. - pp., 15 pls.

WS 111. Observations on the ground waters of Rio Grande Valley, by C. S. Slizhter. 1905. - pp., 5 pls.

WS 142. Hydrology of San Bernardino Valley, California, by W. C. Mendenhall. 1905. 124 pp., 13 pls.

WS 145. Contributions to the hydrology of eastern United States; M. L. Fuller, geologist in charge. 1905. - pp., 6 pls.

Ws 148. Geology and water resources of Oklahoma, by C. N. Gould. $1905 . \quad-$ pF, 22 pls.

WS 149. Prelminary list of deep bormgs in the United States. Second editior with additions, by N. H. Darton. $1905.175 \mathrm{pp}$.

The following pupers also relate to this subjert: Underground waters of Arkansas Valley in eastern Colorado, by G. K. Gilbett, in Seventeenth Annual, Pt. 11: Prelıminary report on artesian watexs of a portion of the Dakotas, by N. H. Darton, in Seventeenth Annual, Pt. 11; Water resources of Illinois, by Frank Leverett, in Seventeenth Annual, Pt. II; Water resources of Indiana and Ohio, by Frank Leverett, in Eighteenth Annual, Pt. IV; New developments in well boring and jrrigation in eastern South Dakota, by N. H. Darton, in Eighteenth Annual, Pt. IV; Rock waters of Ohio, by Edward Orton, In Nineteenth Annual, Pt. IV: Artesian well prospects in the Atlantic coastal plain region, by N. H. Darton, Bulletm No. 138 .

Correspondence should be addressed to

The Director,

United States Geologiral Survey, Washington, D. C. 


\section{LIBRARY CATALOGUE SLIPS.}

[Mount each slip upon a separate card, placing the subject at the top of the second slip. The name of the series should not be repeated on the se"ies card, but the additional numbers should be added, as received, to the first entry.]

\section{Darton, $\mathbf{N}$ [elson] $\mathbf{H}$ [oratio] $\mathbf{1} 865$}

... Preliminary list of deep borings in the United States, 2 d ed. with additions; by N. H. Darton. Washington, Gov't print. off., I905.

175 , iii p. $23^{\mathrm{cm}}$. (U. S. Geological survey. Water-supply and irrigation paper no. 149)

Subject series: $O$, Underground waters, 48 .

1 st ed. issued in 2 pts. as Water-supply and irrigation papers nos. 57 and 61. Bibliographies interspersed.

1. Borings-U. S.

\section{Darton, $\mathbf{N}$ [elson] $\mathrm{H}$ [oratio] $\mathbf{1 8 6 5 -}$}

... Preliminary list of deep borings in the United States, 2 d ed. with additions; by N. H. Darton. Washington, Gov't print. off., I905.

175 , iii p. $23^{\mathrm{cm}}$. (U. S. Geological survey. Water-supply and irrigation paper no. 149)

Subject series: $O$, Underground waters, 48.

1sted. issued in 2 pts. as Water-supply and irrigation papers nos. 57 and 61.

Bibliographies interspersed.

1. Borings-U. S.

\section{U. S. Geological survey.}

Water-supply and irrigation papers.

no. I49. Darton, N. H. Preliminary list of deep brrings in the United States. 2d ed. 1905.

\section{U. S. Dept. of the Interior.}

see also

U. S. Geological survey. 
